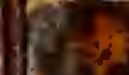 \\ $y+x=-y$ \\ 16. 20.
}

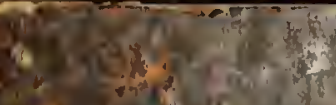

$f(x, y=20$

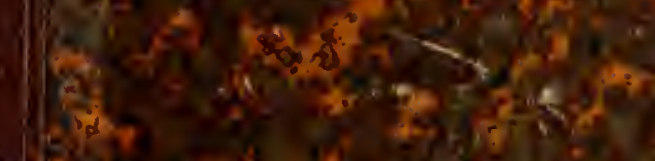

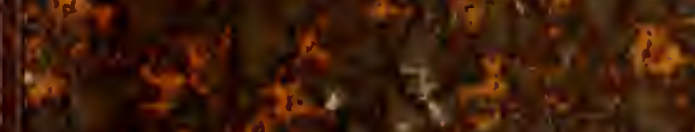

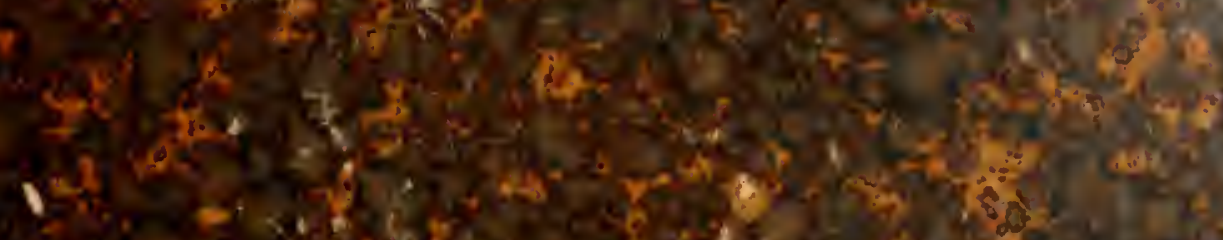

a.t.

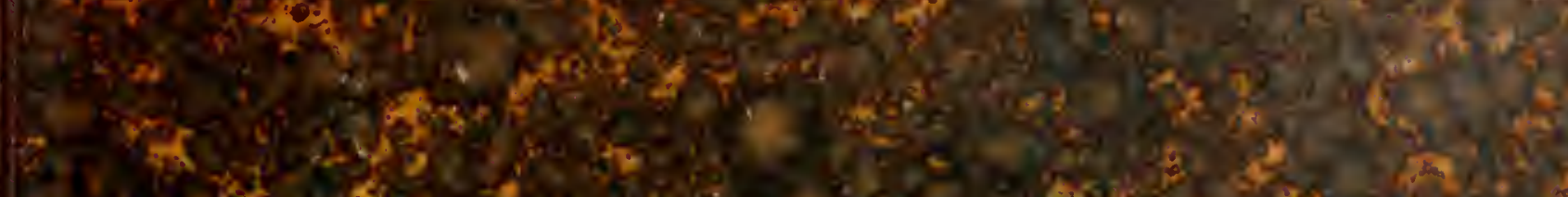

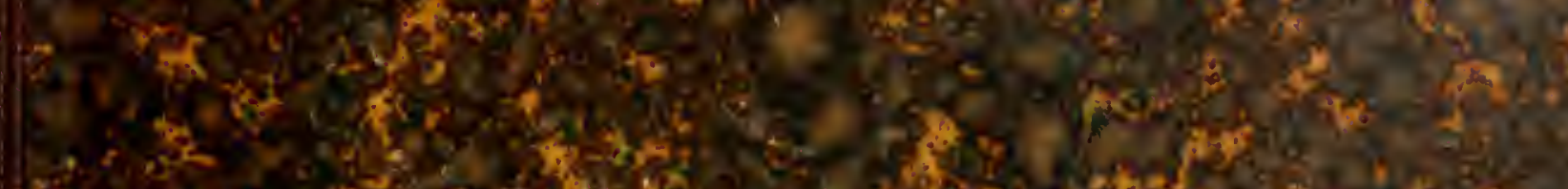

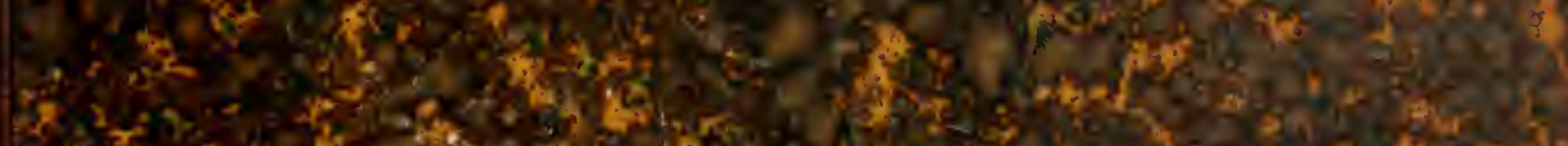

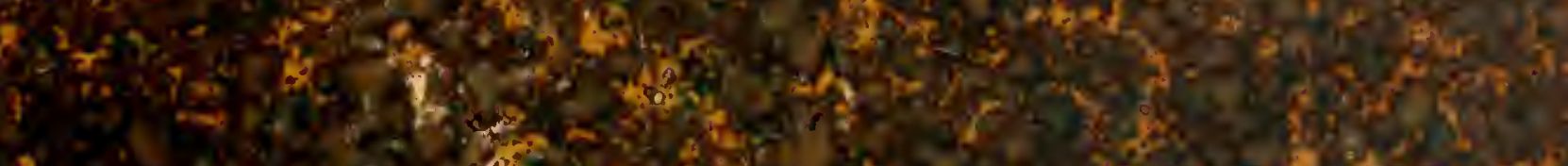

\section{P.}

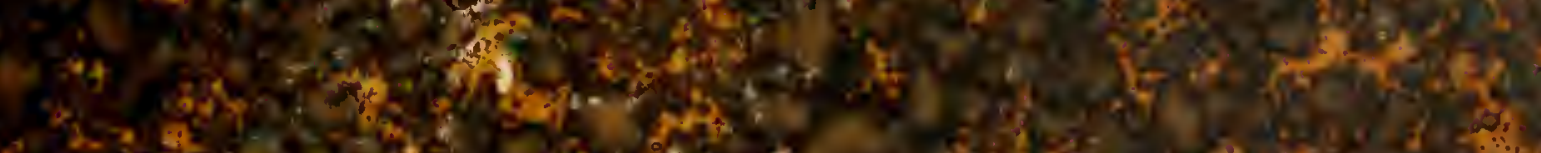

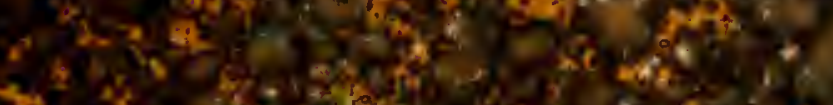

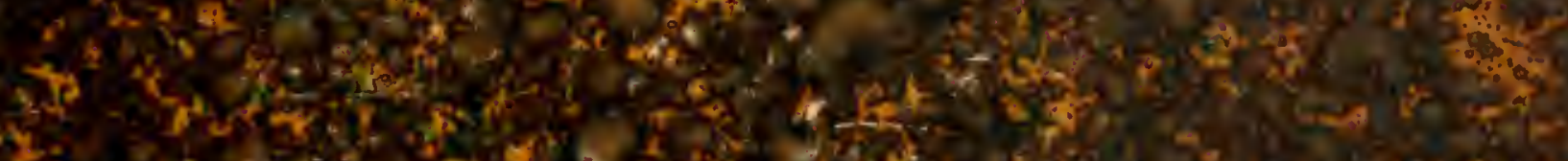
1.4:

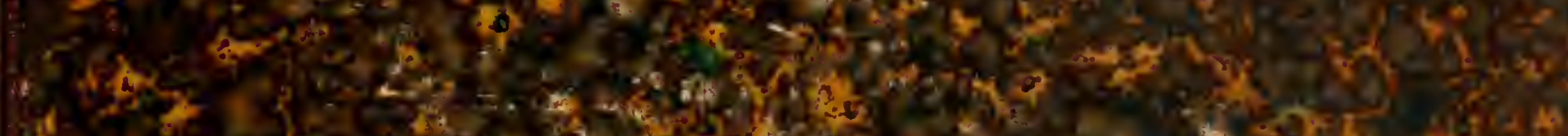

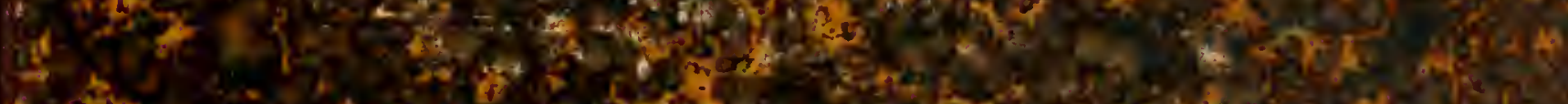

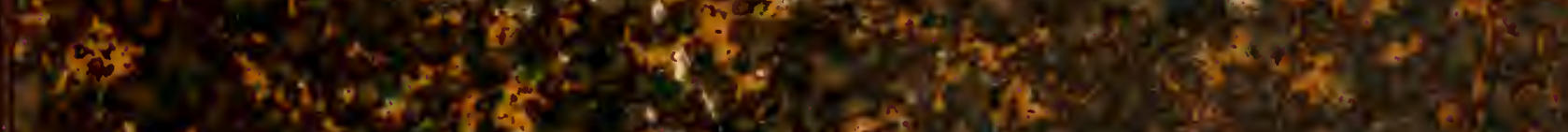
"As the the

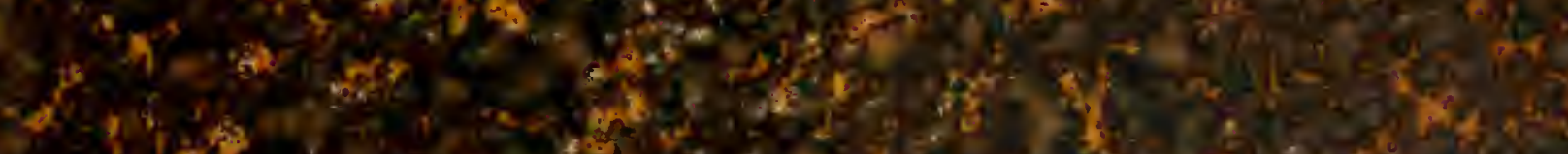

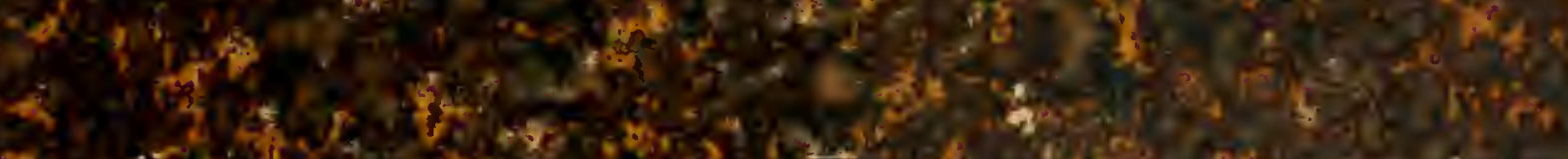

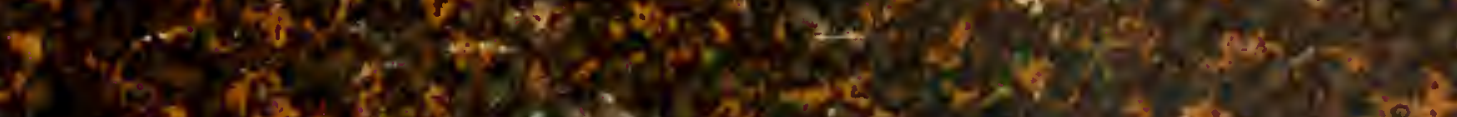

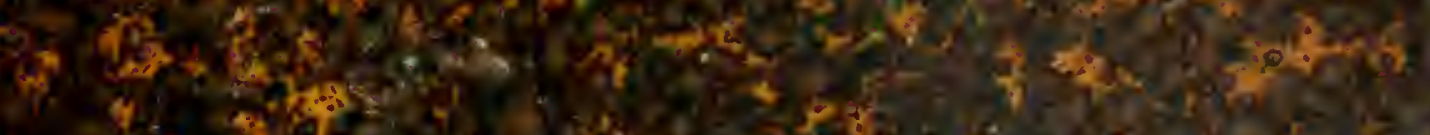

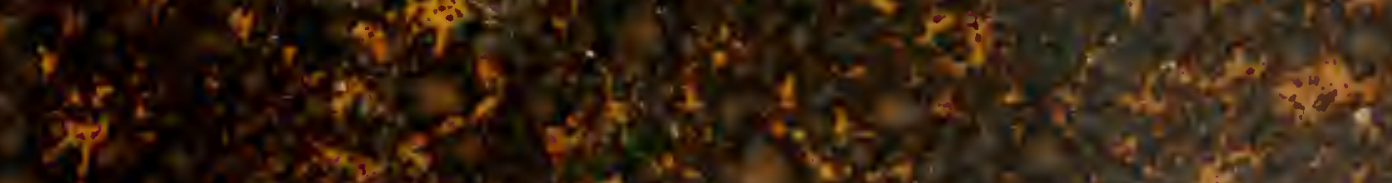

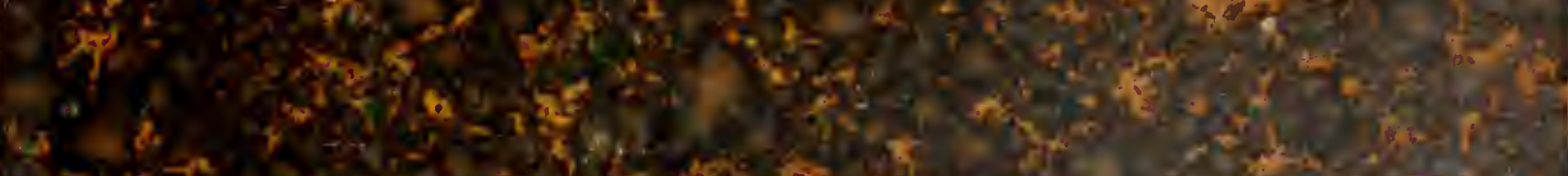

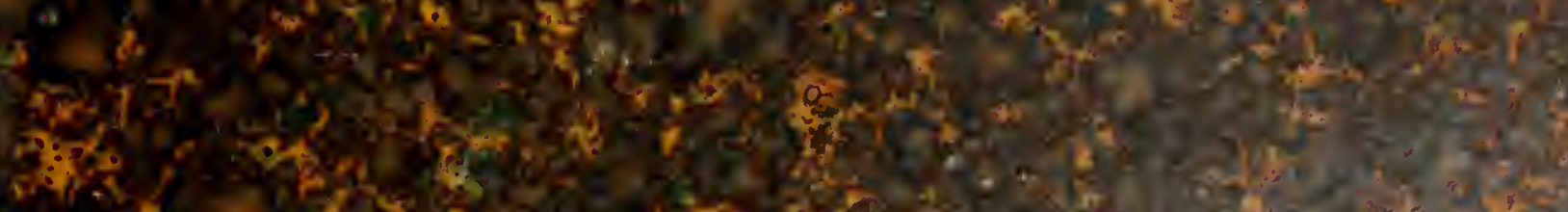




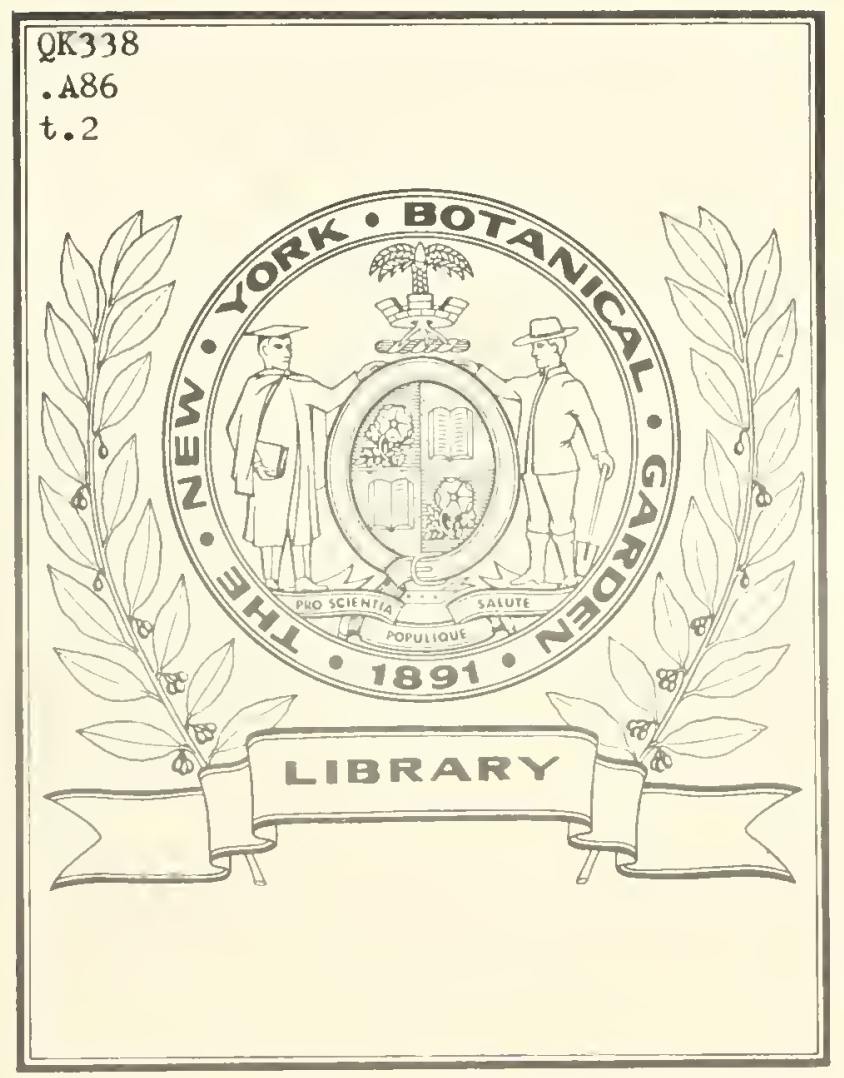








\section{PHYTOGRAPHIA LUSITANIA SELECTIOR}

SEU

NOVARUM, RARIORUM, ET ALIARUM MINUS COGNITARUM STIRPIUM, QUE IN LUSITANIA SPONTE VENIUNT, EJUSDEMQUE FLORAM SPECTANT, DESCRIPTIONES ICONIBUS ILLUSTRAT $Æ$.

\section{$\overline{T O M M_{0} I_{0}}$ \\ A UCTORE \\ FELICE AVELLAR BROTERO}

LQ. REG. ORD. D. B. DE AYIS DOCT. M. AC PHIL. BOtAN. ET PHYTOGEURG. IN ACAD. CONMMER. PROFESS, NUNC EMERITI MUS. ET HORT. REg, BOt. OLIS. IN AJUDA SITI PRAE. SOCIET. IINN. LOND. ET HORTIC. LOND. MEMb. REg. SCIENT. Olisip. PHIlomath. PARIS. hist. Nat. ROSTOCK. PHYSIOGR. LUNDENS. BONN. ACAD. CASAR. NATURE CURIOS. MARBURG. ET ALIARUM SODALIS.

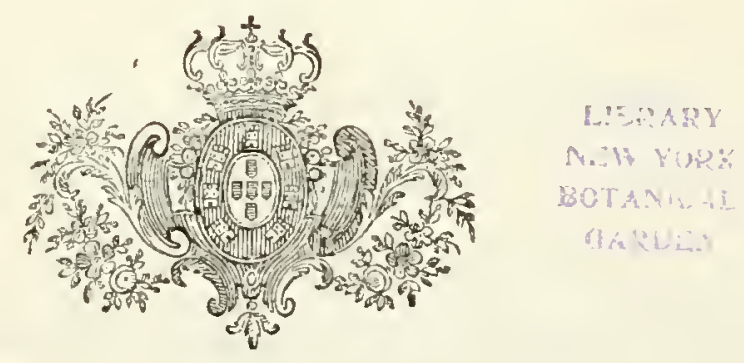

\section{OLISIPONE}

EX TYPOGRA PHIA REGIA.

1827.

Permissu Regio. 



\title{
PHY'TOGRAPHIA LUSITANIE.
}

\section{DIANTHERIA MONOSTYLIA.}

\author{
SALVI A hiemalis.
}

Lusit. Salva de inverno.

S. foliis radicalibus petiolatis omnibus, primariis lanceolato-ovatis, integris, crenatis, aliis ovato seu subcordato-oblongis, sinuatis, aut subsinuato-pinnatifidis, rugosis, glabriusculis, laciniis crenatis, vel inciso-dentatis; canlinis inferioribus formà similibus, subsessilibus, summis sessilibus, cordatis, acuminatis, dentatis; bracteis cordatis, flore brevioribus; spica obtusa, demum late truncata; verticillis sexfloris; corollà calycem longè superante.

S. verbenacoides. Brot. Flor. Lusit. Tom. I. pag. 17.

(Primitus tanquam vera verbenacoidis varielus existimala).

S. polymorpha.

Link et Hoffmansegg Flor. Lusit. Tom. I. pag. 149 cum icone.

Horminum silvestre, inciso folio, cæsio flore, italicum.

Barrel. Icon. 220 Obs. 24.

Horminum silvestre primum, flore vario, secundum et tertium flore purpurascente.

Grisley Virid. Lusit. n. $751-52$.

RaDIX perennis, primùm fusiformis, deinde inferne subramosa, cùm annosa pedem et ultra longe, ar collum ferè crassitudine digiti, lignosa, cortice crasso, nigro, subrimoso; inodora, sapore herbaceo.

Caulis annuus, tetragonus, angulis obtusiusculis, plerumque spithameus, rarissime brevior, interdum pedalis aut paulo ultra altior; inferne glabriusculus, aut subpubescens, supernè villosus, villis patulis guttulì subviscosa terminatis; sæpe birameus ant quadrirameus, raro sexrameus; ramis axillaribus, decussatis, ereêtis, plerumque simplicissimis, raro duobus inlerioribus subdivisis; cum ex junioribus radicibus ortus solitarius, erectus, plures autem cùn ex adul- 
tioribus et grandævis, quorum interiores tunc erecti, exteriores verò basi leviter retrorsum arcuati, deinde erecti; omnes Maio aut Junio siccescunt.

Folı radicalia omnia petiolata; quæ ex germinata seminali plantulâ proveniunt, omnia lanceolato-ovata, seu ovali-oblonga, obtusa, integra, crenata, supra glabriuscula, subtus subtomentosa, et fere ex omni parte illis Salviæ officinalis pariformia: qux secundo, tertioque anno et aliis enascuntur, radicalia primaria, sæpe prædictis formâ, etsi maiora, similia, secundaria vero oblonga, inæqualiter sinuata, interdum plus minusve pinnatifida, laciniis inæqualibus, inxequaliterque crenatis vel dentatis, oblusa aut breviter acuta, rugosa, venosa, utrinque glabriuscula, subtus tamen venis subpilosa, unciam ad sesquiunciam lata, tres ad quatuor longa: eorum petiolus supra canaliculatus, subtus convexiusculus, striatus, subpilosus, sesquiunciam ad dnas uncias longus. Folia caulina duo vel tria paria, opposita, inferiora nunc breviter petiolata, radicalibus similia etsi mirora, nunc sessilia ovata, aut subcordata, acuta, serrata, seu iıciso-dentata; superiora alia cordata, acuminata, subvillosa, sessilia.

Spica verticillosa; verticillis quatuor ad sex, raro ultri, sæpe remotiusculis, sexfloris; verticillo supremo exicrto, abortivo, cito evanido ita, ut spica cito late truncata evadat. Flores pedicellati, pedicellis duas ad fere tres lineas longis, erectiusculis. Bracteæ sub singulo verticillo dux, oppositx, inferiores ovatx, ant subcordatx, calycis longitudine, seu paulo ipso longiores; superiores cordatæ, acuminatx, integerrimæ, subvillosæ, ciliatx, calyce breviores, sxepe reflexæ. Involucellım quadrisetum; setæ utrinque dux inter bra cteas, illasque decussantes, sublineares, molles, villosæ, erectæ, pedicellis florum paulo breviores, cito emarcescentes, caducæ.

Calyx campanulatus, hians, tres quatuorve lineas longus, fructifer subcernums, viridis aut interdum subpurpurascens, extus, et intra usque ad medium, villosus, villis vesiculoso-glutinosis, striatus, costatus, costis scabriusculis, bilabiatus; Jabio superiori sensim ad apicem latiori, plicato, supri bilacmoso, inter lacunas carinato, lateribus refracto, apice recurvo, obtuso, leviter emarginato, ibique denticulis tribus acutis, contiguis, brevissimis, vix conspicuis, instructo; labio inferiore longitudide superiori xquali, bidenteo, dentibus incurvis, lanceolatis, acuminatis, subpungentibus.

Corolla bilabiata; superiori labio ab inferiori remoto, cæruleo, compresso, subfalcato, obtuso, leviter emarginato, extus pubescenti, calycem ad tres lineas superante; Jabio inferiori paulo breviori, extus villoso, trilobo, laciniis duabus lateralibus cærulescentibus, brevibus, obtusis, deflexis, lobomedio maiori, albo, subrotundo, concavo, vix emarginato, aut vix crenulato. Faux tumida; tubus glaber, calyce angustior, albus. Corolla tota alba in hac specie rarissima est. 
Stam. filamenta duo arcuata, transversim pedicello brevi aflixa: antluera sub labio superiori corollx reclusie. Præeter lixc duo filamenta sunt et alia duo minima, simplicissima, erecta, sterilia, in lauce corollæ sita.

Pist. germen quadrifidum. Stylus filiformis, albidus, seu ex albido caruleus, arcuatus, labio superiori Corollæ incumbens, jlloque et staminibus sape parum longior. Sligmata duo setacea, acutissima, aliud alio brevius.

Semina nuda in fundo calycis sila, plerumque duo abortientia, et duo fertilia, subrotunda, ex fulvo fusca, hinc convexa, inde obsolete uniangulata.

HА R. ad vias, aggeres, et solo raro circa Conimbricam, Olisiponem et alibi in Bcira el Extremadura. Floret ex Novembri usque ad Martium, raro Aprili. Perennis.

Usus ignotus. Planta inodora, sapore herbaceo.

Obs. 1. Nimis aftinis S. clandestince Lin., sed differt radice perennante, nec bienni, foliis caulinis latioribus, radicalibus, non rugosissimis, nec ut illa Salvix ceratophyllo. Phrasis et Icon 220 Barrelieri, qua ex Clariss. Sinith fide ad aliam speciem a S. clandestina Lin. di. versam amandandæ, nostræ $\mathrm{S}$. hiemali apprimè quadrant.

Ons. 2. Etsi nostrâ in Flora Lusitanica istam cum alia Salvia, sub nomine S. verbenacoides, tanqualu duas ejusdem speciei varietates conjumxi, nunc illas, uti duas diversas species, sejungendas esse opinor. Vera SALVIA verbenacoides, quæ a Clar. Link S. polymorpha acutata et parviflora un cupatur, pliss ad S. verbenacam Lin. et ad S. Lusitanicam (La Mark Dict. Bot Encycl.) accedit, quìm ad S. clandestinam Lin., et ad nostram S. hiemalcm; namque altiori ramosiorique caule gaudet, foliis rugosioribus, raro pinnatifidis, spica acutatâ, nec late truncala, verticillis proprioribus, sæpe 5 ad 8 , seriusque florentibus, corolla minore, interdum calycem paulo superante, utroque labio penitus caruleo, atque approximato. Itaque cium sit S. verbenace Lin. et Lusitanica La Mark nimis allinis, et forte earum varietas, usque dum ulterioribus observationibus decernatur, sitne diversa species, an illarum tantim varietas, sub nomine S. verbenacoides, ut opinor, relinquenda.

Oes. 3.' Neque confundenda cum nostra Salvia sclareoide, quæ ab illa longe diversa, non solum quia ei perseveranter elatior et ex omni parte maior, sed etiam quia viscosior, atque foliis radicalibus cordatis, seu subcordatis, integris, aut subsinuatis, nec unquam verè pinnatifidis, rugosissinis et minutissine bullulatis, utrinque villosis, florendi tempore semper verno, et aliis notis. Vid. de hac Plnytogr. Tom. 1. pag. 3 et 203.

Tom. II. 


\section{SALVIA patula.}

\section{Lusit. Salva larga.}

S. foliis ralicalibus petiolatis, cordatis, sinuato-dentatis, caulinis sessilibus; caule calycibusque villoso-glutinosis; bracteis corratis, mucronatis, integerrimis, calycem xquantibus, aut paulo brevioribus, summis vacuis.

S. patula. Link et Hoffm. Flor. Lusit. Tom. I. pag. 151. Tab. 20.

S. Fethiopis. Brot. Flor. Lusit. Part. I. pag. 18.

S. patula, foliis radicalibus corlatis, lanatis, sinuoso-erosis; caule calycibusque villosis, glutinosis; bracteis concavis unucronatis; fluribus summis evanidis. Desfont. Flor. Atlant. Vol. I. pag. 25.

Eadem varians folis radicalibus tomentosis, aut interdum ferè glabris.

S. patula. La Mark. Dict. Bot Encycl. Meth. Tom. 6 pag. 630.

S. palula, viscosa, foliis radicalibus cordatis, dentato-sinuatis; caulinis sessilibus, oblongis; bracteis calycem requantibus.

Valh. Enum. Plant. V. I. pag. 272 N. 116.

Sclarea Lusitanica, glutinosa, amplissimo folio.

Tourn. J. R. II.

Huic potius refcrenda, quim nostra S. sclareoidis. Ex fide Herb. $\checkmark$ aillant.

Hornmeu silvestre, 4 et 5 , latifolium, flore amplo cæruleo, aut interdum albo. Grisl. Vir. Lusit. N. $753-54$. Huic quoque potius, quàm S. sclareoidi referendum.

RADIx perennis, infernè subramosa, annosa crassitudine digiti, lignosa, cortice crasso, subrimoso, fusca.

Caúlis annuus, sape solitarius, erectus, pedalis, bipedalis et ultra, firmus, tetragónus, angulis obtusiusculis, quadrisulcatus, ex virili albidus, pilis patentibus apice glutinosis instructus, infernè simplex, 
supernc in ramos numerosos, ferc paniculatos, oppositos patulosque, divisus.

fous radicalia in orbem procumbentia, magna, septem uncias et $\|$ Ira Jonga, tres et ultra lata, petiolata, cordata seu subcorlato-oblonga, interdum nomunlla subovalia, laud profundè sinuata, inacquaJiter et acutè dentato-crenata, utrinque tomentoso-villosa, sulitus incana, raro supra feré glabra; petiolis crassis, latis, compressinsculis, suprì canaliculatis, subtus convexis. Folia caulua panca, oppnsita, rale minora, sursum sensiu decrescentia, ovato-oblouga, acnta, dentata, infima interdum breviter petiolata, alia sessilia.

Splca verticillata; verticilli plus minusve remoti, sexflori. Flores subsessiles, interdum, etsi raro, secundi ; rachi villosî, villis apice vesiculoso-riscosis. Bractex oppositx, ovatx, seu cordato-ovate, acutata, integerrima, ciliatx, pubescentes, venosx, calyci acquales, aut paulo breviores, sensin versus spicie apicem decrescentes, suprema parva, absque floribus.

Calyx viridis, campanulatus, striatus, villosus, villis gutlulì glutinosa terminatis, bilabiatus; labiis subequalibus, superiori tridentato, dentibus parvis, inferiori bidenteo, dentibus longis; omnibus subulatis.

Cororla magna, roseo-alba, rarissimè cæruleata, bilabiata, labiis remotis; superiori compresso, arcuato, leviter emarginato, interdum obsolete crenulato, extus subpubescenti; inferiori vix breviori, trilobo, lobis lateralibus minoribus; tubo calycem vix superante.

STAM. filamenta duo transversim pedicello infernè latissimo affixa. Antheræ lutex sub labio superiori corollse reclusx.

Pıst. Germen depressum, quadrifidum. Stylus filiformis, arcuatus, labio superiori corolia incumbens, illoque longior. Stigmata duo, acıtissima, aliud alio brevius.

SEarisa quatuor, exquibus nonnulla sæpe abnrtiva, nuda in fundo calycis, lavia, fusca, subrotunda, hiuc convexa, inde nedio uniangulata.

$\mathrm{HAB}_{\mathrm{A}}$. in pascuis et ericetis prope Viligueira, et inter Pacem-Juliam et Mrtilem, atque alibi in Transtagana. Floret vere usque ad Jusum. Perennis.

\section{Usus ignotus.}

Ors. Nimis affuns S. Ethiopidi ita, ut nonnunquam varietas ejus existimata sit, attamen diftert caule, ramis et calycibus villosis nec lanatis, corolla duplo ferc̀ maiori, et bracteis sunmis absque forıbus. 


\section{E R O I A Lusitana.}

\section{Lusit. Veromica Teucrieta.}

V. racemis axillaribus; foliis ovatis, rugosis, grosse aculeque serratis, hirtis, subsessilibus; canle erectiusculo undique hirsuto; calycibus quadripartitis, corolla maioribus; capsulis profunde emarginatis, calyce brevioribus.

V. Teucrium. Brot. Flor. Lusit. Tom. I. pag. 13-14.

V. micrantha. Link et Hoffm. Flor. Lusit. T. I. pag. 286-87.

$\mathbf{R}_{\mathrm{ADIX}}$ perennis, tenuis, lignosa, ramosa; ramis multifibratis.

Caviss sæe solitarius adscendens, aut erectiusculus, interdum ad basin reptans, teres, undique circum circa hirsutus, septem ad uncias decem longus, racemis supputatis; ad apicem ramosus, racemosus.

Fol a opposita, ovato-cordata, grosse acuteque serrata, rugosa, venosa, hirsuta, sessilia seu brevissime petiolata; petiolo vix ultra linam longo, lamina tredecim ad quindecim lineas longa, decem lata.

$R_{\text {AcEM I }}$ axillares erecti, plerumque oppositi, 5 ad 7 uncias longi; flores subconferti, alterni, pedunculatı; pedicellis vix lineam longis. Bractex sublineares, seu lineari-lanceolatæ, nervosæ, integerrimæ, villosse, pedicellis longiores, calyce autem breviores.

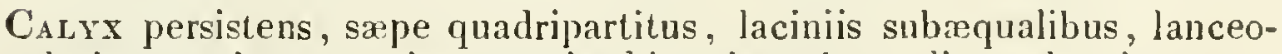
latis, acutis, nervosis, rugosis, hirsutis, ad tres lineas longis.

Corolla alba, annulo faucis purpurascente, calyce paulo brevior; limbus quadripartitus, laciniis ovatis, latitudine subazualibus, extus ad apicem pubescentibus; tubus brevissimus.

Sts m. filamenta duo alba, adscendentia: Antheræ cordatx, purpurese.

Pıst. Germen compressum. Stylus declinatus, purpurascens, staminum longitudine. Stigma simplex.

CAPSUla compressa, profunde emarginata, obcordata, margine acuta10, bilocularis, laciniis paulo brevior, qux post florescentiam ex- 
crescunt, et tandem 4 ad 5 lineas longx, lineam ad sesquilineam latie sunt.

Semixa plurima, subrotunda, deplanata.

Habıт. in umbrosis silvaticis, et uliginosis circa Conimbricam, præsertim prope Cænobimm Divi Antonii Montis Olivarum, et alibi in Beira, sed ibi infrequens. Floret Maio et Junio. P'erennis.

PLanta amaricans, et viribus Veronicie officinali similis, et pro illa usitata, sed debilior.

OBs. Culta in hortis, et inculta in locis fertilibus non opacis, interdum variat caule adscendente, calyce in anthesi xquali corolla, aut parum breviore, quinquepartito, lacinia quinta minina ferèque obsoleta; inde species parum distincta esse videtur a V Teucrio V. montana et prostrata, quibus nimis aftinis.

Tom. 11 . 


\section{GR A T I OL A linifolia.}

\section{Lusit. Graciosa do Reino.}

Gr. foliis oppositis, sessilibus, lanceolatis, integerrimis; pedunculis axillaribus, solitariis, foliorum sape longitudine.

Gr. officinalis (ut varictas) Brot. Flor. Iusit. P. I. pag. 15.

Gr. linifolia. Vahl. Enum. I. pag. 89.

Gr. linifolia. Link et Hoflm. Fl. Lusit. pag. 225. Tab. 31.

Gratola alia, Lusilana, pituitam ac bilem supernè el inferuè vehementer purgans. Grisl. Vir. Lusit. N. 628.

Drgitalus linifolia, Lusitanica, palustris. Tourn. I. R. H. pag. 165.

RADIX perennis, calamum scriptorium fere crassa, subgeniculata, albida, obliquata, aut interdum fere verticalis; fibrillis subramosis.

CAvus adscendens (in herbosis erectus) cylindraceus, simplex, glaber. Rami perpauci, alterni, erecti.

Forra opposita, sessilia, semiamplexicaulia, acuta, angustè lanceolata, trinervia, glabra, sape integerrina, interdum uno aliove dente prope apicem instructa.

Fıores axillares, solitarii. Pedunculi erecti, foliis aquales aut vis longiores.

CALYx quinquepartitus; laciniis sublinearibus, acutis, erectis, persistentibus; interdum basi uno aliove foliolo auctus.

Cororla monopetala, ingequalis, fere labiala: tubus albus, calyce paulo altior: limbus e purpureo albus, glaber, intus ad faucen pubescens, quadripartitus, licinia sujeriore latiori, emarginata, refe$\mathrm{xa}$, tribns inlerioribus subacqualibus, rotundatis.

Stam. filamenta qualnor, corolla breviora, quorum duo inferiora breviora, sterilia. Antheræ subrotundxe. 
Pist. Germen superum, conicum : stylus rectus, subulatus: stigma bilamellatum, post frecundationem comnivens.

Peric. Capsula conica, bilocularis, bivalvis, polysperma. Semina plurima, parva.

Habitat in humentibus et inundatis ad Mundam, Durium, et Vaccam, vulgò Rio Vouga, in Beira. liloret Junio, Julio, Augusto. Perenuis.

Oes. Tota planta inodora est, sed valde amara et nauseosa. A pecoribus respuitur. Viribus medicamentosis Gratiolx officinuli ommino similis. 
O R C H I S , longicruiris.

\section{Lusit. Flor dos rapazinhos ou dos} macaquinhos dependurados.

O. nectarii labio inferiori oblongro, quadripartito, laciniis linearibus, duabus extremis protensioribus cum mucrone longo interjecto; petalis ovato-lanceolatis, acutissimis, distinctis conniventibus, apice patulis, duobus internis duplo minoribus; germine labio paulo breviori, calcare autem fere duplo longiori; bracleis brevissimis; spica ovata, densissima.

O. longicruris, labello germinis longitudine, tripartito levi, laciniis linearibus, intermedia bifida cum mucrone interjecto; petalis conniventibus acutis; cornu germine duplo breviore; bracteis membranaceis aristatis, germine duplo brevioribus.

Wil!d. Spec. Plant. Tom. 4. P. I. p. 22. Ead. Link in Schrad. Diar. bot. 779.323.

Radix bibulbosa; bulbis solidis, indivisis, ovalibus seu ovali-oblongis, supernè sub caule unà aliàve serie longarum simplicium radicularum filiformium comatis.

Foula radicalia procumbentia, lanceolata, lineata, glabra, integerrima, sæpe undulata, basi caulem vaginantia, tres, quatuorve uncias longa, decem ad quindecim lineas in medio lata. Caulina pauca, duo triave, minora, lanceolata, alterna, erecta, sese et caulem vaginantia.

$\mathrm{C}_{A}$ Uu, an anuus, cylindraceus, glaber, erectus, quinque ad octo uncias altus.

Fores plurimi, sessiles, in spicam ovatam, atque fere conicam, ad uncias duas aut paulo ultra protensam, arcte congesti. Bractex minimæ, germine florum quadruplo et ultra breviores, sæepe dilute purpurascentes, acute, nonnullie interdum truncatx, seu apice erosæ.

CALYX nullus.

Corolda pentapetala; tribus superioribus externisque petalis æqualibus, ovato-lanceolatis, acuminatis, lineatis, concavis, subpurpureis, 
quinque sexve lineas longis, conniventibus, basi tamen distinctis, apice patulis; duobus internis formà similibus, sed duplo minoribus.

Necta ru labium superius ( seu aliis columna gynandra) pelalis internis, quibus subjacet, brevius, obtusum, erectiusculum, purpurascens. Labium inferius propendens, oblongum, germineque paulo longius, dilute roseum, punctis purpureis unculatum, quadripartitum, laciniis linearibus integerrimis, duabus extremis longioribus, pauloque latioribus, mucrone ipsis interjecto valde longo, sicque pendulxe simixe formam aliquatenus referens. Calcar, seu tubus corniculi formis, pendens, labio concolor, germine ad dimidiam tertianve partem brevius.

Sta m. filamenta duo, tenuissima, lutea, sesquilineam longa, singulum in singula vaginulà membranacea, univalvia, labio nectarii superiori adnata, reconditum; utrumque glandula globosa mucosæ infernè insertum, supernè in ramusculos plurimos, pollinis grana in congeriem subglobosam, seu antheram, coarctata ferentes, divisum: grana pollinis lutea, angulosa, solida, inaperta.

Germen inferum, sulcato-angulosum, sessile, subcontortum. Stylus brevis, qui mihi pars crassa posterior labii superioris, et stigmaíis. Verum mihi stigma fornix faucis nectarii mucosus sub labio superiori, et sub glandulis, quibus staminum filamenta inseruntur.

Perıc. Capsula oblonga, sulcata, unilocularis, trivalvis. Semina plurima, scobiformia, seu subglobosa, arillo scobiformi inclusa.

Ha вгт a $\mathrm{T}$ in collibus siccis ex Olisipone usque ad Turres-Veteres, Cmtra, et alibi in Extremadura et Beira. Floret primo vere. Perennis.

OBs. 1. Orchis tephrosanthos Willdenovii (Spec. Plant.) quxe a La Marckio (Dict. Bot. Encycl.) Orchis simia nominatur, huic nostræ nimis affinis, et ejus quasi varietas, sed diflert petalis confluentibus, nec distinctis.

Ors. 2. Tota planta inodora est, saporeque mucilaginoso prædica. Ejus bulbi, uti etiam alii Orchidearum Europæarum, naturà viribusque Salep orientali similes sunt, atque extra omne dubium pari successu, sive ut alimentum sive ut medicamen, ei substitui possunt Orchideos bulbos ab orientalibus, antequam caulis floreat, colligi ferunt; sed apud nos optinum eos colligendi tempus illud cim seminibus jam formatis caulis marcescere incipit, tunc enin novi bulbi, qui unicè in usum avellendi, suam plenitudinem perfectam adepti sunt, et a veteribus marcescentibus satis benè dignoscuntur. Avulsi frigida lavantur aqua, deinde in ferventi alià injiciuntur, unde illico extraluntur, et eorum cuticula ope linteoli rudis detergitur; postea in patena dispersi in furnum pistorium introducuntur, ubi per quinque ad octo minuta retinentur; exinde in conclavium transferuntur, et ibi per aliquot horas soli exponuntur usque dum tandem omnino sic. Tomı. II. 
cescant, inhurescant et pellucitatem quasi cornu politi alipiscautur. Nommulli plarmacopolie eos semicoctos, vel in aqua calida per aliynod tempus retentos, exinde pelle expurgant, filo transigunt, et sic instar monilis soli exponmt usquequo siccentur et indurescant. Secundum Clariss. Percival etsi eorum cuticula nou separetur, nec ideo saporis et salubritatis aliquid deperdunt.

Ors. 3. In Orchideis structura florum singularis, insolita et ab illa reliquarum plantarum summopere diversa est; idcirco a Botanicis aliverse intelligitur et explicatur, uti jan Tom. I. pag. 103 et seq. retulimus. Nus in istius et sequentis generis speciebus describendis cum Limmeo earum llores corolla quinquepetala, nectario bilabiato, staminibusque duobus proditos esse asserere non dubitanus. Alii eorum florum corollam ut subringentem et hexapetalam considerant, cujus superiora petala quinque, vel ex his nonnulla, sxpius conniventia, distincta aut confluentia, pro galea, pro petalo autem sex10, seu corollic labio, inferius nectari labimn a Linnæo alnissum reputant, et ejusdem nectarii superius labiom columnam gynandram, seu genitalium utriusque sexus, appellant; sic quamvis aliis ad arbitrum terminis utantur, cum eadem tamen in se essentialia enuntiant, facillimum assensun conciliaverunt. Alii tam in his, quam in plerisque Orchiclearum generibus unicam tantummodo antheram, et hanc bilocularem, nectarri superiori labio innatan esse censent; antheras autem duas, a Linnæo sic dictas, nonnisi duo pollinis receptacula in duobus contenta loculis, antheramque al unam eandem sessilem attinentia, esse contejdunt; quapropter plantas Orchideas Monandras esse aflirnant. Hoc, ut videtur, indicatum, quippe quòl natura scopus antheras biloculares potiùsquain uniculares formare sxpius sit, atque ex analogia antherarum Orchidearun cum antheris aliquarum Tribuun sessilibus et bilocularibus. Attamen in Orchideirum floribus, (nostrarum saltem) pollinis receptacula ab omnibus aliariun Tribuum vegetabilium tali anomalia diflerunt, ut non satis probatum alluc, an ea unicam tantim antheram biloculurem bivalvem anonalam constituant, quim duas antheras uniloculares univalves anomalas, seu an pa polius unica anomala anthera, quàn duæ anomalæ dicenda sint; et enim verò in antheris florum alius cujuscunque Tribus, tain sessilibus bilocularibus quim aliis, pollinis granula loculorum dissepinento aut parietibus ipsorum granulorum recuptaculo vero, longitudinaliter innascuntur alque adharent; at in Orchidearum floribus nostrarum pollinis granula a pradictis loculorum partibus, quibus continentur, libera onnino sunt, et duorum filamentorum summitatibus rumulosis, quarum ramuli in racemuli subglobosi, seu claveformis plus minusve subdividi solent, immascuntur atque adherent: ex duobus istis filamentis, ut supra dictum est, singulum cuidam glandula pistilli glolosæ insidet, et per ipsam nutritur insimul cum suo racernulo pollinifero, donec tandem in istins plena maturitate venereo excititur aestro, loculi membranam subtus fundit, ex illo elastice erumpit, deorsum curvatur, congeriemque pollinis clavatam stigmati madilo applicat, ut ex granulis solidis inapertisque sperma exsudatum ab jpoo 
absorbealur, seminibus deinde deferatur, ipsaque fecundet. In nostris tamen Orchicleis interdum evenire lateor, nt stanina vehementi elaterio convulsa longe a cellulis vix dum apertis exsiliant, aut contrà, ut ex istis non exrant, et ibi diu inclusa sint usque adeo donec marcescant; at in primo casu semimum fecundatio nula est, ac ideò stiguna diutissime post exsultas longè aulheras mucosum persistit; in secundo anten fecundatio seminum ita imperfecta est, ut vix ulla maturescant, tunc posteaquam antherarum granula cum suis cellulis siccescunt, stigma madorem summ diu adhuc servat, sicut ex nuperrimè observatis agnovi. In nostris Urchideis seminum fecundatiora nobis visa sunt illa, quæ ab staminibus ex suis cellulis eruptis, curvatis. antherisque suis stiqmati madido applicatis vel qux a quamplurimis ipsi stigmati ejaculatis granulis per antheras, sicut quampluribus regularibus mos est, fecundata fuere, et huic noc alteri lini naturam ejusmodi staminibus elaterium eorumque cellulis aperturam derlisse videlur.

Ex his equidem colligitur antheras florum in Orchideis nostris structura irui peculiari anomala, atque ab omnibus aliis quibuscunque aliarım Tribunm vegetabilium antheris diversa; sed ex hujusmoli structura unicam in ipsarum floribus antheram bilocularem sessilem dari non demonstratur, cum pollen nulli dissepimento, nullibique locorum duorum membranis adhareat: dantur ibi re veri duo pollinis receptacula, sed ista ad unam eandem antheran non atinem; nam ejusdem nec dissepimentum nec loculormm membranas constitumnt, sed duo tilamenta tantummodo sunt, ab istis penitus libera, et in plurinos ranulos polliniferos in apice subdivisa; cim vero antherse a lilamentis, cum dautur, apice polliniferis supputentur, antheras igiur potius duas anomalas, quam unicam, Orchideis nostris tribuere, istasque potius diandras, quim monandras, dicere cum Linnæo, quidquid aliis placeat, prosequemur.

OBs. 4. In hac et nonnullis aliis bujus sequentisque generis speciebus bulbi sæpe duo approximati, subglobosi aut ovales, brevissimo filo sub caulis basi adhærent et ab illo pendent. Ex his alter vetus est, anno scilicet immediate anteacto productus, alius vero novissimè evolutus; uterque infernè omnino arhizus, supernè longis radiculis filiformibus é basi caulis circummatis comatus. Transacto vere, et vetus bulhus et caulis cum radicu, is omnibus siccescunt, ac penitus, superstite tantimn novo bulbo, peremnt. Post aquas aquinoctiales, Octobri aut Noveubri, novus iste bulbus ex apice suo, seu ex suo hilo gemmaceo, intra filum siccum, quo canli olim adharebat, radiculas primodum extrudere sensim incipit, deinde in liyeme et vere folia et caulen; tunc insimul secundus alter novus bubus ex caulina basi evolvitur sat veteri similis, qui cum illo radiculis hasilaribus caulis coronatus vegetat, ei ad posterum usque annum supervivit, et pari modo progerminat, ac sobolem novam profert. Utrum hac radicalia solide carnosa corpora bulbis potins, quan tuberibus annumeranda, usque adhuc indeterminatum. Tan in bulbis, quàm in tuberibus, peruultx gradationes a natura stabilitx, et carum melx nondun a Butanicis generali assensu perlecte definita suut; recen- 
tiores nonnulli radicalia illa corpora, de quibus hic agitur, a bulbis separant et tuberibus conjungunt, cùm ex apice primodum, nec ex basi, radiculas trudant, ideoque plìs tuberibus quàm bulbis regularibus affinia esse censent; alii cum Linnæo ea bulbis annumerant; nos illa etiam pro bulbis habere prosequemur, sed istos ut irregulares et fibrillis caulis basilaribus comatos consideranus.

Ors. 5. Orchidearum semina in Lusitania, sicut alibi, sive ex fecundationis perfectæ, sive ex sufficientis in capsulis nutriminis defectu, sive ex aliavis causa, difficillime ulla tantùm, aut interdum nulla germinant; nonnulli hortulani, qui hoc defectui nutriminis imputant, ut illa vegetiora evadant, ac plura germinent, novum bulbum primo vere vix evolutum resecare suadent; alii has stirpes in Caldariis, aut in ollis penitus terræ intrusis colunt. 


\section{OR CH IS papilionacea rubra.}

\section{Lusit. Herva borboleta.}

Orcr. nectarii labio indiviso, latissime ovato, rotundato, nec emarginato, denticulato; petalis ovato-lanceolatis, acutis, laxe conniventibus at erectis; calcare infernè crassiore, germine breviore; bracteis membranaceis, coloratis, germine longioribus.

Orcr. (rubra) labello obovato, indiviso, crenato; petalis nervosis, erectis; cornu conico, germine breviore; bracteis membranaceis coloratis, germine longioribus.

Willd. Sp. pl. T. 4. P. 1. p. 24.

Orcu. (rubra) bulbis indivisis; nectarii labio indiviso crenulato ampliato; cornu subulato; petalis erectis.

Jacq. Icon. Pl. var. I. Tab. 183. Collect. I. p. 60.

Radrx bibulbosa. Bulbi indivisi sunt, subrotundi, approximati; ex radicula filiformi brevi, é basi caulis exorta, propendent, atque aliis longioribus ex eadem caulina basi protrusis supernc̀ instructi sunt.

$\mathrm{C}_{\text {Aulis }}$ annuus, simplicissimus, erectus, teres, glaber, quinque ad octo uncias altus, duobus tribusve foliis lanceolatis vaginatus, et. ipsis fere undique obtectus. Folia radicalia quatuor quinqueve caulis basin vaginantia, caulinis maiora, lanceolata, acuta, recurvata, nonnulla interdum subundulata, nervosa, carinata, supra canaliculata, utrinque glabra, viridia, tres quatuorve uncias longa, novem ad undecim lineas in medio lata.

Flores terminales, quinque ad septem, in spicam ovatam dense congesti. Bracteæ membranaceæ, dilute purpureæ, lanceolatæ, acutæ, nervosx, carinatæ, concavæ, germine longiores, flore autem breviores.

Calyx nullus. Corolla pentapetala, purpurea, aut interdum subviolacea; petalis ommbus distinctis, laxe conniventibus, tribus exterioribus ovato-lanceolatis, acutis, nervosis, duobus lateralibus paulo Jatioribus pauloque longioribus; interioribus duobus lanceolatis, angustioribus, vix brevioribus.

Tom. II. 
Nectaru labium superius, seu aliis columna gynandra, erectum purpureum, petalis fere triplo brevius, acutum, postice convexum. La. bium inferius dependens, milobum, maximum, plus latum quaim longum, magnitudine unguis pollicis, rotundatun, sxpe absque ulla emarginatura, denticulatum, denticulis tantum perpaucis obtusis, dilute purpureum, et venis punctisque purpureis varicuatum, ad basin valde attenuatum, sicque quasi flabelliforme: calcar leviter arcuatum, infernè crassius, germine dimidio brevius, raro illius fere longitudine.

Reluava Generis.

Ilanitat in humidiusculis circa Setubal, in Arrabida, et alibi trans Tagum. Floret prino vere. Perennis.

Usus bulborum pro Salep substituendo.

Ons. Nectarii labium inferius in hac nostra planta etsi sæpe tota ora marginali nec emarginatum nec retusum, sed lantummodo undique denticulatum seu crenatum sit; interdum tamen emarginatura quadam parva obsolete mucronata donatur; quapropter illam uti Orclı. papilionacece varietatem consideramus. 
OR C II IS coriophora symplypetala.

\section{Lusit. Herva porsobeja.}

Orch. labello inferiori nectarii pendulo, trifido, laciniis lateralibus crenatis, intermedia longiori, integerrima; petalis ovato lanceolatis, acmminatis, comniventilus, tribus superioribus ad nedium coalitis, binis interioribus solutis, brevioribus; calcare conico, arcuato, et germine breviore.

Oncn. coriophora, labello tripartito, laciniis inæqualibus, crenatis, dependentibus; petalis conniventibus; cormu conico, adscendente germine triplo breviore.

Willd. Spec. plant. Tom. 4. Pärs. I. pag. 16.

Orch, odore lirci minor.

C. Bauh. Pin. 82. et Vaillant Bot. Paris. Tab. 31. fig. 30, $31,32$.

Ranix bibulbosa: bulbi subsessiles, indivisi, parvi, subglobosi, aut obovato-subrotundi, superuè ad caulis originem nomnullis radiculis filiformilus longis coronati.

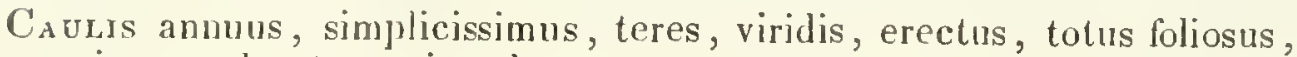
quinque ad octo uncias altus.

Fousa radicalia quinque ad septem, angustè lanceolata, acuta, suprà canaliculata, subtus carinata, vaginantia caulis basin, glabra, virilia, patentia, quatuor uncias aut paulo ultra longa, sex lineas ad novem in medio lata; caulina similia, sed minora, atque versus apicem caulis decrescentia, alterna, erecta.

Flores saturate purpurei, aut interdum ex viridi purpurascentes, in spicam sesquiunciam ad tres uncias, ant paulo ultra, longam densè congesti. Bractea sub singulo Janceolata, acuminata, sessilis, virilis, germinis basin amplexans, ipsoque vix longior in foribus infi$m$ is, in aliis brevior.

CALyx nullus. Corollæ petala quing̨e purpurascentia, erecta, contigua; tria exteriora paulo infra apicem coalita, lateralia ovato-linceolata, acuminata, intermedia angustior; bina interiora soluta, lanceolata, breviora, angustiora. 
Nectarium purpureum; labium superius, seu columna gynandra, petalis interioribus fere dimidio brevius, convexo-concavum, acutiusculum, erectum, stamina lutea tegens. Labium inferius pendulum calcare dimidio brevius, ad faucem punctis saturate purpureis pictum, trifidum, laciniis acutis, lateralibus crenatis, intermedia parum longiore, integerrima. Calcar conicum, arcuatum, germine paulo brevius.

Pisr. Germen tricostatum, contortum, apice valde attenuatum, cernuum.

Reliqua ut in Genere.

Habitat in collibus calcareis, et locis interdum subhumidis, prope $S$. Pedro Dias circa Conimbricam, in montibus quoque de Cintra, Monsanto circa Olisiponem, et alibi in Beira et Extremadura. Floret mensibus vernis. l'erennis.

SAPor totius plantæ herbaceus. Flores odore quasi cimicis fetent.

Usus radicis pro Salep. 


\section{OR CIIIS cordata.}

Orch. nectarii labio inferiori apice trifido, calcare brevissimo, scrotiformi ; foribus spicatis, laxis, secundis; petalis conniventibus; bracteis lanceolatis, germine vix longioribus; canle diphyllo, foliis cordatis, aculis, alternis, basi petioliformi vaginante.

Orcu. cordata. Willd. Spec. Plant. Tom. 4. Pars. I. pag. $25-26$.

Satrkum diphyllum. Link in Schred. Diar. Bot. 1799. p. 323.

Idem. Brot. Flor. Lusit, Tom. I. pag. 22.

Ramx bulboso-comosa; bulbi bini, indivisi, ovato-s!ubrotundi, supernè radiculis flexuosis, $e$ basi caulis exortis, comati.

$\mathrm{C}_{\text {Aulis }}$ teres, filiformis, striatus, simplicissimus, glaber, erectıs, semipedalis, aut parum longior, basi squamis alternis vaginatus, supernè diphyllus.

Folia alterna, cordata, basi petiolari vaginantia caulem, acula, quinquenervia, glabra, patula, integerrina.

Sprca terminalis; flores laxi, secundi, arcuati, sessiles. Bractea sub quovis flore lanceolata, acuta, lineata, viridis, glabra, erecta, germine parum longior, petalis autem exterioribus paulo brevior.

CaLyx nullus. Corolia pentapetala, purpurascens. Petala subæqualia, lineari-lanceolata, erecta, conniventia, tres fere lineas longa, marcescentia.

Necta Ru labium superius, seu galea gynandra, ovale, obtusum, petalis fere dimidio brevius, satmrate purpureum, stamina lutea tegeus: labiun inferius dilute purpureum, deflexum, germine paulo brevius, pianum, sensim ad apicen dilatatum, ibique trifidum, laciniss a qualibus, acutis, sublanceolatis, integerrimis; basi bursa brevissima scrotiformi postice instructum.

Stamna el Pistillum ut in Genere.

Tom. II. 
Capsula ovoidea, brevis, striata, sæpe corolli nectarioque arescentibus coronata.

Habitat in silvis ex Arrabida usque ad Azeiläo.

Floret mensibus vernis. Perennis.

Planta inodora, sapore herbaceo.

Usus bulborum pro Salep. 


\section{ORCHIS conica.}

ORCH. labello inferiori tripartito, laciniis denticulatis, Jateralibus sublinearibus, intermedia obovato-elongata, emarginata; petalis conniventibus, tribus exterioribus valde longioribus, ovato-lanceolatis, acuminatis, aristatis; calcare germine breviore; spica densa conica; foliis lanceolatis.

Orcir. comica, labello tripartito, lacinia media elongata, apice dilatata emarginata; petalis conniventibus aristatis; cornu geruine breviore; spica densa conica; foliis ovatis. Willd. Sp. Pl. Tom. 4. Pars. I. p. 14.

Orch. ylobosa. Brot. Flor. Lusit. Tom. I. pag. 18.

RADIX bibulbosa; bulbi ex ovato-oblongi, quandoque quasi fusiformes, supernè ad caulis originem nonnullis radiculis filiformibus coronati.

$\mathrm{C}_{\text {AULis }}$ simplicissimus, teres, glaber, viridis, erectus, foliosus, quatuor ad septem uncias altus.

Foma radicalia quinque sexve, et in omnibus individuis, qux mili observare contigit, semper oblongo-lanceolata acutaque, nervosa, integerrima, viridia, carinata, glabra, alia ex patenti-procumben1ia, alia patula, seu erectiuscula, laninis semiunciam ad fere unciam in medio latis, tres ad quatuor uncias longis; petiolis dılatatis, caulis basin vaginantibus. Caulina pauca, similia, sed sessilia, appressa, minora, el sursum sensim decrescentia.

FLores ex albido-purpurei, alterni, sessiles, in spicam terminalem, sesquiuncialem et ultra, obtusè conicam, aut acutè conicam, densè congesti, bracteis interstincti. Bracteæ lanceolatæ, acuminatæ, virides, sessiles, grerminis arcuati basin ferè amplexantes, illo parum longiores, flore autem breviores.

Calyx nullus. Corollæ petala conniventia, tria exteriora lanceolata, acumınata, aristata, nervosa; duo interiora anguste lanceolata, acuminata, dmmidio exterioribus fere breviora.

Nectari labium superius, seu columma gynandra, ovatum, acutim, intus concavun stamina tegens, extus convexum, petalis internis brevius. Labium inferius reflexum, germine brevius, planum, punctis saturate purpureis pictum, tripartitum; lacinis onmibus apice 
denticulatis, duabus lateralibus angustis, sublinearibus, obtusis, internsedia latiore, obovata, emarginata, sepe cum brevissimo mucrone in emarginatura. Calcar gracile, germine paulo brevius.

Rereua ut in Genere.

Hantat circa Bellas, prope Cintra, et alibi in Extremadura. Florel vere el astate. Peremnis.

Inodona et sapore herbaceo prædita.

Usus bulborum pro Salep.

Ors. Nim is aftinis Orch. globosa, acuminate, et lactce: sed differt a glubosa labio inferiori nectarii non resupinato, ejus laciniis lateralibus denticulatis, spica conıca, el calcare fere germinis longitudine. Differt ab acuminate, foliis radicalibus non ellipticis obtusis, sed lanceolatis acutis, labelli inferioris laciniis lateralibus denticulatis, nec integerrimis, intemedia sæpe emarginata, nec sxpe rotundata absque ulla emarginatura, pront depicta in Tab. 247. Desfont. Flor. Allant. Dillert etiam ab Orch. lactea (La Marck Dict. But. Lncycl. Tom. 4. p. 594, quæ ex Clar. Poiret eadem est cum Orch. acumina(a) tolis radicalibus non ovatis obtusis, labelli nectarii laciniis lateralibus denticulatis, nec integerrimis: attamen tam ista quàm acuminata fortasse ad nostram uti varietates anandandx. 


\section{OR CH IS latifolia labrovaria.}

Orcu. nectarii labio inferiori obovato-subrotundo, denticulato, lateribus reflexo, apice brevissime subtrilobo; petalis superioribus acutiusculis, conniventibus, lateralibus binis parum longioribus reflexiusculis; calcare germine fere dimidio breviore; bracteis lanceolatis, flore longioribus; caule folioso, fistuloso.

Orch. sesquipedalis, labello obovato, lateribus rellexo, emarginato, dentato; petalis superioribus acutis, conniventibus; cornu cylindraceo, germen subæquante; bracteis lanceolatis, flore longioribus. ivilld. Spec. Plant. 'Tom. 4. Pars 1. pag. 30.

Oncur. latifolia. Lin. et Brot. Flor. Lusit. Tom. I pag. 21.

Овсн. palmata, pratensis, latifolia, longis calcaribus.

C. Baul. Pin. 85, et Vaill. Bot. Paris. Tab. 31. fig. 1, 3, 4, 5.

RADIx bibulbosa, supernè ad caulis originem radiculis longis albis filiformibus coronata; bulbi palmati, crassi, albi, tetradactyli, digitulis infernè acutis, demum radicula longa terminatis.

$\mathrm{C}_{\text {aulis }}$ foliosus, squamis albidis vaginantibus ad basin tectus, simplicissimus, erectus, angulosus, glaber, fistulosus, pedalis, sesquipedalis, et nonnumquam altior.

Foula alterua, vaginantia, late et longe lanceolata, nervosa, carinata, patula, nomulla apice cernuo, pendulove, lete viridia, immaculata.

Flores purpurascentes, alterni, in spicam speciosam, quinque ad octo uncias longam, congesti; germine patulo, leviter recurvo, viridi, sessili. Bractea sub singulo flore ipso longior, sessilis, germinis basin amplexans, lanceolata, acuminata, nervosa, carinata, erecta, viridis.

CALyX nullıs. Corollse petala tria superiora lanceolata, acutiuscula, conniventia; duo lateralia parum longiora, lanceolata, acuta, patula, patentia, aut demum leviter reflexa.

Nectarn labium superius, seu columna gynandra, saturate purpuren!n, petalis superioribus dimidio et ultra brevius, stamina lutea tegens. Labium inferius obovato-subrotundum, purpureum, punct is Tom. Ir. 
lineisque saturatioribus pictum, ora marginali inæqualiter denticula. tum, lateribus rellexun, apice sæpe tribus lobulis minimis terminatum, quorum intermedius al sesquiliniam longus, vix ac nec vix lateralibus lougior, nunc crenatus aut obsolete emarginatıs, nunc obtusıs edentulus: in hujus labelli apice rarissime lobulos tantummodo duos brevissimos cum enarginatura minima inter ipsos mibi observare contigit. Calcar obtusum, supernè latius, sæpe germine dimidio brevius, raro tantummorlo in infimis spicæ floribus ipsius ferè longitudine.

Religua wit in Genere.

Habitat in uliginosis, et pratis humidis prope Conimbricam, circa Setubal, et alibi in Beira et trans Tagum. Floret vere. Perennis.

Planta inodora, sapore fatuo, et vix in foliis leviter amaricante.

Ous. Orchis scsyuipedalis Celeb. Willdenovii (Spec. Plant.) nonnisi hujus varielas est, et phrasis specifica, quam ipsi apposuit, ex spiciuninis sicci foribus variantibus, aut forte imperfectis, é Lusitania ad eum missi, desumpta esse videtur. 


\section{OPHR YS tenthredinifera.}

Opu. caule subnudifolio; labello germinis longitudine, ant vix brevio+ re, obcordato-bilobo, emarginato cum appendicula sursum versa, disco villoso; petalis patentibus, distinctis, exterioribus tribus subovalibus, binis interioribus brevissimis, acutis, ovalis; bracteis germine longioribus; bulbis subrotundis.

OPH. (tenthredinifera) caule folioso, labello villoso obovato bilobo appendiculato, petalis patentibus, tribus exterioribus oblongis obtusis, binis interioribus brevissimis. Willd. Spec. Plant. Tom. 4. pag. 67.

Opri. (insectifera $A$. rosea) labello villoso oblongo-obovato, apice bilobo appendiculato. Desfont. Fl. Allant. T. 2. pag. 320.

Opн. (arashrites) folia caulina oblongo-lanceolata. Bractexe floribus inulto longiores. Petala tra exteriora oblonga obtusa, interiora duo acuta purpurea. Labii lacinix laterales obsolete, media rotundata enarginata, appendice carnosa in emarginatura fusca, ambilu flava, apice villosa. Link in Schrad. diar. bot. 1799. 2. p.325. Exclndenda ab Oph. aranifera Clar. Willdenovii, et ad hanc nostram amandanda.

RaDYx bulboso-comosa; bulbis indivisis, subglohosis, solidis, binis, eorum uno vetere alio novo, utroque supernè sub caule radiculis longis, simplicibus, flexuosis, filiforinibus, comato.

Fous radicalia in orbem procumbentia, tria, quatuor, quinqueve, sessilia, acutiuscula, lanceolata, ant interdun fere elliptica, utrinque glabra, ilitegerrima, duas ad tres uncias longa, octo arl undecim lineas in medio lata, nervosa, supra canaliculata, sublus carinata. Inferiora caulis similia, sed minora, ijsum vaginantia, erectopatula.

$C_{\text {Aulis }}$ annuus, teres, glaber, ereclus, simplicissimus, tres ad septem uncias altus, spica supputata, paucifulius, sxpe uno aliove folio tantùm prope basin vaginatus.

Flores spicati, quinque ad septem, laxi. Bractex lanceolatx, concave, erectr, inferiores viriles, superiores rosex, sive purpurex, omnes germine longiores, corollx incerdum xquales.

CAIrx nullus. Corollæ petala supera distincta, rosea, ant purpurascentia, nervosa; tria exteriora oblongiuscula, obtusa, fere elliptica 
patentia, demum refexa; bina interiora ovata, acutiuscula, erecta, exterioribus triplo breviora.

Nectaril labium superius, seu columna gynandra, arcuatum, apice obtusum, pallide rosenm, petalis internis paulo longius. Labium inferius sxpe germine paulo brevius, petalis exterioribus longius, suprì ad fancem excavatun el ibi lineis roseis pictum, convexum lateribus subterflexis, in ambitu flavum, in centro fuscum villosumque, inferuè latius, rolundatum, emarginatum cum appendicula carnosa sursum versa in emarginalura instructum sicque obcordatobilobum apparet; subtus glabrum, sordide flavum, concavum, supernè ad faucem nectarii utrinque callosum.

Reliqua ul in Genere.

Habitat in collibus calcareis in Arrabida, et circa Olisiponem et alibi in Extremadura. Floret Februario, Martio et Aprili. Perennis.

Planta inodora, sapore mucilaginoso prædita. Bulbi pro Salep orientali substituendo a nommullis pliarnacopólis leguntur et præparantur.

Ons. Ophr. aranifera et Ophr. arachnites Willdenovii (Spec. Plant.) lunic nostrae nimis aflinis et forte varietas; nostra tamen ab utraque dillert labello nectarii apice latiore, bilobo, et fere obcordato, petalis quoque interioribus ovatis, acutiusculıs, nec lanceolatis ant lineari-lanceolatis. 


\section{O P II R Y S labrofossa.}

OpH. Caule subnudifolio; nectarii labio infero germine multo breviore, tripartito; laciniis duabus lateralibus oblongis, auriculaformibus, villosis, sursum deorsumque protensis; intermedia obovata, sub apice, interque subterflexa latera, fussula mucosa excavata; bracteis germine brevioribus; petalis patentibns, tribus exterioribus ellipticis, binis interioribus brevissimis, ovatis, acutis; bulbis aliis subsessilibus, aliis longo filo pendulis.

$\mathrm{R}_{\text {A DIX }}$ perennis, bulboso-comosa; bulbis subglobosis, ino alterove ad caulis basin subsessili, duobus autem filo sesquiunciam ad quatuor uncias longo pendulis. Cuncti radiculis nonnullis filiformibus longis, simplicibus, flexuosis, é caulis basi exortis, comati sunt.

Fonsa radicalia quatuor arl sex, patentia, seu procumbentia, lanceolata, acutiuscula, integerrima, nervosa, ntrinque glabra, ut tota planta, inæqualia, duas ad quatuor uncias longa, semiunciam ad unciam in inedio lata, subtus carinata, suprì canaliculata, basi caulen vagrinantia. Inferiora caulis duo ad tria similia, alterna, erectopatula.

CAulis annuus, simplicissimus, paucifolius, subteres, uno aliove angulo obsolete notatus, viridis, glaberrimus, erectus, tres ad quinque uncias altus, spica supputata.

Frores spicali, in racli subangulata alterni, laxi, tres ad quinque, erecti, pedunculo unam ad tres lineas longo impositi. Folium florale spatheforme, lanceolatum, concavum, erectum, viride, nervosum, sessile, pedunculum, nec spica rachin, amplexans, germine dimidio ferè brevius.

Caty nullus.

Corolla pentapetala; petalis tribus exterioribus patentibus, ant reflexiusculis, glabris, penitus viridibus, obtusis, ellipticis, intus concavis, marginibus revolutis, tres quatuorve lineas longis, longitudine aqualibus, nedio seu supremo angustiore, ipso et lateralibus infernè solutis; duobus interioribus minimis, triplo et ultra minoribus, reflexis, ovatis, acutis, marginibus revolutis, supri convexis, subvillosis, é medio ad apicem viridibus, inde usque ad basin utrinque fuscis.

Nectarium apici germinis insimul cum corolla aflixmm, bilabiatum. Tom. II. 
Iabium superius, aliis colnmna gynandra, sesquiliniam ad lineas duas longum, incurvum, convexo-concavum, apice obtusum, flavescens, infernè fuscum, dilatatum, atque cum inferiore coalitum. Faux ampla, profunda, fusca, marginjbus elatis glabra nitida, ibique utrinque unidentata, brevissinaque auricula villosi instructa. Labium inferius pendulum, ad faucem excavatum, ex fusco coccineum, petalis exteriøribns et germine brevius, tripartilum : lacinia dux laterales longa, mediæ longitudine xquales, auriculæeformes, sursum deorsumqure protensæ, quarum pars superior breviter conicè elata, villosa, ex flavo fusca, postice subtus concava glabraque, inferior vero pars oblonga plana acuta, antrorsum oblique versa coccinea glabra: lacinia media obovata, glabra, apice tanen subvillosa, supri convexa, subtus concava, basique ad faucem subcarinata, carind in tuberculi formam, ad sesquilineam fere prominentis, abeunte; ejus apex obtusus brevissimus, absque ulla emarginatura, vel ulla appendicula, sed inter duas lacinulas laterales subler flexas, coccineas, clabras, leviter recurvus. et fossula sesquilinean lata, mucosa, uniglandulata, profunde subtercavatus.

Pıst. Germen inferum, viride. sexsulcatum, sexcostatum, decem ad tredecim lineas longum, leviter reflexum, vix ac ne vix contortum. Stylus, seu pars postica dorsualis labii superioris nectarii et stigmais, brevis. Stigma verum nectarii faucis fornix madidus postice cum stylo confusus, cujus muculentise quamplurina pollinis granula ab antheris elasticis ejaculata diu adharent.

Stam. filamenta duo lutea, lineam ad sesquilineam longa, glandulis duabus globosis in apice stigmatis sitis inserta, sensim sursum versus cràssiora, et singula in congeriem granulorum, sed racemulum graniferum subglobosum clavatumve terminanlia; gramula lutea, angulosa, solida, inaperta, racemuli ramusculis varie subdivisis adhærentia. Racemuli dno isti, antheras duas constiluentes, in cellulis tolidem membranaceis, sub labio nectarii superioris sitis, penitus soluti includuntur; in anthesi vero ex ipsis antice apertis elastice erumpunt, et deorsmu curvati stigmati applicantur (sicuti quamplurimis staminibus stigmate altioribus mos est) ab eo spermatica fluida substantia, qualiscunque ea sit, absorbctur, unde postea ad ovula germinis exportatur, istaque fecundat.

Peric. Cilpsula ohlonga, sexsulcata, sexcostata, unilocularis, trivalvis, angulis sub custis dehisceus.

Semrna numerosa, minima, scobiformia, s. globosa, arillo. scobiformi inclusa, receptaculo lineari simgula valvulx pericarpii afixa.

Habitat in collibus calcareis de Monsanto, et alibi circa Olisiponem. Floret Februario, Martio, Aprili. Peremis.

Oss. 1. Planta non alio sapore nisi mucilaginoso predita, et inodora est. Bulbi, ut illi aliarmu Orchidearmn nostrarum pro Salep orienta- 
li substiluendo leguntur ac præparantur; ferventi aqua immittuntur, ex ipsa dein illico auferuntur, et pelle expurgata calore solis aut furni siccantur.

Ors. 2. In nostris Orchideis nullæe alixe species nobis notæ, qux bulbos longis tilis pendulos ferant, nisi hæe, et Serapias linqua et cordigera. Hi bulbi irregulares, quos alii Botanici luberibus annumerant, eodem modo progerminant ac novan prolem proferunt, quo bulbi approximati subsessiles. Vide Orch. longicruris Obs. 4. 


\section{O PHR Y S apifera sublerrostruncu.}

I.usit. Herva abclha.

Orn. Caule folioso; nectarii labello inferiori obovato-subrotundo, convexo, quinquelobo, lobis lateralibus ovato-cordatis, patulis, extremis duobus minimis obtusis, subtus inflexis, intermedio terminali subulato, subtus pendulo retrorsumque in rostrum uncinatum recurvato; petalis patentibus, tribus exterioribus obtusis ellipticis, binis interioribus triangularibus brevissimis.

RADIx perennis, bulboso-comosa; bulbi duo é filis brevibus penduli, quorum unus velus sutrotundus minor, alius duplo maior novus oblongo-ovalis, ambo radiculis nonnullis filiformibus flexuosis, é basi caulis exortis, comaij.

Caulis annums, erectus, simplicissinus, pins minusve semipedalis, teres, glaber, viridis, é basi ferè usque ad apicem foliosus.

Foura ad caulis basin plerumque tria ipsum vaginantia, lanceolata, acutiuscula, subtus carinata, supra canaliculata, utrinque viridia, nervosa, patula, tres ad quatuor uncias longa, unam in medio lata; internedia et superiora caulis similia, sed sensim minora, acuminata, alterna, erecta.

Flores quatıor quinqueve dense spicati, magni, subsessiles, alterni. Practea sub quovis eorum lanceolata, acuta, nervosa, viridis, sessilis, germiuis basin semiamplexans, ipso longior, petalis autem exterioribus altitudine subæqualis.

Catyx nullus. Corolla pentapetala; petalis tribus exterioribus patentibus, solutis, obtusis, ellipticis, dilute purpureis, lineis tribus viridibus notatis. grabris, subxqualibus, medio vix longiore, quinque sexve lineas longis, tres quatuorve latis; duobus interioribus brevissimis, triangularibus, viridibus, solutis, patulis.

Nectaru labium superius, seu galea gynandra, tres quatuorve lineas Jongum, viride, rostratum, arcuatum, stanina duo lutea tegens, et ita cum staninibus aviculx capnt referens. Labinm inferins lateribus reflexum, convexum, obovato-subrotundum, supra velutino-fuscum et iufra medium ad faucem lineis luteolis arcuatis variatum, germine fere dimidio brevius; subtus virescens, glabrum, trilineatum: quinquelobum, lobis lateralibus duobus prope faucem bicallosam corda- 
to-ovatis, acutiusculis, ferrugineis, seu ex viridi fuscis, villosis, patulis apice reflexo; lobis terminalibus duobus minimis brevissimis, obtusis, subtus inflexis, istis absque emarginatura, intermedio subulato, lutescenti, ad tres fere lineas longo, subtus recurvato, pendulo, apice uncinato.

Reliaua ut in Genere.

Haвiтат in collibus calcareis, pascuis, silvisque in Arrabida, et circa Conimbricam. Floret vere, Perennis.

Usus bulborum pro Salep.

Ors. 1. Nimis aflinis Oph. apiferce Willd. Spec. Plant. et nommisi ejus varietas mihi esse videtur. Orchys fucum referens Vaillant Bot. Paris. 146. Tab. 30. fig. 9. ab ista nostra non diversa. Ophrys arachnites (Flur. Lusit. Tom. I. pag. 23.) cum ista conjungeuda.

Ors. 2. Ophrys apifera pro varietate Oph. arachnitis antea habita nuper a recentioribus Botanicis ab ista separata fuit ob nectarii labii inferioris dillerentiam; Opln. arachnites enim diflert ab illa labii apice brevissime trilobo. 


\section{O P H R YS aurita.}

Opn. Caule folioso, paucinoro; labello inferiori nectarii trilobo, subvilloso; lobis lateralibus villosis, sursum versis, intermedio ovato, obtuso, convexo, lateribus conniventer revolutis, apice integerrimo; appendiculato; petalis patentibus, viridibus, tribus exterioribus ovatis, obtusis, duobus interioribus sublinearibus, multo brevioribus.

RAnı bibulbosa; bubi globosi, subsessiles, radiculis fliformibus ó basi caulis exortis coronata.

Fol.1 a radicalia quatuor quinqueve, erectiuscula, late lanceolata, acuta, viridia, nervosa, carinata, glabra, petiolis dilatatis, caulis basin raginantibus, quatuor quinqueve uncias longa, undecin ad tredecim lineas in medio lata. Caulina perpanca, duo triave, similia, sed sensim minora, erecta, semiamplexicaulia.

Catlis anuuus, simplicissimus, teres, glaber, viridis, erectus, quinque ad octo uncias altus.

$F_{\text {Lor }}$ quatuor ad sex terminales, alterni, recurvi, sessiles. Bractex lanceolatx, aculx, concave, erectx, basin germinis amplexantes, jpso parm longiores, flore autem breviores.

CaLyx nullus. Corolla reflexiuscula; petalis tribus exterioribus ovatis : obtusis, aut ovato-subrotundis. subequalibus, medio vix angustiori et breviori; duobus interioribus sublinearibus, duplo et ultra brevioribus.

Nectaru labium superius, sel columna gynandra, ex virili pallescens, petalis interioribus longius, concavum, stamina tegens, arcuatum, rostratum, sicque aviculix caput referens. Labium inferius oblongum, trilobum; lobis duobus lateralibus sursum arcuatim versis, ovatis, acutis, villosis, fuscis, intermedio ovato, subvilloso, fusco, convexo lateribus glabris fulvis conniventer revolutis, prope faucem lineis exalbilis arcuatis picto, apice integerrimo, ibique appendiculato; appendicula crassa, flava, late ovata, mucronala sicque quasi triangulari, sursum reflexa. Hæc pars floris, si es industria omnino expandalur, ovato-subrotundo similis.

Relaqu ut in Genere. 
Hanitat trans Tagum in Arrabida, circa Setubal et alibi. Floret vere. Perennis.

PLANTA inodora, et sapore herbaceo prodita.

Usus bulborun pro Salep.

Ors. Oph. bombylifera Celeb. Willdenovii (ed. Lin. Sp. plant. Tom.

4. p. 68.) huic nimis affinis, el nonnisi ejusden varietas esse videtur. 


\section{OPHR Y fusca.}

\section{Lusit. Moscardo fusco.}

Opн. fusca, caule folioso; radicis bulbis duobus subrotundis; nectarii Jabio oblongo, germine breviore, trilobo, laciniis lateralibus reflexiusculis, obtusis, brevioribus, media obovata, obtusa, villosa, fusca, profunde emarginata, inappendiculata; petalis viridibus, patentibus, tribus externis subovalibus, binis interioribus linearibus, parum brevioribus.

Opı. (fusca) Willd. Sp. plant. It. Link in Schrad. Diar. Bot. 1799. 2. p. 324 .

Opr. (myodes) varietas $\zeta$ La Marck Dict. Bot. Encycl, Meth. Tom. 4. p. 572 .

Opr. insectifera myodes. Lin. Sp. pl. 1343.

Opr. myodes fusca Lusitanica. Breyn. Cent. $\frac{1}{2}$.

Raprx bibulbosa; bulbi indivisi, subrotundi, subsessiles, fibrillis filiformibus, flexuosis, é caulis basi protrusis, supernè instructi.

Fol a radicalia caulis basin vaginantia, tria quatuorve, procumbentia, interiora erectiuscula, omnia lanceolata, viridia, glabra, integerrima, quatuor quinqueve uncias longa, semiunciam ar unciam in medio lata. Inferiora caulis similia, sed minora, ipsum vaginantia, erecta, sessilia.

Caulis annuus, simplicissimus, teres, viridis. glaber, erectus, sex ad novem uncias altus, plerumque fere nudifolius, supernè subangulatus.

Fıores laxe spicati, tres quatuorve alterni, sessiles, remotiusculi, erecti. Bracteæ basin germinis amplexantes, ipsoque longiores, lanceolatæ, concavæ, erectæ, virides, floribus paulo breviores.

Calrx nullus. Corolla supera, pentapetala, viridis, expansa; petalis tribus exterioribus subrequalibus, obtusiusculis, subovalibus, nervosis, margine revolutis, supremo valde concavo, duobus interioribus linearibus, obtusis cum acumine, paulo brevioribus, omnibus infernè inter sese solntis. 
Nectarı labium superius, seu columna gynandra, concavum, obtusum cum obsoleta emarginatura, viride, petalis internis dinililio brevius. Labium inferius nunc germine brevius, nunc aquale aut paulo longius, oblongmu, obovatum. trilobum, lobulis omnibus obtusis, subvillosis, reflexiusculis, fuscis, orâ seu linea maryiuali obscure coccineis, duobus lateralibus brevioribus, intermedio latiore, acute marginato, inappendiculato, supra $\dot{e}$ medio disco usque ad faucen duabus maculis longis dilute fuscis glabris notato, et nonnunquam etiam aliis albis aut subcoccineis; prope fancen canalicnlato; subtus viridi, glabro et sub fauce duobus callis instructo.

Stamnum filamenta duo, totidem cellulis nectarii labinm superius constituentibus inclusa, lutea, lineam longa, duobus glandulis g!obosis, in apice faucis concavæ nectarii sitis, inserta, sensim sursum versis crassiora, el singula in racemulum graniferum clavieformem, qui vera anthera, terninata. Granula lutea subturbinata, angulosa, solida, inaperta, racemuli rachi capillari elasticæ, aut ejus ramulis adbærentia.

Reliqua ut in Genere.

Habitat in collibus calcareis circa Olisiponem, in Arrabida, et alibi in Extremadura. Floret vere. Perennis.

Usus bulborum, at alii Orchidearum aliarum, pro Salep orientali substituendo.

OEs. Differt ab Oph. lulea et vespiferc, quibus affinis, nectarii lobis omnibus fuscis, reflexis, nec erectis, non planis, lateralibus laxioribus nec vix fissura disjunctis. Nec ut varietas $\mathrm{Oph}$. myodis consideranda; ab illa enim differt petalis exterioribus non lanceolatis, Jobulis labii nectarii fuscis, lateralibus non lineari-lanceolatis, latiorique spatio inter sese dissitis.

Tom. HI. 


\section{OPHRYS corniculata.}

Opı. caule folioso; nectarii labio infero trilobo, lobis lateralibus villosis, altera parte conica indivisa sursum, altera profunde sinuata deorsum versa, interuedio oblongro, convexo, lateribus conniventer revolutis, apice obtuso, integerrimo, appendiculato; petalis tribus exterioribus oblongo-subovalibus, ohtusiusculis, binis interioribus brerissimis sublinearibus, acutiusculis.

RADrX bibulbosa; bubis subglobosis, alio vetustiore sensim decrescente demumque rugoso, alio juniore sensim increscente, utroque supernè radiculis filiomibus é basi caulis exortis comato.

Folı radicalia pauca, tria quatuorve, patentia, seu erectiuscula, lanceolata, acuta, subcarinata, integerrima, viridia, ytabra, nervosa, basin canlis vagrinatia, tres uncias aut palo ultra longa, novem ad matecim lineas in medio lata. Caulisa perpanca, duo triave, similia, sed minora, sessilia, vaginantia, erecta.

Caulrs annuus, simplicissimus, teres, supernè obsolete angulatus, glaber, viridis, erectus, quatuor ad septem uncias altus.

Flores terminales, spicali, subsessiles, quinque ad novem, alterni; recurvi, inferiores remotiusculi; rachi glabra, subangulata. Bracteæ spathalornes, hasin gerninis amplexantes, lanceolatx, acutæ, concava, virides, erectx, inferiores germine floribusque longiores, superiores autem germine longiores, floribus breviores.

Calyx nullus. Corolla pentapetala, patens ant reflexiuscula; petalis uribus exterioribus oblongo-subovalibus, obtusiusculis, subrequalibus, medio paulo angustiori el breviori, concavis, purpureis, nervo dorsuali viridibus, marginibus leviter revolutis, utrinque glabris, duas lineas latis quatuor longis; duobus interioribus dilute purpureis, brevissimis, triplo brevioribus, sublinearibus, basi paulo latioribus, et ibi utrinque uno punclo obscure purpureo notatis, apice acutiuscnlis, marginibus leviter revolutis interdum subvillosis.

Nectarum bilabiatum. Labium superius (aliter galea sen columna gynandra dictum) petalis interiorihus dimidio altius, virile, infernè latius, crassius et excavatum, supernè angustius, biloculare, concavum, apice incurvo rostrato, sicque aviculx caput quasi effingens. Labium inferius dependens, superiore duplo aut paulo ulira longius, et cum illo germinis apici intra petala adnatum, oblongum, gibboso-convexum, suprà subvillosum fuscum, subtus glabrum ex viridi flavescens, 
infra medium lineis exalbidis arcuatis pictum, ad nectarii faucem crassius et ibi duobus minimis callis fuscis nitidis notatum, tripartitum; laciniis duabus lateralibus villosis, ex fusco viridibus, alterit parte surrecta acuta conica el intus concava, altera deorsum versa latiore profunde simuata, sen biloba, lobo wno ad fincen nectarii intorte protenso; lacinia media ovata, lateribus deorsum conniventer flexis, flavis, glabrisque, (qua si ex industria expandantur, lacinia tunc latissime ovata redditur) apice obluso integerimo cum appendicula sursum versa, subovata, plus lata quim longa, mucronata, flava, crassa, glabra.

Sta m. filamenta duo lutea, sesquilineam fere longa, singulum in sinnula vagrinula membranacea sacculi bilocularis labii superioris nectarii reconditum, et glandulæ slobosx, in summitate faucis ejusdem nectarii sitw, insertum. Anthera obovata seu subclavata, simplex in simgulo filamento; grana pollinis, lente visa, racemalim cousesta, rachis elastica pedicellis minimis adlixentia, lutea, angulosi, obovata, inaperta.

Pistallum: Pericarpium el Semina ut in Genere.

Habitat in Arrabida, circa Selubal, Olisiponem et alibi in Extremadura. Floret vere. Perennis.

Usus radicis pro Salep.

VAR1AT petalis albidis. 


\section{TRIANTHERIA MONOSTYLIA.}

\section{CR OCUS autumnalis multifidus.}

Cr. foliis sex quatuorve simul cum flore prodeuntibus, linearibus, angustis, subtus bistriatis, et inde pro revolutis habitis; floribus sxpe solitariis binisve, raro ternis; corolla sæpius violacea, ad faucem villosa, laciniis tubo sæpe multo brevioribus; stigmatibus tribus longe cuneilormibus in fila tenuissima inaqualiter multifidis, penicilliformibus, antheras superantibus, corolla brevioribus.

Rндотоми neotericis Lusitanis = Acafram bravo $=$ (Crocus sylvestris). In Transtaganæ maritimis $=P e$ de hurro $=$ (Pes asininus) vulgariter appellatur; sed falsò atque nimis impropriè nam solis Colchicis hoc vulgare nomen, olim ex radicis forma bulbosa unguiculo terminatx ipsis tributum, proprie donabile, illudque tantumnodò eis relinquendum. Minus impropriè, etsi inspecificè ac valde indeterminatio, a nonuullis rusticis $=$ Nozetas pequenas $=$ (Nucula parra seu avellanex) et ab aliis = Cebolinhas (Parve cepx) quo nomine omnes minores bulbos ipsi nuncupare solent, eliam vocatur.

Cr. montanus exsors odoris.

Theophr. Hist. Plant. lib. 6. cap. 7. (Vers. Gazæ).

Crocum montanum primum. Clus. Hisp. et Hist. post.

Cr. serotinus. C. Bauh. Pin. pag. 65, dum Cr. montanum I. Clus. respicit.

Cr. montanus autumnalis. I. Bauh. Hist. Plant. 2. pag. 646.

CR. montanus autumnalis, flore purpureo, violaceo, albo.

Grisl. Virid. Lusit. N. $1530-31$.

CR. cricetorum autumnalis flore albo et vario.

Grisl. Virid. Lusit. N. 1532.

CR. autumnalis, sativo similis, florum capillamentis tenuissimis, minus odoris. Tourn. Cor. 25.

Cr. autumnalis. Lin. Sp. Plant. et Brotero Flor. Lusit. Tom. I.

Cr. Serotinus, stigmatibus erectis, multipartitis; foliis cum flore prodeuntibus. Ait Hort. Kew. nov. edit. I. pag. 82. Rotan. Magaz. Tab. 1267. Salisb. Parad. 30. Park. Parad, 168, N. 4. 
RADIX bulbose perennans; bulbus (in autumnali plantæ anthesi) duplicatus, alius scilicet alii insidens. Qui subterpositus, seu qui autumno superioris anni ex alio prodierat, maior nucis avellanex fere magnitudine, quamplurimis tunicis squamisque siccis, quæ olim vaginarum et foliorum bases fuerant, reticulatis, ex virili fulvis, obtectus; harum externa laxiores, crassius fibrata, filis laceris; interiores minis laceræ, tenuiores, quarum intima maxima, umbilico basilari bulbi adhærens, alix inverse infundibuliformes, sensim sursum versis minores, bulbi lineolis circinatis pariter sensim minoribus, levissimè adhase. Bulbus, omnibus suis tunicis siccis denudatus, minor quim in saivo, solidus, seu tıberiformis, rotundıs, quatuor quinqueve linearum diametro, desuper depressus, in medlio cavatus, lineolis subfulvis circulatim pictis, sursum versùs sensim minoribus, et quasi internodiis, distinclus; interdun ad ejus latera unam aliamve gemmam minimam, seu bulbulum articulatum, emitteus: infernè subplanus, permultis albis radiculis fibrosis in orbem pertusus, centro umbilicatus, ibique funiculo quodam brevi sicco instructus, hoc bulbis veteribus exsuccis emortuisque, sub lamellarum rotundarum nigrantium formà sibi suppositis, laxe conjunctus est.

Burbus superpositus, seu novus, subglobosus, Vicia sativæ grano (tunicis supputatis) subxqualis, in bulbi subterpositi cavatione terminali fere semiclausus, ejusdem fibrosis fasciculis centralibus adnatus, squamulis siccis, rufulis, brevibus, ovatis, acutis, inæqualibus, la$x$ is, foris obvallatus, basibus novarum vaginarum foliorumque albidis tunicatus, centrali parte parvula solidus, ibique scapiferus.

VAGrN basi novi bulbi, simulque subterpositi apici adnatæ; alixe extrafolıcex, intrafoliacex aliæ. Qux folia cingunt, quatuor quinqueve, membranaceæ, tubulosæ, apice oblique truncatæ, nervosæ, glabra, exalbidæ, sese mutuo imbricatim involventes, sensim sursum versis longiores, suprema biuncialis, obtusa cum mucrone, striata, foliis etfloribus brevır. Quæ intra folia tot quot scapi, quos cingunt, extrafoliaceis similes, sed tenuiores, albissima, acuminatx, scapis pistillique germine longiores, spatha tamen floris valde breviores. Interdum, cum duo tresve flores ex bulbo prodeunt, vagina intrafoliacea exterior suum proprium scapum et insimul alias (secundam terliamque) vaginas cum suis scapis propriis cingit.

Folı sæpissime sex quatuorve, rarissimè tria, quinque, septemve, solido novo bulbo adnata, simul cum floribus prodleuntia, et sensim sese elongantia, glabra, viridia, versus basin albida, linearia, unam lineam, vix ultra, lata, prope apicen angustiora, in eo obtusiuscula; suprì in medio subcanaliculata, atque linea albida longitudinaliter notata, lateribus marginalibus utrisque integerrima, lente tamen visa aculeolis minimis mollibus hyalinis vagis ibique instructa; subtus bistriata, sen canaliculis binis exarata ita, ut inde revoluta videantur, costâ valde compressa, utrinque dilatata el quasi alata. Torr. 11. 
In anthesi corollis breviora = et interdun eis suhxequalia, scapis antem tunc et postea multo longiora; vix evaginata, et adluc planta florente decumbentia. Si folis Croci sativi comparentur similia, sed. eis valde breviora.

Scapus, nisi lunc pro pedunculo radicali sumas, šepissimè solilarius (raro duo, rarissine tres) é centro novi bulbi exortus; filiformis, obsolete trigonus, sursum sensim incrassatus, vagina sibi proprià cinclus; duin.sub terra albus, pollicaris, postea bi, tripollicarisve, fuscus.

FLores tot quot scapi, ideo, ut ipsi, sppissimè solitarii.

Perhanthum nullum; ejus loco spatha unica, monophylla, tubulosa, sursum sensim latior, vaginis foliormm similis, sed longior, apici scapi sub germinis base adnata, germen et corollx tubum cingens, is. tuque panlo brevior.

Corolia supera, monopetala, inodora. Tubus angustissimus, sesquiunciam, duas uncias et ulta longrus, (prout bubus plus minusve sub terra latel) inferne albus, superne sæe violacens, in summitate longior, ibique intus villis albis hyalinis instructus. Limbus campanubutus, sexpartitus; divisuris petaloideis, lanceolatis, acntiusculis, glabris, foris convexis, intus concavis, primim erecto-patulis, deinde patentibus, sape violaceis, anl ex albo-vinlaceis, interdum purpureis, raro albis, exterioribus tredecim ad quindecim lineas longis, interioribus unam lineam aut paulo ultra, quàm externæ, brevioribus.

Sтам. filinenta tria antheris breviora, flava, subulata, tubi villosæe summitati, subtribus alternis corolla divisuris, inserta. Anthera flavæ, erectx, filamentis adnatx, oblongx, lineari-sagittatæ, biloenlares, utrinque longiludinaliter dehiscentes, pracociter pollinis grana flava globosa ejaculantes, corolla divisuris dimidio ferè, stigmatibus autem unam ad tres lineas, breviores.

PIst. germen ollongum, subovale, exalbidum, obtusc̀ triquetrum, obsoletè trisulcatum. Stylus filiformis, flavus; ejus extremun (ubi incipit in stigmata findi) corollse tubo longius, antheris paulò brevius Stigmata tria, inodora, flava, aliquantum convoluta, longitudine xqualia, longè cuneiformia, infernè indivisa, ex medio, aut paulo infri, in plura fila, seu lacinias subcapillares, inxequalia nultitissa ita, ut penicillifurmia videantur, antheras plus mimusve altitudine superantia, corolla divisuris inclusa, ipsisque duas ad tres lineas breviora, primum erecta, seu erecto-patula, demun reflexa, laxiora.

Peric. Capsula subovalis, trigona, trilocularis, trivalvis, polysperma. Semina plura, subrotunda, subfusca, seu ex fusco rufa.

Habitat in dumetis circa Olisiponem, trans Tagum in Caparica, et 
alibi in Extrenadura et Transtagana, prosertim in locis, qui non longe í mari absunt. Florel post aquas axuinoxiales, Septembri, Octobri, Novembri, Decenbrique; sed ejus fruchus nonnisi primo vere periecte maturescil. Bubosé peremial, bulbis sub terra tres ad quinque uncias latitantibus.

Тот planta inorlora ést, el vix alio, quan herbaceo, sapore donata. $\therefore$ Usus Lusilauis nón alius, quàn flormiu studiosis ad hortorum areas - in autumno exornandis; nanj stigrmata, cun inodora sint, non le- guntur, nec feculam ex bulbis anylacean extrahendi praxis ulla.

Oss. Crocus multifulus Ramond, Ia Marck el aliorum, insimulque Crocus muliforus Smith jonnisi hujus nostri varietales, ex Jocorum situ frigidiori, vel ex labitudine, quan eo ipso adepti fuere, unde folia serins emiltere solent, mihi esse videntur. Nonnulli alii Croci angustifolii, qui ab Autoribus brmnales, verni, serolini, montani, etc. dicuntur, et quorma stignata primin brevissimi incisa, seu quasi crenata, videntur, demum vero in eorum periecta vegetatione multifida fiunt, etiam ad mostrum anandandi. Notre specilicx, sive sint illæ, que ex stigmations cum antheris quoad altitudinen comparatis, sive qua ex eornm divisuris desumi solent, tantumnodu lirmæ cim ex jpsis perfecte evolutis desumuntur. Nostri Croci interdum stigmata in aliquibus individnis vis sublaciniata, antherisque breviora vel xqualia primim observantur, etsi tunc jam corolla limbus apertus sit; at sensim indies excrescentia in fila plura finduntur, plus elongantur, demún quasi penicilliformia redduntur, et antheras altitudine plus minusve superant. 


\section{R I S trialata.}

IR. pedunculis radicalibus; foliis canaliculatis, distichis, recurvis ; corolla tubo longissimo, laciniis maioribus imberbibus, adimedium dilatatis. obtusis, reflexis, alternis aliis minimis, lanceolato-spathulatis, obtusis, serrulatis, patentissimis; stignatum lobulis acutis, denticulatis, introcurvis, corollæ unaquaque lacinia maiori brevioribus.

IR. Transtagana. Brot. Flor. Lusit. Ton. I. pag. 52.

Ir. alata, imberbis, foliis ensiformibus; tubo longo filiformi; petalis interioribus minimis, patenti-reflexis. La Marck Dict. Bot. Encycl. Tom. 3. p. 302. Il. Poiret Voyage en Barbar. vol. 2. p. 86.

Ir. microptera, inberbis, foliis ensiformibus; tubo longo filiformi ; petalis interioribus minimis, patenti refexis. La Marck Illustr. Gen. Toll. I. 13. 571 . p. 124.

In. scorpinides, acaulis, foliis canaliculatis; corollæ laciniis tribus erectis minimis; tubo longissimo. Desfont. Fl Atlant. Tom. I. p. 40. Tab. 6.

Ir. bulbosa latifolia, sive 1. Clus. Hist. 1. p. 210.

Eadem Grislei Vir. Lusit. n. 1565 It. Dodon. Pempt. p. 212.

Ir. bulbosa latifolia carulea. Swert Floril. Tab. 36. fig. 2.

Ir. bulbosa latifolia Lusitanica 1. Clusii. Theath. Flora Tab. 42.

Ir. bulbosa latifolia, acaulos, odora. Baul. Pin. pag. 38.

IR. bulbosa latifolia, flore cæruleo et candido.

Io. Bauh. Hist. Pl. Tom. 2. p. 703 cum ic.

Hyacintues poetarmm latifolius. Lob. Ic. 96.

RADIX fasciculato-bulbiceps; bulbus fere avellans magnitndine, menbranis striatis tunicatus, demum foliis vaginatus; e hasi nodosa radices quinque, et ultra, prælongas, inæquales, fusiformes, obliquas, crassitie trium ad quinque linearum, in radiculam longam abeuntes, emittens, el ejusdem circa latera nomullos novos bulbulos progignens.

Folia subtriquetra, canaliculata, subtus carinala, acuta, basi vagi- 
nantia, glabra, pallide viridia, octo ad tredecim lineas lata, sex ad novem uncias longa, disticha, patula, et in terram arcuata, primis annis tantìm é bulbo, postea tìn ex ipso quìm é cauliculo subterraneo exorta.

Caules aut scapi primis annis nulli a bulbo protruduntur; postea duo tresve scapi, seu potius pedunculi radicales, ab eo emiltuntur breves el sub terra latitantes; at sepius cauliculus brevissinus ab codem profertur, qui sub terra sensim adolescil, leres, foliis vaginatus, duobus tribusve pedunculis brevissimis, in anthesi subterraneis, demun terminatus.

Flores duo vel tres, quorum cum primus marcescit, alii mox ipsi succedunt, singuli spatha cincti sxpe diphylla, interdum polyplyylla, foliolis lanceolatis, acutis, pedunculo infra germen alternatim adherentibus, sub terra albidis membranaceis . extra ipsam viridibus, erectis, tubo corollae tandem paulo brevioribus, persistentibus.

Perianthium nullum. Corolla supera, crerulea, vix ac ne vix odora, monopetala, limbo sexpartito, inaequali, basi tubuloso: Jaciniase omnes petaliformes; tres maiores, erectiuscula, deinde refexæ, inberbes, tres fere uncias longæ, apice rotundatx, ibique vix ennarginatx, oris marginalibus vix crenulatx, paulo infra medium latiores, seu in lobulum dilatata, versus basin angustatx, sicque quasi ovato-spathnlatre apparent, intus in medio inacula lutea longa crassiuscula notatæ, ad cujus latera exalbidx, lineisque cæruleis pictæ sunt; lacinix tres ipsis alternæ valde minores, ad unam unciam longre, ex albido cæerulex, lanceolato-spathulatx, obtusæ, infra medium angustatæ, ibique canaliculatx, integerrimx, ultra illud serrulatx, patentissima, demum reflexx, sicque tres alas extensas effingentes. Tubus longissimus, tres quatuorve uncias longus, spatha laxe stipatus, illaque parum altıor, ad corolla faucem latior, infernè filiformis cum stylo coalitus, germinique apici cum illo adhærens.

Sta M. filamenta tria, alba, subulata, semiunciam fere longa, fauci co. rolle inserta, ejusdem laciniis maiorhus opposita. Antheræ erecta, albida, quinque fere lineas longx, lineares, compresse, infernè bifidx, apice obtusx, biloculares, inter stigma et corollx lacinias maiores reconditæ. Pollinis granula subglobosa, hyalina, succosa.

Pist. Germen oblongum, trigonum, sub terra in fundo spatliæ latitans. Stylus tenuissimus, paulo infra corolla faucem tubo illius connatus. Stigmata tria petaloidea, dilute seu ex albido cærulea, oblonga, laciniis corolla maioribus patılo breviora, intus dorso carinata (carinâ sulco marsinato exarata) extus concavi, antheris incumbentia, bilabiata; labium extcrius minimum, albidum, membranaceum, obtu. sun, obsolete emarginatum, labium interius maximum, profunde bifidun, laciniis acutis, denticulatis, sxpe introrsum flexis.

Peric. Capsula obtuse trigona, trisulca, trilocularis, trivalvis, polyTom. II. 
sperma. Semiua in duas series singulo in loculo disposita, subrotunda, subrugosa.

Inaritat in locis lmuiliusenlis, interdumque in rupibus circa Elvas, Eboram, et in collium radicibus non procul ab Anà flunine sitis. Floret Decembri, Januario, Februario. Perennis.

OBS. 1. Variat, etsi raro, corolla alba, interdum quoque stigmatum laciniis fere edentulis, vix ac ne vix introrsum flexis, et illas corollx maiores longitudine æquantibus; item lacinis corollæ minoribus patnlis el obliyuatis. Quapropter Iris patula Poirel, microptera La Marchii, et scorpioides Desfont., quæ in Barbaria occurrunt, hujus tantum, quæ in Lusitana et Hispania fertur, ut varietates habendæe.

Oвs. 2." Nimis aflinis Ir. Persica; sed differt colore cæruleo corollæ, nec semper valde variegato, stigmatum laciniis aculis, nec rotundatis, laciniis quinque corollæ minoribus obtusis, nec acutiusculis, denique foliis præcocioribus, quæ, in anthesi plantse triplo, et ultra, flore longiora, nec flori longitudine sequalia vel paulo ipso longion. Utraque media esse videtur inter Ir. verè imberbes el barbatas, seu unde natura intermediis semibarbatis, ni ír. Sisyrinchio, transit ad barbatas; nam macula lutea crassinscula in utriusque laciniis corollinis maioribus sita, lente furtiter augescente visa, minimis aculeolis deuse echinata, seu villis brevissinis inumeris contiguis constructa esse apparet. 


\section{IR IS subbiflora.}

Lusit. Lirio cardeno, ou Lirio roxo ordinario.

IR. foliis ensiformibus, caule subbifloro paulo brevioribus; corollex litciniis tribus, reflexis, obtusis, barbatis, oblongo-cuneiformibus; tribus alternis eas longitudine subxquantibus, erectis, obtusis, conniventibus; tubo spathis laxè incluso, germen ferè triplo excedente; lobulis stigmatum acutis, subdenticulatis.

Ir. subbifora. Brot. Flor. Lusit. Tom. I. Pag. 50.

Ir. biflora, barbata, foliis ensiformib!ı, brevioribus scapo subtriforo; germine tereti. Lin. Spcc. Plant.; sed uti varietas in hortis extra Lusitamiam culta.

IR. biflora, corollis barbatis; caule subtrifloro, foliis longiore; petalis violaceis. La Marck Dict. Bot. Encycl. Tom. 3. pagg. 295. Etiem uti varietas in hortis cultas.

Ir. vulgaris Lusitana. Grisl. Virid, Lusit. n. 1560.

IR. vulgaris Lusitana, flore albo et vario. Idem Ibidem n. 1561 .

Ir. biflora, et Iris Iatifolia maior. Clus. Hisp. et Hist. 22.

$I_{R}$. humilis latifolia, et Iridis alind genus humilius. Clus. Hisp. el Hist.

IR. biflora, flore minore, odore lilii convallium. C. Baul. Pin. 32.

Chamerras latifolia saxatilis Lusitanica. Idem Ibid. pag. 34 .

Ir. biflora Lusitanica, flore violaceo. I. Bauh. Hist. Pl. vol. 2. p. 722.

IR. Lumilis latifolia, colore violaceo saxatilis. Id. Ibid. p. 725.

$R_{A D I X}$ perennis, oblonga, obliqua, pollicaris fere crassitudinis, intus pulposa candidaque, extus rodosa, subtus multis radiculis filiformibus summa tellure hærens et repens, subinde in plures alias radices similes é lateribus exortas divisa, ima parte denum putrescens, suprema vero gemmas nonnullas foliosas protrudens, quarum sæpe primava tantìm annuatim caulifera. Inodora est; crmm mansa initso ingrata, paulo post fervide acris, sapore fervido sensim augescente et longe perdurante. 
Folla radicalia et infima caulis quinque ad septem, vix ultra, ensiformia, subfalcata, viridia, sabra, striata, interiora erectiuscula, exteriora obliqua, quinque ad fere undecim lineas lata. quatuor ad septem uncias et ultra longa, disticha, basi sese et caulen vaginan. tia, isto sxpe breviora, rarissime illius longitudine, vel illo parum longiora, corollaque tubum xquantia, fere omnia xstate penitus siccescentia; caulina sxpe duo, raro tria vel unicum, radicalibus valde minora, sessilia, alterna, distantia, concava, ventricosa, acuminata, erecta, caulen vaginantia: cum prope caulis apicem ramulus protruditur, istius basin folia duo brevia opposita, spathre foliolis similia, cingunt.

Cauls annuus, quinque ad tredecim uncias altus, erectus, teres, glaber, sxpe trinodis usque ad florem, simplicissimus, aliquoties paulo infra apicem mo brevi ramulo instruclus.

Flos subsessilis, seu pedunculo brevissimo intra spatham insidens, saepe unicus, interdum duo, terlius sanè rarissimus, illum enim in silvestri planta nuspian vidi et forsan solummodo in luxuriosa vel culta.

Spatila diphylla, persistens; foliola fere opposita. unam ad lineas duas insertione inter sese distantia, subxqualia, tubi corollæ longitudine, ipsique approximata, oblongo-subovalia, compressa, nervosa, concava, ventricosa, subcarinata, viridia, apice subpurpurascentia, ibique membranacea, scariosa, acutiuscula: interdum (prosertim cum flos unicus terminalis) preter hac duo foliola tertium aliud minimun, membranaceum, convolutum, in axilla supremi folioli spathae situn, adest.

Corola supera, violacea, suaviter odora, monopetala, sexpartita; laciniæ onnes petaliformes, exteriores tres oblongæ, obovato-cuneiformes, viginti quatuor lineas ad triginta longx, quatuordecim ad octodecim supernè lata, ibique obtusæ, integerrima, raro obsolete crenulatæ, patulx, deinde reflexæ, saturatè purpurex, inferne venis albidis ranosis pictse, in medio linea longitudinali barbata notatæ, cujus villi succosi et diapliragmatibus dividui sunt, omnes non prorsus candidi, sed superiores albidi, seu cærulei, vel ex albido cxrulescentes, inferiores autem prope faucem corollx lutescentes: lacinixe tres alteræ, exterioribus interpositæ, illis longitudine el latitudine xquales, aut vix breviores vixque angustiores, erectæ, introrsnm inter stigmata conniventes, cærulex, subovales, apice obtusæ, ibique obsoletè crenulatæ, interdum etsi raro brevissime emarginata, infernè in unguem brevem canaliculatum, marginatum, venis. que albido-flavescentibus pictum, sensim angustats. Tubus trigonocylindraceus, viridis, sen ex viridi crerulescens, tristriatus, sexdecim ad octodecim lineas longus, supernè ad corollx faucen latior et paulo infra illam cum stylo comnatus.

Stam. filamenta tria, subulata, ex albido carulea, septem lineas lon- 
$\mathrm{ga}$, laciniis corolla reflexis opposita, ejusdem fauci inserta, ibique decurrentia. Antheræ lineari-sagittata, compress $x$, quinque sexve lineas longre, biloculares, cærulex, seu ex albido caruleata, erectæe, singula singulo stigmati incubita et sub eodem recondita. Grana pollinis subglobosa, succulenta, hyalina, inaperta, demum exsucca.

Pist. Germen trigono-cylindracem, supernè attenuatum, ex viridi albidum, obsoletè trisulcatum, sexstriatum, quinque ad octo lineas longum, corolla tubo fere triplo brevius, intra spatham subsessile. Stylus triangularis, intra corolla faucem, quatuor ad sex linearum spatio, solutus, postèa illius tubo coalitus, et ejusdem longitudine. Stigmata tria, petaloidea, oblonga, sublinearia, violacea, laciniis corolla barbatis opposita, ad eas recurvata, eisdemque dinidio fere breviora, extus concava, antheris incumbentia, intus carinata, carina sulco longo marginato exarata; bilabiata, labio exteriore minimo, vix lineam longo, obtuso absque emarginatura, albido-caruleo, laciniis acuminatis, serrulatis, siepe introrsum flexis.

Capsula oblonga, ad verticem angustata, trigona, angulis rotundatis, trisulcata, trilocularis, trivalvis, polysperma. Semina in singulis loculis plura, ovato-subrotunda, fusca, aut pallida, subrugosa; nonnulla abortiunt.

Habitat sxpe in rupibus calcareis, vel solo ipsis vicino, rarius in arvis, circa Conimbricam, Olisiponem usque ad Cascaes, Alhandra, Villa Franca ad Tagum, et alibi in Extremadura et Beira. Floret in Beira sepe pracocius, Novembri scilicet et Decembri, serius circa Olisiponem, Januario nempe, Februario, Martio et veris initio. Peremis.

Flores Tinctoribus, radices Medicis in usu sunt.

Obs. I. In hac specie maxima individıorum pars unicum tantùm florein in suis caulibus, et hunc semel in anno in Lusitania fert; nonnulla tamen individua inter quamplurima, quxe uniflora sunt, habitantia dıos flores interdum in eodem caule protrudunt; alia praterea sunt, quæ bis in anno, hoc est, in ejusdem anni duabus diversis tempestatibus, et in caulibus diversis aliquando forent, sed hæc rariora: quapropter speciem potiùs subbiforam, quàn biforam, esse dicendam existimavi.

OBs. 2. Variat circa Olisiponen, etsi raro, corolla alba, aut interdum lutescenti :ninus odora, qua tunc est Iris lutescens Clariss. La Marck (Dict. Bot. Encycl.) nam toto habitu et notis specificis ab cả non diversa.

Ozs. 3. Nectarinm, ex Celeb. Linnxi sententia, in Iridibus nonnullis est linea longitudinalis barbata, inferuè lacınis coroll:e reflexis insculpta, in aliis puncta tria externa ad basin floris: ex opinione allTom. Il. 
tem Clariss. Jussiae Nectarium est snlcus marginatus in carina unius cujusque stigmatis, qui in styli vertice terminatur. Quidquid sit de his partibus denominandis; succi, qui in eis secernuntur, alii ad corollax tubum stylo connatum, alii ad ipum stylum diutine humectan. dum, ne illius properata siccitas ovula in ovariis frecundatione privet, naturaliter destinati esse videntur. Tres partes petaliformes, qua stigmata communiter dicuntur, antherarum dorso inaperto incumbunt, arcuate supereminent, et ad illas contra pluvias aliasque injurias externas tegendas, vix ac ne vix autem ad pollinis earmm substantiam spermaticam absorbendam, inservire a nonnullis Botanicis existimantur, qui adhuc insuper pollinis grana tam arcte colıxrere dicunt, ut vi solummodo quadam externa ab illis removeri possint. et ileo seininum fxcundationem locum non habere opinantur nisi Insectorum ope perficiatur; sed capsulx, tam in hac specie, quam in aliis ejusdem generis hieme in Lnsitania florentibus, ubi nulla Insecta iu earum floribus tunc observantur, semina perfecte fecundata ferunt: itaque eorum fxcundatio aliunde pendet, et aliter explicanda, etsi stigmata vera negentur; hoc sequenti modo explicari posse videtur. Antherarum venter, qui lacinis corolle refle$x$ is oppositus, cum longitudinaliter aperitur, grana pollinis partim istarum linc:e barbalx aut imberbi crassa et asperæ incumbunt, partim attritu quodam convelluntur et in stylum faucenque corollæ desilimnt; sperma tunc é granis exsudatum vel immediate ab stylo absorbetur, vel mediate, hoc est, a linea laciniarum reflexarum et tubo corolla cun stylo coalito, exinde postea ad ovula, ut fæcundentur, transmittitur. 


\title{
TRIANTHERIA DISTYLIA.
}

\author{
T R I T I C U M litorcum.
}

$T_{R_{\text {r }}}$ culmo basi repente ibique ramoso, ex procumbenti erceto; spica simplici, disticlia, elongata, in anthesi nutante; spiculis ultra novem, approximatis, sessilibus, lanceolatis, octofloris; calycibus corollisque obtusis, muticis; germine nectarioque superuè villosis.

Triticum junceum. Brot. Flor. Lusit. I.

Gramen phænix ramosa maritima.

Grist. Frid. Lusit. n. 670.

Gramen maritimum spica loliacea, foliis pungentibus nostras? (uti varietas). Plukenet. Phytogr. Tub. 33. Jig. 4.

Granen spartium spicatum, foliis mucronatis longioribus, vel spica secalina? (uti varictas). C. Bauh. Pin. 5.

Gramen caninum maritimun, spica triticea, nostras? (uti varietas). Scheuch. Agrost. p 6. et Ray Hist. 1256.

Gramen radice repente maritimum? Tourn. Inst. R. H. 516.

RADIX perennis, longè repens, ex quinque ad decem pedes et ultra, crassitudine fili sutorii, albescens, crebrò geniculata, nodlis semiunciam ad uncias duas inter sese dissitis, nonmullis præsertim extremis culmiferis, omnibus radicantibus, radiculis villosis; internodia tunicis paleaceis valde longis latisque vestita.

Culıı annui, sesquipedales ad bipedales, crassitudine penıx gallinaceæ, teretes, farcti, glabri, nodosi, nodis noven et ultra, unam all duas uncias plus mirusve inter sese distantibus, foliis longe vaginati, ad apicem nudi enodesque, debiles, ex procumbentibus erecti, basi ex uno aliove nodo repentes, ibique cespitosi seu confertè approxinıteque ramosi, ramis alternis adscendentibus, culmi primarii fere longitudine ipsique simillinis.

Folı sex ad novem, alterna, disticha vel ferè disticha, approximale sese invicem vaginantia. Lamina in foliis infimis ad culmi basin radicantem plus minusve brevis, semiunciam ad tres uncias longa, lineam sesquilineamve lata; in aliis inferioribus semipedalis aut peda- 
lis, exinde versus apicem culmi ramornmque sensim brevior, duas a! tres lineas ant paulo ultra lata, sublinearis, acula, patens, subtits viridis glabra laevis convexiusculaque absque carina, suprà longitudinaliter subconcava glauca striata, lente visa subpubescens seu hinc inde ad strias pilis minimis instructa, nec tamen scabra, marginibus integerimis glabris lævibus, demum convoluta junciformis apjice rigidulo subpungenti. Ligula membranacea, semilineam ad lineam longa, truncata sen obtusa, glabra. Vagina glabra, substriata, marginibus membranaceis lavibus, laminâ valde brevior, internodiis autem longior; in infimis foliis albescens paleacea latior, in aliis prasertim versus apicem culmi atque ramorum angustior et sensim Jongior.

Sprca terminalis, simplex, septem ad novem uncias longa, é folii ultimi vaginâ cùm penitus evoluta et in plena anthesi plus minusve nutans; rachi communi subflexuosa, glabra, articulata, internodiis extus convexis striatis, intus planis sursum versus spicularmm basin crassioribus, istisque semper plus minusve brevioribus, marginibus integerrimis levibus.

Guvma calpcina bivalvis; valva subxquales, alia vix longior quinque sen sex lineas longa, ad spiculæ medium seu paulo nltra elongatæ, sublineares aut lineari-lanceolatæ, coriacex, dilute virides, glabra, striatx, multinerves, obtusx, muticæ, latere exteriori ad rachin communem leviter introhexo subcarinatoque, carina lævi, marginibus submembranaceis, albidis, glabris, incegerrimis, lavibus.

Corolla bivalvis; valva inæquales, externa in flosculis imis calyce paulo longior, in aliis longitudine calycis aut brevior, dorso ad apicem subcarinato (carina lavi) obtusa cum brevissimo seu obsoleto mucrone, coriacea, nervosa, glabra, marginibus membranaceis, inlegerrimis, lævibus; valva interior panlo brevior, lanceolata apice obtuso ad lentem subciliato, albida rigidula nervosa, hinc concava inde ad genitalia convexiuscula, marginibus scariosis ad genitalia arctè introllexis, utrinque in flexum carinatis, carinà lineà viridi alata, ala albida, ad lentem minutissimè serrato-ciliata.

Nectarucm intra corollam in basi germinis ipsoque longius, diphyllum; foliolis ovato-lanceolatis, albilis, usque ad medimm crassis glabrisque, supernè tenuissine nembranaceis, aculiusculis, villosis, ciliatis, lente visis.

SтAм. filamenta tria capillaria, receptaculo ad basin germinis intra nectarium inserta. Anthera exertx, versatiles, lutescentes, tres lineas longæ, utrinque furcillatæ, quadrisulcæ, hebetato-tetragonæ, biloculares.

Pısт. Germen obovatum subvillosum, hinc convexum, inde unisulcatum. Styli duo brevissimi, albidi. Stignatta plumosa, reflexa. 
PERIC. nullum. Corolla semen arcte foret, dehiscit tamen ac demittit. Semen longitudine fere valva interioris corollie, gracile, sublineare, basi acutum, apice oblusmm pubescens, hinc convexum inde unisulcatum. Plurima siepe abortant, duo vix fertilia in hasi spice.

Hanitat an sepes litoreas infra Belem prope Olisiponem, Cezimbre atque ad Bourcos, Figueira et alibi in arenosis maritinis. Floret Maio, Junio. Peremne.

Usus. Radix subdulcis, et vi blande resolvente, aperiente demulcenteque non minus, quim illa Tritici repentis, predita est. Culmi el folia gratum pecori pabulum præstant.

Ors. 1. Afline Tritico junceo Lin., et pro illus varietate primitus a me habitum; ex posterioribus autem ubservationibus re veril specilice diversum esse opinor; diflert enim culmo breviore, ex procumbenti erecto, basi ramoso, nodis proprioribus, folis margine Jevibus, et corollæ valva externa ad carine apicem non scabra.

Ors. 2. Affine quoque Bromo ramoso Lin., qui Festuca phanicoides ejusdem Botanicu (nobis antem Triticum phanicoides;) sed specilice differt folns latioribus, ultra duas uncias longis, et eorum ligula membranacea; spiculis non teretibus, non breviter aristats, nec breviter pedunculatis, non unica, duabus, tribus ant paucıs; calyce non acuto, el corollæ valva externa non dentıculato-ciliata, nec brevi aristì terminata. Quantùm verò a Tritico muritimo, repenti, farcto, et aliis ejusdem generis specıebus hucusque cognitis diflerat ex descriptione satis patet.

Tom. II. 


\section{BROMUS cylindraceus.}

BR. panicula spicata, oblonga, subtereti; spiculis ovatis, subsessilibus, congestis, quatuor ad sexfloris, compressis, planiusculis; calycis valvulis acutis, inæqualibus, muticis; corollæ valvula externa dorso subcarinata, scabra, pilosa, paulo infra apicem brevissime aristata.

Dacruers cylindracea Brot. Flor. Lusit. vol. 1. pag. 59.

Festúca phlcoides, panicula spicata; glumis ciliatis; spiculis quinque ad octofioris; arista infra apucem brevissima. Dcsfont. Fl. Allant. Tom. 1. pay. 90. 1ab. 23.

Festucs crishala, panicula spicata, lobata; spiculis ovatis, latis, sexforis, hirsutis. Lin. Spec. plant. curante Willd. Tom. 1. pag. 426.

I'o cristata, et Poa phleoides, ut varietas. La Marck Dict. Bot. Encycl. Toin. 5. pag. 75-78. Hllustr. Gen num. $975-976$.

Granen spicatum, spica cylindracea, molli, densa.

Tourn. Inst. R. Herb. 520 .

Gramen alopecurum viridi et molli spica.

Barrel. Tab. 123. fig. 5.

Gramcs typhoides molle. Sclienclı. Gram. 246. Tab. 5. fig. 5.

GRAMEN alopecuroides vulgare el alopecuroides minus.

Grusl. Virıd. Lusit. 11. 582-83.

$\mathbf{R}_{\mathrm{ADIX}}$ annua; radiculis capillaribus, in fasciculum collectis, nonnullis subdivisis, pubescentibus, albid.s, viridibus, demum fuscis.

Culm ex eoden nodo radicali sape plures (sex ad triginta. pro soli macritate aut fertilitate) fere filiformes, simplices aut simplicissimi, glabri, centrales erecti, laterales extrorsum arcuali deinde surrecti, sape duas ad sex uncias alti, interdum in solo pingui ad uncias undecin et ultra longi, tuncque subramosi, rams duobus ad quatuor, alternis, erectis, binodes ad quadrinodes, omnes folis vaginati, supernè tantummodo nudi.

Folsa planiuscula, acuminata, binncialia ad quinquemcialia, sesquilineam ad duas lineas cum dimidia lata prope ligutam; inferiora su- 
perioribus breviora, superiora internodiis longiora et erecta; omnia subtiliter striata, itrinque et ad margines villosa, interdum subtus glabriuscula, sed lente visa tenuissine lanuginosa. Vagina longiuscula, striata, dorso el ad margines pilosa. Ligula brevis, lacero-denticulata, ciliato-pubescens.

Paxicula terminalis, erecta, spicata, cylindracea, sen ovalo-cylindrica, sesquiunciam ad tres uncias longa, sensim versus apicem angustata, et ibi acutiuscula, densa, in anthesi laxinscula, ante et post Illam subteretiformiter contracta; rachi communi glabriuscula, ramulosa; ex singulis ejusdem nodis inferioribus ramuli tres quatuorve brevissimi, subpubescentes lente visi.

Spicule in ramulis subsessiles, conticum et quasi inbricatx, ovate, compressa, duas lineas ad fere quatuor longre, sesquilineam, aut paulo ultra, in medio latx, sxpe quatuor al sexflore, raro trilorx, septem sen octoloræ in eadem panicula rlosculi distichi, propinquissime alterni, sen fere oppositi. sessiles, sensim versus spicula apicem minores; extremus interdum elletus.

Gluma calycina, flosculis communis, bivalvis; valvuix acula, mulica, trinerves, compresse, marginibns scariose glabracque, dorso virides et subcarinate, carind, seu panlo ultra illius medium, scabra et pilosx, vel pubescentes, inæquales, alia angustata brevior, alia latior sxpe sesquilineau longa et paulo ultra spiculie mediun protensa.

Coroll $\approx$ valvula compressæ, inxquales; externa acuta, parum altior et largior, trinervis, viridis, nuarginibus et apice scariosa glabraque, dorso subcarinata, ihique scabra et sxpe pilosa, apice nunc integerrima, nunc leviter bifida, paulo infra apicem aristata, arista brevissina, scabra, erecta: valvula interna nenbranacea, albida, subplana, apice profunde bifida, nutica, glabra, margine utroque uninervis, el ibi pubescens lente risa.

Nectarum bilamellatum; lamellis albidis, ovatis, oblusis, basi gibbis, germine brevioribus.

Sta . filamenta tria intra nectarium, capillaria, brevia. Antheræ lutex, oblongre, lineares, utrinque furcalx.

Pist. Germen subovale, stylis duobus minimis reflexis terminatum. Stigmala plumosa, hyalina.

SEзEN unicum, orale, acutiusculum, corolla tectum.

Habitat ad vias, aggeres, segetes circa Coniubricam, Olisiponem et alibi in Beira et Extremadura. Flonet vere et interdum usque ad Julium. A muna. 
Ors. 1. Semina plurima abortiunt. Valvula externa corollæ semper aliquantim infra apicem aristata est; cum apex bifidus, tunc ex angulo fissurce inter lacinulas, vel paulo infra eum, arista erumpit; cum apex integerrimus, tunc arista paulo infra ipsum dorso aflixa est; in utroque casu arista ultra ipsum apicem ex semilinea ad lineam sursum protenditur. Spicularum extreni flosculi sæpe mutici, seu brevius aristati. Interdum corolla valvula externa in flosculis inferioribus penitus pilosa est, in superioribus autem tantummodo prope apricem pilosa: aliquando, etsi raro, calycis utraque valvula et illa corolla exterior in nomullis flosculis penitus glabræ sunt.

Ors. $2^{\circ}$ Planta Dactylibus nimis affinis; eam illis olim adjunxeram ob spiculas compressas, et ob calycis valvulas tantillum carinatas; sed cìm Dactylium caracter genericus valde varians et requivocus, insuperque arista corollæ ipsarum terminalis sit, dum é contrà nostrie plantae corolla semper infra apicem aristata, quod Bromis proprium, ideo eam istis potius quàm illis associandam esse nunc existimo. Neque ad Poas aut Festucas, quibus etiam nimis affnis, amandanda, hoc enim cum arista corollæ infra apicem sita non concordat. 


\section{BROMUS caudatus.}

Br. panicula subspicata, oblonga, sublobata; spiculis quadri-quinqueflorisve, obovatis, compressis, contiguis, subsessilibus; calycis valvulis dorso scabris; corollac utraque sape glabra, exteriori infia apicent aristata; arista illins fere longitudine, erecta.

$\mathrm{Br}_{\mathrm{r}}$ rigens, panicula spicata; spiculis subsessilibus, erectis, pubescentibus, subqnadrilloris?

Lin. Sp. pl. curante IVilld. Tom. I. pag. 436.

Gramen alopecuroides maximum, spica divisa.

Scheuch. Gram. 247. tab. 5. fig. 6.

Gramen alopecuroides segetum et campestre.

Grisl. Virid. Lusit. n. $588-89$.

RADIX annua, fibrosa; radiculis ad nodum dense congestis, ex albido virescentibus, nommullis subdivisis.

Culmi plures ex eadem radice, octo ad triginta et ultra, semipedales ad perlales, filiformes, trinodes ad quinquenodes et ulira, centrales sæpe erecti, laterales iufernè curvati, deinde erecti, sæe glabri, raro infra paniculam subpilosi, simplices, tres ad sex ramos subdivisi; ramis culmo brevioribus, erectis.

Folı planiuscula, acuminata, striata, utrinque subpilosa, ora margimali subciliata, ibique scabriuscula, duas ad quatuor fere lineas prope ligulam lata, duas ad quatuor uncias longa; suprema breviora. Vagina longa, striata, margine et dorso subpilosa. Ligula brevis, lacero-ciliata.

Panicula subspicata, biuncialis ad quinqueuncialis, in anthesi valde laxa, ante et post illam contracta in forman ovato-lanceolation, lateribusque sublobatam. Rachis subangulosa, sape glabra, raro pubescens, é nodis alterne ramosa; rami pluries divisi, in panicula primaria tres quatuorve infernè ex eodem nodo exemnt, deinde sensim numero decrescunt versus ejusdem apicem, ubi denum solitarii sunt.

SPıculæ plurimx, obovatæ, compressæ, sesquilineam ad lineas duas cum dimidia longa, similiter in summo lata, trifloræ ad quinqueflora, alterna, dense aplroximatx et quasi imbricata, breviter pedunculatx, nonnullæ subsessiles.

iom. Il. 
Glema calycina bivalvis; valuulæ acutæ, muticæ, subcarinatæ, giabræ, marginibus scariosæ, dorso scabræ, nonnumquam ibique subpilosæ, inæquales, alia paulo longior et latior.

Corolt玉 valvulæ sæe læves, glabræ, interdum, in flosculis spicula. rum inlerioribus, dorso subpilosæ, subæquales; externa parum longior, latiorque, lateribus et apice scariosa, subcarinata, Jeviter bifida, in angulo fissuræ inter lacinulas, vel parum infra, aristata; arista illarum longitudine, sesquilineam scilicet ad lineas duas cun dinidia earum apices excellens; interna omnino membranacea, albida, subplana, profunde bifida, mutica.

Nectaricar bilamellatum; lamellis albidis, ovatis, obtusis, basi gibbis, germine brevioribus.

STA . filamenta tria, capillaria, intra nectarium. Antheræ luteæ, lineares, utrinque bifurcatæ.

Pist. Germen subteres. Styli duo minimi, reflexi. Sligmata plumosa.

Semex unicum, ovale, corolla tectum. Sxpe in omnibus fere spiculis effetum.

Habitat ad vias, aggeres, interque segetes circa Olisiponem, Conimbricam, et alibi in Extremadura et Beira. Floret vere. Anmuus.

PLANTA a pecore grate pascitur.

OBs. Species nimis affinis præcedenti, et pro illius varietate frequenter habita; sed differt præesertim habitu najori, et panicula, cum laxa in anthesi, triplo quadruploque latiori, dumque contracta crassiori, lateribus sublobata, et minus cylindrica, ramis quoque valde longioribus et plus divisis, arista corollæ longiori, alque istius fere Jongitudine; insuper corollæ ralvula exteriori s:e glabra lævique, nec sæpe pilosa et scabra. Media inter Dactylem, Poam et Festucam; sed ab ipsis ob aristam ralde iufra apicem corollæ sitam removenda, et bromis associanda. 


\section{BROMiUS geniculatus.}

Br. panicula erecta, subramosa, late expansa, demum secundè contracta; spiculis sxpe quadrifloris, pedicellis ensiformibus superrè incrassatis; calycis valvula exteriori spiculam xquante; arista recta, flosculi longicudine.

Br. gcmiculatus, panicula erecta, flosculis distantibris, pedunculis angulatis, culmo genu procumbente.

Lin. Sp. pl. curante H'illd. $10 \mathrm{~m}$. 1. pay. 434.

Idem Sclureb. Gram.2.60. Lab. 31. Ubi tamen corolla, uti Fcsincis propria, depicta.

Festuca geniculala. Brol. Flor. Lusit. Tom. 1. pag. 118.

Granex Festuca arenacea minor. Grisl. Irir. Lusit. n. 629.

Festica stipoides, panicula erecta, secunda; spiculis subquinqueforis; glumis breviter aristatis, pedicellis ensiformibus. Desfont. Fl. Allant. Tom. 1. pag. 90.

Br. stipoides, panicula erectiuscula, pedunculis ensiformibus. Lin. Spec. plant. et Mant. 557.

Bu. incrnssnlus, panicula erecta, ovato-pyramidata: spiculis glabris, subquadrifloris; pedicellis supernè incrassatis. La Harch. Dict. Bot. Encycl. Tom. 1. pag. 469.

RADIX fibrosa, annua; radiculæ capillares in fasciculun collectæ.

Culm raro solitarii, siepe plures ex eodem radicali nodo, tres ad octo, filiformes, glabri, semipedales ad sesquipedales, infernè tri-quadri. nodes aut quinquenodes, geniculis nigrescentibus, aut ex virescenti fuscis, ad ima extrorsum curvati, seu refracti, deinde erecti. nonnulli simplicissini, alii ex inferioribus geniculis aut interdum ex singulis raniferi, foliis vaginati, supernè nudi: rani eis breviores, erecti.

Folı plana, acuminata, striata, angusta, sesquilineam ad tres lineas Jata, duas ad quatuor uncias longa, subtus glabra, suprà lente visa subrillosa, margine vix scabriuscula. Vaginæ longa, striatæ, glabræ. Ligula brevis, membranacea, glabra, truncata, lacera. 
Panicula terminalis, rachi erecta, tres ad septem uncias longa, striata, subangulosa, scabriuscula. subramosa; ramis scabris, inaqualibus, aliis indivisis, aliis plus minusve divisis, bispicatis, trispicatis el ultra, sxpe diobiss ad quatuor ex rachis inferioribus nodis simul prodeuntibus, omnibus in antlesi cum spiculis late sparsis et distantibus, deinde contractis, quasi secundis.

Sprculd plurima sxpe virides, raro subpurpurex, late lanceolatx, compressiusculæ, tres ad quinque fere lineas longa, aristis non supputatis, sæpe quadrifloræ, nonnulla interdum triflorx in eadem panicula, raro quinquefloræ aut sexfloræ, flosculis alternis, subdistichis, rachi scabræ laxè adhæsis; omnes pedunculatw; pedicelli virides, seu interdum dilute purpurei, sesquilinean ad tres lineas et ultra longi, compressi, ancipites, seu subtriquetri, sensim sursum latiores et crassiores, angulis scabriusculi, apice obtusi.

Gruna calycina bivalvis; valvulæ sublanceolatx, acuminatæ, canaliculatx, marginibus scariosx glabraque, nervo dorsali virides et ibi scabræ, apice muticæ etsi rigidè ibidem mucronatæ, inæquales, alia $\frac{1}{3}$ brevior, alia sape spicula Jongitudine, aristis non computatis, rarissine illa paululum brevior. Corollse valvula exterior axi spicula nodoso insessa, Janceolata, canaliculata, glabra, dorso viridis, ibidem infernè lavis superne scabra, marginibus scariosa, et ibi interdum perpaucis pilis ciliata, apice in mucronem scariosum miniluum bifidum aut integerrimum terminata, infra istum, aristam rectam, scabram, tres quatuorve lineas longam, et semper ei longitudine xqualem, emittens: valvula interior paulo brevior : fere plana, apice hidentea, mutica, albido-membranacea, utroque margine nervo scabriusculo viridi prædita, raro ibique subciliata.

STam. filamenta tria capillaria, receptaculo inter nectarium et germen inserta. Antheræ luteæ, lineares, bifurcatæ.

Nrctarium bisquamulosum; squamulx crasse, ovatx, acutiusculx, basi gibbx, albidx, glabrx, germinis longitudine, seu vix eo longiores.

Pıst. Germen turbinatum, albidum. Styli duo brevissimi. Stigmata plumosa.

Perrcarplum nullnm. Semen unicnm, cui corolla arcte clausa adnascitur, lineare, hinc convexum inde unisulcatum, duas lineas longum aut paulo ultra, arista et dentibus corollæ terminatım.

Habitat in siccioribus, ad vias, et aggeres frequens circa Conimbricam, Olisiponem et alibi in Beira et Extremadura. Floret. vere. A 1 nuus.

Ṕranta pecori gratum pabulum prostat.

Obs. 1. Arista corollæ nunc in nonnullis flosculis hujus speciei re vo- 
rî terminalis est, nunc in plurimis ab apice corollæ scarioso non separata, seu vix ac ne vix quidem sub ipso emissa esse videtur; ideo ea interdum potius Festucis quàm Bromis facile a Botanicis adscribitur; sed si lente satis augescente observetur, infra corolla apicem scariosum sive bidenteun, sive integerrimum, linea aut fere sesquilinex distantia, sita esse evidenter cognoscetur: quapropter species a Festucis ad Bromos, quibus certe plus affinis, sejungenda.

Ors. 2. Bromus stipoides Lin. qui dubio procul idem ac Bromus incrussulus La Marck, et Festuca stipoides Desfont. est, a nostro Bromo genculato nulla nota verc̀ specifica differt, ideoque uti ejustlem tantum varietas, a solo, climate, expositione, aut alia causa proveniens, habendus esse videtur. 


\section{FESTUCA barbata.}

TEST. racemo subspicato, simplicissimo, subsecundo, erecto; spiculis sex ad decemfloris; corollie valvula maiori aristata, hirsuto-ciliata, calycis alia brevissima, alia longissima, utraque acuminata, mutica, glabra; pedicellis compressis, supernè incrassatis.

Fest. ciliata. Brot. Flor. Lusit. Tom. 1. pag. 115.

KADices sub nodo radicali numeros:e, in fasciculum collectæ, capillares, fuscæ, interdum pubescentes, annuis.

Caules plures ex eodem nodo radicali, primodìm declinali, seu obliqui, deinde erecti, flexuosi, glabri, teretes, alii simplicissimi, simplices alteri unum aliumve ranum protrudentes, geniculati, geniculis quatuor ad septem sensim versus basin proprioribus, foliis vaginati, supernè aphylli.

Folıs solitaria in singulo geniculo culmi, glabra, planiuscula, duas lineas aut paulo ultra lata, uncias duas ad fere tres longa, inferiora breviora, omnia denum filiformiter convoluta: vaginæ glabræ, leviter striatæ, supernè fissiles; ligula brevissima, truncata.

$\mathrm{R}_{\text {ACEnUS }}$ subspicæformis, simplicissimus, erectus, sesquiunciam ad tres uncias vel paulo ultra longus, subsecundus, in anthesi laxus, deinde sensim contractus. Spicule septem ad quindecim, planiuscule, oblanceolatæ. virites, alternæ, pedicellatæ; pedicelli erecti, seu erecto-patuli, duas lineas aut paulo ultra longi, spiculis fere triplo breviores, aristis non computatis, compressi, versus apicen dilatati.

Grouna calycina bivalvis, erecta, flosculos sex ad decem continens, distichos, alternos, supremos sæpe steriles; valvulæ acuminatæ, gstabrx, inæquales, inferior minima vix lineam longa, superior maxima sextuplo et ultra longior, seu flosculi infimi longitudine, mucronata seu interdum in brevissimam aristan terminata. Corolla bivalvis, valvula exterior dorso versus apicem scabriuscula, marginibus scariosa, ibique intus quamplurimis pilis albidis instructa, cæterum glabra, apice arista recta scabra, ipsius longitudine, terminata; valvula interior minor, membranacea, albida, apice bifido subciliata, vel penitus glabra.

Nectarica diphyllum, foliolis albidis, succosis, ovatis, obtusiusculis, concaris, gibbis, germine paulo brevioribus. 
Srsm. filamenta tria capillaria, corolla breviora. Antherx oblongx, lutex, versatiles, basi el apice bifurcatx.

I'st. germen obovato-subrotundum, albidum. Styli duo breves, reflexi. Stigmata plumosa.

Senrya oblonga, tenuia, corolla valvula interiore arcte tecta, hinc unisulcata: plurima abortiunt.

Habitat juxta littora maris, ad ripas Durii prope Porlo, ad Tagum infra Belem, et alibi iu solo macro arenoso. Floret vere. Annua.

Ors. Nimis affinis Fest. ciliata La Marck (Dict. Bot. Encvel. Meth. Suppl. Irag. 634.) differt tamen valvula calycina superiore longissina et infiui losculi longitudine aut longiore, nec minuta brevissinam inferiorem parum excedente; insuper, numero flosculorum in spiculis sape maiori, racemo sxpe breviore, et semper simplicissimo. $\mathrm{Ni}$ mis affinis etiam Fest. aloperuro La Marck (Ibid. pag. 636) et Schonbusc. (Maroc. I. pag. $28 \mathrm{I}$ ) sed diflert valvulis calycinis non longitudine æequalıbus nec intus hirsulis pariter cum corolla. 


\title{
A GROST IS miliacen suffrutesccns.
}

\author{
Lusit. Talhadente.
}

Agr. culmis cespitosis, multinodibus, suffrutescentibus; foliis subasperis; panicula ramosa, maxima, florente laxissima, antea et postea contracta, subnutante; pedunculis semiverticillatis, trichotomis, nonnullis bifidis; calycis valvulis subæqualibus, corolla glabra longioribus, istiusque arista terminali recta caduca dimidio brevioribus.

Agr. miliacea. Brol. Flor. Lusit. Tom. I. pag. 74.

Eadem Lin. Sp. pl. ut varietas.

Radices fibrose, ramose, dense sub nodo radicali fasciculatx, fuscie, vivaces.

Cutmi plures ex eodem nodo radicali, bipedales ad tripedales, crassitudine fere pennx corrina, teretes, fistulosi, multinodes, rigidi, glabri, obsolete striati, alterne subramosi, sxpe per aliquot annos plus minusve infra medium vel supra istud virentes, tuncque ex nodis lateraliter proliferi, gemmas scilicet duas ad quinque conjunctas et ramiferas ex lateralibus alternis nodorum protrudentes; rami erecti, nonnulli floriferi, basi ad exortum é gemma, squamis, seu vaginis aliquorum tenuium foliolorum, imbricatis, siccis, albidis, amicti.

Forsa plana, acuminata, viridia, striata, utrinque glabra, suprà et margiubus scabra, subtus levia nervo dorsali taution scabriuscula; radicalia aliqua et inferiora culmi semipedalia ad pedalia, duas ad fere quatuor lineas lata; superiora culmi et illa ramorum breviora et angustiora: omnia internodiis longiora, siccata convoluta, demum albida. Vaginæ glabræ, striatæ, absque ulla scabritie, duas tresve uncias longa, ad ramorum basin breviores. Ligula lineam vel paulo ultra longa, membranacea, albida, lacera, seu denticulata, glabra, ad latera interdum pilosiuscula.

Paxicura ampla, in florescentia laxissima, patens, ante illan et cinı fructifera contracta, submutansque; rachis semipedalis ad fere pedalis, striala, infernè lævis, supernè scabra, ramosa; rani, seu pedunculi, tres ad quinque ex nodis inferioribus simul prodeuntes, et alternos semiverticillos constituentes, internodiis longiores, sipe ra. mosissimi, pluries trifidi, nonnulli bifidi, versus apicem rachis longitudine et numero decrescentes, extremi floriferi: tlores alterni, erecti, pedicellati; pedicelli breves, apice nodosi. 
Gsuma calycina uniflora, acuminata, ovato-lanceolata, glabra, bivalvis, sesquilineam fere longa, vix ultra lineam Jata; valvulis longitudine el latitudine subxqualibus, corulli longroribus, muticis, infernè tricostalis, costa media apice scabra, superuè et al margines nembranaceis Corolla elliptica, sen sublanceolata, glabra; valuulis submembranaceis, exalbidis, obunsiusculis, subxqualibus, exieriore vix longiore, obsolete trilineata, aristata; arista terminalis, recta, scabra, caduca, calyce dimidio longior, vel extra illum sesquilineain ad lineas duas elata.

Nectaricm diphyllum, foliolis, seu squamulis. ovatis, obtusiusculis, albidis, succosis, basi gibbis, germine paulo brevioribus.

STA filamenta tria, capillaria, gluma calycina vix breviora, receptaculo inter germen et necfarium inserta. Antherx oblong:x, lutex, versatiles, basi et apice bifurcs.

Pist. Germen superum, obovato-subrotundum, albidum, succosum. Styli duo, reflexi, brevissimi. Stigmata oblonga, plumosa.

Semina plurima, singula in singulo flore, nonnulla sterilia, omnia corollæ valvulis arcte obvestita, fere elliptica, exigua, lineam aut vis paulo ultra longa, glaberima, nitida.

Habutat ad vias: sepes, interdum in silvis et agris, in omnibus fere Lusitaniæ provinciis. Floret vere et xstate, rarius autumno. Perennis.

Plant inadora, et sapore graminum proprio prodila. Ob cnlmorum rigiditatem, foliorum et panicula scabritiem a pecore rejicitur.

Ors. Cim ab Agr. miliacea. Lin. nolis essentialibus specificis non diversa esse videatur, ideo cum illa conjunxi. A gr. melanosperna La Marck (Dict. Bot Eucycl. Meth.) seu Milium paradoxum Lin. vix a nostra differt, nisi culmo minus nodoso, seminibus minoribus et nigris: Agr. comosa ejusdem La Marck (Ibid. Suppl. tom. 1. pag. 257.) cum ipsamet specificè convenit, exclusis synonymis, qux ad A Iran cespitosım amandanda. Itaque hæ omnes plantæ non pro diversis speciebus, sed pro eadem specie, Agr. scilicet miliacea variante, ut probabiliter videlur, assumendx. 


\title{
TETRANTHERIA MONOSTYLIA.
}

\author{
T EUCRIUM polium Lusitanicum.
}

T. capitulis terminalibus ovatis laxis; foliis oblongiusculis sublanceolatis, obtusis, crenatis, tomentosis, sessilibus; caulibus longè prostratis, demum adscendentibus.

Lusit. Polio montamo.

Teucr. polium Brot Flor. Lusit. tom. I pag. 164. Lin. Sp. pl. 792. La Marck Dict. Bot. Encycl. 2. p. 699 . et seq. Desfont. Fl. Atlant. 2. p. 7.

Teucr. Lusilanicum. Link Flor. Lusit. 1. p. 86. tab. 3 Lin. Sp. pl. edit. Willd. 3. p. 38.

Poutum Lusilanicum supinum minus incanum, caulibus perpurascentibus, flore albo. Tourn. Inst. R. H. 206.

Polıum montanum supinum odoratissimum. Grisley Vir. Lusit. n. 1 lil.

Radix lignosa, ramosa, perennis.

Cavles plures ex eadem radice in orbem fusi et longe procumbentes, demuin plus minusve adscendentes, septem uncias ad undecim longi, terétes, ad apicem incano-tomentosi, infra medium nonnunquam purpurascentes, ramosi, florentes infernè effoliati, suffruticosi.

Folia sessilia, opposita, parum inter sese dissita, sublanceolata, obtusa, é medio marginum crenata crenis reflexis, rugosa, utrinque tomentosa, infernè tamen magis incana, sex ad decem lineas longa, sesquilineam ad tres fere lineas in medio lata, suprema sub floribus minora, uti etian illa, que in axillari ramulorum exortu quasi fasciculata proveniunt.

$\mathrm{C}_{\text {A Pitula }}$ caulem et ramulos terminant, et subius circumfoliata sunt, ovata, laxa, multiflora, in ramulis tamen nonnullis pauciflora. Flores subsessiles. Bracteæ sıb calyce parvæ, lineari-lanceolatæ, integerrimi, floribus breviores.

$\mathrm{C}_{\text {ALYX }}$ subcampanulatıs, angulatus, villoso-tomentosus, quinquedentatus, dentibus brevibus, subæqualibus, acutiusculis.

Corolla alba, unilabiata: labium superius nullum, sed ejus loco fis- 
sura profunda, ubi stamina; labium inferius quinquefidum, lacinis omnibus obtusis, media terminali maiori oblonga.

Stamina quatuor dilynama, lateri superiori corolle fisso incumbentia, arcuata. Antherse jarva, subovales.

Pistull germen quadripartilum. Stylus silu et longitudine staninum, filiformis. Stigmata duo tenuia, brevia, acuta.

Pericarpium nullum. Calyx persistens in suo sinu semina quatuor subovalia continet.

Habitat in collibus calcareis circa Conimbricam et alibi, raro circa Olisipouem. Floret æstate. Suffrutex.

Planta subacris, amariuscula, odore aromatico grato pradita. Olim cum therebentina Veneta contra podagran inter I:alos usitata, hodie tantummodo in Theriaca et Mithridatio.

Ors. Variat foliis magis minusve latis, longis, et incanis; caulibus plus minusve longè prostratis, vixque demum adsceudentibus, et pro varietate potiìs Tencrii polii, quàm pro distincta specie habenda videtur, neque cum nostro Teucrio capilato confundenda; vide quæ de illo referemus. 


\section{T E U C R I M capitalum Lusitanicum.}

Tever. capitulis subrotundis, caulem ramosque terminantibus; foliis oppositis, lineari-lanceolatis, obtusiusculis, margine reflexis, antice crenatis, ex viridi tomentosis, minoribus aliis ad alas fasciculatis; caulibus multinodibus, incano-tomentosis, centralibus erectis, lateralibus ex deflexo erectis; calyce æqualiter quinquedentato, bracteis longiore.

\section{Lusit. Teucrio capitoso.}

T. copilalum, capitulis pedunculatis; foliis lanceolatis, crenatis, tomeıtosis; caule erecto. Lin. Spec. plant. 792 La Marck Dict. Bot. Enc. Meth. tom. 2. p. 700. (Idem cum sequentibus, el aliis, multimodis varians.)

T. capitatum. Brot. Flor. Lusit. tom. 2. p. 482.

T. Lusilanicum, capitulis terminalibus axillaribusque; foliis linearibus obtusiusculis, margine reflexis, crenatis, tomentosis; caule adscendente, toment oso. Hoffm. el Link Flor. Lusit. tom. 1. p. 86.

T. Lusitanicum, capitulis laxis, foliis linearibus obtusis, crenulatis, incanis; caule pubescente, corymbifero. Schreb. Unilab. p. 47. n. 59. Willd. Sp. pl. tom 3. p. 58 . quod Teucr. album. La Marck Dict. Bot. Encycl. Supp. tom. 2. p. 770.

Polium montanum tenuifolium, erectum.

Grisl. Virid. Lusit. n. 1170.

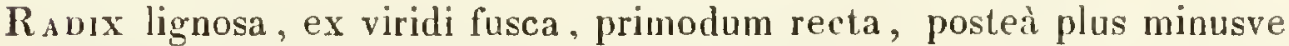
tortuosa, subramosa, collo ad terræ superficiem radiculis capillaribus cincta, ibique caules, qui infernè perennant, emittens.

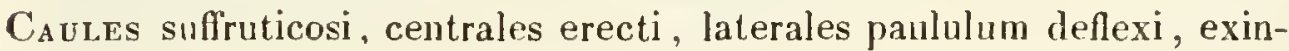
de recte superelati, octo ad tredecim uncias alti, teretes. multınodes, nodis inferioribus propioribus, incano-tomentosi (nulli, quos vidi, purpurascentes) ramosi, supernè foliosi, et ibi uıo alterove anno cum ramis siccescentes, infernè effoliati plus ninusve perennantes, ramosque novos cauliformes protrudentes, tunc ad exortum é veteri radice, nec lougè ab illa, fibrati. Rami ex axillis erumpentes, oppositi, interdum nonnulli ex infimis novis cauliformibus alterni, omnes foliosi, multinodes, erecti, incano-tomentosi, uti canles altitudine inæquales, alii simplicissimi, alii plus minusve subdirisi, trifidi, bifidi, apice demum capituliferi. 
Four opposila ( terna nulla) sessilia, lineari-Janceolata, oblusiuscula, semiunciam ad mncian longa, sæpe internodiis inferioribus longiora, antrorsmn latiora ibiq!ı lineam ad sesquilineam lata, marginibus valde revoluta, é medio usque ad basin integerrima, ex illo usque ad apicen crenata. supra sxpe ex viridi teniussime tomentosa, raro incana, Jongitudinaliter in nedio disco unjsulcata, ad crenas subrugosa, subtus, prosertiu in nervura dorsali, exalbido tomento demsiori tecta; axillaria utrinque plurima, quasi fasciculata, quatuor ad sex, dimilio fere breviora et angustiora, ex gemmis ramigenis exorta; suprema cauliun et ramorum forma et magnitudine sæe aliis inferioribus similia.

Capitusa subrotunda, copiosa, el quasi paniculata, in summitale canlium et ramulorum tenuium, qui pedunculorum vices agunt: folia duo opposita aliis structura similia, sub singulo capitulo sita, ipsoque breviora, involucrum constituunt. Folia floralia parva, oblanceolata, calyce paulo breviora. Flores erecti, inferiores laxi, patuli.

CALYx tomentosus, campanulatus, obsolete angulatus, quinquedentatus, dentibus brevibus, æqualibus, acutiusculis. Corolla alba (purpurascentem nullibi vili.) Labium superius nullum, sed ejus loco fissura; labium inferius quinquelacimatum, terminali lacinia oblonga, acutiuseula, integerruna.

Sтам. filamenta didynamica, albida, arcuata, inter corollæ fissuram prominentia. Alleræ parvæ.

Pısт. germen quadripartitum. Stylus filiformis situ et longitudine staminum, incurvus. Stjgmata duo, temia, acuta.

Semina quatuor subrotunda, fusca, in fundo calycis persistentis recondita.

Habitat frequens in collibus, rupibusque calcareis de Monsanto et Alcantara prope Olisiponen, et alibi in Extremadura. Floret Junio, Julio. Suffrutex.

Opor aromaticus, gratus; sapor ingratè amarus. Vires ut Teucr. polii.

Ons. Nimis afline. Teucrio polio, quod circa Conimbrican, rarissine verò circa Olisiponem, occurrit; sed cum jllo non confindendum, differt enim statura sxpe altiori, et caulibus numquam prostratis, sed centralibus erectis, Jateralibus brevi spatio elsi extrorsum deflexis, illico erectis; insuper, novi rami, qui é basi emortuorum caulium perennante, sive illa erecta sive deflexa sit, erumpunt, omnes sursum versus erecti excrescunt. Hiec species ex solo, situ et aliis causis, plus minusve variare solet, tomento scilicet partium niveo aut subvirescente, pertenui aut densiore, nonnullis caulibus plus minusve dellexis, foliis angustioribus aut latioribus, capitulis minoribus aut maioribus, subrotundis aut oblongiusculis; jolcirco Teucrum Tom. II. 
Valentimum, pseudohyssopum, pycnopluyllum, istud Lusitanicum, qux omnia a Clar. Schrebero et Willdenovio uti nova species habita, et eadem qua in Barrel. Icon. 1048, 1078, 1079, 1091, 1096, all Teucrium cupilatum Lin. et La Marck, ut ejusdem varietates, amandanda et cum illo conjungenda videntur. Nec tamen phrasis specifica Tournefortii "Polium Lusitanicum supinum, minus incmum, canlibus purpurascentibus, flore albo ", ad iden Teucrium capitatum, sed potius ad nostrum Teucrium polium, quod longe supinum est, referenda. 


\section{TEUCRIUM Lusianicum salviastrum.}

Trucr. folit inferioribus breviter petiolatis, subovalibrs, obtusis, crenatis, rugosissimis, suprit virescentibus, subtus tonentoso-incanis, supremis bractexformibus, ovato-lanceolatis, integriusculis, integerrimisve; racemis subsecundis; calycis dente summo ovalo, latiore.

T. salviastrum. Liuk et Ilofin. Flor. Lusit. tom. 1. pag. 84. Lab. 2. Schreb. Uml. pas. 38, n. 33. Lim. Sp. pl. Ed. Willd. tom. 3. jag. 27.

T. Lusitmicum. La Marck Dict. Bot. Encycl. Meth. tom. 2. Pag. 604. Brot. Fl. Lusit. tom. 1. P. 163.

Cuamadrys fruticosa Lusilanica, Melisse folio minori, hore purpureo? Toumel. Inst. R. H. pag. 205.

RADiX perennis, lignosa, ramosa.

Catlis lignosus. frutescens, teres. creclus, torluosus, pedalis al sesquipedalis, difuse ramosus; ramis oppositis, erectis, foliosis, tenuiter tomentosis, junioribus virescentibus, villo crispo lumorem viscosum excernente opertis.

Folra opposita, patentia, parva, lamina quatuor ad sex lineas longa, duas ad tres lata, subovalia, obtusa, obtuseque crenulata, crenulis reflexis, rugosissima, supra virentia pilisque nultis brevissinis tecta, subtus venosa et lomentoso-albida; suprema sub floribus bractexformia, valde minora, ovato-lauceolata, acuta, integriuscula aut integerrima; utraque breviter petiolata, petiolo linean ad sesquilineam, vel paulo ultra, longo.

RAcent duas ad quatuor uncias longi. Flores axillares, oppositi, solitarii, subsecundi, breviter petiolati; pedicellis lineam ad sesquilineam longis, calyce sæepe brevioribus.

CaLrx campanulatus, brevi pube hirtus, striatus, quinquedentatus, dente suprenıo ovato, mucronato, reliquis latiore, qui quasi subulati et inter sese aquales sunt.

Corold tubus albidus, calyce parum longior; labium superius nullum; inlerius dilute purpureun, externe hirsutum, quasi quinquelacinialım, laciniis lateralibus ovatis, acutiusculis, rqualibus, intemedia inulto maiori, rotundata, subcrenulata, conciva, venosa. 
STAM. filamenta didynamica, erecta, purpurea, basi pilosa, duo breviora, laciniis lateralibus corollæ labii æqualia, duo alia eis longiora. Antherse parva, crocex.

Pist. germen quadripartitum. Stylus longitudine inferiorum staminum, aut paulo eis longior. Stigmata duo tenuia, brevissima, acuta.

Semina quatuor in fundo calycis recondita, subrotunda, fusca.

HABıTAT in summis Herminii jugis ad ortum, præsertin circa Lacum do Penhäo, qui sic ob rupes (vulgó Penhas) ei vicinas a pastoribus Herminiensibus, ut ex ipsis audivi, appellari solet.

Floret xatate. Frutex.

Saror amarus; odor ut ille Nepeta Cataria, sed remissior et gratior. Affine Teucr. Massilicnsi; sed differt caule lignosiori et tortuoso, folis minoribus supra virescentibus, subovalibus nec subcordato-ovatis, rugosissimis nec parum rugosis, obtusis obtuseque crenulatus, nec acutis crenato-serratis; corollæ labio extus hirsuto, nec leviter pubescente; odore grato, nec quasi rancido. 


\section{T E U C R I U M scordium lanuginosum.}

T. foliis ovato-oblongis, serratis, lanuginosis, sessilibus; floribus axilJaribus, solitariis geminisve, breviter pelunculatis; caule ramoso, hirsuto.

\section{Lusit. Escordio.}

T. lamuginosum, foliis lanceolatis, sessilibus, crenatis, villosis; floribus axillaribus, subsolitaribus, pedunculatis; calyce brevi, dentibus ovatis. Link et Hoflin. Hlor. Lusit tom. 1. Lab. 1. It. La Marck Dict. Bot. Encycl. Meth. Suppl. tom. 2. pag. 768 .

T. scordium. Brot. Flor. Lusit. tom. 1. p. 164. Scordium. Grisl. Vir. Lusit. n. 1279.

T. scordinm, foliis ovato-lanceolatis, serrulatis, sessilibus ; floribus sapius binatis. Lin. Hort. Clifort. 302. Flor. Suec. 476, 513 , et Spec. 1). 790 , uti varictas. It. La Marck Dict. Bot. Encycl. Meth. tom. 2. p. 695 , uti varietas.

$R_{A D I x}$ teres, ramosiuscula, lineam ad sesquilineam supernè crassa, deorsum in radiculas sensim tenuiores, tandemque capillares, subdivisa.

Caulis semipedem ad pedem longus, quadrangulus, hirsutus, ex decumbenti erectus, é basi ramosus; ramis oppositis, hirsutis, foliosis, ex patentibus sursum arcuatis, infimis prope nodum rarlicalem procumbentibus, flagelliformibus, plus minusve reptantibus, demum adscendentibus.

Folia sessilia, ovato-oblonga, aut quasi lanceolata, obtusiuscula, serrata, dentibus acutis, perpancis obtusis, utrinque hirsuta, juniora præsertiu, pilis articulosis, subrugosa, ex viridibus incanescentia, septem ad quatuordecim lineas longa, quatuor ad septem lata.

Flores axillares, oppositi, fere omnes, seu ex maiore parte, solitarii, tantummolo in paucis axillis hinc bini, inde solitarii, vel ibidem utrinque bini, breviter pedicellati, pedicellis tenuibus, pubescentibus, duas lineas longis, et calyce longioribus.

CALYX campanulatus, unam lineam longus, villosus, quinquedentatus, dentibus ovatis, acutis, æqualibus.

Corolua non resupinata; tubus brevis, albidus; labium superius nulTum. II. 
lum; inferius dilute purpureum, seu ex cxrulescenti albidum, externe subpubescens, quasi quinquelaciniatum, laciniis lateralibus ovatis, acutiusculis, intermedia maiori, oblonga, obovata, emarginata.

Stam. filamenta didynamica, corollæ fauci supernè, ubi labium superins deest, incumbentia, incurva, labioque inferiori breviora. Antheræ parvæ, flavæ.

Pısт. germen quadripartitum. Stylus simplex, situ et longitudine staminum, aut vix longior. Stigmata duo brevissima, tenuia, acuta.

Semina quatuor in fundo calycis recondita, subrotunda, subrugosa, fusca.

Habitat in uliginosis el fossis humentibus dumetorum inter Conimbricam et Boarcos, ad oram maritimam de Trafaria el inter Turres Veteres, Mafra, Cintra in locis aquosis, unam alianve leucam a mari remotis. Floret æestate. Perenne.

SAPOR, præsertim foliorum, alliaceus, sed remissior quàm in Allio sativo; sapore quoque lac animalium alliaceo inficere fertur; insuper amarus, acriusculus.

Ons. 1. Hoc nostrum meridionale Scordium ab illo, quod in septentrionalibus Europe regionibus spontaneum occurrit, tantunmodo accidentaliter differt, nam proprietatibus verisque notis essentialibus specificis eidem est consinile, inde pro eadem specie variante, nec pro nova specifice diversa, habendum mihi esse videtur.

Ons. 2." Neque confundendum cum Teucr. resupinato (Desfont. Flor. Atlant.) quod ab illo recedit horibus omnibus semper solitariis, sessilibus aut subsessilibus, corolla pallide lutea et resupinata, foliis obovatis, brevem in petiolum decurrentia, seu basi cuneiformia, ac ramis infimis non procumbentibus nec repentibus. 


\section{A JUG A Iua heterantha.}

A. foliis sublinearibus, obtusiusculis, anticè utrinque uni-bidentatisve, pilosis, oppositis, sessilibus; caulibus ramisque procumbentibas, apice surrectis; floribus oppositis, solitariis, sessilibus, plurimis penitus clausis, sicque fructiferis.

\section{Lusit. Iva moscada, on Herva crina.}

A.rutia Iva. Schreb. Unilab. p. 25. Linn Sp. pl. ed. Willd. 3. p. 11. Link Fl. Lusit. 1. p. 77 . et seq.

Tevcricar Iva. Brot. Fl. Lusit. 1. p. 163. Linn. Sp. pl. 2. p. 782. Valik Symb. I. p. 40. La Marck Dict. Bot. Encycl. 2. p. 698. Cavan. Icon. 2. p. 18. tab. 20. Desfont. Fl. Atlant. 2. p. 3.

ANтнrlus allera. Clus. Hisp. p. 480. Hist. 2. p. 186.

Chamapitrs moschata foliis serratis. C. Bauln. Pin. p. 425.

Chamapitrs, s. Iva moschata Monspeliensium. Joh. Banh. Hist. Pl. 3. p. 296. Moris. Hist. 3. p. 425. Sect. XI. tab. 22. fig. 3.

Chamapitys vulgaris folio trifido, flore roseo Lusitanica. Tourn. Inst. R. H. pag. 208 .

Moscharia asperifolia. Forsk. Fl. Egypt. - Arab. (ut gynandra habita.) pag. 158 .

$R_{A D I x}$ dura, lignosa, infernè ramosiuscula, perennis.

Caules plures ex eadem radice, sæpe longe procumbentes, demun erectiusculi, incann-villosi, quinque ad octo uncias longi, ultra medimn dense foliosi et obtuse quadranguli, infernè effoliati, teretes, é casu foliorum scabri, ramosi; ramis sxpe simplicissimis.

Folra approximata, versus apicem caulis et ramorum confertiora, opposita, sessilia, utrinque villosa, subviridia, oblonga, sublinearia, antice siepe Jatiora, duas ad quatuor lineas lata, unciam ad sesquiunciam longa, obtusiuscula, marginibus revoluta in medio subcanaliculata, prope apicem utrimque unidentata aut bidentata, dentibus obtusiusculis, aliqua integerrima ( nulla verè serrata uspiam in hac specie vidi.) 
Flores axillares, solitarii, sessiles, aut subsessiles, alii in anthesi aperti, corolla scilicet alque genitalibus extra calycem elongatis, inaperti alii, corolla nempe genitalibusque calyce inclusis et illo occultatis.

In floribus apertis calyx brevis, campantulatus, pilosus, quinquedentatus, clentibus ovatis, acutis, æequalibus, uno tantim minore. Corolla flavescens (rubro-flavam, purpurascentem, aut roseam nullibi vidi) calyce triplo fere longior, basi tumida, supernè unilabiata; labio superiore nullo, sed ejus loco denticuli duo minimi in apice tubi ; inferiore longo, trifido, laciniis lateralibus parvis recurvis, intermedia maxima emarginata quasi obcordata, extus subpubescenti. Staminum filanenta filiformia, didynama, inter duos tubi corollæ denticulos erecta, labio paulo breviora: antheræ didymæ. Pistilli ovarium quadripartitum, seu germina quatuor; stylus filiformis, staminibus panlo altior; stigmata duo tenuia. Semina sæpe quatuor, interdum tria, oblongiuscnla, quasi obovata, aliquantulun incurva, punctata, calyce subglobose contracto tecta, corolla jam discussa; interdum tamen tubi corollæ basis tumida siccata intra calycem aliquantisper persistit, el simul cmu illo semina legil.

Is floribus inapertis caly $\mathrm{x}$ similis Corolla non penitus evolvitur, sed vix calyci longindine xqualis evadit, et intra illum delitescit, sub forma membranx tenuissima, apice mammilliformi inaperto genitalia tegens, infernè vero germina circumcirca iurolvers. Staninum filamenta nulla; antheræ quatuor æquales, didymæ, hinc summitati mammillıforni corolla sessiliter adharentes, inde sligmatihus cruciatim adeo appropinquatæ, ut quasi cum illis coalitæ videantur. Pistilli germina quatuor illis similia, qux floribus apertis; stylus brevissimus, albus, crasse subulatus, in centro germinum situs; stigmata quasi duæ laminulæ, saturate purpurea, brevissima, antheris nimis approximata et ab illis tecta. Semina ut illa florum apertorum, et non solùm a calyce sed a corolla etiam siccata teguntur usque dum ab illo decidant, istâ tunc in quatuor lacinulas æequales obiusas cruciformes separatâ.

Habitat in solo raro ad aggeres, arvorum margines, et ad rupes calcareas circa Olisiponem, Conimbricam el alibi. Florescit apertè Maio, Junio, Julio, inaperte autem ferè toto anno. In Lusitania semper perennis est.

Plaxta amara, et moschum redolens: a medicis inter aperientia, cephalica, emmenagoga, anti-rheumatica et anti-arthritica medicamina enumeratur.

Ors. Hujus speciei florescentia in maximo florum numero tam in Lusitania et australi Europa quàn in Africa septentrionali usque ad Agyptum inaperta est, el antheræ sessiles, corolla mammillo vix visibiliter adharentes, pistilloque subsessili quasi coalitxe plantam gynandram eflingunt, et pro tali habere imponunt, ut Forskalæo 
imposuerunt, sed hæc fructificationis partium facies singularis non decipiet, si planta cum aliis habitu similibus aperte llorentibus com. paretur. Istiusmodi variatio, sive illa, ex tempestatum favorabilium ad alias plante plus minusve adversas permulatione, sive ex succorum nutrientium perfecte elaboratorum defectu, sive ex alia causa veniat, in nostra Ajuga Iva annuatim semper evenire solet. 


\section{STACH S Tusitanica.}

Sr. verticillis multiloris, supremis contiguis; foliis radicalibus petiolatis; cordato-oblongis, obtusiusculis, superioribus sessilibus, ovatolanceolatis, acutiusculis, omuibus obtuse crenatis, rugosis, viridibus, utrinque villosis, cruciatim oppositis; caule supernè lanato; caJyce quinquedentato, subbilabiato, dentibus acuminato-spinulosis, tribus superioribus maiorihus.

ST. germanica. Brot. Flor. Lusit. Tom. 1. pag. 165.

ST. incrmodia, verticillis multilloris; calycibus subpungentibus; foliis oblongis, snbcordatis, crenatis; caule sublanato? Aiton, Hort. Rew. vol, 2. paig. 201 , et Willd. Spec. Plant. vol. 3. pag. 99.11. 7.

Lriostonum Lusitanicum. Link et Holfm. Flor. Lusit. Tom. 1. pag. 105. Lab. 7 .

R.s DrX plus minusve perennans, lignosa, ramosa.

CAUt.Is annuus, solitarius, ant dıo tresve ex eadem radice, erectus, pedalis ad bipedalis, interdum prope basin brevissine deflexus, et ibi subtus radicescens, simplex, seu duobus ad quatuor ramis oppositis erectisque instructus, obtuse quadrangulus, quadrisulcatus, intus farctus, medulla alba acute quadrangulata, virescerss, lanatus prosertim supernè, et inter verticillos, pilis ex viridi albidis, longis, crispis, nultinodibus, lente satis augescente visis.

Fouta radicalia cordato-oblonga, obtusiuscula, obtuseque crenata, qualuor ad sex uncias longa, sesquiunciam ad tres uncias prope basin lata, coriacea, rugosa, venosa, supra saturate viridia, et brevibus pilis tomentosa, subtus dilute virilia et pilis longioribus villosa, petiolata, petiolo sesquimcian ad tres uncias longo, subtıs convexo, suprà conaliculato, undique lanato; infima caulis similia, sed minora, breviusque petiolata; reliqua omnia sessilia, ovato-oblonga, seu ovato-lanceolata, acutiuscula, similiter obtuse crenata, et utrinque villosa, sensim versus floriferum caulis et ramormm apicem decrescentia, et decussatim sita.

Verticilli caulem et ramos terminantes, inferiores remoti, superiores stricte approximati et in spicæ formam dispositi, subrotundi, dense multiflori, floribus sessilibus sexdecim ad viginti el ultra, omnes duobus foliis oppositis suffulti, circumcirca el intus bracteati. Folia verticillis longiora, plus minusve reflexa, ovata, acuta, in 
verticillis inferiorihus obtuse crenata, in supremis integerrima. Bractex omnes lanats, integerrimx, qux inferme verticillos ambiunt, lineari-lanceolatx, acutx, calyci longitudine xquales aut parum longiores, dux tamen utrinque foliorum marginbus contigux latiores et altiores, calycem longiludine valde excedentes; alic supra ipsas setacea, calyce paulo breviores.

Calyx subcampanulatus, sex ad octo lineas longus; decemnerveus, quinqueangularis, fere bilabiatus, quinquedentatus, dentilus inaqualibus, deorsum sensim decrescentibus, supremo paulo latiore et longiore erecto, duobus intermediis illo parun 'angustioribus' et brevioribus patulis, infimis singulo intermedio paulo:brevioribus et angustioribus leviter deflexis; omribus acutis et rigido acumine subpurrenté semilineam ad lineam longo flavescente praditis, extus et intus usque al faucen. calyeis lanatis, qui exinde usque ad fundum glaber.

Corolra labiata; tubus albidus, striatus, dentibus calycis panlo brevior, ad fancem latior et leviler arcualus, extus glaber, infra mediun utrinque fossulì notatus, jutus contra utranque fossulam circulo barbato cinctus, et ad filamentomm decurrentiun hasin villosus, cxterum glabriusculus, receptaculo extra scutellam nectariferam insertus: labia dilute purpurea, extus pilosa, intus glabriuscula; superius erectum, subovale, concavmm, leviter emarginatum; inferius maius parumque longius, deflexun, oblongo-obovatum, trilobım, lobis duobus lateralibus parvis acutuisculis simul cum marginibus revolutis, intermedio maximo, subrotundo, subundulato, enıarginato.

STam. filamenta quatuor, subulata, apice leviter curvo in antluesi a labio corolla superiore simul cum antheris tecta, illoque valde breviora, omnia corollse unbo inserta, et usque ad illius circulum bal. batum decurrentia, sujseruè glabriuscula, infernè valde villosa, duo superiora, seu intermedia, semper parallela. erecta et parum breviora, alia parum ab illis distantia, demum deforata ad latera fancis recurva.

Pist. germen quadripartitum, seu potius granula quatuor obtusa, glabra, cruciation contigna, receptaculo, ut in aliis gynnospermis labiatis, supra calycis fundum in scutella formam prominenti, inserta. Scutella nectarifera, minima, viridis, succosa, glabra, granula germinis cingens, ipsis paulo brevior, persistens. Stylus scutella fundo, in centro inter ovarii granula, insertus, el ibi quatuor in funiculos vasculares cruciatim divisus, in anthesi situ et longitudine staminum, aut paulo brevior, postea illis aliquantulum sape longior. Stigmata duo tenuia, brevissima, acuta.

Pericarpium nullum. Calyx in fundo semina quatuor fovens, obtusa, subtrigona, castanea, scutellà exsuccà siccàque infernè cincta. 
Habitat in calcareis, ad ima collium, et aggeres circa Olisiponem, Conimbricam et alibi in Extremadura et Beira. Floret Maio ad Julium. Perennis.

Odor ingratus; sapor leviter adstringens. Usus ignotus.

Ors. Nimis affinis Stach. germanica et lanatoe, et media inter ipsas; differt a prima foliis radicalibus semper cordatis, nec ovatis, superioribus omnibus obtuse crenatis, nec serratis seu serraturis aculis imbricatis, acumine calycinorum dentium longiore et flavescente, insuper quia ex clariss. Lirk hiemes germanicos non fert: differt a lanata habitu minus lanato et valde minus candido, caulibus basi non procumbentibus, foliis radicalibus cordatis nec ovato-lanceolatis, superioribus non lanceolatis, nec utrinque albissime lanatis, calycis dentibus non brevibus submucronatis, et corollæ labio superiori emarginato, nec integerrimo. Stachys intermedia Aiton potius ad hanc nostram, quàm ad germanicam et lanatam referenda videtur. 


\section{A R R U B I U II cincreum.}

M. foliis corlatis, subrotundis, crenatis, rugosis, liirsutis; calycibus pubescentibus, hypocrateriformibus, limbo decemdentato, dentibus ovatis, acutis, alternis minoribus integris bilidisve; corolla labio superiore fisso, laciniis acutis.

II. cincreum. La Marck Dict. Bot. Encycl. 3. p. 719. Brot. Fl. Lusit. 1. 1. 168. Link Fl. Lusit. 1. p. 117. tab. 8.

Makrucuum Dictamni spurii foliis et facie. Herm. Pararl. p. 200, tab. 200.

RADlx lignosa, ramosa, peremnis.

Caules sxpe plures ex eadem radice, pedales sesquipedales et ultra, anmui, aut nonnulli infenè interdum perennantes, erecti, tetragoni, Jirsuti, ramosi, ramis erectis.

Folsa opposita, corlata, obtusa, fere omnia subrotunda, crenata, rugosa, hrsuta pilis subtus densioribus, supri cineracea, infra candicantia; inferiora breviter petiolata, petiolis canaliculatis, superiora subsessilia aut sessilia.

Vertellu axillares, distincti, multiflori; floribus sessilibus. Bractex lineares, setacex, hirsutx, calyce breviores.

Calyx tubulosus, limbo maximo, utrinque jubescenti, in anthesi plano patenti, decendentato, dentibus quinque maioribus ovatis acutis, mncronatis, quinque aliis alternis minoribus, sxpe uno alterove denticulo acutis.

Coroula labiata, purpurascens, tubo albido illum calycis superante; labio superiore villoso, concavo, leviter arcuato, bifido, laciniis acutis; sæepe uno alterove denticulo acutis; labio inferiore trilobo, lobis omnibus obtusis, intermedio maiori integro.

Sramixum filamenta didynama, longitudine labii superioris corolla, eigue simul cum stylo et stigmate bifido approximata. Semina quatuor oblongiuscula in fundo calycis inclusa.

Habltat in aridis incultis, el rupibns inter Alcoutim et Mertola, atque ex Castello de Vide usque Momtalväo. Florel Jurio, Julio. Perennis, et interdum sufirutex. Amarum et vix odorum.

Torn. 11 . 
Ors. Ninis affine Marrubio hispanico, et pro ejusdem varietate nonnunquam habitum; differt tamen bracteis non subulatis, calycis lim. bo in anthesi non plano nec patenti, sed vix patulo, nullo ex decem ejusdem dentibus subdiviso, et lobo intermedio labii inferioris corollæ non emarginato. 


\section{B A LLO'TA vuiguris.}

B. foliis oppositis, ovato-subcordatis, acutis, crenato-serratis, rugosis, pubescentibus; foribus verticillato-fasciculatis, pedunculo communi solitario, partialibus subnullis; calyce tubulato, supernc ampliato, decemstriato, quinquedentato, dentibus æqualibus, ovatis, acutis, subaristatis; corollæ labio superiori hirsuto, crenato ant bifilo.

\section{Lusit. Marroio negro.}

B. nigra. Brot. Flor. Lusit. tom. 1. pag. 167.

B. fatida, foliis subcordatis ovatis acute crenatis, hirsutis, calyce supernè ampliato venoso, dentibus ovatis mucronalis. Lin! Fl. Lusit. tom. 1. p. 114.

B. vulgaris, foliis subcordatis ovatis crenato-serratis, lirsutis, calyce parum dilatato subcylindrico, dentibus lanceolatis, subulatis.

Id. Ibid. p. 115. ubi eam indicat ut plantam in Lusitania non reperimndan, etsi in Germania, Suecia, et alibi in Europæ borealibus frequentem esse existimet.

B. nigra. La Marck Dict. Bot. Enc. tom. 1. pag. 357. Illust. Gen. tab. 508. Lin. Sp. pl. edit. 1. p. 582. Ed. 2. p. 814 . Ed. cur. Willd p. 107. Flor. Suec. Edit. 2. n. 519. et 530. Savi Pis. 2. P. 57. Smitl Brit. 2. p. $108 \ldots$ Engl Bot. tab. 46. Poll. Palat. n 569.1 Iofm. Germ. 209. Kniph. Cent. 6. n. 209. Roth. Germ. 1. $25 \%$ et 2. 33. Crocker Fl. Siles. 2. p. 332. Scopoli Fl. Carn. ed. 2. tom. 1. p. 415 . Sabb. Hort. Rom. 3. tab. 35. Desfont. Fl Atlant. 2. p. 22. Bull. Herb. tah. 397. Haller Helv, n, 259. Villars Dauph. 2 p. 389. Allionius Fl. Pedem. 1. p. 35 .

Marrubiastrum. Riv. Lab. 66.

B. fatida. Decand. et La Marck Fl. Franc. Moris. 5. 11. tab. 6. fig. 14.

Marrubium nigrum fretidum. Brack. Herb. tab. 136 ,

Marrubium nigrum fætidum, sive Ballote.

Joh. Bauh. Hist. Pl. 3. p. 318. cum Icone.

Marrubium nigrum fatidum, Ballote Dioscoridis.

Casp. Bauh. Pin. p. 230.

Ballote Math. Lac, et al. in Diosc. 
Ballote, s. Ballota. Tourn. Inst. R. Herb. 185. Hort. Clifr. 311 . Roy. Lugdb. 315. Fuchs. Hist. 154. Cresalp. Pl. 445.

Ballote, seu Marrubium nigrum. Lob. Ic. 518.

Marnubum nigrum. Grisley Virid. Lusit. n. 983.

Marrubium vulgare. Clus. Hist. 2. p. 34.

B. fore albo. Tourn. J. R. H. 185. Vaill. Paris. 20. La Marck Dict. Bot. Enc. 1. 1. 357. Sabb. Hort. Rom. 3. tab. 36.

B. alba, corolla alba, calycibus subtruncatis. Lin. Syst. Pl. tom. 3. P. 63. el Sp. pl. Ed. Willd. tom. 3. p. 108. Flor. Suec.2. 11. 540. Cam. Epit. 572.

Radix ramosiuscula, infernè longe fibrata, perennis.

Caules plures ex eadem raclice, annui, aut interdum suffruticosi, erecti, pedales ad bipedales, infernè obtusiusculè quadranguli, sesquilineam ad lineas duas cum dimidia crassi, salurate virides, raro subrubentes, pilis reflexis hirsuti, ramosi; ramis oppositis, brevioribus, erecto-patulis.

Forı sæe ovato-subcorlata, acula, crenato-serrata, denticulis sæpius obtusiusculis, supra saturate viridia rugosa, subtus pallide viridia, et nervoso-venosa, utrinque pubescentia, opposita, patentia, sensim versus apicem caulis et ramormm decrescentia, petiolata; pe. tiolus lamiua dimidio et ultra brevior, villosus, suprà canaliculatus, subtus convexus.

Flores verticilato-fasciculati, utrinque in singula foliorum axilla quinque ad novem et ultra arcte congesti, interdum secundi, sub calycis basi setis pilosis, illo dimidio brevioribus, involucrati; in superioribus axillis sape sessiles, in inferioribus pedunculo communi solitario tereti piloso brevi, in pedicellos brevissimos diviso, fasciculale impositi.

CAIrX monoplyyllus, tres ad fere quinque lineas altus, tubulatus, basi angustalus, sensim ad apicem plus minusve ampliatus, potius infundibuliformis quàm hypocrateriformis, decenstriatus, extus pubes. cens, intus glaber, ore quinquedentato, dentibus ovatis, plus minusve acutis cum mucronè ant brevi arista, sæpe subvenosis, pilose subciliatis, omnibus æequalibus, patulis.

Conolra labiata; tubus cylindracens, albidus, longitudine dentiun calycis, seu vix longior, extus glaber, collo tamen subpubescens, interne panlo infra medium zona villosa instructus; fauce alba gla- 
bra paulum dilatata. Labium superius dilute purpurascens, erectum, oblongum, sublineare, obtusum, convexo-concavum, extus usque ad oras marginales hirsutun, intus glabrinsculum, nunc integrum crenatum, nunc brevissime hifidum, segmentis lateraliblis uno aliove denticulo floccoso crenatis: labium inferins ex albido purpurascens, superiore latius, eoque parum longius, lente vismu exus subpubescens, intus glabrum, trifidum, lacinia intermedia lateralibus amplio. re ef valde longiore, emarginata, obcordata lobulis deflexiusculis, laciniis lateralibus subovatis, obtusis, sæpe intererrimis, interdmu obsulete emarginatis. Utrunque labium in floribus omnibus nonnunquam albun.

Stam. filamenta didynama, subulata, alba, sulıpilosa, fauci corollæo inserta, sub ejus labio superiore recondita, illo paulo breviora, erecta, tandem sæpe divergentia. Antheræ oblonga, didyun, laterales, flavæ.

Pist. germen quadrifidum, viride, glabrum. Stylus filiformis, albidus, glaber, situ et longitudine staninum. Stigna bifidum, breve, tenue, acutum.

Peric. nullum. Calyx immutatè persistens in fundo semina fovet. Semina subovalia, subtriquetra, fusca, glabra, nitida.

Habitat ad silvas, ericeta, agrorum margines, sepes vias, circa Conimbricall, urbem Portensen, Eboram, ad montes et pagos de Cintra, et alibi. Floret Malo ad Augustum. Perennis.

Planta amara, plus minusve fridia, inde ab omni pecore intacta relinquitur. Olim ex Dioscoride et Plinio, ejus folia ad morsus caunm medendos, condylonata, ulceraque sanauda in usu externo erant: in nostris Aræ Christianæ ultimis sxeculis folia et verticilla inter medicamenta tonica, anti-lıysterica, resolventia, et detergentia babita; decocta et infusa a medicis nonnu!lis ad morbos quostam arcendos, qui a Marrubio vulquri depelli solent, laurlata; nunc planta omnino fere oblita, et in Lusitania quod sciam tantım aliqui ruricolx, consilio empiricorum, ejus decocto cum succo limoniorum demum adjuncto ad febres tertianas medendas utuntur, quas felıci eventu sic sæpe expulsas esse asserunt.

Dioscorides de Ballote, seu Marrubio nigro, agens ei folia subrotunda, et flores albos universos assignavit. C Bauhinus illan foliis maioribus et minoribus variare solere retulit. Joh Bauhimus ei folia Melissx et in ambitu serrata tribuit. Tournefortius nullam aliam Ballotes speciem se novisse ait quàm jllam Dioscoridis, insuper ean foribus albis variare adrlit, et ejus forum icone corollæ labium superius integerrime delineatum edidit. Linnæus, inter alias notas characteris generici Ballotæ, labium corolla superius crenatum apposuit, et specificum Ballow nigra (quæ eadem Dioscoridis, Barhinorum, et Tournefortii) in foliis cordatis indivisis serratis, calycibus Iom. II. 
acuminatis, conslituit, ut sic eam ab alterâ distingueret, qux caJycibus subtruncatis interdum in Snecia occurrere dixit; cùn verò millas alias Ballota species Europaas, sive in Succia sive alibi provenjentes, connemoravit, et cum multa Ballotæe individua Euro. pae sint, qux tam foliis quan calyce et corolla inter sese difierunt, eidemque celeb. Botanico non ignota fuisse credibile. illa ad Ballotam nigram, uti varietales, ab eo relata fuisse videntur. La Marck (Dict. Bot. Encycl.) folia Ballotx ovata, subcordata, sed absque satis cavà emarginaturâ in basi, et crenata, in Gallia esse tradit. Allioni corolla labium superius parum emarginatum, inferius vero trifidun, segmentis lateralibus acutis, medio plano crenato, in P'edemontio esse refert. Villars in Delphinatu ei folia subrotunda assignat, el corollae labium superius subbilidum. Scopoli in Carniolia nulla folia cordata in hac specie invenisse ait, sed ovala el serrata corollæque labium superius bifilum, inferioris lacinias laterales acuminatas, median verò emarginatam et clenulatan esse asserit. Koth in Germanix Flora inter alias notas diagnosticas ei folia cordatosubrolunda, obtusa, iuciso serrata, el floralia ovata acuminata apposuit. Crocker in Flora Silesix, de ejusdem varietate maiori, ut videtur. agens folia ejus oblongo-ovala, acuminata, el dentibus latis dentata csse dixit, et labium corolla superius sape emarginatum, inferius trifidum, lacinis lateralibus ovatis, intermedia cmarginata: de minori autem varietate agens ei folia similiter oblongo-ovata, sed minora acutiora, et maqualiter serrata tribuit, Linnæum suspicans cam ad manum habuisse cum characterem Ballotæ nigro designavit. Ex relatis suflicienter agnoscitur quàm Ballota nigra variet; nec illa, qux in Lusitania provenit, invariabilis; aliqua enim ejus individua presertim ad radices montium de Cintra et prope Eboram in Transtagana plus minusve foliis, calyce et corollà variantia vidi; nulia vero uspiam inveni calycibus subtruncatis, et si verè talia alicubi adsint, rara sunt, et cùm sæe simul cum invariatis habitent, fortasse nonnisi plantæ monstrosæ seu norbosæ. Itaque tam Ballota alba Lin., quàm aliæ Suecix indigenæ, et fatidu aliquorun Botanicorum cum Ballota nigra, quæ nobis hìc acceptione latiori vulgaris mominatur, conjungendæ, et ut illius unicæ speciei sui generis in Europa provenientis varietates habenda videntur. 


\section{NEPETA multibracteata.}

N. caule subsimplici; folits oblongis, acutis, crenatis, hasi emarginalis, subtus villosis, inferioribus petiolatis; floribus verticillato-fasciculatis; bracteis lineari-subulatis, pubescentibus, calyce longioribus.

N. vinlacea? (uti dubia) Brot. Fl. Lusil. tom. 1. p. 173.

N. multihracteata. Lin. Sp. pl erl. Wiild tom. 3. p. 55. Desfont. Fl. Atant. tom. 2. p. 11. tab. 123. Link Fl. Lusit. tom. 1. p. 9ł. tab.5.

Radx ramosiuscula, lignosa, perennis.

CaULIS herbaceus, erectus, sesquipedem ad pedes duos altus, solitarius, aut aliis lateralibus ex eadem radice ortis stipatus, simplex seu parce ramosus, tetragonus, pubescens.

Folia opposita, oblonga, acuta, basi emarginata corlata seu subcordata, ibique plus minusve latiora, ora marginali nsque ad apicem crenato-serrati, supra ruyosa pilosaque, subtus villosa seu tomentosa, inferiora breviter petiolata, superiora subsessilia vel sessilia remotiora, inferioribus conformia.

FLoRes verticillato-fasciculati; verlicilli sæpe plus minusve distincti, rarius approximati; singulo hinc inde in utraque foliorum axilla sape flores qnatuor aut quinque fasciculati, quorum pedunculus communis brevis, partialis brevissimus aul interdum nullus. Bracteæ alia in pedicellis aliæ sub calycis basi, istoque sxpe longiores, setacex, acutissimæ, violaceæ seu cæruleæ, pubescentes.

CALYX tubulatus, striatus, pubescens, interdum Jeviter arcuatus, quinquedentatus, dentibus lineari-subulatis, setaceis, subæqualibus, hirtis.

Corolla labiata, violacea vel cærulea; tubus longitudine calycis; Jabium superius emarginatum, subpubescens, inferiore brevius; inferius trilobum, intermedio lobo concavo, subrotundo, integro, crenulato, rubro, punctato, Jateralibus ad tubi faucem minutis, angustis.

STAm. filamenta didynama, sub labio superiore approximate posita, illoque panlo breviora. Anther: incumbentes. 
Pıst. germen quadrifidum, glabrum. Strlus situ et longitudine. staminum, aut vix longior. Stigma bifidum, acutum.

Persc. nullum. Calyx in fundo semina quatuor subovata continet.

Hantat in Castanetis prope Marväo el ericctis in Transtagana, in arvis etiam inter Covilhä et Fundäo. Floret Maio, Junio, Julio. Perenuis.

Planta odore leviter aromatico, sapore amaro acriusculoque prædita. Usıs ignotıs. Pecori displicet.

Ors. Affinis Nep. violacece et italica, sed ab utraque differt caule subsimplici, foliis acutioribus, non nudiusculis, et præsertim bracteis omnimode diversis. 
OR I G A N M vulgare virens.

Or. foliis ovatis laxe subserratis, subtus hirsutis; spicis hrevibus, con. fertis, panieulatis; bractess ovatis, acutis, virescentibus, calyce longioribus.

Lusit. Ouregüo ordinario.

Or. vulgare. Brot. Fl. Lusit. tom. 1. pagg. 169.

Or. virens. Link Flor. Lusit. tom. 1. p. 119. tab. 9. La Marck Dict. Bot. Encycl. Suppl. tom. 4. p. 186.

Radix lignosa, ramosa, perennis.

Caules solitarii, aut pauci ex eadem radice, erecti, obsolete tetragoni, virides, aut interdum subrubentes, hirsuti, pedales ad sesquipedales, sıperıè raıulosi; ramis brevibus, pubescentibus, floriferis.

Fons opposita, breviter petiolata, internodiis triplo et ultra longiora, ovata, acuta, aut interdum obcusiuscula, distanter et brevissime serrata, viridia, supra glabriuscula, subtus et margine villosa, nervosa, sex od octo lineas lata, decem ad tredecim longa.

PANiculæ spicarum coarctatæ in summitate caulis ramulorumque brevium axillarium. Flores in spicam strobiliformem tetragonam brevem dispositi, sessiles aut subsessiles. Bractea sub singulo flore imbricatæ, ovatæ, acutæ, integerrimæ, virescentes, raro apice coloratæ, glabræ, nonnullæ ex infimis subciliatæ, omnes calyce longiores et sæpe corolla breviores.

CalyX sesquilineam longus, extus striatus, pubescens, punctis resinosis conspersus, intus fance villosus, non bilabialns, sed quinque dentibus acutis subrqualibus, nonnullis vix latioribus, terminatus.

Corolla alba, labiata; tubus compressus, apice subpubesceus, calyce paulo altior; labium superius erectum, obtusum, emarginatum; inferius sape longius, trilobum, lobis obtusis, integris, internedio longiore. Stamina didynama, exclusa, divergentia, duo externa sæpe corollà altiora. Pistilli stylus longe exsertus; stigma bifidum. Senina quatuor ovata in fundo calycis recondita.

HaBit A $\mathrm{T}$ in dumetis, rupestribus, ad silvarum margines et sepes circa Conimbrican et alibi præsertim in Lusitania boreali. Floret æstate. Perenne. Planta amaricans, subacris, grate odora: viribus ad Or. Tom. II. 
Majoranam accedit, sed oblita, et nunc rix al condinenta usitata.

Ors. Bractearum raro aliqux corollâ longiores sunt, nec omnes semper virescunt, nomullæ enim interdum apice obscure purpurascunt; corolls magnitudo, sicuti etiam labii superioris altitudo, ratione soli et expositionis, variabilis; nostrum igitur Origanum undequaque Origano vulgari adeo afline, ut pro eodem tantummodo aliquantillum variante habendum existimem. 


\section{OR IGANUM crcticum macrostachyum.}

$\mathrm{O}_{\mathrm{R}}$. folih ovatis, superioribus integerrimis, aliis distanter subserratis, subtus pubescentibus; spicis paniculatis, laxè aggregatis, pralongris, rectis, obsoletè tetragonis; bracteis late lanceolatis, glatris, calyce duplo Jongioribus.

\section{Lusit. Ouregão longal.}

On. creticum. Brot. Fl. Iusit. 1. p. 169.

OR. macrostachyum. Link Fl. Lusit. 1. p. 120. tab. 10. La Marck Dict. Bot. Eucycl. Suppl. Lom. *. p. 187.

RADIx lignosa, ramosa, peremnis.

Caules erecti, novem ad viginti uncias alti, virides aut interdum subpurpurascentes, subvillosi, tetragoni, ramis oppositis, infernè brevibus, supernè longioribus, instructi.

Folia opposita, breviter petiolala, decein ad tredecim lineas longa, ovata, oblongiuscula, acuta, aut interdum obtusiuscula, superiora caulis integerrima, inferiora distanter serrata, supra viridia et glabriuscula, subtus pallide viridia, ant interdum glaucescentia, punctis resinosis conspersa, nervosa, nervis villosa, margineque pilis brevibus ciliata. Spicarum paniculæ caulem ranosque terminant. Spicæ minus coarctatæ quàm in præcedenti specie sunt, atque hrevissime pedicellatæ, rectæ, tredecim ad quindecim lineas longæe, obsolete tetragonæ, et post anthesin fere teretes. Bractex laxiusculæ, late lanceolatæ, seu ovato-lanceolatæ, plus minusve acutatæ, virides, glabræ, tres lineas longæ, duas latæ, caljce dıplo Jongiores, corolla vero sæpe aliquantum breviores.

Calyx brevis, extus pubescens, striatus, punctisque resinosis conspersus, intus fance villosus, quinquedentatus, dentibus subxqualibus, ovatis, acutis. Corolla, organa sexualia, et semina ut in precedente Urigano.

Habitat in dumetis collium circa Olisiponem, Thomar, et alibi in Lusitania meridionali. Floret Maio, Junio, el astate. Perenne. 
SAPORE, odore, viribus et usu pracedenti simile; ab illo tamen differt presertim foliis integerrimis subintegerrimisque, spicis laxioribus inter sese, valde longioribus et tandem subteretibus, sicuti etiam bracteis plus altis et minus arctis; cum autem Origano cretico plus afine, et cum illo notis specifice essentialibus concordare, nec ab illo, nisi ut varietas differre videatur, ab illo non separavi. 


\section{A V A N DULA viridis.}

I.ar. foliis sessilibus, lineari-lanceolatis, rugosis, villosis, margine revolutis, integerrimis, utrinque viridibus; spicis longis, comosis; bracteis sape indivisis; caule villoso.

Lusit. Rosmaninho verde.

Lav. virilis Link Fl. Lusit. 1. p. 91. tab. 4. Lin. Sp. pl. ed. Willd. 3. p. 61. A it. Hort. Kew, 2. p. 288. L'Herit. Sert. Angl. p. 19. La Marck Dict. Bot. Encycl. Suppl. tom. 3. p. 308.

Stechas Lusitanica foliis viridibus lanuginosis.

Tourn. Iust. R. H. pag. 201.

Stechas viridis. I. Bauh. Hist. Pl. 3. 2. p. 279.

Sтесиas flore a!bo, et alia rosmarini folio, Grisley Vir. Luslt. n. 136667. an polius ista quanı Lav. Stachas Lin. incertum.

RADix lignosa, ranıosa, supernè crassiuscula, perennis.

$\mathrm{C}_{\text {A ULEs sape }}$ plures ex eadem radice, suffruticosi, erecti, quadrangu. li, supermè villosi, diffuse ramosi; ramis alternis, longis, erectis.

Folı opposita, internodiis longiora, sessilia, lineari-lanceolata, acuta, utrinque viridia, rugosa et villosa, villo brevi crispo, marginibus integerrimis revoluta, superiora longiora et latiora, ex illorum axillis alia minora plura.

Splc.e in summitate nuda caulis el ramorum pedunculatx, obsolete tetragonæ, et demmn subteretes, coarctatæ, sesquiuncian ad uncias duas longæ, apice comatæ. Flores sessiles. Bracteæ imbricatæ, unifloræ, virides, lanuginosæ, calyce longiores, ovato-subrotundæ, brevissime acutatx, sape indivisæ, interdum tamen subtrilobæ seu subsinuatæ; qux spicæ comain efficiunt longiores, virides, etiam integræ.

Calyx cylindraceus, brevis, dentibus quatuor parvis xqualibus, quinto antem maiori terminatus. Corolla labiata, alba (luteam a Dalechampio et I. Baubino relatam nullibi vidi) tubus calyce parum altior; labium superius obcordatum, inferius trilobum, lobis omnibus obtusis, intermedio paulo maiori. Stamina didynama, é tubo non exserta. Stylus longitudine staminum; stigma bilobum. Semina quatuor ovato-subrotunda in fundo calycis recondita.

Tom. II. 
Hanitat in collibus inter Alcoulim et Mertola, etiam in Monchique et alibi in Algarbiis. Floret vere. Suffrutex.

Planta amaricans, subadstringens, odorata. Nimis affinis Lav. Steechadi gredunculate, et pro illius varietate sxpe habita; differt tamen specifice foliis superioribus longioribus latioribusque, omnibus villosis, rugosis, viridibus, nec tomentosis incanis, bracteis comaque vi. ridibus et sxpe indivisis. 


\section{SIDER I TIS lincarifolia.}

SrD. folits sessilibus, angustis sublinearibus, acutis, subintegerrmis, rlabriusculis; bracteis late ovatis, dentato-spinosis, calyce longioribus.

S1D. Inncarifolix. La Marck Dict. Bot. Encycl. tom. 2. pag. 168 . Brot. Fl. Lusil. 1. p. 161. Link 17. L.usit. 1. p. 100. tab. 6.

Radix lignosa, infernè ramosiuscula, vage fibrosa, perennis.

Caulis erectus, infernè lignosus, ramosus; ramis gracilibus, erectis, tetragonis, pubescentibus, aut interdum fere grabris.

Fouı opposila, sessilia, subviridia, glabriuscula, sublinearia, acula, versus basin angustala, superiora integerrima et internodiis breviori, inferiora distanter et obsolete denticulata internodiisque longiora.

FLores verticillato-spicati; verticilli quinque ad septem in caulis et ramorum summitate, glabri, inter sese distincti, sexflori, sessiles uti etiam flores. Bractex late ovatæ, venosæ, acutiusculæ, denticulatospinosx, subconcava, calycibus longriores.

CAlyx subcampanulatus, venosus, quinquedentatus; dentibus subæqualıbus, ovatis, acuminatis, spinulosis. Corolla labiala, llava, ca. lyce longior; labio superiore erecto, lineari, planiusculo obtuso, bifido, inferiore trilido, laciniis omnibus obtusis, intermedia longiore et duplo latiore.

STamna didynama, simul cum antheris intra corollæ tubum recondita et illius fauce breviora. Pistilli germina quatuor: stylus vix staminibus longior: stigınata duo, inferiore vaginante superius.

Semina quatuor in sinu calycis persistentis contenta, et receptaculo allixa, obovata, fusca.

Manitat in solo calcareo, el rupium rimis inter Loule, Faro et Tarira, in Moncarapaxo et alibi in Algarbiis et Transtagana meridionali. Floret ex Jumio ad Augustum. Sullrutex.

PLANT subamara, acriuscula. Usus ignotus. 
Ors. Nimis affinis Sideriti incance et hyssopifolice; sed a prima differt habitu non tomentoso-incano, bracteis calyce longioribus, ovatis nec cordatis, laciniis lateralihus labii corollæ inferioris obtusis nec acutis, et intermedia non quadruplo latiore; a secunda vero differt foliis non ellipticis, non obtusis nec penitus glabris, verticillis non approximatis, illorum spica longiore, et bracteis ovatis nec cordatis. 


\section{THY MUS.}

In hoc Genere, cujus species plurimæ in Lusitania, calycis tubus cylindricus, supernè non ampliatus, intus ad faucem villo clausus; limbus bilabiatus, superiore labio tridentato, inferiore bidenteo, seu biseto: corolla labiata, labio superiore planiusculo, emarginato aut bifido, inferiore trilobo, lobo medio integro, latiore: Stanina didynamica: Pistilli germen quadripartitum, stylus unicus, stigma bifidum: Semina quatuor in fundo calycis supernè angustati contenta.

Plante sæpe fruticosæ, aromaticæ, suaviter odoræ.

\section{THY M US albicans.}

TH. Caulibus fruticosis, erectis, ramosis; foliis ovato-lanceolatis, acttiusculis, temuiter tomentosis, albidis, utrinque punctatis; capitulis globosis, terminalibus axillaribusque pedunculatis; bracteis ovatis, acntis, margine villoso-ciliatis; calycis dentibus setaceis, ciliatis, subrqualibus.

\section{Lusit. Tomilho alvadio.}

TH. albicans. Link Fl. Lusit. 1. p. 124. tab. 11.

CAules plures ex eadem radice lignosa perenni, fruticosi, teretes, erecti, novem ad quindecim uncias alti, ramosissimi; ramis temuiter tomentosis, erectis.

Foun opposita, sessilia, subsessiliave, parva, duas ad fere tres lineas longa, lineam ad sesquilineam lata, planiuscula, ovato-lanceolata, acutiuscula, integerrima, margine reflexiuscula, sulstomentosa, albicantia, utrinque æequaliter punctata, punctis parcis, resinosis.

Flores capitati; capitulo uno caulen terminante, perpaucis aliis infra illud axillaribus, oppositis, solitariis, pedunculatis, omnibus globosis, diametro trium linearum, aut paulo ultra, erectis, bracteatis: biacteæ imbricatæ, concavæ, ovatæ, breviter acuminata, subtus tomentoso-incanæ, subcarinatæ, margine villoso-ciliatæe, utrinque punctatæ, inferiores seu exteriores calycibus longiores, duas lineas Tom. Ir. 
ant panlo w]tra longæ, sesquilineam prope basin lalæ, superiores seu interiores minores.

CaLYX tubulosus, villosus, unam lineam aut paulo ultra longus; dentes setacei, ciliati, superiores angustiores, inferioribus vix breviores. Villo faucis incluso.

Corolla alba, calyce duplo longior; tubo tenui, Jongo; labio superiore emarginato.

Stamina didynama, exerta, quorum duo corolla breviora, duo alia illà sæpe longiora. Stylus situ et longitudine staminum longiorum.

Iraritat in collibus siccis, dumetis, et locis saxosis ex Tamira usque ad Alcoutim, et alibi in Algarbiis. Floret Junio, Julio. Frutex siavissimè olens. 


\section{T II Y MU U capilellatus.}

TH. caulibus fruticosis, erectis; foliis subsessilibus, ovato-lanceolatis, supra viridibus, margine revolutis; capitulis terninalibus, globosis; bracteis late ovalis, nervosis, virentibus; calyce glabriusculo, dentibus superioribus ovatis latioribus; corolla parum calycem superante.

'Tн. capitellatus. Link Fl. Lusit. I. P. 125. tab. 12.

TH. Lusitanicus cephalotos capitulo minore. Tourn. Inst. R. H. p. 196.

Radix lignosa, ramosa, perennís.

Caules sape perpauci ex eaden radice, pedales ad hipedales, lignosi, erecti, ramosi; ramis oppositis, foliatis, glabriusculis, seu teuuissino tomento incano-virescentibus.

Fona parva, oblongiuscula, tres lineas aut paulo ultra longa, sesquilineam ad lineas fere duas lata, opposita, petiolo brevissimo, ovatolanceolata, integerrima, margine reflexa, apice oblusiuscula, supra viridia, creberrimis punctis, pilisque densis minutissimis instructa, subtus minus crebrò punctata et tomento tenui pal!escentia.

Capitula caulem ramosque terminantia, globosa, trium quatuorve linearum diametro. Bractex imbricatæ, late ovatæ, tres lineas longæ, duas cum dimidia latæ, acuminatx, concave, margine revolutæ, suprà foliis siniles, subtus nervosæ, subtomentosæ, pallidæ; calycibus longiores sunt.

$\mathrm{C}_{\text {a L YX }}$ glabriusculus, seu tantim pilis minutissimis instructus, duas lineas cum dimidia longus, resiuosc̀ punctatus; dentes superiores late ovati, acuti, inferiores setacei, parum ciliati uti eliam superiores; villo faucis subincluso.

Corouna alha, tubo calycem parmm superante, collo pilis viscosis interium instructo; labio superiore emarginato. Stamina duo altiora vix corollà longiora; stylus illis parum altior.

Habıtat in dumetis sabulosis trans 'Tagum ex Almadn usque ad Cabo de Esinchel, et alibi in Lusinania meridionali. Floret Aprili, Maio, Junio. Frutex aromaticus, odore camphorito. 
OBs. Differt á præcedente, cui aflinis, foliorum colore viridi et eorum marginibus multo magris revolutis; bracteis latioribus nervosisque; calyce glabriusculo, ejusque dentibus superioribus multo latioribus, atque corollæ tubo parum calycem superante, nec illo duplo longiore. 
TH Y MUS cephalotos.

TII. caule erecto; foliis linearibus, integerrimis, ciliatis; capitulis maximis, oblongis; bracteis maximis, latissime lanceolatis, integerrimis, acuminatis, coloratis, impunctatis, flores valde superantibus.

\section{Tomilho cabeçudo.}

TH. cephalolus. Lin. Sp. pl. ed. Willden. 3. p. 144. Vahl. Synb. 3. p. 77. La Marck Dict. Bot. Ençycl. tom. 7. p. 650 . Brot. Fl. Lusit. 1. p. 175. Link. Flor. Lusit. 1. p. 127. tab. 13.

Thymes Lusitanicus cephalotos, squamis capitulorum amplioribus Tourn. Inst. R. H. p. 196.

Tragoriganem Dictamni capite, Hispanicum. Barrel. Icon. Rar. tab. 788. Baccon us. 2. p. 30. tab. 48.

Cathes plures ex eadem radice lignosa ramosa, fruticosi, teretes, subtortuosi, erecti, semipedales ad pedales, glabri, ramosissimi ; ramis oppositis, annullis allernis, subdivisis, spissis, tomentoso-subvillosis, erectis, foliatis.

Folra opposita, patentia, approximata, sessilia, angustissima, linearia, acuta, tres ad quinque lineas longa, integerrima, marginibus revoluta, supra punctata, tenuiterque pilosa. Nonnula minora in axillis ad ramulorum exortum subfasciculata.

Capitula caulem et ramos terminantia, maxima, oblonga. acutiuscula. Bracteæ imbricatæ, longe lateque lanceolatæ, acuminatæ, integrerimæ, glabræ, ciliatæ, impunctatæ, oblique extrorsum nerrosæ, purpurascenti-violaceæ, floribus multo longiores.

Flores subsessiles. Calrx tenuiter striatus, subhirsutus; labium superius latın, dentibus brevissimis, inferiorioris duobus setaceis, cilia: tis. Corolla dilute violacea; tubus calyce longior, interdum subvillosus.

Habitat in ericetis ex Faro usque ad Monchiquc et alibi in Algarbiis, etiam trans Tagum in dumetis sabulosis, præsertim ex Almada usque ad vicum Zezimbra. Floret Maio, Junio, Julio. Frutex odore leviter aromatico, et quasi terebinthinaceo. 
TH Y MUS villosus.

Tr. caule erecto, infernè ramoso; folis linearibus, subsetaceis, pilosis; capitul:s maynis, termimalibus, oblongiusculis, oblusis, subrotundisve; bracteis ovatis, dentato-serratis.

Tomilho peludo.

Tr. villosus. I.in. Sp pl. et Willen. 3. p. 145. La Marck Dict. Bot. Encycl. tom. 7. p. 65 1. Brot. Flor. Lusit. 1. p. 175. Link Fl. Lusit. 1. 1. 128. tab. 14.

Thrmus Lusitanicus, folio capillaceo villoso, capite purpurascente oblongo, rotunduve (interdum).

Tourn. Inst. R. H. p. 196.

CAULes plures ex eadem radice lignosa, fruticosi, teretes, filiformes, erecti, sex ad noveln uncias alti, ferè é basi ranosi; ramis dense pilosis, erectis, foliosis.

Folra opposita, sessilia, angustissima, acuta, subsetacea, integerrima, nıarginibus reflexa, ciliata, cælerum glabriuscula, viridia, sıprà punctata, omnia sæe approximata, et in corun axillis ad ramorum exortum alia minora subtasciculata; interdum tamen superiora solitaria, distantia.

Capitula caulem él ramos terminantia, crassa, nunc oblongiuscula oblusa, nunc subrutunda. Bractex imbricatx, ovatx, dentato serratx, nervosæ, pilosiusculæ, malgine ciliatæ, caljce valde longiores, superiores purpurascenti-violacex.

Trones loracteis longiores, subsessiles. Calyx substriatus, glaber, dentibus tribus superioribus brevibus, duobus inferioribus setaceis ciliacis. Corolla purpurea, sen dilute violacea.

Habitat in dumelis trans Tagum in territorio de Almada, et ex CinIra usque ad Othidos, et alibi in Extremarlura. Floret Maio, Junio, Julio. Frutex oclore grato, quasi mastichino. 
TH Y HUS glabratus.

'Tu. caulibus prostratis, repentibus, tetragonis, angulis pubescentibus; folis subsessilibus, distantibus, oblonero-lancoolatis, integerrimis, glabris, basi ciliatis; floribus terminalibus, aliis capitatis, verticilJato-spicatis aliis.

Lusit. Serpäo glabro.

Тн scrpyllum. Brot. Fl. Lusit. 1. pag. 174. Ex fide P. Christophori dos Reys.

Tı. glabratus. Link Fl. Lusit. 1. p. 130. tab 15.

RAdx lignosa, ramosa, vage fusa, perenuis.

Cavles plures ex eadem radice primaria crassa, debiles, tenues, basi lignosi, tetragoni, aciebus densè pilosi, caterum glabri, parum purpurascentes, ramosi, procumbentes, reptantes, ubi autem florent paululum adscendentes.

Foria opposita, distantia, subsessilia, inferiora et in ramis junioribus longiùs petiolata latioraque, viridia plana, glabra, oblongo-lanceolata, acutiuscula, integerrima, basi ciliata, margine reflexa atque scabriuscula, utrinque punctala, punctis resinosis, quatuor quinque. ve lineas longa, sesquilineam ad lineas fere duas lata.

Flores caules et ramos terminant, sæpe verticillato-spicati, interlum tamen nonnulli ibidem capitali; omnes breviter pedicellati.

CALYX brevissimss, lineam ad sesquilineam fere longus, pubescens, pilis brevibus, punctatus, punct is resinosis; dentibus superioribus ovatis, acutis, brevè ciliatis, inferioribus setaceis, Iongè ciliatis: villo faucis exerto.

Corolla violacea, pubescens, punctis resinosis punctata, labio superiore emarginato. Stamina duo maiora corollan paulo superantia, divergentia: Antheræ purpurascentes.

Habıтат in Serra do Rebordäo, prope Muntalegre, Montezinho et alibi in montosis tam in Transmontana quam Interamnia. Floret Junio, Julio. Frutex, odore Thymi vulguris. 
Ors. Differt a Thymo serpyllo, cui nimis affinis, foliis angustioribus minusque obtusis, glaberrimis, caulibus glabris, tantummodo pubescentibus in angulis, corolla minori et odore Thymi vulguris; sed hæ differentiae vix ad speciem a serpyllo diversam constituendam sufficiunt. Vires ut serpylli, et pro tali in Transmontana et Interamnia a Medicis et Pharmacopólis usitatus, qui eum esse serpylli varietatem existimant. 


\section{'T' I I IIS zygis silvestris.}

Tu. caule fruticoso, erecto, tenuiter villoso-tomentoso; foliis sessili. bus, linearibus, obtusis, enerviis, margine revolutis, pubescentibus, basi ciliatis; floribus verticillato-spicatis.

Tir. Zygis Lin. Sp. P. ed. Willden. 3. p. 140. La Marck Dict."Bot. Encycl. tom. 7. p. 644. Brot. Fl. Lusit. 1. p. 176.

Tн. silvestris. Link Flor. Lusit. 1. p. 132. Lab. 16.

Thyma angusto longioreque folio. Barrel. Icon. $77 \%$

CAures plures ex eadem radice profunde lateque ramosa, frutescentes, erecti, octo ad tredecim uncias alti, tortuosi, tomptoso-villosi, ramosissimi; ramis oppositis, nonnullis alternis, erectis, tenuiter incano-villosis.

FolIs opposita, approximala, sessilia, anguste lincaria, el quasi filiformia, superiora paulo latiora, duas ad quatuor lineas longa, obtusa, integerrima, margine valde revoluta, convexa, enervia, utrinque punctis resinosis adspersa; undique pilis brevibus arrectis tecta, basi ciliata; in eorum axillis ad ramulorum exortum alia minora fasciculata.

FLores breviter pedicellati, verticillato-spicati; spicæ in apice caulium et ramorum sesquiuncian ad uncias duas longre; verticilla laxa. Folia floralia verticillorum ut caulina, sed breviora et angustiora.

CALYX sesquilineam ad lineas duas cum dimidia longus, tenuiter tomentosus, bilabiatus; labio superiore tridentato, dentibus brevihus paulo ultra semilineam longis, margine ciliatis, dentibus duobus inferioribus unam lineam aut paulo ultra longis, setaceis, crebrius longiusque ciliatis.

Corolla purpurascens aut inlerdum albida, hirta, punctis crebris resinosis respersa, labio superiori emarginato. Stanina corolì breviola. Stylus staminibus parum longior.

Tom. II. 
Habitat in collibus de Arrabida, Azcilüo, el circa Selubal, atque alibi trans Tagum ad austrum. Floret Aprili, Maio, Junio. Frutex.

OEs. Planta odore Thymi vulgaris, cui nimis aflinis, sed diversa præsertim foliis basi ciliatis, nec ovatis; propriore autem affinitatis gradu ad Thymum Zygis, quàm ad illum aliosque Thymos accedere videlur, ideo ab isto specificè non sejungendum existimavi. 


\section{TH YMUS zygis varialitis.}

Tr. caulibus fruticosis adscendentibus, erectiusculis aliis, pubescentibus, ramosis; foliis linearibus, sublanceolatis aliis, basi cilialis, obtusis, margine reflexiusculis, supra glabris; floribus verticillato-spicatis, verticillis inferioribus laxe approximatis, aut remotis.

Lusil. Serpảo dos Memes.

TH. variabilis. Link Flor. Lusit. 1. pag. 134, tab. 17.

Rabx lignosa, ramosa, collo crasso norloso, peremis.

Caules plures é nodo radicis, frutescentes, exteriores ex declinato assurgentes, seu obliquati, interiores plus minusve erecti, octo ad tredecin uncias longi, pubescentes, ramosi; ramis purpurascentibus, subtetragonis, undique pilosis, pilis brevibus, recurvis, adpres. siusculis

Fouı opposita, alia præsertim juniora linearia, sessilia, tres quatuorve lineas longa, internodiis æqualia, ant vix breviora, obcusiuscula, angustissima, valde convexa, margine reflexa, creberrimè punctata, pilis brevibus arrectis scabra, ut in Thymo pracedenter descripto " adultiora sex septemve lineas longa, internodiis sxpe multo breviora, sesquilineam lata, ad basin angustata, lineari-lanceolata, ohtusa, integerrima, subplana, maryine reflexiuscula, supra viridia, glabra, parce punctata, subtus pallirla, lineata, pilosa, pilis raris brevibus, adpressis, curvis. In axillis ad ramulorum exortum alia minora fasciculata.

Flores breviter pedicellati, verticillato-spicati: spicæ sesquinnciam ad quatuor uncias longæ: verticilli superiores plurifori, inferiores nunc remoli, nunc omnes laxe approximati.

C.ALYX brevis, vix sesquilineam longus, hirtus; dentes superiores latiusculi, acuti, inferiores setacei, ciliati. Corolla dilute liliacea, labio superiore emarginato. Stamina eorollam subaequantia.

Habitat circa Monte-Junto. Floret Maio, Junio. Frutex odore Thymi serpylli. 
Ons. Planta caulium directione, foliorum longitudine et latitudine, uti corum inter sese verticillorumque distantia, nimis varians: hybrida ex Th. serpyllo el. Th. Sygis esse videtur; specimina collecta, et individua omnia, quæ observavimus, plus ad istum quàm ad illum aflinitate accedere visa sunt, quapropter ipsi utpote variato retulimus. 


\section{EUPHR A SIA aspera.}

Eup1. foliis ovalibus, obtuse serratis, rugosis, lineatis, asperis; caule tereti, erecto, superuè scabro, ramoso; bracteis peraculis, subsetaceis, calyce paulo brevioribus; staninibus corollan non superantibus.

Eupn. aspera. Brot. Fl. Lusit. tom. 1. pag. 185. sell non Willd. in Lin. Sp. pl.

Lasiopera aspera. Link Flor. Lusit. 1. p. 302. tab. 59.

Eupirasia aspero valde fragili folio montana perennis.

Grisley Virid. Lusit. n. 37.

RAD DX lignosa, infernè ramosiuscula, perennis.

Caules solitarii, aut pauci ex eadem radice, erecti, pedem ad sesquipedem alti, teretes, infernè laves, supernè scabri, ramosi; ramis oppositis, erectis, pilosis (pilis rigidis adpressis sparsis) superioribus longioribus, floriferis.

Form opposita, patentia, sessilia, internorliis multoties hreviora, ova. lia, obtusiuscula, rugosa, lineata, obtuse et grosse serrata, undique scabra ob pilos rigirlos basi incrassatos adpressos, novem ad undecim lineas longa, quinque ad octo lata, cilo decidua.

SpICA caulem et ramos terminantes. Bractex uniflora, inferiores steriles, superiores maiores et laxiores, ommes acutissinæe, subsetacex, crassiusculæ, canaliculatr, integerrimæ. Flores subsessiles, quasi imbricati, et cum bracteis ramos superiores fere totos occupant.

CALYX bracteis parmm longior, tubulatus, subangulatus, scaber, quadrifidus, dentibus oblongis, subulatis.

Corolla obscure purpurea, labiata; tubus calyce luplo fere longior; labium superius inferiore parum longius, subintegrum sen obsolete emarginalum, concavum, basi flavum, limbo saturate purpureun: inferius fusco-purpureum, trilobum, lobis integris, obtusis, intermedio naiori.

Sтамлем filamenta didynama, per paria approximata, maiora longitudine labii superioris et sub illo recondita. Antherx hirsutw, didymæ, infernè bimucronatæ.

Tom. II. 
Pistilli germen ovatum, pubescens. Stylus situ staminum, illis tamen el labio superiore longior. Stigma integrum, capitellatum.

Capsusa ovato-oblonga, subturgida, obtusa cum acumine, hirsuta, bivalvis, bilocularis, polysperma; dissepimento contrario.

Habitat in dumetis inter Boarcos et Catanhede, in Monte-Junto, Ser$r a$ da Arrabida, et alibi in Beira et Extremadura. Floret æsiate. Suffrutex. 


\section{EUPHRASIA tenuifolia.}

Eupн. foliis subsetaceo-linearihus, integerimis; caule tereti, gracili, erecto, ramoso; corollarum tubo tenui, calycem vix superiute; staminibus corollan æquantibus.

Evph. Icmuifolia. Pers. Synopsis Plant. 2. p. 150, La Marck Dict. Bot. Encycl. Supp]. (on. 2.596. (uti varielas.)

Eup II. linifolia. Brot. Fl. Lusil. tom. 1. p. 105. (non Lin)

Lasiopera tonuifolia. Link FI. Lusit. 1. p. 303. tab. 60.

P'edicularis Lusitanica pratensis gramineo folio.

Tourn. Inst. K. H. p. 172.

Radix subramosa, anmua.

CAULIs teres, gracilis, erectus, pedalis ad bipedalis, infernè effoliatus, supernè suhpubescens, pilis sparsis appressis, ramosissimus; ramis oppositis, longis, subdivisis, filiformibus, erectis.

Folia opposita, sessilia, linearia, fere setacea, vix acutiuscula, integerrima, supra canaliculata, infra subpubescentia prisertim prope basin, semiunciam aut paulo ultra longa, remota, internodiis multo longiora; inferiora caulis precocissine delabentia.

Flores in summitate caulis et ramorum spicati, sessiles, approximati, alterni, secundi. Bracteæ sub singulo flore binæ, foliis siniles.

Calyx tres quatuorve lineas altus, bracteis sæpe longior, compressiusculus, subpubescens, quadrifidus, dentibus quatuor oblongis, subulatis, duobus paulo brevioribus.

Corolla labiata, flava; tubus tenuis, calycis dentibns seuilineam ad lineam altior; labium superius erectum, convavum, integrum; inferius superiore non longius, planum, trilobum, lobo intermedio lateralibus paulo longiore, fere rhombeo.

STaminum filamenta didynama, sub labio corollæ superiore sita, et ibi apice curvata. Antheræ didymx, infernè bimucronatx, floccosx; duæ superiores labio superiori æquilongæ, aut interdum fere exertæ.

Pistilli germen ovatum. Stylus situ staminum, et altiorum longitudine. Stigma obtusum, capitellatum. 
Carsura oblonga, sxpe longitudine calycis, compressiuscula, apice rotundata, venosa, margine hirsuta, bilocularis, polysperina; dissepimento contrario.

Hamatat in dumetis de Ciprerica, in ericetis sabulosis circa Viseu, Montcmor, Catanhcde et alibi in Beira et Extremadura. Floret astaie. Annua.

Ons. Nimis affinis Euph. linifolio Lin. et Eupl. longiflore; at dillert a prima staminum filamentis extra corolla labium superius non exertis, et antheris foccosis; a secunda vero diflert corollis brevibus, nec calyce triplo longroribus, et foliis distantioribus. 


\section{A N T I R R H I N U M.}

Huic Generi nunc apponimus species eas tetranthericas didynamicas monostylias, quarum calyx quinquepartitus, corolla personata, basi vel gibbosa (qux Antirhina vera aliquormm neotericorum) vel calcarata (qux Linarix aliorum) limbo bilabialo, superiore labio bilobo, inferiore trilobo cum palato prominente inter labia convexo clauso; capsula bilocularis, variæe in variis dehiscentia el figura; semina plurima, receptaculo fungoso, quod utrinque dissepimento arlnatum est, adhærentia. Illas verò, quarum corolla etsi calcaratx rictu tamen aperto sunt et palato destituuntur, al novun genus Anarrhinum dictum seponimus.

\section{A NTIRR HINUM majus latifolium.}

ANT. caule frutescente, erecto, supernè villoso; foliis ovato-lanceolatis, acutiusculis, subglabris, inferioribus plerunque oppositis; floribus racemosis; calyce brevi pubescenti, laciniis ovatis inæqualibus, corolla basi gibbosa, ampla, sæpe purpurea.

\section{Lusit. Herva Bezerra.}

Ant. maius Brot. Fl. Lusit. 1. p. 199. Lin. Sp. pl. ed. Willden. 3. p. 256. varictas $a$, et sub eadem varietate La Marck Dict. Bot. Encycl. tom. 4. p. 364 . C. Bauh. Pın. 211. Villar Delph. 2. p. 441.

Antrrinnum maius semperflorens. Grisley Virid. Lusit. n. 107.

Ant. latifolium. Link Fl. Lusit. 1. p. 259. tab. 50. Barr. Ic. 655. Obs. 190. varietas Mill. Dict. n. 4. Bocc. Mus. 2. p. 49. tab. 41.

Axt. Lusitanicum flore rubro elegantissimo.

Tourn. Inst. R. H. p. 168.

$R_{A D 1 X}$ lignosa, ramosiuscula, perennis.

C $_{A U L E S}$ plures ex eadem radice frutescentes, aut suffruticosi, teretes, erecti, infernè glabri, supernè pubescentes, pilis sparsis guttula viscosa terminatis, pedales ad bipedales, ramosi ; ramis erectis, alternis.

Tom. II. 
Folia breviter petiolata, inferiora sæe opposita, superiora alterna, ovato-lanceolata, seu ovato-oblonga, integerrima, breviler acuta, saturate viridia, glabra, seu vix ullis pilis raris adspersa, sensin versus caulis et ramorum apices decrescentia.

Racen terninales; flores pedunculati, pedicellis in foliorum axillis solitariis, alternis, distantibus, erectis, pubescentibus, flore breviori. bus.

Calyx corolla valde brevior, persistens, quinquepartitus; laciniis pubescentibus, ovatis, inæqualibus, duabus inferioribus paulo brevioribus, remotioribus, obtusiusculis.

Corolla personata speciosa, magna, ad sesquiunciam sape longa, et plerumque purpurea: tubus oblongus, inflatus, basi gibbus, limbo bilabiatus; labium superius bilobum, lateribus refexum, inferius su. periori admotum, brevius, trilobum, palato supra lobos prominulo, infato, convexo, lutescente, intus villoso, subtus concavo.

Stamnum filamenta didynamica. sub labio corollæ superiore inclusa, per paria approximata. Stylus unus, longitudine et situ staninums: Stigma obtusum.

Carsula ovalo-oblonga, calyce value longior, basi inequalis obliqua, apice foraminibus tribus oblique dehiscens, et quasi vituli cranium referens, bilocularis, polsperma. Semina numerosa, parva, subrotunda, fusca. lente vitrea visa foveolis undique exarata; receptaculo, quod utrinque dissepinento adnatum est, oblongo, convexo, fungoso, adharest.

Habitat in muris, rupibus, turribus, ad sepes, et nonnumquam inter segetes in tola fere Lusitania. Floret vere et æstate, at culta toto fere anno. Frutex aut sufrutex.

Planta inodora, sapore fatuo; olim ut vulneraria et resolvens in usu medico, nunc exuleta.

Ons. Variat corollis albis præsertin culta, et lutescentibus circa Herminjum et alibi in Beira boreali. 


\section{A N'TIRLUINUM mcionanthum.}

Axtrar caule frutescente, erectiusculo, pubescente; folijs late lanceolatis, in petiolum brevem angustatis, oppositis, alternisque, glaherrimis; calyce hirsuto, lacinis inxqualibus, acutis; corolla basi sibbosa, mediocri, flavescenti-alba.

Axtrarh. molle. Brol. Fl. Lusit. J. p. 199.

ANTrRRH. meonanthum. Link Flor. Lusit. 1. p. 261 . tab. 51.

Caures pauci ex eadem radice ramosa, basi lignosi, fruticosi, teretes, erectiusculi, sesquipedales ad fere tripedales, pubescentes, pilis brevibus, hinc inde tamen glabri, ramosi; lamis erectis, sitpe oppositis, nomullis supremis alternis.

Folıa opposita, superiora alterna, viridia, late lanceolata, acuta, integerrima, glaberrima, in petiolum sesquilineam ad fere tres lineas longum angustata, lannina sesquinnciam ad uncias duas longa, octo ad decen lmeas lata, sensim versus caulis et ramorum apices decrescentia: in axillis nonnullis alia minora, seu ibi ramuli brevissimi.

R.ıcem terminales, hirsuti, semipedem et ultra longi Flores singuli in axillis foliorum floralium solitarii, alterni, pedicellati; pedicellis sesquilneam ad lineas duas longis, hirsutis. Folia floralia solitaria, lineari-lanceolata, acuta, hirta, pedicellis valde longiora.

CalyX corollà multo brevior, duas ad quatuor lineas longus, persistens; laciniis ovato-lanceolatis, acutis, inxerualibus, hirsulis, pilis Jongis.

Cokolla personata, formâ nt illa Antirrh. maioris, sed minor, octo ad decem lineas longa, basique magis prominens, tubo ex flavescenti albido, subpubescenti circa rictum hirsuto, palato luteo, labio superiore emarginato. Stamina didynamica, per paria approxinata, inclusa. Stylus silu et longitudine staminum: stigma oblusum.

CApsula ovata, calyce longior, basi obliqua, bilocularis, apice triforo oblique deliscens, polysperma. Semina fusca, subrotunda, undique scrobiculata. 
Habitat ad ripas Durii prope Porto, et alibi in Lusitania boreali. Floret Maio, Junio, Julio. Frutex.

Nimis affine Antirrh. sempervirenti (Willdenovii et Lapeirouse) sed differt foliis multo longioribus, glaberrimis, racemisque elongatis. 


\section{A N T I R R II I N U M calycinum.}

Ant. canle simplici, foliis oblongo-lanceolatis, in petiolun brevem angustatis, inferioribus oppositis, superioribus alternis angustioribus; spicis terminalibus, foribus distantibus, alternis, solitaris; bracteis corolla Jongionbus; calycis Jaciniis oblongis, lineari-subsetaceis, corolla paulo brevioribus, raro illius longitudine.

Axtrrre. calycimm. La Marck Dict. Bot. Encycl. tom. 4. jag. 365. Frot. F1. Lusit. tom. 1. P. 200 . Link Fl. Lusit. tom. 1. P. 262. Lab. 52.

Anturininum mimis, albo amplo flore. Barrel. Icon. 656.

Antirrhinum medium flore albo pulchro. Grisley Vir. Lusit. n. 109.

Caulis solitarius, simplex, erectus, octo ad tredecim uncias altus, teres, linc inde hirtus, raro glaber.

Folia inferiora sxpe opposita, superiora alterna, nunc ovato-lanceolato obtusiuscula, munc sæpius angrustate et oblonge lanceolata, acuta, in petiolum magis minusve brevem angustata, integerrima, viridia, subpubescentia prosertim ad basin, raro glabra. In eorum axillis ramuli breves.

Spıc e terminales, plus minusve longre. Flores omnes in axillis foliorum foralium, solitarii, alterni, breviter pedicellati, erecti, distantes aut value laxi, supremi conferti. Folia floralia lineari-lanceolata, solitaria, lloribus Jongiora.

CaLYx profunde quinquepartitus; lacinia patula, elongatæ, linearisetacers, pilose, inxullales, tres superiores longiores, omnes corollà sæe paulo breviores, rarissine ipsius longiludine.

Corora personata, basi ecalcarata, sed ibique gibbosa, nunc alba et maior, octo ad undecim lineas Jonga, nunc violacea seu cxrulescenti-rubra et minor. Stamina didynama, inclusa, per paria approximata. Stylus situ et longitudine staminum.

Capsula calyce brevior, subpyramidata, subvillosa, basi gibba, obliqua; poris tribus apice dehiscens. Semina fusca, oviformia, scrobiculata.

Tom. II. 
Habitat in arvis el inter segeles circa Olisiponem, Conimbricam et alibi. Florel Aprili, Haio, Junio. Annum.

Nimis affine Autirrh. Oronio el quasi illius varietas; sed ab illo differt calycis laciniis nunquam corolli longioribus, sed sape paulo brevioribus, aut ad summum ipsius longitudine, quod rarissinum, item corollì multo maiori, prasertim ista albescente. 


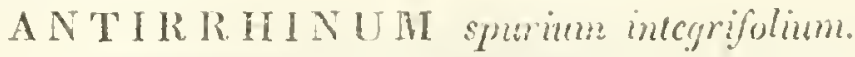

ANт. foliis ovatis, integerriuis, villosis, subsessilihus, inlerioribus oppositis, superioribus alternis; caulihus prostratis, rimuosis; floribus axillaribus, pedicellis sape illos superantibus.

Axт. spurium. Lin. Sp. pl. (uti ver. folis integerrimis) La Marek D)ied. Bot. Encycl. tom. 4. p. 349. Krocker filor. Siles. 2. 1. 382. Roth. Fl. German. 2. p. 62. Brot. Fl. Lusil. 1. 1. 183.

L. NaRIA lanigert. Link Fl. Lusit. 1. p. 231 . tab. 34.

Eratine mas fulio subrotundo. Joh. Bauh. Hist. pl. 3. p 372. (. Bauh. Pin. 1. 25:.

Eratine rotunlifolia, flore luteo. Grisley Vir. Lusit. n. 456.

R.ıor in ramulos exiguos filiformes fibratos divisa, annua.

C.Aves plures ex eadem radice, villosi, teretes, filiformes, procumbentes, nedales sesquipedales et ultra, fere é radice ramosi; rausis inferioribus oppositis, aliis altenis, omnibus prostratis.

Fola inferiora opposita, alia alterna sensiu versus caulium et ramorum apices decrescentia, omnia ovata, sen ovalo-subrotumda, integerrima, apice subacuta, ex pallilo virilia, villosa, subsessilia.

$F_{\text {Lores }}$ in longitulinem tenuiorem caulis et ramormm dispositi, axillares, solitarii, alterni, plus minusve distantes; pedicelli flores aquantes, aut illis longiores.

Calycis lacinix ovatx, acutx, villosx, una interdum latior. Corolla: tubus brevis. luteus; Jahium superiss purpureo-fuscun, inferius favum; calcar aquale, subulatum, antrorsum curvum.

Capsula subrolunda, glabra, apice biloba, calycis longiluline, bilocularis: semina numerosa, minima, fusca, subrotuma, tandique foveolis exarata.

Haltat in arvis et inter segeles circa Olisiponem, Conimbricam et alibi in Extremadura el Beira. Floret Julio, Augnsto. Annumm.

PLANTA amaricans, subacris, olim pro Veronica offecinali in usu medico habila, hodie exoleta. 


\section{A N T I R R II N UIV lanigerum.}

Ant. foliis omnibus alternis, ovatis subcordatisve, lanatis, inferioribus snblentatis, aliis integerrimis; caulibus procumbentibus, villoso-lanigeris, prolongis, ramosissimis; floribus axillaribus, solitariis, pedicellatis.

Axt lanigerum. Brot. Fl. Lusit. 1. p. 189. Lin. Sp. pl. ed. Willd. 3. p. 233. La Marck Dict. Bot. Encycl. Suppl. tom. p. 19.

Linaria lamigera. Desfont. F). Allant. 2. p. 38. tab. 130. (varictas, cui fulic inferiona non dentata.)

Lina Ria dealliáa. Liuk Fl. Lusit. 1. p. 232. tab. 35.

Caures plures ex eadem radice, graciles, cortice albo villoso-lanigero, subviscosi, procumbentes, sesquipedales ad quadripedales, fere é basi ramosi ; ranis etians procumbentibus, elongatis, inæqualibus, alternis, numerosis, patentissimis.

Forra omnia alterna, undique villoso-lanigera et dealbato-viridia, inferiora semiunciam ad uncıam ferè longa, ovata, nonnulla in basi emarginatura mininầ subcordata, subsessilia aut interdum sessilia, alia sensim versus caulis et ramorum apicem decrescentia, integerrima, sessilia.

Frores in longitudinem ramorum dispositi, axillares, alterni, solitari, plus minusve distantes, ad apicem ramorum propiores; pedicellis capillaribus, brevibus.

CALyX lirsutus, persistens, quinquepartitus; laciniis lanceolatis, acutis, subxqualibus, una sape latiore.

Corolla personata, ad tres lineas fere longa, et calyce parmm lon. grior, villosa; tubo albido; labio superiore violaceo, bifido, paulo breviore; inferiore albo, ad gibbum palati punctis caruleis adsperso; calcare subulato, incurvo, corolle longitudine.

Stamrum filamenta sape carulescentia, hinc subvillosa. Antherx sub. cordatie, viscosè adherentes. Pistilli gernnen subrotundum, virile; stylus pubescens. 
Capsula parva, subrotunda, apice biloba, bisulca, glabra, bilocularis, polysperma, calyce tecta. Semina fusca, oviformia, undique scrobiculata.

Habitat in arvis, in Algarbiis, Transtagana, et interdum in Beira meridionali. Floret Julio, Augusto. Annuum.

Ninrs afline Antirrh. smurio, sed differt præsertim habitu dealhato-lanato, nec villoso pallide viridi; canlibus multo longioribus, ranosioribusque; foliis minoribus, sæe ad latera uno alterove dente notatis, et omnibus, uti ramis, alternis. 


\section{A NTIRRIIINUM sparteum.}

A:т. caulibus fertilibus erectis, virgatis, glabris, sterilibus procumbentibus, brevioribus; istorum folis lanceolatis, integerrimis, Hlabris, carnosis, omnibus ternis quaternisve, fertilium supernè alternis , sublinearibus, longioribus; corolla lutea, mediocri.

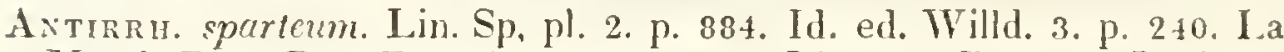
Marck Dict. Bot. Encycl. 4. p. 352. (ex Linnæo) Brot. Fl. Lusit. p. 194.

Lixiras spartea. Link Fl. Lusit. 1. p. 233. tab. 36.

C.tucs plures ex eadem radice alba, ramosiuscula fibrata; alii erecti, octo ad quindecin mncias longi, fertiles, virgati, teretes, glabri, ramosi, ramis erectis, floriferis; alii steriles, procumbentes, multo breviores.

locsa omnia sessilia, in caulibus sterilibus verticillata, lanceolata, plana, subacuta, patentia, in fertilibus prinordialia et inferiora sæpe terna, superiora sparsa, elongata, sublinearia, acuta.

Flores racenosi, distantes, alterni, solitarii, erecti, pedicellati; pedicellis setiformibus, septem ad undecim lineas longis, bractea supposita lineari multo longioribus.

CALYX quinquepartitus, laciniis subæqualibus, lanceolatis, acutis, glabris, margine membranaceis. Corolla flava, grlabra, mediocris, quinque sexve lineas longa, excepto calcare; palato fulvo lanuginoso, fauce villosa; calcare subulato, recto, sex lineas longo, dilutius flavo.

Calsex globosa, glabra, calycis longitudine. Semina numerosa, minima, subglobosa, transverse rugusa.

Habitat in locis sahulosis trans Tagum ex adverso Olisiponis. Floret vere. Annum et bienne.

Ors. Tam istud quàm duo sequentia nimis Antirrhino junceo Liunæi afinia sunt; sed nonnullis notis cum illo specificè non conveniunt. 


\section{A NTIRRHINUAI procox.}

Axт. caulibus fertilibus erectis, simpliciusculis, glabris, superne hirtis, sterilibus procumbentibus, multo brevioribus; istorum folis lanceolatis, glabris, planis, om nibus sepius ternis, paucis quaternis; fertilium inferioribus similibus, superioribus sublinearibus, sparsis; corolla hava, mediocri.

Axtirrhixum junccum. La Marck Dict. Bot. Encycl.4. 1) 352.

Axtrrrh. sparteum. Cavanill. Icon. vol. 1. p. 19. tab. 32.

Livaria juncea. Desfont. Fl. Allant. 2. p. 43.

Lixaria præcox. Link Fl. Lusit. 1. p. 234 tab. 37.

Caules plures ex eadem radice teretes, graciles; alii fertiles, erecti, quinque ad octo uncias alti, glabri, supernè hirti, simpliciusculi, seu parum ramosi. ramis alternis, brevissimis, erectis; alii steriles procumbentes, valde breviores.

Folı sessilia, integerrima, glabra, in caulibus sterilibus sæpe terna, perpatca quaterna, lanceolata, acutiuscula, plana, in fertilibus inferiora similia, superora a'terna, distantia, sublinearia, acuta, carnosa, sæpe canaliculata.

RAcrul terminales, flores pauci; pedicelli quinque ad septem lineas longi, solitarii, alterni, pilosusculi, distantes: bracteæ subulatæ, hirtæ, pedicello triplo quadruplove breviores.

CaLyx quinquepartitus, laciniis subæqualibus, lineari-lanceolatis, acutis, pilosis. Corolla flava, quatuor quinqueve lineas longa, calcare non supputato; labium superius bifidum, lobis surrectis reflexis, inferius trilobum; palato fulvo lanuginoso, fauce villosà; calcare quinque lineas longo, subulato, recto, concolore.

Capsula subglobosa, glabra, calycis longitudine. Semina numerosa, oviformia, transverse rugrosa. 
Habitat in sabulosis, in Algarbiis. Floret Februario, Martio. Annuum, aut bienne.

Antirrhino junceo Linnæi nimis affine, sed differt caule subsimplici, supernè hirto, valde breviore, non sesquipedali, nec subangulato, calyce piloso, palato lanuginoso, et foliis inferioribus sxpe ternis. 


\section{A N T I R R H I N U M virgatulum.}

Ant. caulibus fertilibus virgatis, erectis, glabris, ramosissimis, sterilibus procumbentibus, brevioribus; foliis omuibns angustis, in canlibus sterilibus lanceolatis teruis, in fertilibus sublinearibus sparsis; corolla flava, nediocri.

Antirkı. virgatulum. Brot. F1. Lusit. 1. p. 193.

LiNa Ra meonantha. Link Flor. Lusit. 1. p. 236. tab. 38.

Caules plures ex eadem radice alba ramosiuscula, teretes, glaberrimi, uti tota planta, exteriores steriles, procumbentes, breviores, centrales erecti, octo ad tredecim uncias alti, virgati, sape ranosissimi, prusertim in solo arenoso humido; ranis temuibus, virgatis, erectis.

Folia omnia sessilia, angusta, carnosa, integerrima, acuta ; in caulibus sterilibus lanceolata, terna, rarissime in $\mathrm{imis}$ verticillis quaterna; in fertilibus inferiora terna, subterna, vel fere opposita, alia a!terna canaliculata, sparsa.

Raceni terminales; flores pauci, quatuor ad septem, rarò plures, in singulo racemo; pedicelli setiformes, distantes, solitarii, alterni, glabri, erecti, quinque ad undecim lineas alti: bractex lineares, glabræ, pedicellis multo breviores.

CALYX glaber, quinquepartitus, laciniis subæqualibus, lineari-lanceolatis, acutis, dorso viridibus, margine pallide membranaceis, erectis, sesquilineam longis.

Corolla flava, quatuor quinqueve lineas longa, excepto calcare, in fundo tubi interdum puncta duo saturate fulva; palato holosericeo, fulvo, fance villosa; calcare tres quatuorve lineas longo, subulato, recto. Antheræ bilobæ, flavæ, stylus brevis; stigua bifidum.

CAPSUla ovato-subrotunda, glabra, utrinque unisulcata, longitudine calycis, aut vix brevior. Semina numerosa, ovalia, transverse rugosa.

Tom. II. 
Hamitat in sabulosis ad Mundam et alibi circa Conimbricam. Floret Maio, Junio. Annuum.

Differt ab Antirrhino junceo Linnæi caule non subangulato, foliis caulium fertilium inferioribus verticillatis, superioribus non planis, et corollæe palato non glabro. Nec confundendum cum Antirrh. virgato Linn., a quo multo magis discrepat. 


\section{A NTIRR II N I saxalite.}

Ant. caulibus piloso-riscosis, fertilibus erectis, subramosis, sterilibus subalscendentibus; foliis urinque pubescenti-viscidis, inferioribus ternis el quatemis, nomullis quinis, Janceolatis aut Janceoto-linearibus, superioribus sparsis; calyce hirto, lacinia suprema lougiore; corolla flava, mediocri.

Axtringunus saxalile. Brot. Hi. Lusit. I. p. 191.

Linama saxalilis. Link Fl. Lusit. 1. p. 238. tab. 40.

Fabix ramosa, ramis fibratis, cortice albo, ad collum fere digiti minimi crassitudine. l'erennis.

Caules plures ex eariem radice, alii steriles decumbentes, hreviores, alii fertiles erecti, sen infernè recurvuli deinde erecti. septem ad undecim uncias alti, hasi sublignosi, teretes, pilosi, pilis brevibus densis, apice guttula viscosa terminatis, subranosi; ramis oppositis alternisque, omnibus sæe indivisis.

Fou.1 sessilia, lanccolata, acuta, plana, integerrima, utrinque piloso-viscida, septem ad undecim lineas longa, inferiora in utrisque caulibus terna, plura quaterna, aut interdum nounulla quina, superiora sparsa, breviora el angustiora.

Flones pauci in apice caulium et ramorum conferti, subcapitati primìm, deinde plus minusve distantes pedicellati; pedicellis sesquilineam al lineas duas longis, pilosis, erectis. Bractex pedicellis æquales, aut parum longiores, lineari-setaceæ, pilosæ.

$\mathrm{CAlYX}_{\mathrm{A}}$ pilosus, pilis longis, crispatulis ; laciniis angustis, lineari-setaceis, acutis, quatuor subxqualibus, quinta suprema paulo longiori.

Corolla penitus flava, mediocris, quatuor quinqueve lineas longa, calcare nou supputato; labium superius bifidum, laciniis reflexis, extus subpubescentibus, inferius trilobun, lobis xqualibus, obtusis; palatum intus villosum, bipunctatum, punctis saturate fulvis; faux etiam villosa; calcar subulatum, quatuor quinqueve lineas longun, rectum, aut interdum vix ac nec vix arcuatum. Germen villosiusculıu. Stigma obtusum.

Capsura subrotunda, longitudine calycis, glabra. Semina numerosa, subglobosa, fusca, scrobiculata. 
Iaritat in montibus Lusitanixe borealis, et frequens in Transmontana. Floret vere et interdum xstate. Perenne.

Planta affinis Antirrhino saxatili Linnxi; sed canlibus fertilibus non longè decumbentibus, foliis latioribus, et calycis laciniis non æqualibus nec lanatis, differt. 


\section{A N T I R R II I N M glutinosum.}

Axт. caulibus piloso-viscosis, fertilibus basi subarcuatis, deinde ereclis, subramosis, sterilibus decmbentibus; foliis pubescenti-viscidis, inferioribus ternis et quaternis, lineari-lanceolatis, superioribus sparsis; calyce hirto, lacinia suprema longiore; corolla flava, mediocri.

Ant. saxatile. Brot. Flor. Lusit. 1. p. 191. La Marck Dict. Bot. Encycl. 4. pag. 356 ?

Livaria glutinosa. Link Fl. Lusit. 1. p. $23 \%$ tab. 39.

Cautes plures ex eadem radice ramosiuscula, quorum alii steriles decumbentes, breviores, alii fertiles sæe adscendentes, seu vix basi declinati mox erecti, quinque ad novem uncias longi, teretes, pilosi, pilis apice humorem glutinosum excernentibus, parun ramosi, ramis alternis, brevibus, sape indivisis.

Folda in utricque caulibus inferiora terna et quaterna, superiora sparsa, omnia glutinoso-pilosa, nti caules, angusta, lanceolato-linearia, acutiuscula, interdum canaliculata, integerrima, sessilia.

Foores pauci, in apice caulium et ramorum, primìn dum florent conferti, tandem distantes, pedicellati; pedicellis hirtis, erectis, sesquilineam ad tres lineas longis: bracteæ sublineares, pedicellis xquales, aut paulo longiores, hirtae.

CALYX profunde quinquepartitus. Jaciniis hirtis, lanceolatis, acutis, sumunà angustiore longiore. Corolla flava, mediocris, quatuor quinqueve lineas longa, calcare non supputato, ad palatum interdum puncta salurate lulva: calcar quatuor quinqueve lineas longum, subulatum, rectum. Germen subvillosum. Stigma obtusum.

CApsura ovato-subrotunda, subvillosa, longritudine calycis. Semina subglobosa, fusca, scrobiculata.

Habitat in arenosis maritimis prope Selubal, in rupibus prope Porlo, et alibi. Floret Aprili, Maio, Junio. Perenne.

Tom. II. 
Plaxta nimis aflinis precedenti; sed habitu paulo glutinosiore, foliis angustioribus, et caulibus fertilibus, cum eriguntur, basi plus arcuatis, differt. Admodum quoque affinis Antirhino srxatuli Limæi, ab eo tamen discrepat caulilus fertilibus non longe decumbentibus, et calycis lacinis non aqualibus, nec lanatis. Nec confundenda cum Antirihino vascoso Limmi, a quo difiert præsertim caulibus non lævibus, pedicellis florun cauli non approximatis, calycis laciniis margine non membranaceis, et corollis multo minoribus, nec magnitudine Antirrhini Linaria. 


\section{A NTIR R II I N U II linogriseum.}

Axт. caulibus sterilibus procumbentibus, fertilibus simpliciusculis, ercetis; sterilium folits temis quaternisve, lancenlato-linearibus, onnibus glabris, fertilinu sublinearibus, superioribus sparsis; corolla cxerulescenti, mediocri, tubo subcampanulato, labiis hiantibus, calcare recto, corollac longitudine.

Lixaria linorgrisca. Liuk Fl. Lusit. 1. p. 239. tab. 41.

Antrrmanu incarnatum. La Marck Dict. Bot. Encycl. 4. p. 364.

Lina Ria pumila, Lusitanica, foribus palato carentibus?

Tourn. Hist. R. H. P. 170.

Caules plures ex eadem radice subramosa fibrata: teretes alii steriles procumbentes, breves, tres arl quinque uncias lougi, penilus glabri, fertiles alii erecti, semipedales ad perlales, infernè glabri, supernè pubescentes, larum damosi; ramis alternis, brevibus, indivisis, ereclis.

Four a sessilia; integerrima, glabra, in caulibus sterilibus lanceolatolinearia, quatuor seu quinque lineas longa, terna quatemave, in fertilibus inferiora similia, superiora sparsa, sublinearia, plana, acuta.

RAcem terminales; flores alterni, solitarii, distantes; pedicellis Pubescentibus, erectis, quinque sexve lineas longis: sub singulo valde brevior bractea, setacea, pubesceus.

CAIX profunde quinquepartitus, laciniis setaceis, acutis, pubescentibus, subcaruleis, suprema parmu longiore.

Corolla personata, cærulea, mediocris, quinque sexve lineas longa, excepto calcare; tubo subcampanulato; labiis hiantibus, superiore longo, erecto, bipartito, lacinits obtusis, venosis, reflexis, dilntius carule is parumque rubentibus, inferiore trilobo, lobis longis, obtusis, inturuedio breviore; palato intus villoso; calcare subulato, recto, quinque sexve lineas longo. Stamina inclusa, per paria approximata.

Capsula ovato-subrotunda, glabra, calycis longiturline, aut interdum calyce vis longior. Semina subrotunda, tranverse rugosa. 
Hapitat in solo sabuloso in Algarbiis. Floret Februario, Martio, Aprili. Annumm.

Srnonyon Tournefortii potins Anarrhino crassifolio (Lin. Sp. pl. ed. Willd.) quàm huic Antirrhino, aut sequenti applicandum videtur. Antirrhinum incarnatum (La Mark) nostri linogrisei fortasse tantummodo uti varietas habendum, discrepat enin vix aliter quàm corolla incarnata, et calcare corollam fere duplo superante. 


\section{A N T I R R II I N U M sapphirinum.}

AnT. caulibus sterilibus procumbentibus, fertilibus erectis, ramosis subramosisve; foliis steriliun ternis lanceolato-linearibus, fertilium sparsis, smblinearibus, acutis; corolla mediocri, carulea; tubo cyliudracco, palato albescente, punctis caruleis adsperso; calcare recurvo.

A Nт. srpphivinum. Brot. Fl. Lusit. 1. p. 197.

Linaria sapplivina. Link. Flor. Lusit. 1. p. 241, tab. 42.

Caules plures teretes; steriles procumbentes, breviores, glabri; fertiles erecti, dodrantales ad pedales, inlernè glabri, supernè pilosi, et carulescentes, numc ramosi, nunc perpaucis ramis instructi.

Foua sessilia, integerrima, acuta, in caulibus sterilibus terna, lanceolato-linearia, glabra, in fertilibus sparsa, sublinearia, plana, glabra, suprema interdum pilosa.

RAcemr terminales; Hores alterni, solitarii, distantes; pedicellis quatuor ad sex lineas longis, pubescentibus, erectis: bractex solitarix, setacex, aculæ, pubescentes, pedicellis multo breviores.

CAIrx corollà valde brevior, quinquepartitus; laciniis angustis, acutis, pubescentibus, subxqualibus. Corolla violaceo-carulea, quinqueve lineas longa, calcare non supputato; tubo cylindrico, angusto, violaceo tricalloso in basi; labiis subhiantibus, superiore bipartito, laciniis obtusis, inferiori trilobo, lobis obtusis, violaceo-caruleis, intermedio minori; palato albescente punctis caruleis adsperso, intus fulvo et villoso; calcare subulato, quinque sexve lineas longo, recurvo. Germen glabriusculum: stigma nunc subtruncatum obtusum, nunc bifidum aut fere trifidum.

CApsula ovato-subrotunda, glabra, calyeis longitudine ant ei subxqualis. Semina subglobosa, aut nonnulla subturbinata, onınia tranverse lugosa.

IA ватат in dumetis, locisque sabulosis circa Conimbricam, Herminiun et alibi in Beira boreali. Floret Maio, Junio. Anmuun. Planta nimis allinis precedenti. 


\section{INTIRRHINUM amethysteum.}

Aкт. caulibus primariis erectis, aliis adscendentibus, omnibus simplicibus; foliis linearibus aut sublinearibus, glabris, glaucescentibus, inferioribus quaternis, nonnulls quinis, superiorbus sparsis; floribus paucis, breviter pedunculatis, in summitate confertis; corolla cærulea, mediocri; palato albo-havescenti, cæeruleo juuctato; calcare re. cto, corollis longiore.

Axtrrinum amellystcum. Brot. Fl. Lusit. I. p. 197. La Marck Dict. Bot. Encycl. 4. p. 328 . Lina. Sp. pl. ed. Willd. 3. p. 241.

Antrrennum bipmetatum. Cavanill. Icon. J. p. 20. tab. 33.

LINA RIA amcthystca. Link Flor. Lusit. 1. p. 253 . tab. 47.

Cavles ex eadem radice plures in orhem posili, semipedales ad dodrantales, primarii centrales longiores, erecti, alii ex decumbentibus plus minusve erecti, teretes, glancescentes, infernè glabri, supernè piloso-viscosi, ad apicem subranosi; ramis allernis, brevibus, sape indivisis, erectis.

Folı sessilia, subcarnosa, glabra, plana, subglanca, sublinearia, sen lineari-lanceolata, aculiuscula, inferiora sape quaterna, nonnulla quina, superiora alterna.

RАсем terminales pauciflori; flores tres ad sex, rariù ad decem, supernè conferti, tandem plus minusve distantes, omnes pedicellati; pelicelli hreves, sesquilineam duasve lineas longi, solitarii, alterni, erecti, pubescentes, bracteati; bractex solitariæ. subsetaceæ, acutie, subpubescentes, pedicello aquales aut longiores.

CALvx quinquepartilus, laciniis viridibus, pubescentibus, sublinearibus, acutis, suprema angustiore et longiore, omnibus tubo corolla vix brevioribus, patulis, persistentibus.

Conolua mediocris, quatuor quinqueve lineas longa, calcare non supputato; lahinm superius erectum, bifidum, plus minusve cæeruleum. inferius trilobum, lobis subcaruleis, obtusis, intermedio subæquali; tubus cxrulens; palatmm ex albo havescens, punctis caruleis adsper. sum, intus fulvo-villosum; calcar subulatum, violaceum, rectum, sex septemve lineas longum. 
Capsura globosa, glabra, longitudine calycis, aut vix altior. Semina plurima, complanata, marginata, subscrobiculata.

Habitat in arvis circa Elvas, Grandola, et alibi in Translagana australiore, at aliqua ejus varietates in Beira altiore. Floret Februario, Martio, Aprili. Aunua.

A D ripas Durii varietas occurrit, fortasse seminibus a flumine ex Hispania devectis, labio superiore corollie flavo-albo, et palato punctis tantimm duobus violaceis, qux Antirrhinum bipunctatum Cavanill. Inter Lousüa et Bussaco alia etiam occurit, cui corolla straminea, palito aurantiaco, punctis violaceis adsperso. Antirrlinum subalpinum nostre Floræ, etsi discrepet caulibus minns erectis ramosioribusque, pedicellis florum longioribus, et calyce glabro, forte tamen ad hanc speciem referendum. 


\section{A N T I R R II I N U M polygalcefolium.}

AnT. caulibus prinuariis sæe erectis, ramosis, aliis adscendentibus; foliis infinis subverticillatis, ternis quaternisve, aliis alternis, omnibus sublinearibus, glabris, glaucis, carnosis; corolla magna, flava.

Linaria polygalafolia. Link Flor. Lusit. 1. p. 248 . Lab. 4.1.

Ranı lignosa, biemnis. Caules plures, iufernc lignosi, teretes, supernè subangulati, glabri, hinc inde ramosi, primarii sæpe erecti, alii adsceudentes.

Foura sessilia. angusia, sublinearia, acuta, integerrima, planiuscula, carnosa, glauca, glabra, infina minora et nonnulla subverticillata terna quateruave, alia omnia sparsa, media caulium maiora octo lineas longa, lineam ad sesquilinean lata, subcanaliculata.

SPIC terni, glabriusculi, pilis rarissimis. Bractex solitarix, subsetacex, pelicellis longiores.

Calyx quinquepartitus, laciniis longis, anticè latioribus, obtusiusculis, summà longiore, in omnibus pili vix ulli.

Corolla lineas quinque sexve longa, calcare non supputato, flava; labio superiore longo, bifido, laciniis oblusis, inferiore brevi, trilobo, lobis obtusis; palato villoso, lulvo; calcare corolla longiore, subulato, flavo, striato, striis subpurpureis, recurvo.

Capsula longiludine calycis, ovato-subrotunda, glabra. Semina compressa, margine membranaceo cincta.

Habitat in marilimis in Duriminia, Beira, el Extremadura prope $S$. Martinho, et alibi. Floret Maio, Junio, Julio. Pereme.

Afrine Antirrbino Lusitamico, at diflert radice bienni, caulibus ramosioribus, foliis multo angustioribus, foribus plus confertis, eorum pedicellis multo brevioribus, et corolla parum numori; an tamen specilicè satis diversum?

N.B. Antirrhinum polygalofolium (La Marck Suppl. Dict. Bot. Encrel. tom. 4. p. 21.) foliis trinerviis, calcare recto, longitudine corollix, longe alia diversa species. 


\section{A N T I R R H I N UII pyrenaicum.}

Axt. caulibus simplicibus, aliis recurvato-erectis, procumbentibus aliis, inferue glabris, supernè viscoso-pilosis; folis sublinearibus, angustis, glabris, inferioribus quaternis, nonnullis quinis, supremis alternis; corolla magna, flava.

Antrrnhinum pyrcnaicum.' La Marck Dict. Bot. Encycl, 4. p. 24.

Lina Ria pyrenaica. Liuk Fl. Lusit. 1. p. 249. tab. 45.

Caules ex radice plures simplices, teretes semipedales ad ferè pedales, infernè glabri, supernè pilosi, pilis brevibus, vesicula viscosa terminatis, alii jrocumbentes, alii plus minusve declinati, deinde erecti, foliosi, ad apicem nudi.

Forra sessilia, angusta, sublinearia, seu lineari-lanceolata, octo ad tredecim lineas louga, lineam ad sesquilineam lata, acutiuscula, plana, subcarnosa, inlegcrima, glabra, viridia, approximato-verticillata, inferiora quaterna, nonnulla quina, suprena alterna.

Sprce terminales, breves, floribus confertis, paucis; pedicelli alterni vix linean longi, pubescentes. Bractex solitarix, sublineares, hirtae, pedicellis longiores.

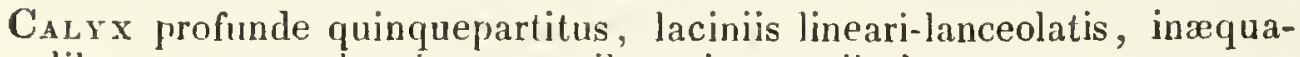
libus, suprema longiore, omnibus viscoso-pilosis.

Corolra flava, quinque sexve lineas Jonga, calcare non supputato; labio superiore bifido, flavo; palato holosericeo, fulvo; fauce villosa; calcare subulato, striato, subrecto, corolla longiore.

Capsula ovato-subrotunda, subpubescens. Semina complanata, marginata.

Hamitat in montosis de Cintra, et alibi. Floret Maio, Junio. Perenue. 


\section{A N T I R R II I N U M glaucophyllum.}

ANT. caulibus simplicibus, aliis procumbentibus, aliis recurvato-ereclis, infernè glabris. supernc viscoso-pilosis; foliis lanceolatis, latimsculis, glaucis, glabris, infin is subverticillatis, omnibus aliis alternis; corolla magna, albida, palato flavo.

Linaris glaucophylla. Link Flor. Lusit. 1. p. 250. tab. 46.

Radix lignosa, ramosiuscula, perennis. Caules plures, semipedales ad peciales, glaucescentes, infernè teretes, glabri, prope basin lignosi, supernè subangulati, viscoso-pilosi, simplices, ramis brevibus alternis, alii procumbentes, alii phus minusve declinati deinde erecti, omnes ad apicem nudifolii.

Foula sessilia, unciam ad sesquiunciam longa, duas lineas lata, lanceolata, aculiuscula, integerina, plana, glauca, glabra, infima subterna sen subquaterna, omnia alia remotiuscule sparsa.

Sprca terminalis, sæe brevis; flores pauci, prinum conferti, demum valde laxi; pedicelli alterni, lineam ad lineas duas longi, pubescentes. Bractex solitaria, sublineares, subpabescentes, pedicellis longiores.

CALX quinquepartitus, Iaciniis sublanceolatis, antrorsum latioribus, acutiusculis, viscoso-pilosis, inæqualibus, summa longiore.

Conolla albida, quatuor quinqueve lineas longa, calcare excepto; ejus lahium superins bifilum, stramineum, inferius trilobum, breve; palatum flavum holosericeum; faux villosa; calcar subulatum, flavescens, lineis purpureis pictur, subrectum, corolla lungius.

Capsura ovato-subrotunda, calycis longitudine, glabriuscula. Semina complanata, marginata.

Habitat in montosis in Transmontana. Florel Maio, Junio. Perenne.

VALDE aftine Antirrhino pyrencico, sed foliis longioribus et latioribus, plus distantibus plusrue sparsis, et corolla minori albescenti, diversum. 


\section{AN'TIRRHINUM diffusum.}

Axт. caulibus erectiusculis, nonnullis adscendentibus, diffusis, pubescentimn; folie mfmis ternis ant quateruis, omnibus aliis alternis, lincaribus seu sublincaritus, planiusculis, integerimis, pubescentibus; corolla parva, ciurulea, calcare currato.

Linania diffusa. Link Fl. Lusit. 1. p. 257 tab. 49.

Caver plures ex endem radice, nonnulli adscendentes, alii ex declinatis erectiusculi, teroles, basi duriusculi, samipedales ad pedales, piloso-riscosi, ramosissimi, ramis tenuibus, alternis.

Fola sessilia, linearia, seu sublinearia, quinque ad septem linens longa, lineain ad sesquilinean lata, inferiora et superiora minora, ommia planiuscula, piloso-viscosa, integerima, acuta, infina terna aut quaterna, alia alterna, distantia.

Racru terminales, longi, pauciflori; floribus valde distantibus; pedicellis alternis, solitariis, piloso-viscosis, linean ad lineas duas Jongis. Bractea brevissinæ, angustissima, pubescentes.

Calyx quinquepartitus, persistens; laciniis lanceolatis, acutis, pilosoviscosis, suprema longiore. Corolla carulescens, tres lineas longa, calcare non supputato; Jabium superius bifidum, laciuiis obtusis, re. nexis, iuferius trilobum, breve; palatum aurantiacum, parum pubescens; calcar subulatum, acutissimum, arcuatum, corolla longius.

CApsura parva, ovato-subrotunda, longitudine calycis, aut vix brevior, glabra. Semina complanata, marginata.

Ha bitat inter Abrantes et Prmhele. Floret Maio, Jinio. Annuun. 


\section{A N T I R R H I N U M multipunclatum.}

Ant. caulibus simplicibus, simplicissimisque, adscendentibus ; foliis lanceolatis, glabris, glaucis, infernè quaternis, supernè alternis; flo. ribus subsessilibus, subcapitatis; corolla merliocri, flava, calcare illam fere duplo excedente, recto, saturate purpureo, palato multi. punctato.

Ant. multipunctatum. Brot. Fl. Lusit. tom. 1. pag. 195.

Linaria mullipunclata. Link et Hoffm. Fl. Lusit. tom. 1. p. 254. tab. 48. (Varietas maior)

$R_{\Lambda}$ dx fibrosa, annua. Caules plures ex eadem radice, quinque ad viginti et ultra, adscendentes, tres ad quinque uncias longi, raro lon. giores, teretes, glabri, supernè interdum subpubescentes, simplicissimi, vel simplices, ramis perpaucis, alternis, erectis.

Forıa lanceolata, acuta, integerrima, glabra, glauca, subcarnosa, plana, inferiora quaterna, superiora alterna, pauca, et ad apicem caulium ramorumque sæpe nulla.

Spica terminalis erecta; rachis brevis, interdum subpubescens, pilis brevissimis, apice viscosis; flores conferti, subcapitati, pauci, tres ad quinque, raro ultra, pedicellati, pedicellis linean ad sesquilineam longis, interdum subpubescentibus, bracteî lanceolatâ calyceque breviuribus.

CALYX quinquepartitus; laciniis oblongis, acutiusculis, sublanceolatis, ad margines lanuginosis, inxqualibus, suprema angustiore et aliquantulum longiore.

Corolla lineas quatuor quinqueve longa, calcare non supputato, istud vero septem octove longum, acutissimum, rectum, saturatè purpureum : labium superius erectum, bifidum, laciniis obtusis, retroflexis; labium inferius trifidum, laciniis subæqualibus, obtusis; palati gibbo quamplurimis punctis atropurpureis asperso, intus villoso, vi]lis nunc luteis nunc purporeis; tubo minimo, luteo, aut interdum extus purpurascenti, intus lineis maculisque atropurpureis variegato.

STam. filamenta didynama, sub labio superiori corollæ sila, illoque valde breviora. Anthera per paria comiventes, bilobx, lutex. 
Ptst. germen subglobosum. Stylus simplex, filiformis, longitudine et situ staminum, marcescens. Stigma obtusum.

Capsula obovata, subrotunda, calyci aqualis, bilocularis, dentibus quinque sexve dehiscens; dissepinentum contrarium, suborbiculare: Semina plurima, levia, complanata, margine membranaceo orbiculato cincta, placenta fungos in medio dissepimenti utrinque elevato affixa.

Maвiтat sapius in solo macro prope Conimbricam, et in agris cultis ant incultis circa Olisiponem, et alibi. Floret vere. Anıuum. 


\section{A N A R R H I N U M bellidifotium.}

A $\mathrm{N}$. caulibus subsolitariis, glabris, erectis, centrali longiore, in summitate ramoso; folis glabris, radicalibus spathulatis, dentato-serratis, caulinis ad basin usque partitis, laciniis linearibus, longis; corolla carulescenti, exigua.

Antirnanum bellidifolium. Lin. Sp. pl. 2. p. 860. La Marck Dict. Bot. Encycl. 4. p. 363. Will. Delph. p. 442. Gouan Illust. p. 39. Brot. Flor, Lusit. I. p. 198.

Anarrmaum bellidifolium. Lin. Sp. pl. ed. Wilklen. 3. p. 250. Link Fl. Lusit. 1. p. 226 . tab. 32.

Lixaria aliquatenus similis folio Bellidis. Joh. Lauh. Hist Pl. 3. p. 459.

Linamia Cellidis folio. C. Paulu. Pin. 212.

Linaria carulea odorata Clusii. Grisley Vir. Lusit. 11. 838.

RAdix lignosa, ramosiuscula, alba, biennis aut triennis.

Caules nonnulli ex eadem radice, centralis valde longior, pedalis, sesquipedalis etultra, teretis, glaber uti tola planta, erectus, strictus, superuc ramosus; ramis alternis, gracilibus, longis, erectis, sæpe indivisis.

For a radicalia in orbem jacentia, spatluuata, seu obovata in pelioJum attennata, serrato-dentata, trinervia, saturate viridia, glabra, duas uncias et ultra longa; caulina ad hasin usque partita, laciniis tribus ad septem, sxpe quinque, linearibus seu sublinearibus, angustis, acutis, integernimis, intermedia sæpe productiore.

Raccu terminales; longissiui, simplices, erecti, multiflori: flores alterni, laxi, erectinsculi. inferiores subnutantes; pelicellis sesquilineam ad lineas fere tres longis. Bractere uniflora, sublineares, acu$1 x$, integerrimx, nonnullx interdum trifidx, omnes pedicellis longiores.

CA YX parvus, sesquilineam fere Jongrus, laciniis subxqualibus, subulatis, laxiusculis, corolla brevioribus.

Corolla labiata, cierulescens, exigua, glabra; tubus teres, calrce 
vix altior; labio superiore bifido; laciunis obtusis, erectis, inferiore trilobo, paulo longiore, lobis obtusis, cernuis, iutermedio maiori; palatum: nullum; faux orhicularis, aperta, glabra; calcar é basi corollw minutum, sursun arcuatum, calyce inclusum, illoque brevius.

Sraminu filamenta didynama, tubo corolla inchusa: antheræ per pares approximatx. Pistilli germen ovatum; slylus unicus; stigma capitalum.

Capsula subrotunda, calycis longitudine aut brevior, bisulca, bilocularis, polysperma, dentibus apice dehiscens, marginc dlssepinenti persisteute. Semina minima, ovalia, tuberculata.

Hantrat in montosis, et sabulosis aridis in Lusitania boreali, frequens circa Conimbrican, rarius in Extremadura. Floret ex Aprili ad Julinm. Bienne aut interdum trienne.

Plaxta amara, sed inodora mihi semper occurrit, etsi aliquantulum odoratam esse in Europa regionibns calidis a Clussio asseralur. A pul Lugduneuses olim in unedico usu, et ulcera sordida purgare, lombricos interficere, et obstructiones expedire a Joh. Baulino refertur. 


\section{A NARRHINUM Duriminium.}

Axarrir. caule hirsuto, erecto; foliis hirsutis, radicalibus spatlunlatis, serrato-dentatis, trinervis, canlinis iripartitis, lacinia media late lanceolata; bracteis imis similibus, supremis integerrimis; corolla parva, exalhida.

Axtirrinum bellidifolium. ( Var. 6.) Lin. Sp. pl. ed. Reich. 3. p. 139. La Marck Dict. Bol. Encycl. 4. p. 363. Gouan Illustr. p. 39.

Axtrannu Duriminium. Brot. Fl. Lusit. 1. p. 198.

Linarua Lusitanica Bellidis folio ampliore et villoso.

Toumef. Inst. R. H. p. 169.

AxsRginum hirsutum. Link Fl. Lusit. J. P. 227. Lab. 33.

Caulis sepe solitarius, teres, hirsulus uti tota planta, erectus, sesquipedalis et ultra, superuè ramosus; ramis gracilibus, longis, ereclis.

Fous saturate viridia, hirsuta, ralicalia in orbem jacentia, spathulata. serrato-dentala, canlina infuna lanceolata, serrata, superiora tripartila, lacinia medià lanceolati, lateralibus multo latiore, acutissinà, sape integrerrind.

RAcem ut in prxcedenti Anarrh. beilidifolio, sed bractex in floribus infericribus tripartitæ, lacinia medià late lanceolata, et lateralibus maiore, in supremis integerrima.

Calyx profunde quinquepartitus, laciniis subulatis, subrqualibus, corolla multo brevioribus.

Corolla albida, sen interdum rarius straminea, labiata, absque palato, ut in pracedenti; lubo et labiis similihus, sed aliquantulum maiorihus; fance pervia; calcare arcuato, intra calycem clauso. Reliqua ut in pracedenti specie.

Habıtat in rupibns, el sabulosis subhumidis inter Durium et Minjum, prosertiun circa urbem do Porlo. Floret Junio, Julio. Bienue ant interdim trienne. 
Planta nimis aftinis Anarrhino bellidifolio, sed habitu hirsuto, foliis valde naaioribus, caulinis bracteisque imis tripartitis, cum lobo medio latissime lanceolato, et corollì maiori nec cærulescente, ab illo satis diflerre videtur, ut potius pro specie verè distincta quàn pro varietate haheri mereatur, et insuper quia culta nil habitu hirsuto nec aliis notis variet. 


\section{OR OB A NCHE larbata.}

Or.on. caule simplicissimo, pubescente; calyce bifolio, foliolis indivisis bifidisve, aristatis, corolla paulo brevioribus; bractea unica florem excedente ; corolla quarlrifida, labis crispis, crenatis, longiudine subæqualibus; staminibus infernè lineari-lanceolat is villosis, supernè giabris, antheris solutis, inclusis, stylo glabrjusculo brevioribus; stigmatis lobis subdistantibus.

\section{Lusit. Herva loira barbuda}

Or. barbata. Brot. Fl. Lusit. tom. 1. pag. 183.

On. larbata, caule simplici, pubescente; calycibus bipartitis, lacinia longe aristata; bracteis calyce longioribus. (Ut varietas.) La Marck Dict Bot. Eucycl. Mel! tom 4. p.621.

Or. gracilis, calycis phyllis lanceolatis bifilis; corolla elongata unciali, çaleà jutearà nargine crispà, Jabio treviore; staminibus basj hirsutis; stylo pilis sparsis; stignate bilobo. (Ut varietas.) Link et Holim. H. Lusil. tom. 1. p. 313.

OR. minor, calycis phyllis sxpe bipartitis; corolla semiunciali lutescente, margine crispa; staminihus basi hirsulis; stylo glabriusculo; stigmate bilobo. (Ut varietas.; Id. Ibid. p. $31 \dot{\text { f. }}$

Or. maior, caule simplici; bracleis lanceolatis flore maioribus.

L.oefb. It. p. 15 1. 11. 35 .

SEx Orobanches species. Grisl. Tirid. Lusit. n. 1598.

Rabux bulbosa obliqua, rarius verticalis, radicibus sibi vicinis aliarum plantarum adherens, plus minusve ovato-oblonga, quatior ad sex lineas in basi lata, ibique ohtusa, radiculisque nonnullis præedita, intus solida subrufa, extus fusca, supernè squanis ad canlis basin lauceolatis, longe acuminatis, laxe imbricatis, fuscis, tecta. Inodora est, uti tota planta, leviter adstringens, vix acris, interdum amariuscula; annua.

$\mathrm{C}_{\text {Aulıs }}$ simplicissimus, nunc farctus nunc fistulosus, erectus, quinque ad novenı uncias a!lus, raro Jongior, infernè crassitudine pennce gal. linacex aut auserine, striato-angulosus, sxpe flavescens, pius miunsve hirsulus, pilis brevibus, apice glanduliferis viscosis, plerumque pancifolius. 
for. squamiformia, Janceolata, longe acuminata, integerrima, extus hirsuta et ciliata, iutus glabra, sordide flava, demuut fuscescentia, distanter alterna, ad caulis basin propriora et longiora, omnia sessilia, erecta, el cauli contigua, cito arescentia, cutoque fragilia.

Spica terminalis, elongata, infernè primillora, apice bracteis et calycibus cassifloris breviter comata. Rachis striato-angulosi, hirsuta: flores inodori, sessiles, alterni, inferne laxi, supernè propiores, et ibi sxpe plus minusve dense congesti. Bractea nuica ad quemvis ho rem, lanceolata, longe acuminata et aristala, obscure rufa, hirsuta, subciliata, sessilis, calycis foliolis contigua, illis corollaque longior, raro in nonnullis floribus longitudine calyus, primum erecta, demum recurva, cito arescens.

Cazyx diplyyllus, foliolis extus hirsutis, intus glabris, obscure rufis vel interdum fuscis, infernè plus minusve inter sese oblique distantibus, singulo nunc indiviso lanceolato, acmuninato, in aristam longitudine fere corolla attenuato, nune bifico, laciniis acutissimis in aristam attenuatis, aristis inæqualibus, alia alia longiure, corollæ tubum xquante aut subrquante.

Corous flavescens (interdun sed raro ex abo lutea) sex ad octo lineas longa, Jongiorem nuspiam vidi, intus glabra, extus subpubescens, bilabiala: tubus supernè latior, ibique p'us minusve cermums, rugosus, basi angustior: labia longitudine sæpe æqualia, interdum aliud alio paulo brevius; superius concavum, postice carinatum, crispum, acute et in:equaliter crenatum, rotundatum, nonnullis in floribus obsolete bilobum, at sæpe integrum absque ulla emarginatura vel fissura, lateribus demum sxpe intro nec retro versis; interdum lineis purpureis, aut colore penitus purpureo, vel carneo, variare fertur. Labium inferius reflexum, al tubi faucem bibullatum, trifidum, laciniis leviter insequalibus, media vix longiore el vix latiore, rugosis, roundatis, acute et inæqualiter crenatis.

St.m. filamenta didynama, dilute rufa, supernè glabra, infra medium villosa et ciliata, ibique latiora lineari-lanceolata, et usque ad tubi basin recte decurrentia, neque eorum nervis ad latera divergentibus aut ulla glandula apparenti terminatis. Antheræ biloculares, bilobæ, lobis in spinulam acuminatis, primum sæpe purpurex, demum rufa, glabræ, conniventes. sxpe distinctx, in anthesi intra corollæ tubum reconditx, postea vix aliqua ex illius fauce subexerta.

Nectaruum ad basin germinis aut nullum, aut glandula minima obsoleta.

Pist. germen superum, flavum, seu ex albido flavescens, apice interdum purpurascens, oblongum, subteres, acutiusculum, glabrum, ntroque latere unisulcatum. Stylus tenuiter filiformis, antheris plus minusve altior, usque ad apicem glabriusculus, seu perpaucis pilis valde dissitis instructus. Stigma nutans, purpureun demum fuscum, 
bilobun (rarissime in nonnullis floribus trilobum) lobis glabriusculis, crassis, obtusis, contiguis, aut plus minusve distantibus.

Capsula oblonga, sublanceolata aut interdum subovalis, acuta, glabra, unilocularis, bivalvis, utrinque misulcata. Semina numerosa, minima obovata, rugosa, ex fulvo fucescentia, receptaculis duobus linearibus, fungosis, bialatis, calraliculatis, capsulæ valvulæ singulæ parieti interno adiatis et supra ipsum elevatis, adhæsa.

Habitat in agris cultis et incultis circa Olisiponem el ajibi, radicibus leguminosarum et aliarum stirpium innascens. Floret vere. Annua.

Ors. In hujus speciei et sequentis individuis, partium pubescentia, magnitudo, longitudo, color, florum densitas vel laxitas in spicis, calycis basis unifolia vel bifolia ita in Lusitania variabilis, ut ad spe. cificas differentias constitnendas valde dubia et diflicilia signa distinctiva suppeditent; qua tamen pro istis duabus speciebus distinguendis selegi, illa minus varia et sæpius obvia, nonnullaque in ommibus individuis semper firma. His signis easdem facile distingui posse ab omnibus aliis Orabanches speciebus existimo. Orabanche gracilis et minor clariss. Link (Fl. Lusit. L. c.) non satis inter sese, nisi uti varietates ad nostram Or. Jarbatam attinentes, differre mihi videntur: Or. gracilis celeb. Smith a nostra differt maximè corollae labio inferiori brevissimo, ejus laciniis obcorlatis, et staminibns exertis, quæ omnia muspianı in nostra observavi; Or. minor ejusdem et clar. Sutton, etsi nosiræ nimis affinis, ab ea tamen differt præsertim laciniis labii inferioris corollæ æqualibus et stigmate retuso. 
OR O B A NCHE fatida Lusitanica.

Oroz. caule unico simplicissimo, pubescente, calyce sape basi indiviso, unifolio, profunde bipartito, laciniis aristatis, bifidis, tubo co. rollix paulo brevioribus; bractea floren xquate vel excedente; corolla cuadrifida, ampla, crispa, imequaliter crenata; staminibus basi dilatatis, ibique obsolete villosis, glandulosis, comfuentibus; antheris coharentibus, superioribus subexertis; stylo sparsiu subpubescente, stigmate biparlito, lobis distantibus.

Lusit. Herva toira denigrida.

OR. barbata atropurpurea. Brot. Fl. Lusit tom. 1. p. 183.

Or. fretida, calycis phyllis bipartitis; corolla semiunciali, atropurpurea, margine crispa; staminibus basi hirsulis; stylo glabrinsculo; stigmate bipartito. Link et Hollm. Fl. Lusit tom. 1. 1) -3 lt. tab. 62.

OR. futide, scapo simplici; bracteis angusto-lanceolatis, corolla longioribus; calyce diphyllo, laciniis bifilis, lanceolato-subulatis. Desfo 11. Atlant. tour. 2. p. 59. Lab. 14\%

Orobaxcile flore specioso fimbriato ruberrimo. Schaw. Specim. n. 452.

$\mathrm{O}_{\text {roв }}$ caule simplicissimo, pubescente; antheris exertis, mucronatospinosis. Poiret Ilin. 2. p. 195.

Oroв. (Iuaior 6.) Vahl. Symb. 2. p. 70.

Oror. fatida, caule simplicissimo, subpubescente; calycibus bipartitis, submucronatis; spica comosa. La Marck Dict. Bot. Encycl. Meth. 10m. 4. P. 621 .

Oлов. Lusilanica, flore atropurpureo. Tourn. I. R. H. p. 176.

RADIX bulbosa, et qualis in Orobanche barbata, sed crassior.

CAUl1S unicus ex eadem radice, simplicissimus, erectus, sex ad tredecim uncias altus (spica supputata) infernè crassitudine pennæ anserine el ibi sxpe fistulosus, striato-angulosus, supe atropurpureus, uti Lota planta, pubescens pilis brevibus apice glandulifero-viscosis, paucifulıus.

Fus a squamiformia, lanceolata, integerrima, acuminala et in aristam Tum. 11 . 
atlenuata, extus pubescentia et ciliata, intus glabra distanter alterna, ad caulis basin propiora et Jongiora, omnia sessilia, crecta et cauli contigua, cilo arescentia ciloque fragilia.

Spica terminalis. crlinuracea, elongata, infernè primiflorens, apice bracte is calycibusque sterilibus fasciculatis conata. Rachis striatoannulusa , birsuta. Flores inodori, sessiles, alterni, subcernui. infernè laxi, supernè propiores et ibi sxepe plus minusre dense congesti. Bractea unica calrci contigua, illoque el corolla siepe longior. sessilis, lanceolata, àcuminata, in aristam atlenuata, hirsuta, ciliata, prinùn erecta, postèa recurra, cito arescens.

Catrx sub latere inferiore corollæ situs illudque amplexans, nunc sæpius ex linea usque ad lineas duas a basi distantes indivisus et unifolius, nunc orario corollaque sensim jllum prenentibus, ibiyne in medio plus minusve rumpitur, bifoliusque redditur, foliolis hitidis; quod tam foribus junis, quam mediis et supremis, erenire solet: liciuna utraque pubescens, ciliata, in aristann atcenuata; earum alia longior interdum corollæ tubum æquans, at sæpe illo paulo brevior. Nomnonquam. etsi rarissime, prope basin laciniarum denticulus minimus, rel seta brevis inter ipsas, occurrit.

Coroul.a sape atropurpurea, interlum plus minusve obscure rufa, giabra, septem ad noren lineas longa: limbus bilabiatus: lubus amjus, sursum rersus sensim latior, nerroso-venusus, crispatulus dorso convesus et carinatus, subtus ferè planus: labium superius inferiori longitudine aquale, aut incerdum parum brevius, intus concarum, extus carinatm. sape obsolete bilobum, seu subintegrum, emaryinatura inter lobulos minima, rel interdum nulla, rotundatum, inæqualiter crenatum, crispum, erectum, lateribus denum retroversis: labium inferius reflexum, superiore latius, ad corolla fancem bibullatum. trilobum, lobis rotundatis, inæqualiter crenatis, rugosis, inxequalibus, intermedio paulo latióri et longiore.

Sray. filamenta didruama, tenuiter filiformia, prope basin corollæ inserta, ibi fere glabra, vis decurrentia, nerrosa, valde dilatata. ner. vis exterioribus divaricatis, inæqualibus, glandulà quadam minimà obscurate fulva Jateraliter terminatis, confluentibus, omnia corolla tubum sxpe non excellentia, sed illo paulo breviora, rel illius longitudine, sub antheris arcuata. et ibi perpaucis pilis sparsis prædita, cæterum glabra. Antheræ didrınæ, biloculares, infernè bispinosx, nunc per paria, nunc sapius simul omnes lateraliter, mediis pilis riscosis, coharentes, cæeterum glabra, plus minusve rufeścentes, longitudine tubi corolla, aut subesertæ, raro et nisi post anthesin, éfauce corollæ omnes exertæ.

Nectarius glandula orata fulva al basin germinis. Pist. germen ohlongum, obtusum. suborale, utrinque unisulcatum, dilute purjuseum, seu ex albido purpurascens, glabrum, interdum apice sub strlo nonnultis pilis instructum. Strlis atropurpureus, ć basi usque 
ad stignatis lobos subpubescens, pilis brevibus, sparsis, apice glandulferis. Slima antheris plus minusve altius, semper versus illas incurruu, pilis brevissimis vel punctis glanduloso-viscosis aspersum bilobum, Jobis distantibus, fuscis, apice obtuso crassioribus, intus planiusculis, extus convexis.

Carsets oblonga, obtusa, suhovalis, glabra, unilocularis, bivalvis, sulcata, sxpe stylo persistenti terninata. Semina ut in Or. barbata; nonulla, el sæepe omnia in spicæ capsulis superioribus, abortiunt.

Haserat in agris cultis et incultis prope Olisiponem. Floret vere. Annu่a.

Tirimes hujus et sequentium specierum, ut illi Asparagorum, rusticis edules.

Ors. Colore interlum rariat fere lutescente, et tunc vix specificè Or. harbate dissimilis, nisi basi staminum dilatata. glandulosa, et confluenti. ut ex recentioribus observationibus mihi innotuit. Or. majo$r i$ etsinimis affinis, et pro illius varietate a celeb. Vahl. habita, at. tamen basi staminum prodicta, necnon corolla rugosiori, crispatiori, ejusqque crenulis plus inæqualibus ab illa specifice differre videtur. Cum Or. fatidu Veotericorum conjunxi, nam essentialibus notis speciticis cum illa concordare verisimile, quanquam odore non fretido, catile unico, et aliis notis variantibus difierat. 


\section{OR O B A N H E ramosa.}

OR. caule ramoso, simplicissimove, subvilloso; corolla recurvata, quinquefida, basi tumida, bracteis ternis nimis longiore; calyce monophyllo, campanulato, profunde bipartito, lacinis bifidis, corolla fere triplo brevioribus; capsula quadrisulcata, seminum receptaculis in utraque valvula in unum coalitis.

\section{Lusit. Herva toira ramosa.}

Or. ramosa. Brot. Fl. Lusit. tom. 1. p. 183.

Or. ramosa, calyce brevi, quadripartito, laciniis angustis elongatis; bracteis ternis; caule sæue ramoso.

Link et Hoflm. Fl. Lusit tom. 1. p. 317.

OR. ramosa. Lin. Sp. pl. ed. Willd. 3. p. 353. La Marck Dict. Bot. En. cycl. Meth. tom. 4. p. 623, et alii neoterici Botanici.

RaDIx bulbosa, oblonga (parasitica radicum vicinarum plantarum) quatuor ad sex lineas infernc̀ crassa, squamis nonnullis ovato-lanceoJatis, acuminatis, fuscis, extus instructa.

Caules ex eadem radice sxpe plures ramosi, interdum unus tantim ramosus ant simplicissimus; omnes erecti, quinque ad septem uncias alti, infernè crassiores, crassiundine stapernè pennæ columbinx, farcti, striati, flavescentes, subvillosi, uti tota planta; rami alterni, erecti.

Foura squamis similia radicalibus, sessilia, subvillosa, é fusco fulva, cito arescentia, alia ad ramorum basin, alia duo triave minora, alterua infra spicas.

Flores spicati, alterni, valde laxi, superiores sessiles, inferiores pedicellati, pedicellis unam ad lineas duas longis. Spica caulem el ramos terminantes; canlina aliis longior, quatuor ad sex uncias longa, erecta uti etian alia; rachis striato-angulosa, subvillosa. Practea ad quemvis florem tres, quarum dux laterales arl basin calycis setacex, villosx, obscure fulve, laciniis calycis approximat $x$ et illis paulo breviores; infima sub floris pedicello, seu sub calyce, maxima, fusca, sessilis, acuminata figura foliormm squamifurminm canlis, lacinis calycis æqualis, aut paulo brevior.

CALYX monophyllus, breviter campanulatus, late concavus, corollam 
infunc ambiens, fulvus, extus subvillosus, intus glaber, profunde bipartitus, latinia utraque bilida, biarsstata, aristis subæqualibus, longitudine germinis, corolla veró fere triplo brevioribus.

Corolda unciam longa, bilabiata; tubus infernè, ubi germen tegil, valde tumidus, uembranaceus, ex albido purpurascens, glabriuseulus, paulo iufra medium nimis coarctatus, exunde sensim ampliatus, longitudinaliter rugosus, posticè carinalus, flavescens, subvillosus, valde cernu : labium superius apertum, concavum, postice carinatum, bifidum, laciniis minimis atutiusculis, extas at intus hirsutis, ciliatis, demun lateribus revolutis: labium inferius reflexum, ad faucem tubi duabus bullis villosissimis elevalum, trifidum, lacinis aqualibus, aut subequalibus, ovatis, obtusiusuculis, obsolete crenulatis, davis, vel purpureis, ciliatis, rugosis, extus et intus lirsutis.

Sta mixum filamenta didynama, tobo in coarctalione inserta, flava, inferuè crassiora, subulata, subvillosa, supernè grabra, in tubo cum antheris recondita. Antherx bilobx, biloculares, inferuè bispinosx, glabre, lavx, demum exalbila, contigux, sed non cohxentes.

Nectarium ad basin germinis vix ullum Pistilli germen ovalum, acutiusculum, obsolete quadrisulcatun, glabrum, ex albido jurpurascens: strlus ex lavo luscus, glaber, longitudine antherarum, aut paulo altion: stigma crassum, nunc retusum, nunc in medio misulcatum aut obsolete obcordatum, fuscum, antheris sæepe paulo altius, et ad ipsas incurvatum.

Capsula ovata; acutiuscula, quadrisulcata, unilocularis, bivalvis Semiua numerosa, minutissima, fusca, unico, raro duobus contiguis, receptaculo fungoso, in medio singulæ valvula elevato, affixa.

Hıптлт in agris et collibus circa Olisiponem, Conimbricam et alibi Floret vere. Aunua.

VARIAT forum colore, flavo, purpurascente, ant istis variegato; item caule simplicissino, elsi ex ejusdem speciei ramosa seminbus, quare pro diversa specie non habenda. 


\section{RIINANTIUS trixago.}

Ru. spica coarctato-telragona; corollæ labio utroque flavescenti; sıperiore panlo breviori, sxpe integerrimo; inferiore trilobo, laciniis lateralibus intermedia latioribus; bracteis scratis, superioribus integerrimis; fuliis oppositis suboppositisve, lanceolatis, obtuse et remote serratis; caule tereti subteretive, sæpe simplicissimo.

Rн. trixago. Brot. Fl. Lusit. tom. 1. pag. 186. Lin. Sp. pl. ed. Willl. tom. 3. p. 189. 1.a Marck Dict. Bot. Encycl. Meth. tom. 4. 1. 59.

LAsiopera rhinanthina. Link et Hoffm. Fl. Lusit. tom. 1. p. 298.

Alectorolophos fiore lıteo. Grisl. Virid. Lusit. n. 57.

RADIX fibrosa, ammua.

C.rulas teres, subleresve, pilis hrevihus, rigidulis, basique incrassatis hirsutus, erectus, sxpe simplicissinus, interdum sinplex tuncque ramis paucis oppositis, nonnulis interdun plus ninusve alterne silis, omnibus indivisis, sxpe brevibus, rarissine longiusculis.

Fouı sæpe opposita, decussata, superiora nonnunquam subopposita, omnia patentia, sessilia, lanceolata, acuta, dentibus obtusiusculis distantibusque serrata, viridia, rugosa, pilis brevibus lirsuta et scabra.

Spica caulem, rarissiue nonnullos eliam ramulos terminans, quasi tetragona, duas ad quatuor uncias longa, noribus foliisque noralibus oplositis, sessilibus, coarctatis, instructa.

For.1 floralia inferiora serrata et caulis supremis foliis similia, pilis vesiculâ resinosâ terminatis liirsuta, foribus longiora, vel interdum aqualia; superiora sensin minora, floribus breviora, ovata vel subcordata, acuta, integerrima; suprema ninima, imbricata, sæpe sterilia.

Catrx monophyllus, subventricosus, brevis, pilis viscosis hirsutus, bipartitus; lacinjâ utraque bidentata, dentibus subrequalibus, obtusis.

Corouda flavescens; tubus calyce longior; labium superius inferiore paulo brevius et angustius, subpubescens, concarum, carinatum, apice sape acutiusculo et integerrimo; labium inferius latum, trilobum, laciniis obtusis, lateralıbus dilatatis, media angustiore. 
Stomxum filamenta didynama, lougiumine labii superioris, vel sub ipso recondita. Anthera birsutas, incumbentes, diulsus, infernè acnti, sipe per paria adhierentes.

Pıstus. rermen ovatum, compressum, villosum. Stylus filiformis, situ staminum, eisque vix longior, basi sxpe persistems. Stigma crassiusc:tum, obtusum, inflexum.

C. psura ovata obtusiuscula, turgida, hirsuta, calyce persistente vix brevior, bivalvis, bilocularis, dissepimento contrario. Semina multa, minuta, oblonga, lente vitred visa striata, angulata, absque ullo margine nembranaceo.

II Bвтат in lumentibus montosis de Cintra usque ad Olisiponensia suburbana, trins Tagum quoque iu ora maritima prasertim prope promontorium barbaricum, vulgo Cabo de Espichel. Floret vere. Ammuns.

Plaxta inodora; sapore leviter amaro el acriusculo predita.

Ors. 1." Variat foliorum magnitudiue, et caulis altitudine, isto ex quatnor scilicet usque ad uncias duodecim etultra alto, simplicissimo ant simplici, tuncque ramis ex una ad sex uncias longis. Folia floralia etian magnitudine marginibusque variant; suprema tamen spicx semper integerrima, corollaque breviora.

Ors. 2.' Rhinanthus maximus (Lin. Sp. pl. ed. Willd) etsi corolla lutea et notis nomullis aliis Bartsia viscose affinis, non ejus tamen, sed potins unstri Rhinanthi majoris varietas esse videtur. Rhin. versicolor adhuc dubia species, et fortè cum Rh. Irixugine nti varietas conjungendus, quamvis caule sepe obtuse quadrangulo, leviter quadrisulcato, raroque simplicissimo, corolla constantissime variegata, et labio superiore sæpe subbifido aut emarginato, specificè dillerre videatur 


\section{SCIR O P ULA R I sublyraia.}

Scr. caule glabro; foliis radicalibus el infimis sublyratis, laciniis obJonginscule ovatis, inciso-serratis, superioribus subinterrupte pinnatis, foliolis lanceolatis, profunde serratis, supremis ad flores simplicissinis; panicula terninali, racemulis brevibus, pedunculis trichotomis; corolla mediocri.

Scr, chulifolia. Link Fl. Lusit. 1. p. 270. tab. 54.

Scr. lyrata. Willden. Hort. Berol. tab. 55. uti varietas pubescens. Eaden La Marck Dict. Bot. Encycl. Suppl. tom. 5. pag. 116.

R،DIX lignosa, perennis Caulis sesquipedalis ad tripedalis, a foliorum petiolis leviter decurrentibus subquadrangulus, graber, erectus, ramosus; ranis brevibus.

Folna omnia sxpe glabra, radicalia et infima canlis pinnatifida, sub1 rata, longe petiulata, foliolis oppositis, subovatis, inciso-serratis, aut interdum duplicato-serratis, oblusiusculis, venosis, rugosis, terminali maxino, ovato, obtuso, in lacisias irregulariter serratas fisso; smperiora pimnata, foliolis anzustioribus, oppositis, breviter petiolatis, lanceolatis, aculis, serratis, nonnullis intermediis minoribus; suprema ternata vel simplicia, in petiolum brevissimum extejuata.

Paxicura terminalis, oblonga, ex racemnlis pluribus, inferioribus oppositis, aliis alternis, composila, plerumque glabra; racemuli axillales, solitarii, breves, panciflori, pedunculis trichotomis, intermedio longiore. Folia floralia lanceolata, acuta.

CALYX quinquefidus, laciniis obtusis, margine late membranaceis, corolla tubo brevioribus.

Coroula mediocris, quatuor quinqueve lineas longa; tubus inflatus, subglobusus; limbus bilabiatus, labium superius fuscum, interdum obscure purpureun, inferiore longius, erectum, hilobum, lobo utroque obtuso, cum appendicula squamiformi emarginata intus ul faucem; lahium inferius trifidum, ex viridi lutescens, laciniis luabus lateralibus patulis, obtusis, intermedia reflexa.

Stamixu filamenta didynama, inclusa, interdum piloso-viscosa: anthere reniformes, lutew. Pistilli gemmen ovatum; stylus staminibus longior; stigma oblusum, fere bilabum. 
Capsula calyce persistente longior, ovala, breviter acuta, glabra, bilocularis, bivalvis, polysperma; dissepimentum per maturitatem foramiue ovali perrimu. Semina tuberculata, receptaculo fungoso, quod dissepinento alnatum est, adherentia.

Ha bitat in marilimis circa oppidum Sclubal, at nonnullæe ipsius varietates in montosis Interamnix et Transmontanx. Floret Maio, Junio, Julio. l'erennis.

Planta odore et sapore ingrato. Usus ignotus. Variat interlmm habitu glabriusculo: species equidem inter Scr. melliferam et sambucifoliarn media, et quasi prioris varietas. 


\section{SCROPHULA R IA Herminii.}

Scr. caule hirsuto; foliis pubescentibns, late cordatis, aculiusculis, non rugosis, dentatis, dentibus acutis, sæpe integerrimis, petiolis lamina brevioribus; panicula terminali, pedunculis axillaribus, solitariis, paucufloris.

Scr. Herminii. Link Fl. Lusit. 1. p. 266. tab. 53.

RaDIX lignosa, infernè ramosiuscula, perennis.

Caules pauci ex eadem radice, quadranguli, hirsuti, erecti, sesquipedales ad tripedales, ramosi, ramis erectis.

Fonı omnia pubescentia, petiolis longiora, opposita, inferiora ad tres uncias cum dimidia longa, el vix latitudine minora, cordata, dentata, dentibus magnis, acutiusculis, fere omnibus plerumque indivisis; superiora sensim versus apicem caulis et ramorum decrescentia, cordata, subcordatave, acuta el profunde serrata.

Panicuta terminalis; racemuli axillares, inferiores oppositi, superiores alterni, omnes breves, paucifori, floribus tribus ad quinque aut paulo ultra: folia floralia sub pedunculis lanceolata, serrata.

Calycis laciniæ parvæe, obtusæ, marginibus subscariosa. Corolla, ut in genere, quinque lineas longa; labio superiore bilobo, erecto, dilute fusco. com appendicula lutea, emarginata; inferiore virente. Stamina inclusa; antheræ flavæ. Stylus staminibus longior; stigina obtusum, fere bilobum. Capsula conica, acuta, glabra.

Habitat in jugis, clivisque Herminii. Floret Junio, Julio. Perennis.

Ops. Variat iuterdum dentihus foliorum in aliquos minores divisis; sed folia munquan oblonga ateo sunt, ut triplo longiora quam lata; quapropter presertim a Scr. betoniccefolia diversa, prout a Linnæo describitur tanquam Lusitanix indigena; quæ tamen species nee a me, nec a clar Linkio, nec ab aliis Bolanicis, qui recentissine Floræ affectu Lusitaniam perambularunt, ullibi in eà spontanea usque adh:ıc reperta fuit. 


\section{I G I T A L IS purpurea tomentosa.}

Dig. Coliis petiolatis, ovalo-lanceolatis, serrato-dentatis, supra viridibus, subrugrosis, subpubescentibus, subtus incano-tomentosis; laciniis calyciuis ovatis, acutiusculis, tomentosis; corollis purpureis, calyce multo longroribus, villosiusculis, limbo subquadrilobo, superne integro.

\section{Lusit. Digilal, Dedaleira, ou Herva dedal.}

Digitalis purpurea. Brot. FI. Lusit. 1. p. 200. (uti varicias)

Digitalis comentosa. Link Fl. Lusit. I. p. 221 . tab. 29.

Digitalıs flore purpureo et albo. Grisley Virid. Lusit. n. 440.

Rabr lignosa, ranosiuscula, alba, amara, acris, biennis.

Cauls solitarius, teres, plus minusve tomentosus, erectus, duos ad tres pedes altus, sæpe simplicissinus, rarò uno alterove ramo terminatus.

Folra radicalia et inferiora caulis ovato-lanceolata, acutiuscula, serrato-dentata, aut nonnulla obtusè crenata, quatuor ad sex uncias longa, duas tresve lata, in petiolum plus ninusve longum attenuata, supra viridia, subrugosa, subpubescentia, sublus incano-tonsentosa; superiora minora, alterna, lanceolata, serrata, sessilia, suprema integerrima.

R iceni terminales, longi; flores alterni, solitarii, laxi, nutantes, secundi. Bractese solitarixe, ovato-lanceolatie, pedunculis sæe longiores.

CAsYX profunde quinquepartitus, laciniis ovatis, acutiusculis, plus minusve tomentosis, quatuor ad sex lineas longis, duas tresve latis, una sape angustiore, omnibus persistentibus.

Cororla campanulata, ventricosa, unciam ad sesquiunciam longa, liubo oblique quadrilobo aut subquadrilobo, supernè inteyro, villosiuscula, purpurea, intus maculis obscurioris coloris, nonnullis ocellaribus, aliis cacis, adspersa: raro alba.

Stamina didynama, corolla breviora. Germen oratum, subpubescens; stylus staminibus subrqualis; stigma bifidun, hirsutum. 
Capsula ovato-pyramidata, subpubescens, bilocularis, bivalvis: dissepimentum ex marginibus valvularum introrsum flexis formatum: valvulx per maturilatem bifidx, interdum fere usque ab basin bipartitae. Semina plurina, parva, scrobiculata, receptaculo fungoso, oblongo, aflixa.

Habitat ad ima montium et collium in subumbrosis, et lumidulis, præsertim in provinciis Lusitaniæ meridionalibus. Floret Maio, Junio. Biennis

OBs. Planta tam amaritie et acritate, quàm viribus medicis et notis essentialibus specificis Digitali purpurea similis; nec differentix accidentales, qux in tomentositate foliorum et calycis, in corollis bre. vioribus, limbo paulo minori et minus prominente, maculisque ocellaribus pauculis, aut omnibus cæcis, satis coustantes ut speciem re vera diversam constituant, sunt enim pro situ locorum, expositione, et solo ninis variabiles adeo, ut planta tunc vix ac ne vis a Digitali purpurca dillerat. 


\section{I G I T A L I S thapsi.}

Dic. foliis lanceolatis, serratis, pilosis, inferioribus petiolatis, superioribus sessilibus, decurrentibus; laciniis calycinis ovato-lanceolatis, acutis, pilosis, inxqualibus; corolla calyee mnlto longiore, purpurascente, hirsuta, limbo quadrilobo, supernè integro.

Digitalis thapsi. Linn. Sp. pl. ed. Willd. 3. p. 284. La Marck Diet Bot. Encycl. tom. 2. p. 279 . Smith. Exot. Bot. Fosc 9. p. 83. tab. 43. Brot. Fl. Lusit. 1. 1. 200. Link Fl. Lusit. 1. p. 223. tab. 30.

Digitalis Verbasci folio, purpurea minor, perennis, Hispanica. Barrel. Icon. 1183.

$\mathrm{C}_{A \mathrm{U} u s}$ erectus, supernè subramosus, pilosus, pilis crispis, subfuscis, pluribus sæe vesiculà viscosa terminatis.

Folia lanceolata, acute serrata, acutaque, suprà pilosa, subtus veno. sa, subtomentosa; inferiora in petiolum attenuata, superiora sessilia, plus minusve decurrentia.

Rлсем terminales. Flores alterni, laxi, nutantes, secundi. Bracteæ mifloræ, acutæ, pilosæ, pedunculis valde longiores.

CALYcis laciniæ ovato-lanceolatæ, acutæ, pilosæ, inæquales, una angustiore, et breviore.

Corolla calyce multo longior, purpurea, hirsuta, intus punctis saturate purpureis, aut subsanguineis adspersa, limbo oblique quadrilobo, supernè indiviso.

CAPSUla ovata. subpyramidata, pubescens, bilocularis, bivalvis: valvula per maturitatem bifidx: dissepimentum ex inflexis valvularum marginibus formatum : receptacnlum oblongum, fungosum, bilamellatum, lamellis, mediante alià integerrimâ transversì, dissepimento adhærentibus. Semina parva, subrotunda, scorbiculata, dissepimento affixa.

Habitat in montosis inter Lamego et Viseu, in convallibus cirea Her. minium, ad ripas Mundæ prope Conimbrican, et alibi in Beira. Flore Maio, Junio. Perennis.

Tom. II. 
Plaxta amara, acris, graveolens, viribus medicinalibus similis præcedenti, et facie nimis afinis specifice tamen foliis presertim decurrentibus diversa. Uti filia Digitalis purpurce é Verbasco Thapso a nonnullis Botanicis habita; an tamen istarum stirpium hybrida proles: 


\section{R T I A caudia.}

LRT. foliis opositis, oratis. grosse serratis, inferioribus orato-subcordatis: spicis monoicis dioiciste. utrinque geminis, simplicibus: masculis linearibns, rachi filiformi alatis, subtus nadiduris. pralongis, patentibus: famineis crlindraceis, pedunculatis. erecto-patuis : =tipula utrinque unica, orata , binerri, apice bidentata.

\section{Lusit. Lrtiga de caudas.}

Ĺrtics Lusilana. Brot. Flor. Lusit. 1. P. 205.

Urrıca annua, longius caudata, rulgatissima, Lusitana et Africana. Grisler lirid. Lusil. n. $1 \frac{49}{2}$.

LrTICA caudala, foliis oppositis, cordatis, racemis reminis, simplicissimis, longissimis. Tahl. srmb. fasc. 2. p. 96.

Rsdrs subramosa, fibrosa, dura, albida, annua.

CAtLEs solitarii. rel plures ex eadem radice, erecti, altitudine nimis variantes. es semipede ad usque tres fere pedes, obtuse quadranguli. quadrisulcati, undique aculeolis adurentibus. uti tota planta, conspersi, ramosi; ramis axillaribus, oppositis : erecio-patulis.

Folia opposita, petiolata, patentia. orata, acuta : grose serrata, unam ad tres uncias Jonga. inferiora caulis interdum orato-suhcordata, aut orato subrotunda. superiora paulo minora. sæpe oratolanceolata, omnia quinquenersi-rerosa. utrinque viridia el urentia; stimuli in superiori paginà punctis corveris parenchrnatis in inieriori autem simpliciter nerris aut renis iusident. Peticlus supra canaliculatus, suthtus carinatus. Iamina foli plerumque paulo brerior. in caulibus rero regetioribus interdum illà longior.

Strptze oppositæ, una utrinque orata. basi latissima angulum caulis ad latera duornm petiolorum et sub duobus pedunculis amplerans. membranacea , riridis. sursum rersus. angustata. margine reroluta. binervis. apice brerisime bifida seu bidenea, qualuor quinqueve lineas longa: patentissima, dexum rejiesa.

Aurar s sæpius monoica, superiora caplis et ramorum omnia integre mascula. inferiora vero omnia interte fxminea: rel eliam in mascuJorum apice, aut secundum jllorum longitudinen. nonnuli fores frminei, sicut in frmineis nonnulli masculi commisti occurrurt. In- 
terdum in omnibus ejusdem radicis caulibus et ramis amenta superiora et inferiora singula merè mascula, sicut in omnibus distinctæe radicis cuncta pure freminea: unde vere dioica.

Anexta mascula axillaria, utrinque gemina; pedunculata, simplicissima, rachi filiformia, utroque tnargine alato-membranacea, sesquilineam lata, duas uncias ad quinque longa, foliorum petiolo lonriora, patentia, ad apicem subarcuata, supernè florifera, subtus nuda et fere inermia. Flores glomerati, subsessiles, pedicellis bre. vissimis, capillaribus. Pedunculi filiformes absque alis membranaceis, supra canaliculati, subtus carinati, semiunciam ad sesquiunciam longi, petiolo foliorum vicinorum semper plus minusve breviores. Amenta faminea etiam axillaria, utriuque geminata, et pariter ut mascula pedunculata, omnia cylindracea, floribus glomeratis subses. silibus, nunc brevissima tres ad octo lineas longa, nunc præsertim in dioicis unam unciam ad usque duas cum dimidia longa, erectopatula, vel patentia.

CALYX in masculis tetraphyllus, foliolis minimis, aqualibus, obovatosubrotundis, concavis, cruciate incurvatis, intus glabris, extus hirsutis, viridibus, aut interdum subpurpureis. Corolla nulla. Staminum filamenta quatuor, subulata, calyce duplo longiora; primodum intra singulum foliolum calycis singula conduplicate recondita, postea in anthesi simul cum antheris elastice erumpentia, recurvata: anthere lntex, subrotundx, didymx. In centro floris rudimentum minimum pistilli glandulosum, hyalinum, cyathiforme.

CALYX in fxmineis tetraphyllus, foliolis viridibus, oppositis, concavis, erectis, cilatis; duobus maioribus, ovato-subcordatis, obtusis, duobus aliis, ad eorum basin cruciate sitis, ovatis, triplo quaduplove minoribus, omnibus persistentibus. Corolla nulla. P'istilli germen superum, ovatum, compressum: stylus nullusi: stigma purpurascens, subvillosum.

Pericarpiun nullum. Semen unicum, ovatum, compressum, nitidum, caljce tectum.

HАBitat in hortis, in subumbrosis incultis, ad sepes, vias, murosque freciuens in tota fere Lusitania Floret vere. Annua.

Ors. 1. Qualitate et viribus similis Urticæ urenti et dioicce, quibus cohabitat, nimis aflinis, et quarum hybrida proles esse videtur. Cum eisdem tamen non confundenda, difért enim a prima præsertim numero et forma stipularum, spicis interdum dioicis, et masculis semper alatis; differt quoque ab Urtica dioica maxime stipulis ovatis, nec lineari-lanceolatis, amentis sæe monoicis, non ramosis, sed simplicissimis et masculis utrinque membranaceis.

OES. $2^{\circ}$ Urticam caudalam stipulis ovatis, quæ apud Tunetum in Africa provenit, cum celeber. Vahl eandem ac nostram Lusitanam esse 
existimamus : sed Urtica membranacea clar. Poiret, Desfont., et Willd. alia diversa planta nobis esse videtur, namque prout a Clar. Poiret describitur (La Mark Dict. Bot. Encycl. 4. p. 638) ei caulis est subalbidus, folia omnia ovata, subglauca, lamini petiolis sem. per breviore, stipula lineares, acuta, flores omnes monoici, spica faminex sessiles; duas tresve lineas tantùm longx: an tamen nostra varietas? denuò observanda. 


\title{
PENTANTHERIA MONOSTYLTA.
}

\author{
VER B A S C M crassifolinm.
}

VERE. foliis utrinque dense tomentosis, radicalibus in petiolum angustatis, caulinis sessilibus, subdecurrentibus; caule simplici; staminum filamentis omnibus sæpe glabris.

Terrascum crassifolium. Link Flor. Lusit. 1. p. 2 I3. tab. 26. Decandolle Synops 1). 255. el Fl. Franc. 3. p. col. (forte idern, varietas (b) cxclusis synomymis.)

R.nux lignosa, ramosa, alha Caulis erectus, duos ad quatuor perles altus, teres a foliis breviter decurrentibus subalatus, dense tomentosus, sæpe simplex, rarius uno aliove ramo brevi terminatus.

Forla venosa, utrinque incano-lanuginosa, ferè integerrima, seu obsolete crenulata; radicalia et intima caulis ovata, obtusa, in petioJum angustata, alia alterna, lauceolata, acuta, sessilia, breviter decurrentia.

Sprca teminalis, simplex, teres, densa: pedunculi breves, tomentosi, fasciculati. Bractere lanceolatx, acutx, subpubescentes, calycibus longiores.

Calyx quinquepartitus, laciniis lanceolatis, aculis, tomentosis, persistentibus. Corolla flava, flus ninusve uncialis, rotata, laciniis rotundatis, subinæqualibus, extus subpubescentibus.

Sramum filamenta quinque, corolla breviora, inæqualia, duo longiora, omnia sxpe glabra, interdum mo aliove ad basin hirsuto. Antherx glabre, fulve, plus minusve reniformes.

Pistill germen ovatum, tomentosum. Stylus glaber, longiludine slaminum. Stigma crassiusculum, obtusum.

C.spula parva, ovati, acuta, pubescens, bilocularis, bivalvis, polys. perma. Scmina angulata. 
Ha вIтA т in sterilibus, et arenosis maritimis, præsertim prope Colares. Floret Maiu, Junio. Bieune.

Qualitates et vires ut illa Verbasci Thapsi, cui nimis afline, et quasi varietas. 


\section{VER B A SCUM macranthum.}

Verb. foliis utrinque dense tomentosis, radicalibus petiolatis, caulinis sessilibus, decurrentibus; caule simplici, tenuiter tonentoso; corollis calycem longe excedentibus; staminum filamentis hirsutis.

Verbascum macranthum. Link Fl. Lusit. 1. p. 215 . tab. 27.

$\mathrm{C}_{\text {avlis }}$ fuscescens, tenuiter tomentosus, tomento hinc inde deciduo nudus, teres, á foliis decurrentibus alatus, simplex, erectus, duos tresve pedes altus.

Folia radicalia ovato-lanceolata, lamina quatuor uncias et ultra longa, sesquiunciam duasve uncias lata, in petiolum ad uncias duas angustata, acutiuscula, leviter crenata, rugosa, crassa, utrinque dense tomentosa, minus tamen quàm in præcedente Vesbasco crussifolio; caulina acutiora, longe decurrentia, sensim versus caulis apicem decrescentia.

Spuca valde laxa; bracteæ lanceolatæ, pubescentes, calycibus longiores, subdecurrentes.

$\mathrm{C}_{\text {ALYX }}$ quinquepartitus, laciniis lanceolatis, acutis, subpubescentibus.

Corolla magna, flava, quinquepartita, laciniis rolundatis, quinque sexve lineas longis, quatuor latis. Staminum filamenta tria tota villosa, duo tantium ad basin. Capsula parva, ovata, acuta, pubescens.

Inabitat in Provinciis Lusitaniæ borealibus, et ibi non raro ad vias. Floret Maio et Junio. Bienue.

Qualitates et vires ut illæ Verbasci Thapsi, et Verb. crassifolii, cui nimis affine, sed differt foliis minus dense tomentosis, spica laxa, corolla multo naiori, et staminum filamentis omnibus villosis. 


\section{VERB A SCUM blallarioides.}

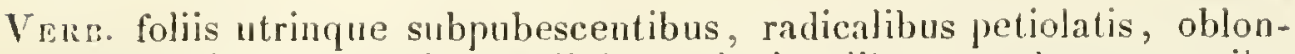
gis, duplicato-creuatis, caulinis amplexicaulibus; caule sparse piloso, pilis apice glandulosis; spica longissima, laxa, bracteis unifloris, billoris aut trifloris; pedunculis calyce brevioribus.

\section{Lusit. Blattaria maior.}

$V$ eriascum blallarivides. La Marck Dict. Bot. Encycl. tom. 4. p. 225. Brot. Fl. Lusit. tom. 1. p. 272. Link Fl. Lusit. 1. p. 219. tab. 28.

Verbascum viscidulum. Person Enchirid. 1. p. 215.

Blattaria flore maximo elegans. Grisley Virid. Lusit. n. 205.

RADlX alba, lignosa, supernè crassitudine digiti, infernè ramosa.

Caulis erectus, dnos ad quatuor pedes altus, angulosus, pilosus, pilis sparsis, glandula viscosa terminatis, subramosus, ramis duobus ad quatuor erectis, raro simplicissimus.

Folı omnia saturate viridia, nitirla, rugosa, utrinque maximè subtus in venis subpubescentia, radicalia septem ad novem uncias longa, dnas ad tres lata, in petiolum angustata, late lanceolata, acuta, et acutè duplicato-crenata, seu subsinuata; caulina alterna, oblonga, lanceolata, acutè crenata, sessilia, amplexicaulia, sensim usque ad spicam decrescentia; suprema ovata, seu subcordata, acuminata.

Spuca terminalis, longissima, laxa: flores inferiores bini, ant terni in siugula bractea, superiores plerumque in qualibet solitarii, omnes breviter pedicellati, pedicellis linean sesquilıneamve longis, calyce brevioribus, pubescentibus. Bráctex alternæ, in loribus spicx infimis formâ foliorum supremormm, denticulatæ, ciliatæ, calyce longiores, ad spica apicem anguste lanceolitie, calyce breviores.

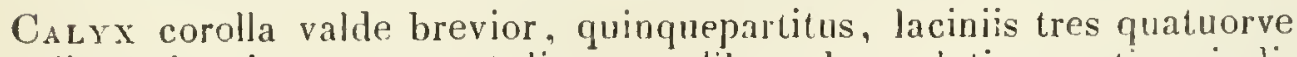
lineas longis, erecto-patulis, æqualibus, lanceolatis, acutis, virıdibus, ciliatis, pilis brevibus, apice glandulosis. Corolla lutea, rotata, tredecim ad quindecin lineas lata, extus subpubescens, iutus ad facem pilis purpureis hirsuta, circuloque purpureo colorata, laciniis rotundatis, inæqualibus, tribus sæpe maioribus.

Stanunu filamenta lutea, corolla dimidio breviora, inæqualia, duo Tom. II. 
alciora, incurva, infernèque tantum villosa, tria alia tota villosa, pilis purpureis: antherx arcuatx, fulva. Pistilli germen ovato-snbrotundum: stylus llavus, glaber, versus apicem crassescens: sligma simplex, obtusum.

Capsula globosa, glabra, lucida, calyce cincla, bilocularis, bivalvis, polysperma, apice dehiscens: dissepimentum duplicatum, ex marginibus valvularmm introrsum flexis formalum. Semina parva, angulo. sa, scrobiculata, utrinque receptaculo centrali, oblongo, fungoso, aflisa.

Hagjtat in collibus et agris circa Conimbricam, item ad Bellas el ex Carnachide usque ad montes de Cintra el alibi in Extremadura et Beira. Floret Junio, Julio. Bienne.

Planta amara et inodora; ejus usus ignolus. Nimis afinis Verbasco blalturice, et quasi illius varietas; differt tamen habitu plus piloso, floribus quamplurimis binis ternisve in qualibet bractea, et pedunculis omnibus calyce brevioribus. Occurrit interdum, etsi rarò. caule simplicissimo; in hortis culta nonnumquam etiam filamento uno minimo sterili, el sic tunc quasi Celsix species. 


\section{LITIIOSPERMUM fruticosum.}

Lıтн. caule frutescente; foliis sublinearibus, integerrimis, margine revolutis, scabris, hispidis; corollis calyce valde maioribus; staminibus longitudine tubi; seminibus lrvibus.

Lusit. Herva das sete sangrias, ou Sargaga hispida.

Lithospermum fruticosum. Lin. Sp. pl. ed. Willd. 1. p.754. La Marck Dict. Bot. Encycl. 3. p. 30. Desfont. Fl. Allant. 1. 1. 156. Brot. Fl. Lusit. 1. p. 292. Link Fl. Lusit, 1. p. 170. tab. 21.

Axcuusa angustifolia. C. Bauh. Pin. 255. Anchusa minor lignosior. J. Baul. Hist. Pl. 3. p. 582 . et Libanotidis species. Id. Ibid. 2. p. 25. Anchusa limnosior angustifolia. Lob. Icon. 578. Anchusa lignosion Monspeliensium, flore violaceo. Barrel. Icon. I/68. Anchusa frutescens tenuifolia, flore caruleo vivacissimo. Grisley Virid Lusit. n. 96.

Buglossum fruticosum Lusitanicum, Lithospermi folio. Tournef. Inst. R. H. 134 Buglossum fruticosun, Rosmarini folio. Id. Ibid. 134. et Garid. Aix 68 . tab. 15 .

Ranix lignosa, fusca, rigida, profunde ramosa, perennis. Caules solitarii, aut pauci, duo tresve ex eadem radice, fruticosi, ex semipede ad pedem longi, sæe subtortuosi, ad basin glabri, nudifoliique, deinde foliosi, hispidi, ramosi ; ramis alternis, hirsutis, longitudine caulis, plus minusve divisis.

Folı alterna, sessilia, angusta, sublinearia, acutiuscula, integerrima, sæpe margine revoluta, ohscure virentia, scabra, hispida; ad exortum ramulorum in axillis ullis plura minora fasciculata.

SpIc $Æ$ terminales, breves, hirsutæ: flores pauci, subsessiles: ad unius. cujusque basin bractea foliacea, ovato-lanceolata, acuminata, hirsula, ciliata, calyce longior.

Caly profunde quinquepartitus, laciniis lineari-subulatis, hirsutis, erectis, persistentibus.

Corolua infundibuliformis, purpurea, seu ex violaceo-cærulea: tubus cylindraceus, extus subpubescens, calyce fere duplo longior: limbus quinquefidus, laciniis ovatis, acutiusculis, patentibus: faux nuda, pervia. 
Staminum filamenta quinque, longiludine tubi corollæ: antheræ fulvæ. Pistilli germina quatuor, glabra; stylus longitudine staminum; stigma obtusum.

Semina quatuor in fundo calycis, albida, aut ex albido cinerea, dura, glabra, lævia, nitida.

Habitat in ericetis, et dumetis sabulosis, præcipue maritimis, frequens. Floret ex Martio ad Junium. Frutex.

Planta insipida et inodora. In pagis ut sudorifera usitata. 


\section{ANCIIUSA Italica.}

Axcr. foliis lanceolatis, integerrimis, hispinlis, superioribus sessilibus; racemis bipartitis, apice recurvis; floribus laxe imbricatis, mo in dichotomiis; squamis faucis corolla pilosis.

\section{Lusit. Lingua de vacca, ou Buglossá do Reimo.}

Axiciusa Ilalica. Retz Obs. 1. pag. 12. Lin. Sp. pl. ed. Willden. 1. p. 756. La Marck Dict. Bot. Encycl. Suppl. toun. 1. p. 735. Trew. Dec. 2. p. 14. tab. 13. Vogel tab. 28. Link. I1. Lusit. 1. p. 175.

Ancuusa officinalis. La Marck Dicl. Bot. Eucycl. tom. I. pag. 502. et Illustr. Gen. tah. 92. Desfont. Fl. Atlant. 1. p. 157. Savi 1'is. p. 204. Gouan Hort. Monsp. 81. Brot. Fl. Lusit. 1. p. 297.

Buglossum. Blakw. tab. 500. Regnaul Bot. Icon. (Buglosse) Sabb. Hort. 2. tab. 24.

Buglossum angustifolium maius, flore cæruleo. C. Bauh. Pin. p. 256.

Buglossum vulgare maius. Joh. Bauh. Hist. Pl. 3. p. 578.

Buglossum vulgare. Grisley Virid. Lusit. n. 233. Raj. Hist. 493.

RADrx oblonga, fere crassitudine digiti, infernè ramosa, extus fusca, intus alba, biennis, aut interdum longius perdurans.

Foura omnia lanceolata, integerrima, acuta, sublucida, hispida, ut tota planta, pilis basi incrassatis tuberculatisque; radicalia el inferiora caulis in petiulum decurrentia, planiuscula, superiora sensim minora, sessilia.

Caulis teres, asper, strigosus, erectus, pedalis usque ad duos pedes altus (raro ultra, nisi in pingui solo, subhumido, unbroso) ramosus; ramis patentibus.

RACEMI terminales, bipartiti, breves, apice recurvi; flores breviter pedicellati, alterni, unilaterales, laxe imbricati, uno in dichotomiis; bractex lineari-subulatæ, pedicellis breviores, superiores sæpe nullæe.

CALYX monophyllus, fere usque ad basin quinqueparticus, lispidus, laciniis lineari-subulatis, subæqualibus, tubo corolla longioribus, aut illius longitudine.
Tonr. $I I$.
$x x$ 
Cololis hypocmeriformis, camlea, aut raro alba; tubus cylinhicus; limbus quinquefidus, butitudine æequalis tubi longjudini, laciniis rotundatis, xqualibus, aut subxqualibus; squanula lacinis oppositæ erectiusculx, pilosie faucemque tubi claudentes.

ST.num filanenta quinque in sumnitate tuhi corollæ, brevissima. Antlerx squamis tecta, oblongiuscula, incumbertes, polline flavo.

Psstum germina quatuor, glabra: stylus longitudine staminum: stigma bilobum.

SEmina quatuor in sinu calycis arcte contenta, ovata, rugosa, Jinc convexa, inde planiuscula, basi insculpla, submarginata.

Habitat in arvis, inter segetes, ad vias, el in collibus incullis circa Olisiponem, Conimbrican, el alibi. Floret vere. Bienuis, el interdim triennis et ultra.

Plaxta inodora, sapore herbaceo, el in omnibus partibus mucilaginosa: ejus tamen mucilago radici manifestior inest. Vires at illx Bo. raginis resolventes, attenuantes, refrigerantes. Flores, etsi olin inter quatuor cordiales enmmerati, hodie obsoleti, nec immerito, nam inodori, nullamque vim nervinam produnt. Herba tenella primo rere pro olere, uti Boraginea, usitata. Qualitate et viribus Anchusx officinali Linnxi, qux in Germania et Europa boreali spontanea crescit, persimilis, ab illa etiam non specificè diflerre diu credita, atque á Botamicis Europx meridionalis pro vero Buglosso vulgari, seu Anchusa officinali vera, habita; demuin verò ex Retzii aliorumque neotericorum observationibıs pro diversa specie stabilita, quatenus scilicet caule altiori, floribus multo minus imbricatis, calycis lacinijs longioribus angustioribusque, corollis cæruleis et patenti lim. bo, ac pracipme ejusdem squamis in fauce barbatis el erectiusculis, nec leviter tautum tomentosis el quasi cucullatis. 
A NCIUSA undulata.

Ancu. foliis lanceolatis, undulatis, obtusè subcrenatis, callosè pilosis, superioribus sessilibus; racemis recurvis, brevibus; floribus unilateralibus, arcte imbricatis; bracteis pedicellos superantibus; calycibus fructiferis inflatis.

\section{Lusit. Buglossa ondeada.}

Ancrusa undulata. Lin. Sp. pl, ed. Willd. 1. p. 757. La Marck Dict. Bot. Encycl. 1. p. 503 . Brot. Fl. Lusit. 1. p. 297. Link Fl. Lusit. 1. P. 177. lab. 22.

Buglossen Lusitanicum Echii folio undulato. Tourn. Inst. R. II. I. p. 134.

Buglossun Lusitanicum foliis asperis, oblongis, angustioribus et crispis. Id. Ibid. p. 131 .

Buglossu marimum elegans. Grisley Virid. Lusit. n. 231.

CAULis sæpe solitarius (interdum nomnulli ad latera capitis radicis crassæ) erectus, decem ad quindecim uncias altus, teretiusculus, pilosus, pilis callo parvo insidentibus, patulisque, foliatus, ramosus; ranis alternis, erectis, omnibus floriferis.

Folu lanceolata, undulata, obtuse subcrenata, et obsolete subsinuata, callose pilosa; radicalia et inferiora caulis in petiolum angusta. ta, obtusiuscula, superiora sessilia, acuta, alterna.

RАсем terminales, breves, apice recurvi. Flores unilaterales, arcte imbricati, breviter pelicellati. Bractex ovato-lanceolatæ, pilosæ, sessiles, podicellis longiores.

CALYx quinquepartitus, laciniis lineari-subulatis, pilosis, corollæe tubo subxqualibus; fructiferus inflatus. Corolla cierulea, aut saturate violacea, quinquefida, iufundibuliformis; tubo exserto; squanis fau. cis breviter floccosis.

Relaqua ut in pracedente. 
Ha Bitat in sabulosis maritimis, ad aggeres, vias, el in arvis collibus. que circa Olisiponem, trans Tagum, circa Scubal et alibi. Floret Februario usque ad Junium. Perennis.

Qualitate et viribus precedenti similis. Variat foliis plus minusve latis et longis, interdumque margine denticulatis. 


\section{Y NOGLOSSUM clandestinum.}

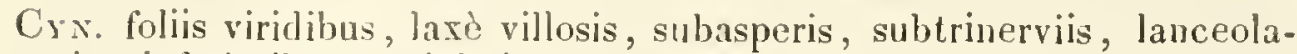
tis, inferioribus petiolatis, superioribus sessilibus basi rotundatis; corolla calyci subxquali; laciniis obtusis, extrì hirsutis, inapertis, antheras squamasque ipsis breviores subtegentibus; nuculis ovatis, polyglochideis.

\section{Lusit. Cynoglossa de flor fechada.}

Crx. clandcstimum, foliis Janceolatis, villosis; corollis calycem xquantibus, apice tomentoso-pubescentibus. Desfont. Fl. Atlant. tom. 1.p. 159. tab. 42. imperf. Item La Marck Dict. Bot. Encycl. Suppl. tom. 2. p. 433.

Çs. officinale, tanquam ejus varietas. Brot. Fl. Lusit. 1. p. 295.

Cynoglossa altera Lusitana. Grisl. Virid. Lusit. n. 427.

$R_{A D I X}$ subfusiformis, supernè crassitudine fere digiti minimi, infernè ramosiuscula, extus nigricans, intus albida; inodora, sapore herbaceo, seu fatuo. Biennis, triennis, rarò ultra.

Fons erecto-patula, lanceolata, acutiuscula, integerrima, semitrinervi-venosa, utrinque viridia et villosa, villis laxiusculis ex miuimis papillis exortis, ideo non mollia, sed scabriuscula; tres ad sex uncias longa, semiunciam ad unciam lata; radicalia et infima caulis sape angustiora, in petiolum longun canaliculatum decurrentia; media et superiora sessilia, basi rotundata, costa subdecurrenti, sursum versus, usque racemorum basin, sensim minora.

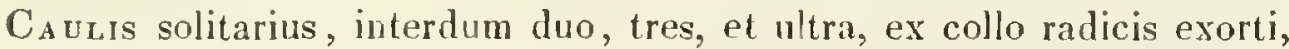
subteres, ex costis foliorum subdecurrentibus obsoletè angulosus, laxè villosus, ex papjillis villorum subasper, erectus, octo ad tredecim uncias altus, sæpe e medio, rarius infra illud, ramosus; ramis alternis, erecto-patulis, racemis terminatis.

Racem uncias tres ad quinque longi, rachi recta, apice recurva. Florum pedunculi solitarii, laxi, ebracteati, erecti, secundi, teretes, villosi, octo ad undecim lineas longi. Interdum unus ad rami racemiferi exortum aliis valde longior, sesquiuncialis.

CAlYX profunde quinquepartitus, laciniis erectis extrà villosis, lanceo. Jatis, obtusiusculis, tres quatuorve lineas in anthesi longis, fere sesTom. II. 
quilineam inferne latis, post anthesin maioribus, ovato-lanceolatis, persistentibus, patulis, nec semina occultantibus.

Corolra infera, infundibuliformis, quinquefida, in anthesi plus minusve clausa, calyci subæqualis Laciniæ viulaceæ, ovatæ, obtusæ, extri et ad margines pilis densis albidis hirsutæ, intus glabræ, tubo duplo breviores, arl ejusdem squamas faucis perseveranter incurvæ, nec unquam perfecte apertæ. Tubus oinnino glaber, albido violaceus, fauce squanis quinque clausus. Squamæ laciniis corollæ oppositæ, ipsis paulo breviores, extìs dilute intus saturate violacer, ad margines villosæ, subovatx, retuse, in faucem tubi arcuatx, cavæ, extra tubum sub laciniis corollæ hiulcæ.

Stam filamenta quinque, in fauce corollæ paulo infra laciniarum fissuras sita, brevissima, vix lineam longa, subulata, glabra. Anthere oblongiusculæ, basi et apice obtusx, subovales, biloculares, lutex, incumbentes, squamarum ferè longitudine, istis arcuatis obtectæ, et in stigma conjunctim conniventes.

Pist. germina quatuor, supera, minima, semiglobosa, lavia. Stylus subquadrangulus, subulatus, exalbidus, glaber, corollæ longitudine, antheris paulo brevior, persistens. Stigma obtusum, subrotundum, obsoletè emarginatum, subviride, marcescens.

Pericarpium nullum.

Semina quatuor, nuculæeformia, evalvia, unilocularia, monosperma, ovata, depressa, latere interiore planiuscula, inde receptaculo subquadrangulo ad styli persistentis basin oblique affixa, latere exterio. re usque ad margines aculeolis quamplurimis, quorum apices uncinis tribus ad quinque terminantur, echinata.

Habitat ad vias, agrorum limites, et in collibus calcareis basalticisque circa Olisiponem et alibi in Lusitania. Floret Februario, et Mlartio. Bienne et ultra.

Differt a Cynoglosso montano La Marck, et a Cyn. officinali Lin., quibus nimis atine, presertim corolla minori, et ejusclem laciniis inapertis extusque nimis hirsutis.

Vares et usus illis Cynog. officinalis similes. 


\section{Y NOGLOSSUM pictum.}

Crx. foliis lanceolatis, deuse villosis, inferioribus petiolatis, superioribus sensin minoribus, subcordatis; corollis calyci subæqualibus, laciniis subrotundo-dilatatis, glabris, apertis, pallide purpureis, ramoso-venosis, venis saturatius coloratis.

Lusit. Cynoglossa de flor listrada.

Crioglossur pictum. Lin. Sp. pl. ed. Willd. I p. 76 1. La Marck Dict. Bot. Encycl. Suppl. tom. 2. p. 431 . Vahl. Symb 2. p. 34. Aiton. Kew. 1. p. 179. Brot. F1. Lusit. 1. p. 196. Link Fl. Lusit. 1. p. 189. tab. 24 .

Crnoglossum Creticum. Villars Delph. 2. p. 457. Allion Auct. 4. Clus. Hist. 2. p. 169. Joh. Bauh. Hist. Pl. 3. p. 600. C. Bauh. Pin. 257. Tourn. Inst. R. II. $1 \cdot 10$.

Cauris teres, pilosus, dense foliosus, erectus, decem ad sexdecim uncias altus, supernè ramosus; ramis alternis, simplicissimis, ere$\mathrm{ctis}$, floriferis.

Fouı lanceolata, acuta, sæpe integerrima, villosa, villis dense appressis, inferiora caulis in petiolum angustata, alterna, approxinata, superiora sensim minora, sessilia, basi subcordata.

R.scem terminales, apice breviter recurvati; flores laxi, inferiores distantes, mediocriter pedicellati. Bracteæ nullæ.

$\mathrm{CALYX}_{\mathrm{A}}$ quinquepartitus, laciniis lanceolatis, hirsulis, patulis, corolla paulo brevioribus.

Corolta glabra, infundibuliformis, breviter tubulosa, quinquefuda, laciniis late rotundatis, pallide purpureis, ramoso-venosis, venis obscurius coloratis: squamæ faucis breviter pilose.

Staminum filamenta quinque, brevissima, squamis in fauce corollx conniventibus tecta. Germina quatuor hirsuta; stylus longitudine staminum, persistens; stigma emarginatum. 
Pericarpium nullum: semina quatuor nuculæformia, ut in præcedente, receptaculo subquadrangulo ad styli basin affixa, extus glochidibus muricatæ.

Habitat in collibus tam cultis quàm incultis circa Olisiponem, Conimbricam et alıbi. Floret Martio, Aprili. Sæpe bienne.

Planta nimis affinis Cynoglosso officinali, et ipsi qualitate et viribus omnino similis. 
RUBIA silucstris.

Kub. foliis perennantibus, senis, quinis, nounullis quaternis, lanceolatis, vel lanceolato-elliptıcis, margine carinaque asperrimis. superiori pagina lucidis, ibnque nervo medio laevi ant sublavi; canle frutescente, longo, scandente, prope radicem tereli, inde sursum acute quadrangulo, angulis aculeatis; corolis sæepe quinquepartilis.

\section{Lusit. Granza brava, Ruiva brava, ou Raspalingua.}

Rubia silvestris. Brot. Fl. Lusit. 1. p. 153.

Rubia tinctorum silvestris? Lin. Sp. pl. ed. Willd. I. p. 603.

Rubia silvestris Monspessulana maior? Joh. Bauh. Hist. pl 3. p. 715.

$R_{A D l x}$ perenuis, teres, primis annis temuis, seu crassitudine pennx gallinacex, postea seusum crassior ramosa, longe reptans, geniculata, geniculisque fibrata, flexibilis, cortice succosa el ex viridi flavescens, intus lignosa. luteola seu rufa; sapore subamaro, acriculo, et levissine adstringente.

Cacles plures, alii ex capite primordialis radicis, alii ex reptantibus, debiles, scandentes, tres ad octo pedes longi, infernè exallidi, teretes, nudifolii, supernè virides quadranguli, angulis acutis retrorsum aculeatis, nodosi, é nodis foliosi et ramosi; ramis patentibus, sæpe oppositis, nonnullis alternis solitariis, raro tribus el ultra subverticillatis.

Fond verticillata, in geniculis inferioribus sena, quina, perpanca septema, in superioribus nomulla quaterna, sessilia, dura, rigida, lanceolata, ovalia, seu lanceolato-elliptica, apice mucrone minimo terminata, margine leviter revoluta, ibique et carina aculeolis recurvis scabrata. payina superiori saturate virulia, lucida, sæpeque omnino lavia, nommila tamen ibique in nervo intermedio interdum uno aliove aculeulo minimo el fere obsoleto iustructa; onnia plus ultra unum ammum viva persistunt; qua maiora sesquiunciam ad uncias duas longa sunt, et tres ad quinque lineas in medio lata; superiora caulis et ramurum sensim nimora.

Flores paniculati; paniculx axillares et terminales, breves, sæpe trichotonis; pedunculis quadrangulis, levibus. Folia Roralia aliis foliis forma similia, sed valle minora, el utrinque lavia; inleriora quater. na seu terna, superiora biua opposita.

lon!. II. 
Calsx vix ullus, seu margo minima obsoleté quinquedentata. Corolla parva, flava, monopetala, absque tubo, subrotata, quinquepartita, Jaciniis jatentibus, ovato-lanceolatis, apice unguiculatis.

Stamiru filamenta quinque subulata, pallida, corolla inserta, illaque breviora: anthera simplices, flava. Pistilli germen inferum, sæpe didymum, subturbinatum; stylus longitudine staminum, supernè bificlus. Stigmata subcapitata.

BACCE dux, in formam obovato-subrotundam coalitx, glabra, nitidre, nigra, silcco rubro farctx: semina in utraque solitaria, subrotunda, umbilicata, quorum unum sape abortat, aut interdum ambo.

Habitat in collibus incultis, dumetis, atque ad sepes in tola fere Lusitania. Floret. Maio, Junio, Julio. Frutex.

Nonnulu flores variant corolla laciniis quatuor totidemque staminibus. Radicis qualitas, vires medica, ef eflicacia, ossa, lauas liquidaque tingendi, illis radicis Rnbia tinctonum stive siniles, etsi aliquantulum debiliores: bacca ad vina coloranda usilata.

Planta nimis aflinis Rubix tinctorum sative necnon Rubie frution$s a$. pereyrince, angustifolia et hudar recedit tamen a $R$ ub. tinct. sativa caule anmuatim non arescente, sed multos per annos virescente et in eis foliifero, florifero; foliis perennantibus, minoribus, plus rigidis, saturate viridibus, lucidioribus, et nervo medio pagina superioris interdum non omnino lavi: discrepat a fruticosu caule debiliori et floribus paniculatis: á pereyrina foliis non linearibus, plurimis non quatemis, sed quinis senisve, et caule debiliori: ab angustifolix foliis non anguste linearibus, monnullis senis, nec valde scahris ullis in medio nervo pagina superioris et ejus lateribus: differt tandem a Incida caule non lævi, et foliis carinà scabris. Attamen he differentiæ non tam firma quàm existimantur; sunt enim plus iniususe rariabiles, sive culurà, sive mutato solo, situ et climate, ideoque omnes istx p'anta Rubre silvestris potius varietates, quàm verse spe. cies ab illa sat!s distmctie esse videntur. 


\section{A CARNA gummifera.}

Ac. foliis oblongis, pinnatifido-sinuatis, laciniis inæqualibus, dentatospiuosis; capilulo sape solitario, scapum brevem subterraneum lerminante; foliolis calycis exterui laxis, fero oblanceolatis, margine spinosissimis, apice tricuspidatis, interni supremis apice longe acuminat is, ibique setaceis, coloratis, flosculorum longitudine.

Lissit. Carlo do visco, Carlina gommosa, Cardo pinto yommoso, ou branco (ex Laguma), Curdo malacäo (ex Grisley).

Acs RNA gummifera. Lin. Sp. p!. ed. Willd. 3. p. 1699.

Cirsellium gummiferum. Brol. Fl. Lusit. 1. p. 346.

Atractrus gummifera Lin. Sp. pl. 1161. Miller Dict. n. 3. Desfont. Fl. Atlant. 2 p. 252. Cavan Icon. 3. p. 14. tab. 228.

Cartuames gummiferus. La Marck Dicl. Bot. Encycl. 1. p. 639.

Carluxa acanlos gummifera. C. Baul. Pin. 380. Shaw Afr. p. 114. Morandi Hist. Bot. p. 147. tab. 67,

Cnicus Carlinx folio acaulos gummifer aculeatus. Tourn, Coroll. 33.

Cuameleon albus Dioscoridis. Fab. Column. Ecphr. 1. p. 1. tab. 12. I.aguna in Diusc. lib. 3. p. 269. Grisley Virid. Lusit. n. 321. Jol. Bauh. 3. p 67.

CarduUs pinea Theophrasti. Alpin. Exot. 126. tab. 124-25.

RaDix profunde penetrans, perennis, primis annis supernè pollicem crassa, annosa vero, prosertim in solo pungui, brachii et demum fere fenoris crassitudiue, sesquipedem ad tres peles longa, infernè ramosa, extus é viridi rufescens, intus alba, lactescens, succo in grumulos ob viscositalem concrescente, non injucundè odora, sapore subdulei.

For,a omnia in orbem procumbentia, octo ad quindecim uncias longa, tres quatuorve lata, pinnatifido-sinuala, laciuiis subundulatis inæqualibus, inaqualiterque dentals, dentibus spinosis, rigida, supra virilia, tomentosa, subtus hirsuta, albicantia; petioli canaliculati, diu persistentes. 
Scapus prinis annis, radice adluac parum crassa, solitarius, brevissimus; illa vero amosa el valde crassa, duo ad quinque, subteretes, leviter angulosi, nonnullis squamis oblongis, inermibus, alternis, distantibus, instructi, tres ad quinque uncias longi, omnes subterranei, apice extra terram floriferi.

FLores capitati; capitula sesquiunciam ad uncias duas cum dimidia lata, mam ad fere duas alta, hracteis obvallata imbricatis, oblongis, squamiformibus, acutiusculis, nervosis, aliis margine spinosis, inermibus aliis.

CALYX duplex; exterioris foliola laxa, rigida, tomentosa, sesquipollicaria, bipollicariave, fere oblanceolata, apice tricuspidata, recurva, marginibus spinosissina, spinis paluatis; calyx interior cylindricus, illius squama sursum sensim longiores, imbricatx, linearisubulatx, rigidula, maroinihus inermes, extus incano-lanatx, intus glabræ, inferiores sela rigida pungenti lerminatæ, superiores et intimi ordinis antustiores, longus acuminate, apice extus et intus purpureo-coloratx, atque in selam mollen, recurvam, disci flosculis sequalem aut vix paulo longiorem, abeuntes.

Corollule omnes infundibuliformes, hermaphroditæ, violacex, aut purpurex, tubo tenui, longo, limbo quinquefido, lacinis aqualibus, erecto-patulis.

Stamxum filamenta quinq̨ue, brevi-sima, collo corollulæ inserta. Antheræ in cylindrum tubulatum, dilute violacemn, coalit:e, corollula laciniis breviores ant aquales, infernè quinquecaudatæ: grana pollinis pellucida, stigmatis villis glomeratim applicata.

Pistilt germen breve, obsolete angulosum, sericeo-viride, apice pilis rigidulis coronatum, et quasi calyculatum. Stylus antheris brevior. Stigma violaceum, non articulatim, oblongum, teres, rigidum, subvillosum, apice bifidum inapertum, exertam, corollula liciniis swe paulo longrius.

Semixa solitaria, oblonga, obsolete tetragona, villis scriceo-viridibus tecta, eisdencue supra verticem productis coronata; omnia sæpius $a b$ insectis infestata et sterilia reddita. Pappus sessilis, per maturitatem deciduus, multiradiatus; radiis basi subpaleaformibus, ibique cuhærentibus, seminis coronà pilosâ obvallatis, ramosis; ramulis capillaribus, plumosis. candidis, et floscnlorm longituline. Receptaculum planum, leviter alveolatum, carnosum, paleaceum; paleis longitudine fere calycis interni, latis, albis, Jucidis, hinc concavis, inde carinatis, rigidis, valde approximatis, supernè setaceo-multilidis; his immixtæ sunt alix nimis angustæ et quasi setiformes, necnon et alterx capillares longx, qux latiorum palearum nervi laterales, ab eis separati, esse videntur.

Habitat in locis incultis soli ardenti exposilis, praesertim in collibus 
calcareis circa Conimbricam, Olisiponem, et alibi in Beira, Extremadura, 'Pranstagani et AJgarbiis. Floret astate, et antumno foliis jan exsiccatis, qua hyeme renascuntur, et usque ad Julium virent. Peremnis.

HÆC species Carlinis valde affinis; sed ab eis præsertim differt calycis squamis intimis nosculormu longitudine, aut vix paulo longioribus, el flosculorum receptaculo nullis setis clavatis instructo. Male igitur a nonnullis autoribus cum Carlina acauli confusa est, quxe nuspiam in Lusitania occurrit, et abunde diversa.

Ex collo radicis, foliis et flosculorum receptaculo effuit gummi quoddam sui generis, insipidum, pallide flavum, quod ipsis adharet: illud aucuparii colligunt, cum pice miscent, et viscum ad aves capiendas parant. Radix tenera, uti etian fosculorum receptaculum, aqua ebulliente cocta, edulis: ejus usus medicus, de quo Dloscorides, exoletus. 


\section{B A IS A IIIT A amma.}

B. foliis pubescentibus, radicalibus nonnullisque infimis bipinnatis, canlinis confertis, pinnatis, quinquefidis aliis, trifidisve; pinnulis et Jaciniis linearibus, acutis; ramis supremis caule longioribus; floribus terminalibus, arcte corymbosis.

Lusit. Joina las searas, Macella fedegosa, Macella gallega mrada.

Balsamita amua. Decand. Flor. Franç. vol. 4. pag. 187.

Tanacetum amuum. Lin. Sp. pl. ed. Willd. vol. 3. p. 1812. Ia Marck Dict. Bot. Encycl, tom. 7. p. 573. Gouan Illust. 66. Royen Lugdb. 155. Vaill. Act. 1716. P. 281 . Brot. Fl. Lusit 1. p. 354.

Helocurysum foliis abrotani. C. Bauh. Pin. 264. Heliochryson quorundam folio abrotani. Joh. Bauh. Hist. pl.3. p. 150 . cum Icon. Pluken Phyt. 160. f. 1. Elichryson Dodon. Pempt. p. 267. Icon. Elicliryson Clus Hist. 1. p. 325 . tab. 326. Heliochrysum Clusii Grisley Virid. Lusit. n. 709. Eliochryson Laguna in Dioscor. lib. 4. cap. 58.

Saxtorna corymbis simplicibus, foliis linearibus, confertis. Miller. Icon. p 152. tab. 227. fig. I.

A esinthium Corymbiferum annum.

Tourn. Inst. R. H. 458.

$R \wedge \mathrm{DIX}$ superne pennx anserinx aut fere digiti ninimi crassitndine, ibique lignosa, valde fibrata.

Caulis solitarius, erectus, pedalis ad bipedalis, teres, striatus, Jeviter hirsutus, foliosus, valde ramosus; ranis alternis, erecto-patulis, suprenis caule ejusque corymbo longioribus.

Fon a omnia pubescentia; radlicalia, et imlina monnulla caulis, bipinnata, caulina el ramea alterna, approximata, conferta, pinnata, aliqua quinquefida vel trifida, basi stipulata; pinnulæ et laciniæ lineares, acutæ, breves, angustr, excavato-punctatæ.

Fiores caulem et ramos terminant, dense corymbosi; corymbo caulino maiori, ramosiori, floribus triginta ad quadraginta composito.

CaLyX communis hemisplaxicus; squama adpresse, imbricatx, inte- 
riores longiores, intus concavæ, nervo dorsali virentes, apice dilata. t: obtus , lutex, radium brevem corollularen mentientes.

Corolrul E tam radii quìm disci ommes hermaphroditx, uniformes, tubulosx, quinquedentatx, lutex, calyci subxquales ant illus longituline. Stamina quimque: anthers luteæ, in cylindrum coalita, corollulà breviores. I'istilli germen parvuın, oblongiusculum, striatum, membranulà minimà coronatum: stylus antherarum longitudine: stigmata duo tenuissima, exerta, demum corollula paulo longiora.

Senuna plurima, oblonga, ad apicem paulo latiora, præesertim illa radii; omnia glabra, striata, margine brevissimo membranaceo denticulato coronata. Pappus nullus. Receptaculum convexo-subconicum, nudum, excavato-punctatum.

Habitat in solo raro et inter segretes ex Alcobaça usque ad Olisiponem, et alibi in Extremadura. Floret xslate, et nonnumquam in autumno, folis jam exsiccatis. Annua.

Planta graveolens el amara. Eliochrysi Dioscoridis aliorumque Veterum medicas vires ei nonmulli Recentiores adscrihuerunt, nune támen penitus exoleta, nec in pagis, ut olim, pro Anacyclo aurco Lusitanis usilata.

Oвs. Obcalycis foliola intina colorata, radii fæmineas corollulas ligulatas effingentia, Tenacetis immista esse solet, sed falsa, namque ab eis re vera differt flosculis omnibus hermaphroditis. Ab A thanasiis, qui. bus affinis, etiam diversa receptaculo nudo, nec paleaceo. Ad eam Tanacetum pilosum (Berg. Plant Cap., et La Marck Encycl. Meth.) specificè nimis accedit, et vix diversum; synonyma saltem, Capensi ibislem applicata, ad hane nostram amandanda. 


\section{A N A C Y CL US aureus.}

An caulibus erectiusculis, villosis, ramosis; foliis pubescentibus, bipinnatis, extremis pinnatis; foliolis brevibus, subsetaceis, excavato punctatis, mucronatis; pedunculo terminali, longo, nudifolio, unifloro; disco flosculorum valde elato, semiovali.

\section{Lusit. Macella gallega vulgar.}

Anacrelus aureus. Lin. Sp. ph. ed. Willd. tom. 3. p. 2173. La Marck Dict. Bot. Encycl. tom. 1. p. 141. Brot. Fl. Lusit. J. p. 363.

Chamenelum luteum, capite aphyllo. C. Bauh. Pin. 135. Tourn. 494.

Ciramamelum aureun peregrinum, capite sine foliis. I. Bauh. Hist. pl. 3. p. 119.

Chamenelum capite nudo vulgare. Grisley Virid. Lusit. n. 322.

Aктnemis Chrysanthemum herbariorum. Lob. Icon. 771.

RADIx dura, fibrata, crassitudine pennæ gallinaceæ, aut paulo ultra. Caules nonuulii ex capite radicis, graciles, substriati, exalbido-pubescentes, supernè subvirentes, omnes foliosi, sæpe plus minusve ex declinatis erecti, tres ar sex uncias longi, iuterdum tamen, præsertim in subhumidis, aliquantum longiores, infernè ramosi aut subranosi, ramis alternis, erectiusculis.

Forra alterna, pubescentia, villis decumbentibus, radicalia et infima caulis bipimala, suprema pinnata; foliolis virescentibus; brevissimis, terectiusculis, subsetaceis, excavato-punctatis, mucronatis, infunis petioli communis stipularibus.

Pedunculi terminales, solitarii, setacei, substriati, subpubescentes, aphylli, erecti, sesquiunciam ad tres fere uncias longi, uniflori. Flos discoideus; disco valde convexo, demum semiovali.

CALYX hemisplhæricus; squamæ imbricatæ, exteriores paucæ acutinscula breviores, alixe oblongx, obtusæ, omnes tomentosx, marginibus et apice scariosæ, planiusculæ, nervo dorsali subviridi, aut interdum lutescente.

Coroldulæ hermaphroditæ, numerosæ in disco, omnes luleæ, infundibuliformes; tubo compressiusculo; limbo quinquefido, paleis rece- 
placuli paulo longiore. Frunere pancas in ambilu, squamis calycis et receptaculi paleis paulo breviores; tubo, seu potius ungue, comjresso, conplanato, late marginato, exalbido, incurvo, apice introrsun ab exeuntibus stiumatibus brevissime fisso; limbo ligulato, seu potius proprie tali mullo.

Stamina in hermaphroditis quinque; antherx lutex, in cylindricum coalitx, sxpe inclusx: in fxmineis stanina penitus nulla.

Pistila germen inferum; in hermaphroditis breve, fere obovatum, virescens, glabrum, compressiusculum; stylus brevissimus; stigmata duo crassiuscula tarde exerta. Famineis germen simile, sed minns; stylus longas; stigmata duo, crassa, lutea, ocissinè exerta.

Semina plurima, paleis receptaculi breviora, glabra. striata, subangulata, sed non alata, quasi obovata, apice obtusa, nuda; nommulla abortiunt. Omnibus papp!ss nullus. Receptaculum alte et acute conicum, punctatum, paleaceum : palese oblongx, concavæ, lateribus el apice scarısx, oblusx cum acumine, vel inordinate subdentatx, sensiun versus receptaculi apicem breviores

Haвıтат sæe in locis sublumidis, at rivulorum, agrorumque margines in omnihus fere Lusitaniæ provinciis. Floret Maio usque ad $A$ ugustum. Annuus aut biennis.

Planta graveolens, anıara et apud Lusitanos frequentiìs, quàm Anthenides, quibus vi medica similis, usitata. Nimis affinis A nacyclo Cretico, sed foliis villoso-virescentibus, nec valde incanis, eorum laciniis, seu foliolis, leretiusculis, nec planis, et aliis nonuullis notis diversa. Nec confundenda cuns Cotula aurea et Santolina anthemoide, quibus habitu similis esse videtur; a prima enim receptaculo fosculorum paleaceo, á secunda verò flosculis fæmineis satis diflert. 
I N UL A viscosa.

Ix. foliis lanceolatis, serratis, utrinque piloso-viscidis, basi reflexis, semiamplexicaulibus; caule ramisque foliosis, supernè racemiferis; pedmenlis axillaribus terminalibusque simplicibus, fere omnibus unifloris, pancis billoris.

Lusit. Taguedu de Dioscorides.

Invla viscosa. Lin. Sp. pl. ed. Willd. tom. 3. p. 2095. Desfont. Fl. Allant. 2. p. 274. Ait. Kew. 3. p. 223. Decand. Synops. Pl. Gall. p. 281 . et Fl. Franç. vol. 4. p. 153.

Erigeron viscosum. Lin. Sp. pl. vol. 2. p. 1209. La Marck Dict. Bot. Encycl. torn. 3. 1) 478. Gouan Illustr. 67. Miller Dict. n. 1. Jacq. Hort. tab. 165.

Solıdago viscosa. Brot. Fl. Lusit. 11. p. 381 . La Marck Fl. Franç. vol. 2. p. 144.

VIRGA aurea maior, foliis glutinosis graveolentibus. Tourn. Inst. R. H. p. 580 .

Conyza mas Thoplirasti, inaior Dioscoridis. C. Bauh. Pin. 265. Conyza maior Monspeliensis odorata Joh. Bauh. Hist. PI. 2. p. 1055. Icon mala. Conyza maior vera Dioscondis. Grisley Virid. Lusit. n. 390. Conyza inaior Dodon. Pempl. 51. Clus. Hist. 2. p. 20. Conyza capitata seu globosa. Bocc. Sic. 14. tab. 7. Moris. Oxon. Hist. 3. p. 114. @. . tab. 20. fig. 14.

R I Dix crassa, lignosa, ramosa, quotannis novos pluresque caules proferens. Caules erecti, stricti, pedales ad bipedales et ultra, teretes, substriati, piloso-viscidi, foliosi, infernè per aliqnot annos sæpe persistentes, et quasi suflrulicosi, valde ramosi; ranis alternis, approximatis, longis, erectiusculis, follosis ex foliorum axillis, supernè et interdum ex medio ad apicem, floriferis.

Folı caulina el ramea alterna, approxinıata, é viridi pallescentia, lanceolata, serrata, acutiuscula, venosa, subrugosa, sessilia, semiamplexicanlia, lateribus basilaribus reflexa, utrinque piloso-viscida, pilis lente visis articulatis basique glandulosis; inferiora tres nncias et ultra longa, uncian ferè lata, versus apicem caulis et ramorum sensim minora, suprema nonmulla interdum obsoletè serrulata, aut integerrima. 
Fuores racemosi; racemi caulem et ramos terminant: pedunculi alii terminales, axillares alii, alterni, parìn distantes, solitarii, filiformes, breves, subvillosi, striati, in longitudinem aplyylli, aut uno aliove brevissimo fóliolo instructi, simplices, uniflori, pauci biflori, vix ulli noununquam triflori.

CAнух glabriusculus, cylindraceus, squameus; squamis imbricatis, subvirentibus, rectis, linearibus, angustis, acuminatis, inæqualibus, gradatim longioribus, internis laxinsculis, omnibus in plena seminnm maturitate reflexis.

Cororta composita radiata, lutea: corollulx hermaphroditæ plurimx in disco, infundibulilormes, quinquedentatæ; fæminex in radio septem ad decem, lignlatæ, lineares, sesquilineam ferć latx, longx, anice tricientatæ, patentissima.

Stamend filanenta in hermaphroditis quinque, capillaria, brevissima: antherx quiuque, lutex, in cylindrum tubulosum coalitæ, singula basi desinentes in setas duas filamentis breviores, supernè semiexertæ. Fæmineis stamina penilus nulla.

Pistilli germen in hermaphrodilis subleres, suhpubescens; stylus unus; stigmata duo, exerta In fxmineis germen simile, stylus unus longus; stigmala duo revoluta.

Semina plurima, oblongiuscula, subteretia, scabra, subpubescentia. Pappus sessilis, longus, subrufescens, capillaris ; pilis lẹnte visis denticulato-ciliatis, seu subserratis. Receptaculum planum, glabrum, excavalo-punctatum.

Hamitat in solo sicco, ad radices collium, et aggeres circa Olisiponem, Conimbricam et alibi in Extremadura et Beira. Floret æstate et autumno. Perennis et quasi suffrutex.

Planta amarinscula, acris, graveolens. Pro Conyza maiori Dioscoridis a nonnullis Botanicis habita, ei viribus similis credita, et olım pro tali nsitata; nunc tamen exoleta Ninis affinis speciebus Solidaginis et Erigerontis; sed antheris in setas decem infernè desinentihus ab illis differt, alque In'lis magis affinis; quapropter istis potius quam illis associari debel. 


\section{PENTANTHERIA DISTYLIA.}

\section{CUSCUT A Europea barbuvea.}

Cusc. caulibus tenuissimis, seliformibus, glabris, ramosissinis, supra racemos viteos innatis incretis, indeque longissimè pendulis; glomerulis florum sessilibus, perpaucis, uno aliove tantum ad ranorum alas superiores.

Lusit. Barba das uvas, ou Fiadeira das barbas dos cachos.

Cuscuta. C. Banl. Pin. 219. Cassuva, sive Cuscuta. Joh. Baub. Hist. PI. 3. p. 266 . (ut varietas.)

Cuscuta Europaca (ut varietas) Lin. Sp. pl. ed. Willd. tom. 1. p. 702. La Marck Dict. Bot. Encycl. 2. p. 229.

CAUlis e radice seminis, quod vere novo intra racemum viteum germinare fortè contigerat, tenuissimus, setiformis, virescens, glaberrimus, primùm linc inde parce ramosus, sese racemi pedunculis circunvolvens, adhærens, radiculis papillaribus exugens, et quamplurimos illius flores omnino steriles reddens; sub racemo postea ramosissimus, duos ad tres pedes longus, ramis distantibus, sæpe dichotomis, inter sese late implicatis, omnibus pendulis, et sic tandem racemo naturo latam longissimamque barbam effingentibus.

Fous nulla, sed sub singulo ramo squama ovalis, membranacea, plus minusve sesquilineam longa.

Flores conglomerati; gloumeruli sessiles, pauci, duo tresve in alis superioribus aliquorum ramorum; nulli verò in omnibus inferioribus axillis. Sub quolibet glomerulo bractea solitaria, squamis ramortin axillaribus similis.

CALYX rubellus, cyathiformis, quinquefidus, in perpancis floribus quadrifidus, laciniis obtusinsculis, ad basin carnosis.

Corolla monopetala, albida, quinquefida, in paucis floribus quadrifida, laciniis acutiusculis, calyce paulo longioribus.

Stamina quinque, in perpancis floribus quatuor, corollà breviora; ad eorum basin squamula totidem nectarifere, corollx basi adnata, lineares, bifidx. 
Pistilli germen subrotundum. Styli duo breves. Stigmata simplicia.

Capsula parva, globosiuscula, calyci ad dimidium ferè immersa, infra medium circumscissa, bilocularis, loculis dispermis. Semina subglobosa, dissepimento prope basin affixa; illorum albumen centrale, carnosunı ; plantula seminalis tenuissine filiformis, spiralis, circa albumen convoluta, ex Linnæo acotyledonea, at ex Adansonio et Gaerinero inonocotyledonea, qualis etiam nobis esse videtur.

INNASCI et succrescere solet nonnunquam in racemis Vitis vimiferce, in Carnachide, Sete-Rios, et alibi circa Olisiponem. Floret æstate. Annua.

Varietas Cuscutæ vulgaris Europere est, quæ rarissime ac tantìm in aliquo racemo altiori $V$ itis viniferce alte cantheriatæ, non verò in aliis racemis, nec alibi in ejusdem ramorum aut caulis cortice occurrit. Nonnulli agricolæe eam ex seminibus maturis Cuscutæ vulgaris, quæ in plantis vicinis increverat, a vento adductis vel ab avibus pulveratricibus supra racemos altiores in anthesi excussis, exortam esse credunt, nec ejus radicem ibi post germinationem tunc arescere, ut in terra solet, sed vigescere et ramusculos ferre autumant. Inodora planta est, acriuscula, sed nil amara, nec adstringens, fortasse racemi causa, cui adhæret; vis itaque ipsius debilior, quam illa Cuscutæ vulgaris, quæ etsi apud veteres nimis usitata, nostro tamen tempore exoleta et superflua. 


\section{ER Y NGIUM amethystinum dilatatum.}

ER. foliis spinosis; radicalibus longioribus, infernè subpinnatis angustioribus, apice dilatatis, inæqualiterque laciniatis; caulinis pinnatifidis, sensin brevioribus; involucello hexa-decaphyllo, foliolis sublinearibus, margine et apice spinosis, capitulo parum longioribus, basi setis obvallatis; receptaculi paleis simplicibus, calycem requantibus, aut vix longioribus.

Eryxana dilatatum. Brot. Fl. Lusit. 1. p. 415. La Roche Hist. Eryng. tab. 4. La Marck Dict. Bot. Encycl. tom. 4. p. 755. Poiret ejusd. Suppl. tom. 4. p 288, ati varietas (b) scquentis.

Errngita amelhystimum. Lin. Sp. pl. ed. Willd. tom. 1. p. 1359. (b) Eryngium minus trifidum Hispanicum. Barrel. Icon. 36. Bocc. Mus. 1ab. 71 .

Eryngum anethrstinum Lusitanicum minus, longiori folio.

Tourn. Inst. R. H. p. 327.

Eringium minus montanum, flore cæruleo pulchro.

Grisley Virid. Lusit. n. 478.

$R_{A D r x}$ extus fusca, ad collum crassitudine fere digiti minimi, ibique squamis inbricatis cincta, infernè subramosa, perennis.

CAuls solitarius, aut duo, tres ex eadem radice, teres, striatus, glaber et carmleus, ut tota planta. erectus, quinque ad tredecin uncias allus, foliatus, supernè subramosus, ramis alternis, brevibus, aliis unifforis indivisis, aliis vix divisis bifloris triflorisve, supremis sape tribus quatuorve subverticillatis, mmbellan fornantibus.

Foma omnia spinosa; radicalia in orbem posita. sape tres uncias longa, petiolo prælongo supputato, infernè suhpinnata, supernè valde dilatata, ibique laciniata, lacinis rigidis, subcuneatis, inxqualibus, inæqualiterque dentatis, dentibus spinosis; caulina alterna, pinnatificla, valde minora, sensim versus apicem caulis decrescentia, sub ranis tripartita, sicut sub umbella, ubi opposita vel subrerticillata sunt. Peliolus in utrisque sublinearis, planus, infernè usque ad basin setis rigidis pungentibus ciliatus.

Umbella caulem: terminat: radii sxpe tres, quatıorve, teretes, striaii, patuli, triflori, aut biflori. Flores capitali: capiulum latum, convexum, seu hemisphæricum, croleum. Involacellum polyplaylum, 
foliolis patulis, sex ad decem, lineari-lanceolatis, margine et apice trifurco-spinosis, capitulo aliquantum longioribus; ad eorum basin seta nonnullæx, rigidæ, pungentes, reflexiusculæ, interjectæ sunt.

Calsx superus, quinquedentatus; dentibus cæruleis, subulatis, mucrone setiformi, spinuloso, terminatis, erectis, corolla longioribus. Corolla pentapetala; petalis cærulescentibus, profunde emarginatis, apice valde inflexo. Stamina totidem, filamentis exertis; antheræ oblongæ, biloculares. Pistilli germen obovatum, striatum: styli duo capillares, longitudine staminum: stigmata simplicia.

Fructes calyce coronatus, bipartibilis: semina duo obovata, hinc pla. na, inde convexula, striata, exasperata, quorum nnum apice triden1atum, bidentatum aliud, utrunque marginibus subciliatın. Recejaculum subconicum, paleaceum; paleæ sublanceolatx, canaliculate, marginibus integerrims, apice simplices, mucronatæ, pungentes, calyci æquales aut vix longiores.

Habitat in collibus calcareis circa Olisiponem, Conimbricam, el alibi in Beira et Lxtremadura. Florel astate. Perenne. Planta nimis aftinis Eryngio amethystino, et potius illius varietas, quàm distincta species esse videtur.

Usus ignotus. 


\section{SELI N U M peucedanoides.}

SEL. caule tereti, striato; involucro universali reflexo; umbellæ radiis - $l a b r i s$, seminibus ovali-subrotundis, dorso quadrisulcis et obtuse quinquecostatis; foliis radicalibus bipinnatis, superioribus pinnatis; foliolis omnium oblongis, angustissimis, sublinearibus, integerrinis, acutis.

\section{Lusit. Bruco.}

Laserpitium peucedanoides. Brot. Flor. Lusit. 1. p. 428.

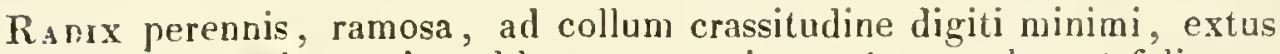
fusca, amarula, acris, sublactescens, sicut etiam caules, et foliorum petioli.

CAULES annni, sæpius plures ex eadem radice, erecti, sesquipedales, bipedales et ultra, teretes, leviter angulati, subsulcati, glabri ut tota planta, ferè dichotomi; rami alterni, pauci, distantes, erecti, striati, simplices, inferiores vix subdivisi, et sæpe altiores.

Forla viridia, petiolata; radicalia bipinnata, pinnis oppositis, infimis longiùs petiolatis, sicque circumscriptione triangularia; caulina alterna, pinnata, suprema ternata simpliciave; folioli oppositi, sessiles, ultimi laterales brevissimè confiuentes, omnes sublineares, seu lineari-lanceolati, acutiusculi, integerrimi, venosi, utrinque glabri, oblongi. angusti, lineam ad lineas duas in medio lati, unciam ad uncias duas et ultra longi. Petiolus communis subteres, striatus, snprà leviler canaliculatus, basi latè membranaceus, vaginans; in foliis radicalibus longior, in caulinis sensim proportionalicer brevior.

UMBell $x$ caulem et ramos terminantes. Involucrum universale polyphyllum. foliolis quatuor ad septem, sublinearibus, subrqualibus, acuminatis, virescentibus, glabris, umbellâ valde brevioribus, reflexis, sxpe caducis: partiale etian polyphyllum, foliolis angustioribus, plus numercsis, forma similibus, inæqualibus, longioribus, umbellulam xquantibus, reflexis.

UMBELLA universalis plana, aut interdum subconvexa, radiis septem ad tredecim, inxqualibus, laxis, striatis, glabris; partiales planiusculæ, radiis tredecim ad viginti et ultra, inæqualibus, longioribus tres lineas fere longis. Flosculi centrales plurimi abortivi.

CALYX obsoletus. Corolla pentapetala; petalis minimis, xqualibus, inflexo-emarginatis, intus albis, exius ante explicationem purpurascen. tibus. 
Stanxum filamenta quinque, patentia, petalis longiora: antherw subrotuntae, lutex demum exalbidx. P'istilli germen inferum, obovatum, striatum; styli duo brevissini, paluli; stigmata oblusa.

Fructus bipartibilis, glaber. Semina duo, compressa, hinc plana, inde convexula, ovali-subrotunda, apice integro stylis persistentibus coronata, marginibus alato membranacea, dorso quinquecostata, costis omnibus obtusis, tribus interioribus plus elevatis, inter costas quadrisulcata; hi sulci immaturis in seminibus, lente visi, interdum brevissime alati sunt, sed alx demun in eormm plena maturitate omnino disparent; ideo a Laserpitiis seprarandun.

Habitat in dumetis uliginosis, ad rivulos, pratorum margines, et in aliis locis humidis, tan in Beira quim in Extremadura et Transtagana. Floret xstate et antumno. P'eremis.

Planta acris, subamara; pecori tamen non ingrata esse fertur. In Extremadura ejus foliorum siccorum infusum aquosum, instar Thex, in renum aflectionibus calculosis el aliis, interdum eflicaciter adhiberi solet. In Beira radix á rusticis pro masticatorio, loco Pyrethri, ad salivan ciendan doloresque dentium exinde sedandos, pari efficacia usitata. 


\section{A U C US halophilus.}

D. caule striato, hispido, pilis reiroversis; foliis radicalibus et infinis bipinnatis, foliolis ovatis, villosis, inciso-dentatis, dentibus obtusis; involucri foliolis pinnatis, involucellormm externis tridentatis, internis indivisis; umbella densa, subradiata, alba, flosculo centrail alrorubente; seminum aculeis apice radiatim giochidiferis.

RADIX alba, dura teres, supernè ad collum fere digiti minimi crassitndine, infernè interdum subramosa: sapore el odore ut illa Dauci Carute silvestris.

Cauls sæpe solitarius, raro duo, tresve ex eadem radice, pedalis aut sesquipedalis, teres, striatus, hirtus, pilis numerosis retroversis, ereclus, subtortuosus, paucirameus.

Folra omnia petiolata, circumscriptione triangularia; radicalia et infima bipinnata, pinnis primariis oppositis, superiora pinnata, subpinnatave; foliolis pubescentibus, viridibus, ovatis, obtusis, inciso-rentatis, dentibus, sen lobulis, obtusis, requalibus, aut subrqualibus: petio'i striali, hirsuti, subtus convexi, basi suprà concavi, membra. nacei, subvaginantes.

UMBeraz terminales, pedunculatie: universalis duas ad tres fere uncias lata, densissma; radiis striatis, hispidulis, in anbitu sesquiuncialibus el ultra, in disco valde brevioribus; dum foret planiuscula, sen subconvexa, fructifera coarctata, concava. Umbellie partiales numerosie, etiain densæ, radiis dnodecim et ultra. Involucrum universale umbellì brevins, polyphyllum, basi tamen monophyllum, ibi enim cum receptaculo mitur; foliolis septem ad novem, pubescentubus, pinnalis, pinnulis brevibus, quinque seu septem, oppositis cun impare, subdecurentibus, lmearibus, aculis, integerrimis, subequalibus. Involncella etiam polyphylla; foliolis septem octove, quorum tres exteriores in umbellulis radi apice tridentati, illas aquantes aut paulo longiores, alii omnes indivisı, hrevores, lineares, acuti; in mubellulis auten disc ferè omnes simplices, vix aliquis externus tridentatis.

Hores fere omnes hermaphroditi, panci ex interioribus masculi abortivi. Calyx obsoletus Corolla universalis subradiata; propria parva, pentapetala, pelalis albis, inlleso-cordat is, exterioribus maioribus. In centro receptaculi umbella exorimr flosculus, petalis quinque atropurpureis æequalibus iustructus, sxpe masculus et pedicello proprio, ad medium foliolis quinque xqualibus inroluto, imixus. 
Sthmom filamenta quinque, patenlia, corolla vix longiona: anthelac parra, albe, biloculares. P'istilli germen infermu, obovatum, hirtum, viride, aut interdum violaceum: styli duo brevissini, erect!: stigmatia obtusiuscula.

Fuctes suhovalis, bipartibilis. Semina duo, parra, hinc plana, inde convexa quadrialata, trisuleata; alis duabus dorsalibus, duabus marginalibus, submembranaceis, dentatis, denticulis acuminatis, rigiclulis, quasi aculeis, apice (leute visis) in glochicles, sen unciuos breves tenuissimos, quatuor ad sex, desinentibus: in tribus sulcis tres nervi prominuli, utrinque hispiduli.

Habitat in rupibus el sterilibus arenosis ad maris littora ex Rriceira usque ad Colares. Fluret vere. Biemis.

Ors. Difrert prasertion folits el umbellarum involucris it Dauco Carola silvestri, cui odore, sapore el viribus consimilis. Diflert etiam á Dau. co muritonico Lin caule sapius humili, paucirameo, subtortuoso, foliorum foliolis ovatis, ohtusis et eorun lacinulis obtusis: recedit insinul a Dauco maximo (Desfout. Fl. At!ant.) eisdem notis, et umbellularum involucellis mon pinnatifidis, nec noribus in disco violaceis. A Dauco muriculo distinguitur tam foliis, quim in volucellis umbellularum. et seminibrs minorihus, eornmque alis et aculeis an gustioribus, nec adeo validis. Daucus hispidus (Desfont. 1. c.) Juic nostro nimis affinis, at diversus esse videtur caule valde longiure et ramosiore, petalis subæequalibus, et pallide flavis, flosculoque centrali atrormbente nullo; an tamen varietas? Hæ atque nonnullæ aliæ lsujus generis species admodum variabiles ex solo, silu el cliuate; ideo deterninatione dificiles. 


\section{A THAMANTA Turisth.}

Aтн foliis radicalibus tripinnatis, canlinis bipinnatis simpliciterque pimatis; foliolis hrevissinis, linearibus, planis, subsetaceis, glabris, simplicibus. ultimis tripartitis; caule tortuoso, dichotomo, divaricato; involucro monophyllo, involucellis polyphyllis; umbellulis densis, convexis; seminibus tricostatis, villosis, stylatis.

SEseli Turlith. Lin. Sp. pl. ed. Willd. Lom. 1. pag. 1462. Amæn. Acad. 4. p. 310. La Marck Dict. Bot. Encycl. 7. p. 134.

Athamanta Turbith. Brot. Flor. Lusil. tom. 1. pag. 435.

Radix exalbida, fusiformis, lignosa et crassitudine pollicis cum annosa, infernè ramosa; acris, aromatica.

Catles plures, teretes, leviter striati, glabri, erecti, pedales aut paulo ultrà, tortuosi, dichotomi, ferè é basi ramosi; ramis similiter flexuosis, divaricatis.

Folı viridia, glabra; radicalia et infima caulis sæpe tripinnata; foliolis linearibus, planis, subsetaceis, brevibus, duas ad quatuor lineas fongis, semilineam ad unam fere lineam latis, mucronatis, ultimis pinnularum subcuneatis, tripartilis, aut bipartitis, lacinulis similiter subsetaceis, sed brevioribus. Petiolus communis octo ad tredecim uncias longus, é medio sen ex pinnullis primariis nsque ad basin subteres, suprì leviter calıaliculatus, infrà et lateribus obsolete striatus, é medio ad apicem perfecte striatus, subtrigonus, basi late membranacens, vaginans: petioli partiales opposıti, sensim breviores. Folia superiora caulis bipinuata, suprema pinnata; foliolis pariformibus, smplicibus, tripartitis a $u$ bipartitis.

UnBeLle plurimæ caulem ramosquue terminant: universalis unultiradiata, radiis octo ad tredecim, insequalıbus, distinctis, striatis, glabris, plus minusve patentibus: partiales convexæ, densæ, multiradiatæ, radiis gracillumis, subvillosis. Involucrum monophyllum, ovatum, acutum, basi leviler decurrens, brevissimum, quinque sexve lineas longum; interdum in aliquibus umbellis nullum: involucella polyphylla, foliolis septem octove virescentibus, linearibus, integerrimis, umbellulì dimidio et ultrà breviorbus.

CALyX superus, quinquedentatus, dentibus scubulatis, corolla triplo brerioribus. Corolla parva, pentapetala; petalis albis, extus interdum subpurpurascentibus, apice acuto inflexis, nec tamen emargi- 
natis. Staminum filamenta quinque, patentia, corollia paulo longiora; antheræ subrotundx. P'istıll germen inferum, subvillosum: styli duo, breves, erecti: stigmata obtusa.

Fructus oblongiusculus, subovalis, calyce et stylis coronatus, bipartibulis. Semina duo, hinc plana, inde convexa tricostata, quadrisulca, villosa, apice stylata.

Habitat in montosis de Cinlra. Floret Junio, Julio. Perennis.

Planta qualitate acri et aromatica tam radicis quàm seminum Athamantre Cretensi et tortuosu satis similis, nec viribus diversa esse videtur; apud Lusitanos tamen penitus inusitata. 


\title{
HEXANTHERIA MONOSTYLIA.
}

\author{
SIS Y M BR IUM catholicum.
}

Sis. caule prinario erecto, lateralibus adscendentibus; folis pinnatis, glabris; folsolis oblongis, serratis, indivisis, laciniatisve; florum corynbis in racenos simplices sensim valde elongatis; siliquis distantibus, longe pedunculatis, erectis, linearibus, oblongis, angustis, compressis, ad semina torulosis, basi acutiusculis, apice stylo persistente, ancipite, termınalis.

Sigymerium ratholicum. Lin. Syst. Veget. p. 597. Mant. 93. Sp. pl. ed. Will. 3. p 505. 1. 43. La Marck Dicl Bot. Encycl. tom 7. p. 217. Brot. Flor. Linsit. 1. p. 587.

Eruca planila, supina, brumalis Lusitanica.

Grisley Virid. Lusil n. 470.

RaDrx alba, longa, teres, superuè crassitudine pennx anserinx, ibidem sublignosa, lateribusque librata, infernè subramosa.

Caules plures ex apice radicis, primarins erectus, alii obliqui, seu ex declinatis erecti, quatuor ad undecim uncias alti racemo supputato, plus minusve striati, subteretes, glabri, nonnunquam aliquot pilis brevissimis remotis basiqus glandulosis scabrisculi, infernè subramosi; ramis tribus ad septen, alternis, erecto-paculis.

Folia glabra, interdum rarissimis pilis brevibus basi glandulosis scabrisque adspersa; raclicalia et infima cauls pinnala, pinnulis oblongis, profundè, acutè inxequaliterque serratis, nonnulis laciniatis, seu pinuatifidis, lacinulis denticulatis, quæ petiolum teminant sæpe confluentes sunt, omnes alixe oppositæ, suboppositxe ant alternæ plus minusve decurrentes: petiolus canaliculatus, subtıs convexus, ad basin sensim latior, demum semiamplexicaulis. Folia superiora caulis alterna, similia, sed mimora; suprema sub racemis nonnun. quam simplicia, lineari-lanceolata, integerrima, aut subserrata. Flo. ralia nulla.

Frores in apice caulis et ramorum conferti, corymhis diu floridis, et sensim in siliquosos racemos simplices valde elongatis: racemormm pedicelli stacei, glabri, plus minusve unciales, inferiores longiores, onnes alterni, inter sese distantes, erecto patuli. 
CaLYX tetraphyllus; foliolis é viridi flavescentibus, glabris : ovato lanceolatis, acutiusculis, concavis, xquatibus, oppositis, patentibus, corolla dimidiu brevioribus. Corolla cruciformis; petalis luteis, laxis, semiuncian lere longis obovato-cuneatis, sen cuneiformiter usque ad basin sensim in unguem minimum attenuat is; eormm lamina obtusx, integerrinx, patentes, sed sub solis occasmin sxpe erectie, convolutie, arcteque comniventes.

Stanxum lilamenta didymana, quormm duo longitudine calycis, alia illo Jongiora, omnia flavescentia, subulala, crectil; anthera lutex, oblonga, erectx, biloculares. Pistilli germen supermm, oblongun, filiforme, glabrum, dilute flavescens, stamium maiorm longitudine: stylus vix linean longus, persistens: stigna capitatum, depressum, subemarginatun, seu obsolete bilobum.

GIANDULe nectariferx quatuor, subglohosæ, virescentes, receptaculo fruclificationis afixu, quarmm dux inter stamina breviora et germen pistilli, dua alia inter Jongiora et calycent.

Silizua linearis, sesquilineam fere lata, unciam plus minusve longa, subrhombeo-compressa, basi et apice angustata, bilocularis, bivalvis, stylo persistente, seu dissepinento elongato, rostrata. Dissepimentum subcontrarium, membranaceum, tenuissimm, sericeo-album, ex impressione seminum scrobiculatum, basi et apice crassius. culum, cuneiforme, et ultra valvas elongatum. Valva longitudinaliter subcarinatx, ad semina torulosx, basi aculx, apice obtusx, utrinque dissepimento articulata, dehiscendo rectæ, neque elasticè desilientes. Rostrum anceps, duas lineas fere longum, stignate sicco terminatum, sixpe sterile, interdum infernè monospermum. Semina plurima, ex triginta ad quinquaginta, parva, globosiuscula, ex lusco rufa, dissepimenti margini hiliformi intervalvulari adhærentia.

HABITAт in locis saxosis, aridis, interdum etian in subhumidis, tam incultis quam cults, circa Olisiponem, Couimbrican et alibi per omnes fere Lusitaniæ provincias. Floret autumno, et præsertim hieme usque ad ver, rarius astate; interdum individua aliquot loto an. ni curriculo florentia occurrunt. Anuuum, aut bienne. Inodorum, subacre. Usus ignotus.

Ors. Species nimis afinis Sinapibus, et ab illis tantum ristincta videtur petalis obovato-cuneiformibus, seu usque ad unguium basin sen. sim cuneiformiter attenuatis nec rectis unguibus; nam cæteris omul. bus notis genericis similis, calyce sclicet corollàque patentibus, glandulis quatuor circa pistilli basin, stylo istius. el rostro siliquæe plus minusve hrevibus. Ha tamen nota diflerentales, jam ex cuneiformibus, jam ex rectis seu lnearibus unguibus petalormm, desumpta nulas determinatas metas habent, sxpe enin, ut in subsequente Sinapi incana, el quibusdam alis observatur, hæ mngulæ intra caljcem usque ad basin, plus minusve lineares, plus minusve cuneiformes sunt; quapropter hæ notw valde sunt ambignæe et insufficien- 
tes ad hac duo genera bene distinguenda. Ad hoc igitur præcipux et efficaciores nota ex stigmate jam sessili jam stylato desumendx videntur ita, ut sisymbria vera tantum illa sint habenda, in quibus stigma sessile, seu immediate situm sit supra apices valvarum insimulque dissepimenti illis aqualis; veræ autem Sinapes illæ tantum, in quibus stigna supra stylum seu dissepimentum demum ultra valras plus ininusve elongalum atque plus minusve rostriforme, insideat. 


\section{SINA PIS incana.}

Sin. Siliquis rachi racemi appressis, glabris, rostro monosperno; foliis radicalibus Jyrato-pinuatis, rentatis, utrinque pubescentibus, é viridi incanis, summis lineari-lanceolatis; caule scabriusculo.

Sinals incana. Lin. Sp. pl. ed. Willd. tom. 3. p. 558 . Amen. Acad. 4. p. 280. I a Marck Dict. Bot. Encycl. 4. p. 344. Gouan. Illustr. p. 45. Brot. Fl. Lusit. 1. p. 385.

Errsumu flore albo. Grisley Virid. Lusit. 11. 485.

$R_{\wedge D \perp x}$ alba, dura ramosa, subacri el quasi napi sapore.

Cauris sxpe solitarius, erectus, sesquipedalis, bipedalis, aut panlo altior, teres, pubescens, subincanus, scabriusculus, ramosus; ramis alternis, longis, rigidulis, patentibus.

Folia radicalia el inferiora caulis petiolata, Jyrato-pinnata, utrinque villosa, é viridi canescentia; foliolis ovatis, dentatis, oppositis suboppositisve, decurrentibus, extremo maiori ovato, sublobato, dentato, obtuso; suprema ad exortum ramorum breviter petiolata aut sessilia, lineari-lanceolata, integerrima, ciliata, raro dentata.

R.ICAI longi primarius ex apice caulis, alii ex ranis quasi axillares. Pedunculi alterni, floribus valde breviores, demum sub siliquis valde incrassati.

CALYX tetraphyllus; foliolis coloratis, sublinearibus, convavis, patentibus, corolli dimidio brevioribus, deciduis. Corolla cruciormis, sex lineas fere lata; pelalis luteis, rarissime athidis, nisi narcescentibus; lamina obovata, obtusa, integerrima, patente; unguibus laxis, supernè subcuneiformibus, infernè linearibus.

Stiminum filamenta sex didymama, ex albido flavescentia, quorum duo longitudine calycis, alia longiora: anthers lutea, acutiuscula, erectx. Pistilli germen superum, subteres, leviter pubescens: stilus hrevis, crassiusculus, alcituline staminum longiorum. Stigna capitatum, obtusum.

GuANDUL⿸ nectariferæ qualuor ovato-subrotundæ, subvirescentes, quarum una. utrinque inter stamen brevius el germen pistilli, atque una utrinque infer stamina longiora el calycem, omnes fructificatio. nis receptaculo aftixa.

Tom. 11 . 
Sulaves plures, rachi racemi appressæ, immaturæ subpubescentes, maturæ glabræ. compressiusculæ, obsoletè tetragonæ, quasi teretes, quatuor ad sex fere lineas longæ, biloculares, hivalves, rostratæ. Dissepimentum subcontrarim, tenue, ultra valvulas rostriformiter elongaimm. Valvulæ obsoletè carinatx, ad semina non torulosæ, dehiscentes rectæ, neque elastice desilientes. Rostrum valvulis dimidio et ulira brevius, teres, apice acutiusculum, stigmate sicco terminatum, intus medullosum, sæpe fertile monospermum.

Semı a sæpe tria quatuorve in utroque siliquæ loculo, parva, subglobosa, rufa, dissepimenti margini filiformi intervalvulari adharentia; nonnul a abortant.

Habitat in aridis, sabulosis, ac interdum ad aggeres, el vias circa Olisiponem, Conimbricam et alibi Floret Aprili, Maio, Junio, Biennis. Planta inodora, subacris. Inusitata. 


\section{HY ACINTHUS serotimus.}

Hrac. Aloribus racemosis, secundis, cernuis, brevissime pelunculatis; bracteis solitariis, ovatis, acutis, pedunculo vix longioribus; corollis profunde divisis, laciniis lineari-lanceolatis, aqualibus, ribus interioribus in tubuli formam approximatis, apice reflexiusculis, exterioribus tribus laxis, magis reflex is foliis linearibus canaliculatıs.

\section{Lusit. Jacintho do tarte.}

H. serotinus. Brot. Flor. Lusit. toin. 1. pag. 536.

H. serotinus, petalis exterioribus subdistinctis, interioribus coadunatis. Lin. Sp. plant. 453. Cavan. pag. 18. tab. 30.

Lachenalia serotina, corollis campanulatis, pedunculatis, secundis; petalis exteriormus longrioribus patulis, interioribus connatis; foliis linearibus, canaliculatis. Willd. Sp. pl. tom. 2. Pars 1. p. 175.

H. scrotimus, floribus secundis exalbido-fulvis, corollarum laciniis exterioribus magis reflexis. La Marck Dict. Bot. Lon. 3. p. 190.

Scllua serotina. Curtis. magaz. n. 859 et 1185.

Hrac. obsoletior Hispanicus, Anglo similis.

J. Bauh. Hist. Plant. tom. 2. p. 587.

R a Drx bulbosa: bulbrs subglobosus, digiti crassitudine, extus et intus tunicatus, nodo basis multifibratıs.

For. a omnia radicalia, linearia, acutiuscula, late canaliculata, viridia, seu ex cineraceis virescentia, nervo medio interdum albido, sex ad octo lineas lata, semipedem aut paulo ultra longa, procumbentia, sapore ingrato et quasi nauseoso.

Scapus cylindricus, gracilis, erectus, firmus, simplicissimus, viridis, glaber, octo ad quatuordecim uncias altus, racemo incluso.

Racenus lerminalis. Flores undecim ad viginti, solitarii, secundi, cernui, inodori, sape ex purpureo obsoleto cineracei. Bractea sub singulo solitaria, altida, membranacea, ovata, acuta, concava, pe. dunculo brevissimo vix longior.

CALYX nullus. Corolla infera, monopetala, usque fere ad basin sex- 
partita, seu laciniis ar $\frac{3}{4}$ partem distinctis, altitudine aqualibus, lineari-lanceolatis, apice obtusiusculis, demum emarcidis, nec deciduis; trabus exterioribus laxis, valde recurvis, rarò profundiù divisis quim ad $\frac{3}{4}$ partem; interioribus erectioribus, nimiun contiguis, aut iuterdum viscositate quadam quasi coadunatis, tubulum 5 ad i lineas altum effingentibus, extremitate auten patentussimis, reflexiusculis.

ST am. filanenta sex inclusa, corollâ valde breviora, subulata, infernè crassiora, ad laciniarum basin corollae inserta, ipsisque opposita. Anthera oblonga, lineares, incumbentes, lutex.

Pist. germen oblongum, obtuse trigonum; trisulcum, viride, absque ullis ad apicem poris visibilibus. Stylus triangulus, staminibus brevior. Stigma obsolete triangulum, iudivisum, guttula interdum madidum.

PERıc. capsula obovato-subrotunda, obtuse triloba, trisulca, trilocularis, trivalvis. Semen unum alterumve in loculo singulo, planiusculum, subrotundum, nigrum.

Habitat in glareosis lumidiusculis trans Tagum in Caprrica, prope oppidum Muntcigas et alibi in Extremadura el Beira. Floret Maio, Junio el xstate. Peremnis.

\section{Usus ignotus.}

OBs. Hrec species olin a Clusio in Hispania inventa in Germaniam et Belgicam ab ipso transmissa, ibique et alibi in horlis culta usque adhuc sxpe variare solet colore corollæ ex albido fulvo, atque ex purpureo, pallido, et virescente permixto, laciniis quoque exterioribus parum longioribus, interioribus connatis; qua tamen in solo natali semper aquales et distincta omnes sunt, etsi interiores plus minusve approximatæ. Quapropter non confundenda cum Lachenaliis. Diflert eliam í Scillis corolla non hexapetala, non patentissima, emarcida, nec decidua. 


\section{A L YSSUM collinum.}

A. caulibus lierbaceis, infernè ramosis; folis obovato-lanceolatis, incanis; staminibus omnibus edentulis, duobus brevioribus squamulâ ad basin adnatì stipatis; calycibus deciduis; siliculis incano-villosis, orbiculatis, leviter emarginatis.

A. montanum. Brot. Fl. Lusit. 1. p. 558.

RADIX annua, tenuis, exalbida, subramosa, radiculis brevibus.

Ca rues nonnulli ex eadem radice tres ad sex uncias longi, filiformes, incano-villosi pilis stellatis, uti tota planta, exteriores adscendentes, interior erectus infernè ramosus, ramis simplicissimis erectiusculis.

Folra obovato-lanceolata, integerrima, utrinque incano-villosa, pilis stellatis, subpunctata, scabriuscula, quatuor ad sex lineas longa, duas tresve lata, alterna, approximata, patula vel patentia.

FLores in caulium et ramorum summitate primùm corymbiformiter congesti, deinde sensin in racemum cilyndraceum simplicissimum abeuntes, pedunculati; pedunculis filiformibus, villosis, duas ad tres lineas longis, patentibus. Bractex nullæ.

CALyx paulo corollâ brevior, quadripartitus laciniis ovatis, acutiusculis, æequalibus, extus incano-villosis, intus glabris.

Corolla cruciformis, lutea, glabra, petalis cuneiformibus, emarginatis, calyce paulo longioribus, patulis et sæpe parum apertis.

Stamnum filamenta tetradynama, quatuor altiora edentula et longitudine calycis, duo breviora etiam edentula, sed squamulà ipsis prope basin adrata et breviore, plana, lineari, apice denticulata, aucta sunt. Antheræ erectæ, obtusæ, șubcordatæ, luteæ.

Pıst. germen suborbiculatum, compressum, villosum; ad ispsius basin glandula dux rufx. Stylus brevis, glaber, persistens. Sligma simplex, obtusum, antherarum altitudine.

Peric. silicula orbiculata, lentiformis, diametro duarum linearum, apice brevissime emarginata, styloque ipsa dimidio breviore terminata, utrinque incano-villosa, tumidula in centro contra interna senina, marginibus complanata, bilocularis, loculis dispernis: dissepimentum parallelum, temuissime membranaceum, pellucidum.

Tom. II. 
Semina ovalo-subrotunda, compressa, rufa, glabra, brevissime marginata, intermedio funiculo umbilicali brevi albo emarginaturæ dissepimenti aflixa, et inde pendentia: nonnulla abortiunt.

Habitat in collibus, et nonnunquam inter segetes circa Olisiponem. Illoret primo vere. Annua. Inodora et atque vix acriuscula. Inusita.

Is pravo hujus plantæ specimine sicco, quod sub nomine Alyssi montani mecum communicatum erat, genitalium structuram observare rite non potui, sed ea tandem in viva planta observata, speciem non tantum ab Al. montano Lin. sed etiam ab Al. calycino et campestri, quibus nimis aflinis, diversam esse mihi clare innotuit. Differt ab Al. montano presertim radice annua et staminibus quatuor altioribus apice non bifidis; ab Al. calycino præcipue calyce deciduo, staminibus ommibus edentulis; denique ab Al. campestri flamentis duobus brevioribus, non seta contigua, sed squamula apice denticulata prope basin adnata, instructis, siliculis non ovatis, sed orbiculatis, apice emarginatis nec integris. 


\section{COLCH I C U Lusilanum.}

C. foliis planis, oblongo-lanceolatis, infimo caulem vaginante, supremis sublasciculatis, capsulas pedicellatas involventibus; corollae laciniis lanceolatis, plus minusve tesselatis.

\section{Lusit. Colchico.}

Colsulcum flore purpurco tesselato.

Grisley Virid. Lusit. n. 1525

Corcincum Lusitanicum purpurei cum albo mixti coloris. Jolı. Rauls. Hist. Pl. tom. 2. p. 655. ex Clusio, qui Colchico Bizantino latifolio, polyanthemo affne illud esse existimabat Vide Ait. Kew. ed. nov. p. 328 , et Curtis Bot. Magaz. tab. 1122. Colchicum Bizantinum.

Radix bulbosa; bulbus, maturo fructu, foliis cauleque siccatis, e terra ellosus, subrotundus, uncialis, sesquiuncialis et ultra, hinc convexus, inde sinuatus seu canaliculatus, extus nonnullis tunicis siccis nigricantibus cinctus, intus solidus, carnosus, albus; superne, ubi caulis inserebatur, brevi foveolâ umbilicatus; infernè, ubi veteres radiculæ harebant, ofbiculari cicalricula notatus, et inde deorsum in luberculum unguiformem protensus; hoc inmersa sub integumen. to denticulato gemma latet minima, solida, ovato-acuminata, alba, qux sequenti autumno floralis; interlum alia quoque prope terminalem bulbi foveolan secunda gemuna adest, qux gracilior, debilior, et licet bulbifera raro sequenti autumno florifera est.

Mox post primas aquas autumnales é gremma, in tuberculo unguiformi sita, nova alia cito evolvitur plantula sub forma brevis bulbuli subrotundi sulidi. qui lateraliter tuberculo veteris bulbi intus adharet, basi radicnlas trudit, apice autem in brevissimum cauliculum, ad sesquilineam longun, floriferumque protenditur.

Frores sex ad tredecim, quorum aliqui nonnunquam inaperti marcescibiles, omnes pedicellati, spathisque cincli. Pedicelli cauliculo sunt impositi, breves, unam an tres lineas longi, interiores breviores, cuncti albidi, tenerrimi, subancipites, striati. Spathx tres ad quinque ex novo bulbulo exolta, quarum exterior longior, albida, striata, cylindrica, apice hinc fissa, inde obtusa, corollarum tubis, quos connectit, sxpe paulo brevior, infernè tunicis veleris bulbi siccis extus obtecta: ejusque lateri sinuato incumbens.

Periantujum nullum; ejus loco spathæ. Corolla glabra, monopetala, 
tubulosa, supernè sexpartita: tubus quatuor ad sex uncias longus, angulatus, subtriquetrus, ex spatha exteriore plus minusve exertus, patulus, aut reflexus; limbi laciniæ petaliformes, albicanti-purpureæ, lanceolatæ, obtusiusculæ, concavæ, carinatæ, sesquiuncian longæ, semiunciam fere in medio latæ, plus minusve tessellata, subæquales, erecto-patulæ.

Sтммким filamenta sex, fauci corollæ inserta, subnlata, albida, quorum tria aliis alternis longiora, corolla tamen paulo breviora; antheræ quadrivalves, oblongæ, lutex. Pistilli germen superum, pedicello brevissimo simul cum corolla impositum, oblongiusculum, trigonum, trisulcum, glabrum: styli tres, glabri, ad apicem dilute purpurei, staminibus longiores, corolla verò paulo breviores: stigmata purpurasceutia, subvillosa, canaliculata, reculva.

Florescentia finita, bulbulus augescere pergit, non radiculis solum suis, sed succo etiam, quem ex veteri bulbo ei infermè adhærente exsugit, usque donec iste penitus exsuccus pereat, enutritus. Folia nova tnnc ex ipso bulbulo evolvuntur, paulation sub terra increscunt, et ibidem latent sape fere usque ad hiemale solstitium; postea ex illa ermmere incipiunt, et citius crescunt ita, ut veris initio plenam fere inagnitudinem adepta sint; eo tempore oblongo-lanceolata sunt, acuta, aut obtusiuscula, octo ad quindeciu uncias longa, unain ad duas lata, integerrima, striata, viridia, glabra, plana, non undulata, neque plicata nisi obsolete et sic rarissime, subtus leviter carinata, supra vix canaliculata; foljum infimum exterius bulbum norum tunicat, superneque caulem vaginat, intermedia caulina vix ulla, et cum adsunt, caulem semiamplexantur; suprema sessilia, inbricata, subfasciculata, capsulas aggregatas involventia, cauleque summopere longiora sunt.

Cauls ex apice novi bulbuli exoritur, primodum subterraneus est, demum ex una ad tres uncias supra terram erigitur, teres, crassitudine pennæ anserime, simplicissimus, glaber, apice valde foliatus, ibique frugiferus.

CAPSul tot quot pistilli germina, aggregatæ, sen quasi umbeliatæ, breviter pedicellatx, nonnullæ abortivs, quatuor quinqueve sape fertiles, omnes inter folia terminalia canlis reconditæe, ex Maio ad Julium maturescentes; harum quxlibet ovata, acuta, glabra, triloba, composita ex tribus partialibus unilocularibus, inflatis, subtriquetris, ad axem inter sese coadunatis, aliò versum liberis, sutura interna ad usque medium dehiscentibus. Semina plurina, suhglobosa, rugosa, subrufa, funiculis umbilicalibus brevissimis snturæ internæ capsularum partialium adhærentia; nonnulla sæpe abortant.

Habitat in collibus incultis el saxosis de Alcantara prope Olisiponem, et alibi in Extremadura. Floret ineunte antumno absque foliis. Perenne. 
Obs. 1. Nimis affine Colchico autumnali, sed foliis citius é terra erumpentibus, floribus sape numerosioribus, corollaque laciniis plus minusve tessellatis, dissimile. An tamen varietas? Ejus bulbus amarus est, ac illo pro Colchici autumnalis bulbo Pharmaceutici Olisiponenses interdum utuntur.

Ors. 2. Nostrum Colchicum bulbocodioides (Fl. Lusit. 1. p. 597, et Pliyt. Lusit tom. 1. p. I19. (ab. 50) longe sane diversum est a Colchico bulbocodivide Marsh. Flor. Taur. Cauc. I. p. 293; istud enim monopetalum et multiflorum est. Clusius olim illud pro Colchici montani varietale minori habuerat; Lapeirousius et Desfontaineus postea illud ad Bulbocodium amandarunt; Ramondus tandem ex illo, ntpote stirpe media inter Colchicum et Bulbocodium considerato, novum genus instituit, eique nomen Merendera imposuit, quo Colchica vulgus Hispanum appellare solet. Hoc arbitramentum Clar. Poiret et alii recentiores secuti sunt. Vid. La Mark Dict. Bot. Encycl. Suppl. tom. 3. p. 665. Merendera bulbocodium. 


\title{
OCTANTIERIA MONOSTYLIA.
}

\author{
1OLIGALA microphylla.
}

P. Roribus racemosis; calycis foliolis duobus aleformibus obovato-subrotundis, corollam imberbem wquantibus; caule frulescente, ranoso ; foliis minutis, lanceolatis, acutis, caducis.

P. microphylla. Erot. Fl. Lusit. tom. 2. p. 30. Link Fl Lusit. 1. p. 297. tab. 56. Lia. Sp. pl. ed. Willd. 3. p. 889. La Marck Dict. Bot. Encycl. tom, 5. p. +34 .

P. Lusitanica frutescens, magno flore, foliis minimis.

Tourn. Inst. R. H. 175.

Polycala, seu flos ambarvalis, Leisitana.

Grisley Virid. Lusit. n. 1172.

RaDIX ramiosiuscula, lignosa, apice nodosa, ibique crassitndine fere digiti minimi, perennis.

CaUles plures ex eadem radice, obliqui seu erecliusculi, octo ad tredecin uncias longi, fruticosi, virides, glabri, virgati, filiformes, subangulosi, sulcati, internè prope radicem teretes, sub basibus foliorum calncorum dentati seu tuberculati, diffuse ranosi; rami alterni, striati, glabri, sed recentiores lente visi subpubescentes.

Folta mimuta, lineam ad sesquilineam in medio lata, tres quatuorve longa, lineari-lanceolata, acuta, integerrima, in nedio proninenter costata, sessilia, tuberculo decurrenti insidentia, glabra, sed lente visa subpubescentia; omnia alterna, remota, erecta, caduca.

Flores racemosi ; raceni caules et ranos terminant, componuntur ex racenulis plurimis alternis, unam ad tres uncias longis, erectiusculis, quinque ad novenfloris. Folia floralia ovato-lanceulata, acutiuscula, vel ovito obtusa, ex abidlis cxerulea, cadnca; sub singulo ilore sxpe tria. Pedicelli flurum approximati, altermi, tenuissimi, brevissimi, cærulei, sæpe plus minusve recurvi.

CaLyx pentaphyllus, cujus folia tria parva, æqualia, ad margines cærulescentia, lanceolati, peracuta, glabra; duo alia maxina, alas corolla efligentia, plana, tenuissime venosa, obovato-subrotunda, vix acutiuscula, et vix ungulata, in anthesi cierulea, postea ex albidis lutescentia. 
Corolıs omnino cærnlea, irregularis, subpapilionacea, figura tamen propria, nonopetala, tubulata, limbo diviso, et vexillum atque ca. rinan constituente: vexillum bipartitum, segmentis obtusis, obovatis, concaris, altero alterum amplexante: carina minina, concava, vexillo tecta, inberbis antheras includens.

Stamon filamenta diadelpha octo, in duos fasciculos collecta, simul cum antheris carinæe inserta, et eì inclusa. Antheræ octo oblongiuscula, lutescentes, uniloculares.

Pistilla germen subovale, suhpedicellatum. Stylus germini impositus, filiformis, erectus, ligula acuta concava carulea terminatus. Stigma deflexo-mncinatum, liberum, infernè ligulà styli vaginatum.

Capsula pendens, obcordata, compressa, glabra, bilocularis, bivalvis, dissepimento valvis contrario, suturis marginum utrinque dehiscens. Semina in utroque loculo solitaria aut duo, ovalia, umbilico glandulosa, albuminosa, embryone inverso.

Habitat in dumetis montium circa Conimbricam, in Beira boreali et Interamnia, in Monte-Junto et alibi. Floret Aprili, Maio, Junio. Frutrex.

PlNTA inodora, amara. Usus ignotus. 
POL Y G L A Monspeliaca.

Pot. floribus racemosis; calycis foliolis alæformibus corollâ valde longioribus, ovali-oblongis, trinerviis; caule herbaceo, sæpe solitario, erecto; foliis lineari-lanceolatis, peracutis.

PoL. Monspeliaca. Brot. Fl. Lusit. tom. 2. p. 29. Link Fl. Lusit. 3. p. 278. tab. 55. Lin. Sp. pl. ed. Willd. 3. p. 874. La Marck Dict. Bot. Encycl. 5. p. 487. (uti P. vulgaris varietas.) Desfont. Fl. Atlant. 2. p. 129. Decand Fl. Franç. 3. 457. et Icones Plant. Galliæe p. 3. tab. y. Villars. Delphin. 3. p. 387.

Polygata vulgaris coloris obsoleti, foliis angustisssimis. Joh. Baul. Hist. Pl. 3. p. 318.

RADIX simplex, brevis, parce fibrata, annua in cunctis hujus speciei individuis a me in Lusitania observatis.

Caulis sæpe solitarius, subteres, filiformis, quatuor ad octo uncias Jongus, erectus, glaber, simplex, ramis perpauculis alternis indivisis instructus, interdum simplicissinus.

Folı anguste lanceolata, acutissima, integerrima, dilute viridia, glabra, subsessilia, sessiliave, alterna, erecta, sæpe laxa seu remotiuscula.

Rs.емı caulem et ramos terminant; flores minores quàı in specie præcedenti, mutantes, subsecundi, pedicellis longiores. Bractea sub singulo pedicello brevissima, caduca.

Calyx pentaphyllus, cujus foliola tria brevia, lanceolata, acuta, duo alia alxformia membranacea, ovali-oblonga, acutiuscula, pallide rosea aut virescentia, trinervia, reticulata.

Corolla rubens, lineis virentibus variegata; carina cristata.

Stamina el Pistillum ut in Polygala vulgari; capsula quoque similis, sed minor. Semina ovalia; unicum in singulo loculamento.

Habitat in coltibus aridis et incultis circa Conimbricam et Olisipo- 
nem usque ad radices montium de Cintra, et ex Monte-Junto usque ad Obiclos, et alibi. Florel Maio, Junio, Julio. Annua.

Planta inodora et amariuscula. Usus ignotus.

Ors. Nimis aflinis Polygale vulgari, et pro illius varietate a nonnullis Botanicis habita; sed ex foliolis calycis aleformibus corolla longioribus, atque ex alis commemoratis nolis, diversa esse nobis videtur. 


\section{DECANTHERIA MONOSTYLIA.}

\section{ONONIS Hispanica.}

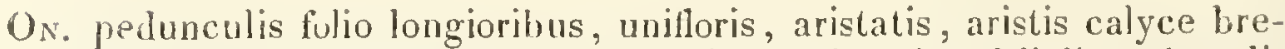
vioribus; foliis omnibus ternatis, villoso-viscosis, foliolis subovalibus, ferè usque ad basin serrato-dentatis, canaliculatis, recurvatis; stipulis subulatis, recurvis, integerrimis, nonnullis unidentatis; floribus cernuis; corollis leguminibusque calyce valde longioribus.

Lusit. Joina dos matos.

Ononis Hispanica. Lin. Sp. pl. ed Willd. 3. p. 1008. et Lin. fil. Suppl. 324.

Onoxis crispa. La Mark Dict. Bot. Encycl. 1. p. 510. (non Lin.)

AnoNis mon spinosa, villosa el viscosa Hispanica. Barrel. Icon. 775.

Ononis non spinosa, flore luteo perennis.

Grisl. Virid. Lusit. p. 1083.

R.a dix lignosa longe et valde ramosa. Caulis siepe mox a basi divisus, seu ex capite radicis sxpe plures, lignosi, teretes, tortnose erecti, octo ad quindecin uncias longi, ranosissimi; ramis alternis, inferioribus patulis, defoliatis, teretibus, superioribus foliatis subancipitibus, arcte approximatis, villoso-viscosis, ut tola planta.

Folua approximata, omnia usque ad ramorum apices ternata, patentia, foliolis oblusis, subovalibus aut obovatis, tuobus lateralibus quatuor lineas longis duas latis, subsessilibus, intermedio panlo maiori, pauloque longius petiolato, Jateribus et apice usque fere ad basin dentato-serratis, recurvatis, rigidulis, utrinque saturate viridibus et viscoso-villosis, subtus carinatis, supernè canaliculatis et ferè conduplicat is cum juniora sunt. Petiolus viscoso-villosus, supra canaliculatus, subtus subcarinatus, usque ad stipularum adnationem tres quatuorve lineas longus. Stipulæe duæ, viscosæ, inferuè adnatæ, amplexicaules el subvaginantes, supernè subulatæ, integerrimx, aut nonnullæ uno alterove dente instructæ, recurve, petiolo aquales aut paulo breviores, in ramis junioribus internodia superantes.

Ftores laterales, axillares, pedunculati, cernui; pedicelli filiformes, persistentes, fulio plus minusve longiores, solitarii, unillori, rarisii- 
me aliqui biflori, aristati; arista lineam fere lata, villosa, pedicello ad quatuor lineas infra calycem inserta, calycinisque laciniis valde hrevior.

CAlyx profunde quinque parlitus, laciniis patulis, lineari-subulatis, subaqualibus, integerrinis, villosis, corolla dinidio brevioribus, persistentibus.

Corola lutea, glabra, magnitudine ut illa On. Natricis. Vexillım obovato-subrotundum, rubris venulis longitudinaliter pictum, aliquantulum reflexum. Alæ oblonga, sublineares, oblusa, vexillo jarmm breviores. Carina stanina pistillumque involvens, falcata, acuminata, alarum longitudine, basi bilida, bidentata.

Stauxu filamenta decem, basi monadelpha, ibique in tubum cylindricum exalbidum, coalita, et pistillum raginantia Anthera incun. bentes, lutex.

Pistuls germen lineari lanceolatum, acuminatum, villoso-viscosum, villis hyalinis. Siylus glaber, assurgens, staminibus vix longior, persisters. Stigma simplex, subpubescens.

LEGumen teres, turgidum, subvillosum, calyce fere iriplo longius, pendulum, stylo terminatum. Semina sxpe quatuor quinqueve reniformia, subnavescentia; nommulla sæpe abortiunt.

Habitat in collibus incultis el solo macro sabuloso, circa Olisiponem, trans Tagum, et alibi in Extremadura, Transtagana el Algarbiis. Floret vere et restate. Frutex.

ODor totius plantx resinosus, sed non ingratus; sapor levissime amarus, subacris Usus medicus ignotus. Nimis aftinis $\mathrm{On}$. pingui et $n n$ trici, ah eis autem diversa præsertim foliis minoribus, non planiusculis; plus viscidis, non oblongis, nec apice tantìm denlatis, aristisque pedunculorum flore brevioribus, et foliis floralibus non simplicibus. Nec etiam confundenda cum On. crispre, á qua discrepat foliis non undulatis, pedunculis non muticis, calycisque laciniis apice non tridentalis Ononis ramorissima (Desfont. Fl. Atlant.) etsi ei simillima, et quasi varietas, ab ea tamen differt foliis præcipue angustioribus, brevioribus, lineari-obovatis, non recurvatis, nec adeo canaliculatis. 


\title{
DECANTHERIA PENTASTYLIA.
}

\author{
SEDUM Lusitanum.
}

S. foliis succosis, sublanceolatis, convexo-planiusculis, mucronatis, basi solutis, inferioribus in contortas series imbricatis, superioribus vage sparsis; caule ex declinato erecto; cyma glabra, bifida, trifida; corolla sæue bexapetala, obtusa.

\section{Lusit. Herva pinheirce cnxuta.}

SEDun fruticulosum. Brot. F]. Lusit. tom. 1. p. 206.

Radix fibrosa, perennis.

CAULEs plures ex eadem radice, teretes, infernè crassiores, pennæ anserinx fere crassitudine, dilute virictes, glabri ut tota planta, semipedales, pedales et ultra, prinum parum declinati deinde erecti nec unquam nutantes; primo anno sæpe steriles, infernè interdum reptantes, ibique sensim effoliati alterneque ramiferi, ad basin rigescentes ac per aliquol annos vividi, supernè post maturos fructus siccescentes.

Folia carnosa, compressa seu convexo-planiuscula, sublanceolata, sesquilinean ad tres lineas aut paulo ultra in medio lata, seminnciam at sesquiuncian longa. inferiora angustiora et longiora, apice acutiuscula mucronataque, basi soluta appendiculoque membranaceo acutiusculo caudata; ommia lavia, enervia, avenia, integerrima, dilute viridia, raro subglauca; in caulibus sterilibus congesta et interdum quadri seu quinquefariam, rarius sex ant septemfariam, contorte imbricata; in caulibus florentibus inferiora approxinata, alia laxe sparsa, sensim versus eorum apices decrescentia, et sensim remotiora, omnia erecta.

Fuores in cymam terminalem digesti. Cyma glaberrima, in duos tresve ramos, seu radios primarios, divisa, quorum singulus sæpe bifidus ant trifidus, ramulis, seu radiis secundariis, sape subæqualibus, patulis, apice recurvis, multifloris. Involucrum nullum, nisi pro illo folium parvum, quod ronnumquam occurit paulum a cymæe basi dissitum, assumatur. Bractea ad flores etiam nullæ, nisi unum aliudve pusillum fulium, interdum al inferiora ramulorum situm, eas esse existinetur. Flores in duas series alternè dispositi, subsessiles, ere- 
cti, introsum spectantes; unus in dichotomiis seu prope illas solitarius.

CAlXX sape sexpartitus, laciniis ovatis, acutiusculis, lineam ad sesquilineam longis, viridibus, succosis, erectis, maturo fruclu laxulis, persistentibus.

Cororta sxpe lrexapetala; petalis calyce duplo longioribus, patentibus, sublanceolatis, obtusiusculis, concavis, luteolis, ad margines albidis seu ex albido-luteolis, carini virescentibus.

Staminum filamenta sape duodecim, receptaculo inserta, quorum sex calycis laciniis, sex alia petalis opposita, erecta vel leviter obliqua, subulata, inferıè plana, el intus ibi subpubescentia, supernè glabra, omnia corollx longitudine. Antherx lutex, erectx, oblongx, lineares, bisulcatx, biloculares.

Pıst. germina sxpe sex, oblonga, angulosa, acuta, in stylos breves subulatos desinentia; in anthesi primum in pyramirlem hexagonam conjuncta. deinde sensim laxiora, demum matura supernè stella forman referentia. Stigmata sinplicia, acutissima.

A D singuli germinis basin squamula nectarifera emarginata, receptaculo inserta, adeo minima, ut vix ac ne vix interdum lente vitrea visibil:s.

CAPSUl uniloculares, longiludinaliter sutura introrsum deliscentes. Semina plurima oblonga, striata, scobiformia, sutura affixa.

Habitat in solo raro, macro, sabuloso, interdum ad aggeres in Beira meridionali ac Extremadura, maxime circa Olisiponem et ultra Tagun in ora maritima de Caparica. Floret Julio, Augusto. Perenne et quasi suffrutex.

Sapor totius planta subadstringens; odor nullus. Ab empiricis Olisipone usitatum, illi eastem vires tribuentibus, qux Sedo telephio et Sempervivo arboreo lectorumque a peritis medicis assignatur.

OBs. 1. In quibusdan, etsi paucis, floribus ejusdem cymæ variat calycis laciniis quinque cum totidem petalis et germinibus, duploque staminum numero. In locis humidis, aut in hortis culta, et ibi nimis irrigata variat interdum habitu maiori, cyma vage ramosa quasi paniculata, et floribus fere omnibus decandris pentagynis.

Oes. 2. Afine Serlo Hisprmico. sed diversum cyma el habitu non pubescenti, foliis penitus viridibus, nec punctis purpureis picta, floribus non sessilibus, et corolla non omnino alba. A Sedo rupestri, etsi pro ipsius varietate a nonmollis habeatur, plus adhuc longe diflert, ut facile ex descriptione data patet. Sedo altissimo La Markii (Dict. Tom. $\Lambda$. 
Bot.) et Sempervivo sediformi Jacquinii (Hort. T. 81.) similitudine adeo proximum, ut forte illa ambo nonnisi nostræ speciei variata individua sint, nullis foliis teretibus productis, et squamis, quæ ad germinum basin ex more summopere minimæ sunt, abortientibus, sicuti non raro in pluribus nostræ plantæ cullæ floribus, ut ipse observavi, erenire solet. 


\title{
POLYANTHERIA MONOSTYLIA.
}

\author{
II A L V A mauritiana.
}

II. caulibus sæpe adscendentibus, scabriuscnlis; foliis inferioribus septilobis, obtusis, crenatis, superioribus quinquelobis, acutiusculis; petiolis pedunculisque subpubescentibus; calycis externi foliolis late sejunctis, lanceolatis, ciliatis, interno praulo brevioribus; petalis s?turate purpureis, unguibus utrinque villo spisso albo barbatis.

Rapix ramosa, alba, dura, annua.

Caules plures ex eadem radice, sæpe ex prostrato adscendentes, aut obliqui, raro erecti nisi centralis, pedales ad bipedales, teretes, le. viter sulcati, scabriusculi, pubescentes, ramosi; ramis axillaribus, alternis, supremis folio brevioribus.

Folia alterna, patentia, cordato-orbiculata, inferiora sejtemtobata, septemnervia, lobis obtusis, crenatis, supernè glabriusculis, infernè subpubescentibus; superiora qninqueloba, lobis acutiusculis; omnia longe petiolata, petiolis lamina fere duplo longioribus, subteretibus, scabriusculis, suprà canaliculatis valde villosis, subtus convexis, leviter pubescentibus, sell glabriusculis Stipulæ membranaceæ, subvillosæ, erectæ, approximatx, sed non coalitæ, ovatæ, in axillis inferioribus apice obtusiusculæ el obsolete denticulatæ, in superioribus acutiusculx.

Flores axillares, tres quatuorve fasciculati, infimi quandoque solitarii, omnes pedunculati; pedunculis inæqualibns, semiunciam ad ses. quiuncian longis, simplicissimis aut compositis, petiolo multo bre. vioribus, subvillosis, erectis, fructiferis reflexis.

Calyx duplex, persistens; exterior triphyllus, foliolis basi late disjun. ctis, lanceolatis, acutis, integerrimis, ciliatis, trinervis, extus villosis, intus glabris; calyx interior monophyllus, seniquinquefidus, externo paulo longior, laciniis late ovatıs, acutis, ciliatis, extus virid.bns villosis, intus glabris in centro atrojurpuress.

Corolte petala quinque, saturate purpurea, singula tribus venis saturatius purpureis picta, plana, patentia, obcordato-cuneiformia, tredecım ad qundecim lmeas longa, tubo staminum infernè affixa, unguibus purpurascentibus, utrinque in basi villo denso albo instru. ctis, unde maculæ quinque albæ in fundo floris. 
Stamxum filamenta numerosa, purpurea, glabra, infernè in tubum coalita, supernè libera, petalis fere triplo breviora. Antheræ purpurascentes, reniformes, uniloculares, bivalves.

Pistrluı germèn superum, sub tubi staminum basi dilatata reconditum, orbiculatum, flavescens, glabrum. Stylus brevis, cylindricus, infernè lutescens, tubo staminum vaginatus. Stigmata duodecim, setosa, purpurea, longitudine staminum, illis demum paulo longiora.

Capsula subrotunda, depressa, in centro umbilicata, ex novem ad duodecim composita capsulis partialibus rotundato-reniformibus, subtriquetris, dorso subrugosis, subvillosis, unilocularibus, evalvibus, orbiculatim receptaculo columnari centrali affixis, monospermis. Semen reniforme.

Habitat in saxosis sterilibus circa Olisiponem, præsertim in prodio, vulgo Cerca dos Jeronimos, sed raro occurrit. FJoret vere. Annua.

Qunitate et viribus Malvæ silvestri similis, cui etsi valde affinis et pro illa quandoque habita, ab ea tamen differt præsertim foliolis caJycis extemi remotioribus, Janceolatis, nec ovatis, corollaque valde inaiori, saturate purpurea, nec cærulescenti. Malva maurtiana Linnæi, Cavanilles et aliorum Botanicorum, sicut etiam Malva glabra La Mark, nonnisi hujus nostræ varietates, ex soli naturâ, climatis diversitate, et maxime culturæe causa, mihi esse videntur. 


\section{LA Y A T ER A silvestris.}

LAV. caule herbaceo, erecto, scabro, piloso; foliis cordato-subrotundis, inferioribus septilobis, obtusis, superioribus quinquelobis, acutis; perlunculis aggregatis; calyce exteriori paulo breviore, monophyllo, tripartico, segmentis late ovatis, vix acutis.

\section{Lusit. Malva alla.}

Lavatera silvestris. Brot. Fl. Lusit. 1. pag. 277.

Malva silvestris, amplo flore. Grisley Virid. Lusit. n. 345.

$R_{A D I X}$ ramosa, exalbida, rigida, annua.

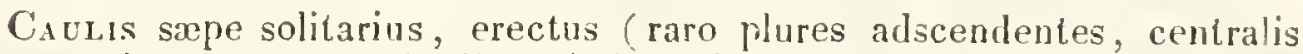
tantìn erectus) altitudine nimis varians, pedalis, bi, tri, quadripedalis et ultra, ramosns, teres, sulcatus, pilosus, ut tota planta, pilis sxpe binis ex eodem puncticulo scabroso. Rami alterni, axillares, floribus onusti, superiores folio laterali breviores.

Folia alterna, petiolata, cordato orbiculata, viridia, utrinque subpubescentia; inferiora tres quatnorve uncias lata, septiloba, Jobis obtusis, crenatis, subtus septemnerviis, nervis scabris, apice venosis; superiora quinqueloba, lobis acutis, acuteque crenatis Petioli lamina folii longiores, erecto-patuli, subteretes, punctato-scabri, pilosi, supra leviter canaliculati, subtus convexi. Stipulæ menbranaceæ, ovatæ, acuminatæ, nervosæ, utrinque pubescentes, piloso-ciliatæ, solutx, appressæ, ant erecto-patulix.

Frores axillares, quatuor ad septem fasciculatæ, omnes pedunculatæ; pedunculis unfloris, inæqualibus, semiunciam ad sesquiunciam longis, filiformibus, pilosiusculis, erectis, fructiferis patulis aut plus minusve reflexis.

Calyx duplex, persistens; exterior vere monophyllns, tripartitus, segmentis late ovatis, brevissine acutis et quasi obtusis, integerrimis, viridibus, nervosis, extus et orà marginali pilosis, intus glabriusculis; interior etiam monophyllus, semiquinquefidus, exteriore paulo longior, laciniis ovatıs, acuminatis, utrmque viridibus, extus villosis, intus glabris.

Corolle pelala quinque albido cærulescentia, sell dilute caerulea, tribus venis eodem colore saturatiori picta, plana, patentia, obcordaTom. II. 
to-cuneiformia, æqualia, decem ad duodecim lineas longa, unguibus albidis, utrinque basi villosis, imo tubo staminum adnata.

Staminum filamenta numerosa, infernè in tubum album apice villosum coalita, superne libera, petalis duplo breviora. Antheræ albidx, reniformes, bivalves, uniloculares; granula pollinaria globosat, alba, numerosa.

PISTLLl germen superum, sub tubo staminum infernè dilatalo reconditum, orbiculatum, flavum, glabrum. Stylus brevis, cylindricus, lutescens, tubo staminum vaginatus. Stigmata octo aut novem, setosa, crerulea, longitudine staminum, illis demum paulo longiora.

Capsula rolunda, glabra, depressa, in centro umbilicata, ex octo aut novem compostla capsulis partialibus, rotundato-reniformibus, subtriquetris, dorso læcvibus, milocularibus, evalvibus, orbiculatim receptaculo colummari centrali adhærentibus, monospermis. Semen reniforme.

Ha fitat in locis cultis el incultis, ad vias, aggeres, muros frequens in tota Lusitania. Floret vere. Annua.

Qualitate et viribus Malvæ silvestri similis, ei nimis affinis, et pro illus varietate swe habita; sed calyce externo vere monophyilo tripartito, nec triphyllo, ab omnibus Malvis difert, et vera Litvateræ species. 


\title{
POLYANTIERIA POLYSTYLIA.
}

\author{
RA.NUNCULUS dimorphorhizus.
}

RAx. pubescens; radice supernè subrotunda bulbosa, infernè fasciculata; caule solitario, erecto, sulcato, subtereti, paucilloro; folis radicalıbus primordialibus ovatis, dentatis, alis tri-quinquepartitis, laciniis cuneilormibus, incisis, acute lentatis; caulinis tripartitis; supremis linearibus, integerminis; pedunculis sulcatis; calycibus patentibus.

RAorx dimorpha, superrè bulbosa, bulbo subrotundo, solido, crassitudine magni pisi, aut aliquanto maiori, petiolis late membranaceis foliorum recentium cincto, extusque aliorum vetermm petiolorum reticulis siccatis obducto; infernè grumosa, tuberculis carnosis, sesquilineam crassis, oblongiusculis, in filformes fibras valde longiores abeuntibus, composita.

Folı radicalia in orben posita, septem ad novem, primordialia ovata, fabelliformia, dentata, alia tri-quinquepartita, laciniis cuneatis, partitis, incisis, acuteque dentatis, utrinque pubescentibus, ut tota planta, pilis arlpressis, omnibus longe petiolatis, petiolis canaliculatis, basi late membranacess, bulbum involventibus; caulina intermedia duo triave, alterna, in petiolum decurrentia, tripartita, lacınis incisis aut mterdun integerrinis; suprema sæpe duo sessilia, fers opposita, lineara, acuta, angusta, brevia, indıvisa.

CAULIs solitarius, erectus, quinque ad novem uncias altus, subteres, sulcatus uti rami et pedunculi, villosus pilıs arctè adpressis, infernè nudifolus, supernè paucifolius, ramisque trobus ad quuinque terminatus; rami erecti, uniflori, inæquales, centrali caulino breviore.

CALYX pentaphyllus, foliolis ovato-lanceolatis, concavis, dorso viridibus, margine membranaceo flavescentibus, intus glabris, extus subpubescentubus, patentıbus, corollæ alpressis.

Corolla pentapelala, diametro tredecim linearum; petalis flavis, obovato-cuneatis, lineatis, nitidis, ad basin macula ex viridi flava notatis; squana nectarifera ad unguem obovata, seu fere obcordata, plana.

Stamia numerosa, corolla dimidio breviora; filamenta lutea: anthere oblongæ, tilanentis adnat:, lutex. P'istilli germina plurima, 
glabra, in capilulum ovatum collecta: stylus nullus: stigma simplex, reflexum.

Fructus ovalis, obtusus, septem ad novem lineas longus. Semina plurima, nuda, mucronata, glabra, receptaculo subvilloso annexa.

Habitat in collibus nonnullis ex Olisipone usque Cintra. Floret vere. Perennis.

Ors. Planta inodora, acris, inusitata. Bulbus radicalis subrotundus in solo sicco sæpe maior evadit, quam in subhumido; penitus solidus est, ei nulla cavitas nisi quæ gemmulam novæ plantæ sub apice sitam continet, nullıbique ova insectorum ulla recondit, ideo ut galla ab ipsis formata existimari non debet. Nimis affinis Ranunculo flabellato (Desfont. Fl. Atlant.) et Ranunculo gregario (nostræ Fl. Lusit.) qui forte ejus varietates sunt, radice supernè non subglobosa, sed ibi sub gemmula tenui tantìm fasciculata, istudque ex solo nimis humido et pingui proveniens sit. 


\section{R A N U N C ULUS adscendens.}

$R$. hirsutus; radice fasciculata ; caule ex prostrato adscendente, alternè ramoso, multifloro; foliis radicalıbus longe petiolatis, cordatoovatis, tripartitis, laciniis latè obovatis, inæqualiter dentatis, lateralibus bifidis; rameis superioribus subsessilibus tripartitis, laciniis cuneatis aut sublinearibus; pedunculis sulcatis, angulosis; calyce reflexo.

R. Jatifolius, radice grumosa oblonga, maior.

Grisl. Virid. Lusit. n. 1608.

R. adscendens. Brot. Fl. Lusil. 2. pog. 370.

Radrces fasciculatie, głabræ, supernè teretes, carnosæ subfusiformes, ibique sesquilineam ad fere lmeas duas crassæ; infernè attenuatæ filiformes, longissimx, ad quinque uncias et ultra longx.

Caubes ex eodem nodo radicali tres, quatuor et ultra; centralis valde obliquatus, laterales, ex prostratis adscendentes, fistulosi, plus minusve hirsuti, ut tota planta, virides, aut interdum ad radicem purpurascentes, ibique teretes, snpernè angulosi, ex imo ad apicem alternè, seu dichotome, subramosi, dodrantales ad pedales, paucifolii. Rami axillares, nonnulli opposifolii, infimi ex decumbentibus adscendentes, superiores erectiusculi, patuli parcè divisi.

Folia radicalia cordato-ovata, profunde triloba, vel tripartita, ses. quiunciam aut paulo ultra lata, laciniis late obovatis, inæqualiter dentatis, venosis, triste viridibus, utrinque hirsutis, duabus Jateralibus sxpe leviter bifidis interdum trifidis; petiolo bi-triunciali et uttra, supra leviter canaliculato, basi latiore; caulina minora, remota, alterna, profunde tripartita, inferiora laciniis cuneatis, dentatis, et interdum etiam fissis, inferiè angustatis basique brevi petioliformi, marginibus membranaceà, caulem aut ramos ainplexante; suprema eliam alterna, sæpe tripartita, laciniis angustis, linearibus aut sublinearibus, integerrimis, nonnulla interdum opposita, indivisa, Jinearia, sessilia.

Flores numero ramis caulium proportionati, pauci ant plurimi, quatuor ad sexdecim in singulo caule, pedunculos longos, striatos, sulcatos, pubescentes, terminantes.

Perianthium pentaphyllum, foliolis in pedunculum reflexis, lanceolatis, acnminatis, nervosis, flavescentibus, extus pilosis, intus glabris concavis, corolla paulo brevioribus, deciduis.

Ton. 11 .

MIMM 
Corolla lutea, diametro novem ad tredecim linearum; petala obovata, sæpe integerrima, rarissime aliqua apice rolundato obsolete emarginata, supernà facie nitida, lineata, ad unguem macula e viridi flavâ notata, ibique foveola et squamulà minima obovata instructa.

STAM. filamenta plurima indefinita, lutea, capillaria, brevia. Antheræ oblongæ, obtusæ, lineares, luteæ, erectæ, corolla fere triplo breviores.

PIST. germina numerosa, in capitulum ovatum antheris paulo brevius collecta, flava, ovata, acuta, compressa. Styli nulli. Stigmata flava, acuta, recurva, minima.

Senrna plurima, ovata, marginata, plana, viridia, glabra, lævia, stigmate minimo acutiusculo leviter recurvo persistente instructa. Receptaculum ovato-subglobosum, villosum.

Habitat in dumetis umbrosis, ad ima collium, in locis humidis, circa Conimbricam, Olisiponem usque ad Cascaes, Cintra, et alibi in Beira et Extremadura. Floret Aprilı, Maio. Perennis.

Usus ignotus, radix ut tota planta acris.

Variat habitu plus minusve hirsuto; caule plus minusve ramoso; foliis radicalibus et infimis caulinis ad sinus seu fissuras maculatis; superioribus caulium el ramorum ternatis quaternatisve, et eorun foliolis oratis, trifidis, petiolatis. 


\section{N D E X}

Plantarum hujus Tomi II. secundum nostre Florce Lusilanice Systema sexuale numericum distribularum.

\section{DIANTIERIA MONOSTYLIA.}

Tab. Pag.

SALVIA hicmalis

$83 \quad 3$

- patula

VERONICA Lusiana

GRATIOLA linifolia

ORCHIS lonyicruris

- papilionacea rubra

coriophora symphypelala

- cordata

conica.

OPIRYS tenthredinifera

TRIANTHERIA MONOSTÝLIA.

CROCUS aulumnalis mullifidus IRIS trialata

\section{TRIANTHERIA DISTYLIA.}

TRITICUMI liloreum

$\begin{array}{rrr}97 & & 51 \\ 98 & & 54 \\ 99 & & 57 \\ 100 & & 59 \\ 101 & & 62 \\ 102 & \text { et } 103 \quad 64\end{array}$

TETR ANTHERIA MONOSTYLIA.

TEUCRIUMI polium Lusitanicum

\section{___ capitatum Lusitanicum \\ __Lusitanicum salviastrum scordium lanuyinosum}

AJUGA Iva heteranilla

STACHYS Lusilanica
104

105

106

107

108

109
66

68

71

73

75

78 
Tab.

Pag.

MARRUBIUM cincreum

$110 \quad 81$

BALLO'TA vidyaris

NEPETA multibracteuta

111

83

ORIGANUM vulyarc virens

111

87 creticum macrostachyum

112

89

L.AVANDULA viridis

113

81

SIDERITIS lincarifolia

114

THYMUS albicans

115

93

95

$116 \quad 97$

—_ capilellatus

117

99

_cphalotos
villosus

118

101

119

102

_ glabratus
zygis silvestris
zygis variabilis

120

121

103

EUPHRASIA aspera

122

105

107

123

109

- temifolia

ANTIRRIINUM maius latifolium

124

125

111

—_ meionanthum

126

113

- calycinum

] 27

115

- spurium integrifolium

128

117

- lanigerum

129

119

_- sparteum

130

120

- proces $x$

130

122

131

123

- virgatulum

132

125

133

127

glutinosum

134

129

135

131

136

133

137

135

138

136

139

137

140

138

$14 \mathrm{l}$

139

diffusum

142

140

ANARRIINUM bellidifolium

143

142

- Duriminium

OROBANCHE barbata

144

144

_ fatida Lusitanica

142

146

149

RHINANTHUS trixago

145

152

145

154

SCROPHULARIA sublyrata

146

158

Herminii

DIGITALIS purpurea tomentosa

$1+7$

158

148

159 thapsi

149

$16 \mathrm{I}$

URTICA caudata

150

163 


\section{PENTANTHERIA MONOSTYLIA.}

Tab. l'ag.

VERBASCUM crassifolinm

macranihum

$152 \quad 166$

$153 \quad 168$

- blatlarioides

LITHOSPERMUM fiuticosum

I $54 \quad$ J 69

ANCHUSA Ilalica

155

171

- undulata

$156 \quad 173$

CYNOGLOSSUM clandestimun:

157

175

$158 \quad 177$ picium

RUBIA silvestris

ACARNA qummifera

BALSA HITA anmua

ANACYCLUS anteus

161

183

162

J 86

INULA viscosa

163

164

188

190

PENTANTIERIA DISTYLIA.

CUSCUTA Europera barbuvea

ERTNGIUM amethystimum dilalatum

SELINUM peucedanoides

DAUCUS halophilus

ATHAMANTA Turbith

\begin{tabular}{|c|c|}
\hline 165 & 192 \\
\hline 166 & 194 \\
\hline 167 & 196 \\
\hline 163 & 198 \\
\hline $160 \mathrm{et} 170$ & \\
\hline
\end{tabular}

HEXANTHERIA MONOSTYLIA.

SISYMBRIUM Catholicum

SINAPIS incance

HYACINTHUS serotimus

ALYSSUM collimum

COLCHICUM Lusilanum

\begin{tabular}{|c|c|}
\hline 171 & 202 \\
\hline 172 & 205 \\
\hline 89 & 207 \\
\hline & 209 \\
\hline
\end{tabular}

OCTANTHERIA MONOSTYLIA.

PORYGALA microphylla Monspeliaca

175

176

214

216

DECANTHERIA MONOSTYLIA.

ONONIS Hispanica

177

218

DECANTHERIA PENTASTYLIA.

SEDUMI Lusitanum

187

220

Tom. II. 
POLYANTIERIA MONOSTYLLA.

MALVA mauritiana

LAVATERA silvestris
Tab. Pag.

POLYANTHERIA POLYSTYLIA.
179

179
223

225

RANUNCULUS dimorphorti: adscendens

180

227

181

229 


\section{INDEX SYNONYMORUM.}

$A$

Absinthium corymbiferum l'ag. 180

A grostis comosa

- melanosperma

A lectorolophos

Alyssum inontanum

Anarrhinum hirsutum

Anchusa anyustifolia

— lignosior frutescens

_- Officinalis

Anonis hispronica

Anthemis chrysanthemum

Antirrhinum bellidifolium 142 -

- bipunclatmm

- iucarnatum

- junceum

- latifolium

__ mimus el medium

- molle

- saxarile sparicum

Anthyllis altera Clusii

Atractylis gummifera

B

Ballota, s. Ballote

- alba, s. flore albo foctida

- migra

Blattaria flore maximo

Bromus incrassatus

- rigens

Buglossum fruticosum

- Lusilamicum el marimum vulyare el angustifolium

\section{C}

Carduus pinea Theophrasti

Carlina acaulos yumifera

Carthamus gummiferus

Chamædrys fruticosa Lusilana 7

Chamæiris lalifolia I.usilana 47

Chamæleon alhus Dioscoridis 183
Chaturemelum capite apluyllo 188

Chan!ixpitys 75

Cirselliun gummiferum 183

Cnicus gnmmifer acrulos 183

Colchicun flore tesselato 211

Conyza maior $\quad 180$

209 Crocus autumnalis ericeloram 40

$1+4$ montamus ibil.

$171-$ scrotimus, etc. ibid.

ibid. — mudiforus 43

173 Cynoglossa allera Lusitana 177

218 Cynoglossum creticum 179

$188-$ Officinale, uti varietas 177

\section{D}

Dactylis cylindracer $5 \cdot 1$

Digitalis Imifolia Lusisamica 10

- flore jurpureo al albo 159

- tomentosa ibil.

- verbascifolio $\quad 161$

E

Elatine

Eliochryson, s. Elichryson Vid. Heliochrysum.

83-84 Erigeron viscosum. 190

84 Eriostomum Lusitanicum 78

83 Eruca pumila 202

ibicl. Eryngium dilatatum 191

169 - flore carmlco ibid.

59 - trifidum minus ibid.

57 Frysimum fiore aliso 205

171 Euplirasia linifolia 111

F

Festuca arenacea $\quad 59$

- ciliala $\quad 62$

54

59

ibid. 
G
Gramen alopecuroides cicalope-
cumum
Gramen Festuca avenacea
- maritimum, clc.
— phanix ramosa
- spartcun spicatum
- Iyphoides molle

Gratiola offinculis, ut varietas 10

- alia Lasiona ibid.

ibid.

ibid.

54
Heliochrysum

Horminum silvestic

Hyacinthus poctarnm latifotius 44

- obsolctior hispanicus

\section{1}

IRIS reluti

- biflora

- Inulbosa latifolia

— Mrmilis lalifolia

- microptera

- palula

— scorpioides

- Transacayana

_ vulgaris Lusitanica

\section{L}

Lachenalia scrotina

Laserpitium peucedanoides

Lasiopera asperu

- lemuifolme

- rhinamthine

Liuaria amethystea

- dcalbuta

- diffusa

- folio Bellidis

- ylancophylla.

_ ylulinosa

- juncea

- lanigera

- Limogrisca

- meoriuntha

- mollipmenctata

- polygalofolia

47

44

196

109

111

154

134

120

139

$1+2-1+1$

129

123

$119-120$

131

125

140

136 ibid. IValva silvestris

- glabra

Marrubiastrum

Marrubium Dictammi folit

186 - nigrum

3-6 Moscharia asperifolic

207

Nepeta violacea

MI
J 23

131

] 37

133

127

122

6.5

225

224

83

8. 1

$83-8 \frac{1}{x}$

75

87

\section{$\mathrm{O}$}

Ononis crispa

47 mon spinosa flore luteo

44-46 Ophrys arachnites

$46-$ bombyliifera

$4+-46-$ insccifera rosea

44

47

Orchis fucum referens

- globosa

- laclea et O. acuminata

- olvre harci

207

138

- pulmata latifolia

_L tephrosmulios

Orobanche gracilis

- jlore raberrimo

_- Lusilanica

- mrior el minor.

ibid.

146

\section{P}

Pedicularis Lusilanica

1]1

Poa cristala, et phlcoides

54

Polium Lissilanicum.

$66-68$ 
I N D E X

Polium montanum supinum

_ mont. temuifolium

Polygala coloris obsolcti

- Lusitana

R

Ranunculus latifolius maior

S

Salvia athiopis

- polymorpha verbenacoides

Santolina corymbifcra

Satyrium diphyllum

Scilla serotina

Sclarea Lusilanica

Scrophularia ebulifolia

- lyrata

Sedum fruticulosum

Seseli turbith

Solidago viscosa

Stachys germanica

- intermedia

Stæchas viridis, et aliæe
66

68

216 Tanacetom amnum

214 Teucrium album

- Iva

- lamujinosmm

- Lusitmicum

229 - pscudohyssopum

- pychompliyllum

- salviastrum

- valentimum

6 Thymus Lusitamicus

3 Lusil. cephalotos

ibid. - serpillum

186 - silvestris

21 - variabilis

207 Tragoriganum

6 Triticum junceum

156

ibid.

220

200 Verbascum viscidulum

190 Veronica tcucrium

78 - micrantha

ibid. Virga aurea maior

93 Urtica Lusitana
186

68

75

73

68

70

ibid.

7 I

70

102

99

103

105

107

101

51

U

169

ibid.

190

163 


\section{NOMINA VULGARIA}

siliquarum stirpium in hoc Tom. II. descriplarum.

Asafräio bravo

listha des uvas

Blattaria maior

Bruco

Buglossa do Reino

- ondeada
Cardo do visco, ou C. matacäo

Cardo pinlo gommoso, outranco

Carlina gommosa

Colchico

Cynoglossa de flor fechada

- de flor listrada

Dedaleina, on Digital

Escordio

Fiadeira das barbas das uvas

Flor dos rapazinhos, ou dos macaquinhos dependurados

Graciosa do Remo

Grança brava

Herva beacrra

- borboleta

- crina

- das scte sangrias

- pinheira enxula

- porsobeja

- toira barbuda

- toira denigrida

- toira ramosa

Jacintho do tarde
Pag. 40 Joina dos matos

192 Joina das searas

169 Iva moscada

196 Lirio cardeno, ou roixo ordi.

173 nario

175 Lingua de vacca do Reino

Macella fedegosa

- galleya miuda

ibid. - gallega vulyar

183 Malva alla

211 Marroio negro

177 Ouregäo ordinario

179 - longal

159 Polio montano

73 Raspalinqua

192 Rosmaninho verde

Ruiva brava

12 Salva de inverno

10 - Larga

181 Sargaça hispida

113 Serpũo glabro

17 dos montes

75 Taqueda de Dioscorides

171 Teucrio capiloso

220 Tomilho alvadio

19 - cabeçudo

146 - pelludo

149 Veronica teucrieta

152 Urtiga de caudas
218

185

75

47

173

186

ibid.

188

225

83

89

91

66

181

93

181

3

6

171

103

107

190

68

97

101

102

8

163 


\section{NOMINA VULGARIA}

Allera quarundam stirpium in Tomo 1. descriptarum.

Alcarnache

Alinciróa

Baracejo

Embude

Esculracho da aréa

Feno de cheiro amargoso

Herva vespa

Hypocisto

Leile de gallinha $\begin{array}{rlr}\text { Pag. } & \text { Morraça } & 13 \\ 57 & \text { Putegus } & 122 \\ 18 & \text { Rhapontico, ou Rhapontis da } \\ 74 & \text { terra } & 69 \\ 15 & \text { Suxifraga da Reino } & 80 \\ 11 & \text { Tojo gadanho } & 133 \\ 6 & \text { Tollar } & 130 \\ 122 & \text { Tomilho de Creta } & 27 \\ 105 & \text { Tormentelo } & 26\end{array}$ 


\section{INDEX ALPHABETICUS}

Plantarum, qua in loc Tomo Secundo descripta sumt.

\begin{tabular}{|c|c|c|}
\hline & Pag. & Tab. \\
\hline ACARNA gummifera & 183 & 161 \\
\hline AGROSTIS miliacea suffrutescens & 64 & 102 et 103 \\
\hline AJUGA Iva heterantha & 75 & 108 \\
\hline ALYSSUM collinum & 209 & 180 \\
\hline ANACYCLUS aurcus & 188 & 163 \\
\hline ANARRHINUM bellidifolium & 142 & 143 \\
\hline$\longrightarrow$ Duriminium & 144 & 144 \\
\hline ANCHUSA Italica & 173 & 156 \\
\hline - undulata & 175 & 157 \\
\hline ANTIRRINUM amethysteum & 134 & 137 \\
\hline - calycinum & 117 & 127 \\
\hline - diffusum & 139 & 14 I \\
\hline glancophyllum & 138 & 140 \\
\hline glutimosum & 129 & 134 \\
\hline _ İanigerum & 120 & 129 \\
\hline _ linogriseum & 131 & 132 \\
\hline - maius lalifolium & 113 & 123 \\
\hline __ meionumihum & 115 & 126 \\
\hline _ multipunctutum & 140 & 142 \\
\hline _ polygalafolium & 136 & 138 \\
\hline - pracox & 123 & 131 \\
\hline - pyrcnaicum & 137 & 139 \\
\hline __ supphirinum & 133 & 136 \\
\hline - suxatile & 127 & 133 \\
\hline - sparteum. & 122 & 130 \\
\hline - spurium integrifolium & 119 & 128 \\
\hline _ virgatulum & 125 & 132 \\
\hline ATHAMÄNTA turbilh & 200 & 169 et 170 \\
\hline BALLOTA vulgaris & 83 & 111 \\
\hline BASAMITA ammu & 186 & 162 \\
\hline BROMUS caurlatus & 57 & 99 \\
\hline cylindraceus & 54 & 98 \\
\hline _ geniculatus & 59 & 100 \\
\hline COLCHICUM Lusitanum & 211 & 173 et 174 \\
\hline CROCUS autmmnalis multifidus & 40 & 94 \\
\hline CUSCUTA Europoa barbuvca & 192 & 165 \\
\hline CYNOGLOSSUM clandestinum & 177 & 158 \\
\hline - pictum & 179 & 159 \\
\hline DAUCUS halophilus & 198 & 168 \\
\hline DIGIT A LIS purpurea tomentosa & 159 & 149 \\
\hline thapsi & 161 & 150 \\
\hline ERYNGIUM amelhysteum dilatatum & 194 & 166 \\
\hline EUPHRASIA aspera & 109 & 123 \\
\hline
\end{tabular}


Pag. Tab.

EUPHRASIA temifolia

FESTUCA barbata

$11 \mathrm{~L} \quad 124$

GRATIOLA limifolia

$62 \quad 101$

HY ACINTHUS serotinus

$10 \quad 86$

INULA viscosa

IRIS subbiflora

$207 \quad 89$

$190 \quad 164$

$47 \quad 96$

$44 \quad 95$

LAVANDULA viridis

1.A VATERA silvestris

LI'THOSPERMUM fruticosum

MALVA mauritiana

MARRUBIUM cincreum

NEPETA multitracteate

ONONIS hispanica

OPHRYS apifera subterrostrunca

- aurita

- corniculata

- filsca

labrofossa

tenthredinifera

ORCHIS conica

- cordala

_ coriophora symphypetala

- Iatifolia labrovaria

longicruris

- papilimencea rubra

ORIGANUM Crelicum macrostachyum vulyare virens

OROBANCHE barbria

- fectida Lusitanica romosa

$38 \quad 93$

91

$36 \quad 93$

$29 \quad 88$

$27 \quad 87$

239 I

$21 \quad 90$

$19 \quad 89$

$25 \quad 92$

$12 \quad 87$

$17 \quad 88$

$91 \quad 313$

$89 \quad 112$

$146 \quad 142$

$149 \quad 145$

$\mathbf{1 5 2} \mathbf{1 4 6}$

$214 \quad 175$

POL.YGALA microphylla Aomspelisca

RANUNCULUS adscendens

216

175 dimorphorhizus

229

181

$227 \quad 180$

RHINANTHUS trixago

$154 \quad 146$

RUBIA silvestris

181

SALVIA hicmalis

160

palula

SCROPHULARIA Herminii

SEDUM sublyrata

- thicum

SELINUM peucerlanoides

SIDERITIS linearifolia

SIN A PIS incrma

SISYMBRIUM catholicum

STACHYS Lasitanica

TEUCRIUM capilatum Lusitanicum Tom. II.

$\begin{array}{rr}3 & 83 \\ 6 & 84 \\ 158 & 148 \\ 156 & 147 \\ 220 & 178 \\ 196 & 167 \\ 95 & 115 \\ 205 & 172 \\ 202 & 171 \\ 78 & 109 \\ 68 & 105\end{array}$




\begin{tabular}{lcc} 
& Pag. & Tab. \\
TEUCRIUM scordium lanuginosum & 73 & 107 \\
\hline Lusianicum salviastrum & 71 & 106 \\
\hline THYMUS albicans & 66 & 104 \\
\hline capilellatus & 97 & 116 \\
\hline cephalotos & 99 & 117 \\
\hline glabratus & 101 & 118 \\
\hline zygis silvestris & 103 & 120 \\
\hline zygis variubilis & 102 & 119 \\
TRITICUM litoreum & 105 & 121 \\
VERASCUM blatlarioides & 107 & 122 \\
\hline crassifolium & 51 & 97 \\
VERONICA Lusitana & 169 & 154 \\
URTICA caudata & 166 & 152 \\
\end{tabular}




\section{EXPLICATIO}

TABULARUM IIUJUS TOMI SECUNDI.

TAB. 83.

S A L V I A hiemalis par. 3.

(1) Una ex superioribus bracteis; (2) flos; (3) corolia; (4) calyx; (5) ejusden labia sejuncta; (6) stylus et stigma cum germine minimo inter labia calycis inlerne dissecti.

\section{TAR. 84.}

S A L V I A patula pag. 6.

(a) Flos; (b) calyx cum pistillo; (c) unum ex duobus staminibus cum pedicello latissino, cui adheret, lente vismm; (d) bractea.

TAB. 85.

VERONICA Lusitanc pag. 8.

(a) Flos; (b) calyx cum pistillo auctus; (c) corolla cum staminibus ancta; (d) calyx cum capsula, prout in istius plena maturitate ạt gescere solet.

TAR. 86.

GR A T I O L A linifolia pag. 10.

(a) Flos; (b) calyx cum stylo et stigmate; (c) corolla; (d) eadem longitudinaliter fissa et aperta cum staminum filamentis.

TAB. 87.

O R CH IS longicruris pag. 12.

Fig. 1. Planta ad naturam expressa, suis cum radicibus, foliis, caule et spica florente. (1) Una ex bracteis apice erosa; (2) alia apice acuta; (3) nectarii labium inferius, corollæque pelala conniventia, insimul et bractea acuta sub germine; (4) nos á fronte visus, petalis de industria expansis.

OPHR YS tenthrcdinifera pag. 27.

Fig. 2. Planta suis cum radicibus, foliis, caule et foribus magnitudine naturali. (a) Flos; (b) nectarii labia antice visa, cum staminibus; (c) nectarii labium inferiıs postice visum. 
TAB. 88.

\section{O R C I I S papilionacea rubra pay. I\%.}

Fig. 1. Planta suis cum radicibus, caule, foliis et floribus ad naturam expressis. (a) Flos á fronte visus, petalis de industria expansis; (b) flos á latere visus, petalis erectis et laxe conniventibus.

\section{O P H R Y labrofossa pas. 29.}

Fig. 2. Planta cum suis tribus bulbis radicalibus et aliis partibus magnitudine naturali. $N 0^{\circ}$ 1. Flos é latere visus insimul cum bractea pedicellum minimum germinis amplexante; (2) corolla cum nectario á fronte visa ; (3) nectarium cum antheris et pistillo, absque corolla ; (4) labium nectarii inferius tripartitum, posticè delineatum, nt sic ejusdem lacinia media margines suos revolutos fossulamque sub apice in conspectum det; (5) idem cum fossula sub apice, et lacinix medix lateribus de industrià expansis.

TAE. 89.

\section{H Y A C IN'T II US serotinus pag. 207.}

(a) Scapus; (b) racemus. N. 1. Corolla ad naturam expressa cum bractea sub pedicello minimo; (2) corolla erectis et disjunctis laciniis observata; (3) eadem longitudinaliter fissa et expansa cum staminibus; (4) pistillum.

O R C H I S coriophora symphypetala pag. 19.

Fig. 1. Flos cum bractea á latere visus; (2) idem á fronte visus; (3) petala tria exteriora; (4) labium superius nectarii cum staminibus elasticè exertis.

\section{TAB. 90.}

O R CH IS cordata pag. 21.

Fig. 1. Planta ad naturam expressa. (a) Flos cum bractea í latere visus; (b) ideın á fronte visus; (c) capsula.

O PHR YS apifera subterrostrunca pag. 32.

Fig. 2. Planta magnitudine naturali. (a) Flos á latere visus cum bracteâ; (b) nectarii labia á fronte visa, cum duobus petalis minoribus inter ipsa adjunctis; (c) labium nectarii inferius quinquelobum, omnihus lobulis de industria expansis; (d) unus ex duobus lobulis, ad ejusdem nectarii faucem sitis, parum auctus, 
TAB. 91.

O R CH IS conica pag. 23.

(a) Flos á latere visus cum bractea; (b) idem á fronte visus.

O P H R Y S aurila pag. 34.

(a) Flos á fronte visus; (b) idem á latere visus; (c) nectarii labium inferius trilobun de industria expansmu, el posticè visum; (d) unus ex duobus lobulıs lateralibus ad ejusdem labii basin.

\section{TA в. 92.}

\section{O R C H I S lalifolia labrovaria pag. 25.}

Fig. 1. Plante radix palmata: Fig. 2. pars caulis cum foliis. Fig. 3. Spica florum. (a) Flos á latere visus cum bractea; (b) flos á fronte visus, in lıujus labio inferrore nectarii lobulus internedius obtusus ac edentulus est; (c) idem, cum lobubo intermedio labii inferioris nectarii dentato; (d) idem, in quo labium nectarii inferius duobus lobulis brevissimis, cum emarginatura minima inter ipsos, terminatur.

$$
\text { TAP } 93 .
$$

O PH R Y fusca pag. 36.

Fig. 1. Planta ad naturam expressa, cum radicibus, canle, foliis et spica. (A) Bractea; (b) flos á latere visus ; (c) pistilli germen sub fauce nectarii, ac sub istius labio superiore, quo antlierie teguntur; (C) iden el alia valde aucta; (d) una ex duabus antheris vaide aucta, glandulx inposita; (e) granula pollinis uni ex ramulis ejusdem antheræ affixa, valde aucta.

\section{O P H R Y S comiculata pag. 38.}

Fig. 2. Planta naturali magnitudine, cujus flos infimus á fronte, et alius superior quasi á latere sese if conspectum prodıt.

$$
\text { TAB. } 94 .
$$

\section{CR OCUS aulumnalis multifidus pag. 40.}

Fig. 1. Planta, cum uniflora est, ad naturau expressa: (a) bulbus subterpositus tunicalus, atque vaginæ quinque radicales extrafoliaceæ; (bb) folia; (c) spatha corollæ tubum cingens. Fig. 2. Corollæ limbus expansus, tubusque ad funcem longitudinaliter fissus, ut stamina et stigmata cum stylo ibique sese clarì in conspectum dent. Fig. 3. Una ex lacinis petaloideis, cui stamen arlharet.

Fig. 4. Planta trillora, onnibus suis vaginis radicalibus, tam extra Tom. II. 
quàm intrafoliaceis, detractis; ( $a a)$ bulbus subterpositus tnnicis suis siccis denudatus; (bb) bulbus novus basibus tantim foliorum tectus; (cc) folia, pront é vaginis radicalibus egressa reflecti solent; (dd) spathx tres é germiıum basibus exortx, qux eaden corollasque cingunt; (e) una ex illis, qux corollx tubum, nec limbum, cingit; (ff) duse alteræ, quæ corollas penitus contegunt. Fig. 5. Folii frustulum transversè dissecti valde auctum.

Fig. 6. Planta biflora, omnibus vaginis radicalibus extrafoliaceis detractis, visa; (aa) bulbus subterpositus denudatus et verticaliter sectus; (b) bulbus novus squamis cinctus; (cc) folia doo intra medium secta; (dd) vaginæ duæ intrafoliacex; (ce) scapi; (ff) spathæ usque ad germinum basin fissie; ( $g g$ ) germina corollis denudata; ( $h$ h) styli ; (ii) stigmata magnitudine naturali. Fig. 7. Stigmata valde aucta.

Tig. 8. Tunicæ interiores, quæ bulbi subterpositi lineolis circinatis alharebant, dimidiatim dissectæ, expansx, parumque auctæ. Fig. 2. Idem bulbus, in quo, detractis tunicis, lineola circinalx, cavitas centralis, tres bulbuli ad ejus latera adnati, radiculx in basi et sub istì nonnullæ lanina nigricantes, seu veteres bulbi exsucci, ostenduntur. Fig. 10. Una ex predictis laminis inferioribus. Fig. I1. Alia eidem bulbo vivo immediale supposita, cujus centro sedes funiculi umbilicalis ad veterem bulbum altimum exsuccum attinentis, conspicitur. Fig. 12. Idem bulbus subterpositus dimidiatim sectus, ut ejus cavitas centralis superior, ubi novus bulbulus præformari solet, insinul et alia inferior cavitas, in qua funiculus umbilicalis brevis siccus bubi exsucci cortinetur, in conspectum veniat. Fig. 13. Ilem cum suo bulbulo germinante.

Fig. 14. Capsula matura. Fig. 15. Eadem transversè dissecta. Fig 16. Semina.

TAB. 95.

\section{R I S trialala pag. 44.}

Fig. I. Planta ad naturam expressa, cum duobus novis bulbulis (fig. $3,4) \dot{e}$ bulbi centralis basi exortis Fig. 2. Eadem, ut srepius occurrit, cum cauliculo subterraneo, foliis (quorum bases hic tantim exprinuntur) vaginato, tribusque brevibus pedunculis et floribus tribus terminato.

(a) Una ex tribus corollæ lacin maioribus; (b) alia ex tribus minoribus; (c) stigmata tria petaloidea, antheris incumbentia; (d) unum ex ipsis cum superiore labio in rectum ducto; (e) corollæ tubus filiformis, stylo coalitus, germinis apici cuu illo adhærens; $(f)$ capsula; (g) eadem transverse secta, insimulque mna ex valvulis ejus longitudinaliter detracta, ut seminum dispositio cernatur; (h) semen.

TAB. 96.

I R I S sublifiora pag. $4 \%$.

Fig. 1. Planta florens ad naturam expressa; fig. 2, pars suprema caulis cum duobus floribus clausis; fig. 3 , una ex tribus corolla laci- 
niis externis barbatis; fig. 4, alia ex tribus internis erectis; fig. 5, stiguata tria petaliformia antheris incubita, et stylus tubo corollix coalitus, germinisque apici cum illo afhxus; item spathe unum tertium minimum foliolum in axilla secundi superioris situm; fig. 6, calpula; lig. 7 , earlem transverse secta, ubi loculi cum seminibus sese in conspe. ctum dant.

\section{TAB. 97.}

\section{T R I T I C U M litoreum jag. 51.}

Fig. 1. Radix et culmi cum foliis. Fig. 2. Spica terminalis.

(a) Spicula; (b) gluma calycina; (c) corolla bivalvis; (d) unins flosculi valvuli interior corolles, nectarium, stamina, et pistilum; $(e, f)$ semen ab uno litere unisulcalum, ab altero convexum, basi acutum.

TAB. 98.

B R O MUS cylindraceus pag. 54.

(a) Spicula sexflora naturali magnitudine; ( $\Lambda$ ) eadem ancta; (b) alia octollora, quæ raro occurrit; (B) eadem aucta; (c) gluma calycina; (C) eadem ancta ; (d) spicula sexfora absque gluma calycina, in dnobus flosculis infinis corollæ valvula ostenduntur apertæ; (D) eadem aucta; (e) unius flosculi nectarium, stamina, et pistillum; (E) ealem aucta; $(f)$ semen.

$$
\text { TAR. } 99 .
$$

\section{B R OMUS caudatus pag. 57.}

(A, B) Paniculæ duse antequam florescaul; (C, D) Paniculæ duæ alterx in anthesi; (E) alia post anthesin contracta; (F) folii ligula; (G) paniculæ ramus unus compositus; (H) panicula ramutus unus partialis; (i) spicula trillora magnitudine naturali; (I) "eadem aucta; (l) spicula altera quadrifora; (L) eadem aucta; $(m)$ gluma calycina; (II) eadem aucta; $(n)$ corolla bivalvis; $(N)$ eadem aucta; (o) unius losculi nectarium, stanina el pistillum; $(\mathrm{O})$ eaclem parum aucta.

\section{TAB. 100.}

\section{B R OM US genicuialus pag* 59.}

Fig. 1. Planta ad naturam expressa; (fig. 2, 3) panicula duæ in anthesi; (fig. 4, 5, 6) panicula tres, plus minusve post anthesin contractæ.

(a) Folii ligula; (b) paniculx ramus; (c) spicula naturali magnitudine; (C) eadem aucta; ( $\left.a^{\prime}\right)$ spicula cum suis qualuor flosculis rachi laxe arlhrsis; (D) eadem aucta; (e) gluma calycina; (E) eadem aucta; $(f)$ corolla bivalvis; ( $F$ ) eadem aucta; $(g)$ unius floscuii nectarium, stamina, et pistillum; (Geadem parum ancta; (h) semen corollà arcte clausum; $(i, l)$ idem ab uno latere unisulcatum, ab altero convexum. 
TAB. 101.

F ES T UC A barbata pag. 62.

(N. 1, 2, 3, 4) Racemi quatuor, in anthesi plus minusve laxi ; $(5,6)$ alteri prout contrahuntur post anthesin et ante illam.

(a) Spicula; (b) eadem laxatis flosculis; (c) gluma calycina; (d) unus flosculus; (c) ejusdem nectarium, stamina, et. pistillum.

TAB. 102.

A GROST IS miliacca suffrutescens (A) pag. 64.

Fig. 1. Culmi plures, prout. ex eodem cespite prodire solent. Fig. 2,3, paniculæ sicuti ante el post anthesin contrahuntur.

TAB. 103.

A GR OST I S miliacca suffrutescens (B) pag. Ibid.

Panicula in anthesi ad naturam expressa. (a) Paniculæ ramulus; (b) unus ex flosculis inapertus, naturali magnitudine; (B) idem auctus; (c) ipsius flosculi dum aperti gluma calycina et corolla naturali magnitudine; (C) exdem valde auctæ; (d) corolla cum staminibus et pistilJo; (D) eadem aucta; (e) pistillum cum nectario; (E) eadem aucta; (f) unum ex duobus nectarii foliolis; ( $F$ ) idem auctum; (g) semen; (G) idem auctum.

TAB. 104.

T E UCR I U M polium Lusitanicum pag. 66.

N. 1. Flos; (2) calyx cum pistillo, et bractea ad basin; (3) jdem auctus; (4) corolla cum staminibus magnitudine naturali; (5) eadem aucta.

TA B. 105 .

T EUC R I U M capitatum Lusitanicum pag. 68.

Fig. 1. Planta ad naturam expressa. Fig. 2, 2, capitula florum in summitate caulium quasi paniculata.

(aa) Folia caulina opposita, infernè visa; (b) eadem superna facie visa; (c) folia in axillis fasciculata; (d) Ilos; (e) calyx cum bractea ad basin; (E) idem auctus; $(f)$ corolla cum staminibus; (F) eadem aucta.

TA B. 106.

T'EUCR I U M Lusitanicum salviastrum pag. 7 I.

(a) Flos; (b) ejusdem calyx cunispillo auctus; (c) corolla cum staminibus parun aucta; (d) folium bractexforme sub supremis fori- 
bus; (e) foliun ex inlerioribus et maioribus supernè visum; $(f)$ idem infernà facie expectatuı.

$$
\text { TAB. } 107 .
$$

T E UCR I U M scordium lanujinosum pag. 73.

(a) Flos a latere visus; (b) calyx cum pistillo auctus; (c) corolla cum staminibus parum aucta In ramulo separato $(*)$ folia naturali, qua sæpe occurrunt, magnitudine expromuntur.

$$
\text { 'TAB. } 108 .
$$

\section{AJUG A Iva heteramtha pag. 75.}

(a) Flos, prout inapertus florescere solet; (b) calyx apertus, corollam tamen et genitalia omnino recondens; (c) idem longitudinaliter scissus et expansus; $(d)$ corolla genitalia tegens; (D) eadem simul cum genitalibus aucta; (e) pistilli germina quatuor, corollà denudata, cum stylo et stignatibus, quorum apici antheræ quatuor cruciatim impositæ sunt; $(\mathbf{E})$ eadem aucta; $(f)$ stylns cum duobus stigmatibus magnitudine naturali; $(F)$ idem auctus; $(g)$ anthere stigmalibus approximatæ, adauctæ uti quoque stylus; (hi) antheræ parum auctæ et seorsim visæ; $(i)$ semina, prout is fundo calycis maturescunt; $(l)$ eadem sejun. ctim observata; ( $m$ ) corolla sicca, in quatuor lacinias cruciformes divisa, prout á seminibus maturis separari solet.

(n) Calyx, corolla, et genilalia in flore aperto; $(o)$ corolla; $(p)$ germina quatuor cum stylo, stigmatibus, insinul et calyce longitudinaliter scisso atque expanso; $(q)$ semina matura.

TAB. 109.

\section{S T A CH Y S Lusilanica pag. 78.}

Planta cum sua spica terminali. (a) Flos; (b) calyx cum bractea ad ejus latus; (c) calyx longitudinaliter scissus et expansus; $(d)$ corolla; (e) calyx á latere visus; $(f)$ pistillum.

\section{Ta 110 .}

M A R R UB I U M cinercum pag. 81.

(a) Flos; (b) calyx cum pistillo; (c) corolla cum staminibus; (d) bractea.

TAB. 111 .

B A LLOTA vulgaris pag. 83.

Fig. 1. Caulis pars superior florens.

(a) Calyx, et bractea ad ejus basin; (b) idem longitudinaliter scissus et expansus; $(c)$ flos á fronte visus; $(d)$ corollæ labium inferius a Tom. $I I$. 
superiore separatum, cum staminibus, et parlicula tubi intus villosa; (e) pistıllum; $(f)$ semina.

NEPE T A mullibracteala pag. 37.

Fig. 2. Pars caulis superior florens.

(a) Bractea; (b) flus; (c) calyx cun pistillo aucto; (d) corolla cum staminbus aucla. TAls. 112.

OR I G A N UI vulgare virens pag. 89.

(a) Flos magnitudine naturali; $(b)$ calyx cum pistillo auctus; (c) corolla cum staminibus alleta; (d) bractea aucta.

$$
\text { TAB. } 113 .
$$

OR IG A NU M crelicum macrostachyum pay. 91.

(a) Fos magnitudine naturali; (b) calyx com pistillo auctus; (c) corolla cum staminibus aucta; (d) bractea aucta.

TAB. 114.

L A V INDULA viridis pag. 93.

(a) Flos naturali magnitudine; (b) calyx valde auctus; (c) corolla - aucta; (d) bractea.

$$
\text { Tab. } 115 .
$$

SI D E R I T IS linerifolia pag. 95.

(a) Bractea; (b) Hos; (c) calyx auctus; (d) corolla.

TAB. 116.

TH Y MUS albicurs pag. 27.

(a) Flos naturali magnitudiue; (b) calyx cum pistillo auctus; (c) iden longitudinaliter fissus el expansus; $(d)$ corolla cum staminibus aucta; $(e)$ folium; $(f)$ bractea.

$$
\text { TAB. } 117 \text {. }
$$

T H Y IN US capicllatus pag. 99.

(a) Flos ad naturam expressus; (b) calyx cum pistillo anctus; (c) idem longitudinaliter fissus el expansus; $(d)$ corolla cum staminibus aucta; (e) bractea; $(f)$ folium. 
TaB. 118.

TH YMUS cephalotos pag. 101.

(a) Fos naturali magnitudine; (b) calyx cum pistillo auctus; (c) idem longitudinaliter fissus et expansus; $(d)$ corolla cum staminibus aucta; $(e)$ bractea; $(f)$ foliun.

TА В. 119.

'TH Y MUS villosus pag. 102.

(a) Bractea; (b) folium; (c) flos magnitudiue naturali; (d) calyx cum pistillo auctus; $(c)$ idem longitudinaliter fissus et expansus; $(f)$ corolla cun staminibus ancta.

TAE. 120 .

T II Y MUS glabrutus pag. 103.

(a) Flos magnitudine naturali; (b) calyx com pistillo anctus; (c) idem verticaliter scissus et expansus; $(d)$ folium sub florıbus capitatis parum auctum; (e) corolla cun staminibus aucta.

TAl: 121.

TII Y MUS zygis silcestris pag. 105.

(a) Flos naturali magnitudine; (b) calyx cum pistillo auctus; (c) corolla cum staminibus aucta; (d) calyx longitudinaliter fissus et expansus; (e) folium.

$$
\text { TAB. } 122 .
$$

'TH YMUS zygis variabilis pag. 107.

(a) Flos arl naturam expressus; (b) calyx cum pistilló auctus; (c) idem verticaliter fissus et expansus; $(d)$ corolla cum staminibus aucta.

TAL. 123.

\section{EUPIR A S A aspera pag. 109.}

Fig. 1. Caulis pars inferior; Fig. 2. ejustern pars superior ramosa Alorifera.

(a) Flos magnitudine naturali; (b) calyx cum pistillo auctus; (c) corolla cum staminibus á latere visa, et valde aucta; $(d)$ eadem fance fissa, ut stamina labio superiore recondita clarius pateant; (e) braclea; $(f)$ capsula parum aucla. 
TAB. 124.

EUPHRASlA tenuifolia pag. 111.

(a) Flos naturali magniludine; (b) calyx cum pistillo auctus; (c) corulla valde ancta, á latere visa; (d) carlen, fauce fissa, ut stamina clariùs sub labio superiore conspiciantur; (e) bractea.

TAB. 125.

A N T I R R H I N U M maius latifolium pag. 1 I3.

N. 1. Flos; (2) calyx cum pistillo; (3) corolla; (4) eadem longitudinalıter fissa, ut stamina cernantur; (5) capsula; (6) semina.

TAB. 126.

A N T I R R I N U M meionanthum pag. 115.

(a) Flos; (b) calyx cum pistillo; (c) corolla; (d) eadem verlicaliter fissa, ut stamina conspiciantur; $(e)$ capsula calyce persistente cincta, et stylo emarcido terminata; $(f)$ semina; $(y)$ semen unum cum scrobiculis suis nimis auctum.

TAB. 127.

A NTIRR H I NUM calycinum pag. 117.

Fig. I. Speciei individuun flores a'bos ferens. Fig. 2, 3, duo alia cum floribus violaceis aut carulescentibus.

(a) Flos albus; (b) ejusilem corolla; (c) ca'yx cum pistillo; (d) corolla prædicta valde fissa, ut stanina conspiciantur; (e) flus violaceus, aut cæruleus.

TAB. 128.

A N T I R R H I N UM spurium inlegrifolium pag. 119.

(a) Flos; (b) calyx; (B) idem cum pistillo auctus; (c) corolla aucta; (d) eadem fissa, ut stamina in conspectum veniant.

TAB. 129.

A N TIRR H I N U M lanigerum pag. 120.

(a) Flos; (b) calyx cum pistillo parum auctus; (c) corolla parum aucta; (d) eadem fissa, et stamina prodens. 
TAB. 130.

A N T I R R H I N U M sparteum pag. 122.

(a) Flos magnitudine naturali; (b) calyx cum pistillo; (c) corolla; (d) eadem fissa, et stamina prodens; (c) capsula calyce persistente cincta; $(f)$ semina; $(g)$ semen unum minis auctum.

TAE. 131 .

A NTIRR H I N U II procox pag. 123.

(a) Flos naturali magnitudine; (b) calyx cum pistillo; (c) corolla; (d) eadem aucta, fissa, et stamina prodens; (e) capsula calyce cincta; $(f)$ semina; $(g)$ unum ex his valde auctum.

TAB. 132.

A NTIR RHIN U M virgatulum pag. 125.

(a) Flos magnitudine naturali; (b) calyx cum pistillo auctus; (c) corolla aucta; $(d)$ eadem fissa, et stainina prodens; (e) capsula aucta, calyce cincta; $(f)$ semina; $(g)$ unum ex his valde auctum.

TAB. 133.

A NTIRRHIN UM saxatile pag. 127.

(a) Flos naturali magnitudine; (b) calyx cum pistillo parum auctus; $(c)$ corolla aucta; $(d)$ eadem fissa et stamina prodens.

TAB. 134.

A N'T I R R H I N UM glutinosum pag. 129.

(a) Flos ad naturam expressus; (b) calyx cum pistillo auctus; (c) corolla aucta; $(d)$ eadem fissa et stamina prodens; $(e)$ capsula calyce persistente cincta; $(f)$ semina; $(g)$ unum ex his cum suis scrobiculis valde auctum.

$$
\text { TAB. } 135 .
$$

A N T I R RHINUM linogriseum pag. 131.

(a) Flos; (b) calyx cum pistillo; (c) corolla; (d) eadem aucta, fissa, et stamina prodens; (e) capsula calyce cincta; $(f)$ semina; $(g)$ unum ex bis cum suis rugis valde auctum.

Tom. II. 
TAB. 136.

A N T I R R H IN U M supphirinum pag. 133.

(a) Flos; (b) calyx cum pistillo; (c) corolla; (d) eadem valde aucta, fissa, et stamina prodens; $(c)$ capsula calyce cincta et aucta; $(f)$ semina; $(g)$ unum ex his valde auctum.

TAB. 137.

A NTIRRH I N U M amethysteum pag. 134.

Fig. 1. Planta et Fig. 2. ipsius varietas bipunctala. (a) Flos naturali magnitudine; (b) calyx cum pistillo auctus; (c) corolla aucta; (d) eadem fissa, staminaque promens; $(e)$ capsula calyce cincta; $(f)$ semina; $(g)$ unum ex his valde auctum.

\section{TAR. 138.}

A NTIRRHINUM polygalcefolium pag. 136.

(a) Flos; (b) calyx cum pistillo; (c) corolla; (d) eadem aucta, fissa, et stamina prodens.

$$
\text { TA B. } 139 .
$$

\section{A NTIRRHIN U M pyrcnaicum pag. 137.}

(a) Flos naturali magnitudine; (b) calyx cum pistillo parum auctus; (c) eadem fissa, et stamina prodens.

$$
\text { TA B. } 140 .
$$

A N T I R R II I N U M glaucophyllum pag. 138.

(a) Flos naturali magnitudine; (b) calyx cum pistillo; (c) corolla; (d) eadem aucta, et fissa, ut stamina in conspectum veniant.

$$
\text { TaB. } 141 \text {. }
$$

A N T IR R H I N U M diffusum pag. 139.

(a) Flos naturali magnitudine; (b) calyx cum pistillo auctus; (c) corolla aucta; (d) eadem fissa, et stamina promens; ( $e$ ) capsula calyce cincta, et stylo emarcido terminata; $(f)$ semina; $(g)$ unum ex his valde auctum.

TAB. 142.

OR OB A N C HE barbata pag. 146.

Fig. 1. Planta ad naturam expressa. (a) Flos simul cum bractea re- 
curva; (b) caljecis foliola duo bifida cum bractea; (c) ejusdcm foliola duo indivisa, insimul et lractea; $(d)$ corolla; $(c)$ ejusden pars inferior í superione separata, et stamina patefaciens; $(f)$ pistillum; $(g)$ capsula; (h) eadem aperta.

\section{ANTIRR IINUM mullipunctalum pag. 140.}

Fig. 2. Planta magniludine, qua sapissime occurrit. N*1. Flos cum bractea sub pedicello: (2 calyx cum pistillo; (3) corolla; (4) ejusdem labimn inferins cmu gibbo palati mulipmnctato; (5) jdem intus maculatum: (6) lahium superius; ( 7 ) corolla apertis labiis stamina prodens; (8) stanina ancta: (9) pistilum; (10) capsula calyce cincta ; (11) eadem denticulati: dehiscens, ejusque dissepimentmu; (12) semina; (13) unum ex his valde anctum.

TA B. 143.

\section{A N A R RHINUM bellidifolium pag. 142.}

(a) Flos naturali magnitudiue; (b) calyx cum pistillo parum auctus; (c) corolla aucta; (d) eadem, tubo longitudinaliter fisso laxatoque, stamina prodems.

\section{TAB. 144.}

\section{A NARR II I U M Duriminium pag. 144.}

(a) Flos ad naturam expressus; (b) calyx cum pistillo parum auctus; (c) corolla aucta; (d) eadem, tubo verticaliter fisso laxaloque, staunina promeus.

$$
\text { TAB. } 145 .
$$

\section{OROB A N H E ramosa pag. 152.}

Fig. 1. Planta, prout sxpe occurrit, caule ramoso. Fig. 2. ejusden varietas, canle sin.plicissino.

N. 1. Flos a latere visus, cum bracteis al hasin; (2) calyx cum tribus bracteis; (3) idem cum duabus tantin bracteis, avulsa tertia, ut ipsius cavitas clarì in conspectum veniat; (4) corolla a latere visa; (5) eaden á fronte visa ; (6) stamina, stylus, et stigmata; (7) capsula aperta, valvulis intus visis; (8) cadem clausa.

OROB A N C H forlida Lusilanica pag. 149.

Fig. 1. Plantæ pars infina cum radice. Fig. 2; ejusdem pars superior cum spica. (a) Flos cum bractea al basin; (b) calyx cum bractea; (c) calyx absque braclea visus; (d) calyx, prout in medio interdum rumpitur, et quasi bifolius redditur, illum ovario corollaque premente; $(e)$ corolla; $(f)$ stamina imo corollxe tubo (qui hic in lamellæe formam protenditur) inserta, ibique singula binervia, biglandulosa; $(g)$ pistillum cum glandula in basi germinis; (h) capsula; (i) ejusdem valvulæe apertx. 
TAL. 146.

R H I N A N T H US trixago pag. 154.

Fig. 1. Plantx typus, quo sxpius occurrit. Fig. 2, varietas grandifolia, et caule altiori, ramosiori. Fig. 3, varietas nana. (A) Flos; (b) calyx cum pistillo; (c) corolla; (d) eadem é latere fissa, et stamina prodens; (c) anum é foliis floralibus inferioribus; $(f)$ alterum ex superioribus; ( $g$ ) capsula.

TAB. 147.

SC ROPH ULA R I A sublyrata pag. I56.

Fig. 1. Plante pars inferior. Fig. 2, ejusdem pars supreina racemosa. Fig. 3. folium radicale. (a) Flos; (b) calyx cum pistillo parum auctus; (c) corolla aucta, álatere visa, (d) eadem á fronte visa; (e) capsula calyce persistente cincta.

'ТА 148.

SCROPHULARIA Herminii pag. 158.

(a) Flos; (b) calyx cum pistillo auctus; (c) corolla aucta, á latere visa; (d) eadem á fronte visa; (e) capsula infernè calyce persistente cincta, el aucta.

\section{TAB. 149.}

D I G I T A L I S purpurea tomentosa pag. 159.

(a) Flos cum minor; (b) calyx cum pistillo; (c) corolla cum minor fissa, et expansa, stamina podens; (d) bractea.

N. 1. Capsula submatura, calyci persistenti aperto insilens cum pedunculo et bractea sub ijso, superne stylo emarcido terminata; (2) capsula valvulis bifidis erectisque dehiscens; (3) eadem valvulis profunde bipartitis, patentibusque, prout aliquoties demum aperiri solet, insimul et seminum receptaculum in centro; (4) semina.

\section{TAB. 150.}

\section{I G IT A L I S thapsi pag. 161.}

(a) Calyx; (b) idem parum auctus cum pistillo; (c) corolla á latere visa; (d) eadem á fronte visa ; (c) eadern tissa el expansa, ut stamina prodat; (f) capsula ancta el transverse secta, cum receptaculo lamellato seminum in centro.

$$
\text { TAE. } 151 .
$$

UR T I C A caudata pag. 163.

Fig. 1. Speciei, cum dioica, individuan masculum. Fig. 2, ejus- 
dem individuum fæmineum: Fig. 3, speciei, cum monoica, seu individui monoici pars caulis infima faminea, qua superiori mascula unita consideranda (qualis illa Fig. 1.) Fig. 4, stipula tam dioicis quâm monoicis propria.

(a) Spica mascula; (b) flos masculus clausus; (B) idem auctus; (c) idem apertus et auctus, suis cum quatnor foliolis, staminibus, et pistilli rudimento; (d) stamina cum pistilli rudimento glanduloso, aucta; (c) una ex spicis frmineis longioribus; $(f)$ flos fæmineus; (F) idem auctns; $(g)$ calycis foliola aucta ; $(h)$ germen suo cum stignate sessili, villoso; (H) idem auctum; (i) semen; (I) idem auctum.

TAB. 152.

VER B A SCUM crassifolium pag. 166.

(a) Flos; (b) calyx et pistillum; (c) corolla cum staminibus; (d) unum ex staminibus valde auctum; $(e)^{\circ}$ bractea.

TA B. 153.

VER B A SC U M macranthum pag. 168.

(a) Flos; (b) calyx cum pistillo; (c) corolla cum staminibus sibi affixis; (d) unum ex duobus filamentis basi tantummodo villosis, auctum; $(e)$ aliud ex tribus omnino villosum, etiam auctum; $(f)$ bractea, quæ sub floribus superioribus breviter decurrit.

TAB. 154.

VER B A SCUM blattarioides pag. 169.

Fig. 1. Caulis pars superior; Fig. 2, spica terminalis. (a) Bractea; (b) flos; (c) corolla cum staminibus sibi affixis; $(d)$ calyx cum pistillo; (e) unum ex duobus staminibus basi tantum villosum, auctum; $(f)$ aliud ex trihus brevioribus omnino villosum, etiam auctum; $(g)$ capsula calyce persistente cincta; (h) eadem aucta, et transversè dissecta, cum dissepimento et seminum receptaculo fungoso.

TAB. 155.

L I T H OSPER M U M fruticosum pag. 171.

(a) Flos; (b) calyx cum pistillo; (c) corulla; (d) eadem tubo fisso, ut stamina prodat.

TAB. 156 .

A NCHUS A italica pag. 173.

(a) Calyx; (b) corolla fissa et expansa, squamas atque antheras promens; (c) ejusdem tubus scissus et expansus cum syuamis pilosis in apice; (d) pistillum; (ee) semina.

Tom, II. 
A NCHUSA undulaia pag. 175.

(a) Flos; (b) calyx cum pistillo; (c) corolla; (d) eadem fissa et expausa, squanulas atque stamina quinque fancis promens.

$$
\text { TAB. } 158 .
$$

\section{Y NOGLOSSUM clandestinum pag. 177.}

(*) Plantx pars infiua; (**) ejusdem pars suprema florens. N. 1. Calyx et corolla in anthesi; (2) corolla, limbi laciniis intronsum flexis, prout in anthesi observatur; (3) eadem fissa et expansa. extus visa; (4) eadem intus observata cum squamulis et stamiuibus; (5) calyx híc de industria apertus, ut pistillum promatur; (b) semina matura jarmm aucta, insimul et calyx sub ipsis.

(a) Calyx reflexus sub seminum receptaculo in stylum persistentem desinente; (b) unum ex quatuor seminibus é latere exterure visum cum suis aculeolis; (c) idem é latere interiore; (d) tres ex aculeolis apice uncinatis valde aucti; (c) semen decorticatum.

TAB. 159.

\section{Y NOGLOSSUM pictum pag. 179.}

Fig. 1. Plantre pars inferior. Fig 2, ejusdem pars superior ramosa, racemosa (a) Flos; (b) calyx; (c) idem auclus cum pishllo; (d) corolla; $(e)$ eadem, tubulo fisso, expansa, el squamas staminaque in fauce promens; $(f)$ semina quatuor nuculaformia, quorum duo dimilio decorticata, omnia recepticulo, in stylum persistentem desinenti, adhresa.

\section{TAE. 160.}

R U B I A silvestris pag. 181 .

N. I. Folium ex inferioribus caulis postice visum; (2) flos; (3) ramus panicula frucliferus; (4) bacce dux coalite; (5) bacca monusperma alià abortente; (6) eaden cum semine et plautula seminali transverse secta; ( 7 ) eadem cum semue secta, plantula seminali tamen illiesa servala.

$$
\text { Tse. } 16 \text { \%. }
$$

\section{A C A R A gummijera pag. 183.}

Fig. * Planta brevissimus scapus solitarius, foliis radicalibus contectus, et capitulo florifero terminatus. Fig. ** Capituli receplaculum carnosum, verticaliter dissectum, intus alveolos paleasque, extus calycis interioris squamas, promens. N. 1. Una ex bracteis, quibus calyx exterior obvaliatur; (2) unum ex foliolis tricuspidatis calycis externi; 
$(3,4)$ calycis interni squamx inferiores et supremx; (5) flos simul cum suo pappo in anthesi; (6) flos dempto pappo; (7) pistillum; (8) pappus explicatus, et prout in seminum maturitate; $(9, a)$ corolla longitudinaliter fissa. (b) stamina cum suis antheris caudatis et auctis; (10) stylus cum stigmale auctus; (11) semen cum sua corona pilosa; (12) idem longitudinaliter dissectum.

TAR. 162.

\section{B A LS A M I'T A annua pag. 186.}

(a) Calyx communis cum flosculis; (b) ma ex ipsius squamulis interioribus apice lutea; $(c)$ flosculus tam disci quim radı; (d) idem auctus; (e) semen maturum; $(f)$ idem auctum, quale indisco; (y) idem, quale in radio. etiam auctum; (h) plantula sominalis dicotyledonea denudata, et aucta; (i) seminum receptaculum, et calyx in eorum maturitale patentissinus.

TAR. 163.

\section{A NACYCLUS aareus pag. 188.}

(a) Calyx communis cum receptaculo communi conico in centro; (b) flos longitudinaliter dissectus; (c) flusculus radii fiemineus valde auctus; (d) flosculus disci hermaphoditus similiter auctus, veluti palea ad ejus latus, ex receptaculo desumpta; (c) semen maturnm ad naturam expressum.

TAE. 164.

I N U L A viscosa pag. 120.

(a) Flosculus radii ligulatus fremineus; (A) jdem anctus; (b) flosculus disci tubulatus masculus; (B) idlem aucuss; (C) idem, corolla longiturlinaliter tissa el expansa, ut genitalia c arius conspiciantur; (D) corolla cun staminibus plus adancta, et iusuper antherarum tubus fissus et expansus, ut earum setæ binæ, in quas singulx basi desinunt, apertius manifestentur; (e) semen cum suo pappo; (E) idem auctum; (f) seminum receptaculum, et caly $\mathrm{x}$ in eorum maturitate admodum expansus; (G) receptaculụm excavato-punctalum, valde auctum.

TAB. 165.

\section{USC U T A Europcea barbuvea pag. 192.}

Fig. 1. Vitis ramus cum racemo maturo et plantâ. Fig. 2, ista pedunculis racemi adhærens, et ex illis pendens. Fig. 3, plantæ ramus lougus seorsim visus, in quo supernè florum glomeruli duo, et infernè ad ramulorum basin squamulæ steriles.

( ) Flos; (b) calyx; (c) corolla; (d) endem longitudinaliter fissa et expansa, cum stammibus, valde aucta; (e) calyx cum germine et stylis auclis; $(f)$ capsula calyce cincta; $(g)$ eadem aperta cum seminibus in situ; (h) semina separata; (i) plantula scminalis monocotyledonea, 
spiraliter circa albumen convoluta, et valde aucta; $(l)$ eadem absque albumine, distensa.

$$
\text { TAB. } 166 .
$$

E R Y NG I U M amelhystinum dilatatum pag. 194.

(a) Flosculus cum palea ad hasin; (A) jdem insimul cum palea auctus; (b) corolls petalum; (B) idem auctum; (c) fructus bipartibilis, dispermus; (C) idem parum auctus; $(d)$ unum ex duobus seminibus tridentatum; (e) aliud bidentatum.

$$
\text { TAB. } 167 .
$$

\section{SEL I N U peucedanoides pag. 196.}

Fig. * Planta pars superior umbellifera. Fig. ** Folium ex radicalibus. Fig. ***: ejusdem petiolus in sua basi.

N. 1. Flos magnitudine naturali; (2) unum ex corollæ petalis; (3) idem auctum; (4) pistillum.

(a) Fructus dispermus, bipartibilis; (A) idem auclus; (b) fructus transversè dissectus; (B) idem auctus; (c) unum ex duobus fructûs seminibus dorso visum; (C) idem auctum; (d) ipsum ventre plano; (D) et istiusmodi auctum.

TAB. 168.

\section{A UCUS halophilus pag. 198.}

(a) Umbella, dum floret, supernè visa; (b) eadem tunc postice ob. servata; $(c)$ eadem fructifera; (d) una ex umbellulis radii, dum floret, supernè visa; $(c)$ eadem poslice unnc visa; $(f)$ una ex unbellulis disci posticè visa; $(g)$ flosculus in centro umbellæ universalis situs; $(h)$ unus ex flosculis exterioribus; $(H)$ idem auctus; (i) vmbeliula una fructifera; ( $l$ ) pistillum parum auctum; $(m)$ fructus bipartibilis, dispermus; (M) unum ex duobus seminibus transverse dissectum, et valde auclum.

TAB. 169.

\section{A TH A M A N A lurbith (A) pag. 200.}

Caulis, rami, folia, flores, et plantæ alia, quæ in icone etsi minorata, ad natura nn tamen verè conformia exprimuntur.

TAB. 170 .

A T H A M A N T A turbill (B) pag. ibid.

Fig. 1. Plantæ folium radicale, naturali magnitudine. Fig. 2, umbella universalis florens. Fig. 3 , una ex partialibus posticè visa.

(a) Flosculus naturali magnitudine; (A) idem parum auctus; (b) corollæe petalum parum auctum, el anticè visum; (c) idlem postice observatum; (d) pistillum cum calyculo supero; (D) iden auctum; (e) 
fructus dispermus; $(f)$ ejus semina uti disjungi incxptant; $(G)$ eadem conjuncta et aucta transverse dissecta.

$$
\text { TAB. } 171 \text {. }
$$

S I S Y M B R I U M catholicum pag. 202.

(a) Racemi apex corymbosus; (b) calyx; (c) flos; (d) corollæ pelalum; (e) stanen; $(f)$ pistillum; $(y)$ siliqua.

TAB. 172 .

SI N A P I S incana pag. 205.

(a) Flos; (b) calyx; (c) corolla petalum; (d) stamina cum pistillo; (e) siliqua rostrata; $(f)$ eadem et rostrum monospermum separatum; $(g g)$ ejusdem valvulx cum seminibus apertx; $(h)$ semina.

\section{TAB. 173.}

\section{O L CHIC U MI Lusitanum (A) pag. 211.}

(a) Bulbulus é latere veteris bulbi, cui infernè adhæret, autumno florens; (b) corollæ una ex laciniis petaliformibus, quæ plus minusve tesselatæ esse solent; $(c)$ bulbus vetus denudatus, medıoque Iransversè dissectus, insimul el bulbulus lateral s sexflorus cum duabus spathis (híc longitudinaliter fissis) ipsis et floribus adhuc subterraneis; (d) bulbulus cum cauliculo, pedicello et pistillo unius floris corollà denudato; (e) bulbulus cum cauliculo brevissimo; $(f)$ pedicelli tres cauliculo impositi; (y) unius floris pistillum tubo corollæ discisso incumbens; ad ejusdem latus duorum florum germina, quibus styli dissecti.

$$
\text { TAB. } 174 \text {. }
$$

\section{O L C H I C U M Lusitanum (B) ibid.}

(aa) Bulbus novus, prout vere el maturo fructu observatur; (b) cicraticula orbicularis, ubi veteris bulbi radiculæ hærebant; (c) tuberculum unguiforme, sub cujus integumento, et alio in latere, bulbuli gemma latet sequénti autumno floralis; (d) folium infimum, seu radicale, bulbum novum tunicans, el caulem sub terra pauloque supra ipsam vaginans; ( $e$ ) folia suprema capsulas aggregatas involventia; $(f)$ capstia, ex tribus partialibus composita, dehiscens; $(y)$ eadem transversè dissecta; $(h)$ semina

TAB. 175.

POL Y G A L A microphylla pag. 214.

(a) Flos; (b) calyx parum auctus; (c) corolla aucta; (d) eadem aperta cum staminibus.

Tom. II. 
POL Y G A A Monspeliaca pag. 216.

(a) Flos: (b) calrx parum auctus cum pistillo: (c) corolla aucta ; (1) eadem aperta cum staminibus in carina cristata; (e) una ex dua. bus capsula ralvis, dissepimentum et loculos monospermos pronens.

TAB. $17 \%$

\section{ONONIS Hispanica pag. 218.}

$(1,2)$ Flores cum pedunculis aristatis, et folia cum stipulis petiolo adnatis; ( 3 ) calyx: ( 4 ) corollæ petala: (a) vexillum (bb) alx (c) carina; (j) staminum cylindrus cum strlo exerto; (6) idem longitudinaliter fissus: ( 7 ) pistillum; (8) legumen; (9) idem apertum; (10) seuina.

$$
\text { TAE. } 1: 8 .
$$

\section{SEDUII Lusitanum pag. 220.}

Fig. 1. Pars infima caulis; Fig. 2, ejusdem pars terminalis florens.

(a) Flos: (b) calyx longitudinaliter tissus et expansus; (c) petalum; (d) stamiua duo; (e) calyx cum pistillis primum in pyramidem conjunctis; (f) pistilla sensim laxala; ( $g$ ) eadem cum squamulis nectariferis ad basin; (h) unum ex pistilis seorsim risum; (i) capsulæ ferè naturæ: (I) exdem aucı : (l) una dehiscens aucta; ( $m$ ) alia etian aucta matura semina promens; $(n)$ semina; $(N)$ unum ex his valde auctum.

$$
\text { TА B. } 179 .
$$

II A L I A mauriliana pag. 223.

Fig. 1. Caulis pars suprema florens.

X. I. Flos; (2) calyx duplex, interior semiclausus; (3) iidem aperti, et posticè risi; (4) calsx exterior; (5) calrs interior; (6) capsula coinposita matura, calrcibus contecta; ( 7 ) eadem calrcibus nuda; $(8-a)$ una ex capsulis partialibus; $(8-b)$ eadem aucta; $(9-a)$ semen; $(9-b)$ idem auctum.

\section{LA TATER A silvestris pag. 225.}

Fig. 2. Caulis pars suprema florens.

(a) Flos; (b) calrx duplex, uterque semiclausus; (c) calyx duplex, uterque apertus et postice visus; (d) calyx exterior; (e) calyx interior; (f) tubus staninum cum stigmatibus ex ipsius apice exertis; ( $g$ ) pistilIum; (h) capsula composita matura, calscibus contecta; (i) eaden ca. II cibus nuda: (l) una ex capsulis partialibus; $(L)$ eadem aucta; $(m)$ senien: (M) idem auctum. 
TA B. 180.

RANCUNCULLS dimorphorhizus pag. $22 \%$

(a) Radix supernè bulbosa longitudinaliter dissecta; $(b)$ eadem inferne fasciculata; (c) calyx, stamina, et pistilla: (d) unum ex petalis corollæe cum squanula nectarii ad unguem; (c) stamen; $(f)$ pistillorum capitulum; (F) idem fructiferim; $(g)$ unum ex semiuibus seorsim risum.

\section{A L Y SSU II collinum pag. 209.}

(a) Flos; (A) ejusdem calyx auctus et apertus: (b) corolla naturali magnitudine; (B) ejus petalum unum auctum; (c) stamina aucta; $(d)$ pistillum; (D) idem anctum; (e) silicula; $(f)$ ejusdem valvulæ; $(g)$ dissepimentum; (h) semina.

TAB. I8I.

RANUNCULUS adscendens pag. 229.

(a) Flos; (b) unum ex petalis cum squamula nectarii ad unguem; (c) pistillorum capitulum, et calsx reflexus; (d) calccis foliolum unum; (c) semina in capitulum collecta; $(f)$ ex his seminibus unum seorsin risum. 
Pag. Lin.

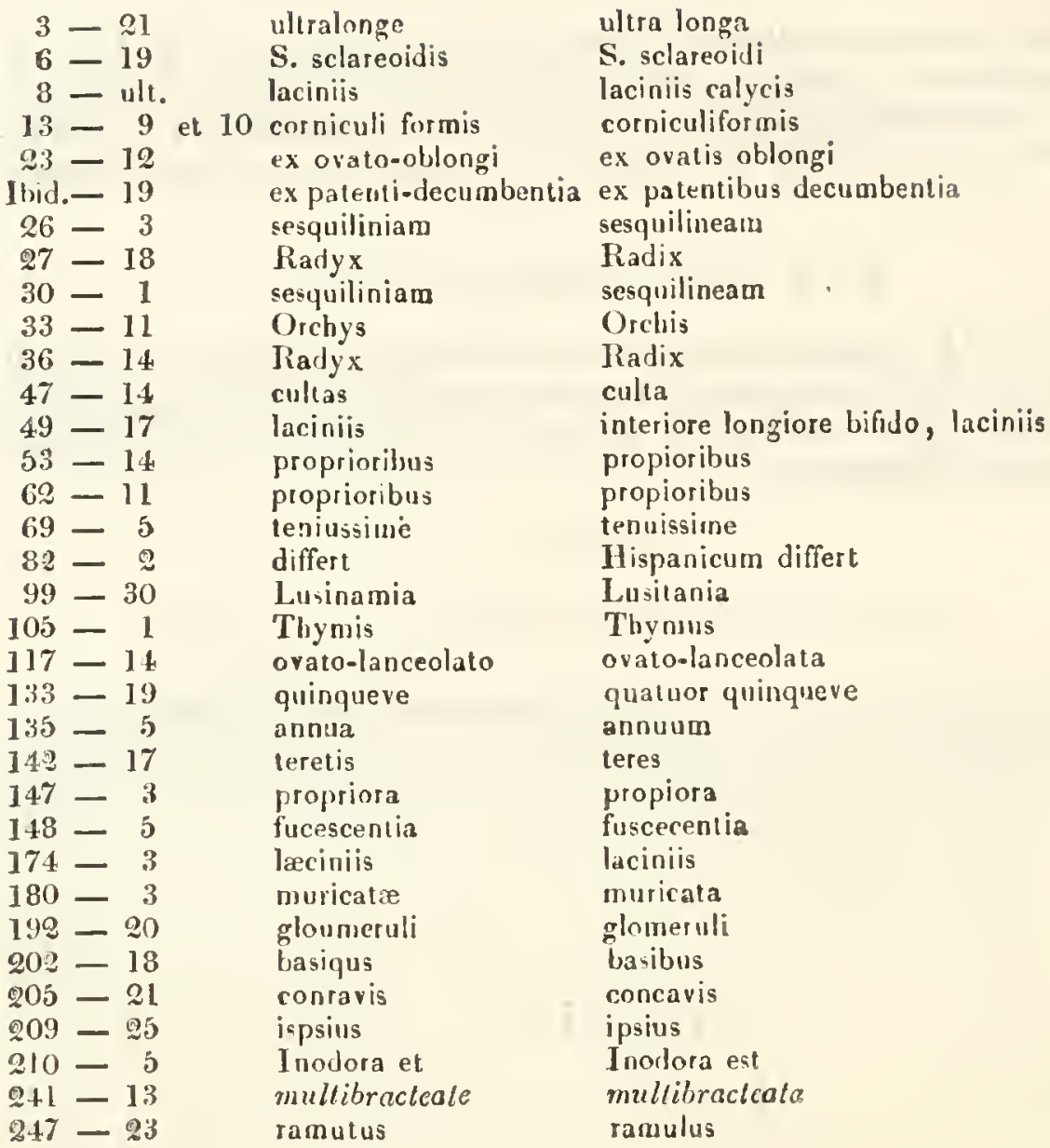




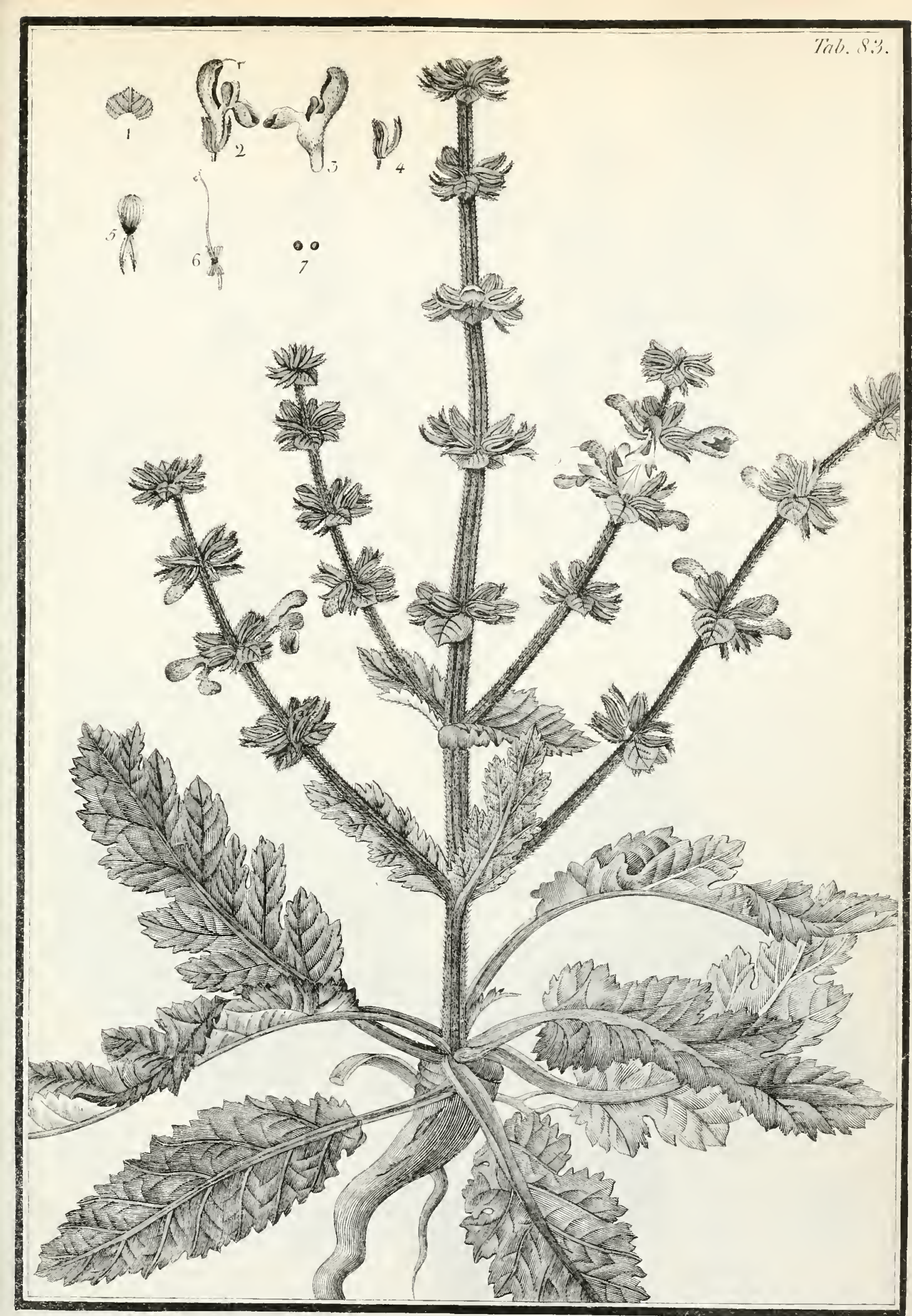

SALTHA hemali. 




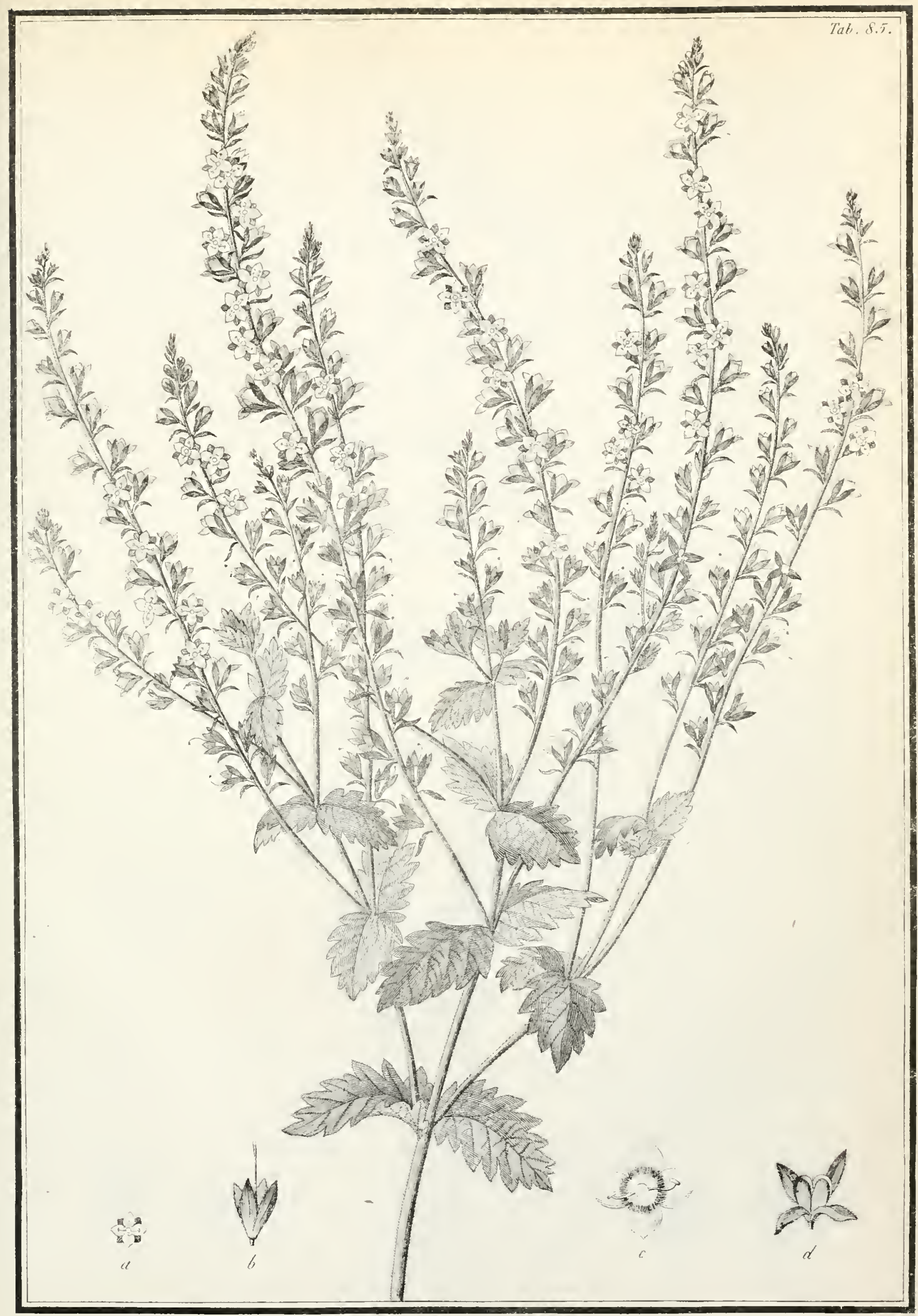





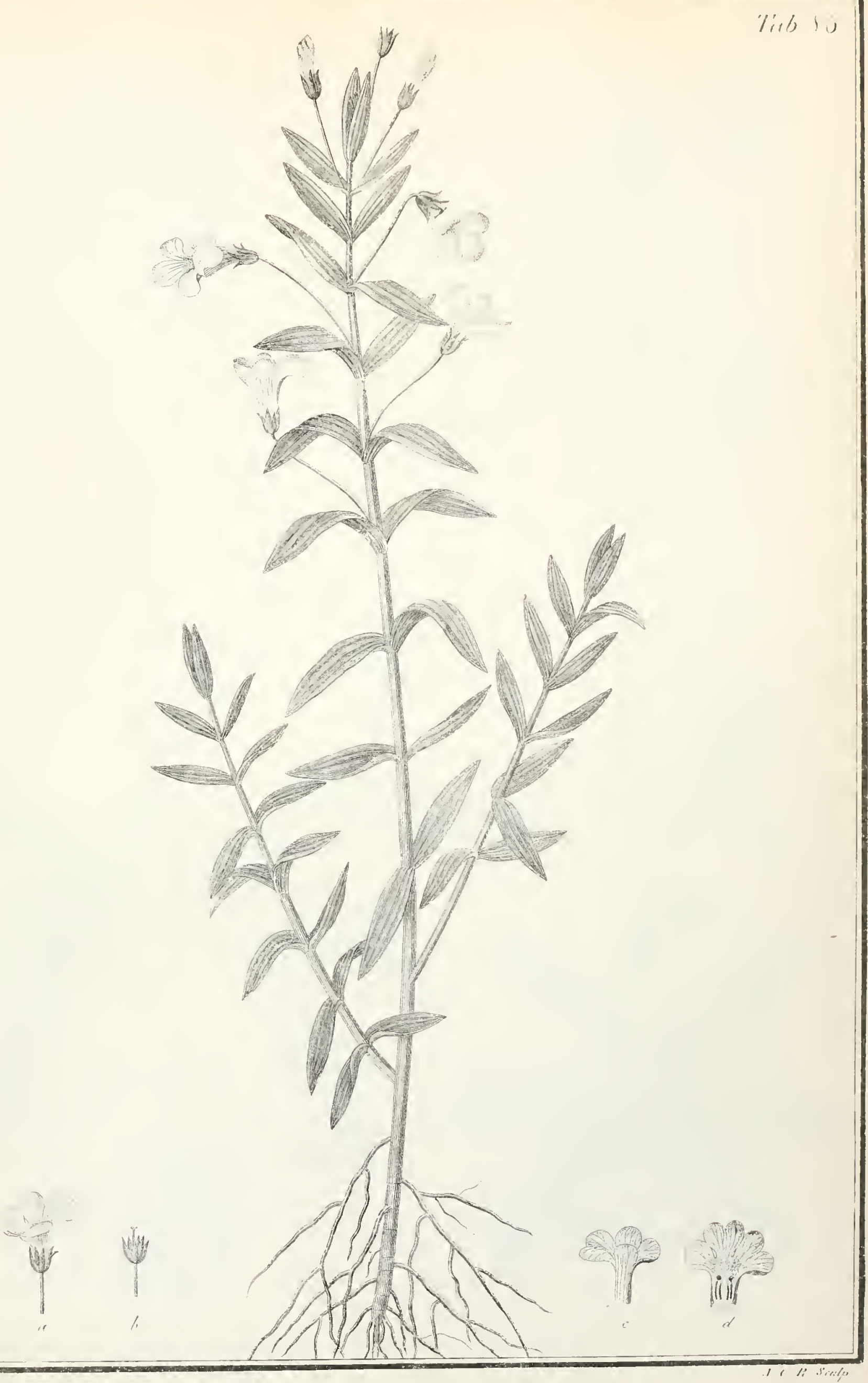

GIRATTOAA lenefintere 



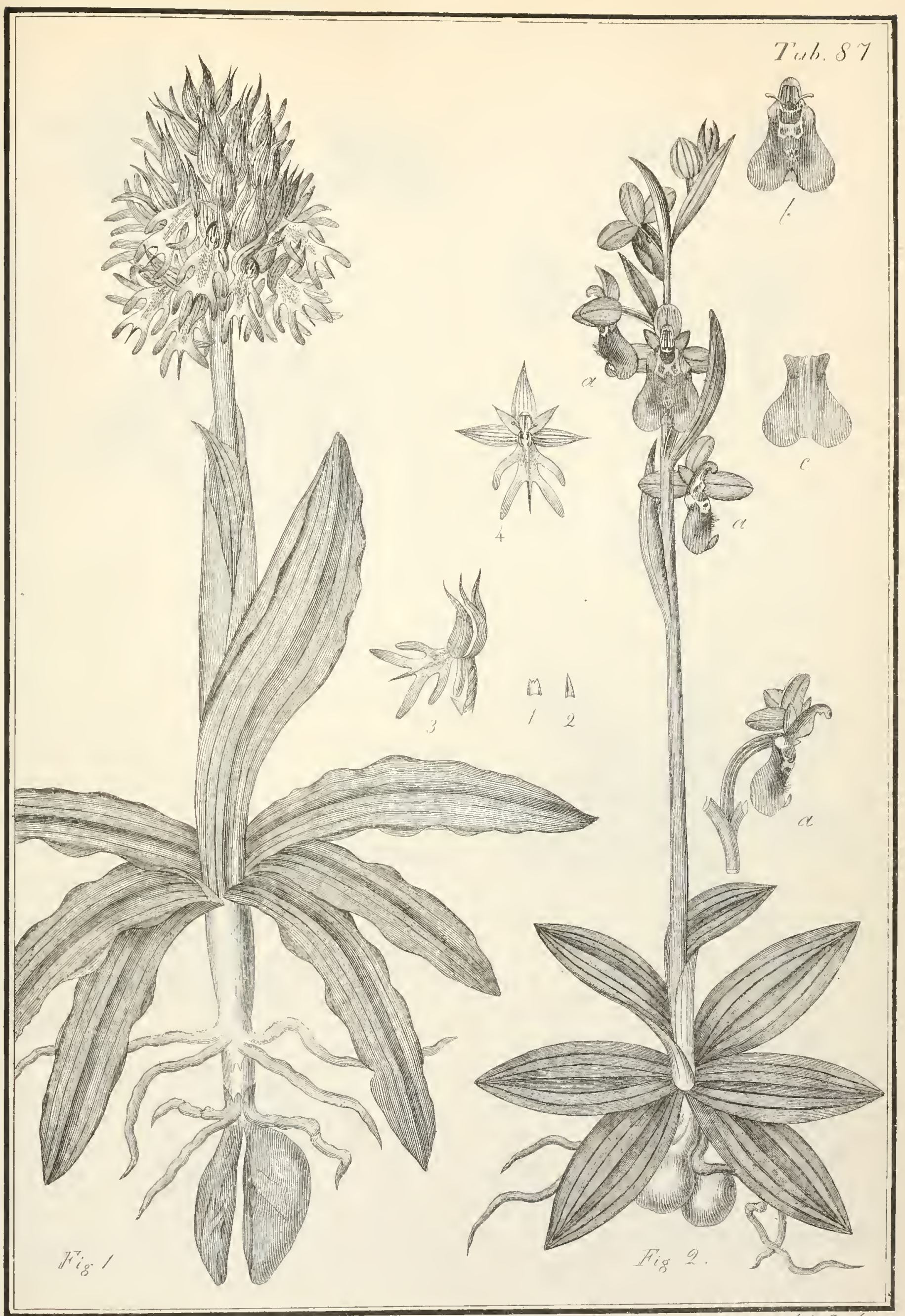

1. DRCHTS Gengicrement.

III OPHIRTS temetrmedizifered 



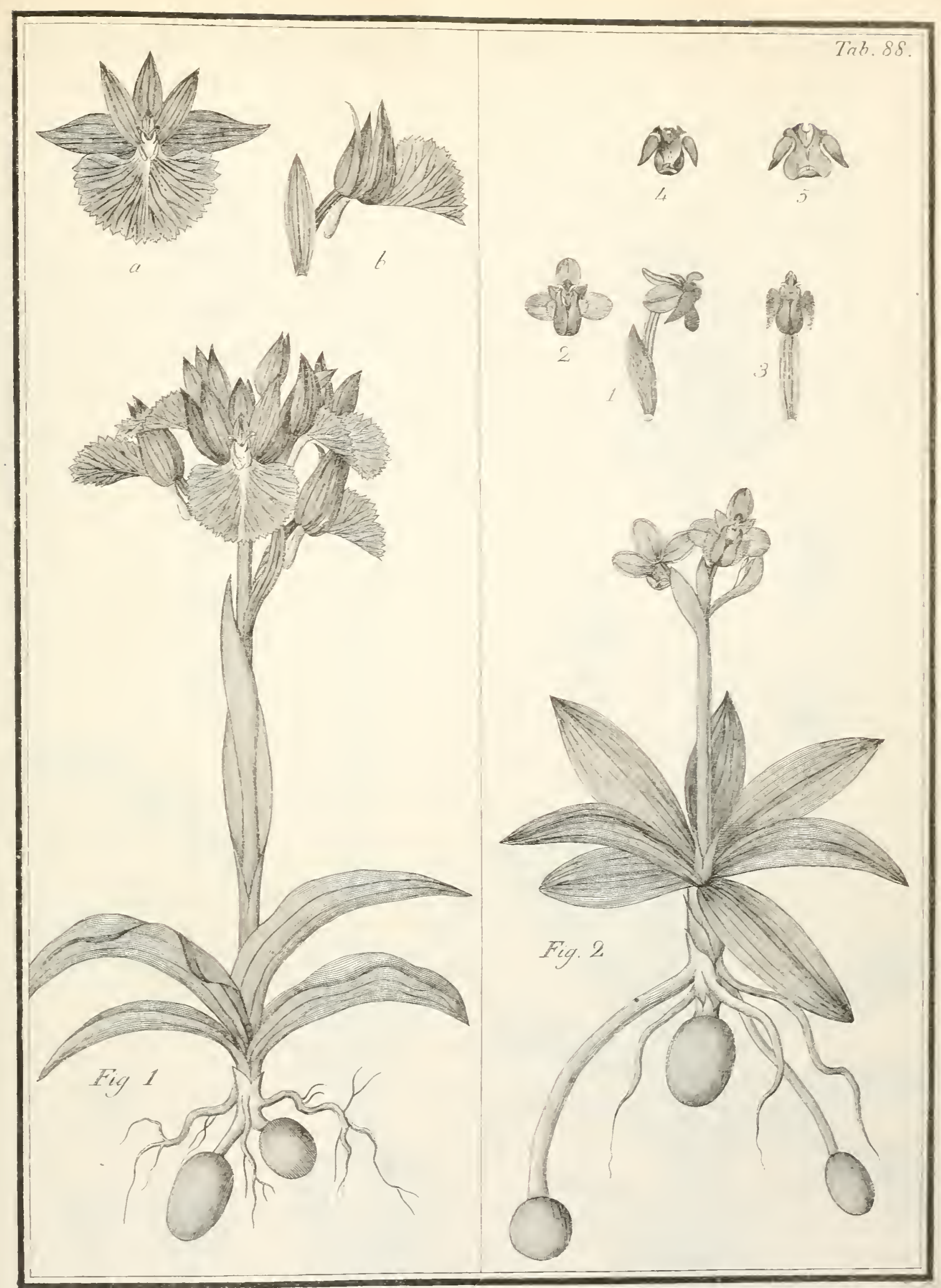

I ORCHIS papilonacen nubra -

II. OPHRYS labrefasa 




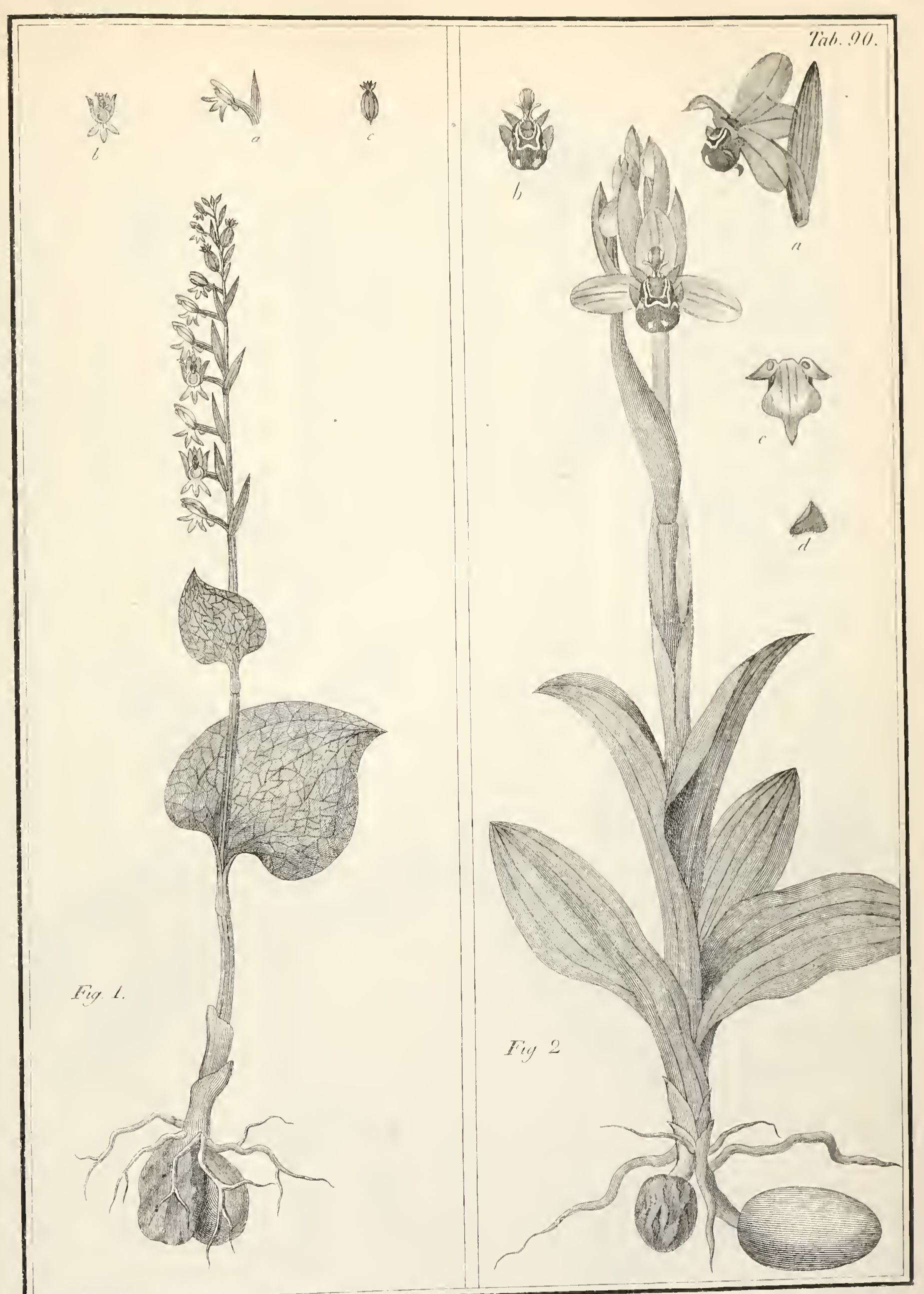

1. ORCHIS icidete

2. OPIIEXS apefere sublerratizun 



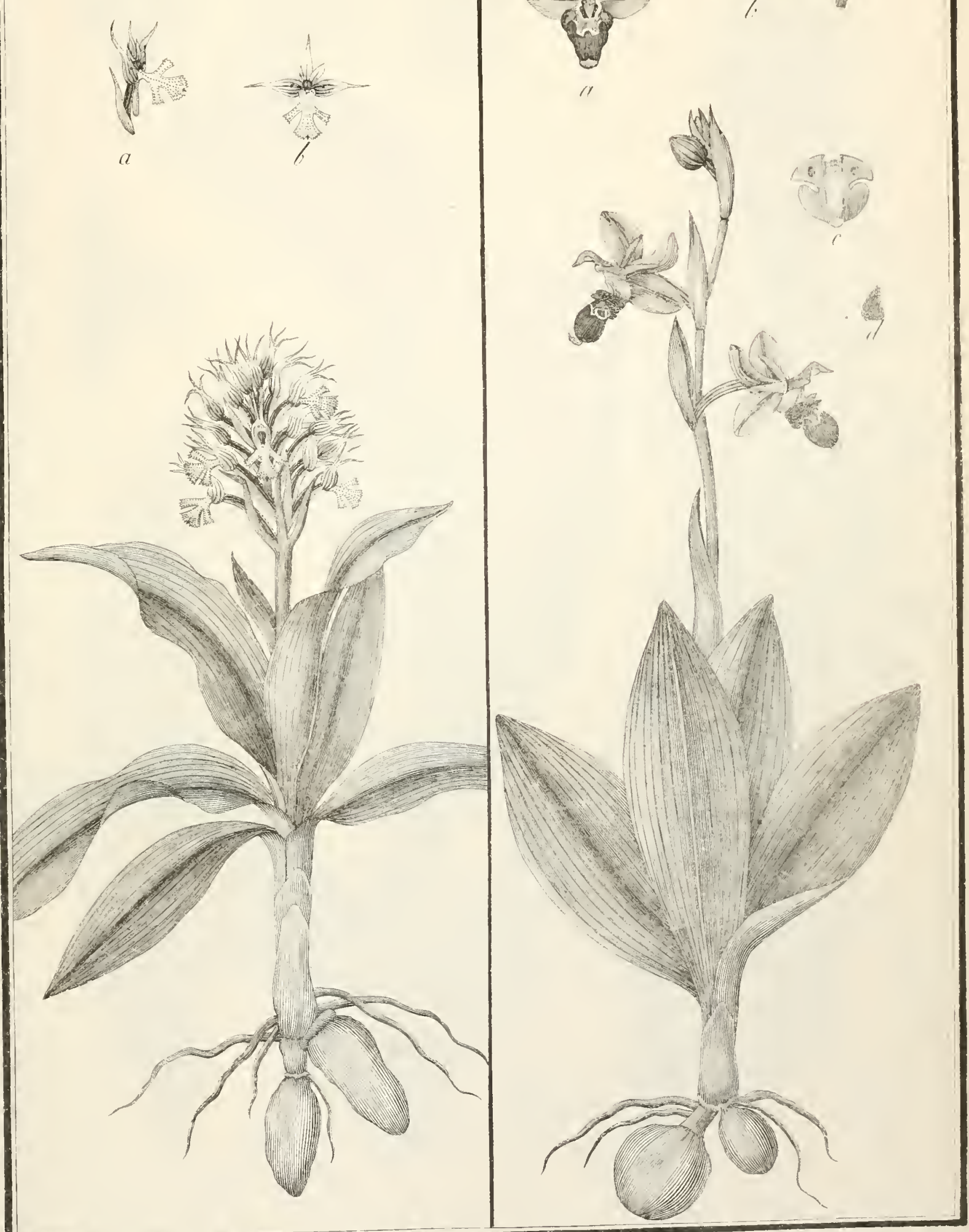

1.ORCHIS murre

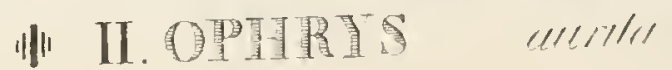





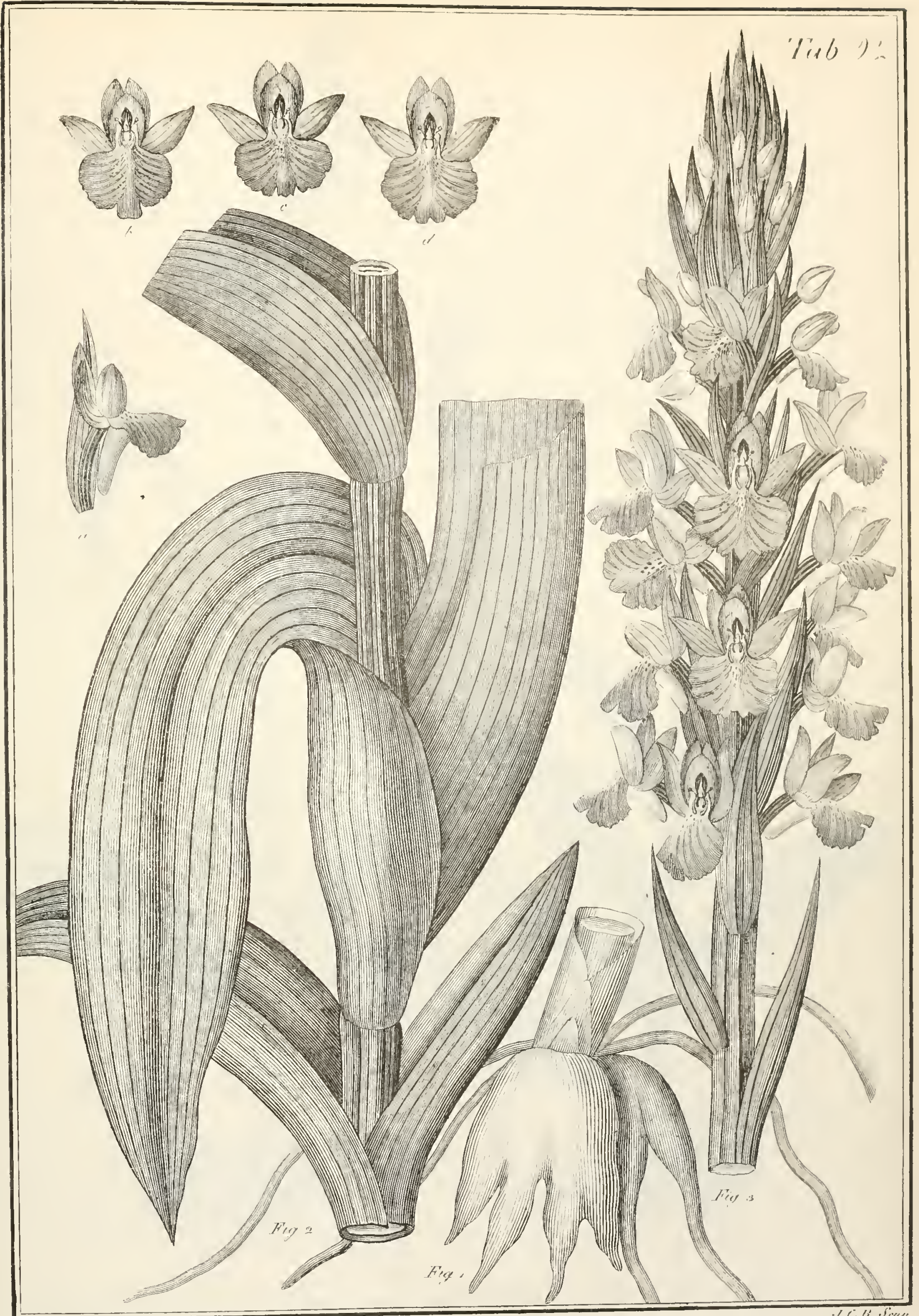





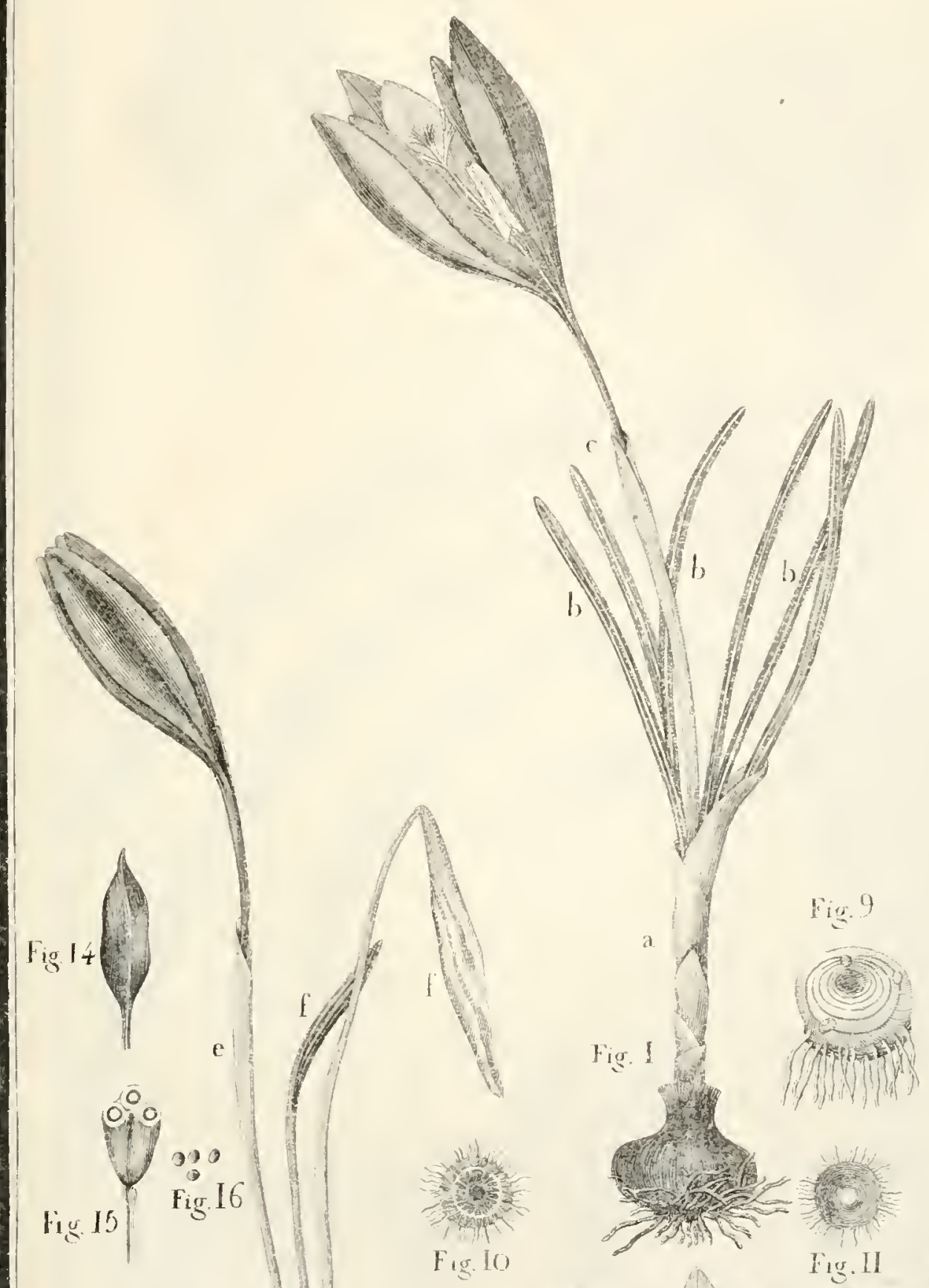

lig. 7

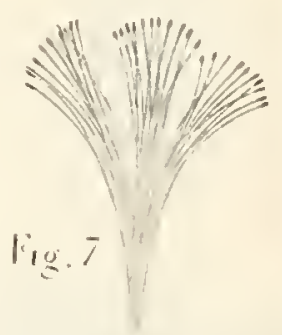





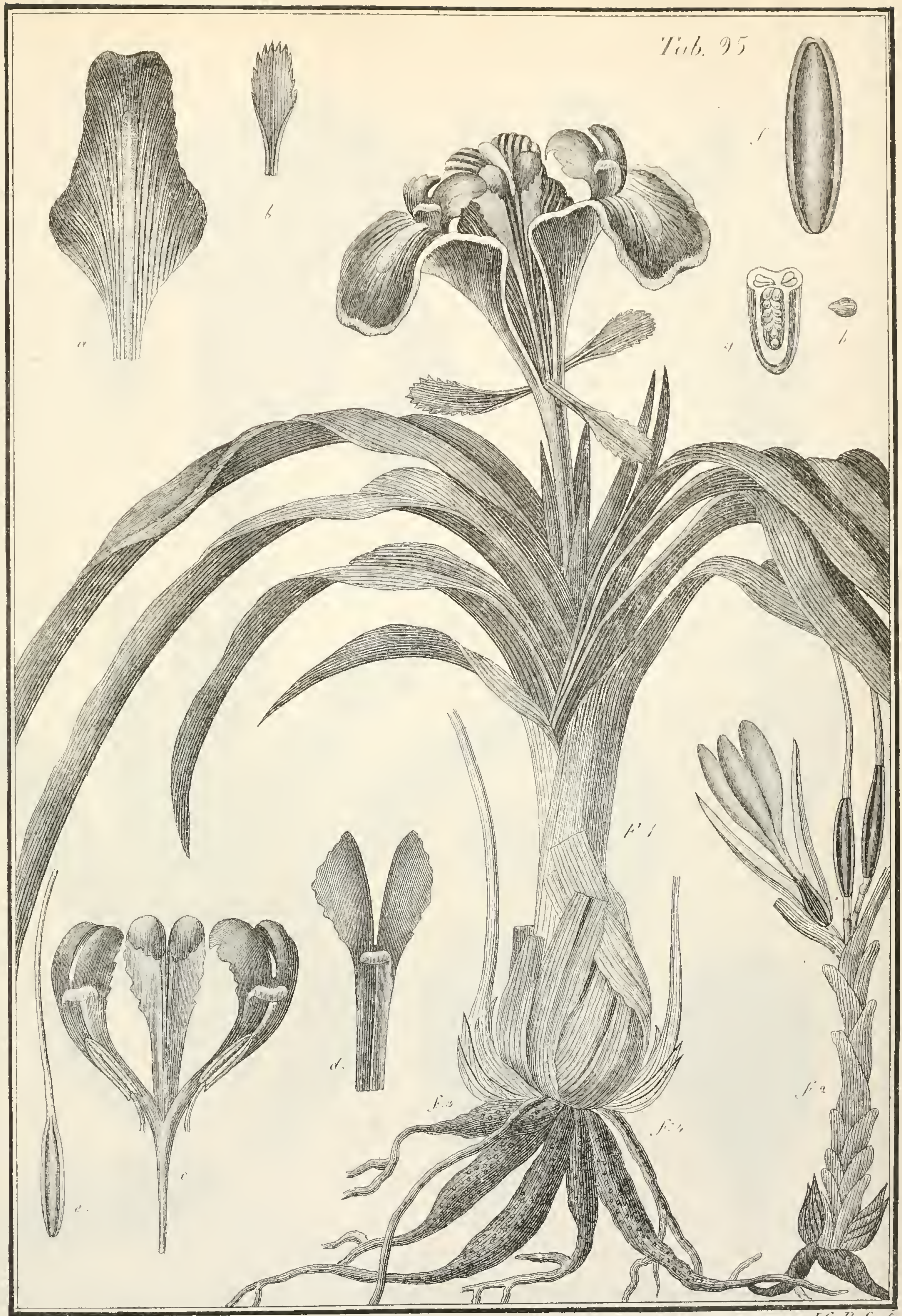

IRTS molaten 



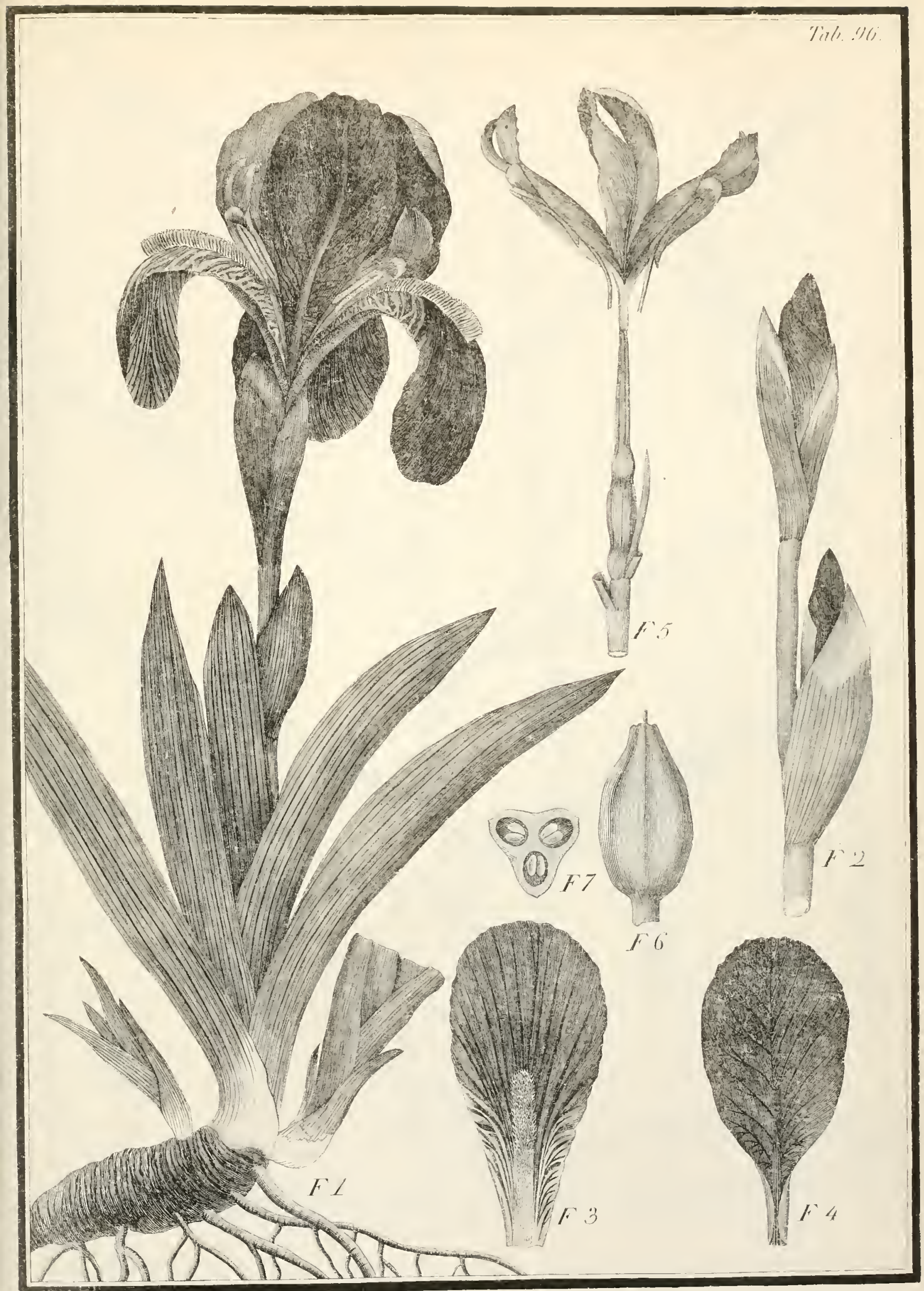

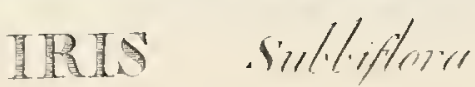





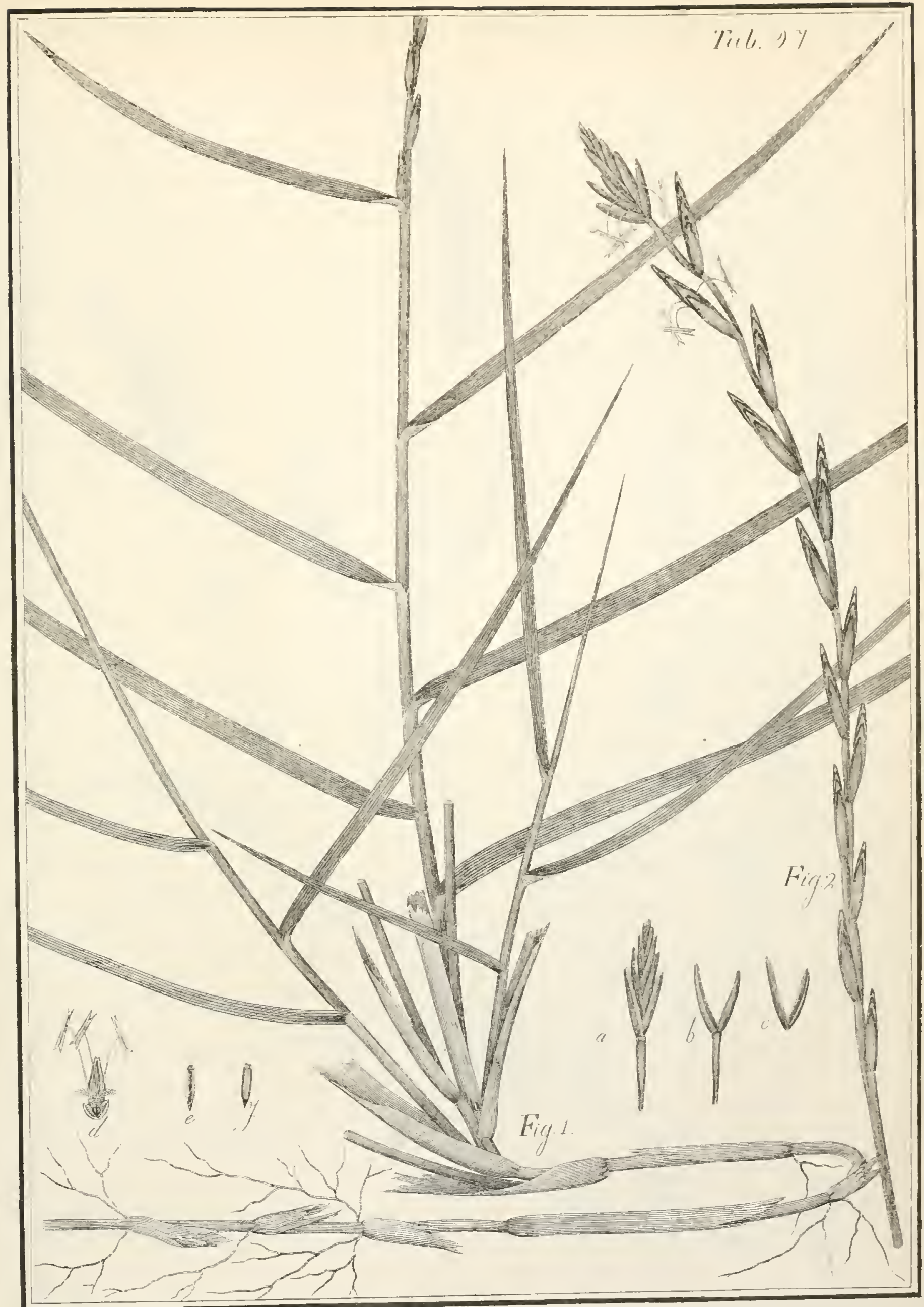

TRITITITII Littometh. 



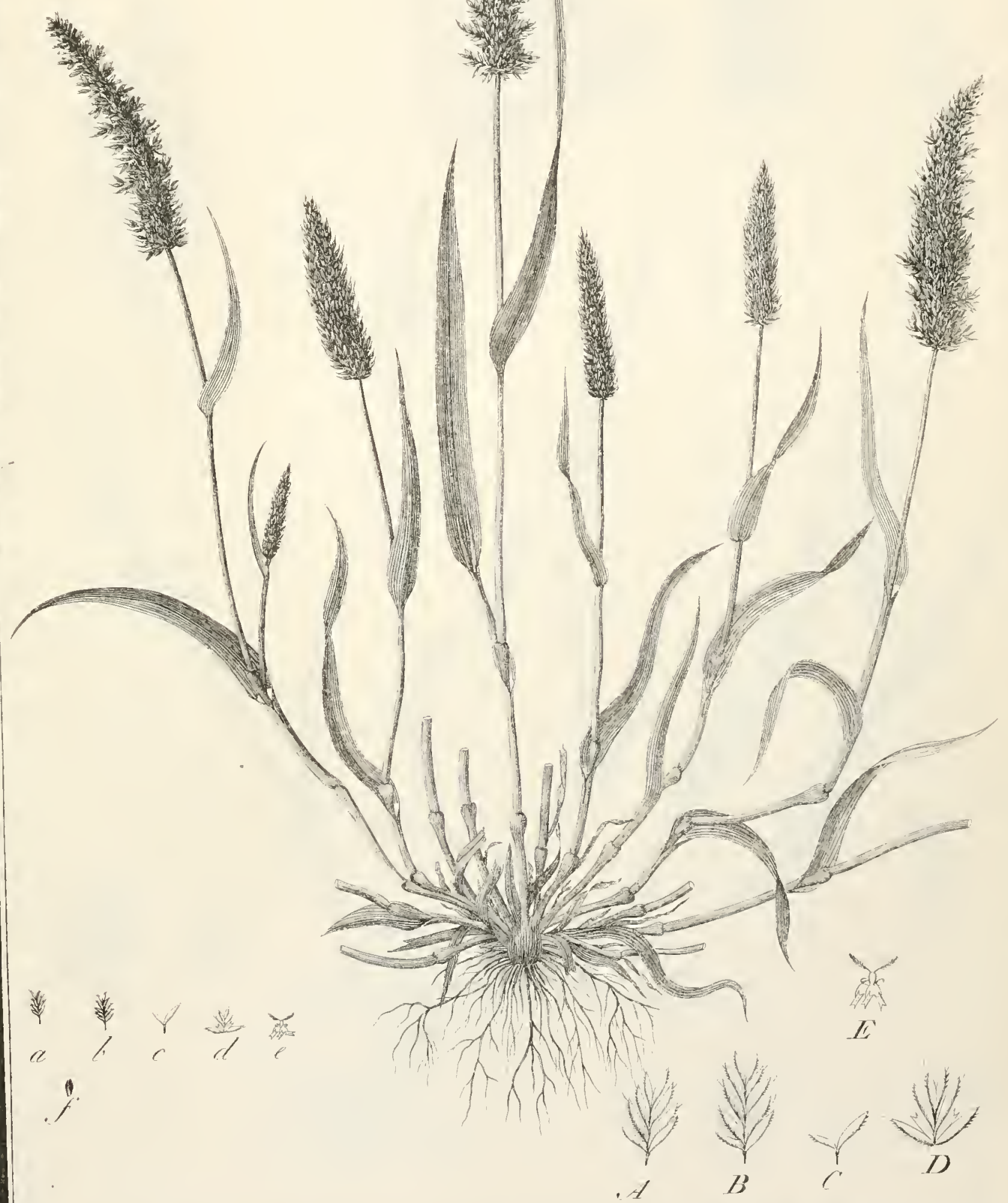





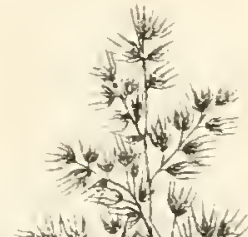

jor.

1. I

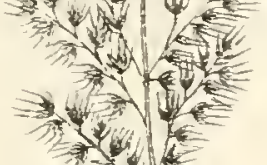

by
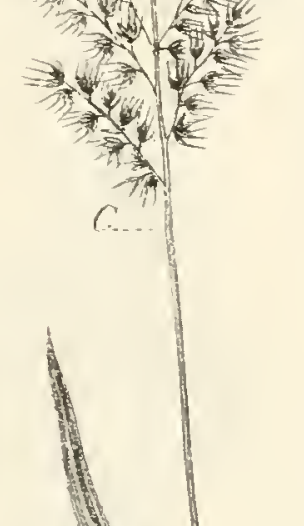

$\operatorname{Gic}^{2}$
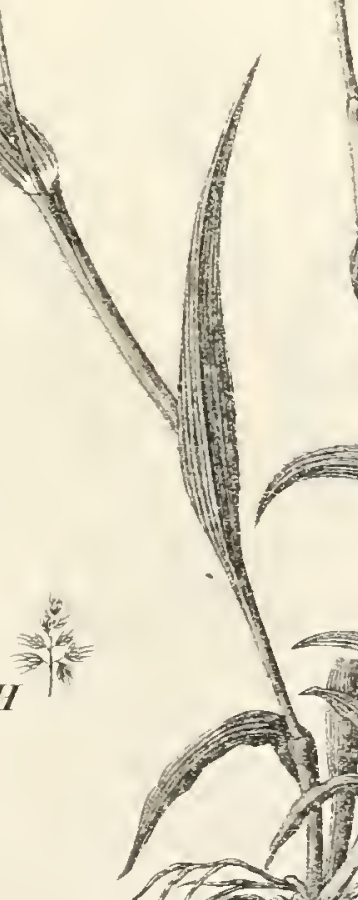

此

Y.

(viv)

N

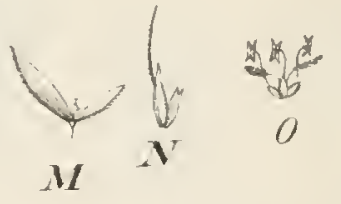







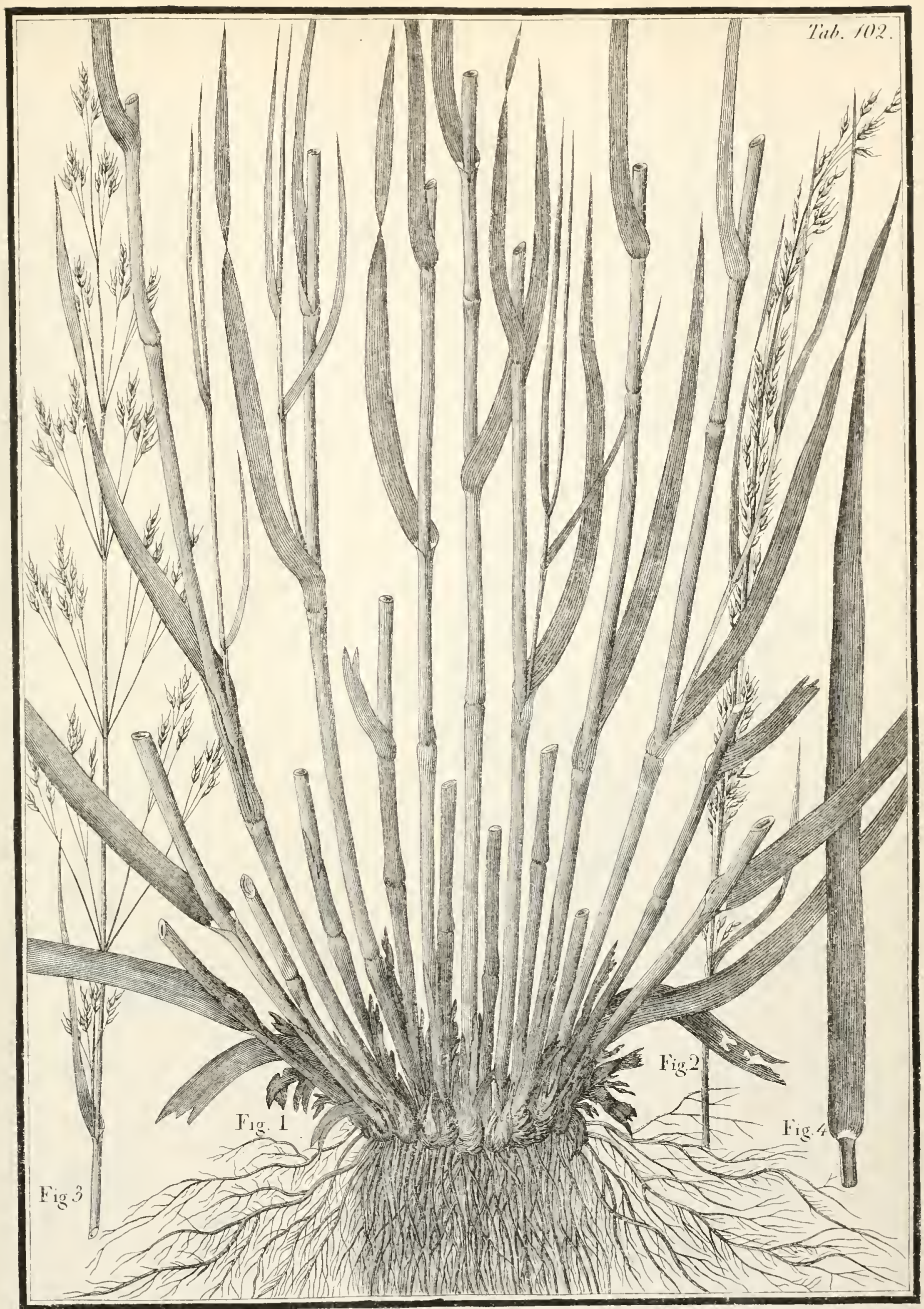

A G D D 



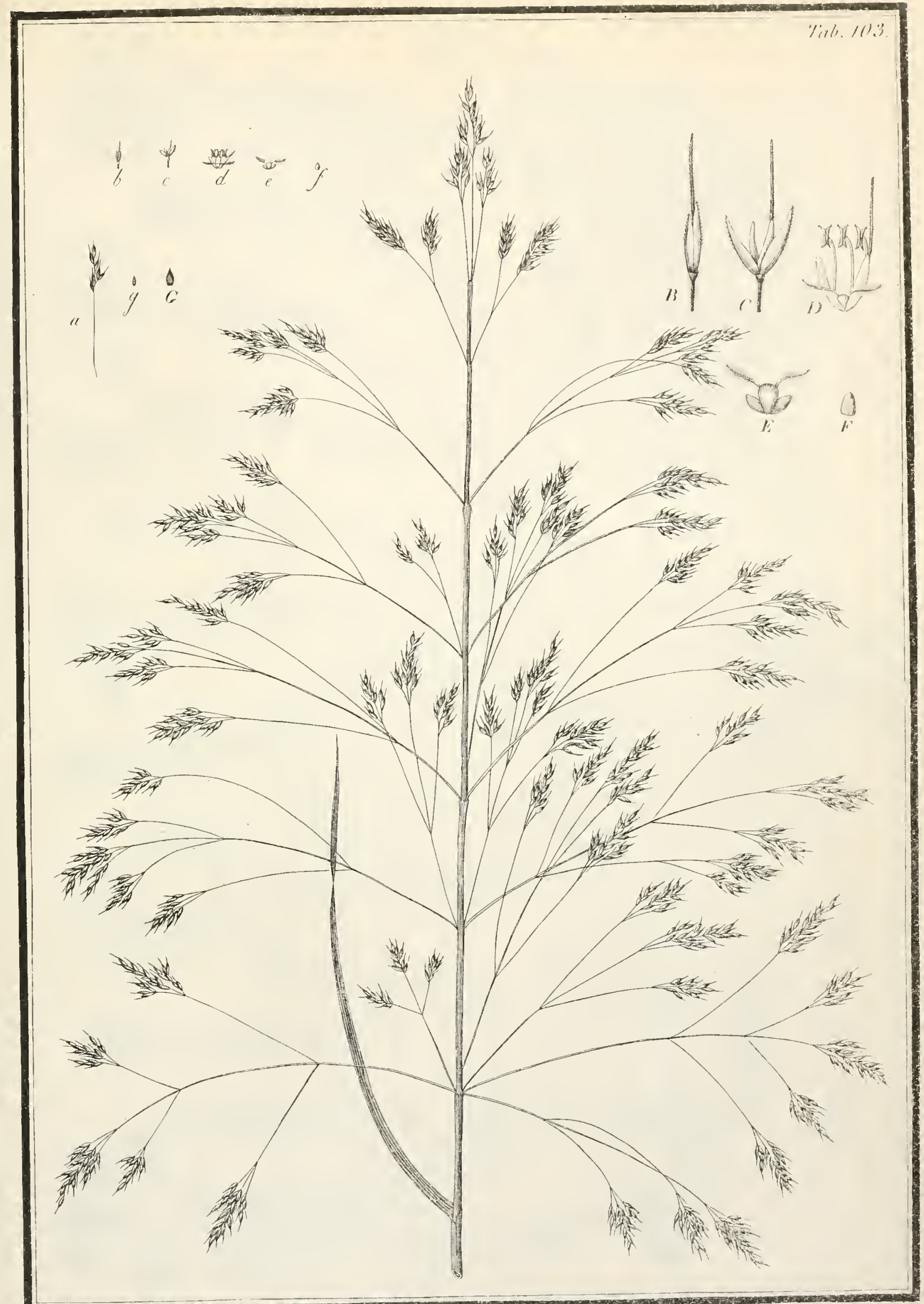

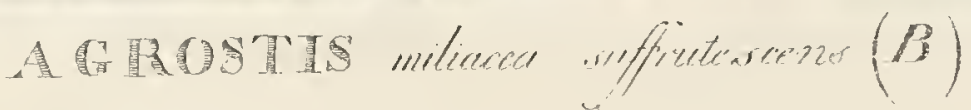





\section{(10) (1)}

X.1

准

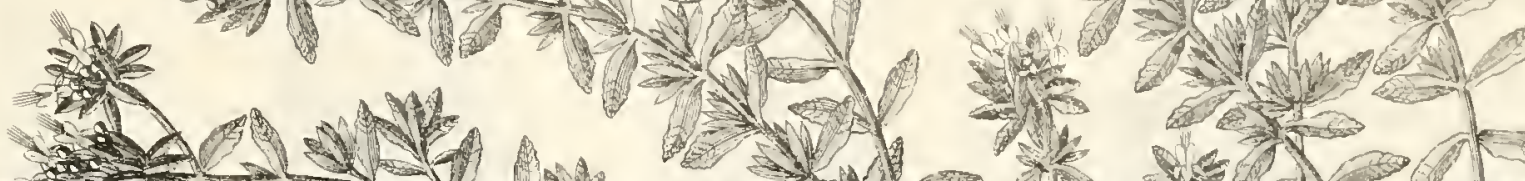

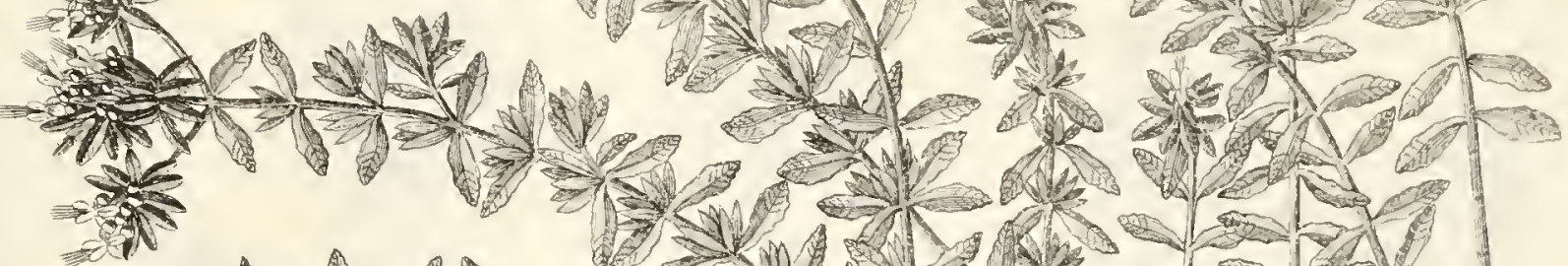

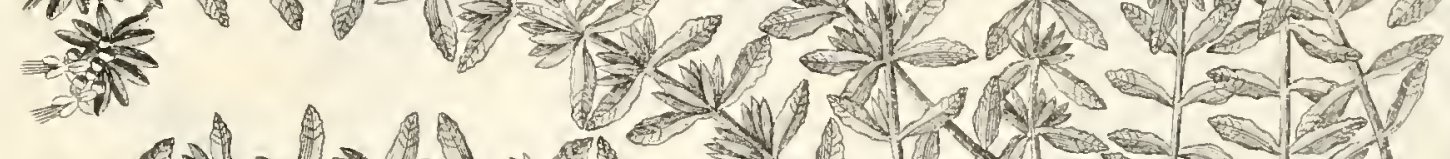
* (1)

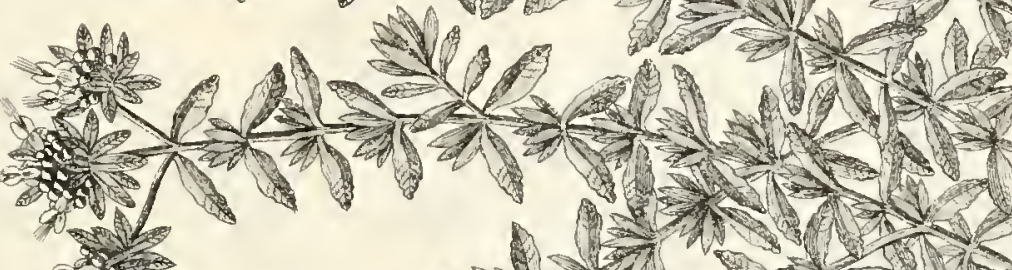

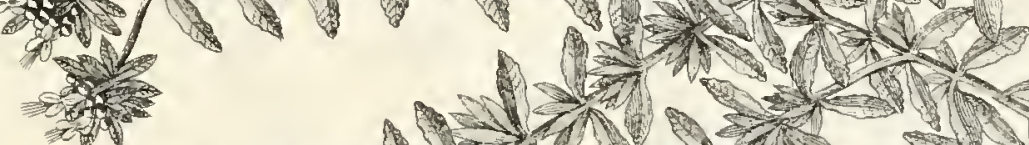

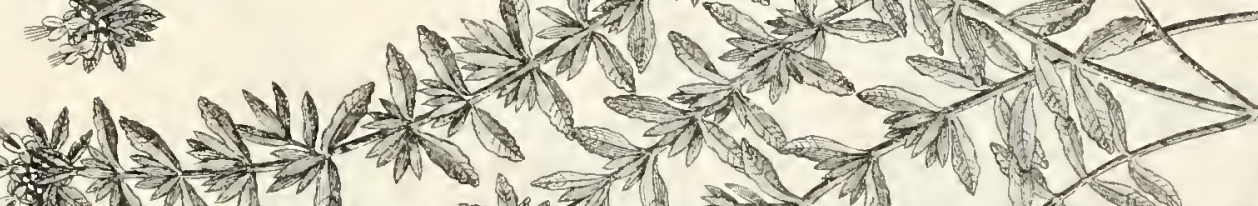

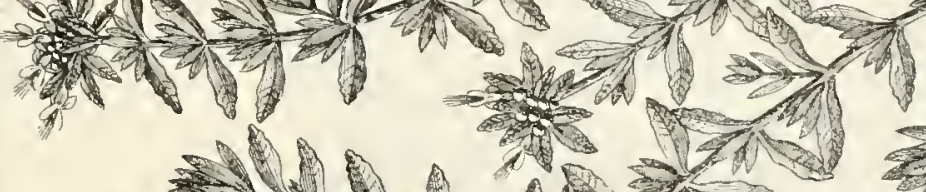

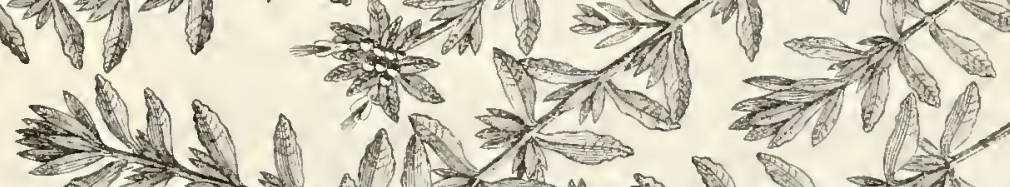
H

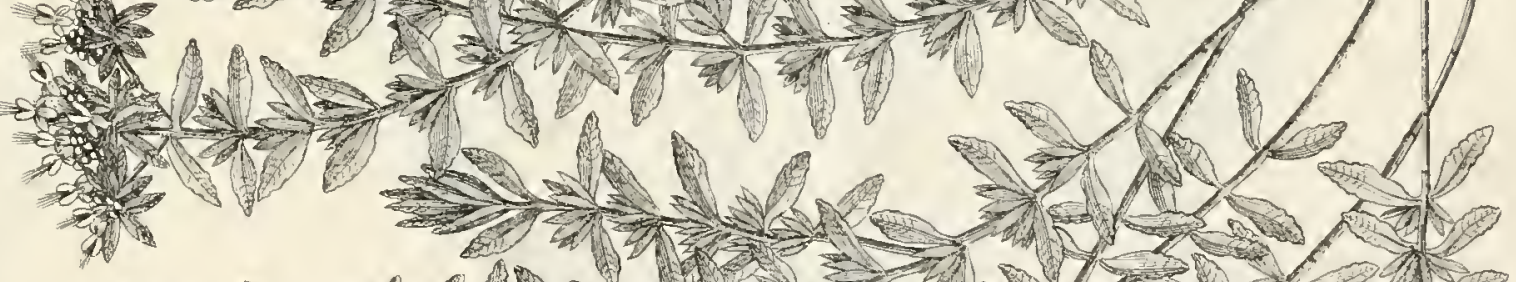

H. n.

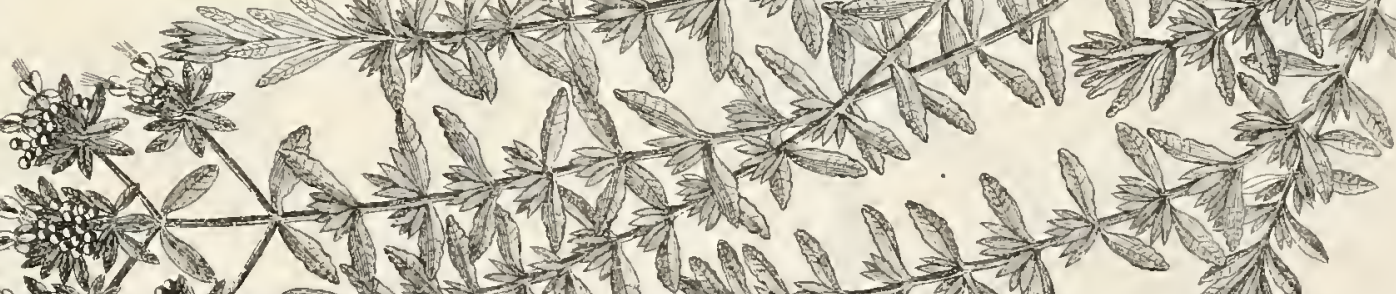

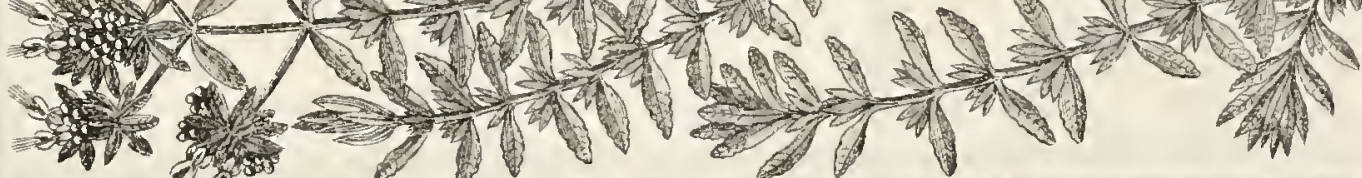
$109^{\circ}$ 




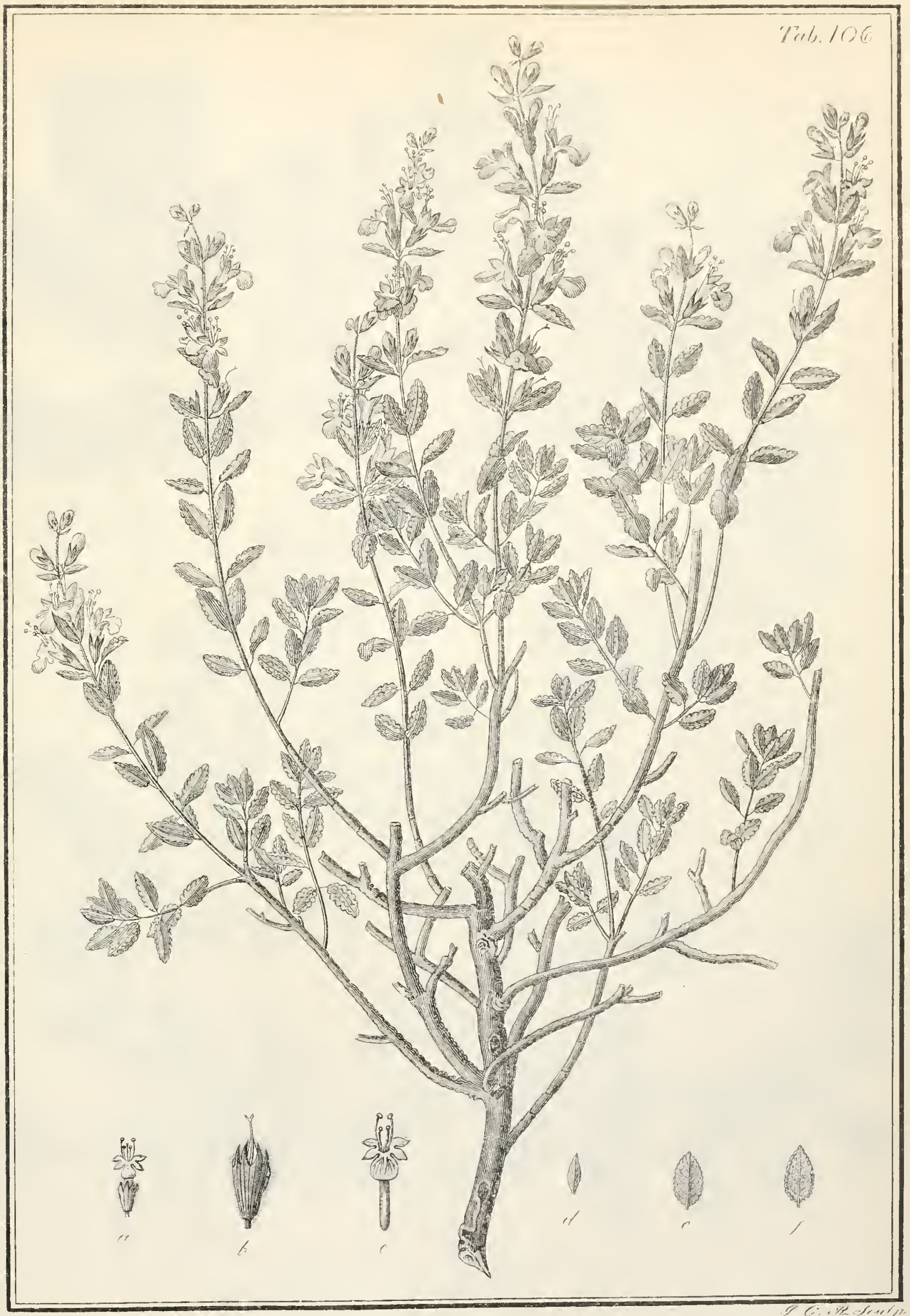





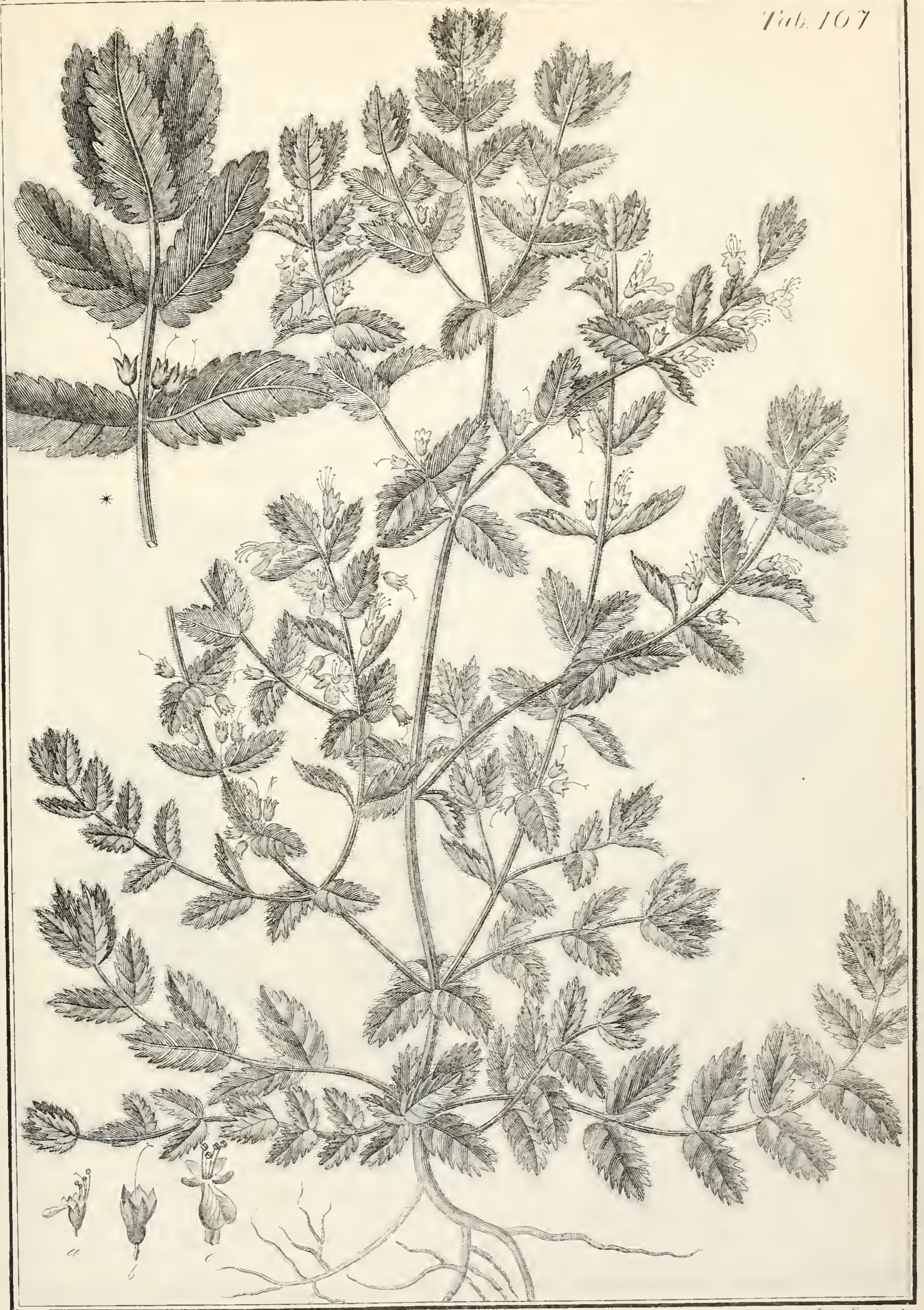





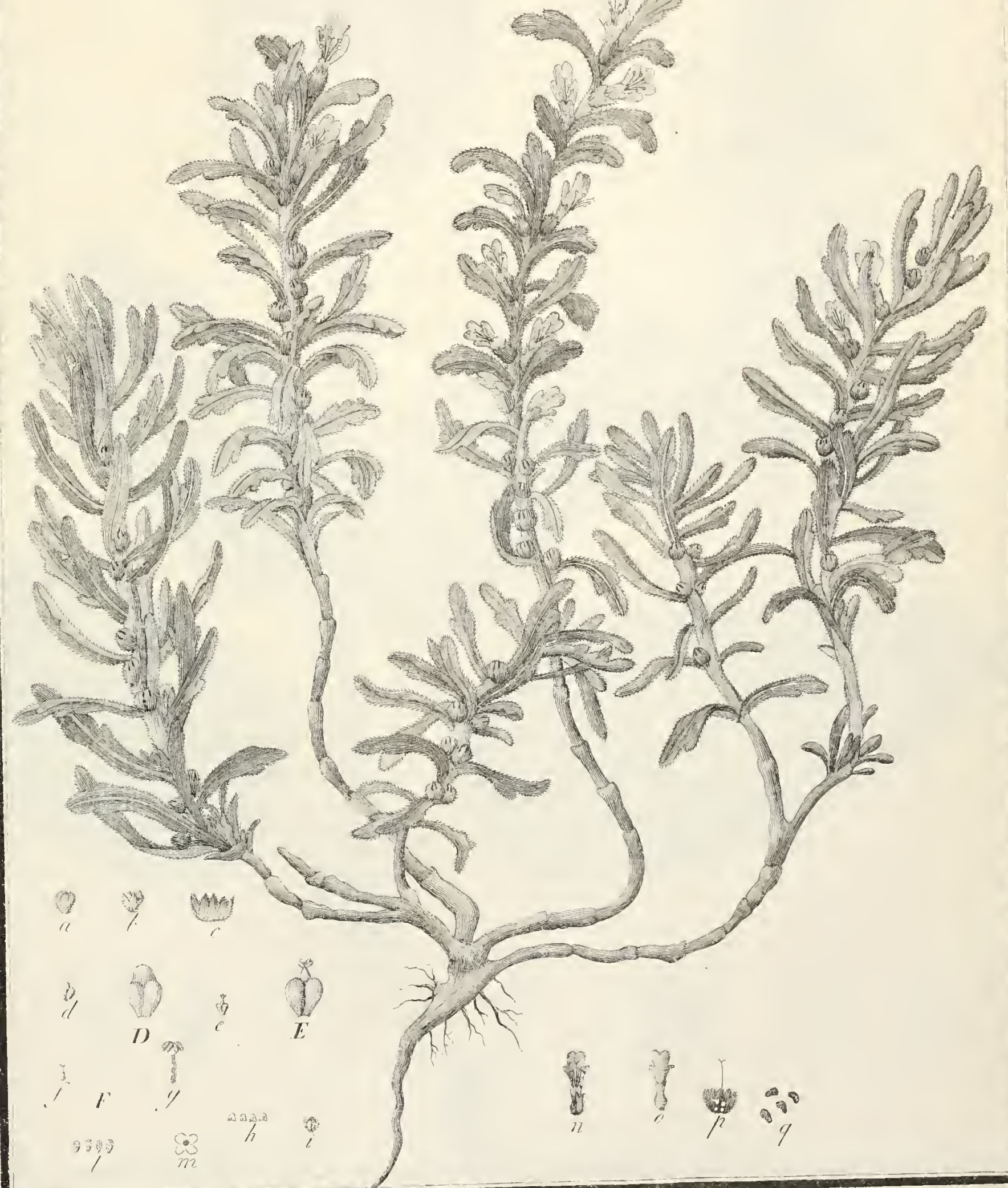
ATCA 程A 



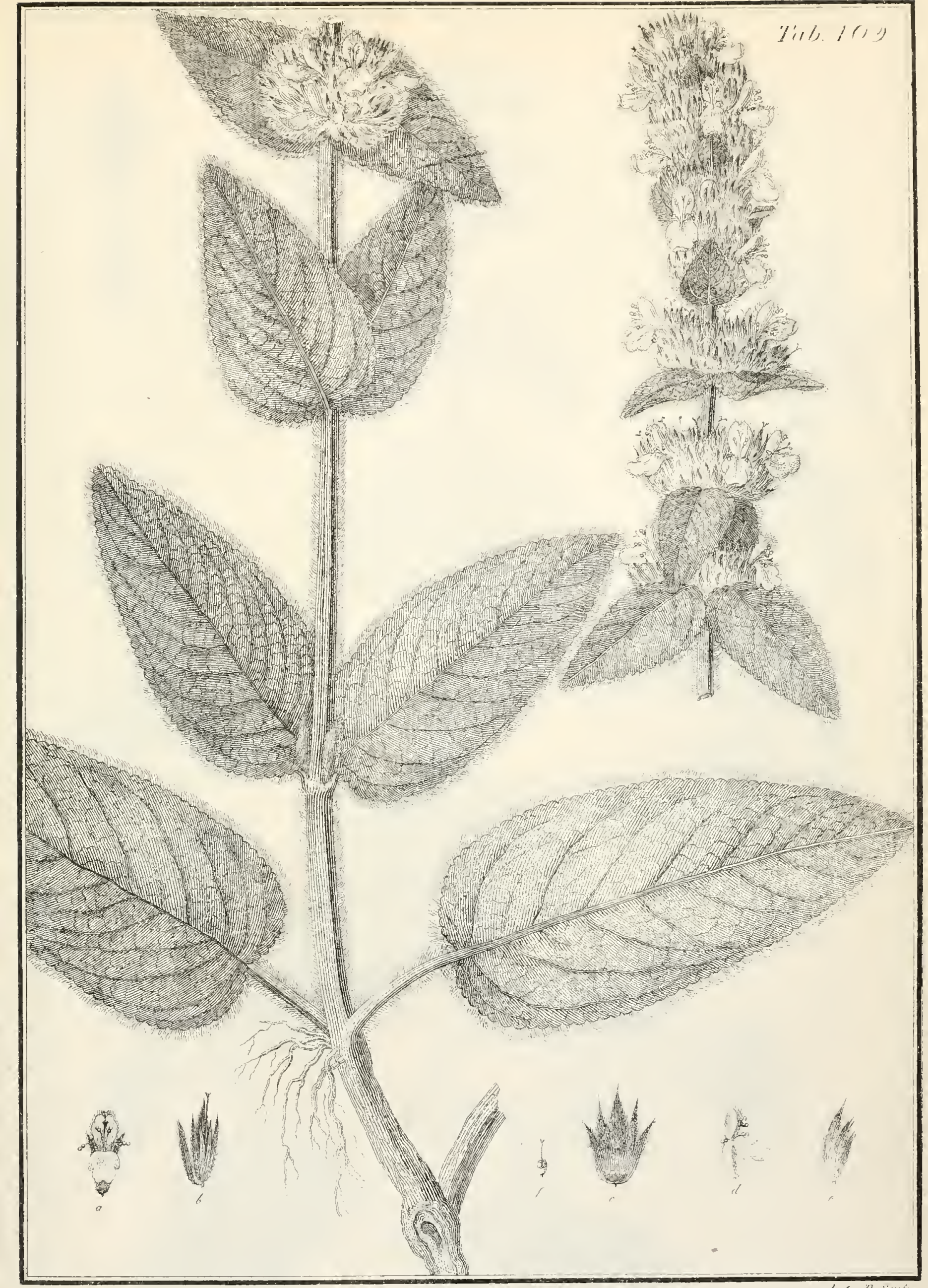





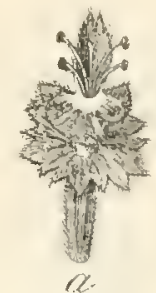

$y^{2}$
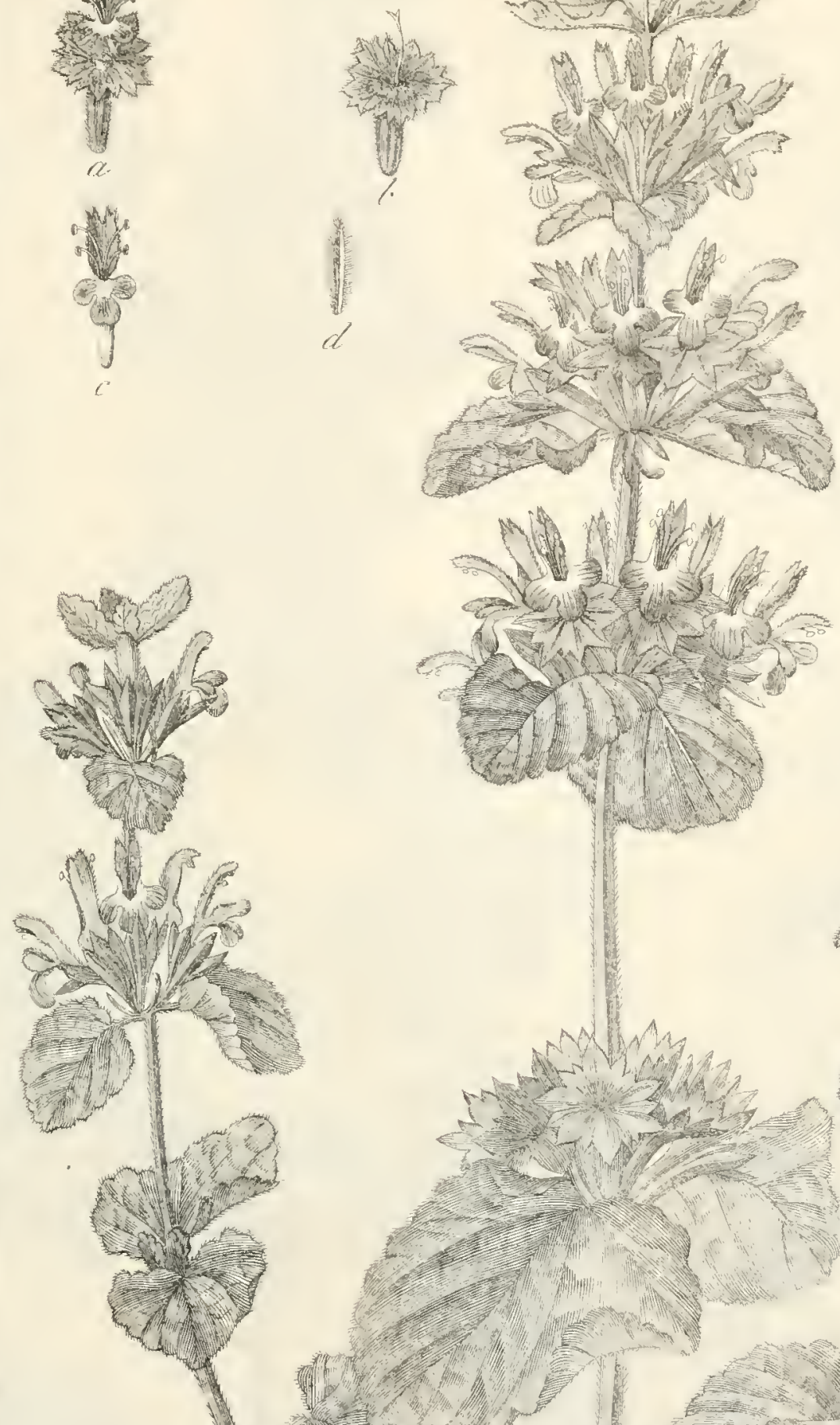

nom $m^{2}$
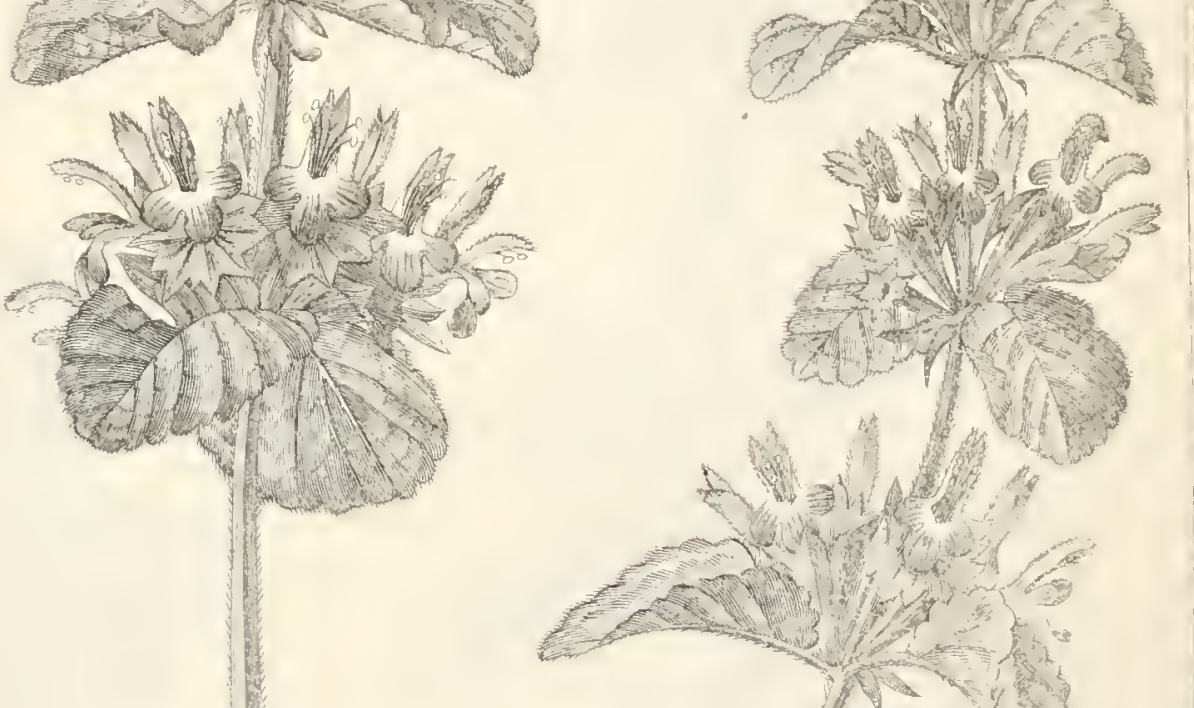




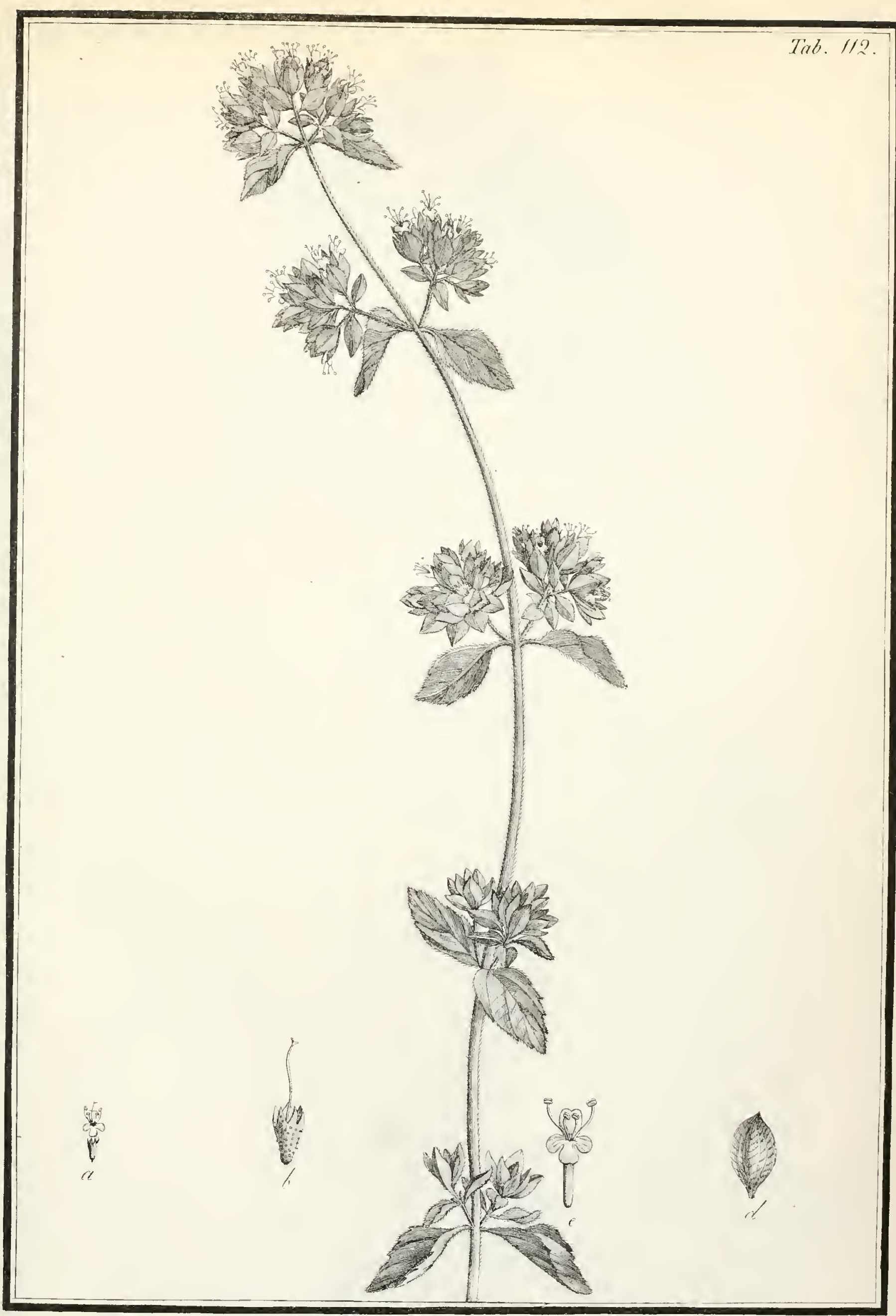

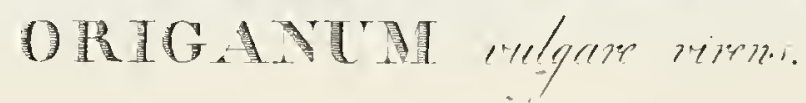





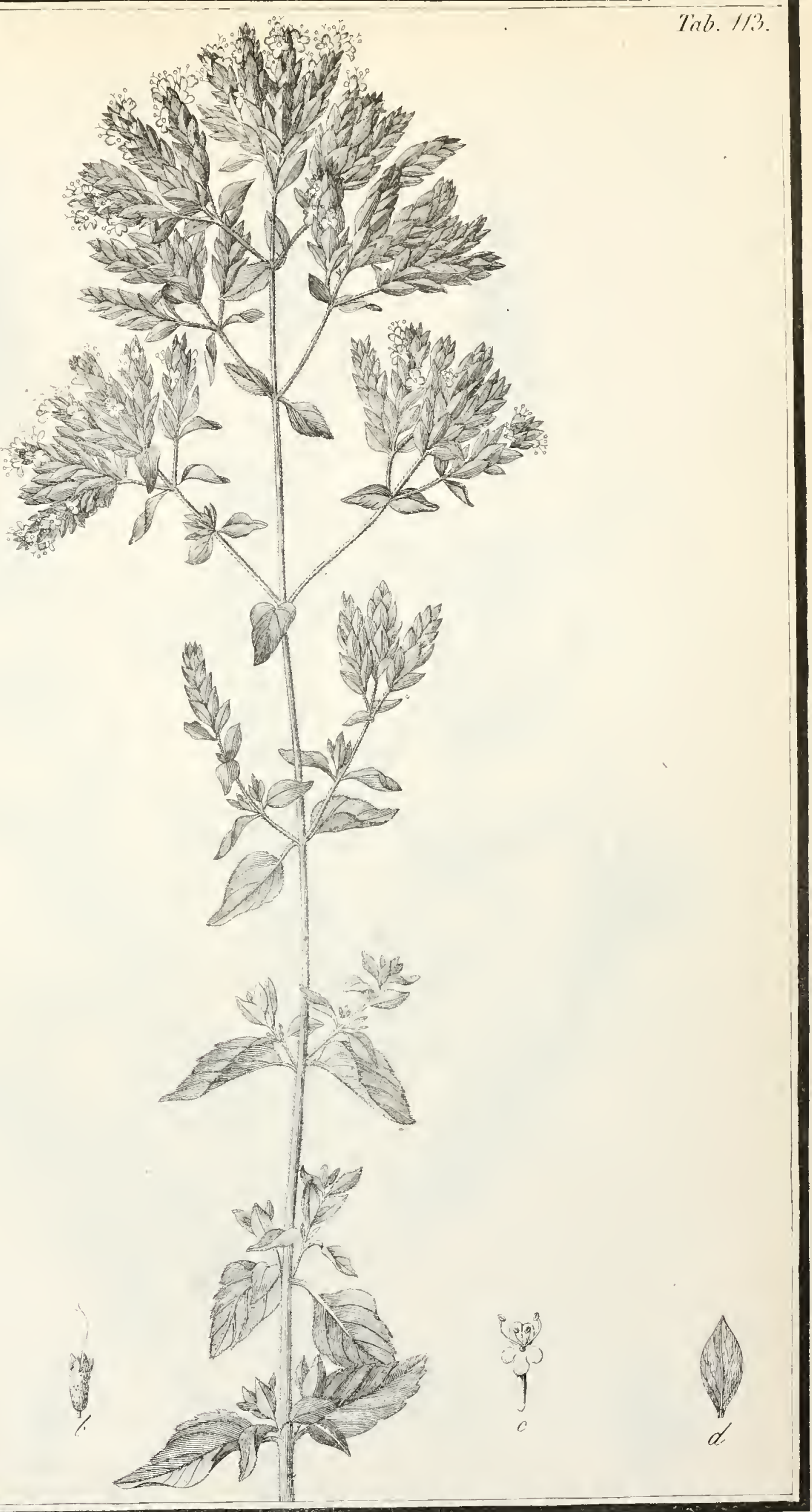

OTH IG creticum macrostachyum 



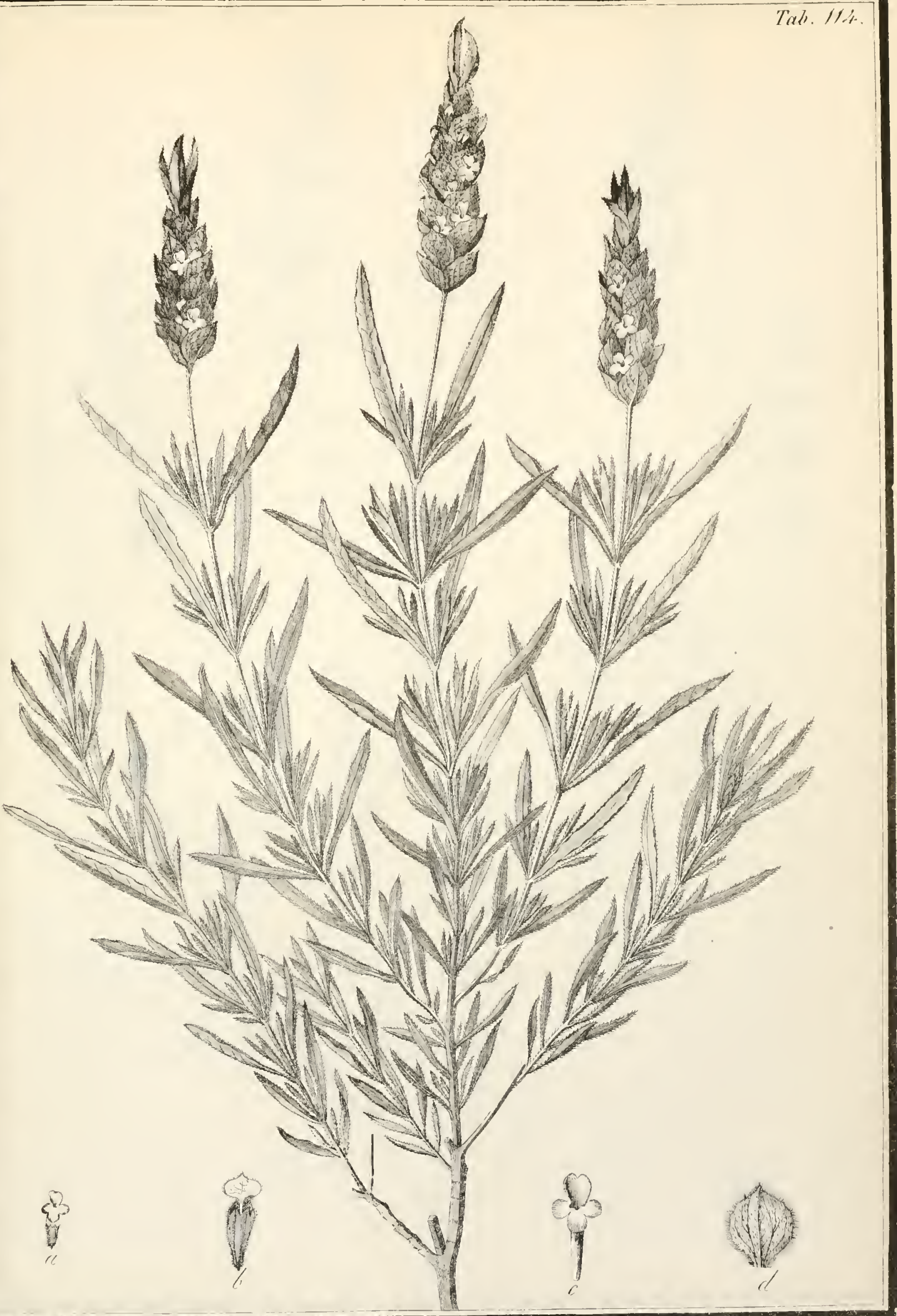





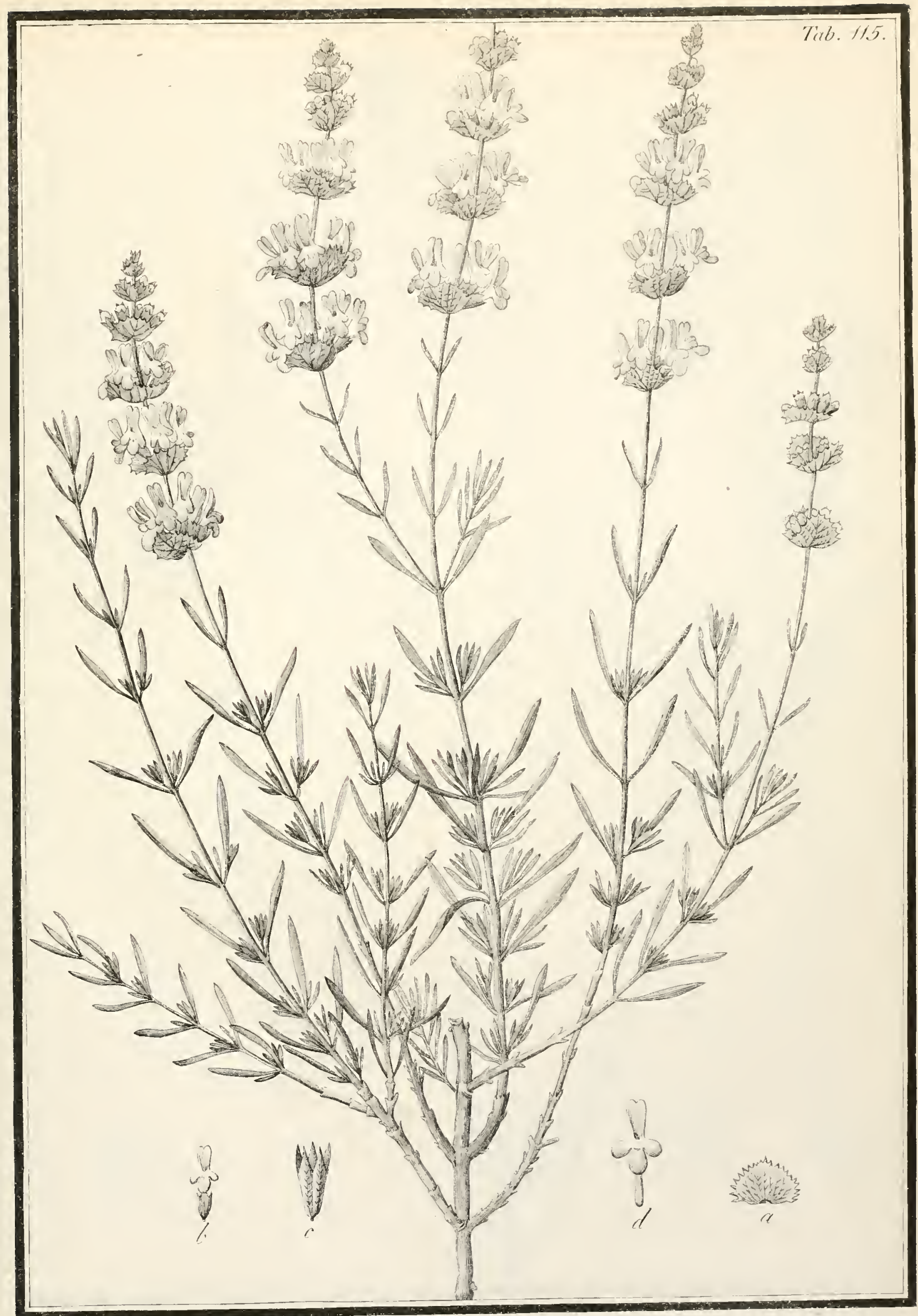





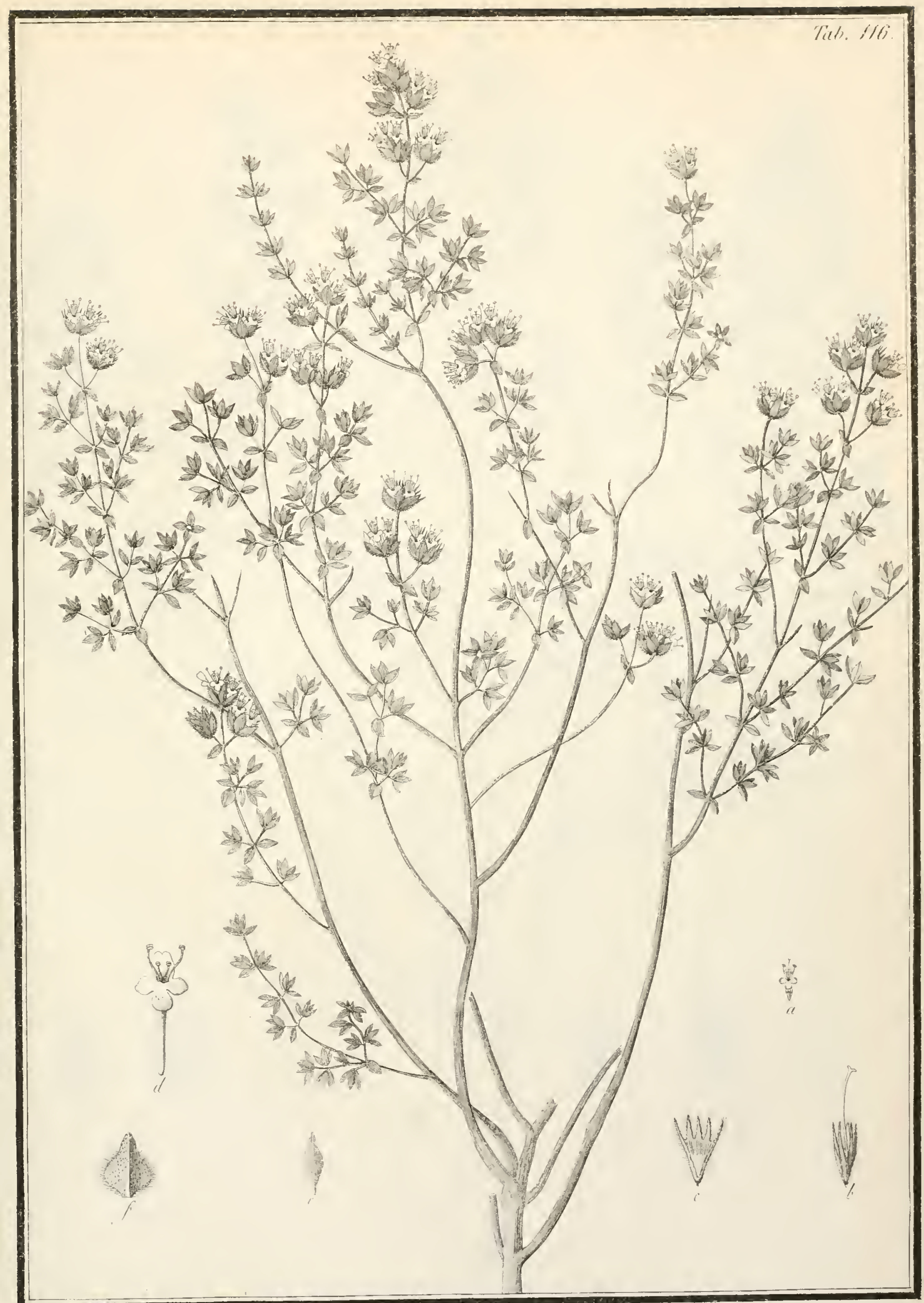





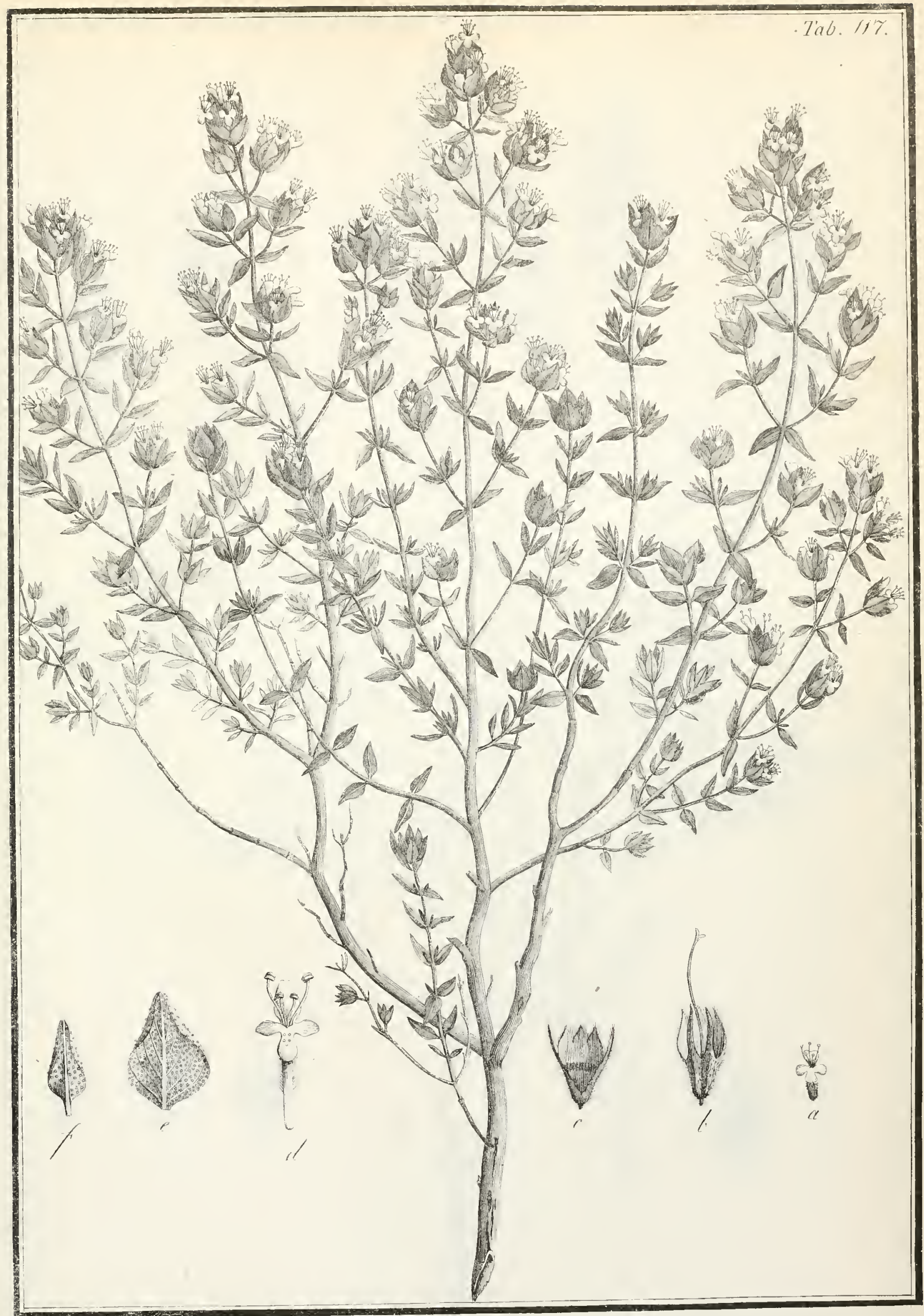





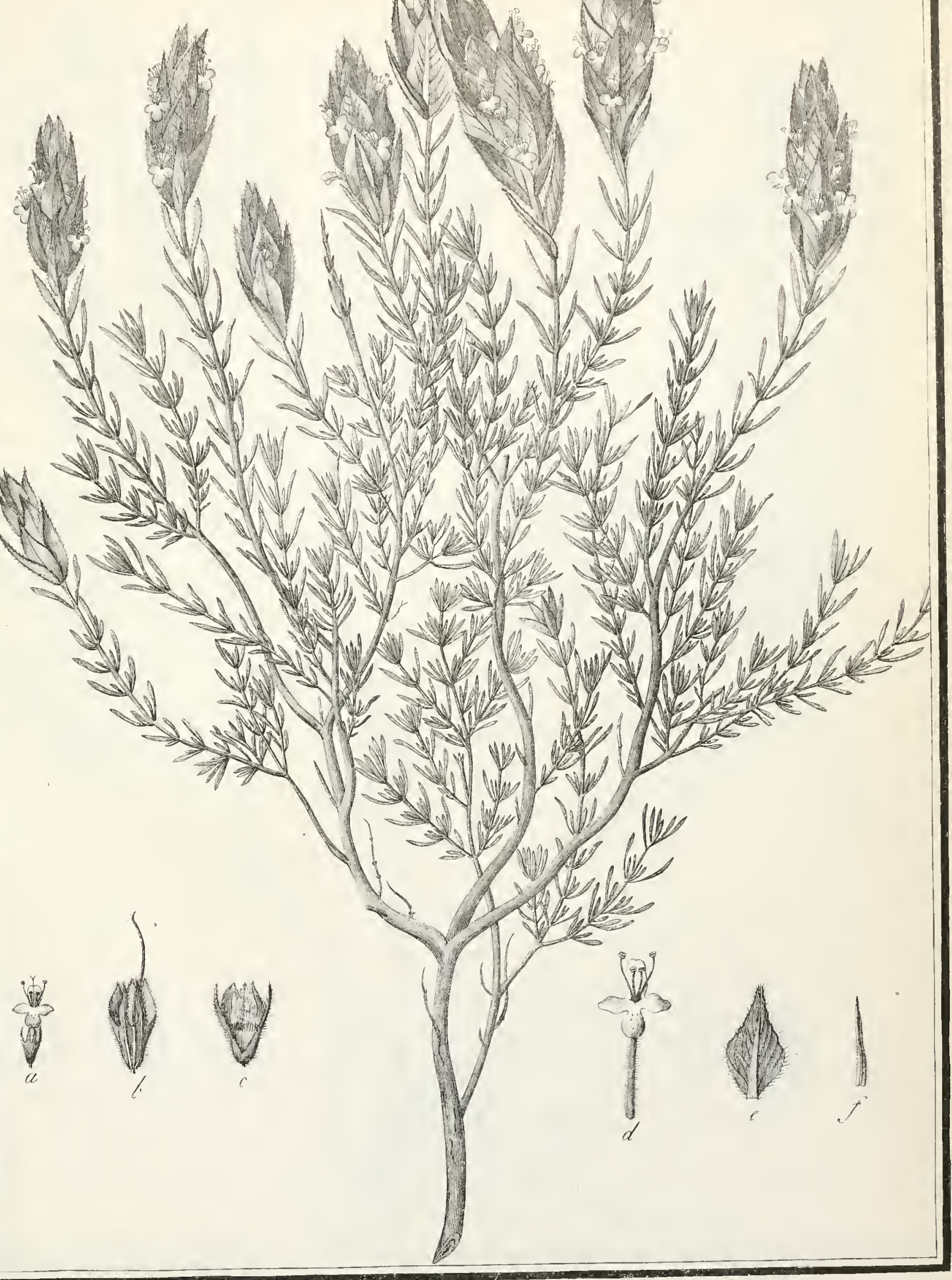



(1)

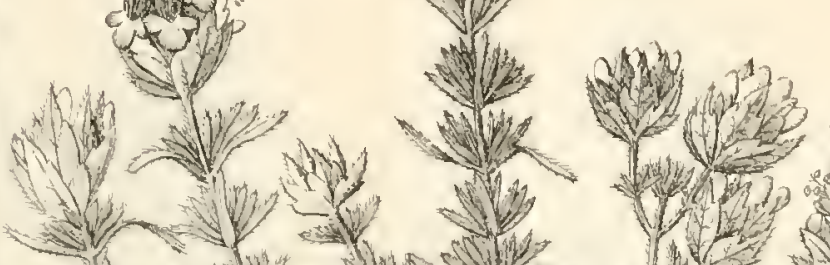
$\sqrt{1}+10$

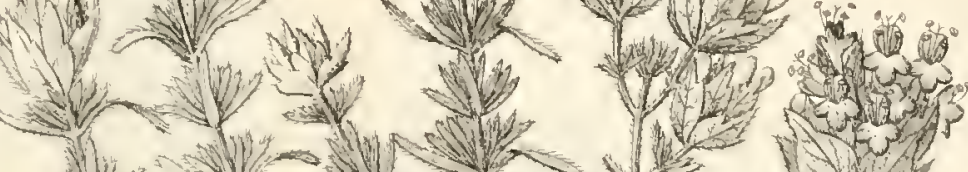

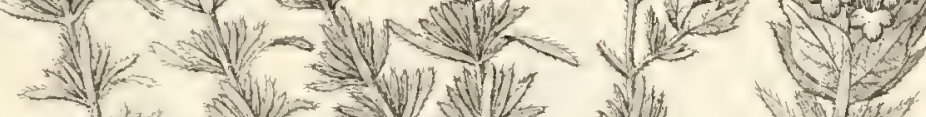

N 1

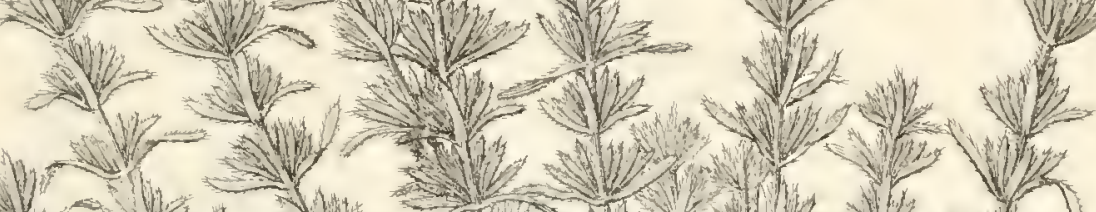

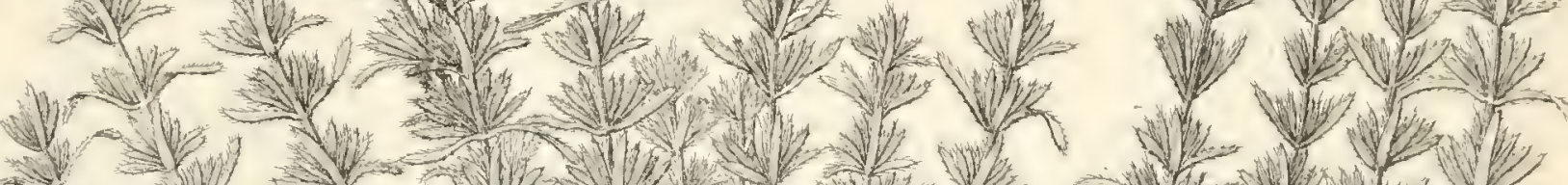
Non -1 -

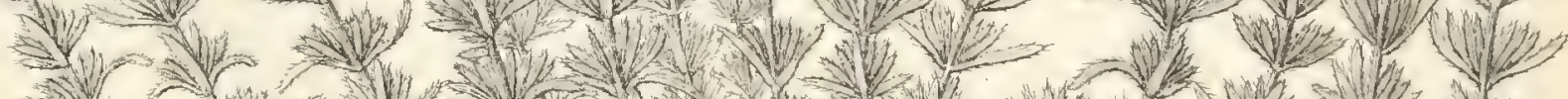

DUt

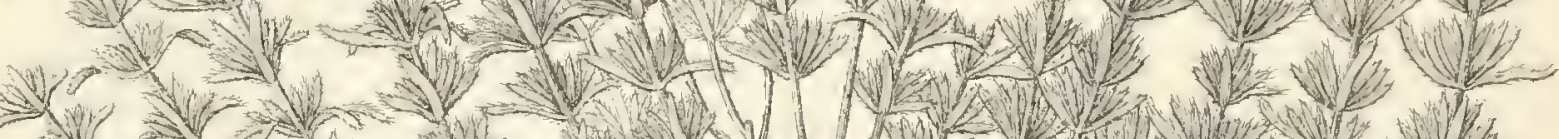

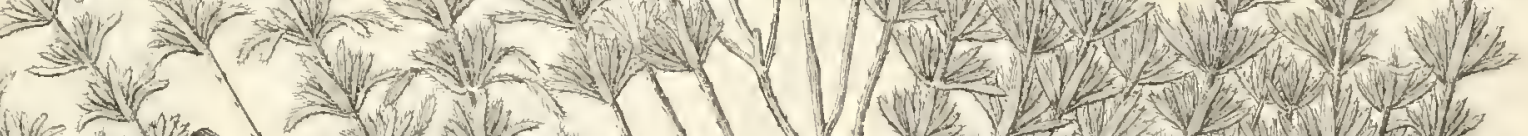

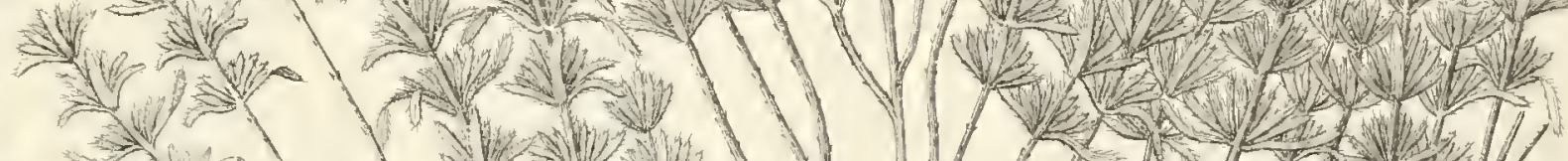

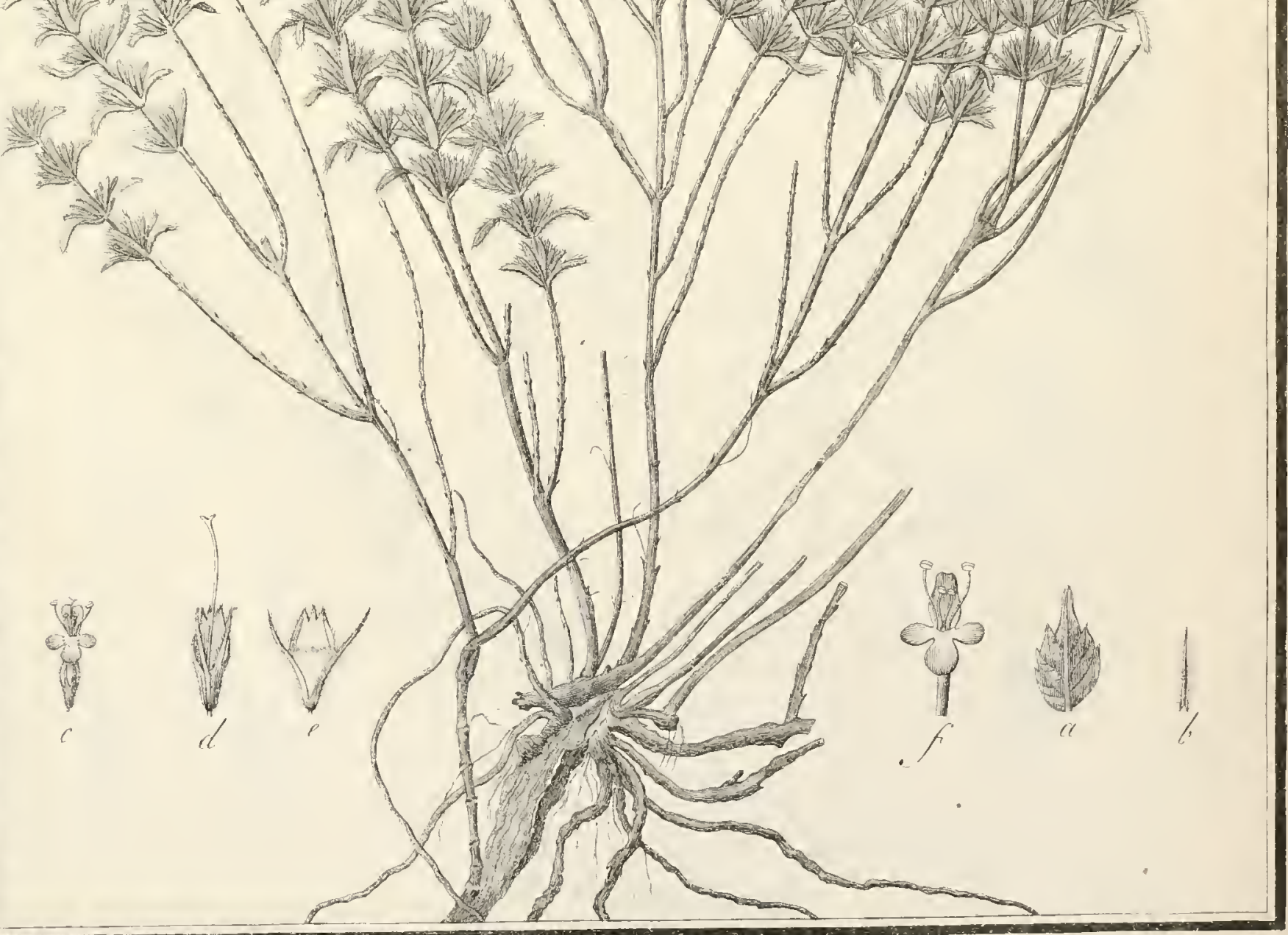





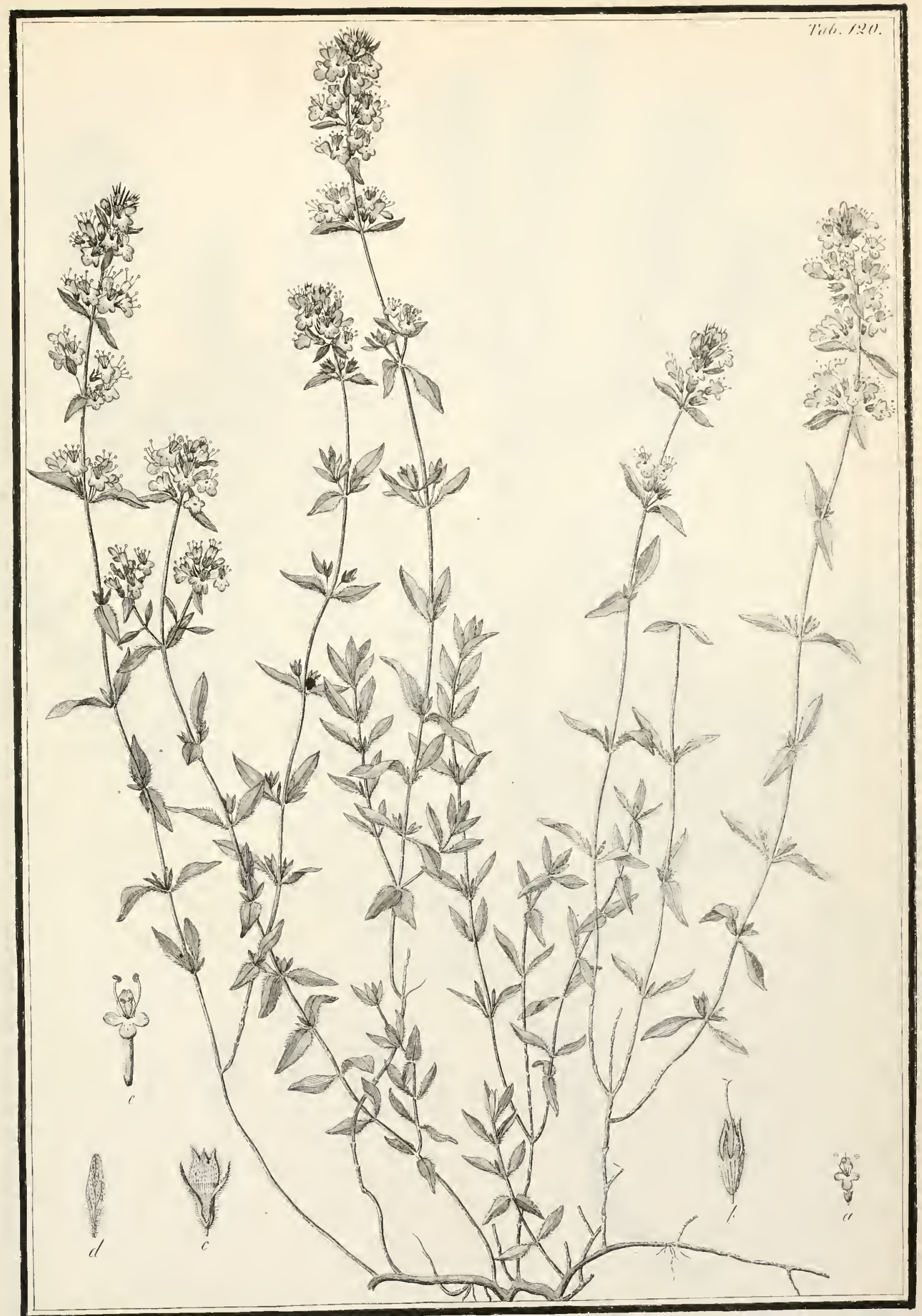



2.t.

S.

int

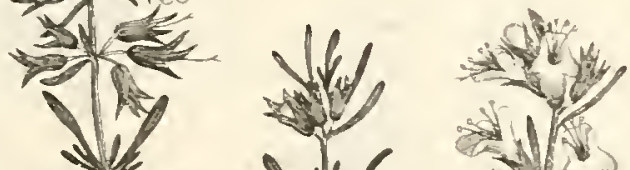

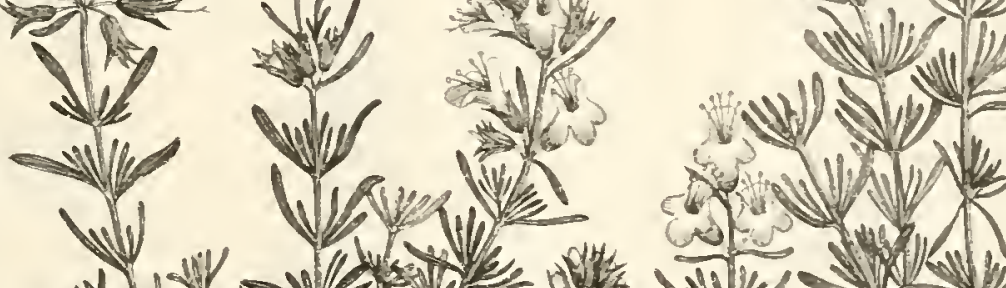

ate

Tiuh. (2)

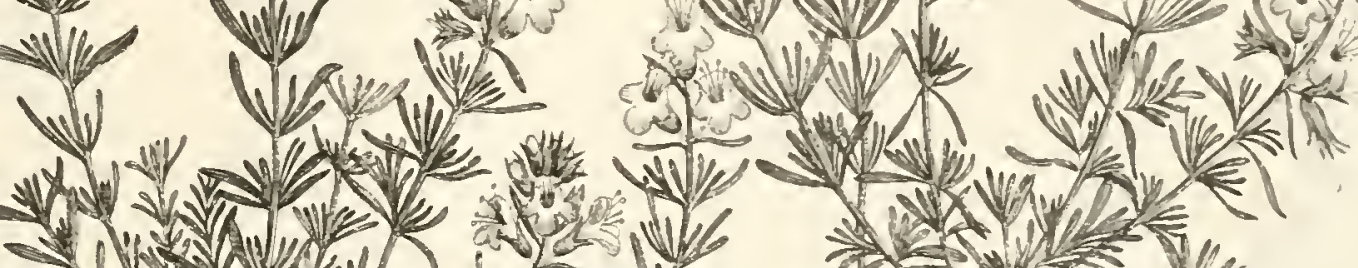

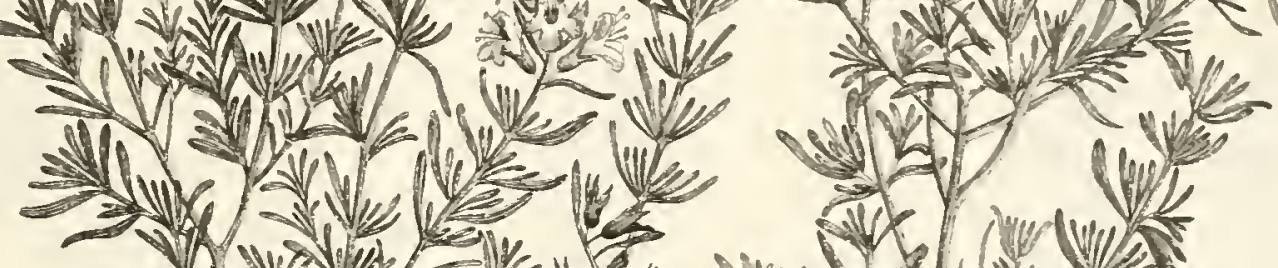

- v vive

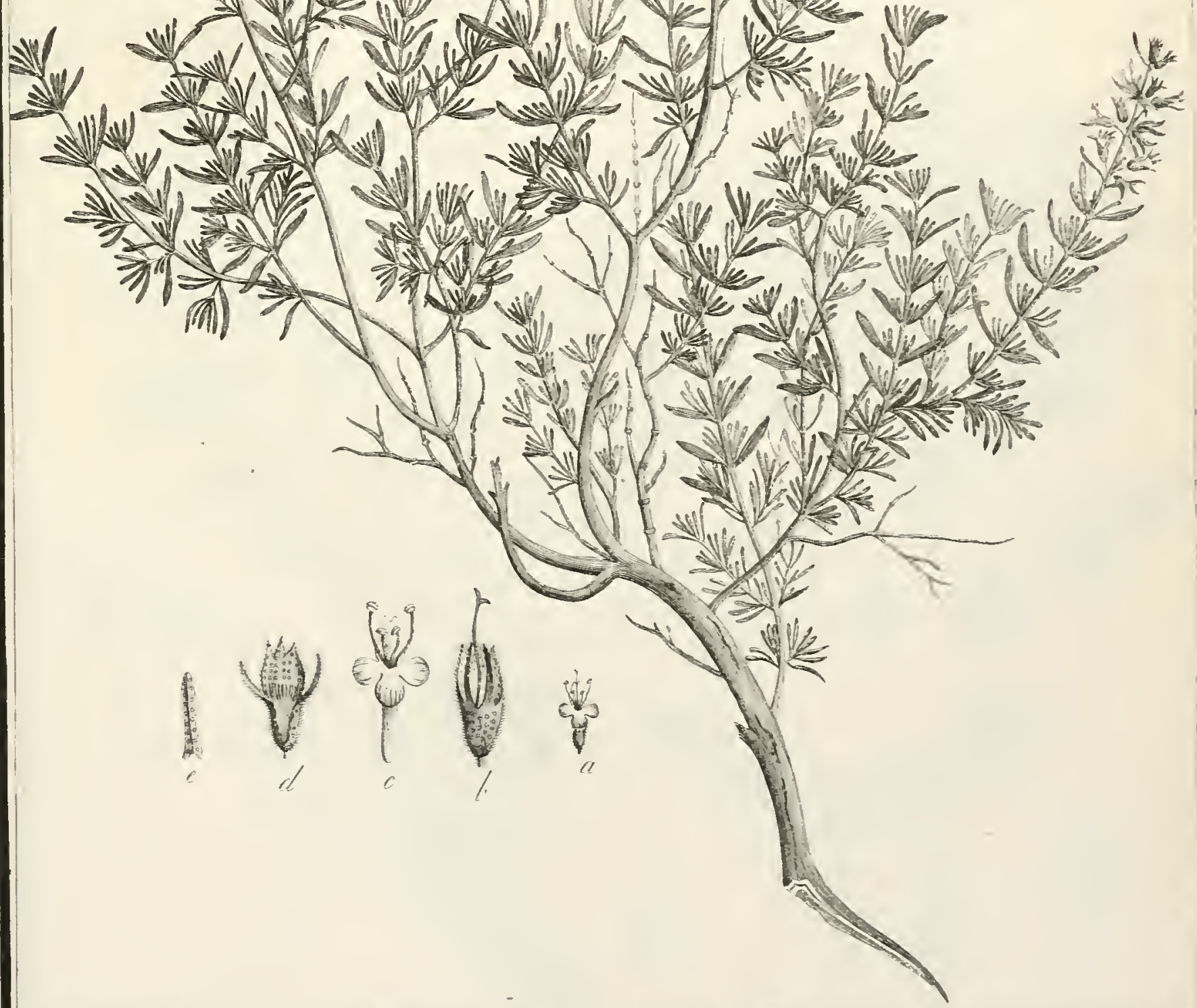





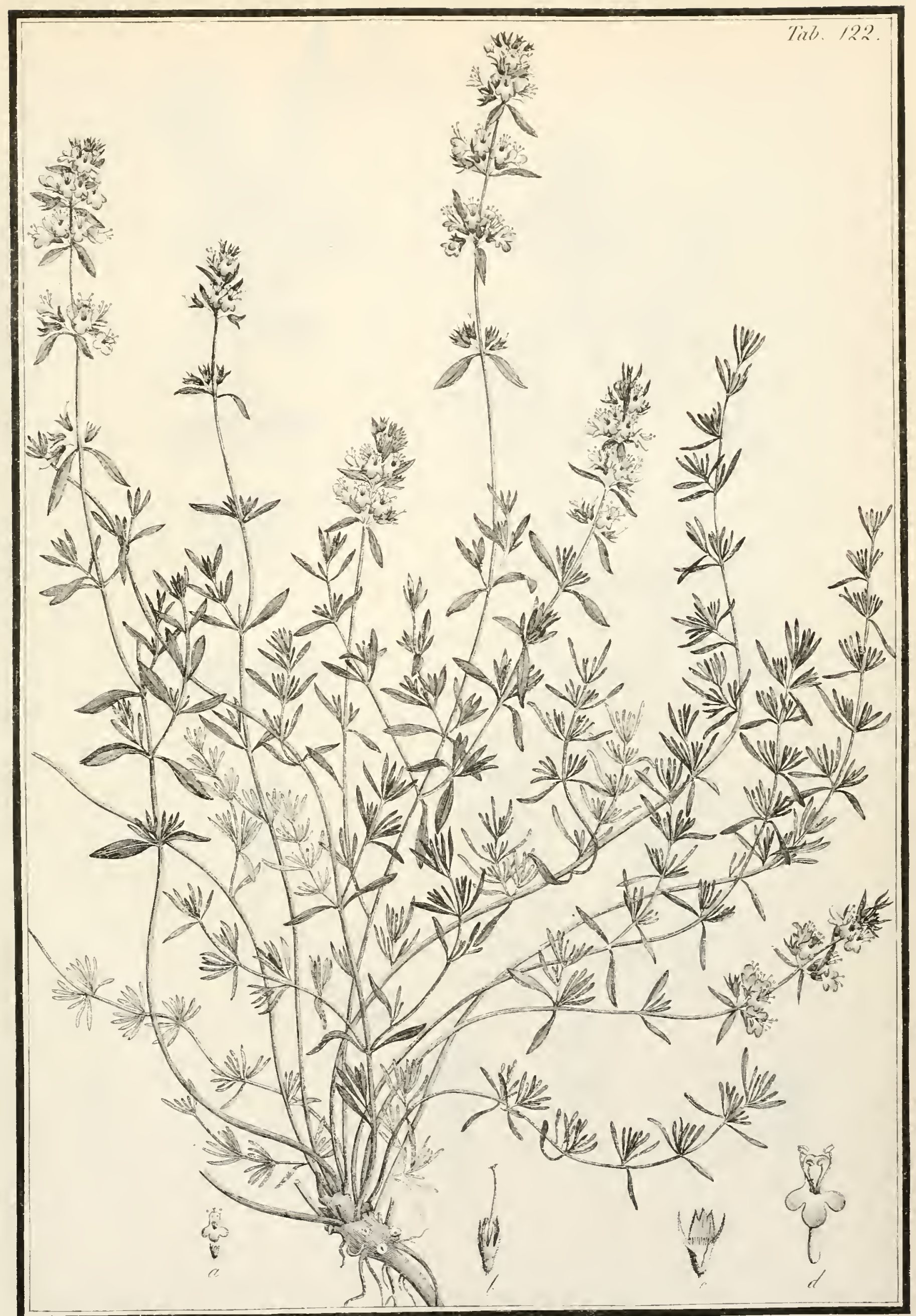





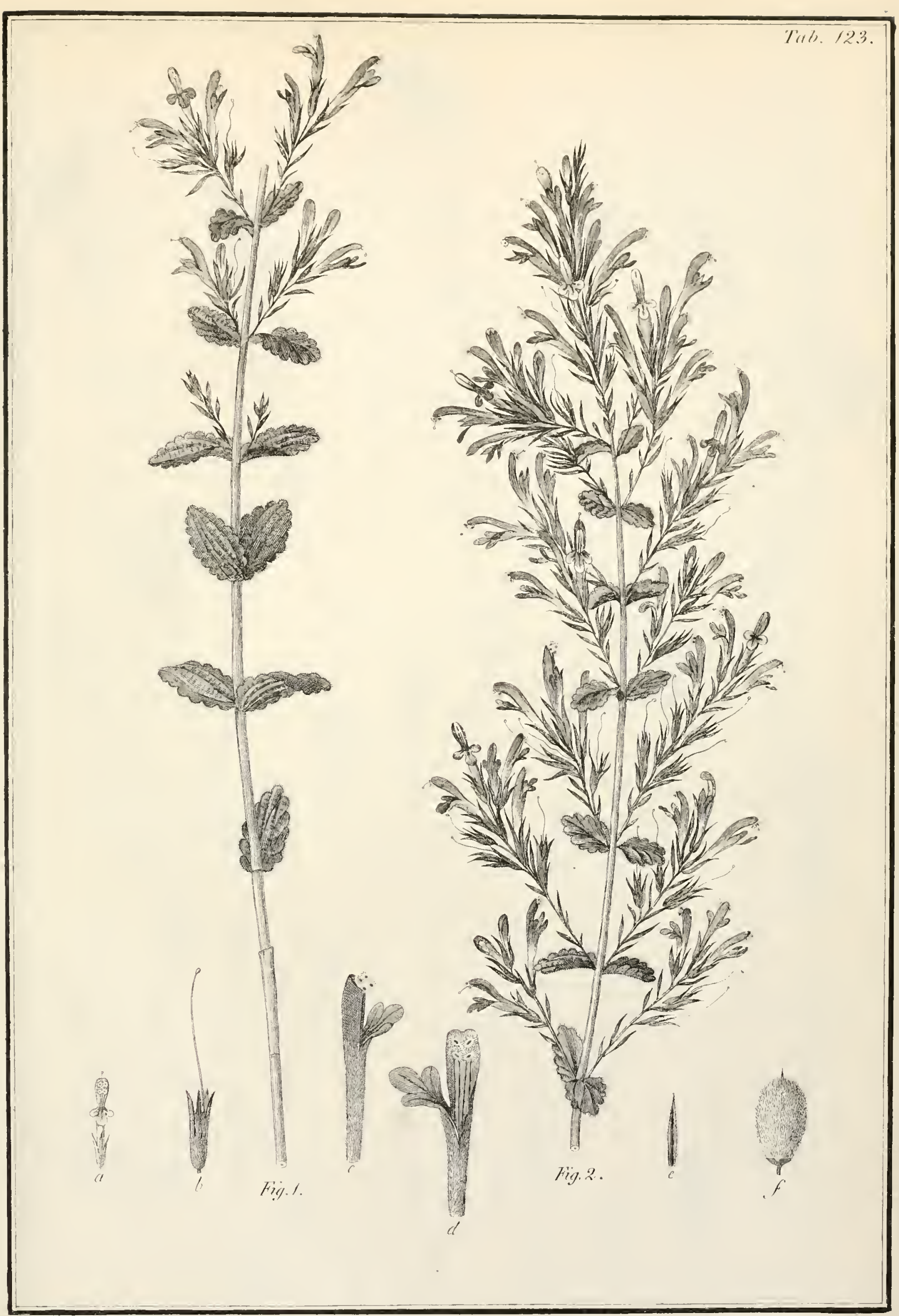




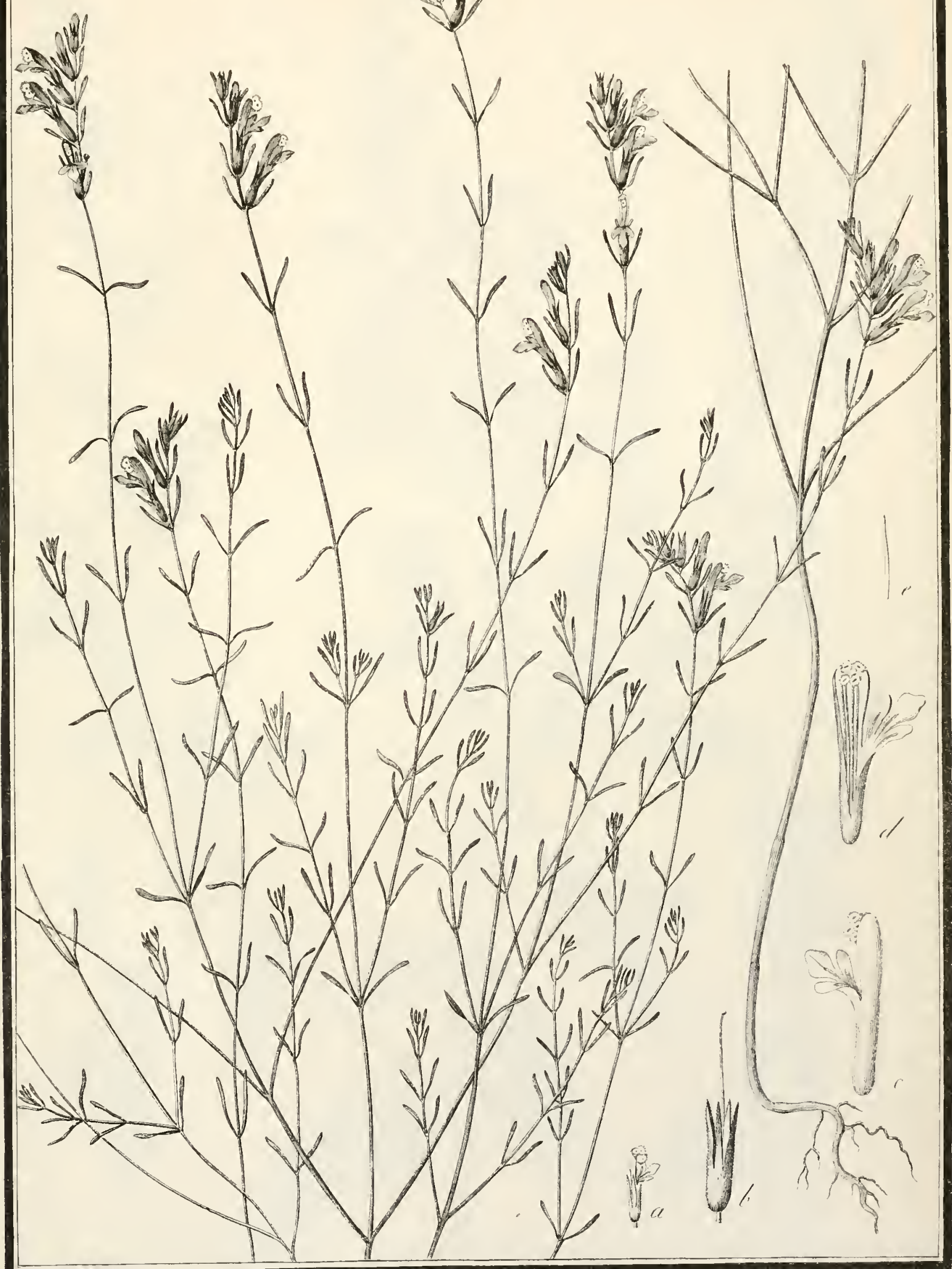

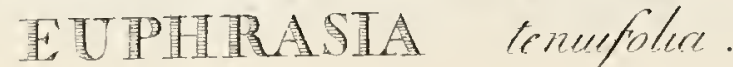






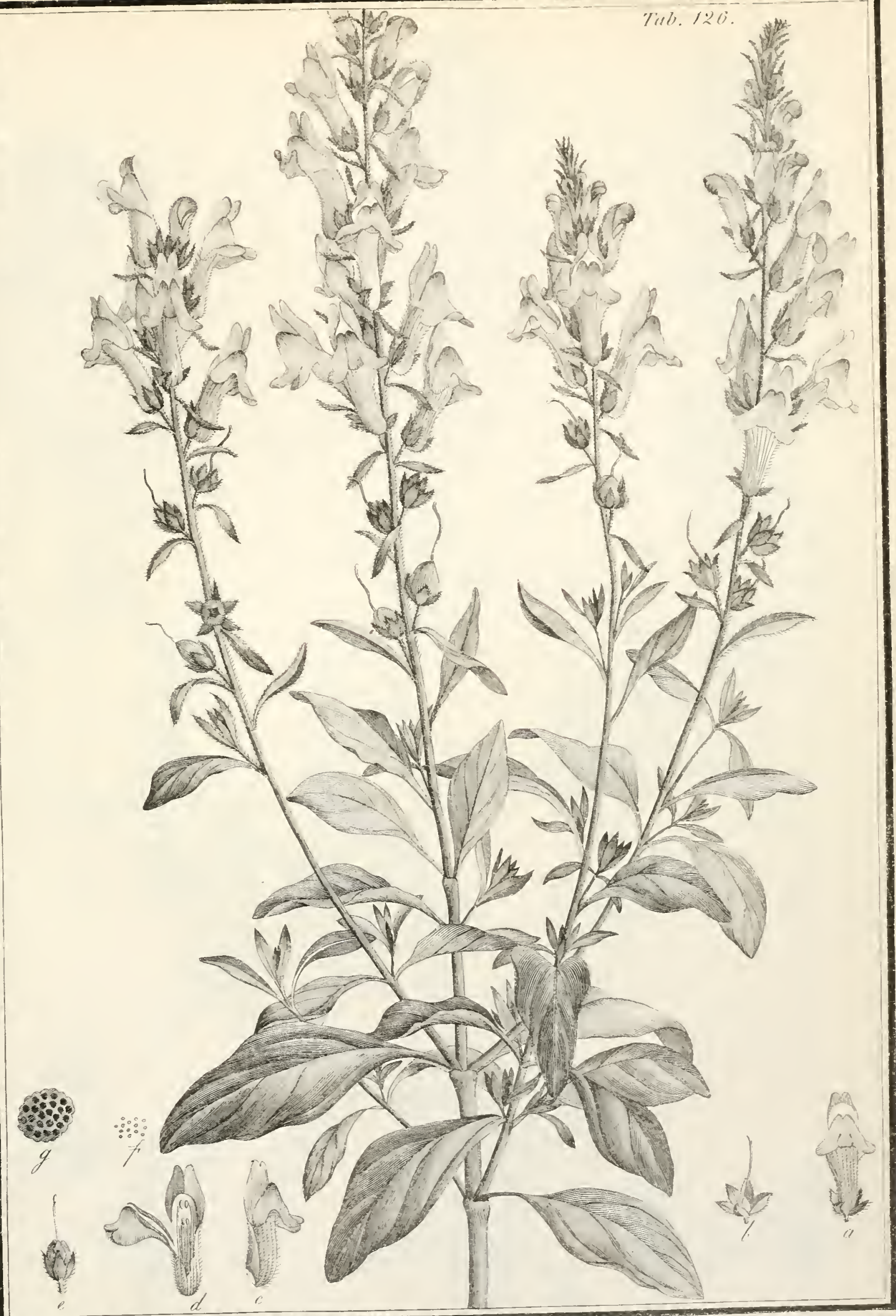





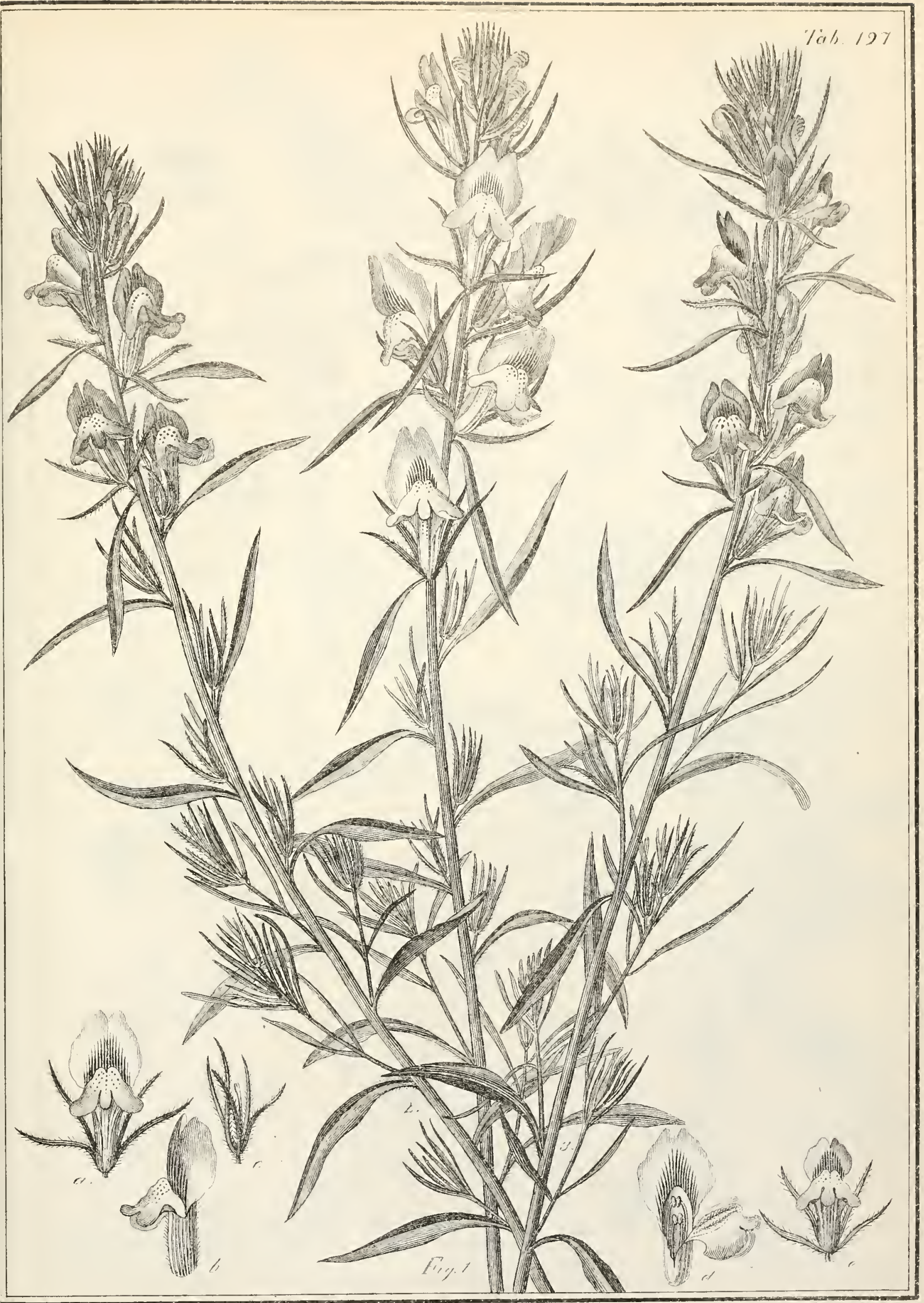





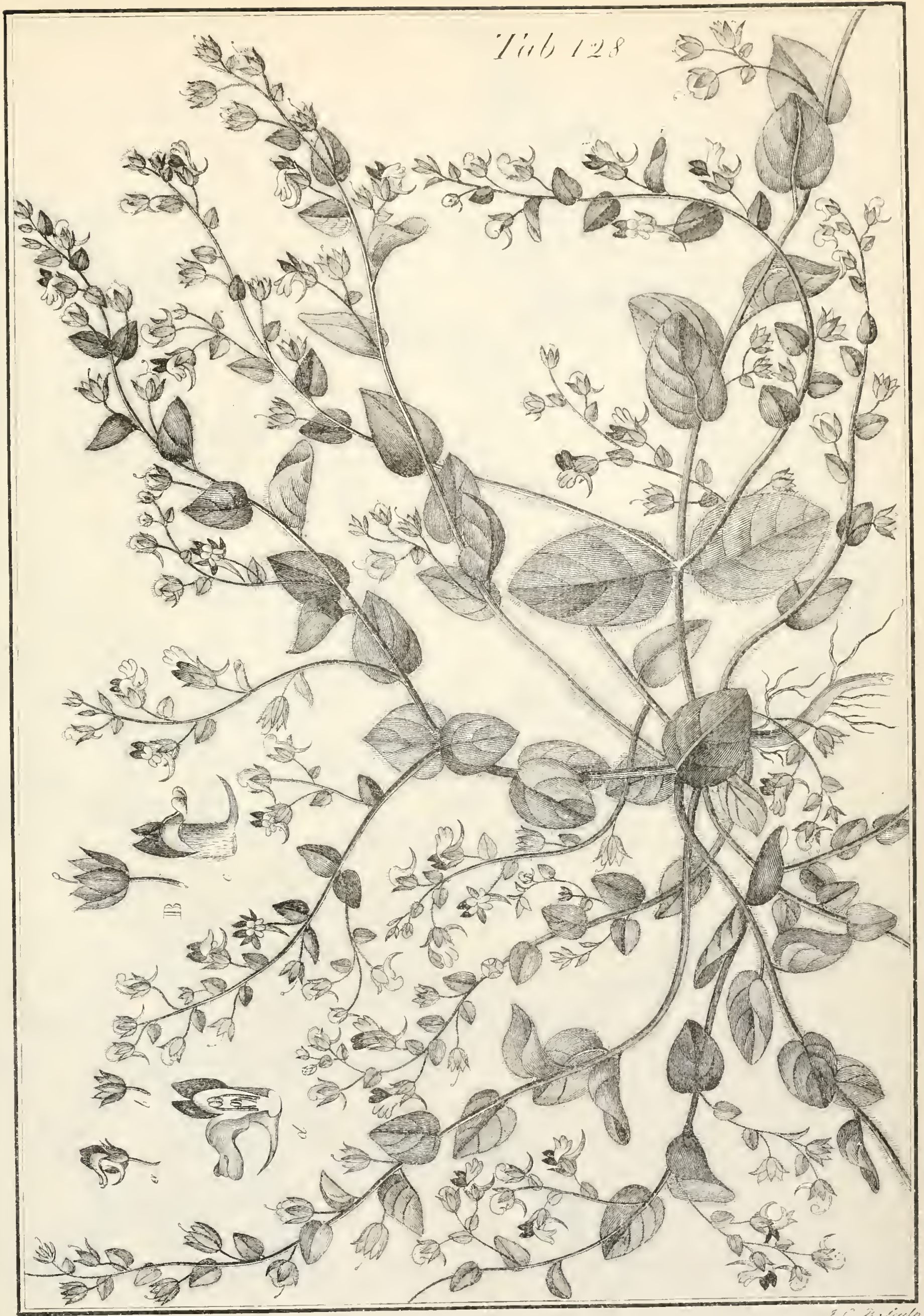



Pex
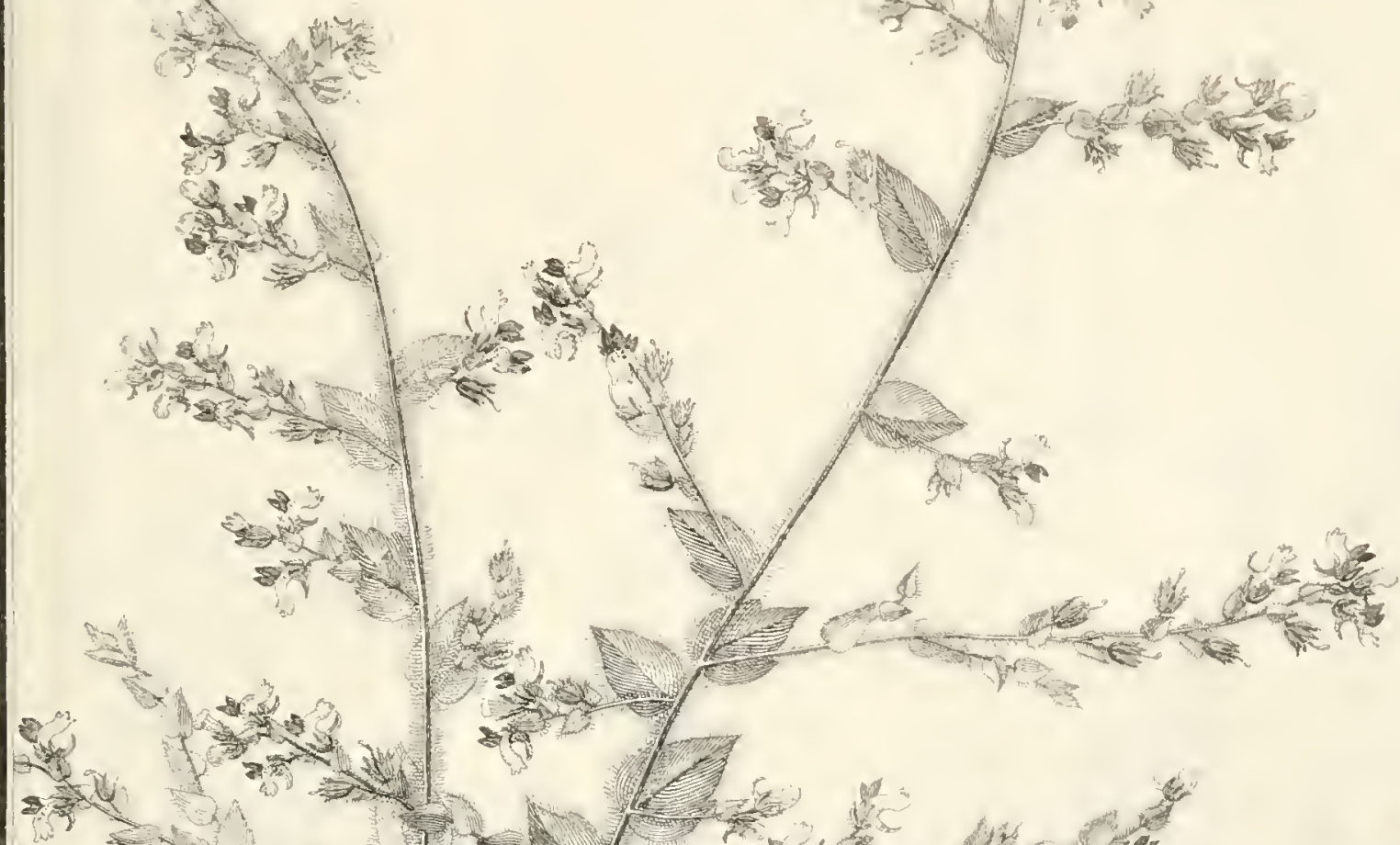

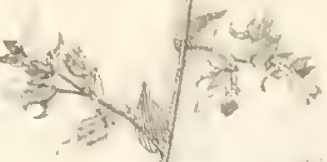

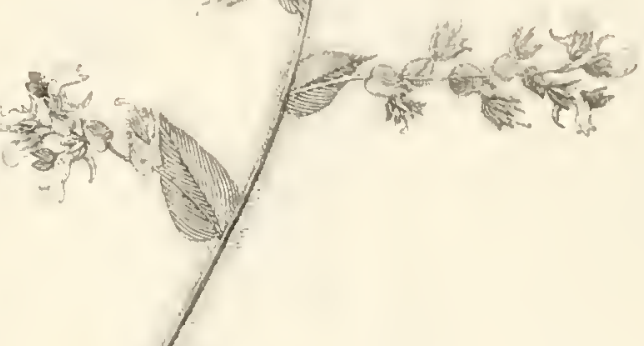

का

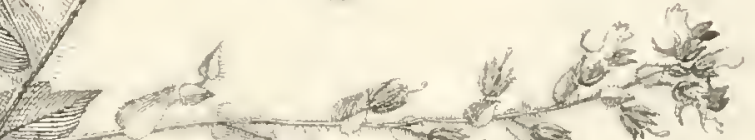

\section{ICl). 129}

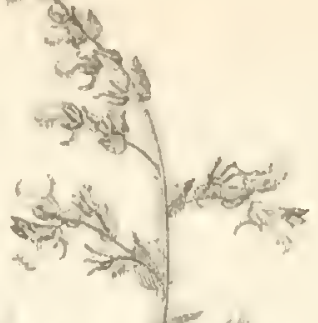

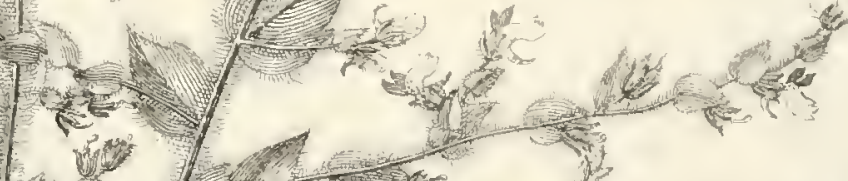

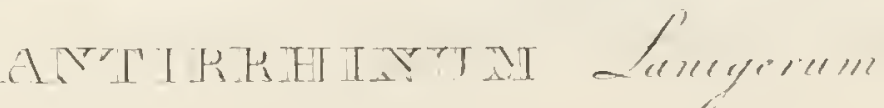





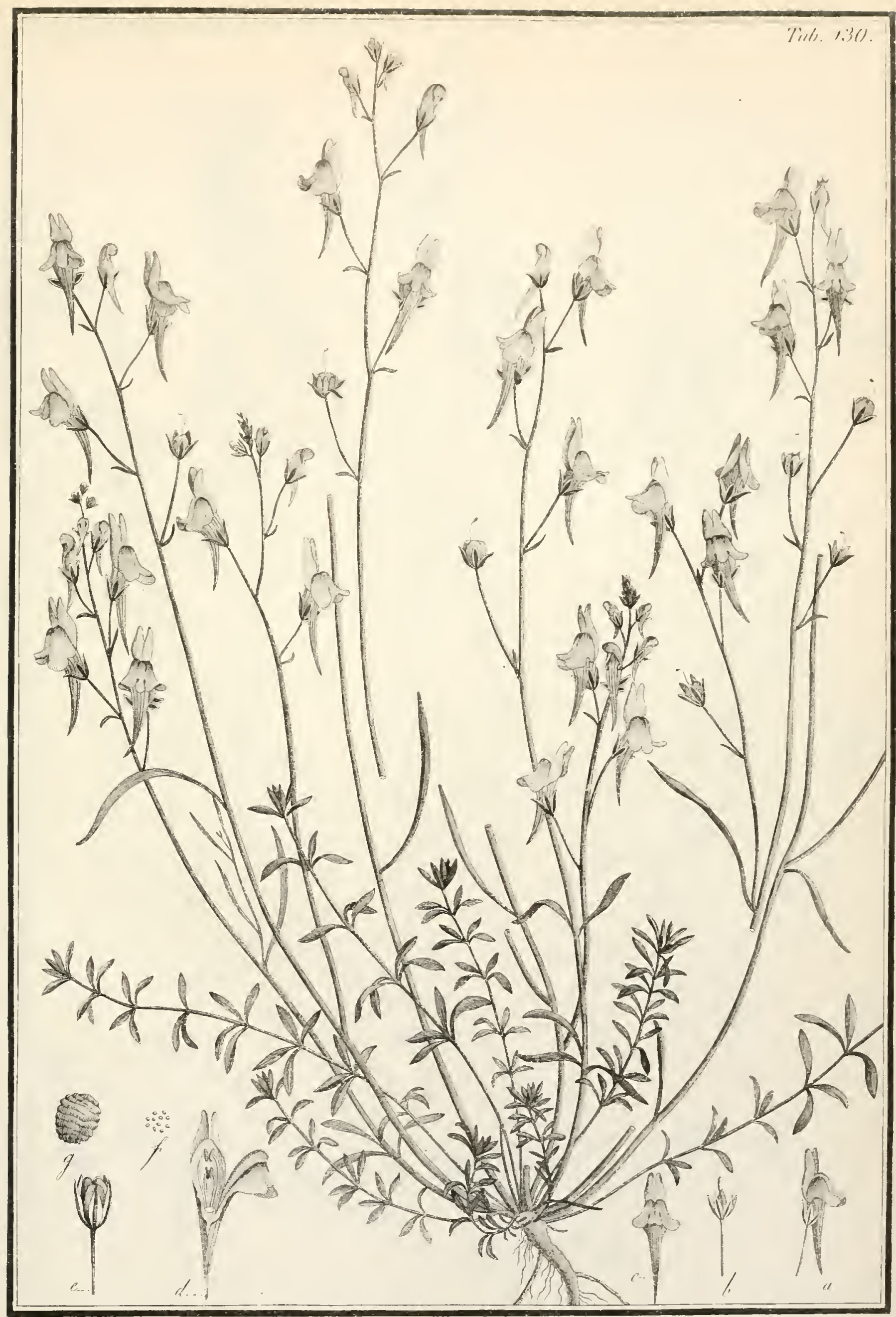





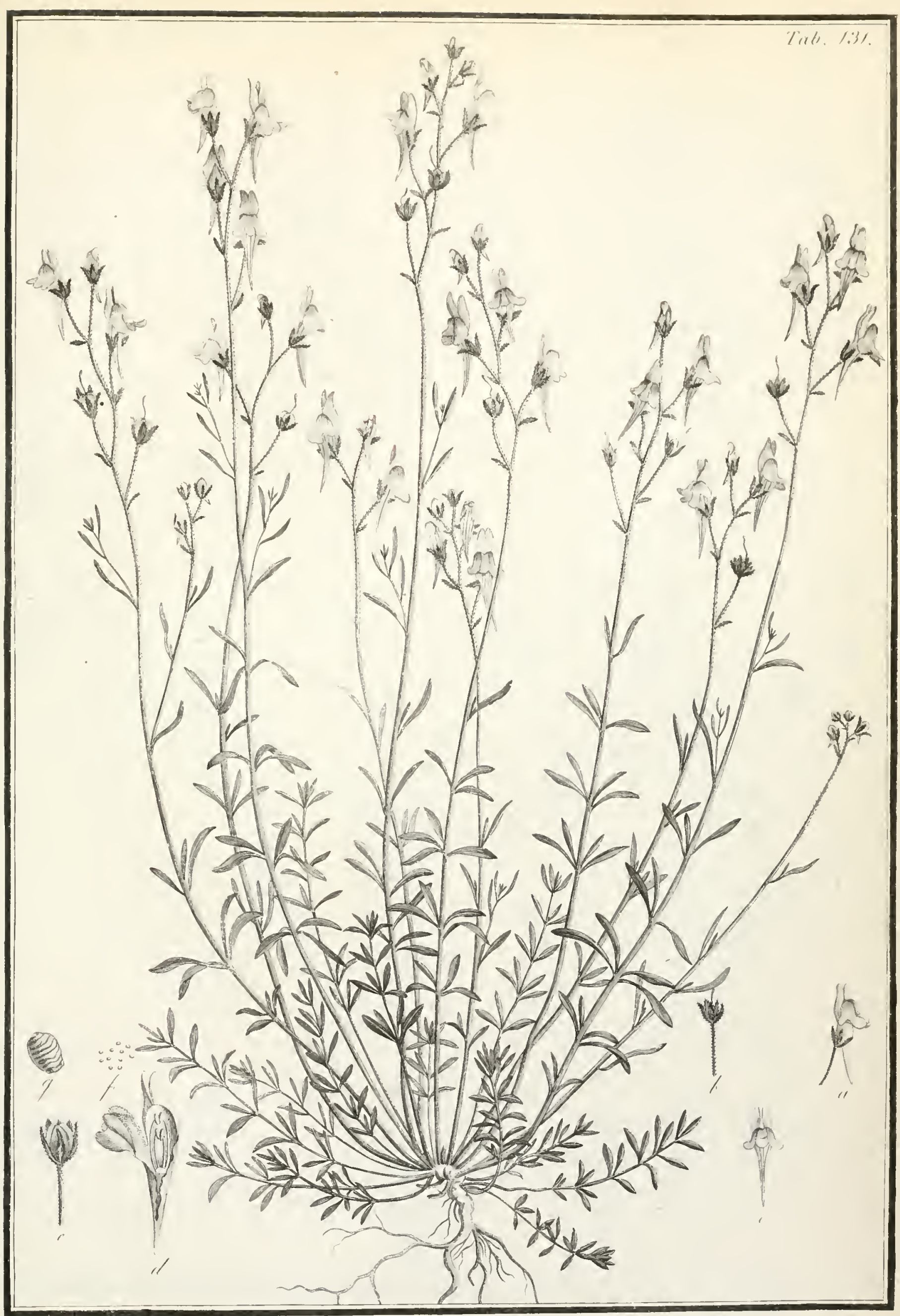





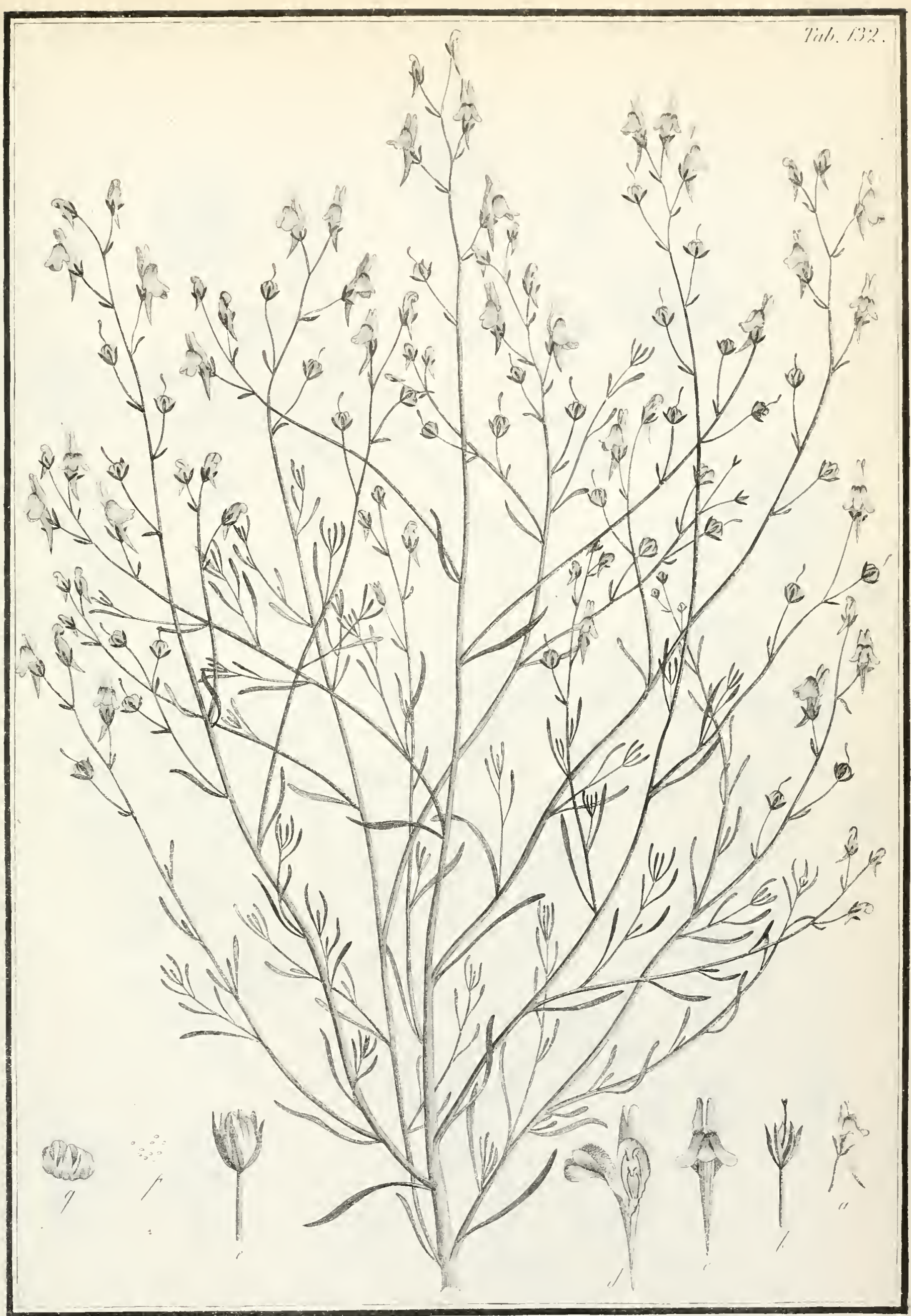






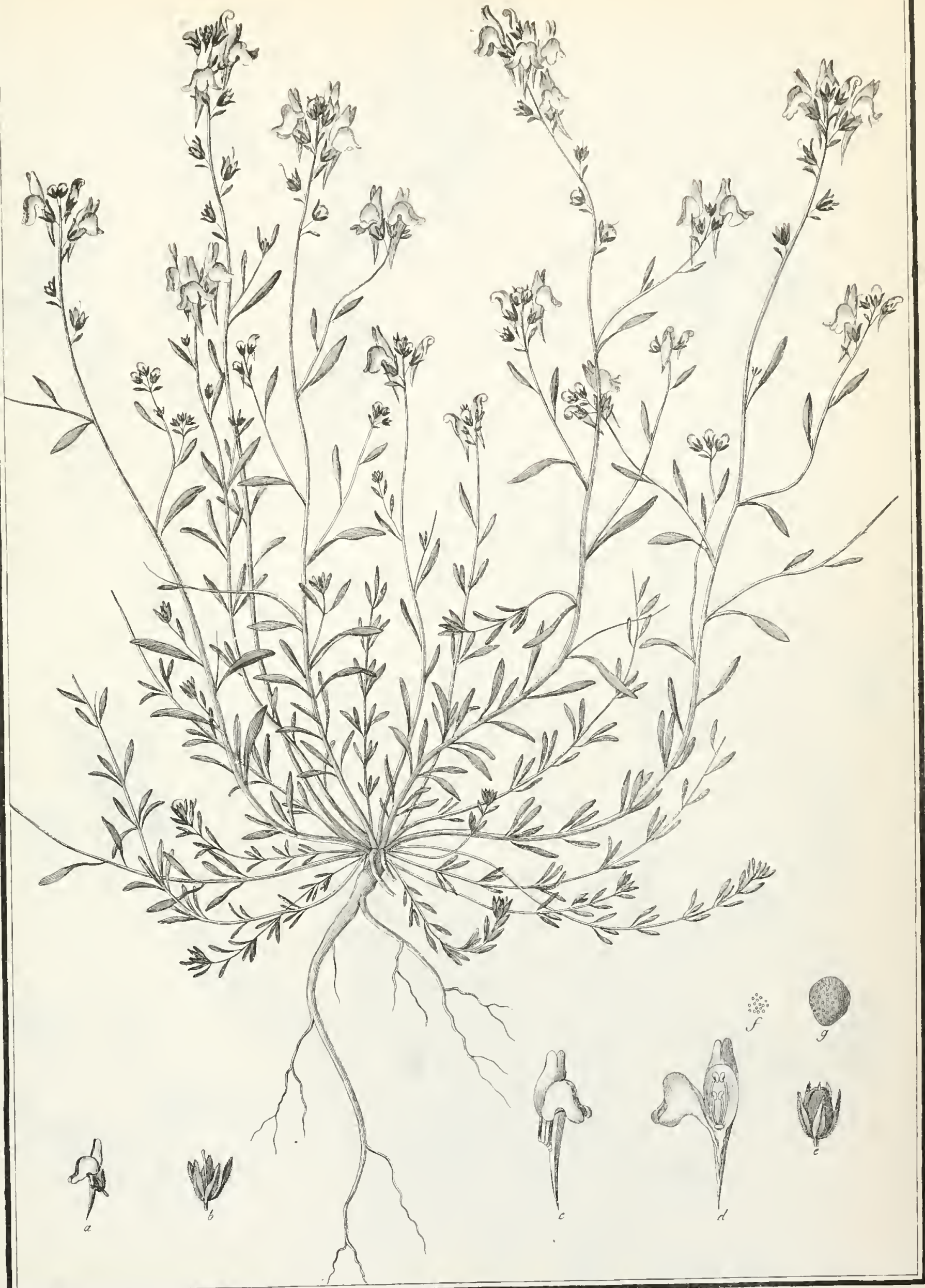





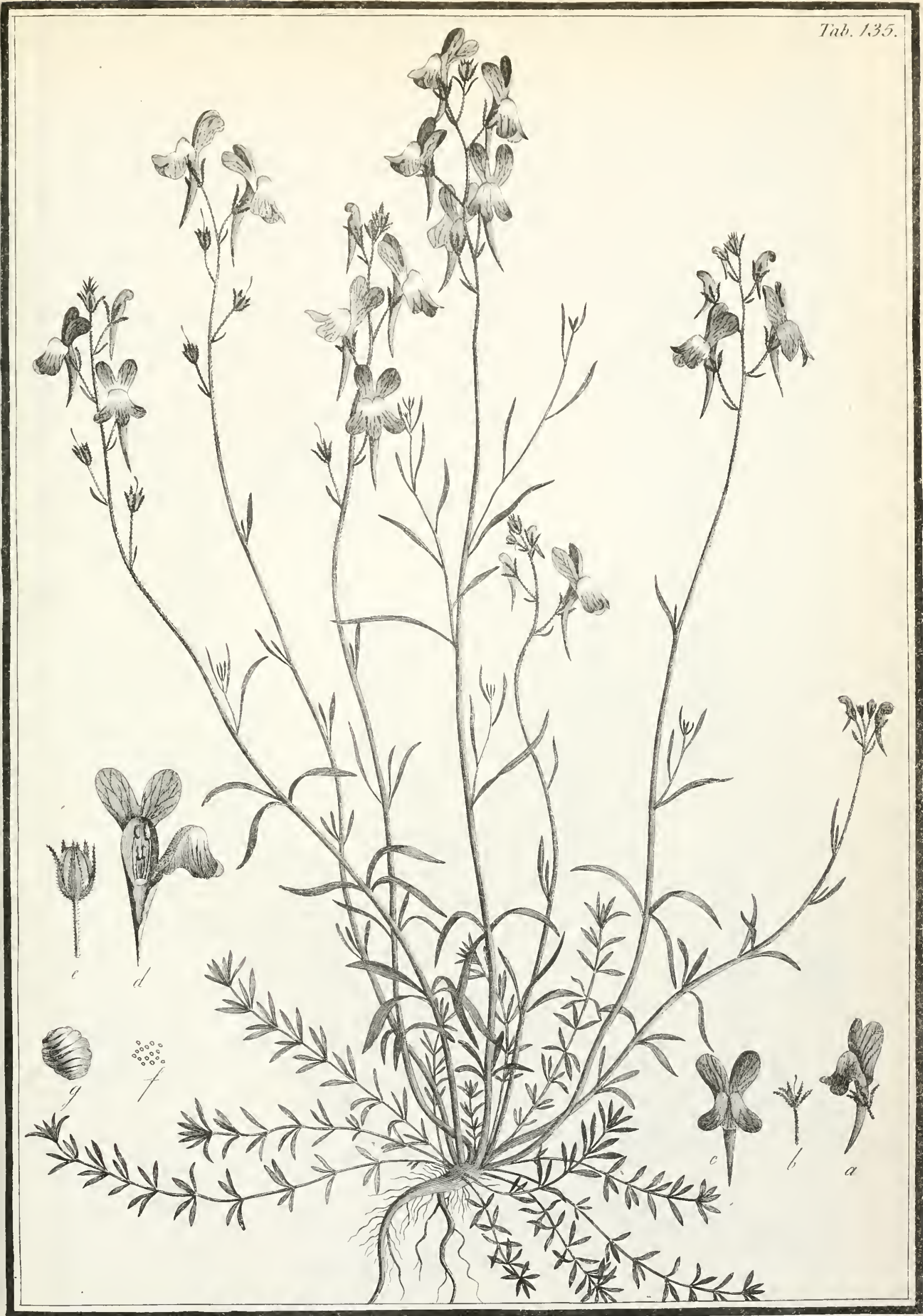



* ${ }^{4}$

1

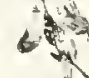

1
$y$
$y$

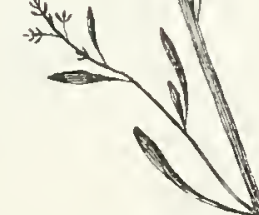

VI Nu
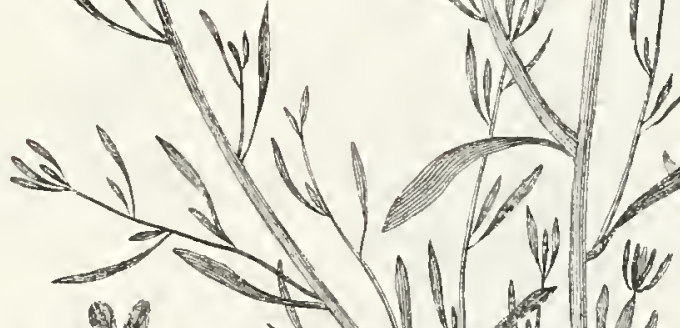

*1.
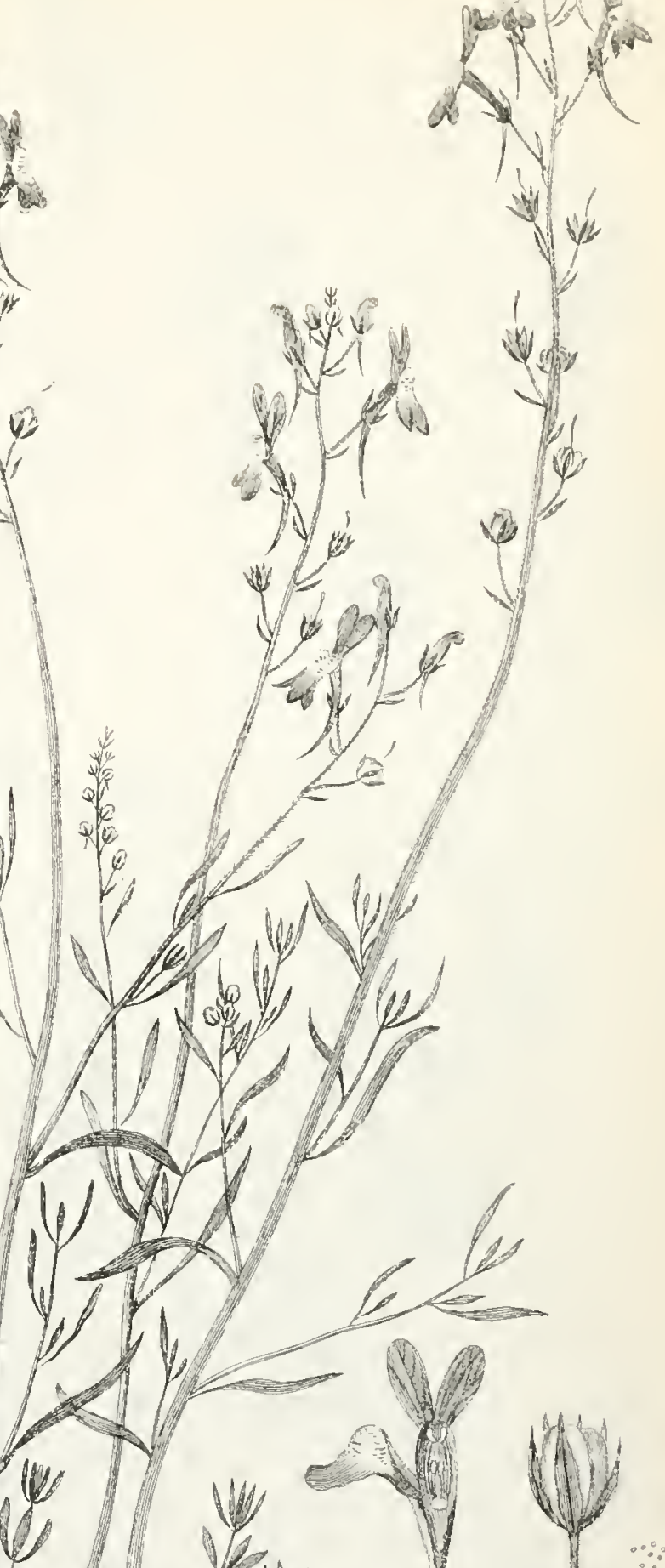

$\sqrt{4}$
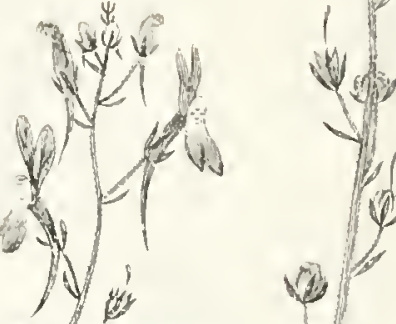

4
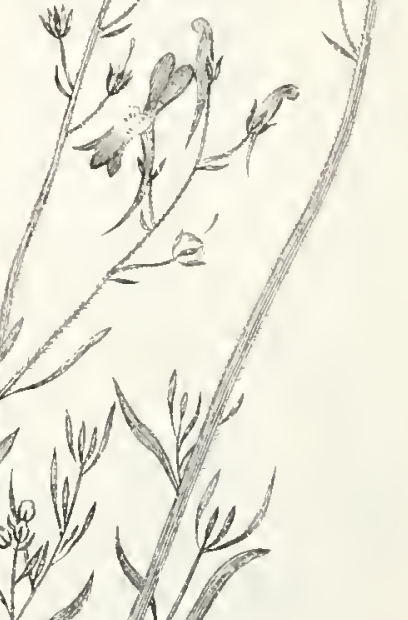

Tab. 137

dit?

9

40

$\times$

If

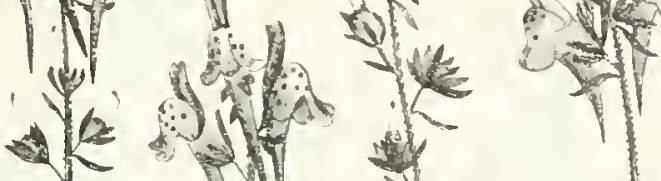
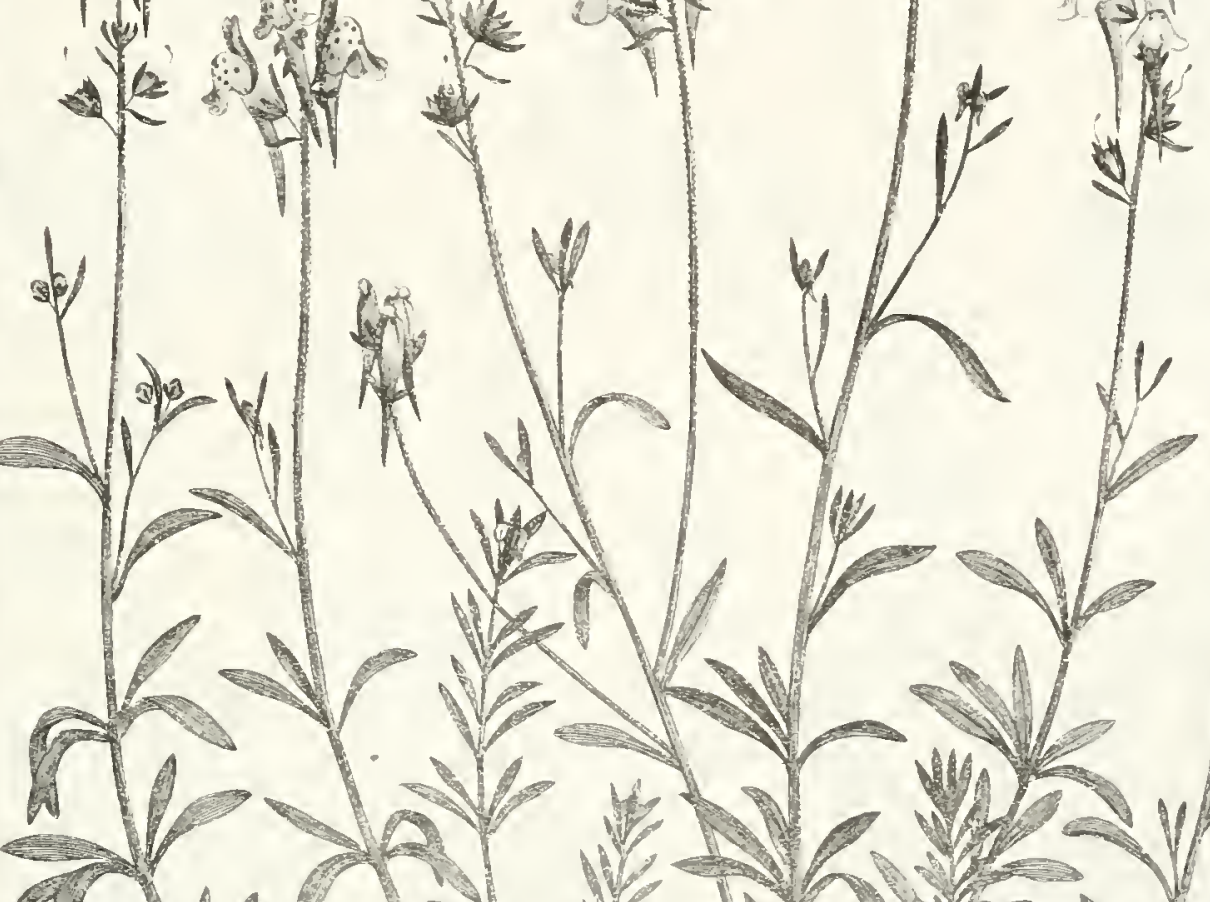

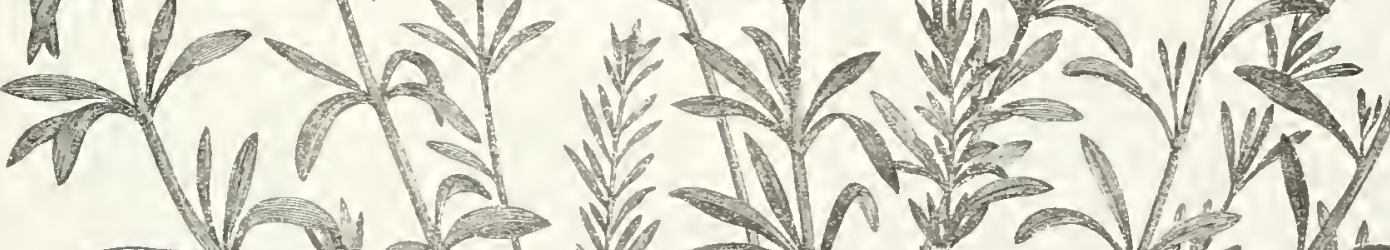

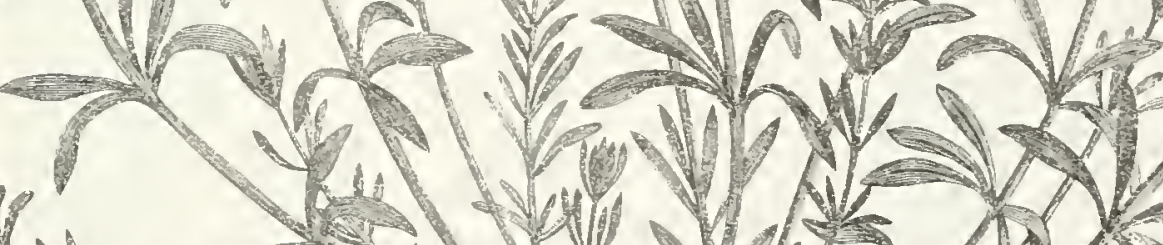

H

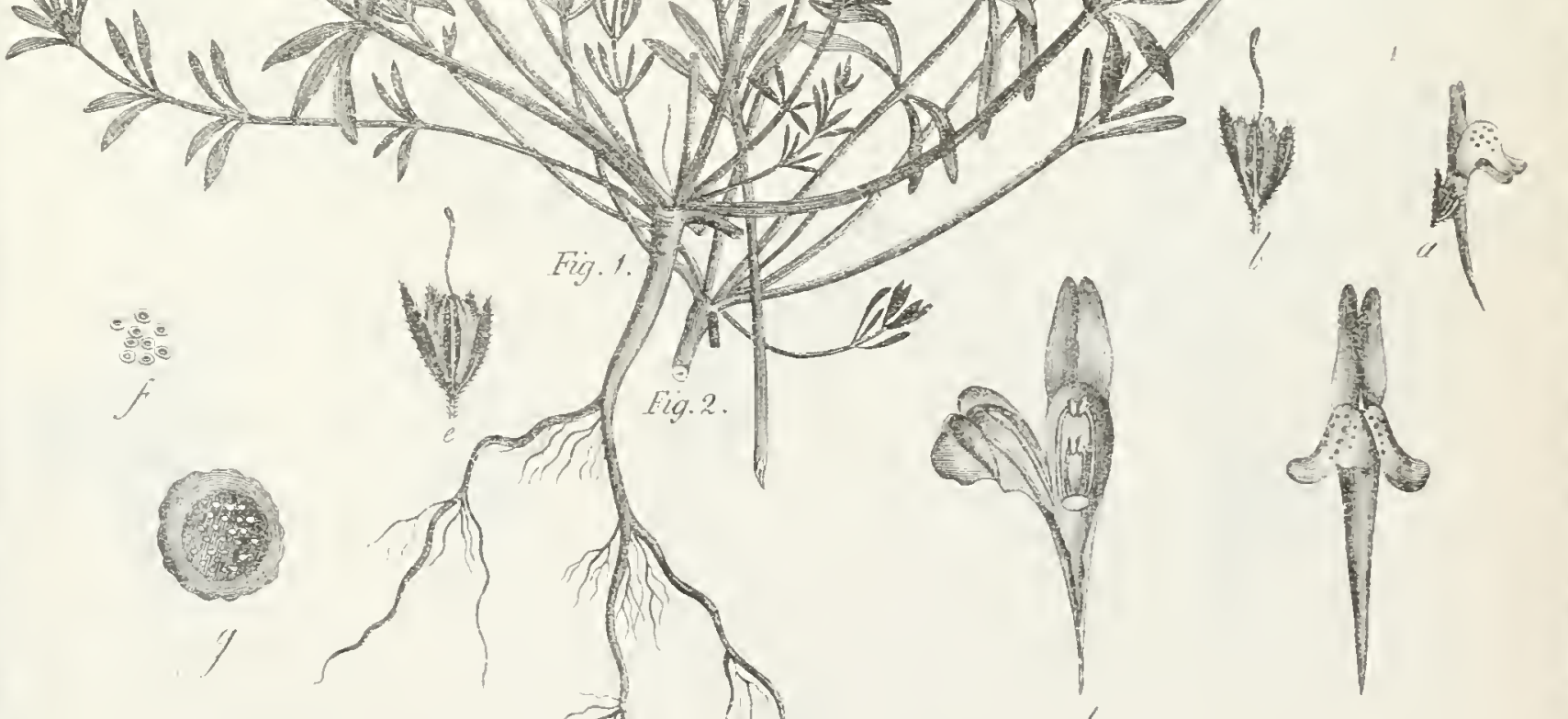





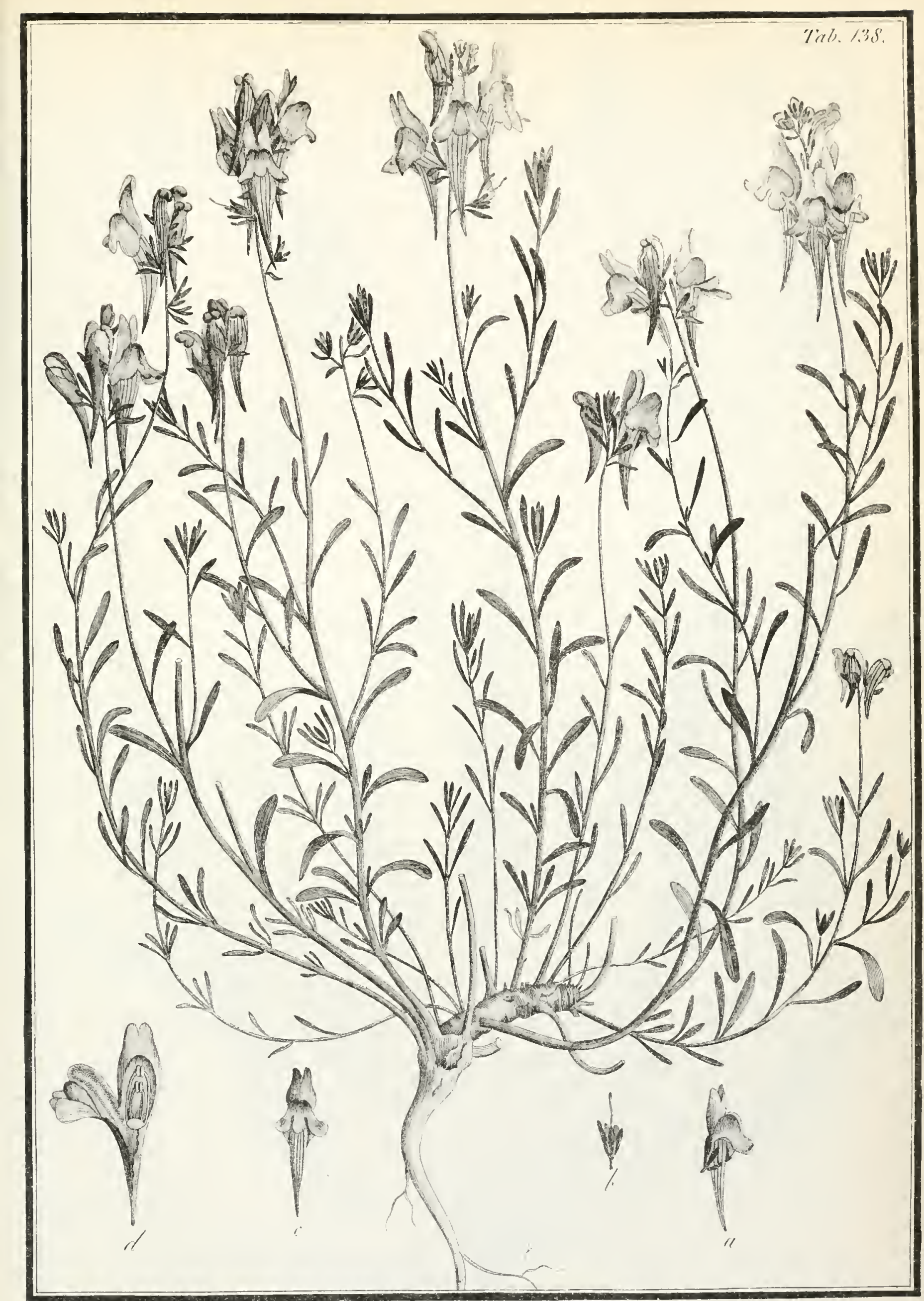





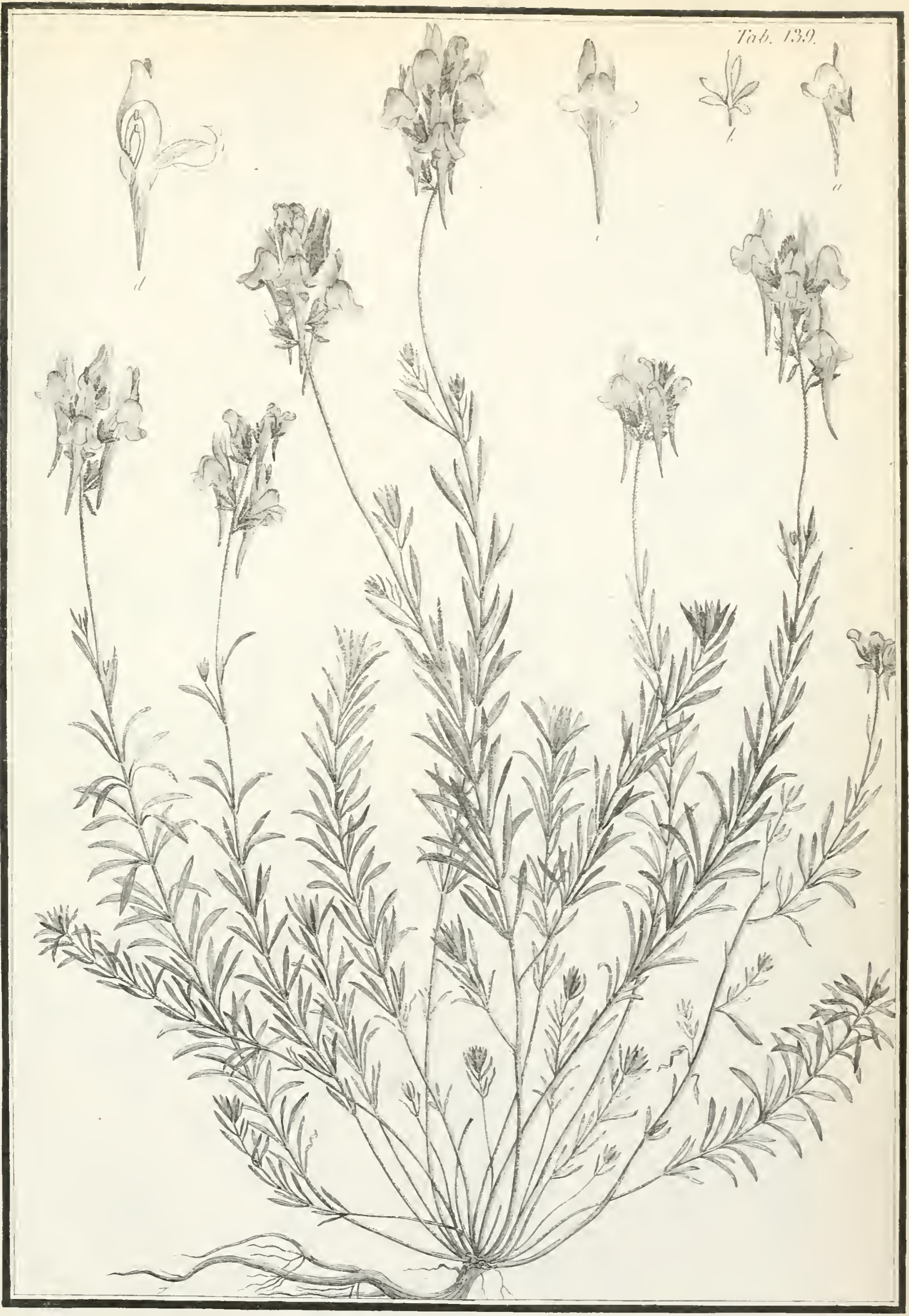





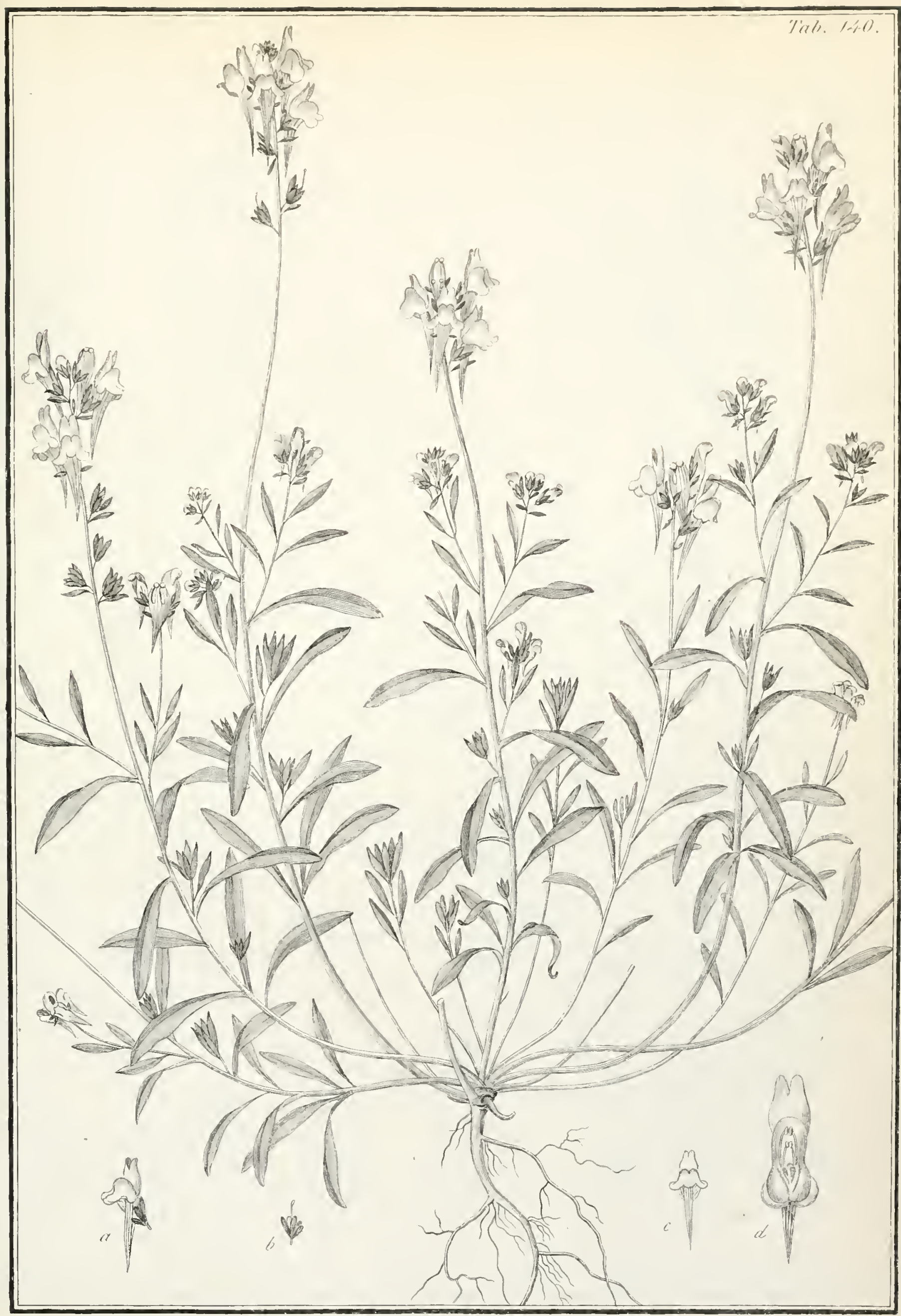





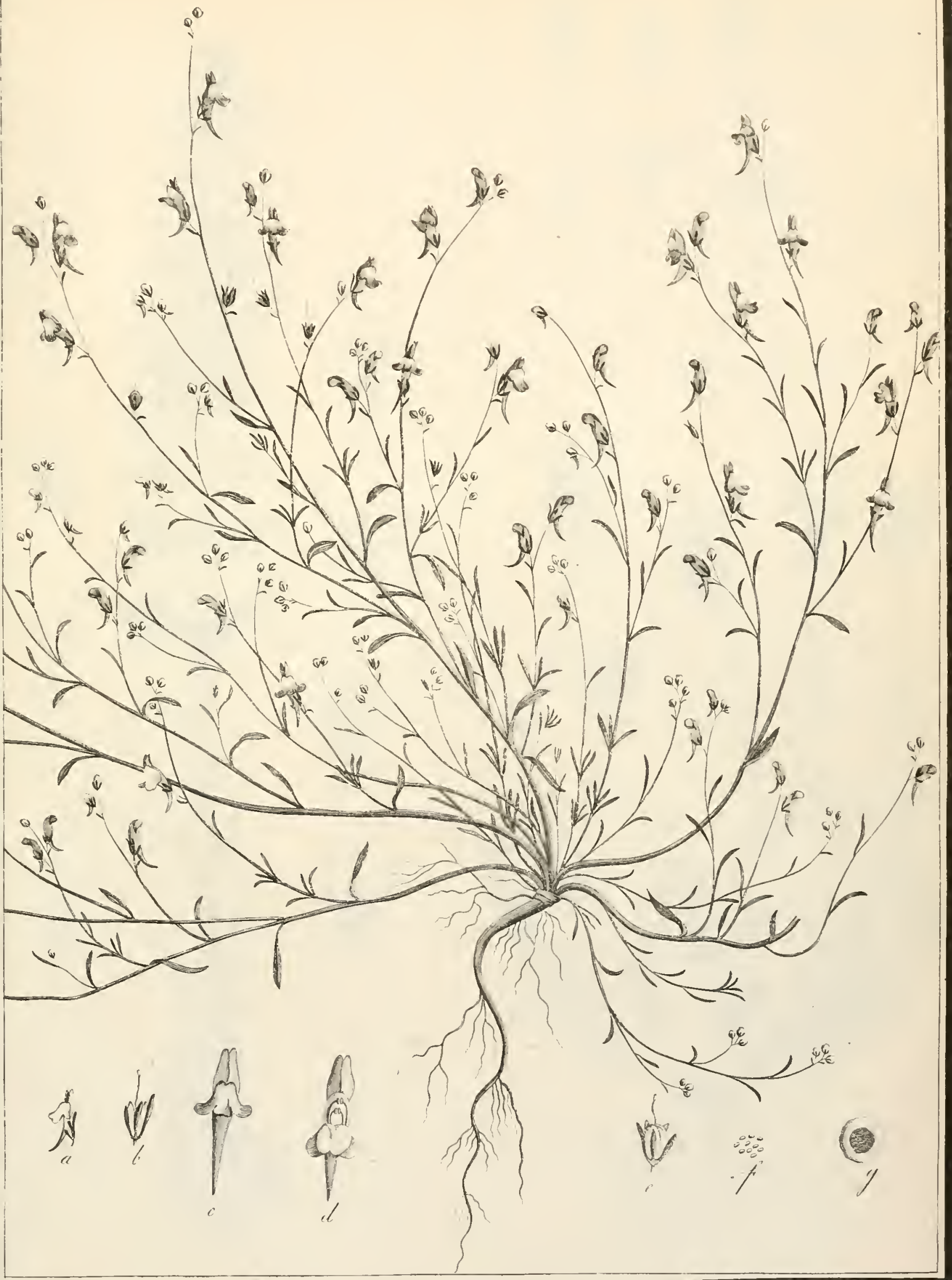




$\sqrt[4]{1}$

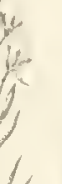

$\sqrt{(2)}$

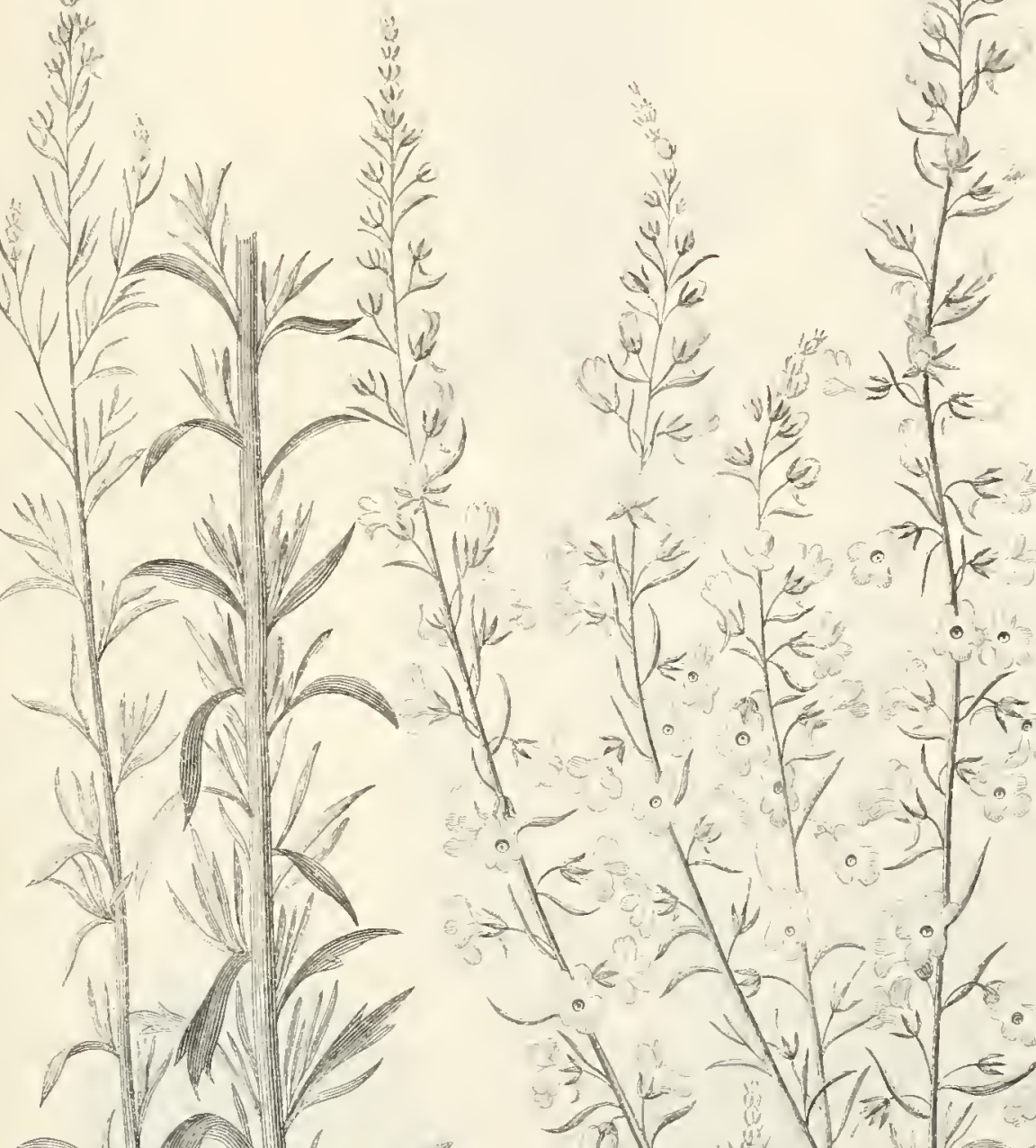

$\sqrt{2}$
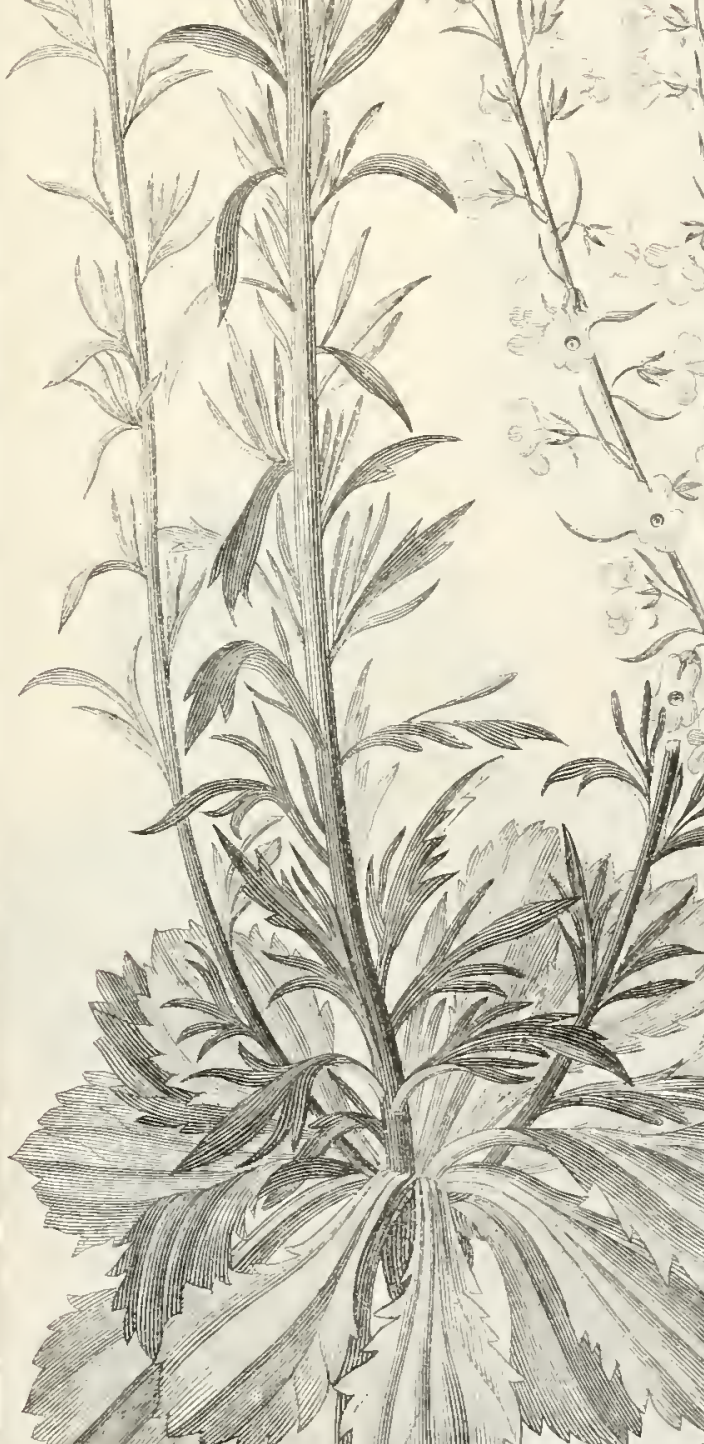

1) 11

$1+1(-1)$

31

M- ML to तi : t

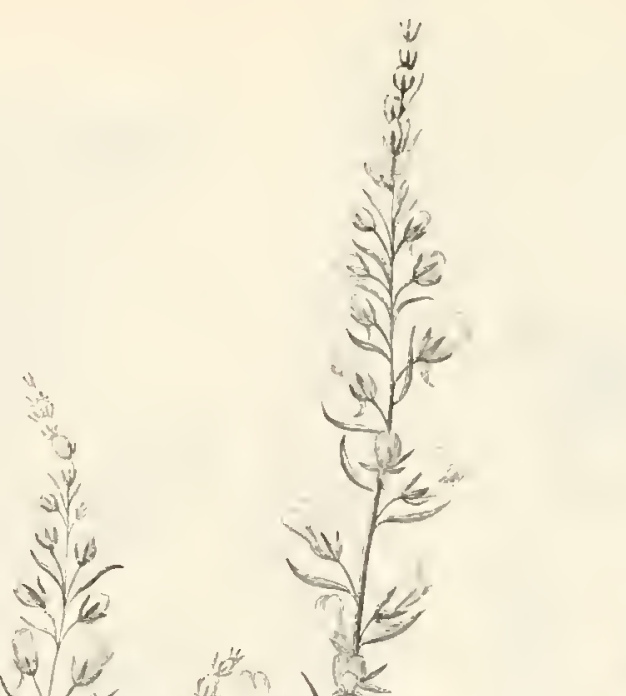

鹿

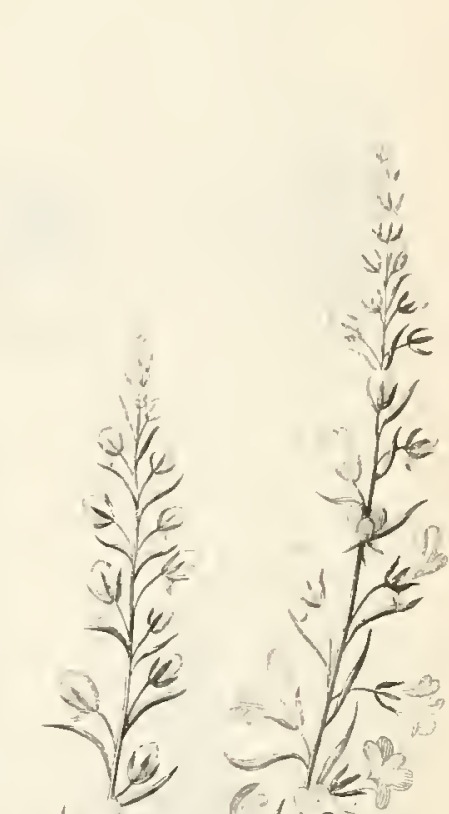

$+1$

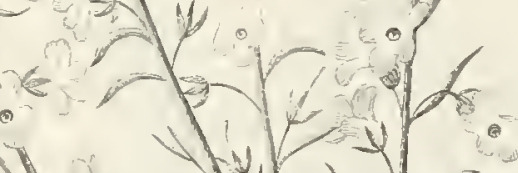

to.
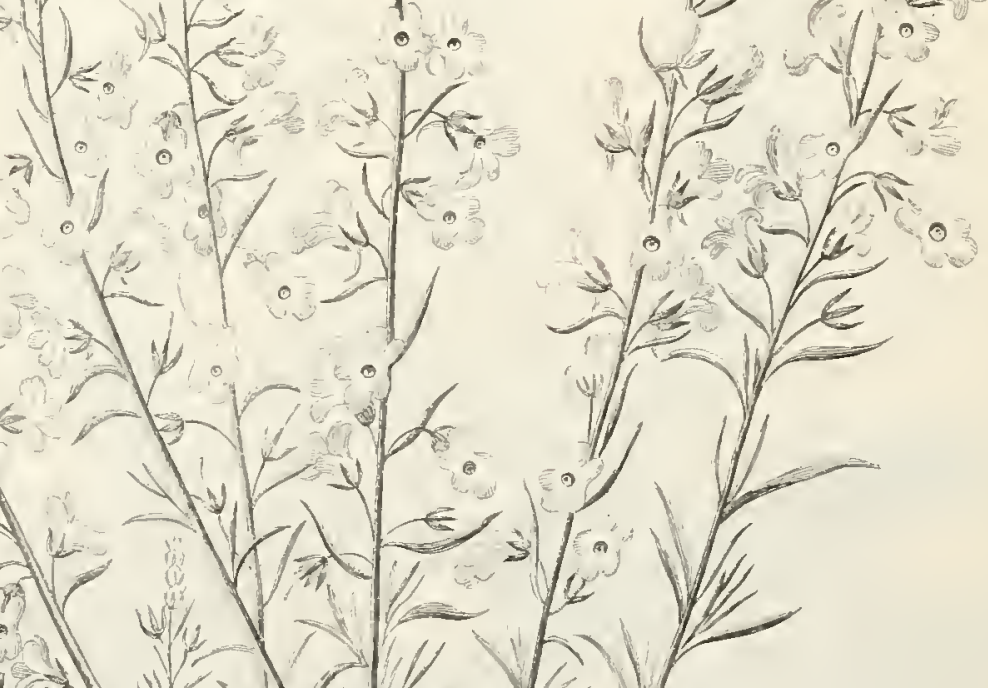



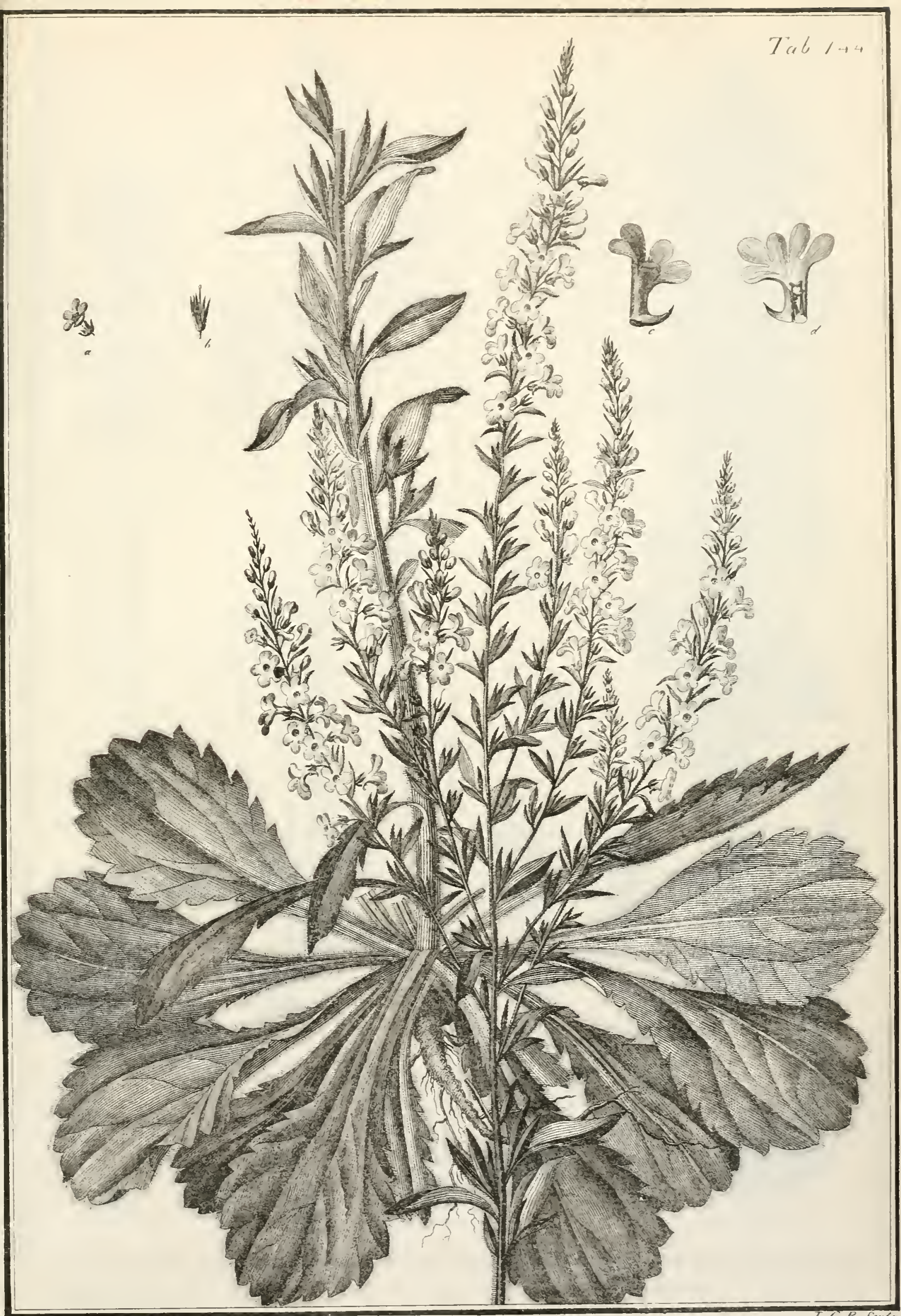





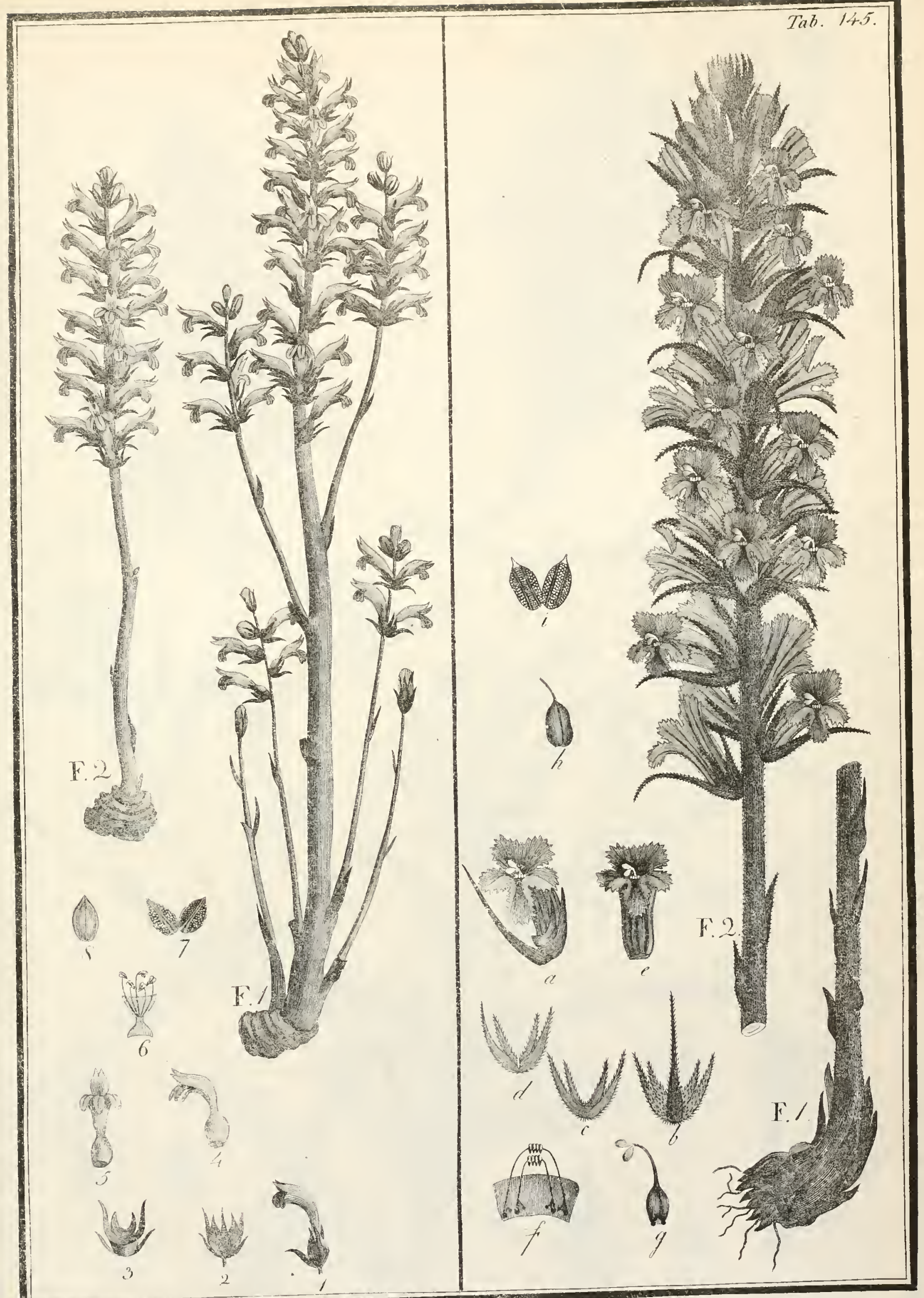

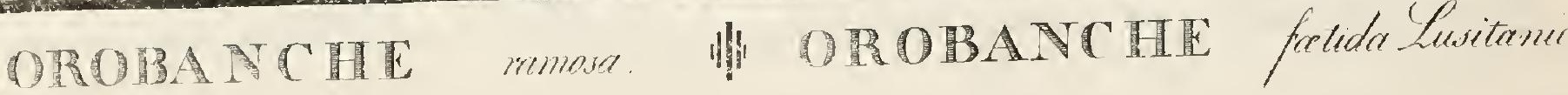





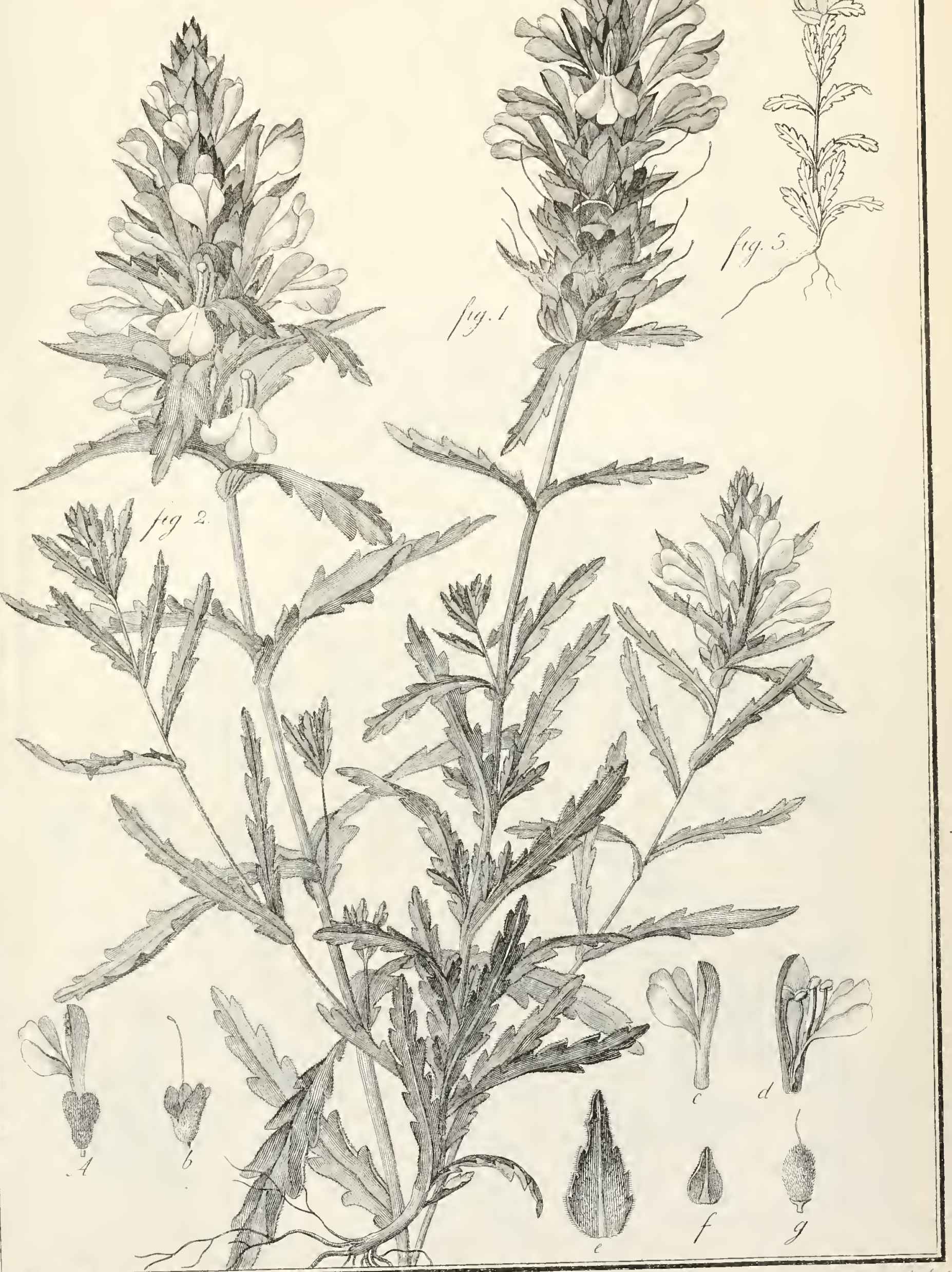





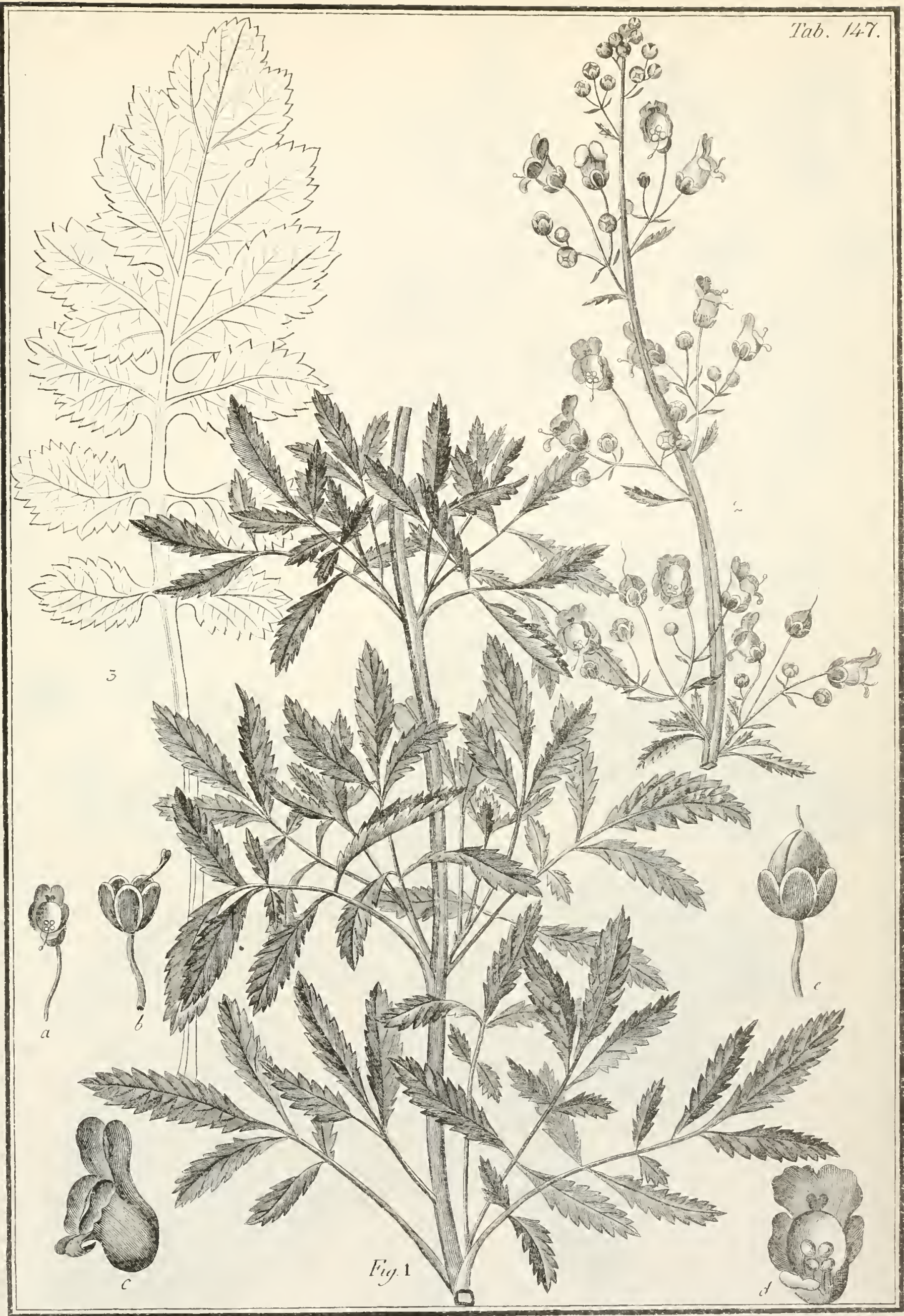





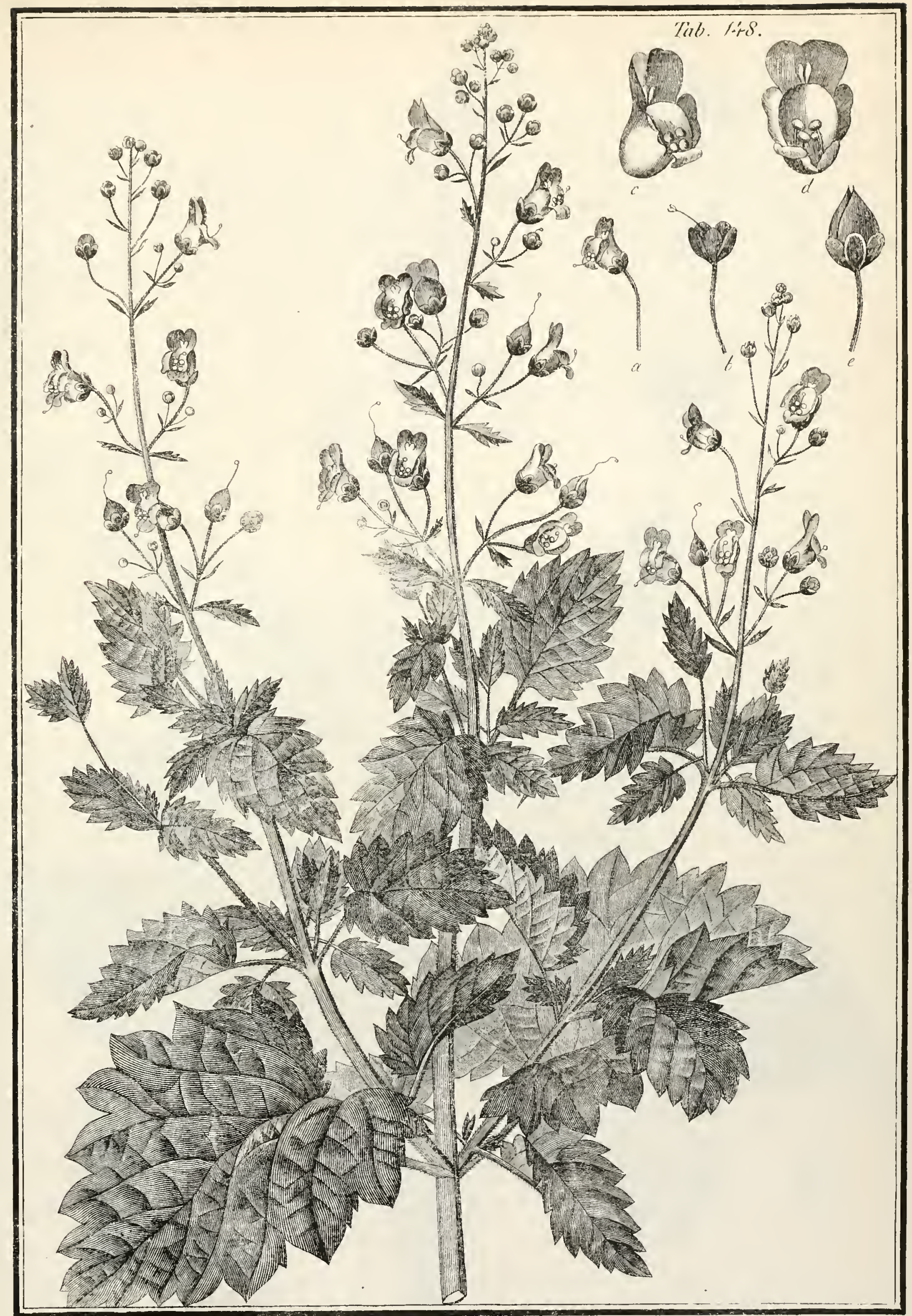





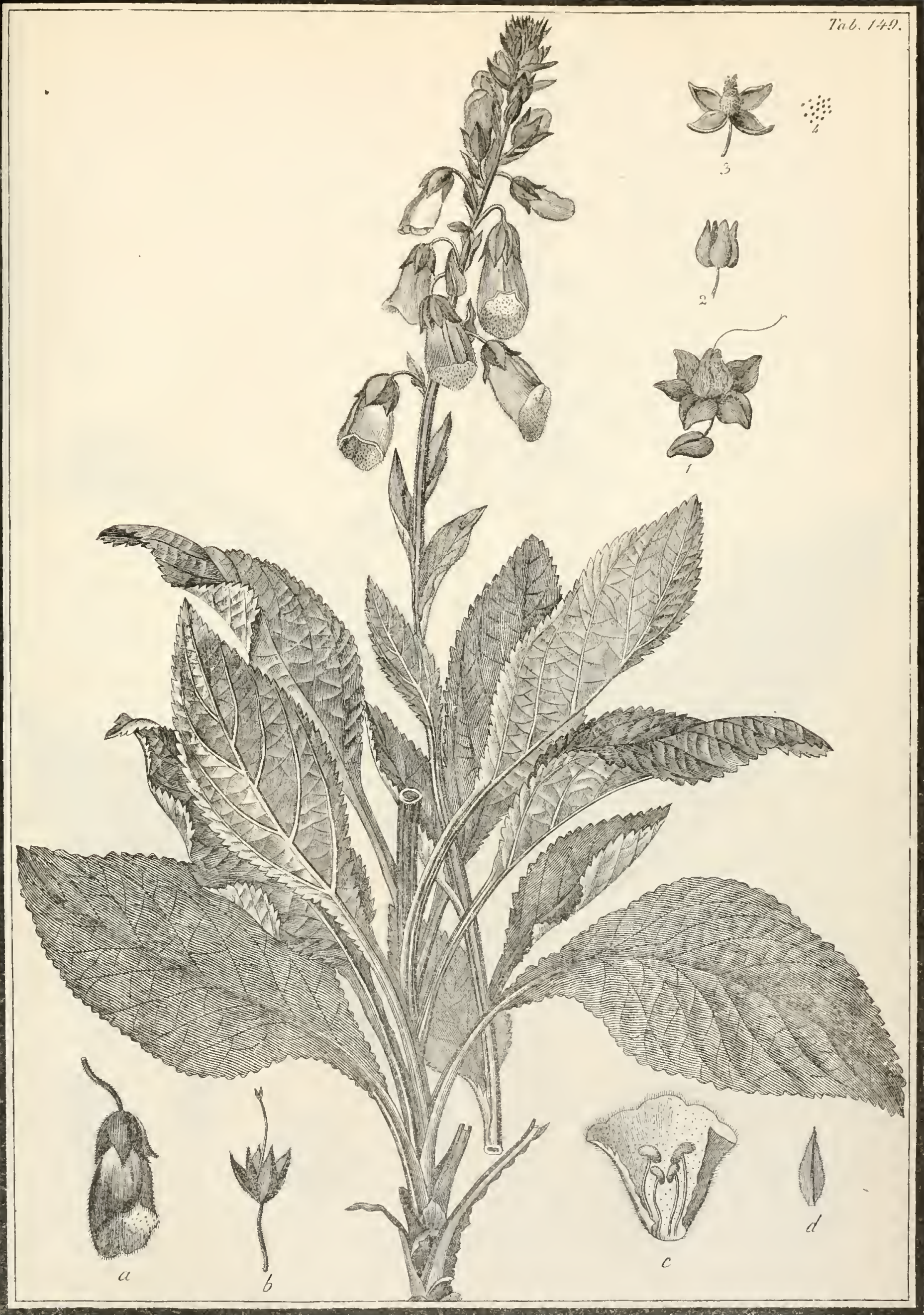

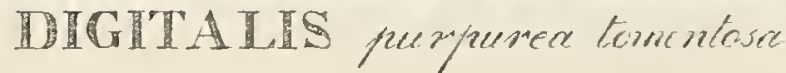





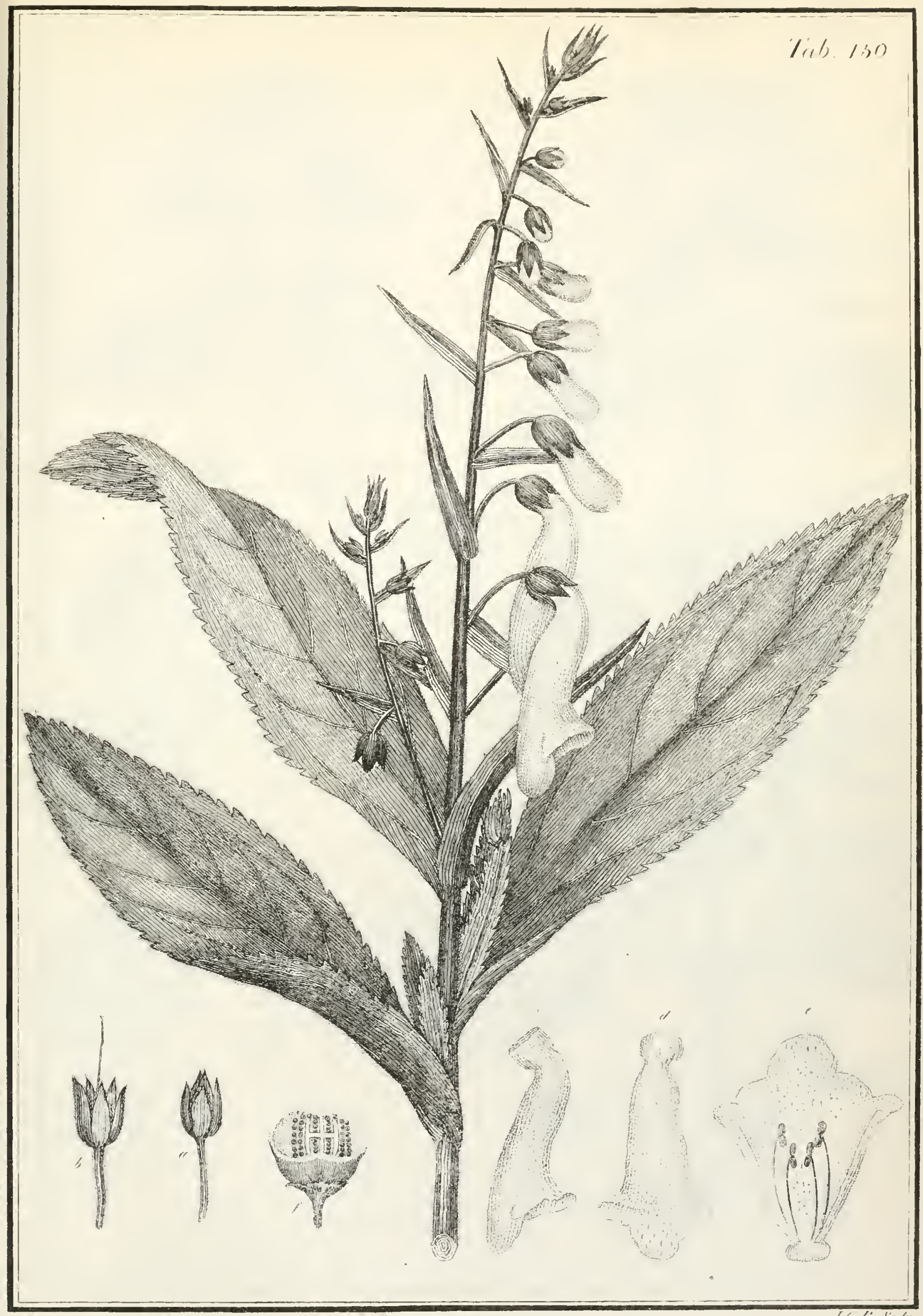





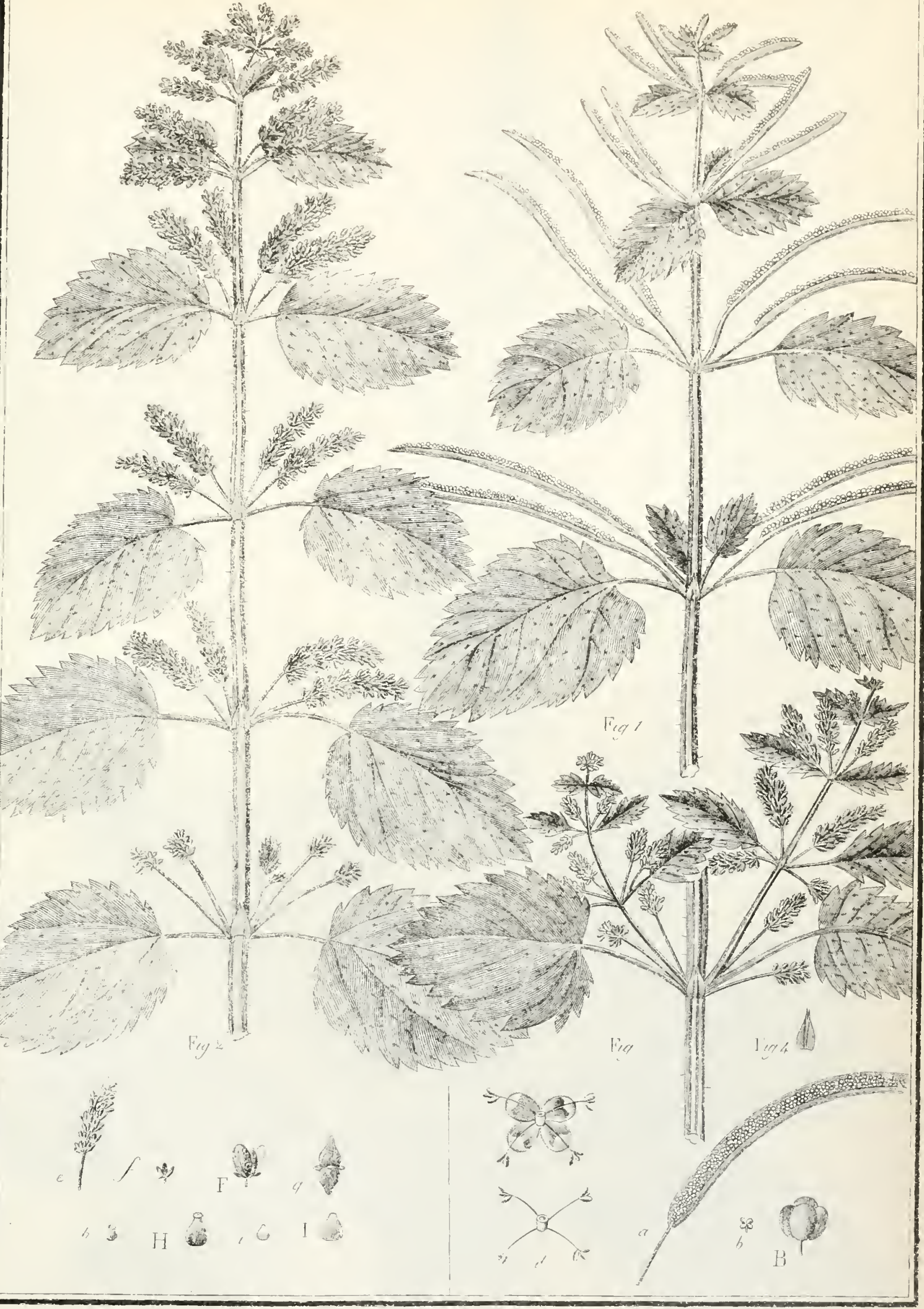




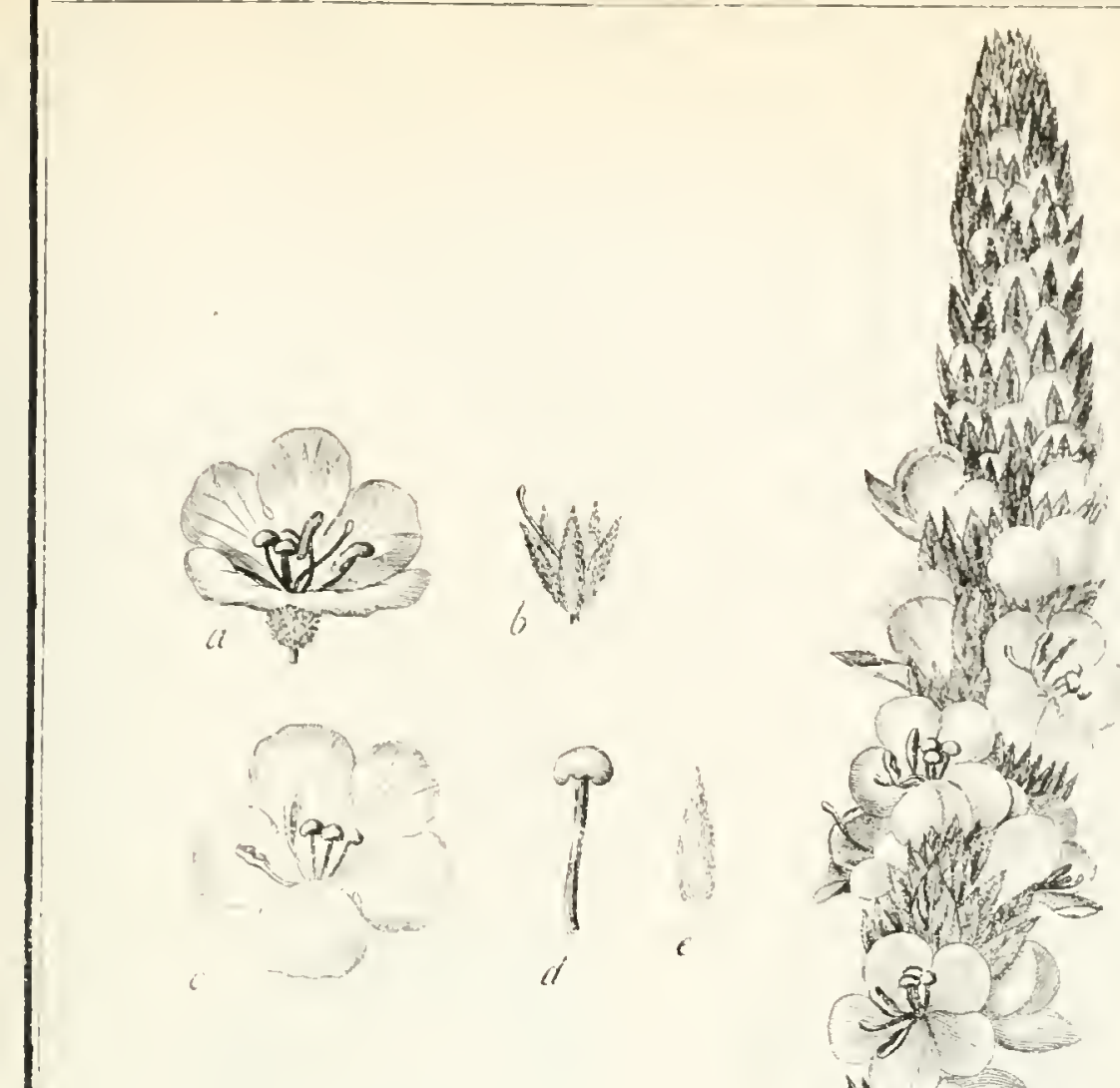

Tiub. $15:$ 


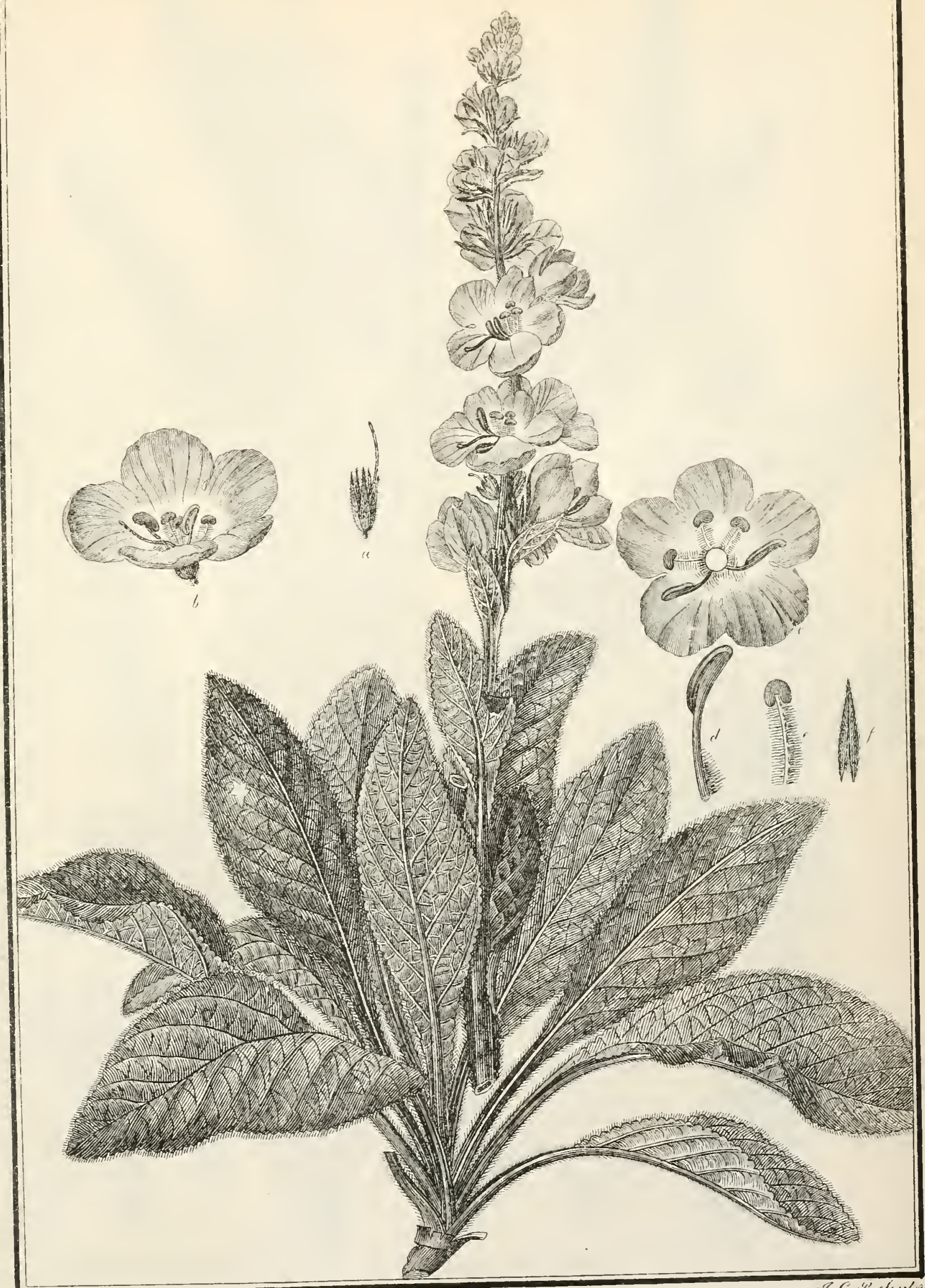



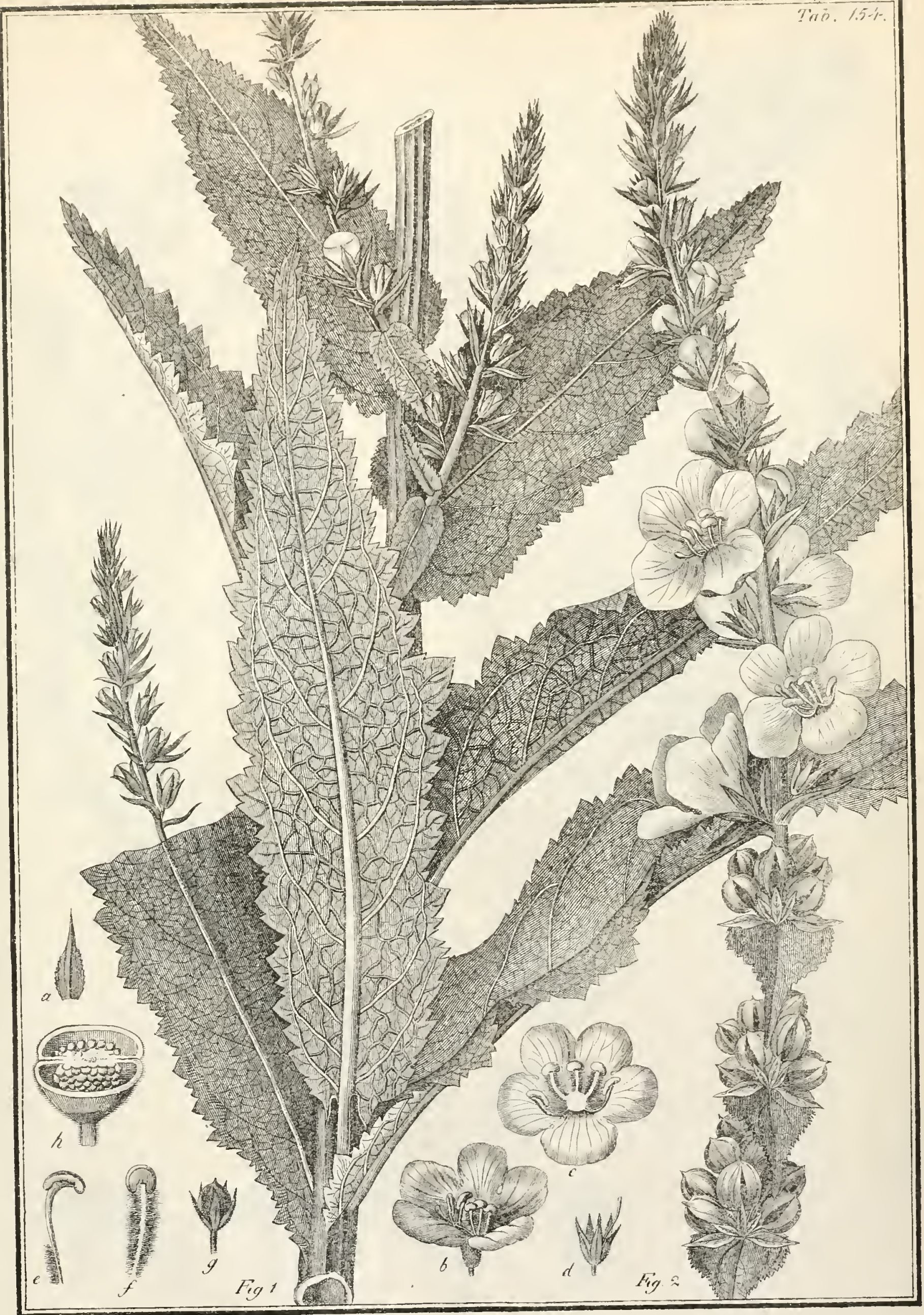

VERBASCUM blallarioudes 



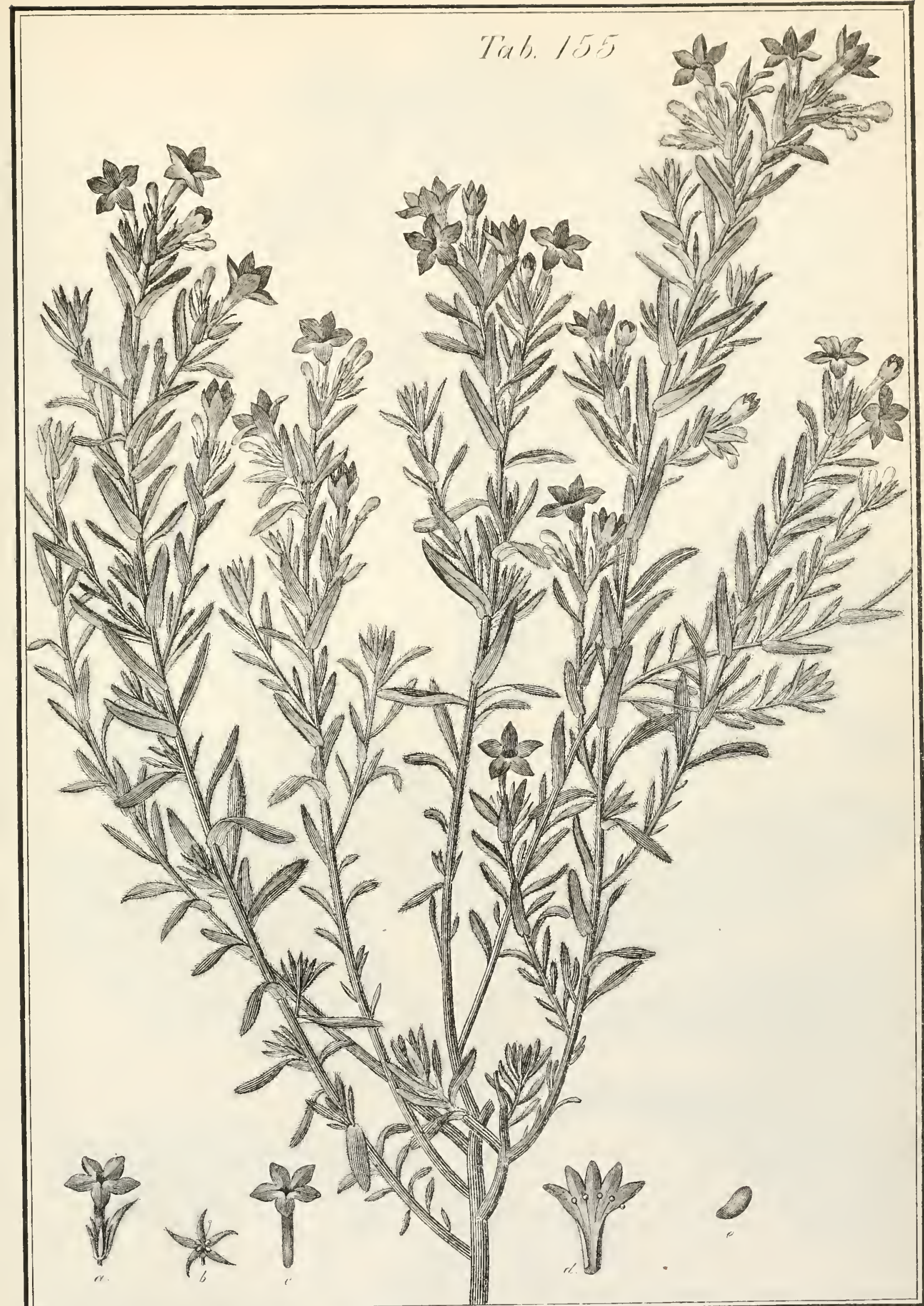





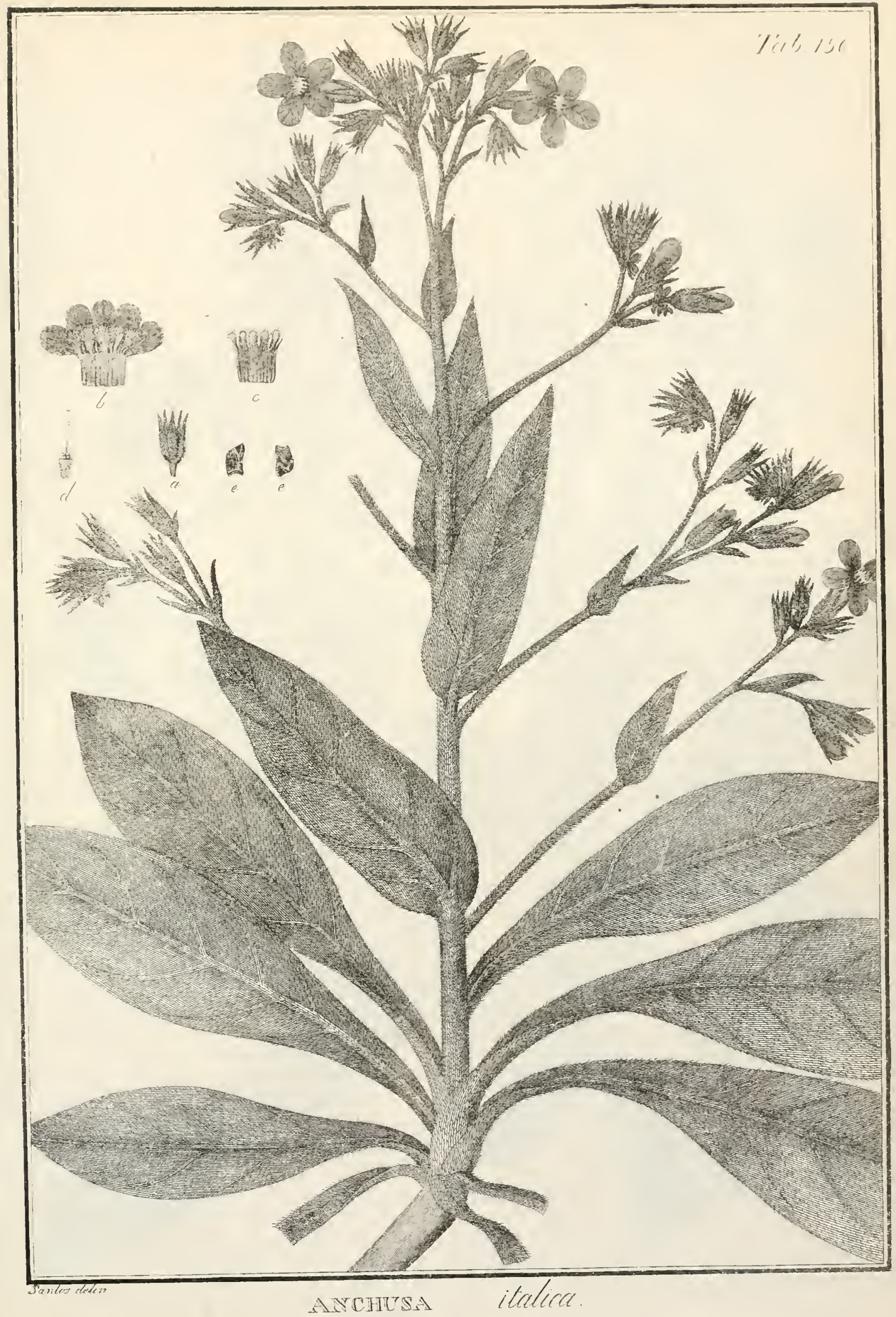





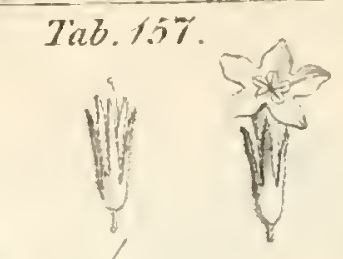

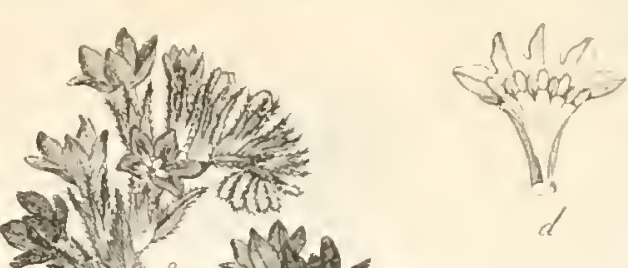

$v^{2}$

$\sqrt{1}$

nt)

$2+1$ (n)

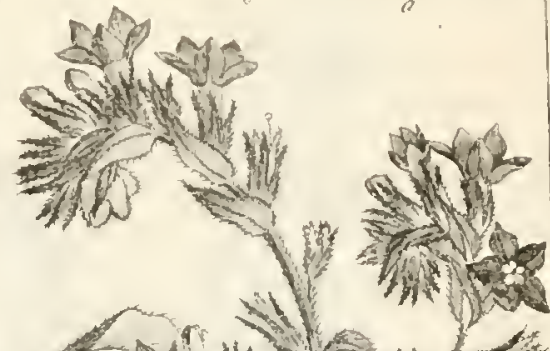

1.1.4.

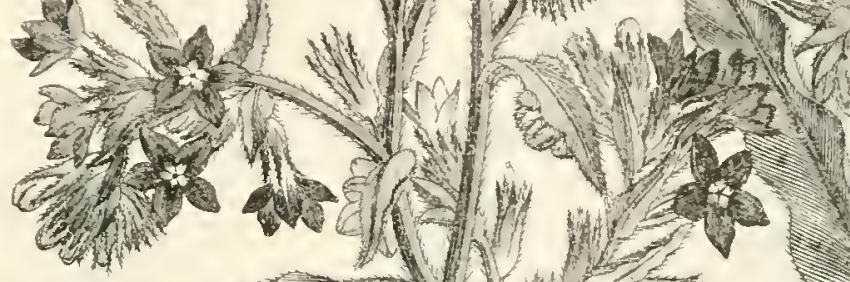

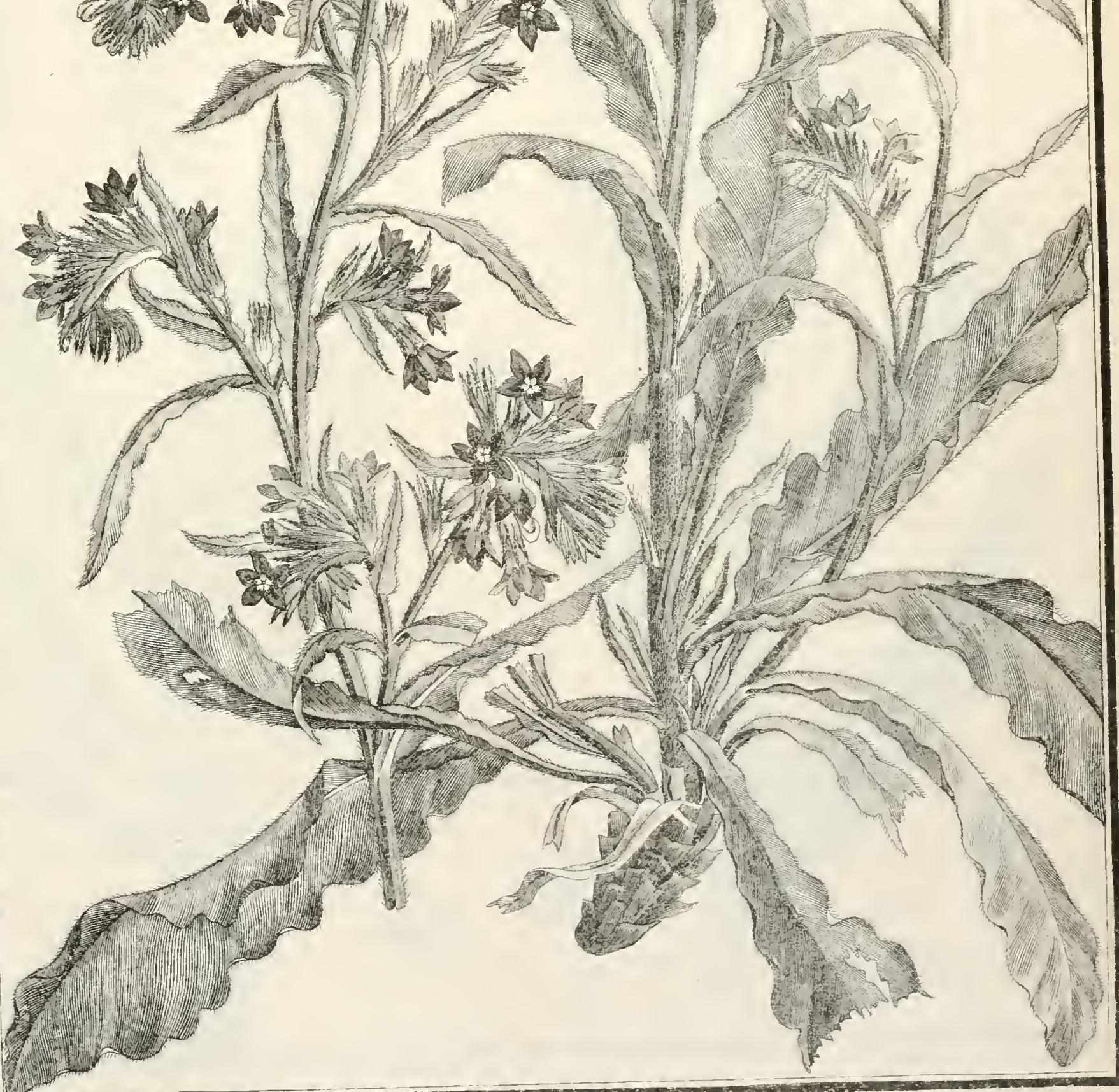





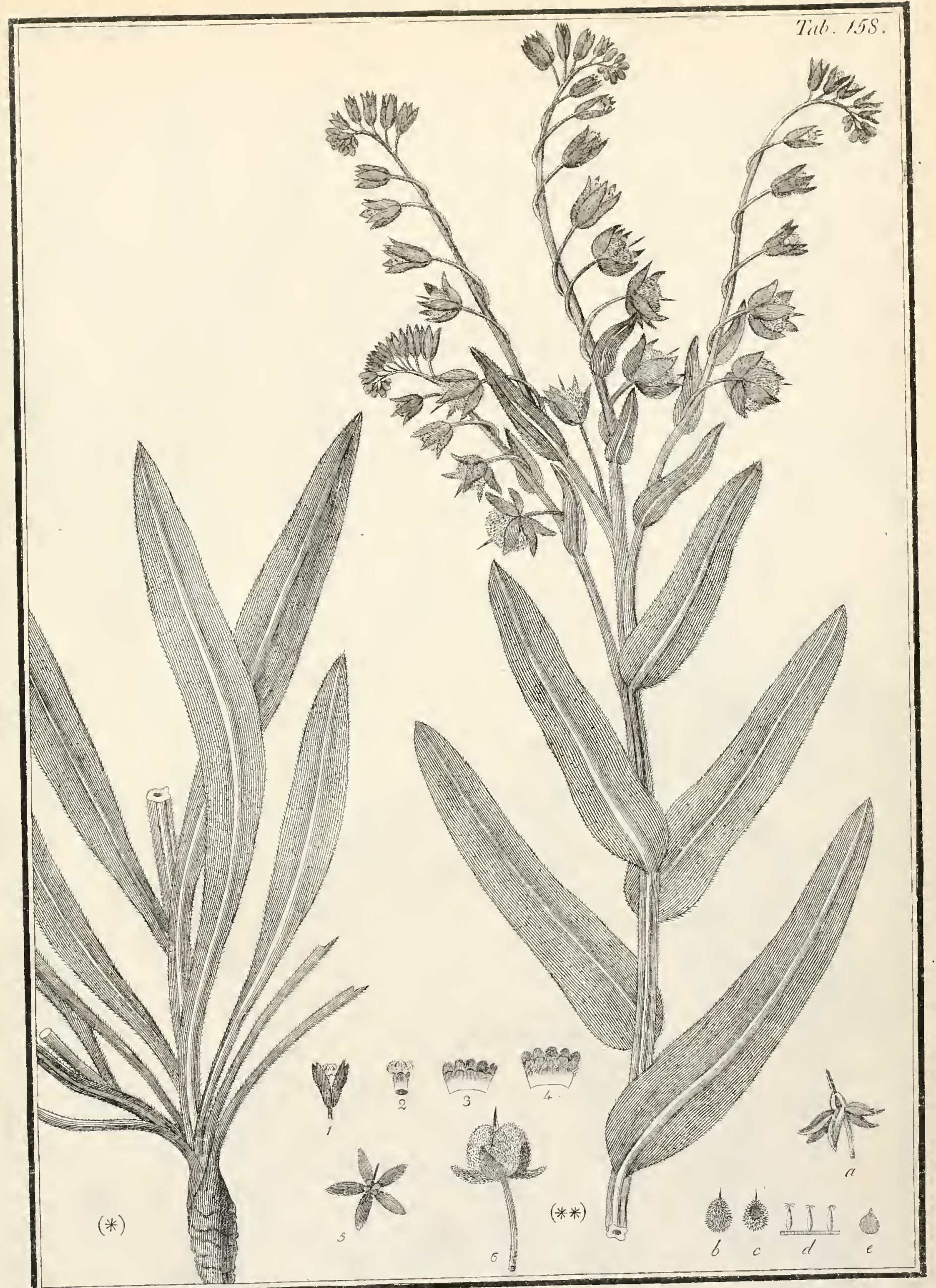

CYNOGLOSSU M clandestinum 



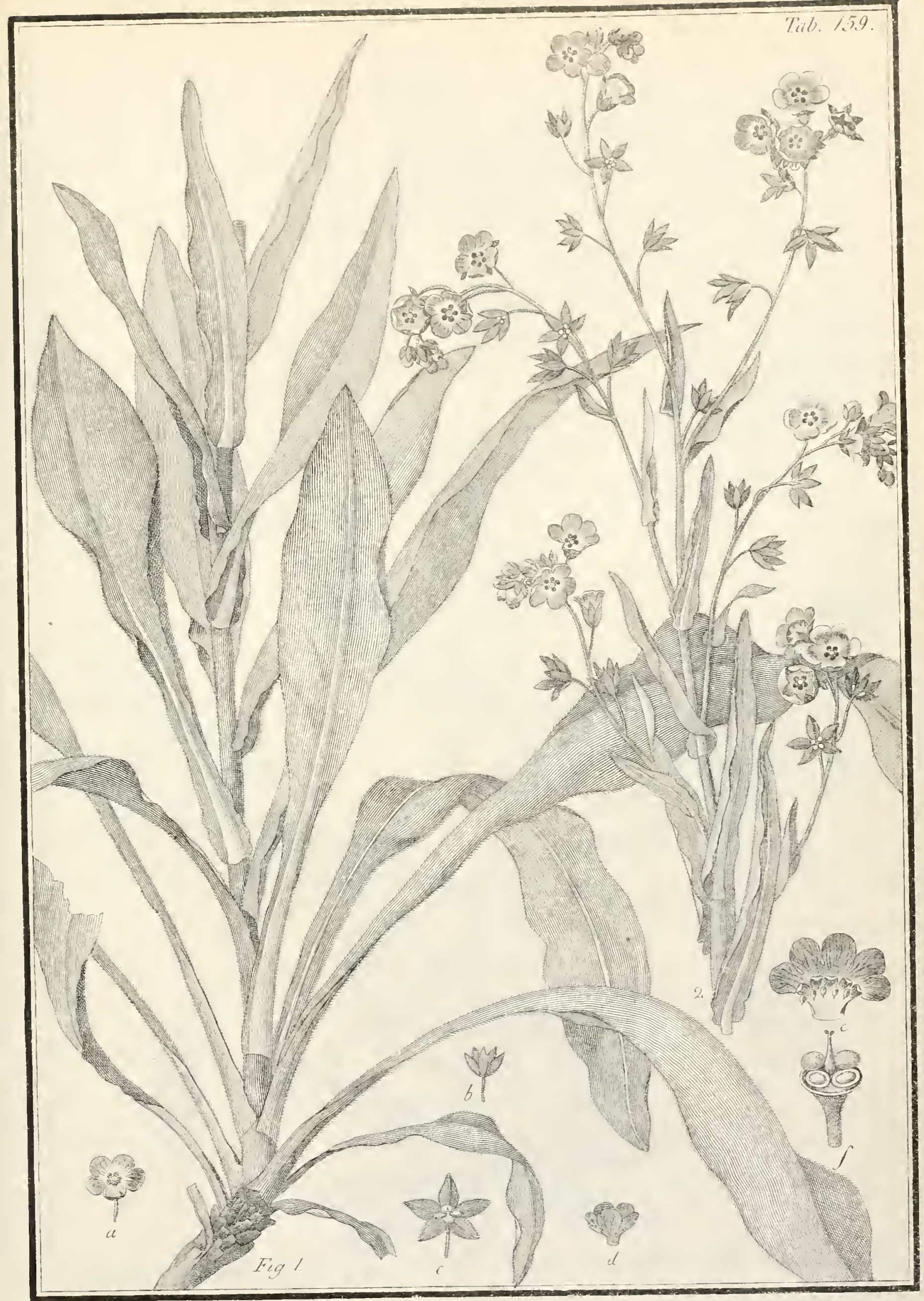





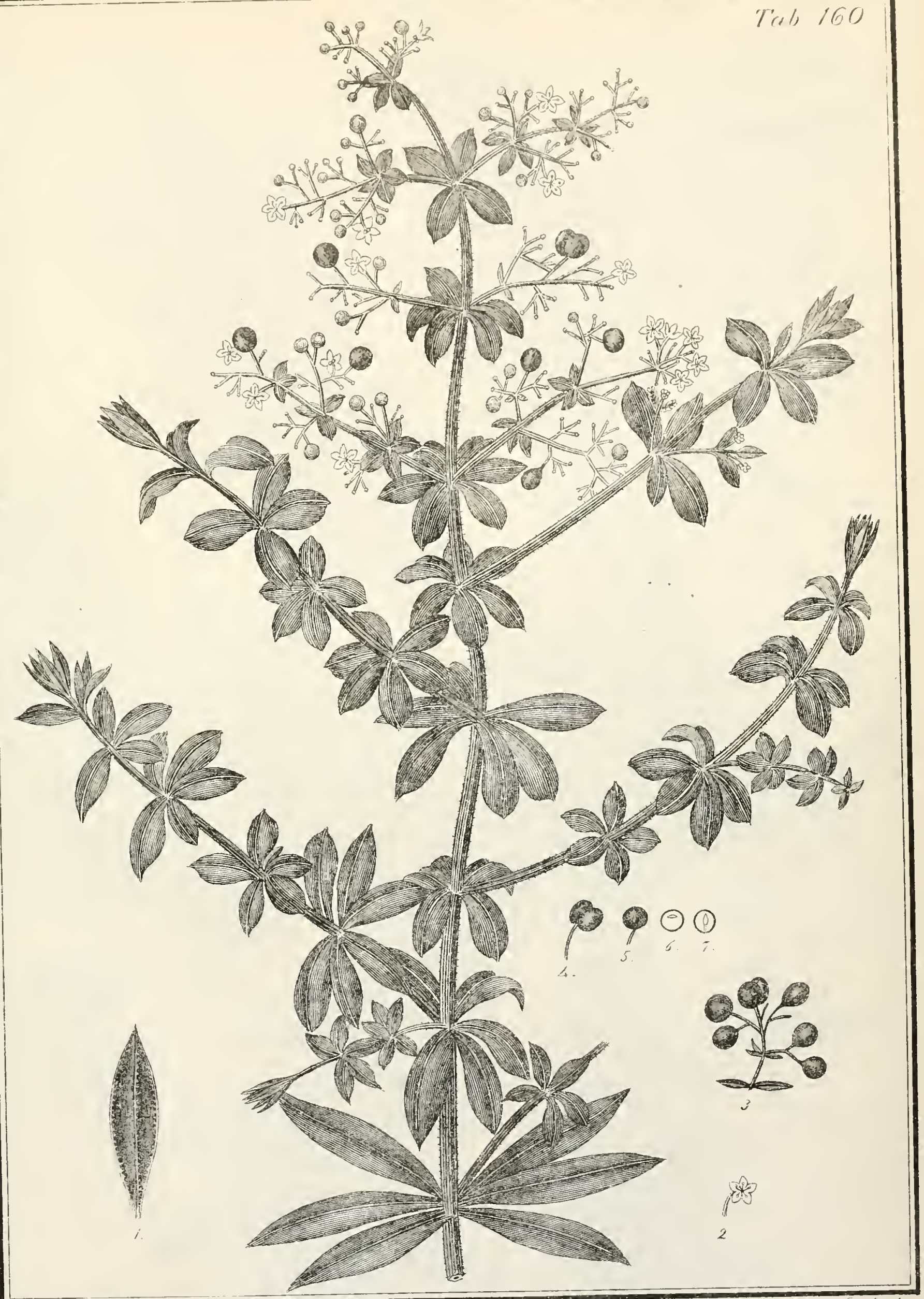

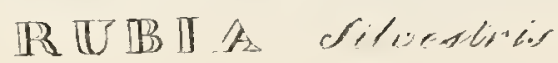





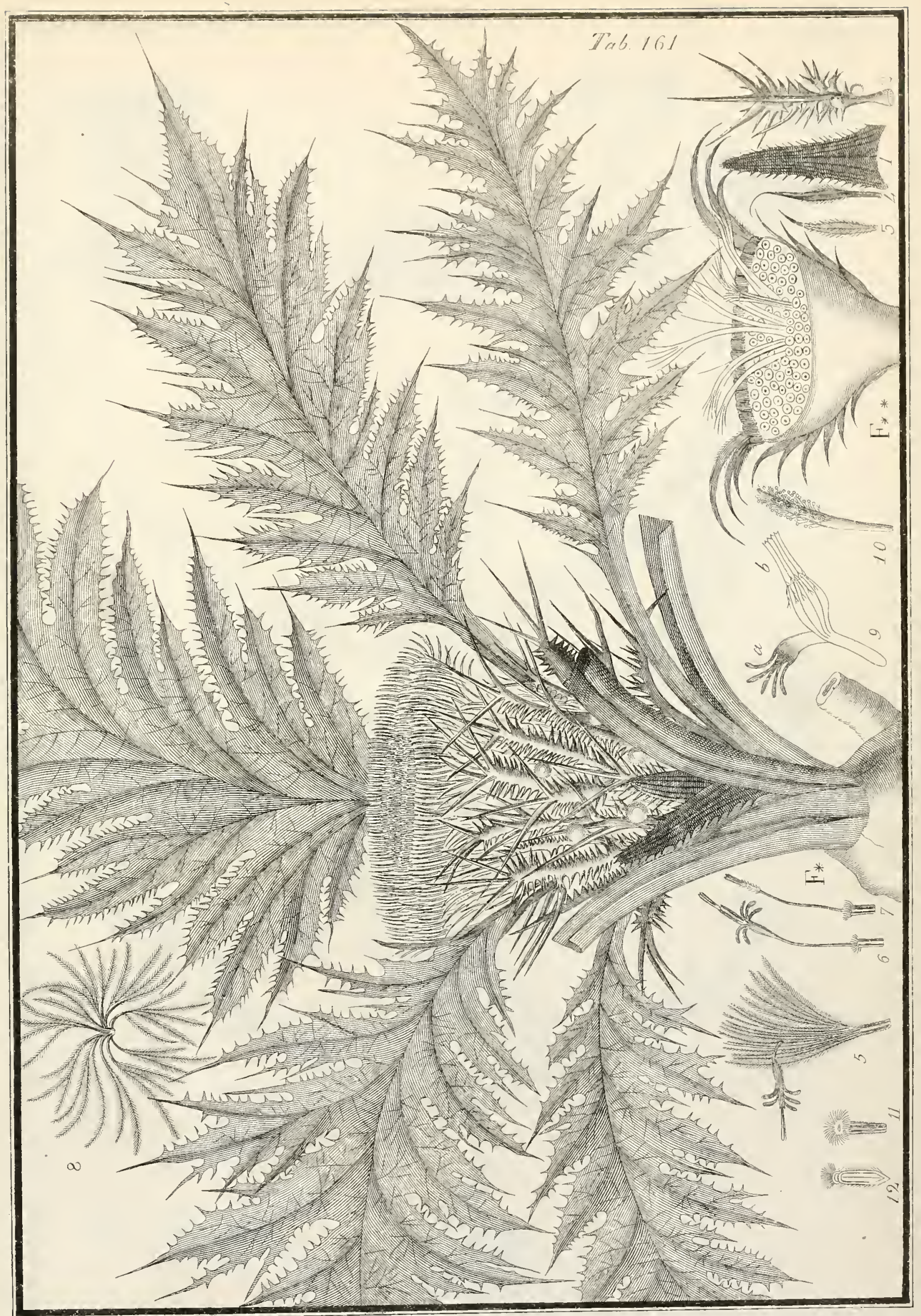

$A \subset \mathbb{R} \mathbb{A}$ gummera 



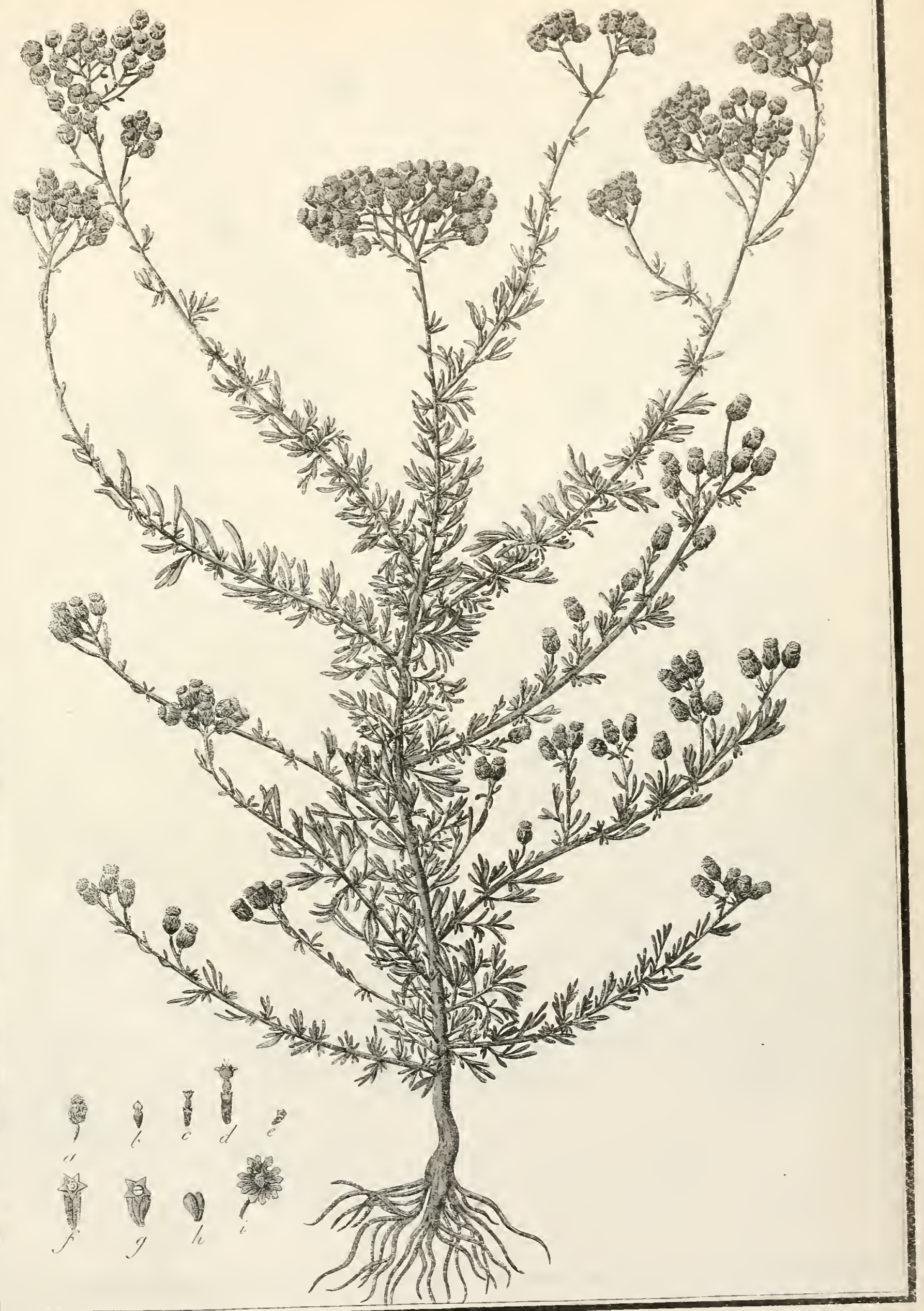





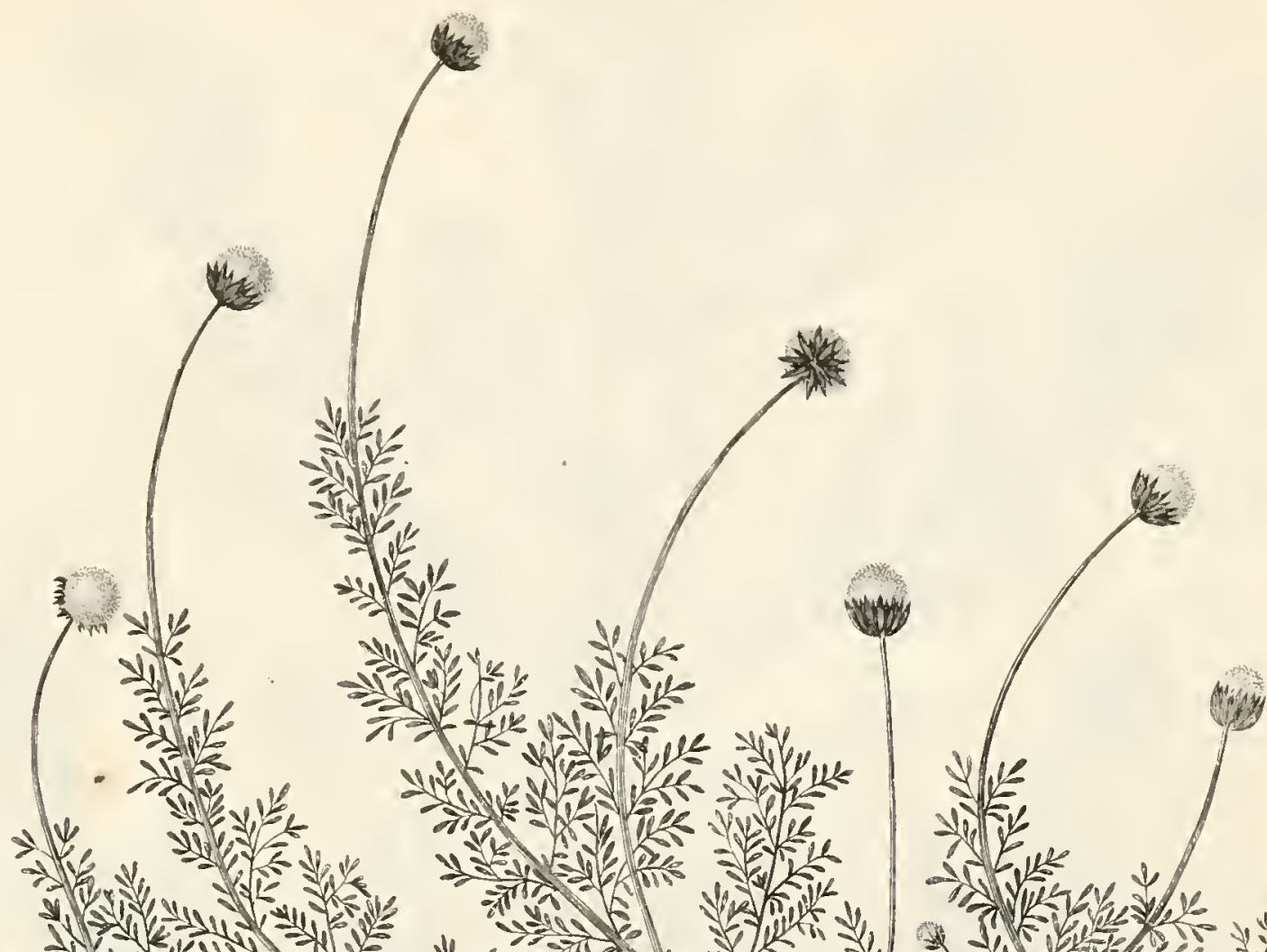

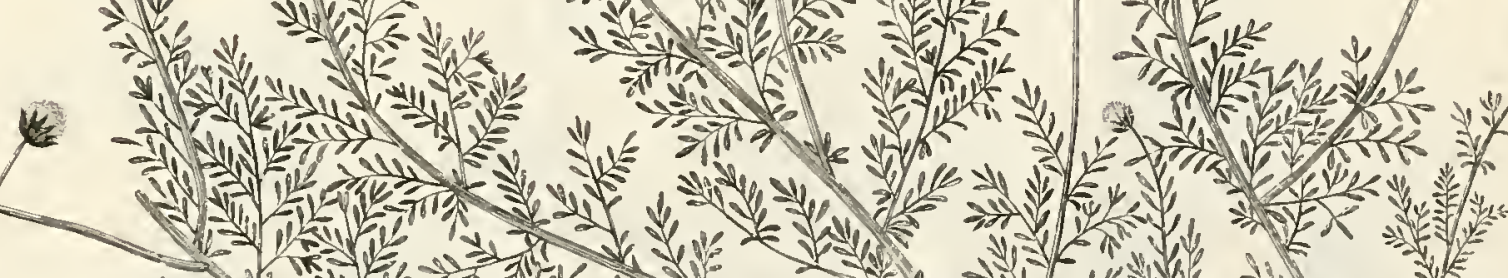

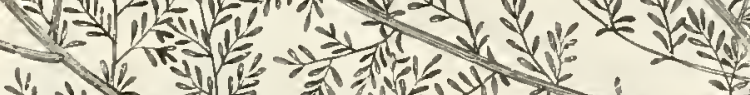

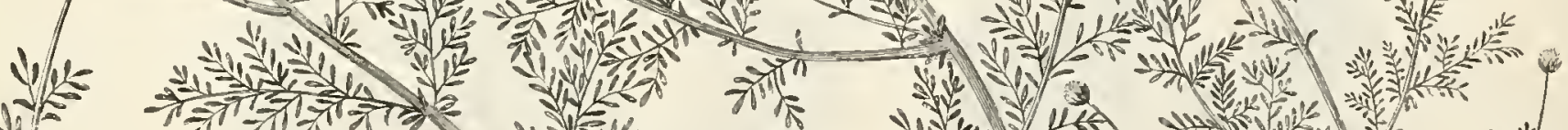

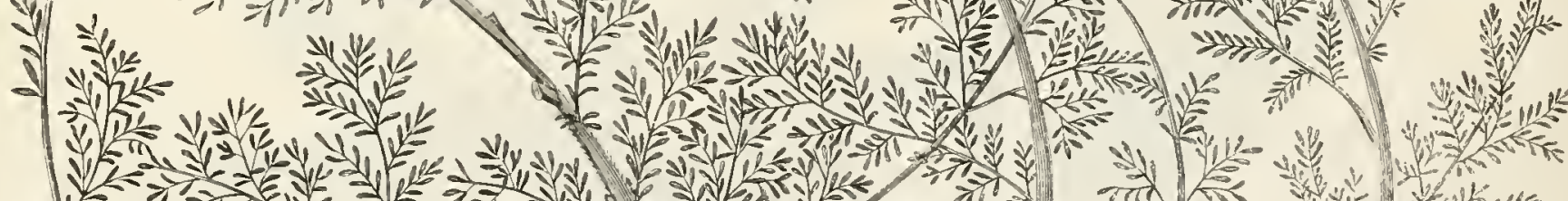
V-

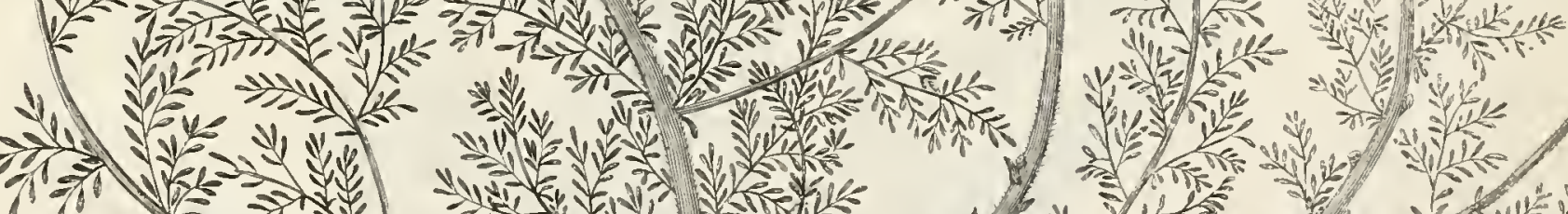

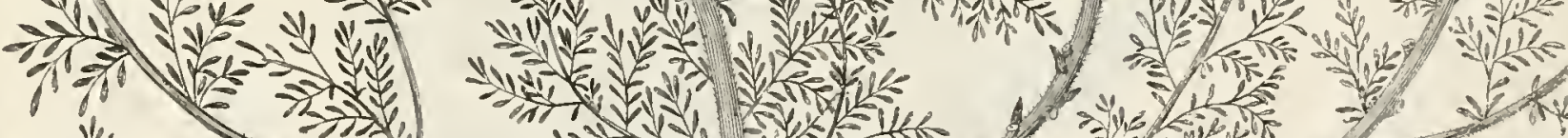
当光

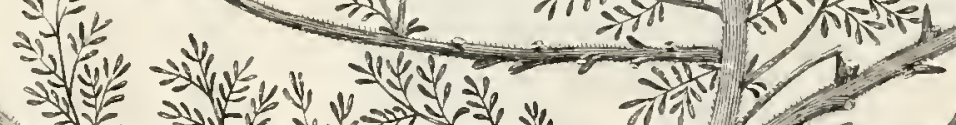
1.

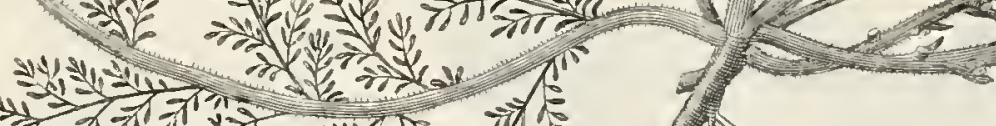

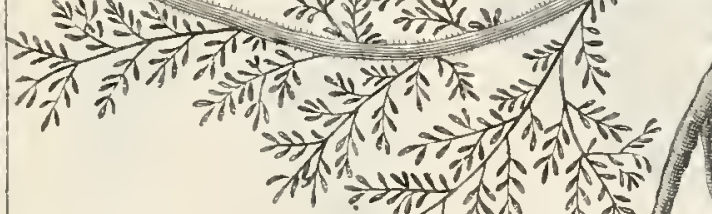
भ秎 



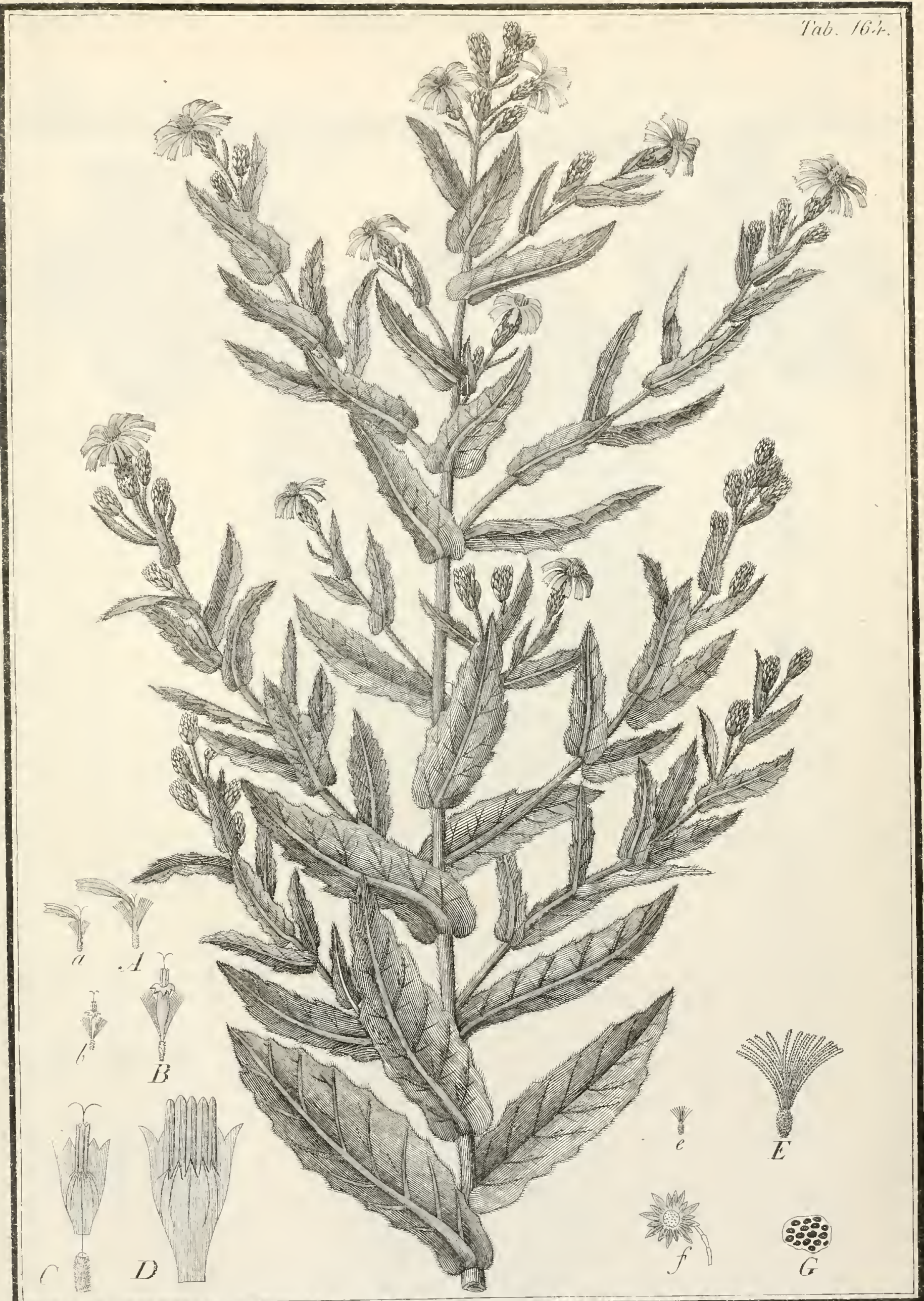

HNULA Viscosel 



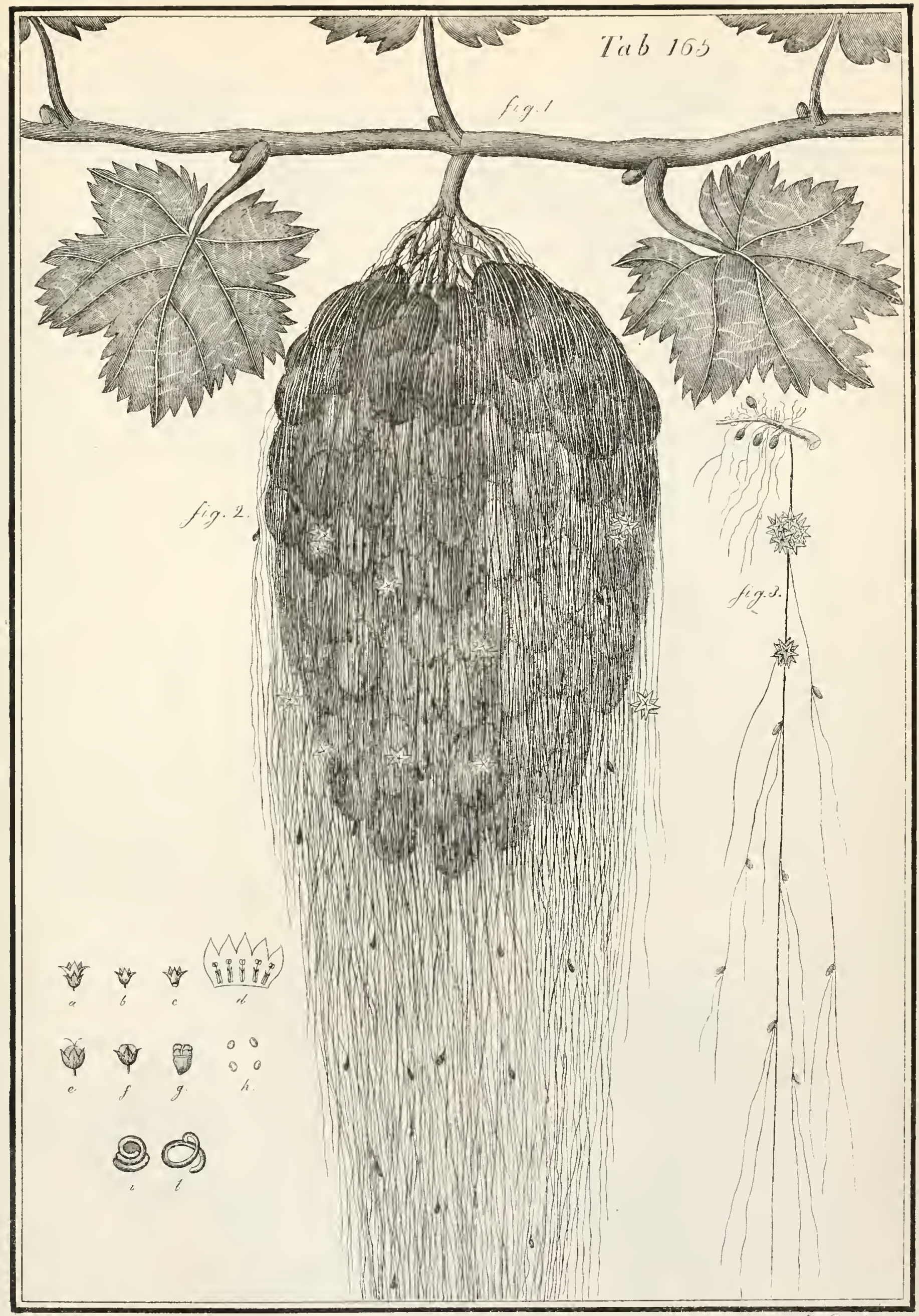





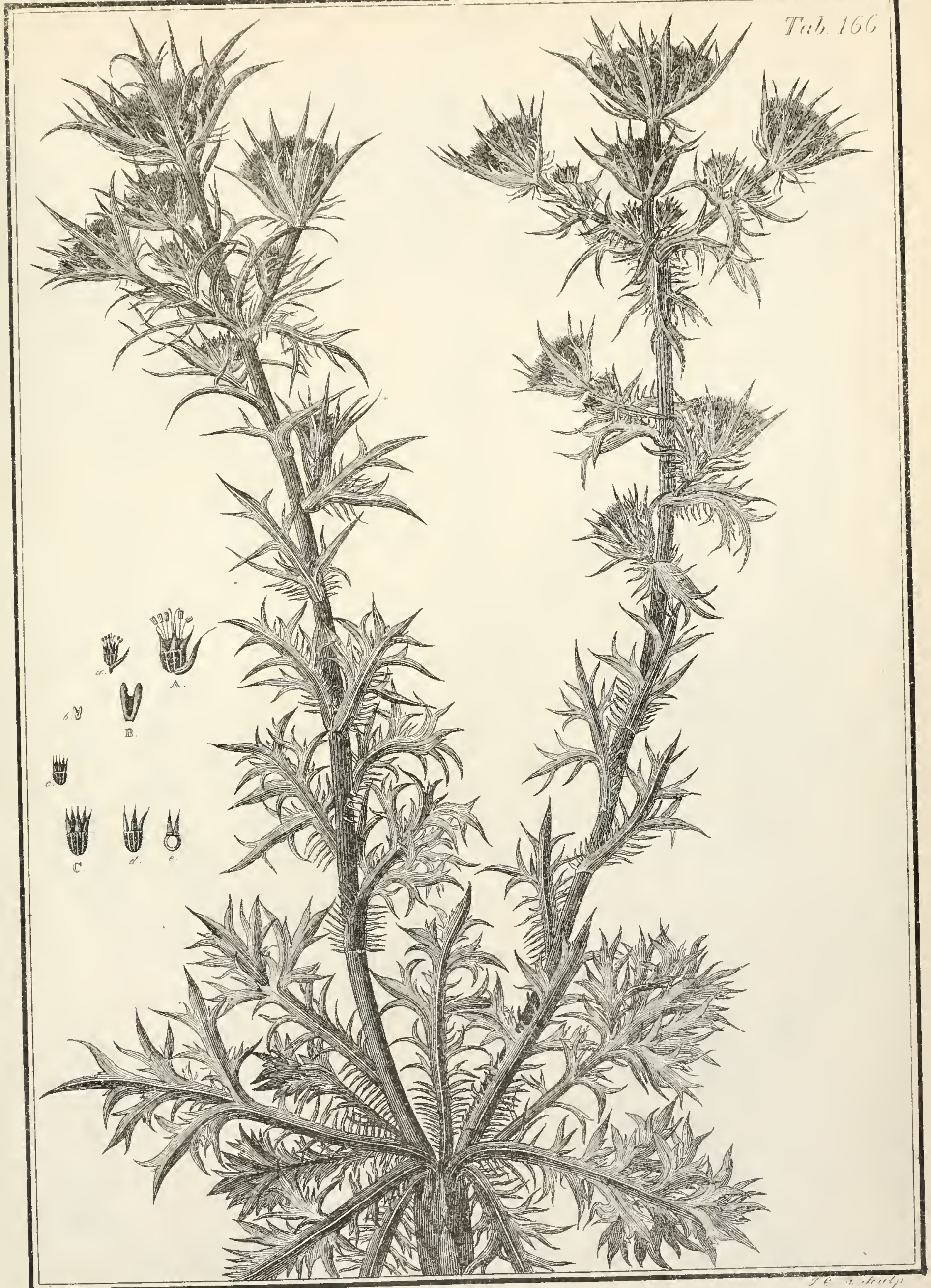





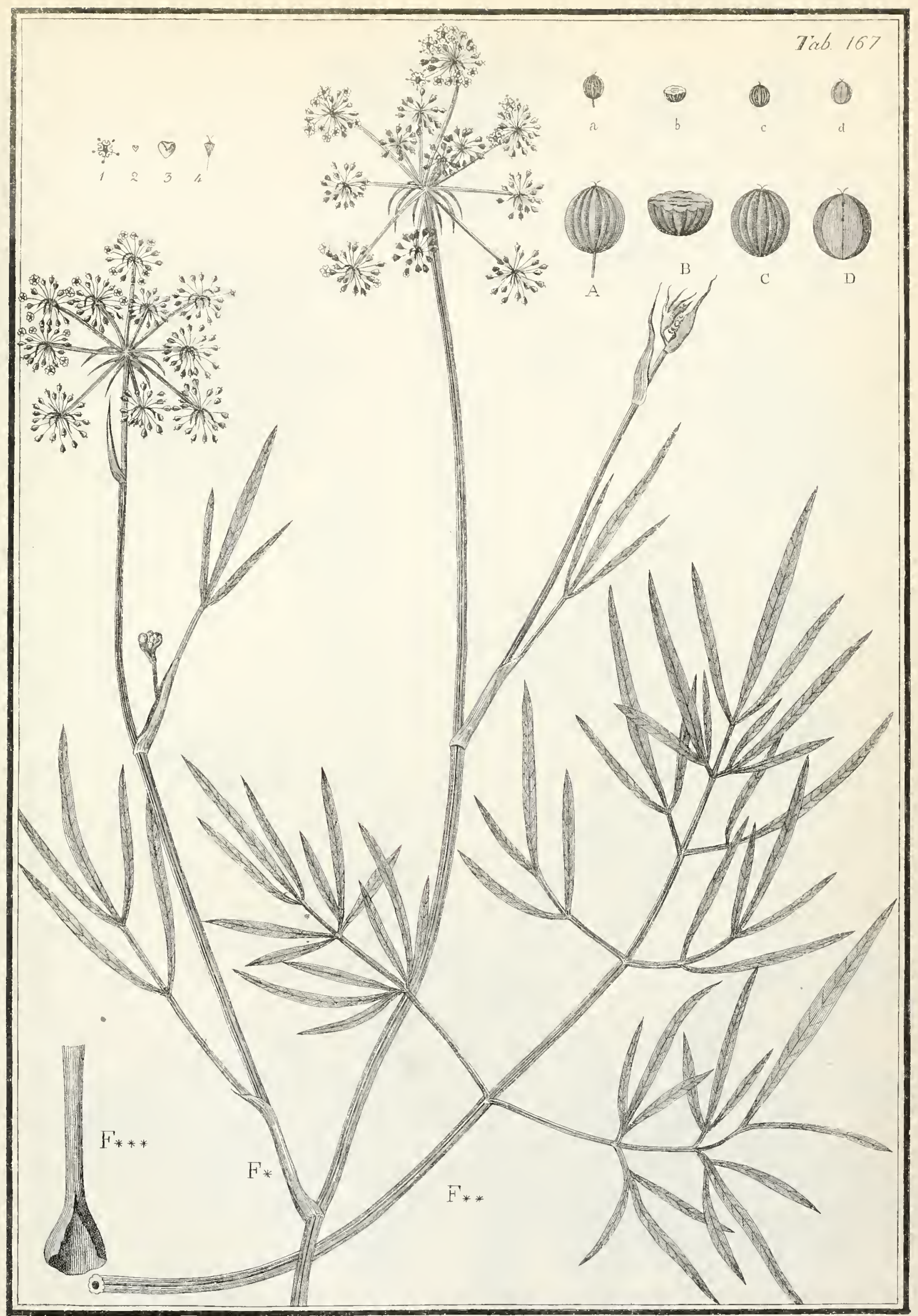





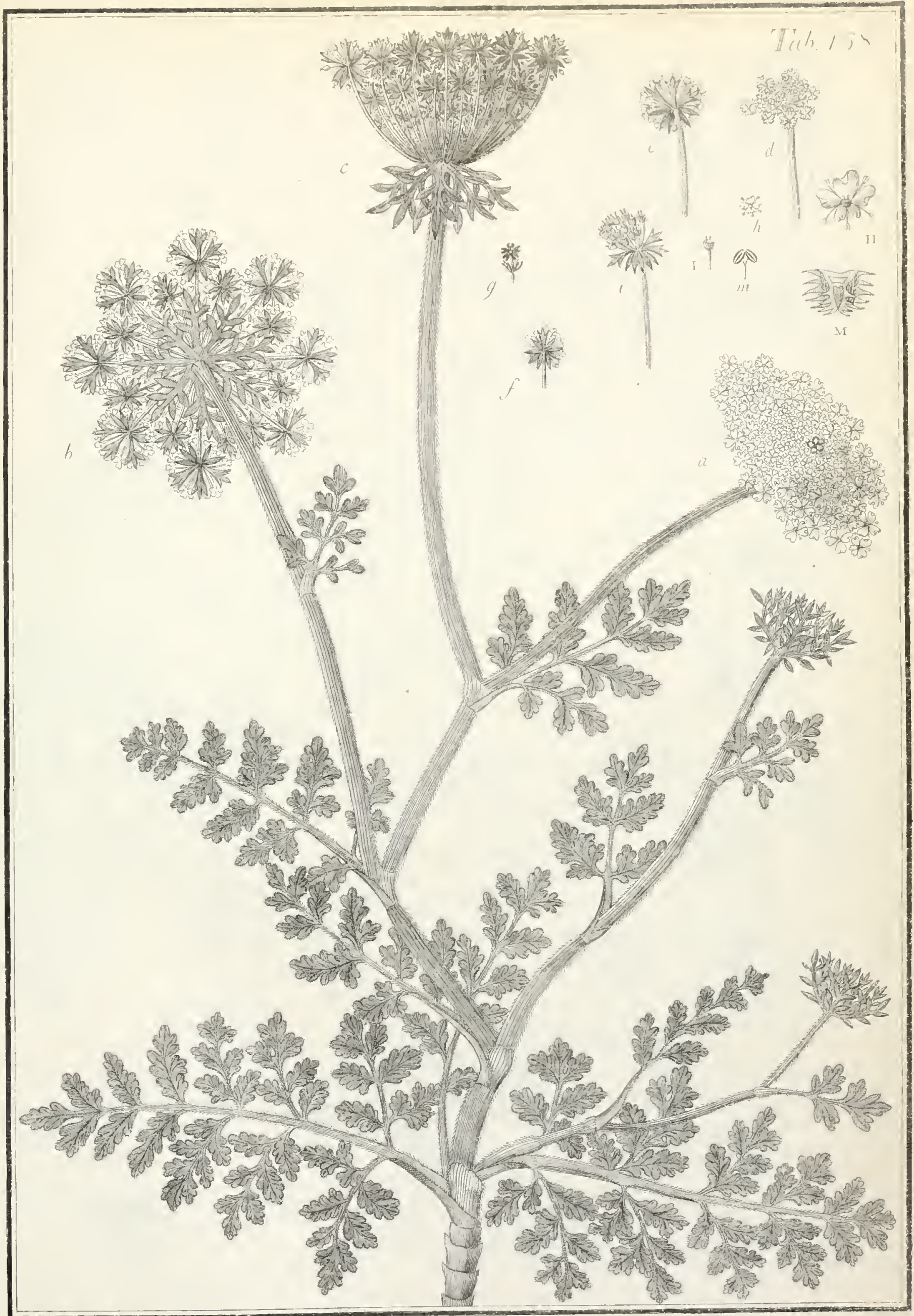

DUUTS halophaluw 


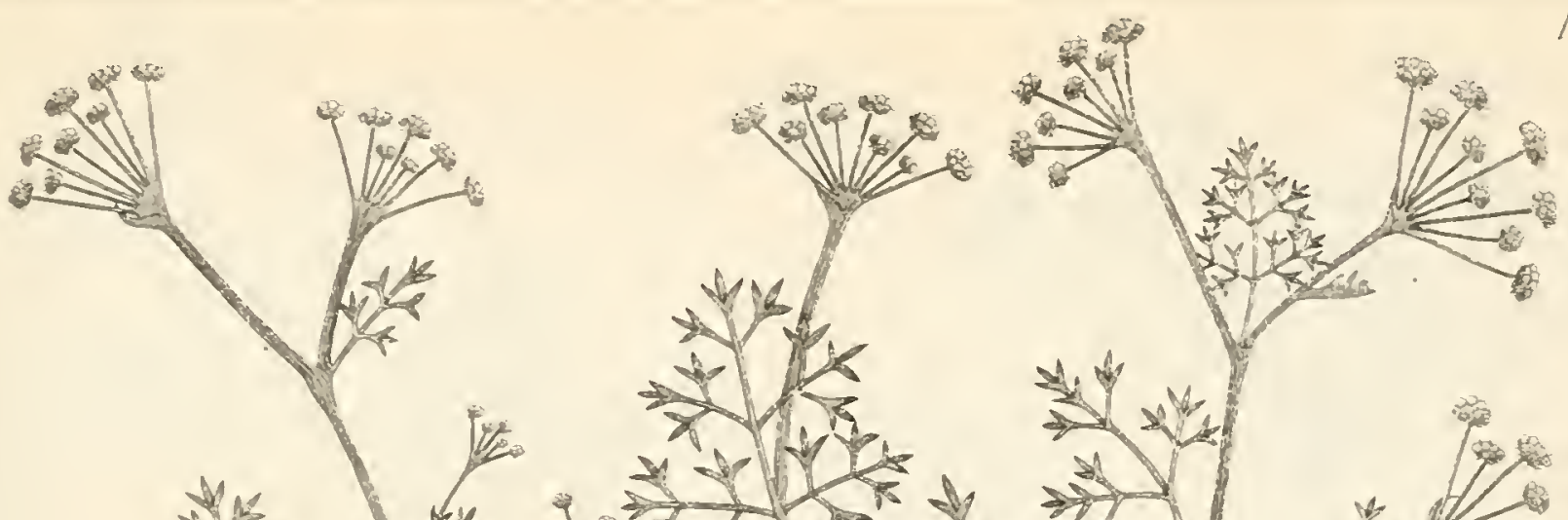

Cint it
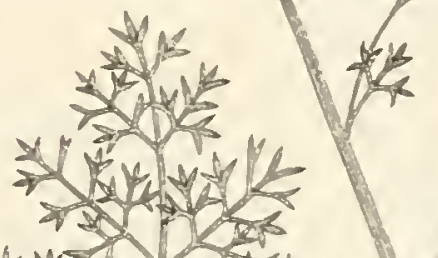

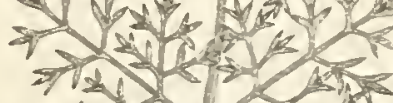

*v.

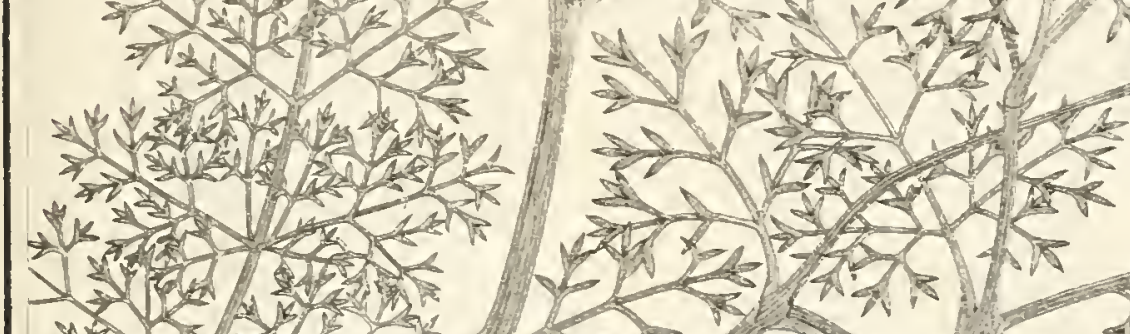
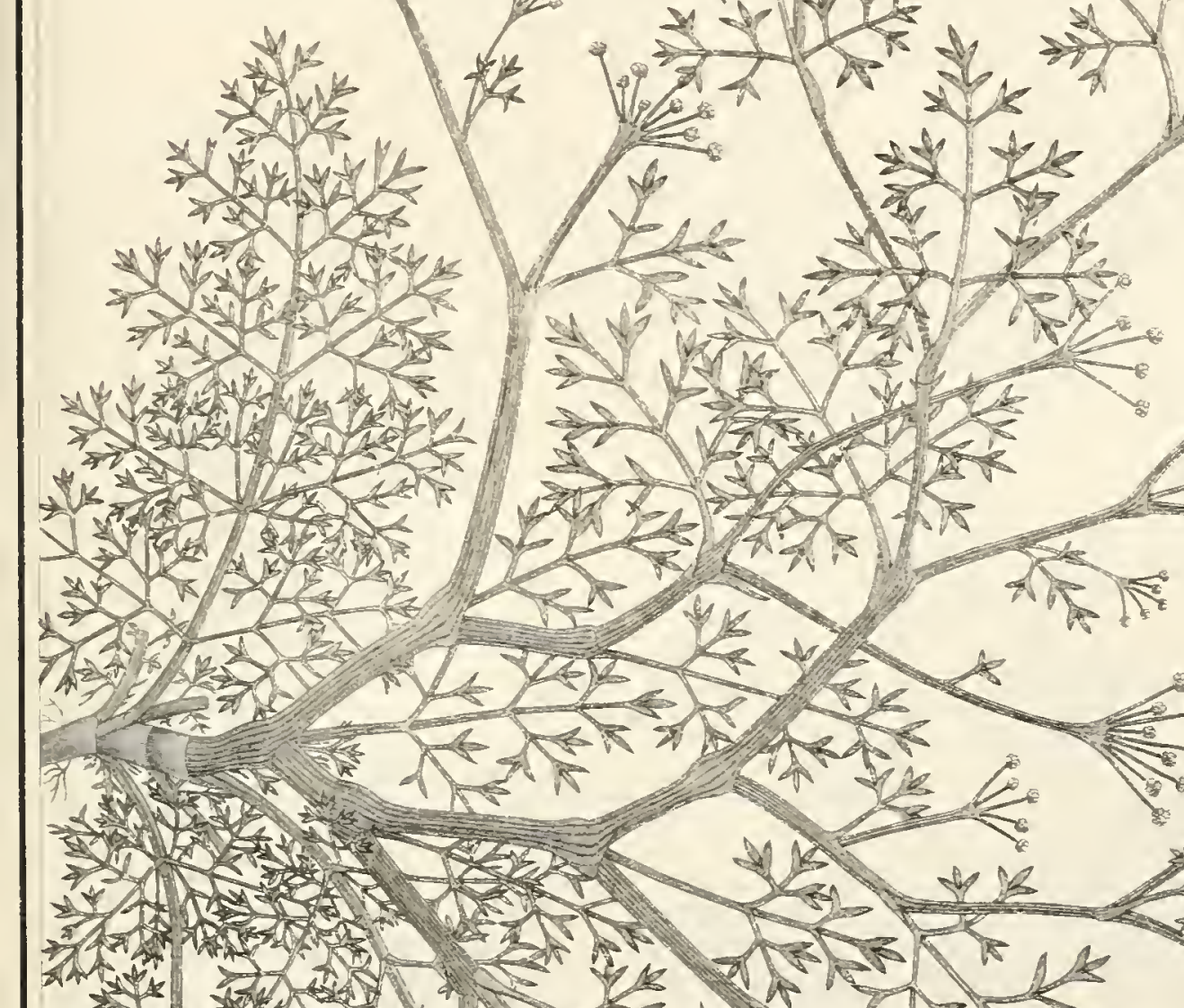

$\geqslant 2$
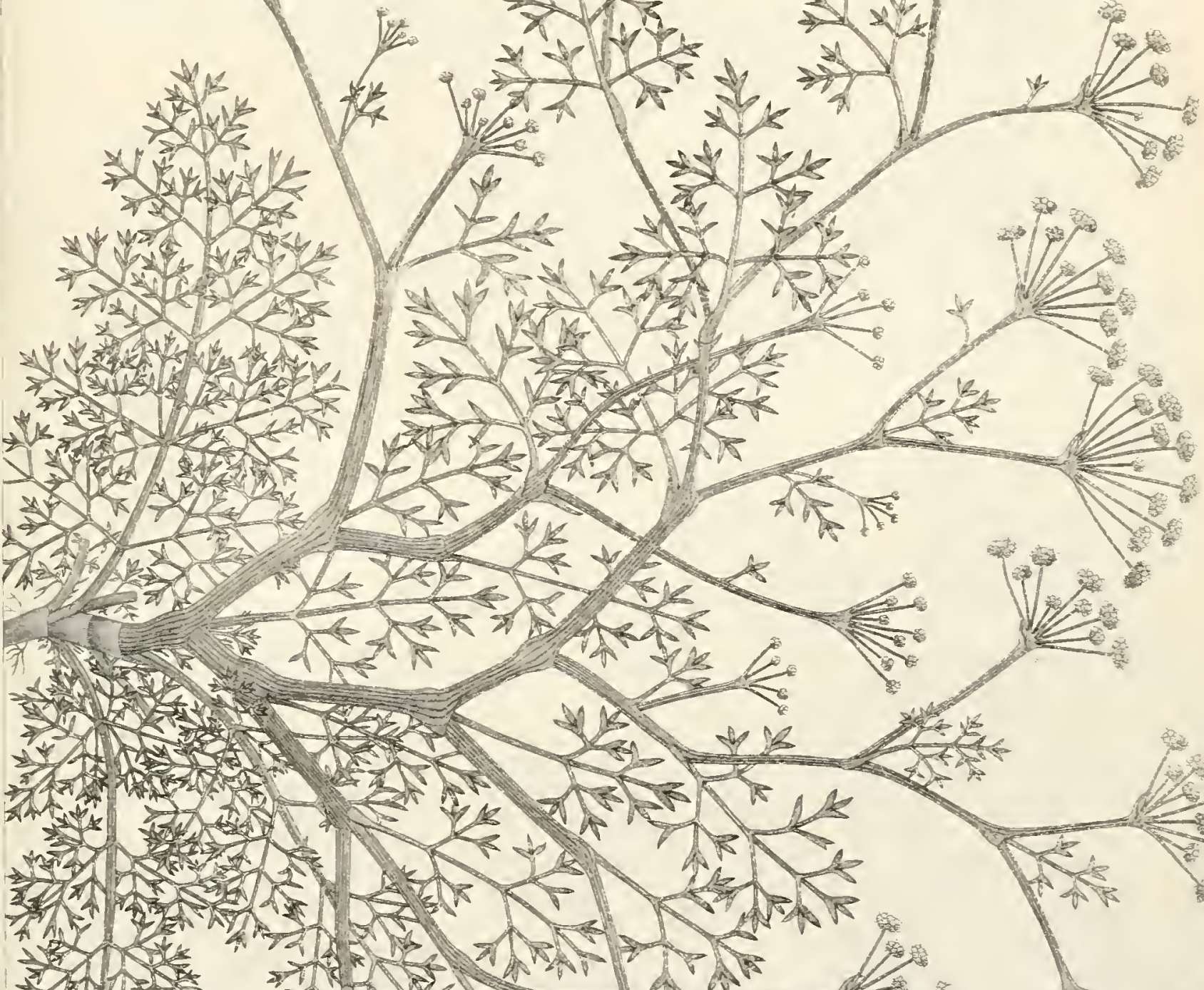

称特,

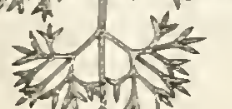

行

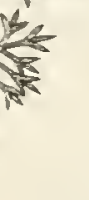

.).

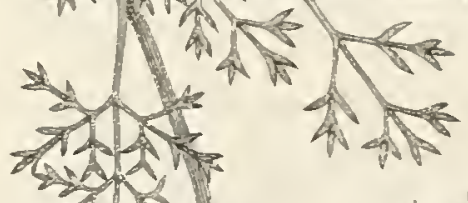
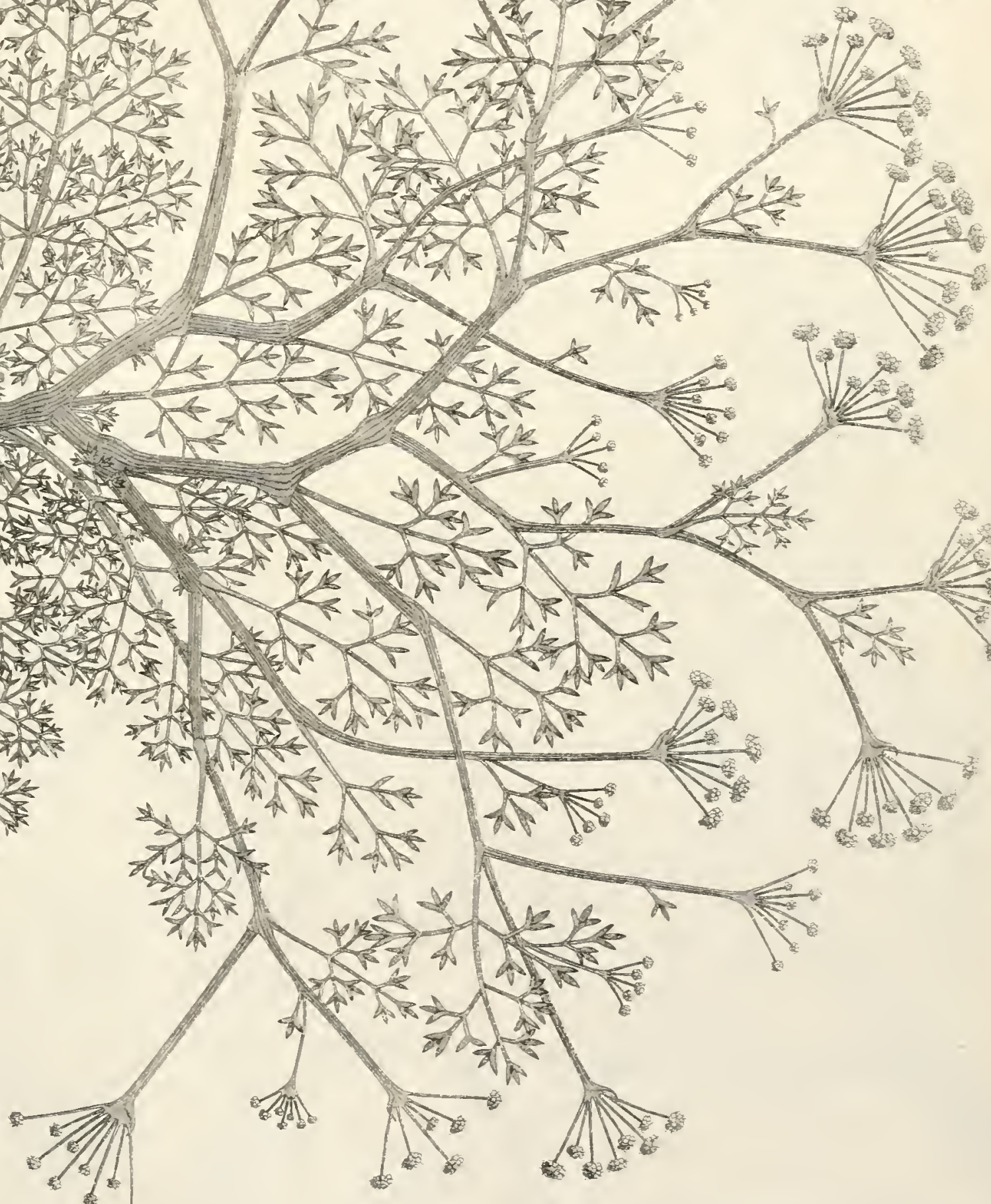

(ำ

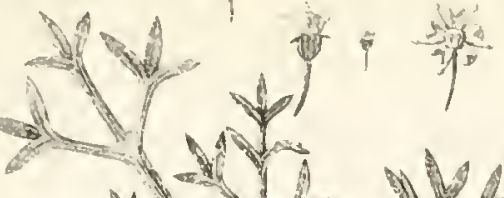

$+\frac{2}{2}$

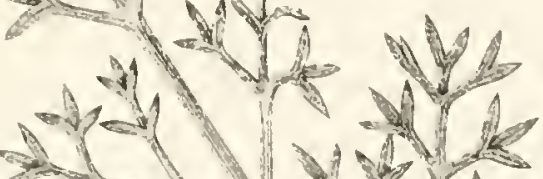

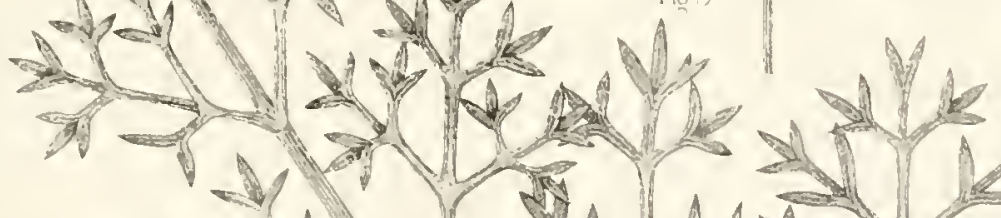

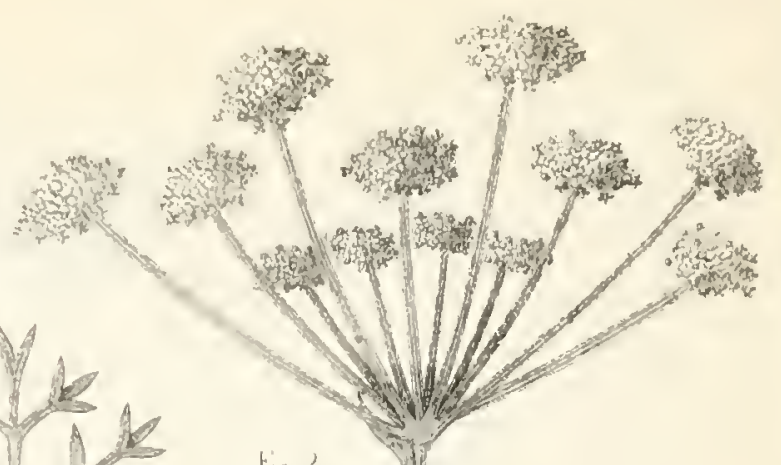

Cit. 170

ints y A4t

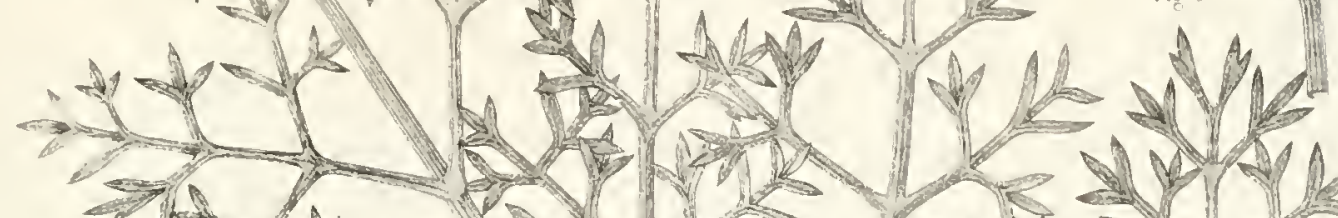

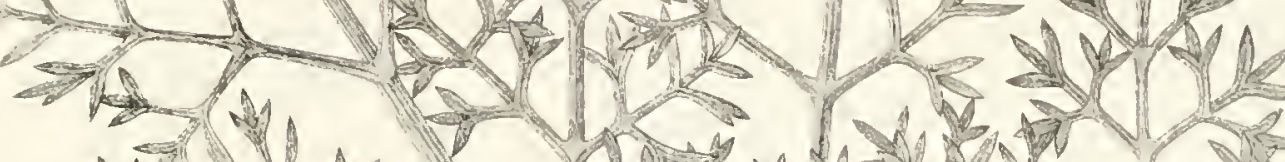

H=1

更an

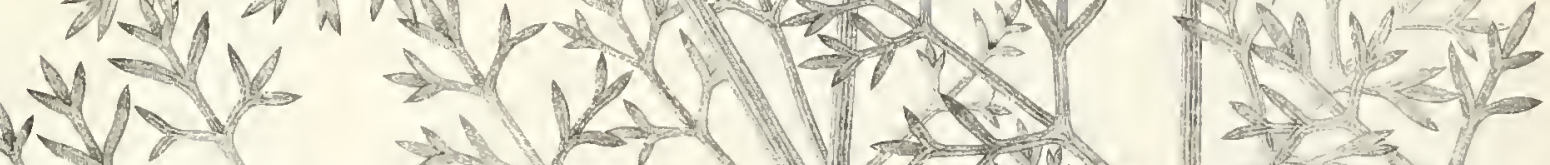

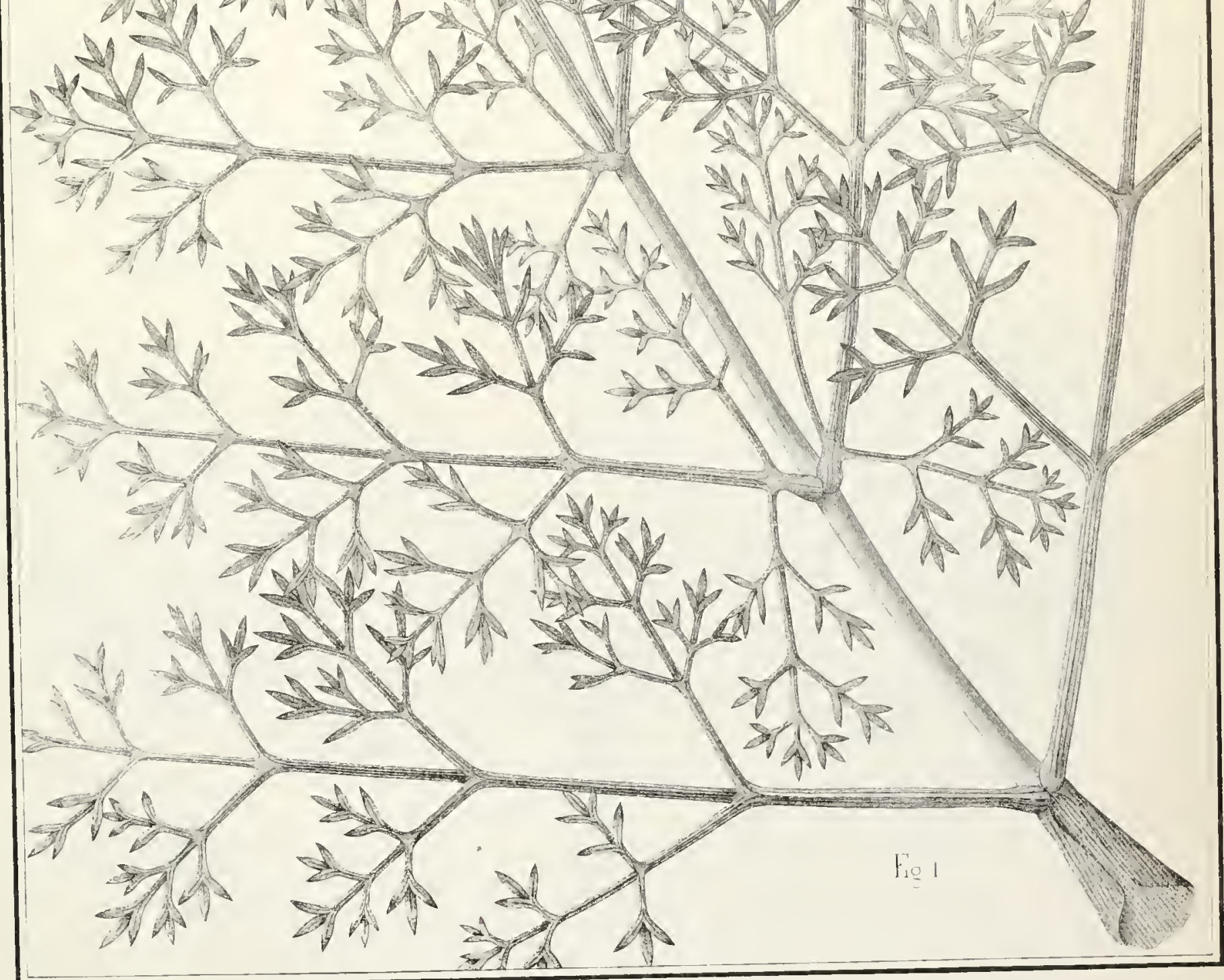





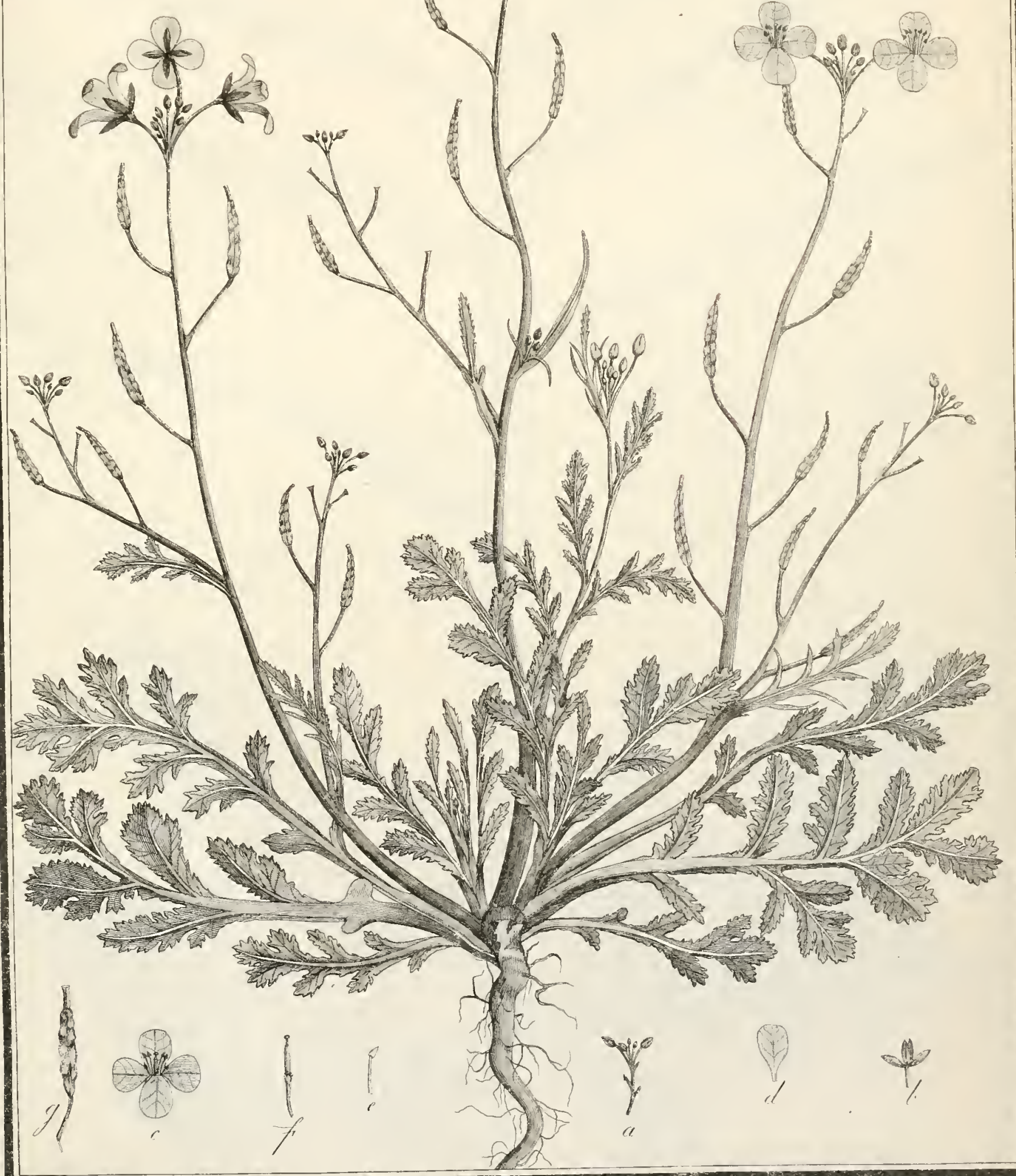





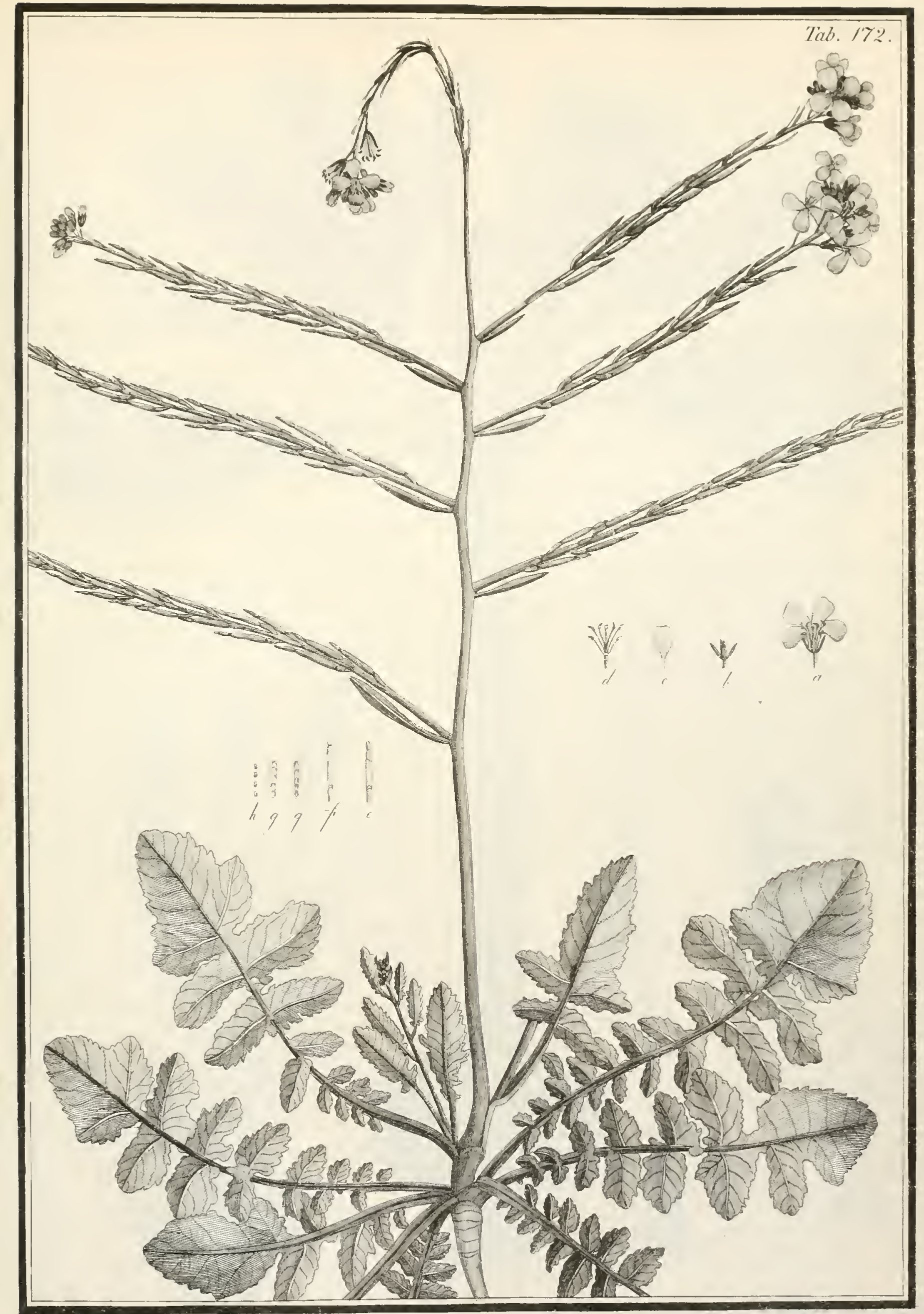





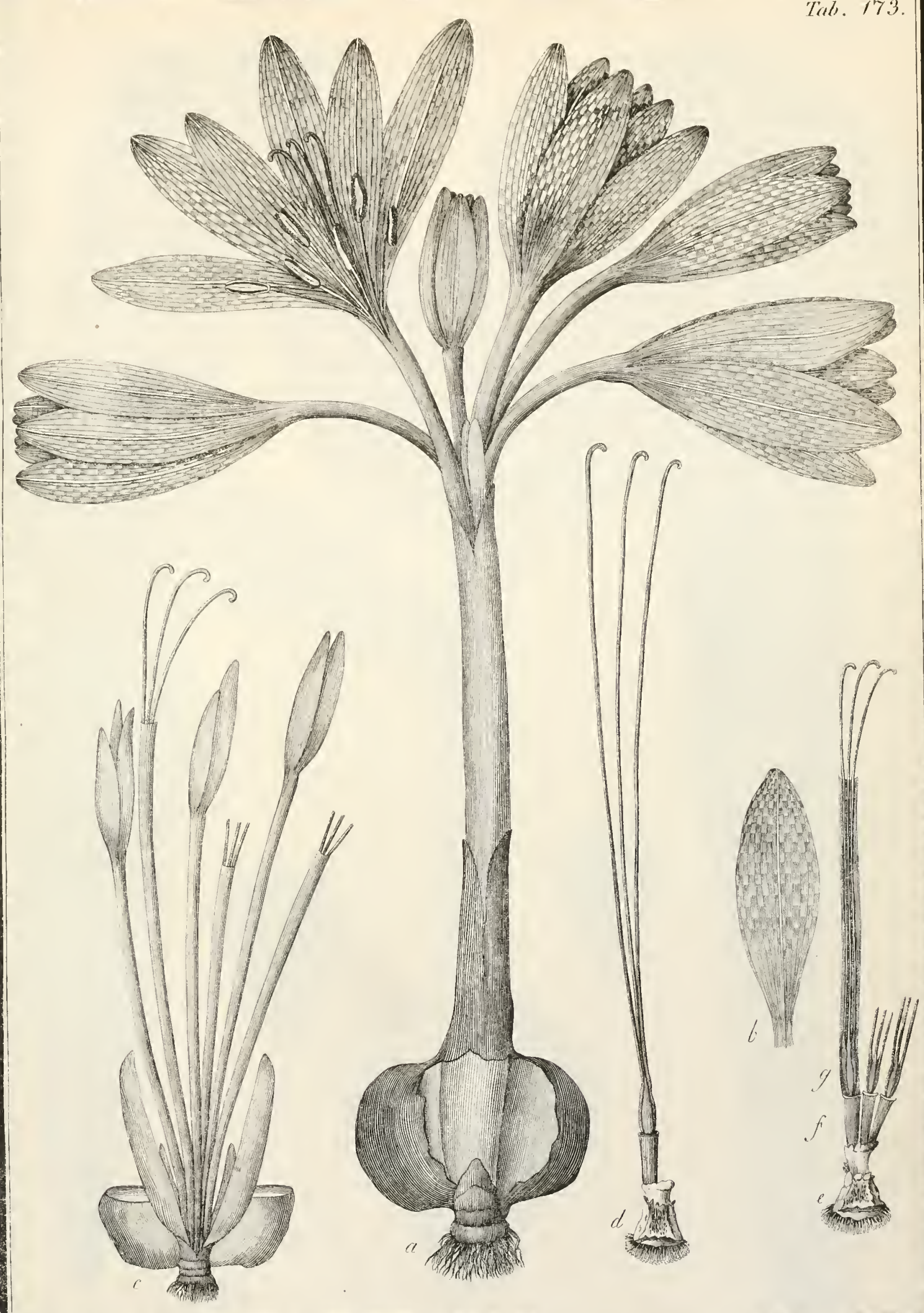





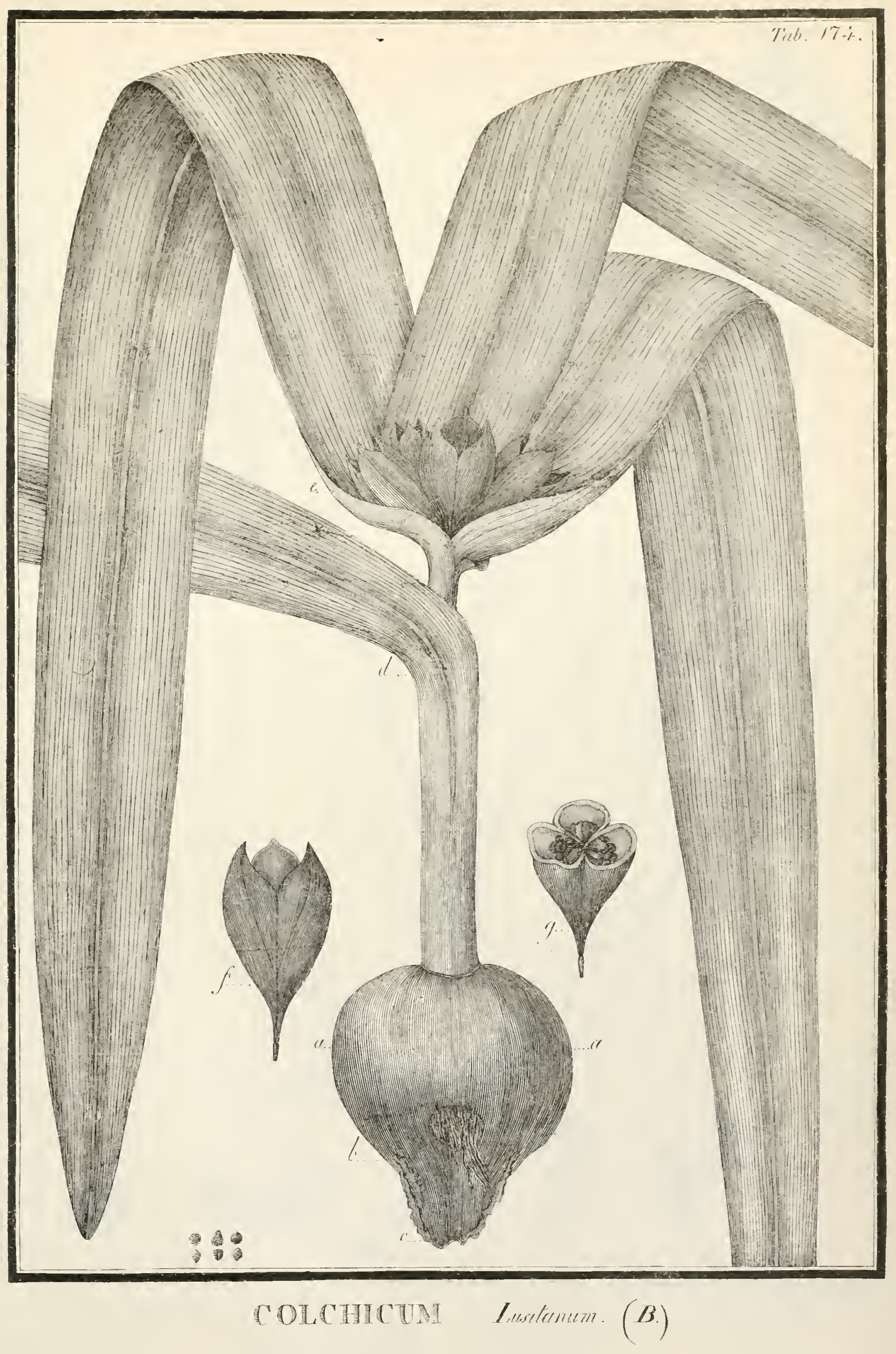





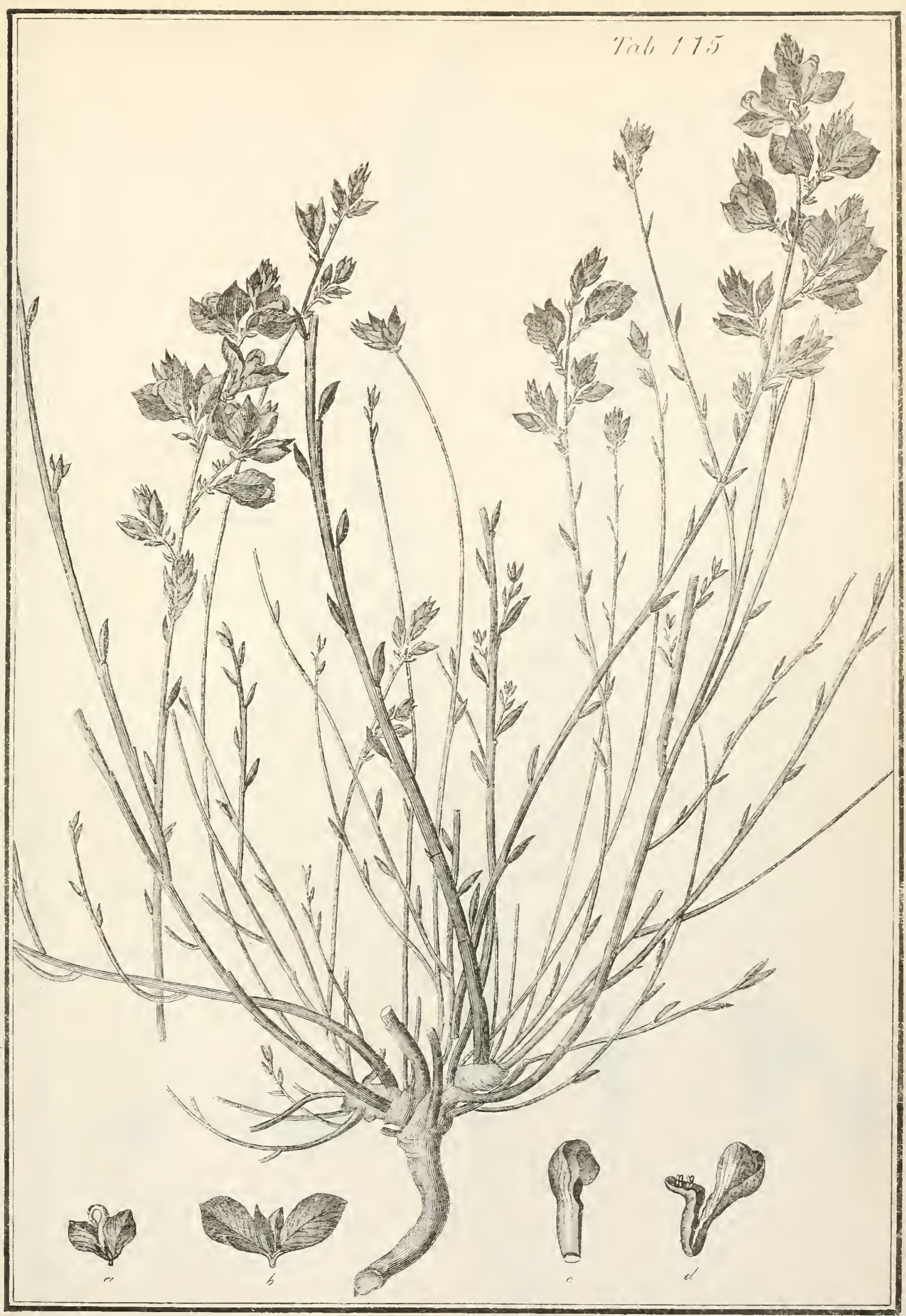





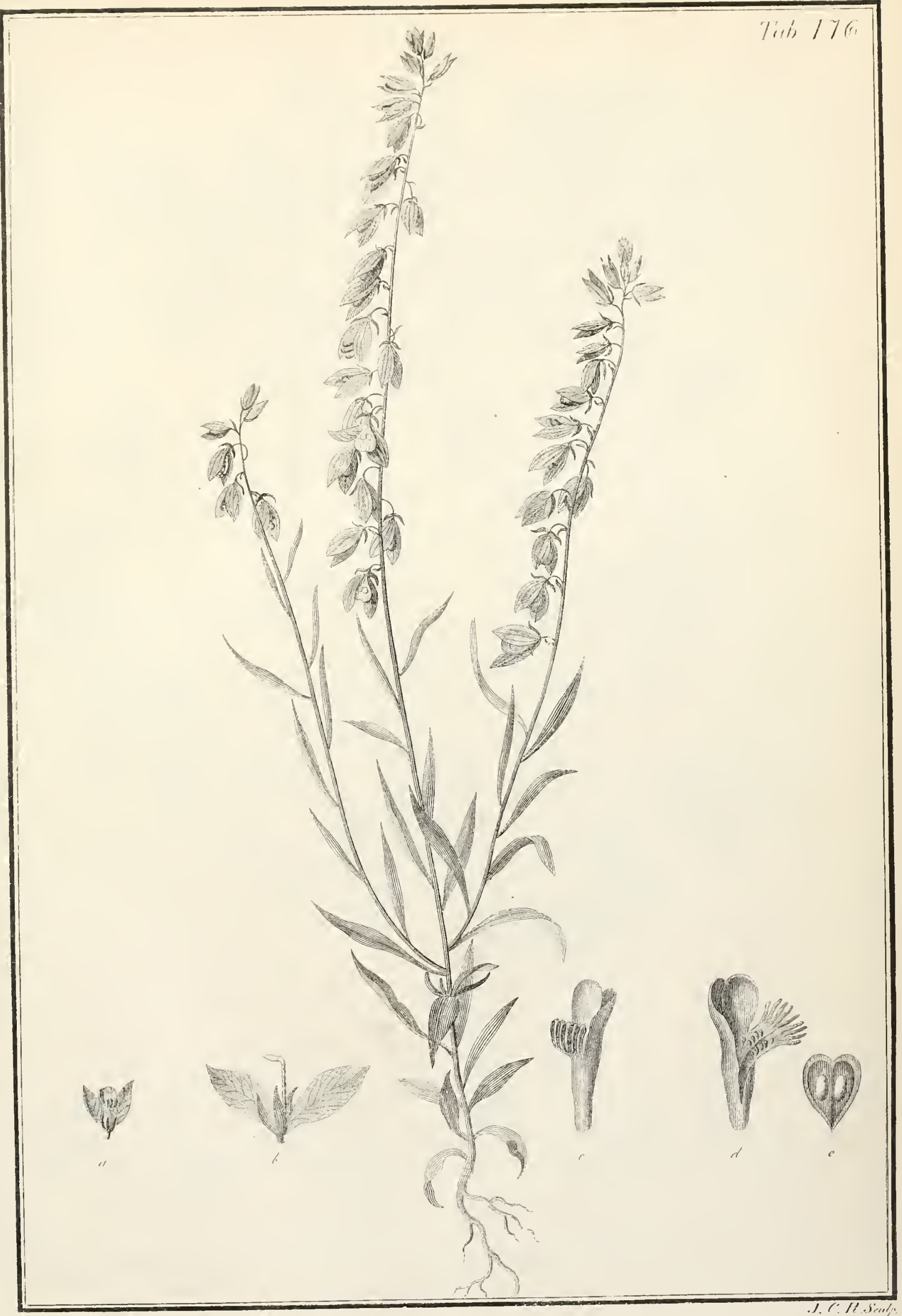

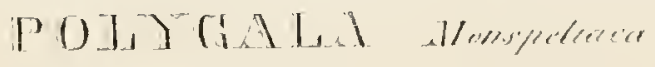





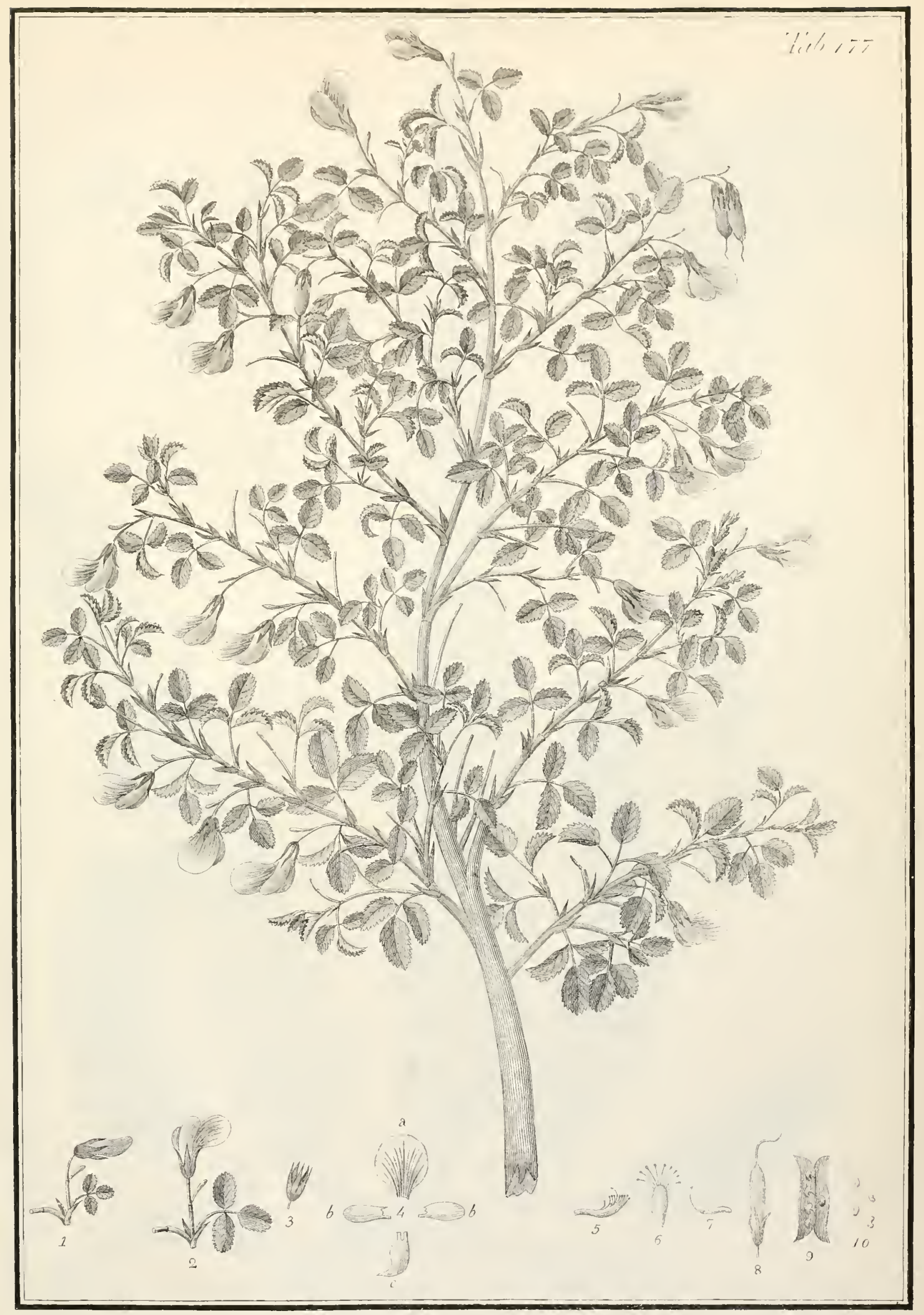





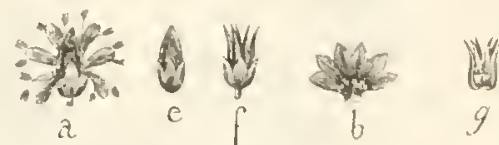

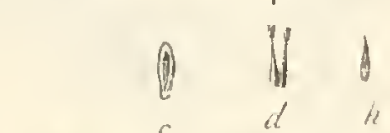

幽
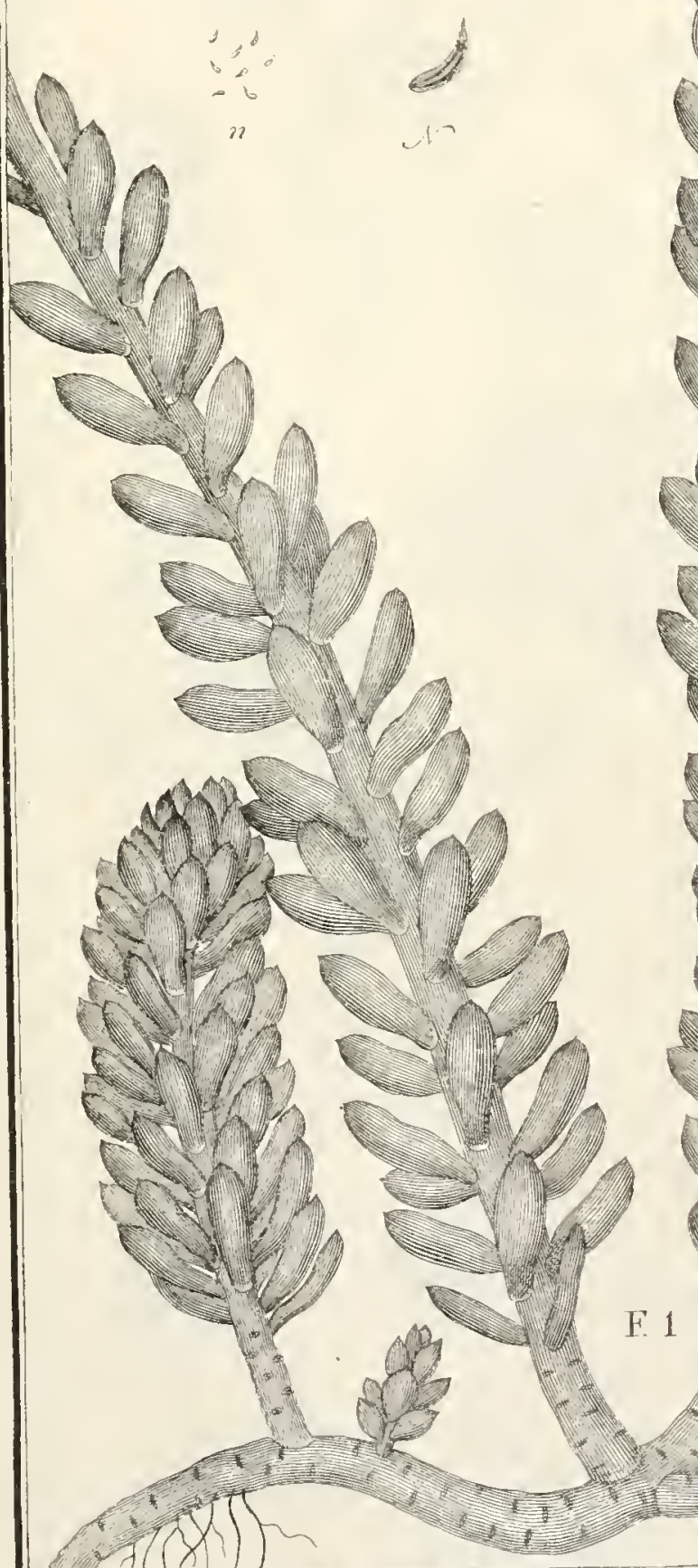

Tixb. 178 .

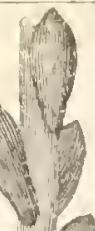

A 1

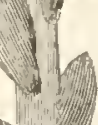

P

(1)

A
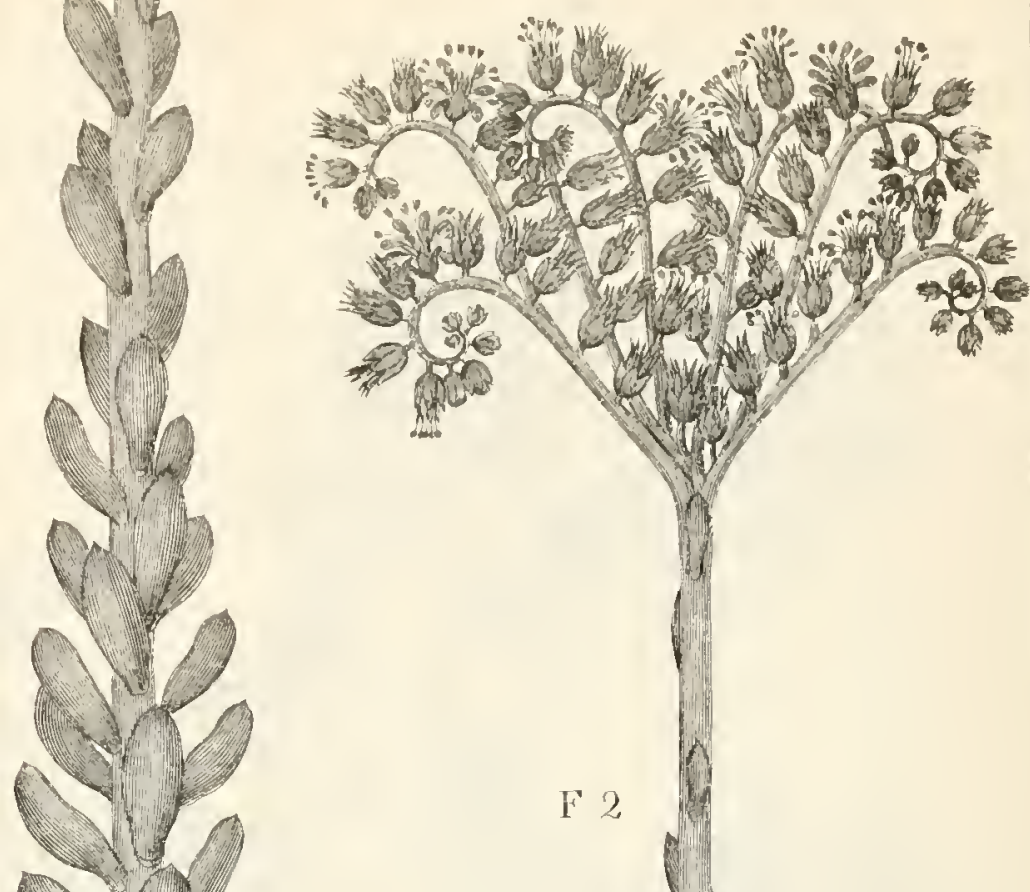

$-112$
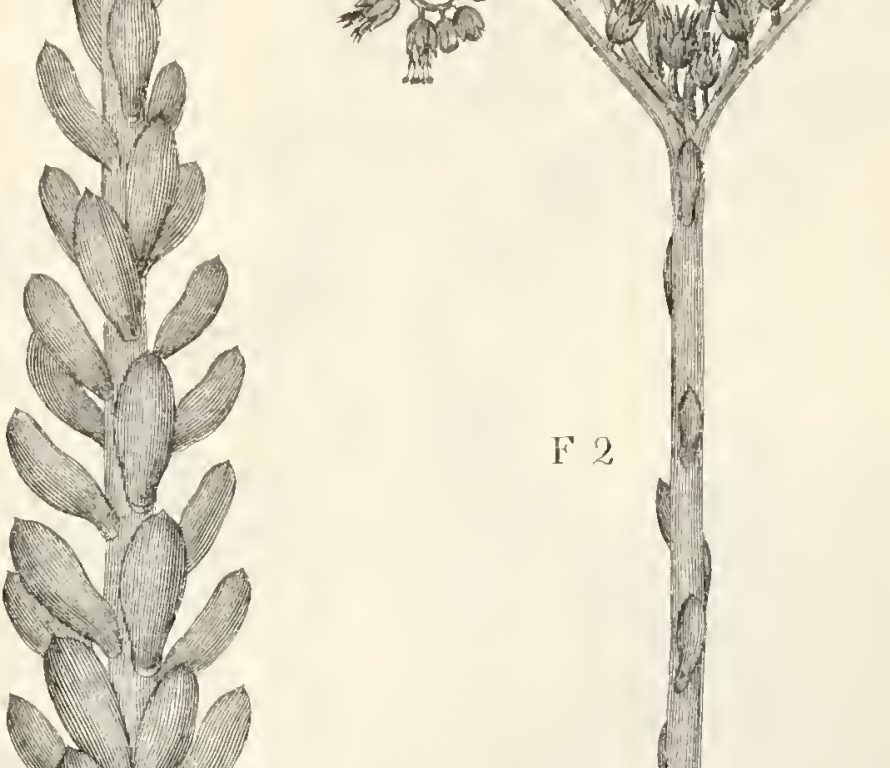



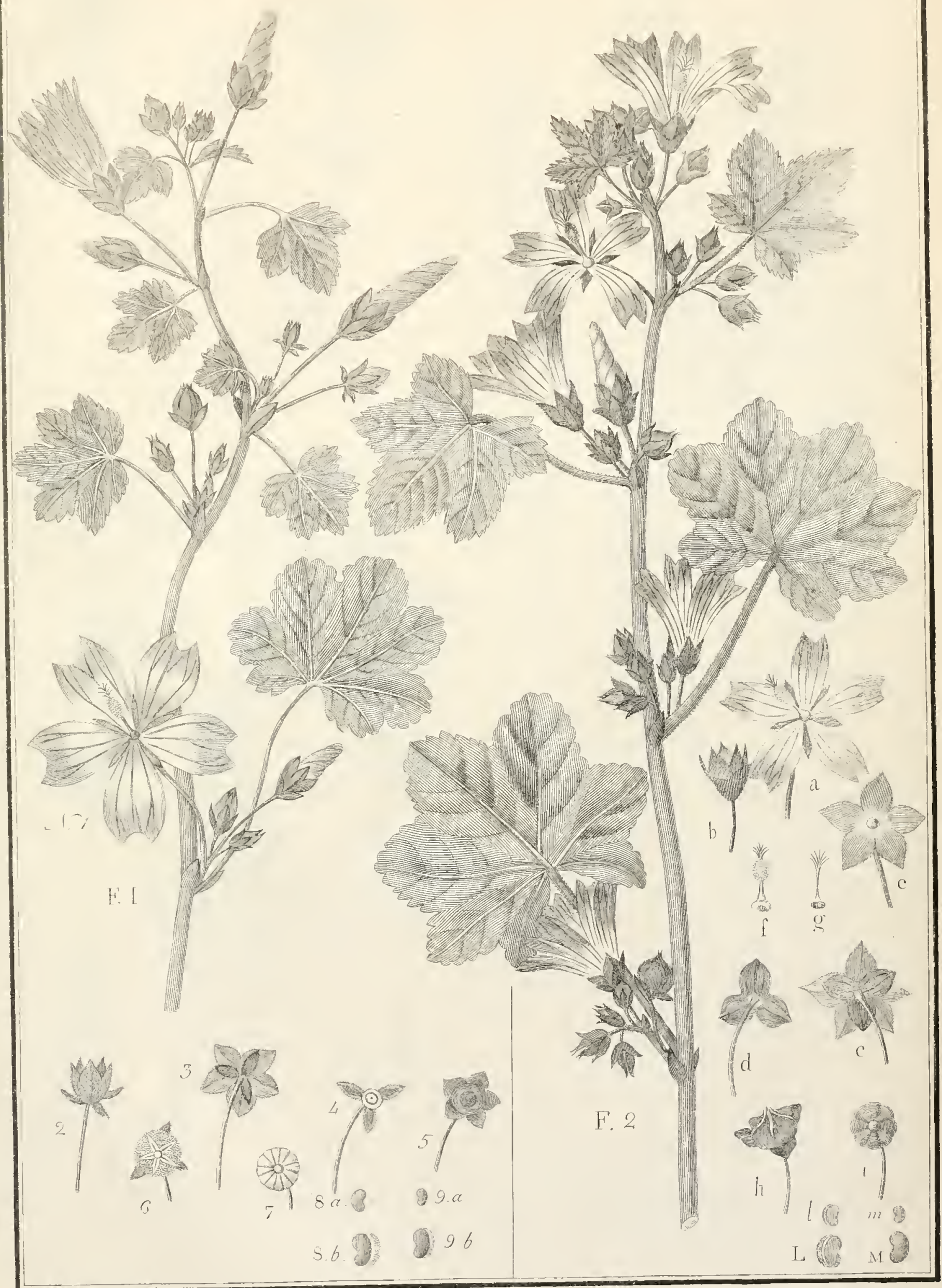

MAIDA mametiana - 



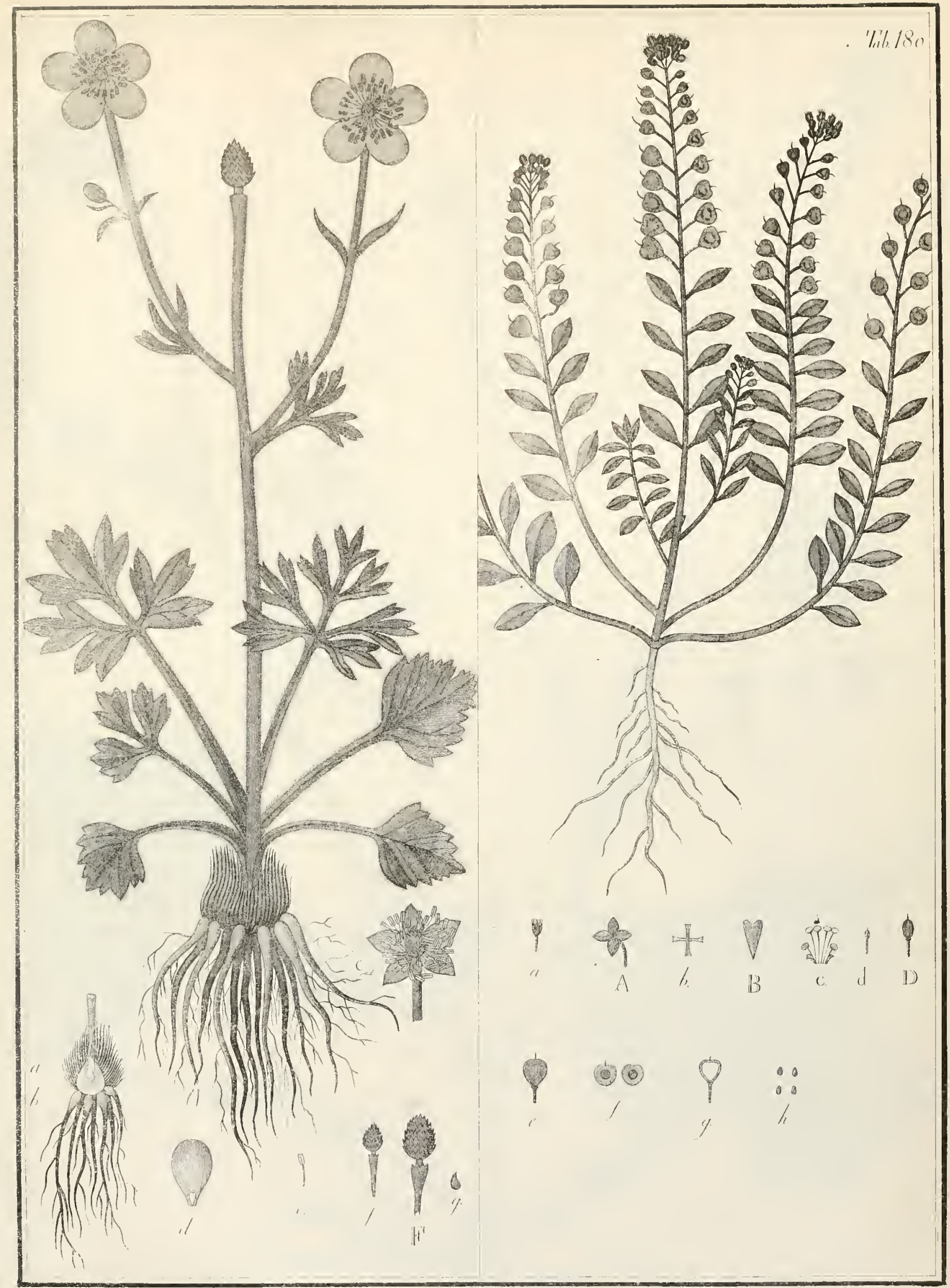

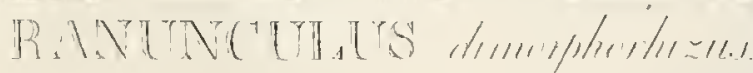

ALASSTMM iollimum. 








\section{4 \\ $+2$}

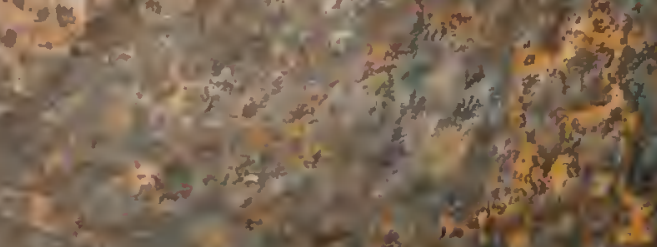
1.

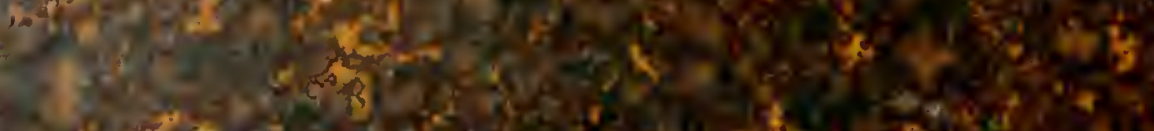

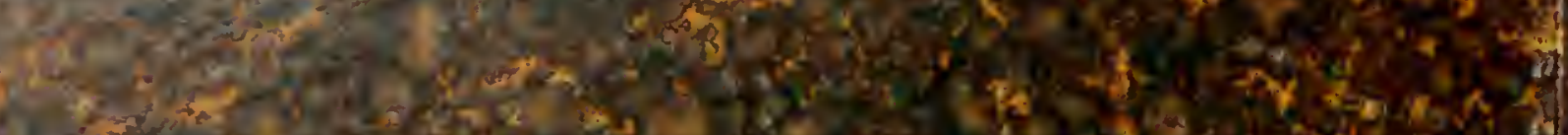

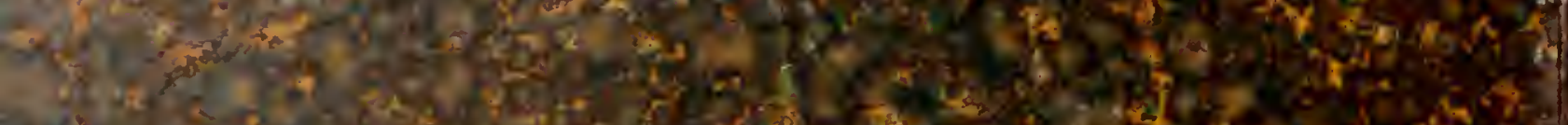

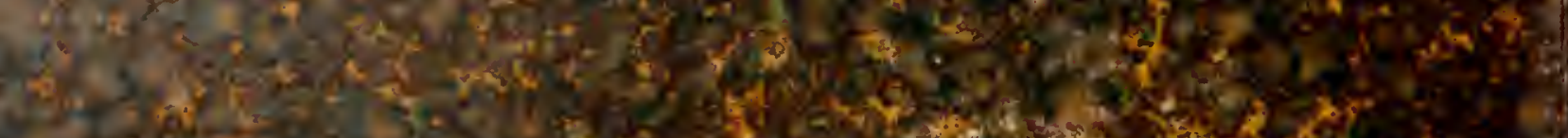

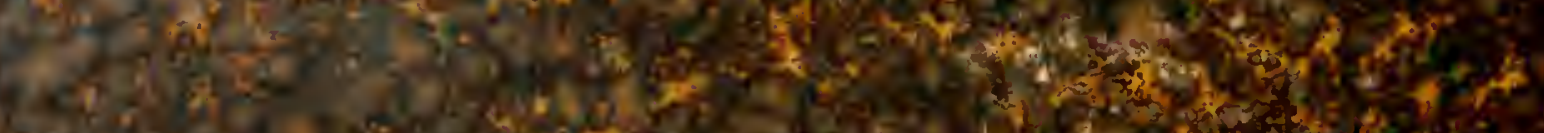

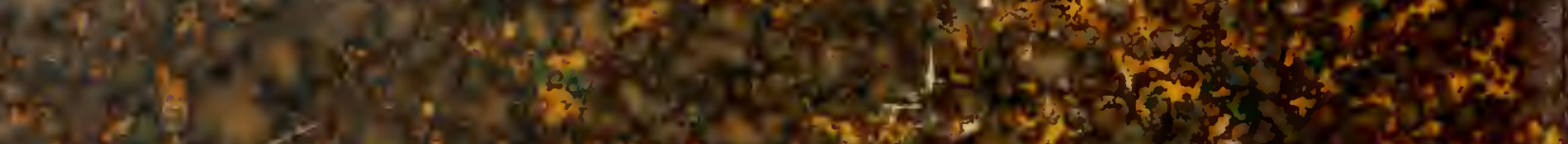

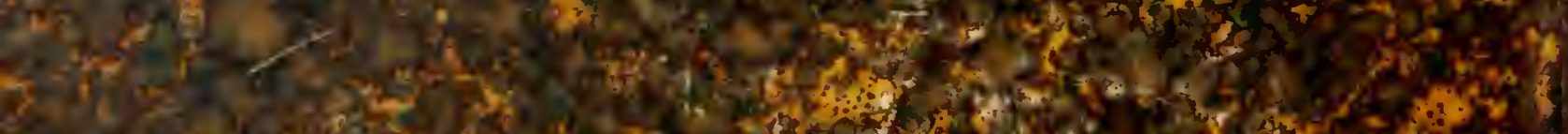

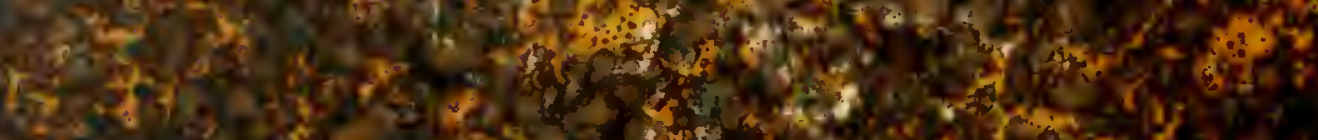

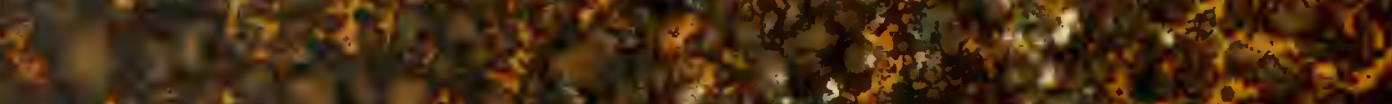

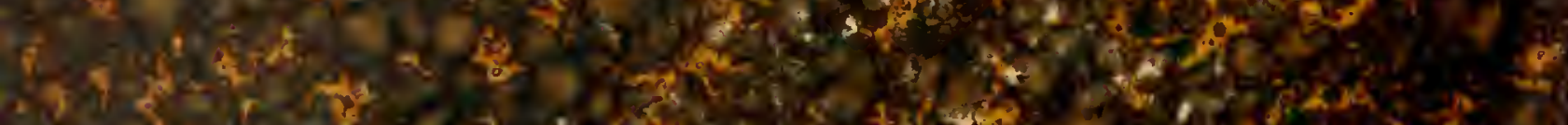

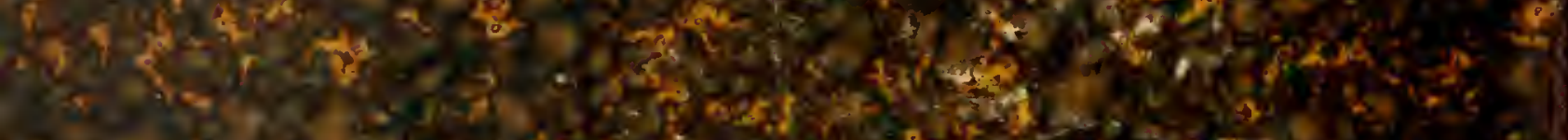

Las.

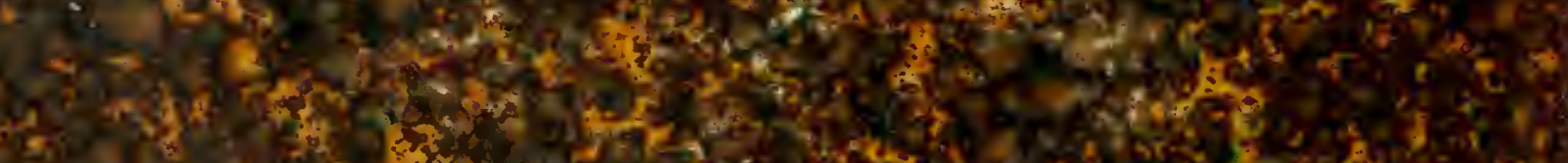

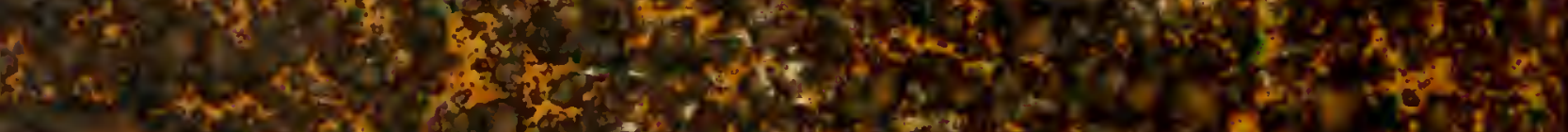

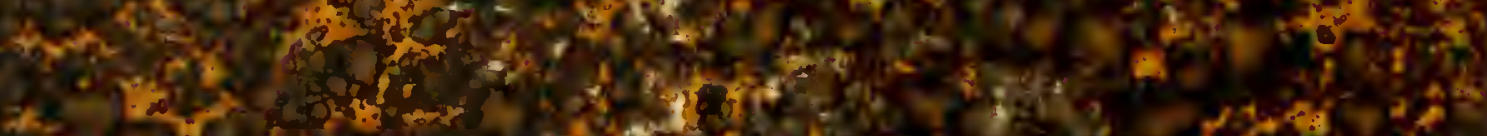

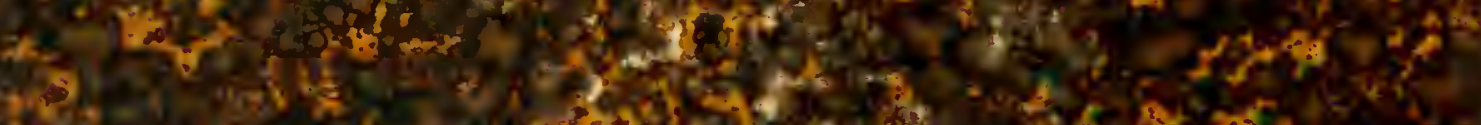

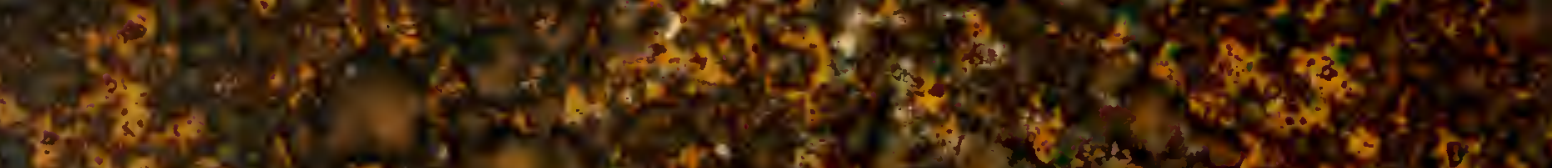

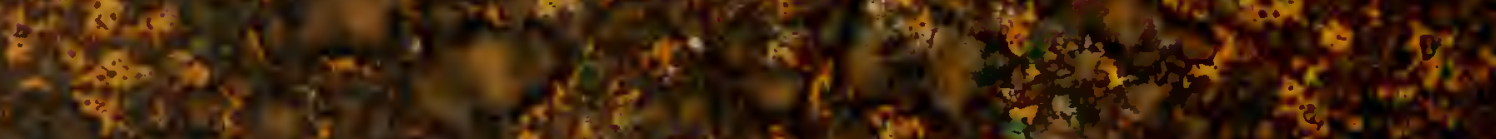

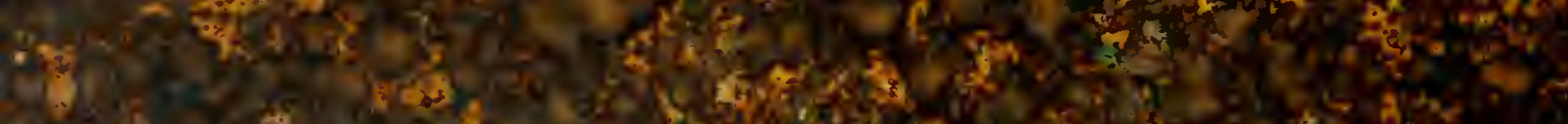

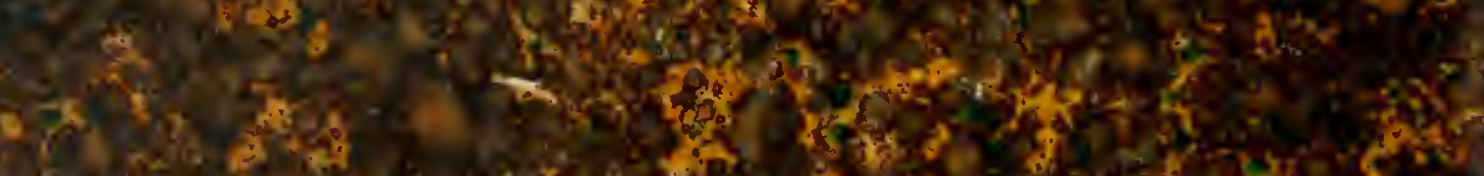

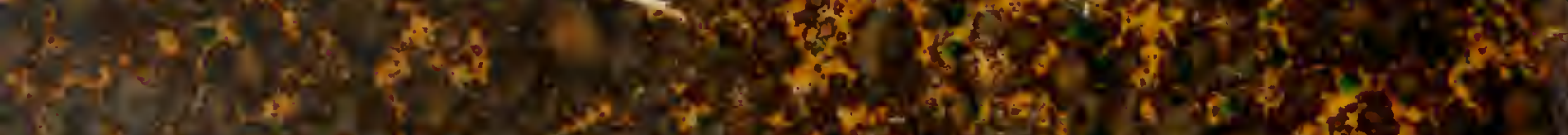

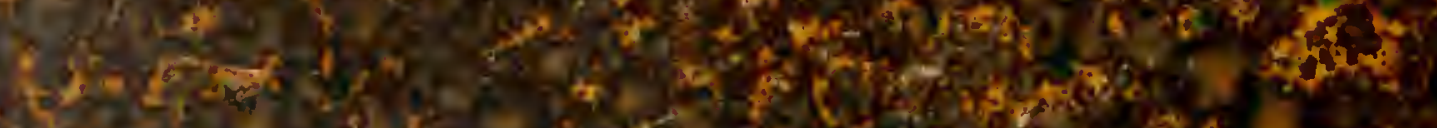

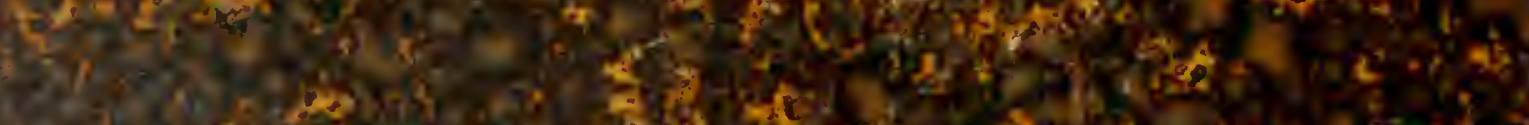

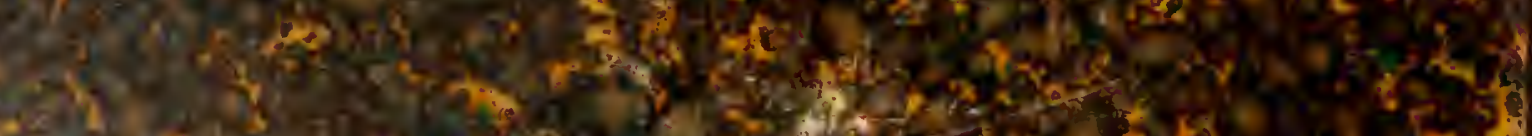

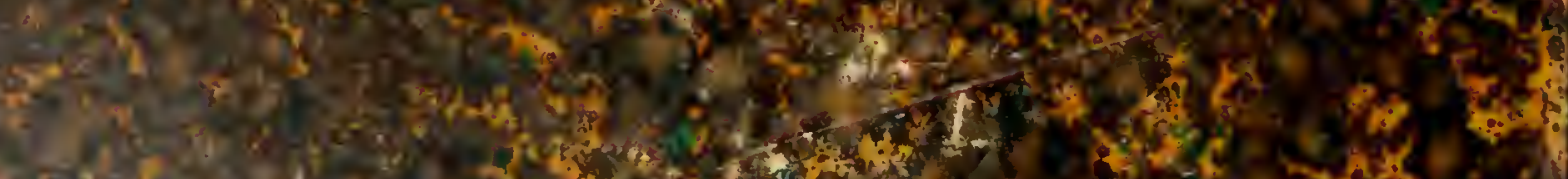

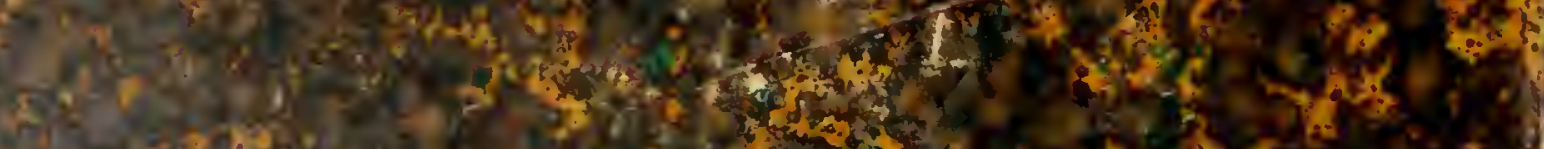

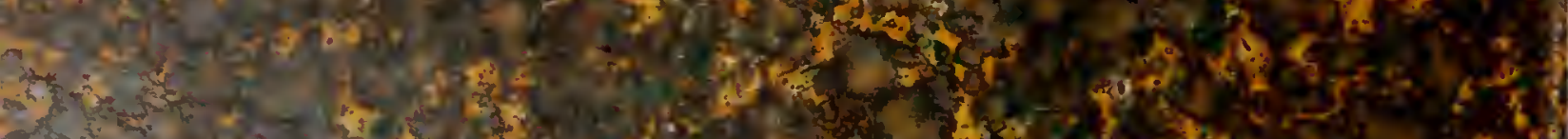
at

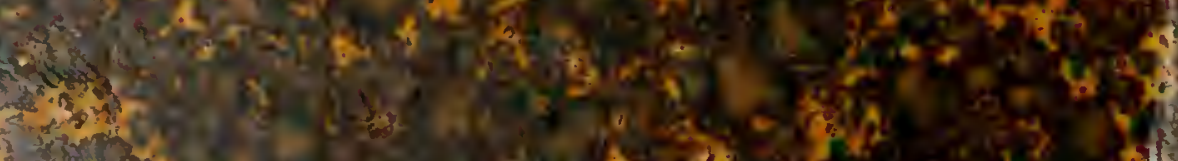

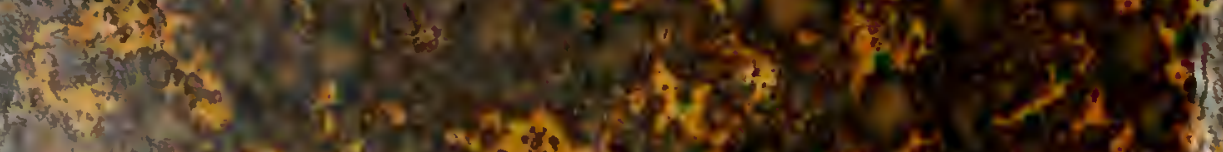

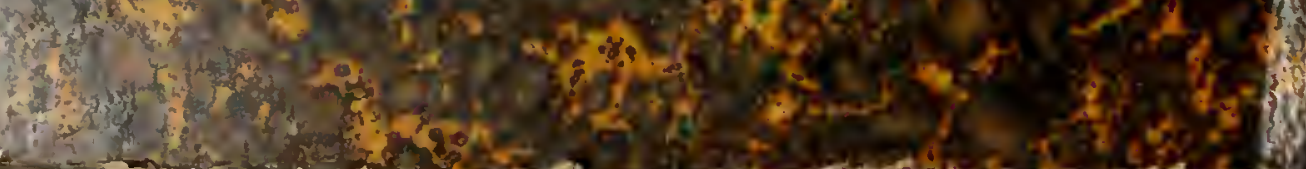

